Utah State University

DigitalCommons@USU

\title{
The Working Environment and the Health of Workers in Bituminous Coal Mines, Non-Ferrous Metal Mines, and Nonferrous Metal Smelters in Utah
}

The Division of Industrial Hygiene; National Institute of Health; U.S. Public Health Service

The Utah State Board of Health

Follow this and additional works at: https://digitalcommons.usu.edu/elusive_docs

Part of the Environmental Sciences Commons

\section{Recommended Citation}

U.S. Public Health Service, The Division of Industrial Hygiene; National Institute of Health; and Board of Health, The Utah State, "The Working Environment and the Health of Workers in Bituminous Coal Mines, Non-Ferrous Metal Mines, and Nonferrous Metal Smelters in Utah" (1940). Elusive Documents. Paper 92. https://digitalcommons.usu.edu/elusive_docs/92

This Article is brought to you for free and open access by the U.S. Government Documents (Utah Regional Depository) at DigitalCommons@USU. It has been accepted for inclusion in Elusive Documents by an authorized administrator of DigitalCommons@USU. For more information, please contact

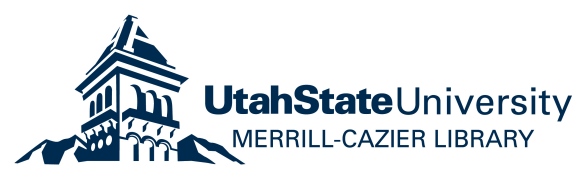




\section{Endineering Lbrary \\ UNIVERSITY OF UTAH IIBRARY}

Crass 331.822 Book U58W 


THE WORKING ENVIRONMENT AND THE HEALTH OF WORKERS IN BITUMINOUS COAL MINES, NONFERROUS METAL MINES, AND NONFERROUS METAL SMELTERS IN UTAH

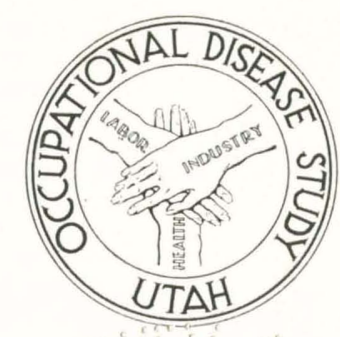

By

THE DIVISION OF INDUSTRIAL HYGIENE NATIONAL INSTITUTE OF HEALTH U. S. PUBLIC HEALTH SERVICE

and

THE UTAH STATE BOARD OF HEALTH 


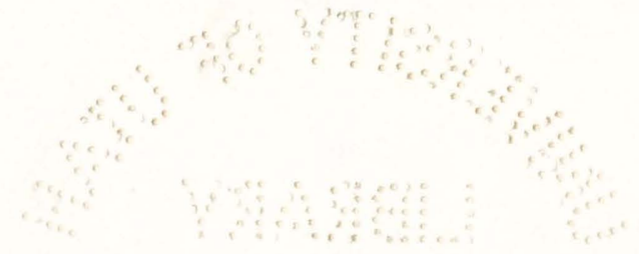




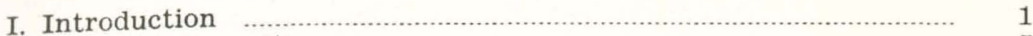

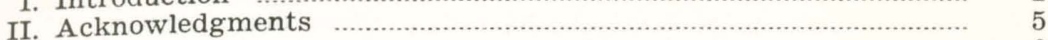

III. Summary 6

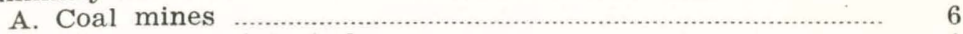

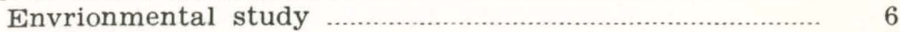

Medical study ....................................................................

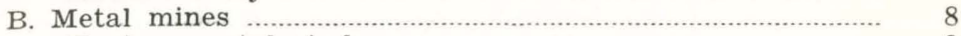

Environmental study ………………………......................... 8

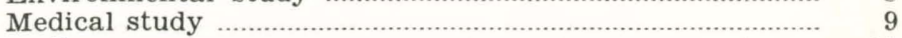

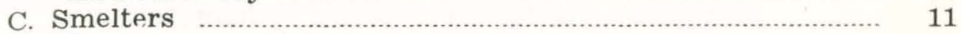

Environmental study ......................................................... 11

Medical study _............................................................ 11

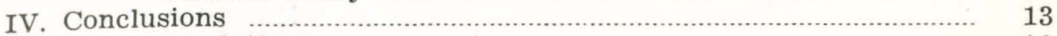

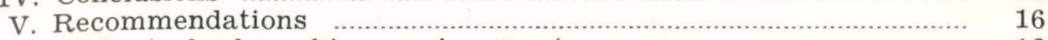

Control of working environment.............................................. 16

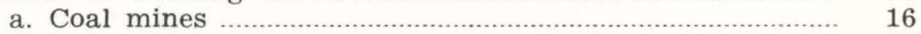

b. Metal mines ………..................................................... 17

c. Smelters ……................................................................. 17

d. General recommendations for engineering control........ 18

Medical control of occupational diseases and promotion 19

VI. General Procedure ………............................................................. 23

Environmental study .......................................................... 24

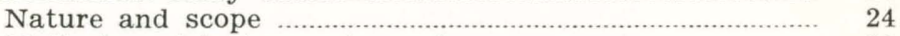

Methods and instruments used........................................... 26 Field sampling and analysis..................................... 26

Laboratory methods of analysis.................................... 27

Laboratory methods of analysis...................................... 27

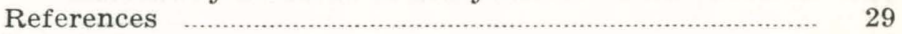

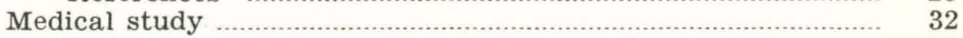

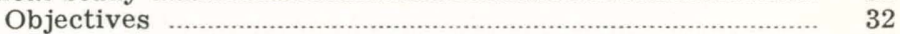

Medical examinations _............................................ 32

VII. Coal Mines

Environmental study $\quad 38$

Mining and preparation of bituminous coal............................ 38

Geography of the bituminous field............................... 38

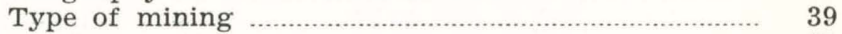

Loading methods .................................................. $\quad 39$

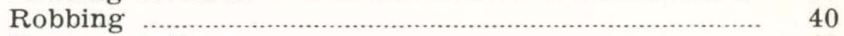

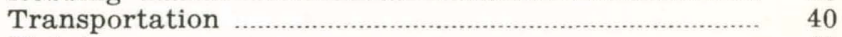

Maintenance …......................................................... 41

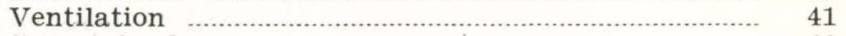

Superintendence ……............................................... 41

Conveyance to tipple .............................................. 41

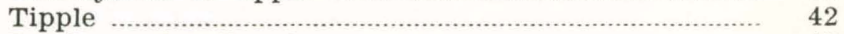

Loading of railroad cars......................................... 42

Other outside activities ............................................. 42

Occupational analysis and description of chief occupations $\quad 42$

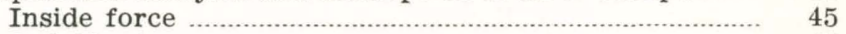

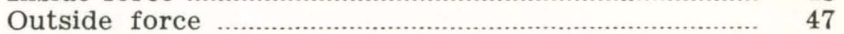

Ventilation ………........................................................... 48

Nature of mine air ........................................................... 49

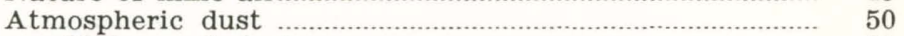

Nature of dust........................................................ 50

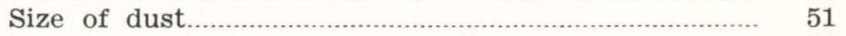

Dust concentrations by occupation.............................. 51

Summary ............................................................... 55

Atmospheric lead concentrations ................................. 56

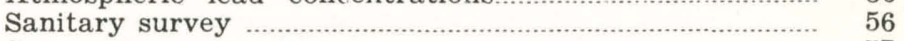

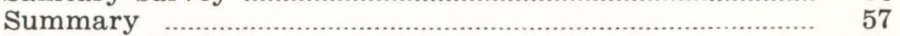

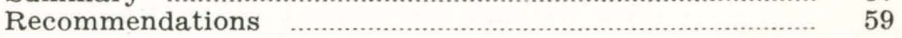

III. 248950 
References

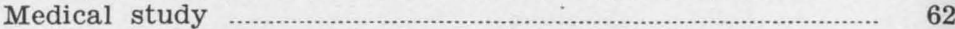

Characteristics of the coal mining population................. 62

Comparsion with census data...................................... 62

Workers with experience in other dusty trades......... 62

Age distribution ................................................... 63

Length of employment ........... 64

Employment outside of Utah....................................... 64

Diagnosis and symptomatology of silicosis..................... 64

X-ray findings ........................................................ 65

Symptoms and physical findings............................... 67

Diagnosis .................................................................... 68

Symptoms and signs in relation to lung-field workings.... $\quad 70$

Present complaints ................................................. 71

Past medical history ....................................................... 71

Physical findings with relation to X-ray findings...... 72

Miscellaneous physical findings ................................. 74

Anthraco-silicosis among bituminous coal miners... $\quad 75$

Dust concentration and duration of employment....... $\quad 77$

Incidence by princpial occupation............................... $\quad 79$

Summary ................................................................... $\quad 79$

Representative case histories............................................ 85

Pulmonary tuberculosis among bituminous coal miners 108

Cardiovascular findings .................................................... $\quad 110$

Blood pressure ............................................................. 110

Arterial hypertension ................................................ 111

Arteriosclerosis ......................................................... 112

Heart disease ................................................................ 112

Rheumatic heart disease ........................................... 112

Other health hazards ............................................... 114

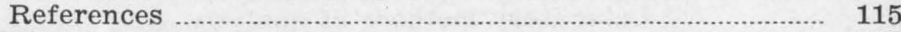

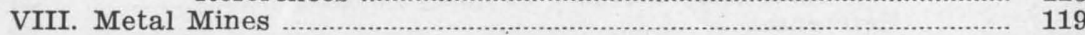

Environmental study ............................................................... 120

Geography and geology of Utah ore deposits.................. 120

Park City district ................................................. 122

Bingham district ........................................................ 122

Tintic district ....................................................... 123

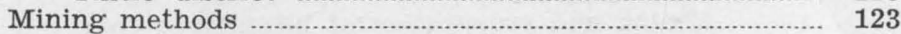

Mine development and exploration........................... 125

Shafts and adits........................................................... 125

Drifts, crosscuts, and raises...................................... 125

Stoping .................................................................... 127

Transportation of ore and waste................................ 128

Hoisting in cages and skips........................................ 130

Other underground operations .................................... 131

Outside activities .......................................................... 133

Occupational analysis and description of chief occupations 133

Ventilation, temperature and humidity.............................. 141

Illumination ................................................................ 145

Atmospheric dust ....................................................... 146

Siliceous content of dust........................................... 146

Size of dust ............................................................. 147

Dust concentration of siliceous dusts........................ 148

Occupational dust exposures ..................................... 148

Methods of minimizing the silica dust hazard..................... 153

Face operations ......................................................... 153

Transportation, underground ..................................... 154

Maintenance and construction, underground................. 155

Surface operations ................................................... 155

Summary ................................................................. 155

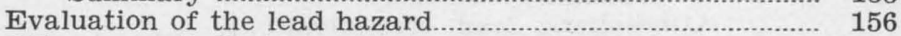

Other potentially hazardous exposures................................. 157

Noxious gases ............................................................... 158

Skin irritants and sources of infection..................... 161 


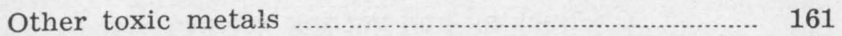

Sanitary survey ......................................................... 161

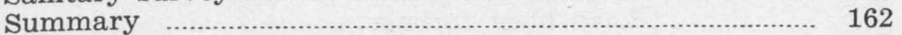

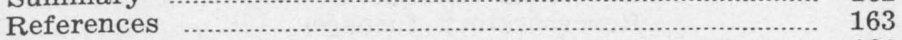

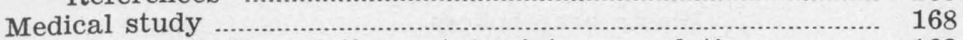

Characteristics of the metal mining population................ 168

Comparison with census data..................................... 168

Workers with experience in other dusty trades........ 168

Age distribution .................................................... 169

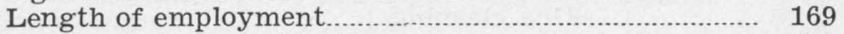

Employment outside of Utah ................................... 170

Diagnosis and symptomatology of silicosis........................ 170

Symptomatology in relation to lung-field markings

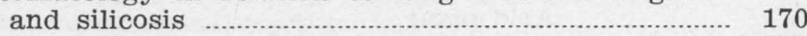

Present complaints ............................................................ 170

Past medical history ……................................................ 171

Physical findings .............................................................. 171

Weight deviation ........................................................ 172

In relation to X-ray findings...................................... 172

Incidence of silicosis ................................................ 173

Dust concentration and duration of employment....... 173

$\mathrm{X}$-ray findings of silicosis cases................................... 176

Employment outside of Utah...................................... 176

Silicosis by principal occupation …………..................... 177

Representative case histories............................................. 183

Pulmonary tuberculosis ……....................................... 192

Reinfection tuberculosis ............................................. 192

Primary tuberculosis ………………………................. 193

Lead poisontng …........................................................... 194

Past history of lead poisoning .................................. 194

Present incidence of abnormal lead absorption......... 195

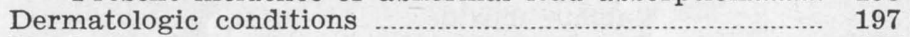

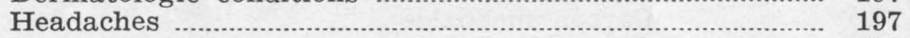

Diseases of the heart and vascular system …………......... 197

Cardiovascular signs .................................................... 200

Blood pressure …….................................................... 200

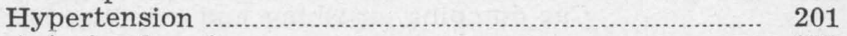

Arteriosclerosis …...................................................... 201

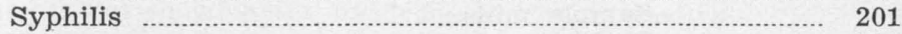

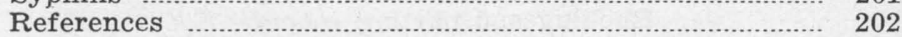

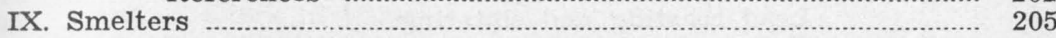

Environmental study ......................................................... 206

Description of the working environment during the preparation and smelting of complex lead and copper ores …......................................................... 206

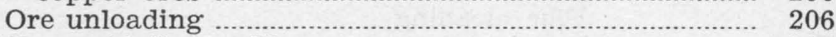

Concentrating mills …............................................ 208

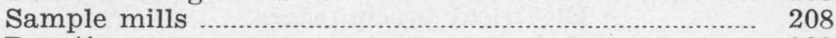

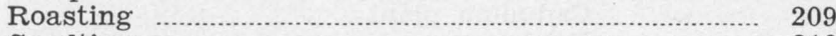

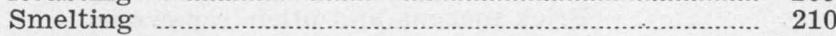

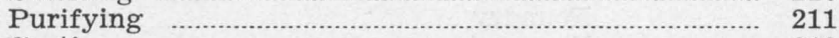

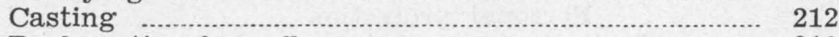

Reclamation from flue gases................................... 212

By-products …........................................................ 213

Other operations ......................................................... 214

Occupational analysis and description of chief occupations 214

Administrative and supervisory personnel ……….... 217

Foremen ….................................................................. 218

Loading and unloading .......................................... 218

Yard crews ............................................................ 218

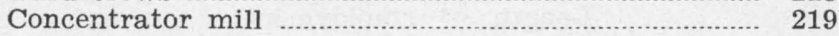

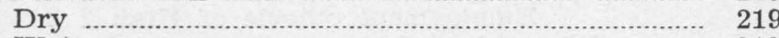

Wet

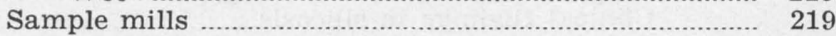




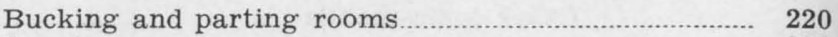

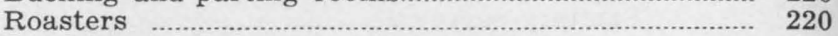

Lead blast furnace ...................................................... 221

Reverberatory furnace ……….................................. 221

Waste heat boilers ................................................... 222

Dross kettles and furnace........................................... 222

Copper converters ……........................................... 222

Lead casting .

Copper casting ............................................................ 223

Flue cleaning …................................................. 223

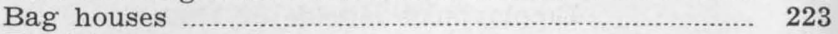

Electrical precipitators …….................................... 223

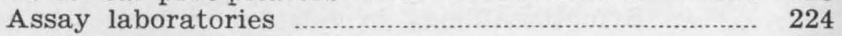

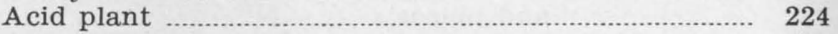

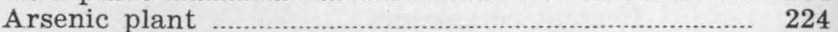

Cadmium plant ........................................................ 224

Power houses ……................................................. 224

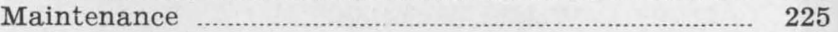

Atmospheric dusts ………........................................... 227

Nature of dust ....................................................... 227

Size of dust ....................................... 228

Dust concentration by occupation................................. 228

Atmospheric concentration of metals ……........................ 232

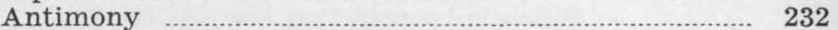

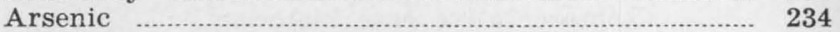

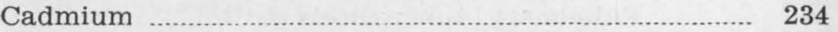

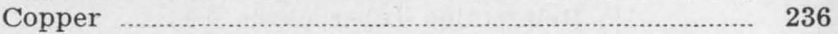

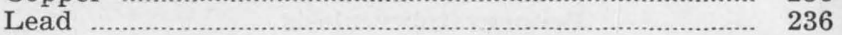

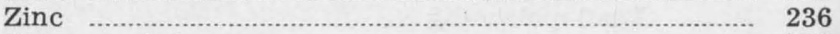

Other metals ........................................................... 236

Atmospheric concentrations of toxic gases...................... 237

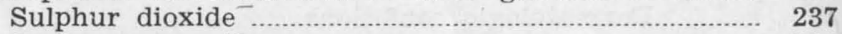

Carbon monoxide ................................................... 240

Other toxic gases.......................................................... 240

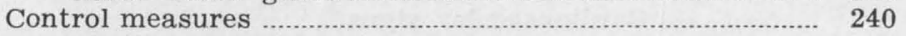

Loading and unloading docks...................................... 241

Car dumping, crushing and grinding in the
concentrator

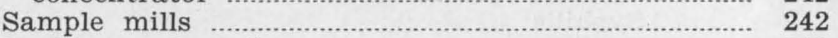

Bucking and parting rooms........................................... 242

Lead roasting and sintering ....................................... 243

Copper roasting .................................................... 243

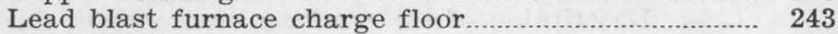

Reverberatory furnace .............................................. 243

Converters and cranes..................................................... 244

Flue cleaning ……................................................. 244

Bag houses ……...................................................... 244

Electrical precipitators .............................................. 245

Cadmium plant .................................................... 245

Brick masons and other repairmen ………................... 245

Foundry ........................................................... 245

Personal protection ………........................................ 245

Sanitary survey ............................................................. 246

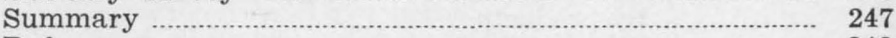

References

Medical study

Characteristics of the smelting population

Comparison with census data...................................... 250

Workers with experience in other dusty trades....... 250

Age distribution .................................................. 251

Length of employment............................................ 251

Employment outside of Utah ................................... 252

Diagnosis and symptomatology of silicosis.......................... 252

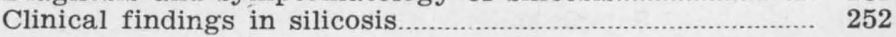


Incidence of silicosis

Dust concentration and duration of employment......... 255

$\mathrm{X}$-ray findings .................................................. 256

Silicosis by principal occupation.................................. 256

Representative case histories............................................ 261

Pulmonary tuberculosis among smelter workers................. 270

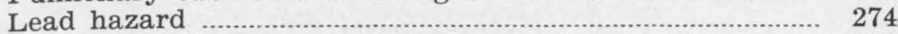

Present incidence of abnormal lead absorption............ 274

Past history of lead poisoning.................................... 274

Criteria indicative of abnormal lead absorption........ 274

Sulphur äioxide ................................................................ 278

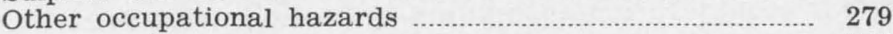

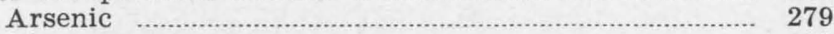

Other metals

Miscellaneous physical findings ............................................ 283

Cardiovascular disease …...................................... 283

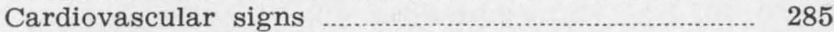

Arterioscleŕosis ................................................... 285

Blood pressure ….............................................. 285

Hypertension …................................................. 286

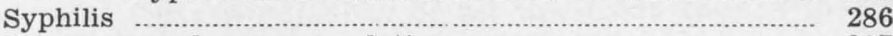

Summary and recommendations ……….......................... 287

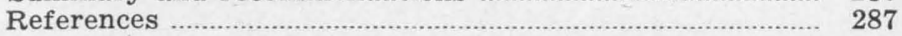

\section{APPENDIXES}

I. Results of dental examination of Utah workers........................ 290

II. The phsiological response of peritoneal tissue to certain Utah coal and metal mine and smelter dusts.

III. Spectrochemical analysis as applied to samples from the Utah study

IV. Method of calculating weighted average dust exposures........... 302

V. Summary tables showing the incidence of certain medical findings among workers in the coal mines, metal mines, and smelters in Utah.

VI. Correspondence and memorandum relating to the investigation 308 



\section{THE WORKING ENVIRONMENT AND THE HEALTH OF WORKERS IN BITUMINOUS COAL MINES, NONFERROUS METAL Mines, AND NONFERROUS METAL SMELTERS IN UTAH}

\section{INTRODUCTION}

In 1936, the Utah Industrial Commission requested the Federal Government to make a study of the nature and prevalence of occupational diseases in Utah industries. Following a number of conferences the U. S. Public Health Service agreed to undertake such a study with the cooperation of Utah State agencies, such as the Industrial Commission, the State Board of Health, industrial organizations, labor groups, and others.

In order that the objectives of the proposed study and the responsibilities of each agency affected would be well understood, the U. S. Public Health Service prepared a memorandum in the form of an agreement, which could be used for the guidance of all the organizations that were to take part in the proposed survey. A copy of the signed memorandum is appended to this report. As set forth in this memorandum, the purpose of the study was to evaluate the various factors bearing on the health of Utah workers, in order that this information could be used as a guide in the drafting and enactment of legislation for the compensation of injury to health resulting from exposure to industrial health hazards. It was also pointed out that basic data such as would be revealed by these studies would be important in the support and application of a program designed to control industrial health hazards.

In the memorandum submitted on October 6, 1936, the plan called for two studies: the first, of a preliminary and qualitative nature, was expected to be more in the form of a general inventory of working conditions in order to reveal the potential industrial health hazards existing in the State. It was thought that from this preliminary survey it would be possible to determine which particular health hazards were in need of further study. The second survey was to be more detailed and specific, quantitative in nature, and include medical examinations of workers, engineering studies of the working environment in order to determine the relationship between the environment and the health of workers, and investigation of any other factors which may throw light on the industrial health problem.

The responsibilities of all cooperating agencies were clearly defined in this memorandum, which was signed on February 24, 1937, by representatives of industry and labor.

The first part of the study, or preliminary survey, was conducted during the latter part of 1937 and the early part of 1938 by personnel from the Utah State Board of Health under the guidance of U. S. Public Health Service officers. The data were analyzed and the report prepared and published by the U. S. Public Health Service. This report, which was issued in October, 1938, showed the number of workers in the various industries in the State of Utah who were exposed to certain materials and conditions which might be considered potentially hazardous to health. As a result of this study, it was possible to determine the major potential hazards in Utah industry, in which industries they occurred, and those 
which merited further study. The report also brought out present facilities for coping with industrial health hazards in the State and specific data on the extent of control measures then in vogue. In connection with these findings, however, attention was called to the limitations of the data which were collected. Since no quantitative measurements of the working environment were made, and no medical examinations were conducted at this time, the information obtained disclosed only the potentialities involved, and in no way could exposure be implied to indicate actual injury. Likewise, the listing of control measures merely indicated that such control measures were available, and did not show whether or not they were effective. Hence, although it was known from this first study that conditions existed favoring the occurrence of certain occupational diseases, it was still necessary to determine to what extent these diseases occurred and the public health and economic implications involved. These answers could be obtained by carrying out the second series of studies as outlined in the original agreement of 1937. For this reason, the State legislature was requested to appropriate sufficient funds for the conduct of such a study. They were assured that the U. S. Public Health Service, in compliance with the original agreement, would assign personnel to work in cooperation with the State Board of Health and other agencies for the purpose of conducting detailed studies of industrial health hazards revealed in the first survey.

In March, 1939, legislation was passed authorizing and directing the State Board of Health, in collaboration with the U. S. Public Health Service, and the State Industrial Commission, to carry out such a study. This legislation included an appropriation of $\$ 25,000$.

After analysis of the data obtained in the first survey, the U. S. Public Health Service considered that the major problems for detailed investigation in Utah were exposure to siliceous dusts, lead and other metallic dusts, fumes, and gases. The chief industries in which these hazards might exist were the coal mines, nonferrous metal mines, and nonferrous smelters.

The time allowed by the legislature in which to complete this study necessarily limited the number of industries which could be investigated. Hence, this study was limited to these three industries. There are potential health hazards in other industries of the State which are now being studied by the industrial hygiene personnel of the State Board of Health. Information already exists concerning the health hazards in some of these industries which should permit the planning of a preventive program for their control.

The United States Census for 1930 showed that there were approximately 170,000 persons gainfully employed in the State of Utah, out of a total population of 507,847 . The industries included in this study employed approximately 16,000 workers. Representative plants employing some 3,000 workers were selected for detailed study. The selection of plants studied was made by the U. S. Public Health Service and was based on all available data contained in the report of the preliminary survey. Three coal mines, three metal mining enterprises, and two smelters were selected for intensive medical and environmental study.

The plant operators furnished certain services and facilities to assist the field staff in its study of working conditions in the plants and of the 
health of the employees. The local labor unions assumed the responsibility of supplying members for physical examination and assisted in various other ways with the study. Every available employee of each plant, including the clerical staff and officers, was examined. It was decided that all records obtained in the study were to become the property of the U. S. Public Health Service, and that all information obtained would be strictly confidential. In this connection, instead of recording the man's name, he was given a serial number. Physical examination findings of the individual were not revealed to the employer and the environmental findings of the plant were not revealed to employees.

The field work of this study was started early in July, 1939, and continued until the latter part of December. During this period occupational and medical histories, and physical and roentgenological examinations were made on 2,839 men in the three industries. The medical examination included a complete oral examination by a dentist and the following laboratory examinations: serological tests for syphilis; punctate basophilia and reticulocyte estimations for lead absorption; hemoglobin determinations; and routine urinalyses. Also, 961 urine specimens, collected from workers who were exposed to various compounds of lead, were examined spectroscopically for lead content.

Engineering studies were made in each plant to evaluate the working environment in the various occupations by making determinations of the environmental factors which may have a bearing on health. In this connection, examinations were made as to the nature and concentration of various types of dust, such as silica, lead, arsenic, and cadmium, to which the workers were exposed. Studies of ventilation and humidity were carried out, and exposure to various gases, such as sulphur dioxide, carbon dioxide, carbon monoxide, hydrogen sulphide, hydrogen cyanide, methane, and others, were determined. Also, methods and facilities for the control of health hazards, already in use by the industries, were investigated, with the view of recommending additional control measures which may be necessary to eliminate such hazards. The results of the medical and engineering studies, with a general summary of findings, conclusions and recommendations, are presented in the following sections.

A general sanitary survey of these plants, and the communities in which the workers live, was carried out by the Sanitary Engineering Division of the Utah State Board of Health. Such items as water supply, sewage disposal, milk sanitation, housing, and other data germane to the problem were studied. A summary of these findings, with recommendations, is included in this report.

In the original memorandum of 1937, the U. S. Public Health Service stressed the importance of a continuous program designed to control industrial health hazards. For this reason, the Service agreed to assume full responsibility in carrying out the provisions of the law relative to this study, and in consideration of this, recommended to the Utah State Board of Health that it employ the $\$ 25,000$ appropriated by the legislature for the conduct of the study toward the development of a permanent industrail hygiene service in the State. This recommendation was adopted and such a service is now available in the State Health Department, consisting of a physician-director, an engineer, a laboratory technician, and a clerk, and is provided with facilities and equipment necessary to carry 
out a program of industrial health conservation. The above personnel augmented the staff of the U. S. Public Health Service in carrying out all phases of this study, and thereby have gained practical training and experience in the practice of industrial hygiene. In addition to the above services contributed by the State Board of Health, all of the fulltime district health officers of Utah took an active part in the medical field studies; serological tests were conducted by the State public health laboratory; the dental division cooperated by furnishing the services of a dentist for the oral hygiene studies; the Division of Epidemiology furnished valuable statistical information concerning the extent of certain diseases in the communities in which the workers live, and, finally, the Division of Sanitary Engineering carried out a sanitary survey as mentioned above.

Thus, it is evident that through the medium of these industrial hygiene studies an earnest effort has been made in Utah to lay the basis for the modern approach to the industrial hygiene problem, integrating this service with the various other services of the State health department, and cooperating with all other interested State agencies and organizations.

The results of the study, which follow, establish the extent and nature of the industrial health problem in Utah, as requested by the legislature, and, in addition, yield sufficient data on which to base a permanent program in industrial hygiene, toward which a fair beginning has already been made. 


\section{ACKNOWLEDGMENTS}

The U. S. Public Health Service and the Utah State Board of Health wish to express their appreciation of the assistance rendered by all agencies and individuals who cooperated in this study. The entire report is the result of a cooperative undertaking so extensive that it is not possible to acknowledge by name all those who participated. However, it is desired to acknowledge the valuable cooperation of the officials of those industries which made their plants available for study and to the workers who submitted voluntarily to a physical examination. Acknowledgment is due to the U. S. Bureau of Mines for performing analyses on gas samples obtained in the environmental study. It is especially desired to commend the Utah Industrial Commission for having assumed leadership in initiating the present investigation. 


\section{SUMMARY}

\section{A. COAL MINES}

\section{Environmental Study}

The present report is based on a study of three representative bituminous coal mines in the State of Utah. An occupational analysis revealed that 41 percent of the workers were employed at the face in getting out coal. These workers encountered the highest dust exposures. Ventilation studies showed that although each mine was supplied with air much in excess of the 150 cubic feet per minute per man required by the Industrial Commission of Utah, more than half of the working faces had air velocities of less than 40 feet per minute. The air movement in some working places was practically zero. Dry bulb temperatures in the mines were found to be very constant, averaging $60^{\circ} \mathrm{F}$., while the relative humidity averaged 85 percent, with considerable variations.

The results of mine air analyses indicated that carbon dioxide, oxygen, and nitrogen did not vary greatly from the usual concentrations found in the general outdoor atmosphere. Carbon monoxide occurred only in the samples taken immediately after blasting, and was quickly dissipated. In only one sample did the concentration of methane exceed the recommended maximum of the Bureau of Mines (less than 0.5 percent).

Studies of the nature of the dusts to which workers are exposed showed that the majority of the underground workers ( 55 percent) were inhaling dusts containing small amounts of free silica in the form of quartz. In fact, the highest concentration found at the face was 11 percent, but most of the face workers were exposed to less than this amount. With further reference to the nature of the dust exposure, measurements of 2,000 particles of dust showed that 83 percent of these particles were less than 5 microns in average diameter. The median size particle was found to be 2 microns, indicating that practically all of the dust suspended in the atmosphere of these mines is capable of entering the lung.

The amount of dust to which the various workers are exposed was determined by collecting 168 atmospheric dust samples. The results which follow are expressed as weighted averages so as to take into consideration the dust exposures varying with each activity in any occupation. These results indicate that the dustiest operations are associated with the underground occupations of handloading, undercutting, rock dusting, and drilling. Hand loaders were found to be exposed to a dust concentration of 38 ; undercutters, 34 ; rock dusters, 34 ; and drillers, 26 million particles per cubic foot of air. The dust exposure for other underground workers varied from 4 million for timbermen to 23 million particles for rock workers. The dustiest occupations above ground were found in the tipple. Car loaders, with a dust concentration of 119 million particles per cubic foot, exceeded all other occupations. The next greatest concentrations in the tipple were for car dumpers and couplers, rope tenders, and switchmen, who were exposed to approximately 30 million particles. The only occupation above ground, with the exception of the tipple, which had a high concentration of dust, was sand drying, with 98 million par- 
ticles. All other surface workers had an exposure of 5 million particles or less.

If all occupations are considered, irrespective of location of work, then the engineering studies show that only 24 percent of the workers are exposed to more than 30 million particles per cubic foot of air. The majority of the workers (59 percent) are exposed to concentrations varying from 5 to 29 million particles. The remaining 17 percent of the workers had the negligible dust exposure of less than 5 million particles.

Atmospheric samples were also obtained for evaluating the exposure of coal workers to lead. The results of the analysis of these samples indicated that atmospheric lead exposure is so negligible that the possibility of lead poisoning in these coal mines must be dismissed.

The studies of sanitary facilities, both in the mines and in the communities in which the mines were located, showed that in some instances poor sanitary facilities were present, and these merit further consideration. Recommendations for the improvement of some of the existing conditions will be found in the section dealing with that subject.

Methods of reducing the dust hazard, directed at those activities which contributed the largest proportion of the workers' total dust exposure, will be found in the sections which follow.

\section{Medical Study}

Medical examinations, including an X-ray film of the chest, fluoroscopic chest examination, and standard laboratory tests of the blood and urine, were made on 545 workers in the same three bituminous coal mines. This sample represents about one-fifth of workers in bituminous coal mines in Utah. ${ }^{1}$ Thirty-eight workers who had had more than two years of employment in other dusty trades such as metal mines were eliminated from statistical study because of the probability that their previous experience would affect the results showing the relationship of working conditions in coal mines upon the workers' health. This group of 38 men included 4 with second-stage silicosis showing moderate disability, and 2 with first-stage silicosis showing little or no disability.

Anthraco-silicosis, a modified form of silicosis due to silica admixed with large amounts of carbon dust was the principal occupational disease found by the medical examination of the remaining 507 coal miners. This disease may occur during the mining and processing of either anthracite or bituminous coal. This diagnosis was based upon characteristic $\mathrm{X}$-ray findings, symptoms and physical findings, and a history of several years' employment in bituminous coal mines. It is thought that the free silica $\left(\mathrm{SiO}_{2}\right)$ exposure of these men resulted from rock work, the handling of coal containing bony, rock dusting, and from the dispersion of fine sand in the haulageways. Anthraco-silicosis was found in 16 (3.2 percent) bituminous coal miners in addition to the 6 cases excluded above. Fifteen of these 16 workers showed evidence of first-stage anthracosilicosis with but little disability, one worker showed evidence of secondstage anthraco-silicosis with moderate disability, and in no instance was third-stage anthraco-silicosis found with severe or total disability.

Anthraco-silicosis was found only in workers whose principal occupation was in the mines, no cases being found among tipple or other surface

1 See footnote on page 62 . 
workers. Thirteen cases occurred among men working at the face and 3 cases occurred among transportation workers. The incidence of anthraco-silicosis among the 346 underground workers was 4.6 percent. Also, 26 cases of early or borderline anthraco-silicosis were found among this group. The X-ray changes, symptoms, and physical findings in all these cases were similar to those found by the Public Health Service in previous medical studies of anthracite miners, pottery workers, and pegmatite miners.

Among underground workers, the incidence of anthraco-silicosis increased with increasing weighted average dust concentrations and increasing duration of employment. Anthraco-silicosis was not found among workers with less than 10 years of employment in bituminous coal mines, and was found in only two instances among workers with an average weighted dust concentration of less than 20 million particles per cubic foot of air. Duration of employment was of importance as the incidence of anthraco-silicosis rose from 1.7 percent for those employed from 10 to 19 years and 5.1 percent for those employed from 20 to 29 years, to 22.5 percent for those employed 30 or more years.

Previous employment in bituminous coal mines outside of Utah was found to be an important factor in this study, as 10 of the 16 cases of anthraco-silicosis observed gave a history of employment in other sections of the United States or in England. These 10 men with a varied coal mining experience had averaged 16.2 years in Utah coal mines, and 17.6 years in other bituminous coal mines.

Other occupational hazards did not appear to be of significance. Pulmonary tuberculosis, syphilis, and heart disease were found in about the same proportion as in other industrial surveys. Miners' nystagmus, bursitis, and related conditions were not observed. No evidence of lead or other metallic intoxication was found. As a group, these bituminous coal miners enjoyed good health.

\section{B. METAL MINES}

\section{Environmental Study}

The study of the working environment and the health of workers in metal mines in Utah was conducted in three metal mining enterprises, located in the three chief Utah mining areas.

Ore and rock varied from limestone, containing no detectable free silica, to quartzite consisting of more than 99 percent free silica. Since all miners had worked in various locations, it was difficult to distinguish between those who had had high or low free silica exposures. Consequently, for statistical purposes, it was assumed that all underground workers had been exposed to atmospheric dusts having an average free silica content of $30 \pm 10$ percent. Particle size determinations of the dust suspended in the atmospheres of the various metal mines showed that the dust had a median diameter of 0.9 micron and that more than 96 percent of all the atmospheric dust particles were of a size which might readily reach the smallest air sacs in the lungs.

Of the 830 persons working the metal mining enterprises studied, less than 1 percent were exposed to average dust concentrations higher than 30 million particles per cubic foot. Seven hundred and eleven, or approxi- 
mately 86 percent of the workers, were found to be exposed to dust concentrations between 6 and 30 million particles per cubic foot, and about 13 percent were exposed to less than 6 million particles. High dust exposures were usually associated with drilling, breaking and handling of ore, but ventilation with vitiated air in some stopes also increased the dust concentrations.

Examples of good mining practice with regard to the control of the principal sources of dust contamination showed that the dust can be reduced to concentrations below 6 million particles by proper use of present control measures; such as wet methods, adequate ventilation, air cleaners or settling chambers, and local exhaust ventilation.

Gas analyses of mine air showed that toxic gases, or atmospheres deficient in oxygen, are present at times, but that such conditions are of a temporary nature so long as adequate ventilation is maintained. Accidents from this cause can be prevented by constant supervision and investigation of all working places.

Extremely high and low temperatures, rapid temperature changes, dusts of toxic metals, illumination, and poor sanitary facilities, both in the mines and in the surrounding communities, were found to merit consideration. Recommendations for the improvement of some of these conditions will be found in the section dealing with this subject.

\section{Medical Study}

This medical study of non-ferrous metal mine workers included 783 persons representing slightly less than one-fourth of the total number in this occupation in the State of Utah as reported by the United States Census of $1930 .^{1}$ The age distribution of the group studied was similar to that shown in the Census for all Utah metal mine workers.

A detailed analysis was made of medical examination findings for the 727 workers whose entire experience in a dusty trade has been in metal mines. The remaining 56 workers had at some time in the past worked for more than two years in a dusty trade other than metal mines, hence their present physical condition cannot be attributed entirely to experience in one industry. This mixed exposure group showed an older age distribution and a higher incidence of silicosis (25.0 percent) than the group working only in metal mines.

Among the group of 727 metal mine workers there were 66 cases, or 9.1 percent, affected with silicosis and 42 cases, or 5.8 percent, diagnosed as borderline silicosis. No cases of silicosis were found among metal mine workers exposed to an average dust concentration of less than 6 million particles, but only two face workers are included, each having worked only one year underground. Among those employed for a period under ten years' duration, no case of silicosis was observed until the average dust concentration exceeded 18.0 million particles. The severity of pulmonary fibrosis among cases with silicosis increased greatly with increasing length of employment.

The silicosis problem among metal mine workers was found to be most acute for those persons engaged principally at the face, namely, muckers, miners, and drillers. The combination of a heavy dust concentration and a silica content of 20 to 40 percent resulted in a silicosis

1 See footnote on page 168 . 
incidence of nearly a fourth of the face workers if those with less than 6 years' of employment are excluded. The 4 men with 34 years and more employment all had silicosis. Next in importance from the standpoint of silicosis incidence was the group of workers engaged underground in occupations not at the face, including transportation workers, maintenance workers, and supervisors. In this group, 23.8 percent showed silicosis among those who had been employed for 20 years and over. Among those workers whose principal experience had been at the surface there was found only one case of first-stage silicosis (milling operations excluded).

Eighteen metal mine workers had reinfection pulmonary tuberculosis, an incidence of 2.5 percent. Fourteen had minimal and four moderately advanced tuberculosis. The four who had moderately advanced tuberculosis were thought to be active; they also had silicosis. The other 14 were quiescent, apparently arrested or healed. Nearly 14 percent (9 cases) of the silicotic workers also had pulmonary tuberculosis whereas only 1 percent of those not affected with silicosis had pulmonary tuberculosis.

Lead poisoning ranks next to silicosis as an occupational disease of workers in the three non-ferrous metal mines in Utah investigated. The health problem as regards lead in these mine workers, like the dust problem, seems to be essentially one of face workers. About 20 cases of plumbism causing periods of disability ranging from a few weeks to two months occurred in the 727 metal mine workers in the last five years, according to information recorded in their past medical histories. Seventyfive workers were diagnosed as having abnormal lead absorption (latent lead poisoning) at the time of examination. Subjective symptoms, when present, were usually gastrointestinal in character. No disabled cases of lead intoxication were found and nervous disorders such as lead encephalopathy and lead palsy were not observed, although two men (one of whom was excluded from general tabulation) were convalescing in non-leadusing occupations at the time of the study.

No other form of metal intoxication was observed, possibly because of the low exposure to the more toxic metals and metalloids, and the relatively innocuous nature of other metallic compounds such as those of gold, silver, and copper.

Complaints of headaches were much more frequent among metal mine workers than among coal mine and smelter workers. Although the incidence of headache among surface and underground other than face workers was not appreciably greater than that found for the other Utah industries studied, the percent complaining of headaches among face workers was 23.7. This excess at the face suggests the possibility of inadequate ventilation which allows the accumulation of gases, dust, and fumes after blasting. "Powder" headaches were often reported by the metal mine workers.

A few cases of mild dermatitis were attributable to contact with sulphide ores.

The prevalence of the arteriosclerotic-hypertensive group of heart diseases was approximately the same as that observed in other comparison groups of employed industrial workers, but rheumatic heart disease was slightly more prevalent. No severe cases of cardiac decompensation were examined. In spite of differences in occupational exposure to various 
toxic agents, the percentage of metal mine workers with arterial hypertension is nearly the same as employees in the Utah coal mines and smelters. On comparing the percentage of metal mine workers with hypertension by specific age groups with percentages of hypertensive potters, the rates for Utah metal mine workers is consistently lower.

Only six cases of latent syphilis were observed, which represents an incidence rate $(0.8$ percent $)$ less than half that observed in coal mine and smelter workers, and the State of Utah as a whole.

\section{SMELTERS}

\section{Environmental Study}

Studies were made of the working environment in two non-ferrous metal smelters in Utah. Atmospheric dusts were found to contain an average quartz concentration varying from 21.5 to less than 1 percent, being highest in the departments handling ore and lowest in the other departments. The median size of atmospheric dust particles was approximately 1 micron, with 97 percent of the particles being less than 5 microns.

The dust concentrations ranged from negligible amounts to as high as 400 million particles per cubic foot for certain bag house operations. However, in order to interpret the significance of these dust concentrations, it is necessary to consider the nature of the dusts. Certain workers in the sampling mills and in the other departments handling raw ore, although not exposed to dust concentrations as high as those in the bag house, were exposed to relatively high percentages of quartz, whereas the bag house dust contained only traces of this material.

Appreciable concentrations of some toxic metals, especially lead, arsenic, cadmium and antimony, occurred in some departments. The significance of these exposures is discussed in the medical summary which follows. Of special importance were the atmospheric lead concentrations, which ranged from practically none at well controlled operations to an average of nearly 6,000 milligrams per 10 cubic meters of air in certain bag house operations. These latter operations, fortunately, are of very short duration.

The investigation of gas contamination showed that toxic concentrations of carbon monoxide might occur during furnace charging operations and that sulphur dioxide was present in many departments and at times reached extremely high concentrations.

The results of a sanitary survey made at the two smelters and in the three adjacent towns are presented and recommendations have been made for improving water supplies and waste disposal in these locations.

Specific suggestions for minimizing the hazards from dusts, fumes, and gases are made. General recommendations applicable to all Utah smelters for improving the workers' environment are summarized in the section dealing with this subject.

\section{Medical Study}

During a study of the health of the workers in the smelting industry in Utah, 1,511 men were examined from one lead and one copper smelter. This number includes over two-fifths of those employed in the non- 
ferrous smelting industry in Utah. ${ }^{1}$ A group of 120 persons examined was found to have worked more than two years in some other dusty trade. Because of the possibility that their non-smelter experience might have affected their present condition, they were excluded from detailed dis. cussion. Twelve of this group had first-stage silicosis and three had second-stage silicosis. The average age of the remaining 1,391 men is 39.1 years and the average number of years of employment in smelters is 12.8 .

Among the group of 1,391 smelter workers, 37 persons (2.7 percent) showed evidence of silicosis and 65 men were considered to have borderline silicosis. No third-stage silicosis cases were observed and there were only three second-stage and 34 first-stage silicosis cases. Although not so well defined in the smelter industry as in the other industries studied, there is a general trend for the incidence of silicosis to increase with intensity and duration of exposure. This lack of definition is due to the variability of dust exposure, rotation from job to job within the industry, and the fact that free silica content of dust in occupations with high dust counts is not necessarily as great as that in occupations with low counts. Silicosis cases are distributed throughout a number of occupations, but the majority occur in the concentrating department which includes the sample mill, flotation mill, bucking and parting room, and the crushing and grinding mill workers, all processes dealing with the raw ore. Of the men engaged principally in this department for 10 to 19 years, 13.8 percent showed evidence of silicosis, while for those with 20 or more years of experience 22.6 percent were affected. The medical findings in those affected with silicosis are similar to those noted in other studies.

The incidence of pulmonary tuberculosis in the smelter workers is over twice that observed among the coal and metal mine workers of Utah, although most cases are minimal in extent and are apparently healed. No particular occupational group appears to be affected more than another, and the incidence increases with age, showing a preponderance of cases in men over 30 years of age as found in other studies. However, there is a close correlation between the development of silicosis and the incidence of tuberculosis in those affected. One borderline silicosis group has a percentage affected with tuberculosis almost twice as high and the silicosis group has a percentage affected three times as high as the workers who had no evidence of silicosis. Factors other than exposure to siliceous dust apparently play a part in producing the higher incidence of reinfection tuberculosis among smelter workers. The group free from silicotic or pre-silicotic change shows 4.9 percent with tuberculosis among smelter workers, compared with 2.2 percent among a similar group of coal mine workers, and 1.0 percent among metal mine workers.

A total of 41 workers (2.9 percent) was found to show clinical manifestations indicating abnormal lead absorption or latent plumbism. No cases of acute plumbism were observed during the study, although one worker was examined who was convalescing from a recent attack of lead poisoning. These cases occurred primarily in the handling of raw ore and in connection with the roasting processes.

A history of acute disabling lead poisoning during the past five years was recorded in 14 cases (1 percent), and a history of lead poison-

1 See footnote on page 250 . 
ing prior to five years previously was recorded in 28 cases (2 percent), occurring principally in the same occupations. The average duration of disability in these cases was one month.

Although but few manifestations of lead poisoning were found in these smelters, disabling attacks of this disease do occur from time to time. Lead poisoning is a potential hazard in the handling of flue dust in the copper smelters and in all processes in lead smelters where substantial concentrations of lead dust and fumes are present.

Attention has been called to the arsenic hazard and the effects noted in this and other industries. No definite cases of dermatitis or other acute forms of arsenical poisoning were noted in the smelter workers, although the arsenic recovery plant was not in full operation at the time of this investigation. There were, however, 75 cases (5.4 percent) showing performation of the nasal septum, which was presumably due to the action of arsenic compounds encountered in the smelting processes. There was no apparent disability or deformity noted in association with these septal perforations.

Inflammation of the eyes, nose, and throat, and gastrointestinal disorders were observed more frequently in the 1,391 smelter workers than in the coal miners. It is probable that sulphur dioxide is a factor of importance in this connection.

Although no clinical manifestations of intoxication from other metals and gases, not mentioned above, were observed, it should be emphasized that injurious effects are possible in the event of any future exposure to toxic concentrations of these dusts, fumes, or gases. As described elsewhere, certain potentially hazardous processes were not in full operation at the time of the medical study.

The physical findings of diseases apparently unrelated to any occupational exposure observed among the smelter workers compared favorably with those found in previous studies of industrial groups.

\section{CONCLUSIONS}

The correlations between exposure to siliceous dust and the evidence of constitutional changes left little doubt as to the etiological significance of the dust in the air breathed. Like correlations were found between the lead dust exposure and evidence of plumbism.

Silicosis was the principal occupational disease found among 2,839 coal and metal mine workers and smelter workers, as shown in Table A. Sixteen cases ( 3.2 percent) were found in 507 soft coal miners, 66 cases (9.1 percent) were found among 727 metal mine workers, and 37 cases (2.7 percent) were found among 1,391 smelter workers. Thirty-five other cases of silicosis were found in 214 workers who gave a history of having worked more than two years in a dusty trade other than the one in which they were employed during this study, and so were excluded from the above tabulation. Of these 35 cases of silicosis with a varied exposure, six were employed in coal mines, 14 in metal mines, and 15 in smelters at the time of the study. Thus, if these cases with mixed industrial exposures are included in the above groups, there were 154 silicosis cases observed-22 ( 4 percent) in 545 coal miners, 80 ( 10.1 percent) in 783 metal mine workers, and 52 (3.4 percent) in 1,511 smelter workers. 


\section{TABLE A-A Comparison of the Incidence of Silicosis Among Workers in Utah Coal Mines, Metal Mines, Smelters, and in the Mixed Dust Exposure Group, ${ }^{1}$ Classified by Years Employed}

\begin{tabular}{|c|c|c|c|}
\hline \multirow[b]{2}{*}{ Years Employed } & \multirow{2}{*}{$\begin{array}{l}\text { Number of } \\
\text { Workers }\end{array}$} & \multicolumn{2}{|c|}{$\begin{array}{c}\text { Workers Affected With } \\
\text { Silicosis2 }\end{array}$} \\
\hline & & Percent & Number \\
\hline Coal Mines: & \multirow{5}{*}{$\begin{array}{l}507 \\
209 \\
179 \\
119\end{array}$} & \multirow{2}{*}{3.2} & \multirow{5}{*}{$\begin{array}{c}163 \\
0 \\
3 \\
13\end{array}$} \\
\hline Less than 10 years.. & & & \\
\hline 10-19 years & & 1.7 & \\
\hline 20 years and over......... & & 10.9 & \\
\hline Metal Mines: & & \multirow{5}{*}{$\begin{array}{r}9.1 \\
1.0 \\
13.2 \\
30.5\end{array}$} & \\
\hline TOTAL . & \multirow{4}{*}{$\begin{array}{l}727 \\
394 \\
228 \\
105\end{array}$} & & \multirow{5}{*}{$\begin{array}{r}66 \\
4 \\
30 \\
32\end{array}$} \\
\hline Less than 10 years. & & & \\
\hline $10-19$ years ............... & & & \\
\hline 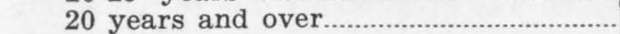 & & & \\
\hline Smelters: & & & \\
\hline TOTAL ........ & \multirow{5}{*}{$\begin{array}{r}1,391 \\
649 \\
471 \\
271\end{array}$} & \multirow{5}{*}{$\begin{array}{l}2.7 \\
0.2 \\
3.8 \\
6.6\end{array}$} & \multirow{5}{*}{$\begin{array}{r}37 \\
1 \\
18 \\
18\end{array}$} \\
\hline Less than 10 years.... & & & \\
\hline $10-19$ years ........................ & & & \\
\hline 20 years and over........................ & & & \\
\hline Mixed Dust Exposure Group1: & & & \\
\hline TOTAL̂L & 214 & 16.4 & $35^{4}$ \\
\hline Less than 10 years & 89 & 9.0 & 8 \\
\hline 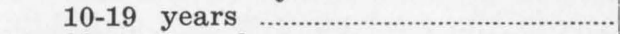 & 79 & 15.2 & 12 \\
\hline 20 years and over & 46 & 32.6 & 15 \\
\hline
\end{tabular}

1 Into this group are classified workers in the coal mines, metal mines and smelters with more than 2 years' experience in a dusty trade other than the one in which they were employed at the time of the study.

2 No cases of third stage silicosis were observed.

3 Anthraco-silicosis, a modified form of silicosis, was found among the bituminous coal miners.

4 Of these, 6 were at present employed in the coal mines, 14 in metal mines, and 15 in the smelters.

Of these 154 cases of silicosis, 113 (73 percent) were considered first-stage with but little disability; 41 (27 percent) were diagnosed as second-stage silicosis with moderate disability; and no third-stage silicosis with severe or total disability was found.

The relationship of pulmonary fibrosis, as shown by the X-ray film, to age and industrial employment is shown in Figure A, where it may be seen that with advancing age the proportion of workers with increased pulmonary fibrosis (ground-glass, nodular, or conglomerate markings) increases rapidly in all three industries, but more rapidly in the metal mines.

Pulmonary tuberculosis was found in 6.2 percent of the 16 coal miners with silicosis, in 13.6 percent of 66 metal mine workers with silicosis, and in 16.2 percent of 37 smelter workers with silicosis, as contrasted with 2.1 percent, 1.0 percent, and 4.9 percent of the nonsilicotic workers in these three industrial groups, respectively. It is apparent, therefore, that tuberculosis occurs several times as frequently among silicotic workers as among workers with no silicosis. The incidence of tuberculosis among the workers with no silicosis in the coal and metal mines is about that of the general population, whereas the incidence of tuberculosis, mostly minimal, among the nonsilicotic smelter workers is about twice as high as the general population.

The incidence of silicosis in all three industries increased rapidly with increasing average dust concentrations and increasing duration of exposure. Both the medical and engineering findings in these industries 


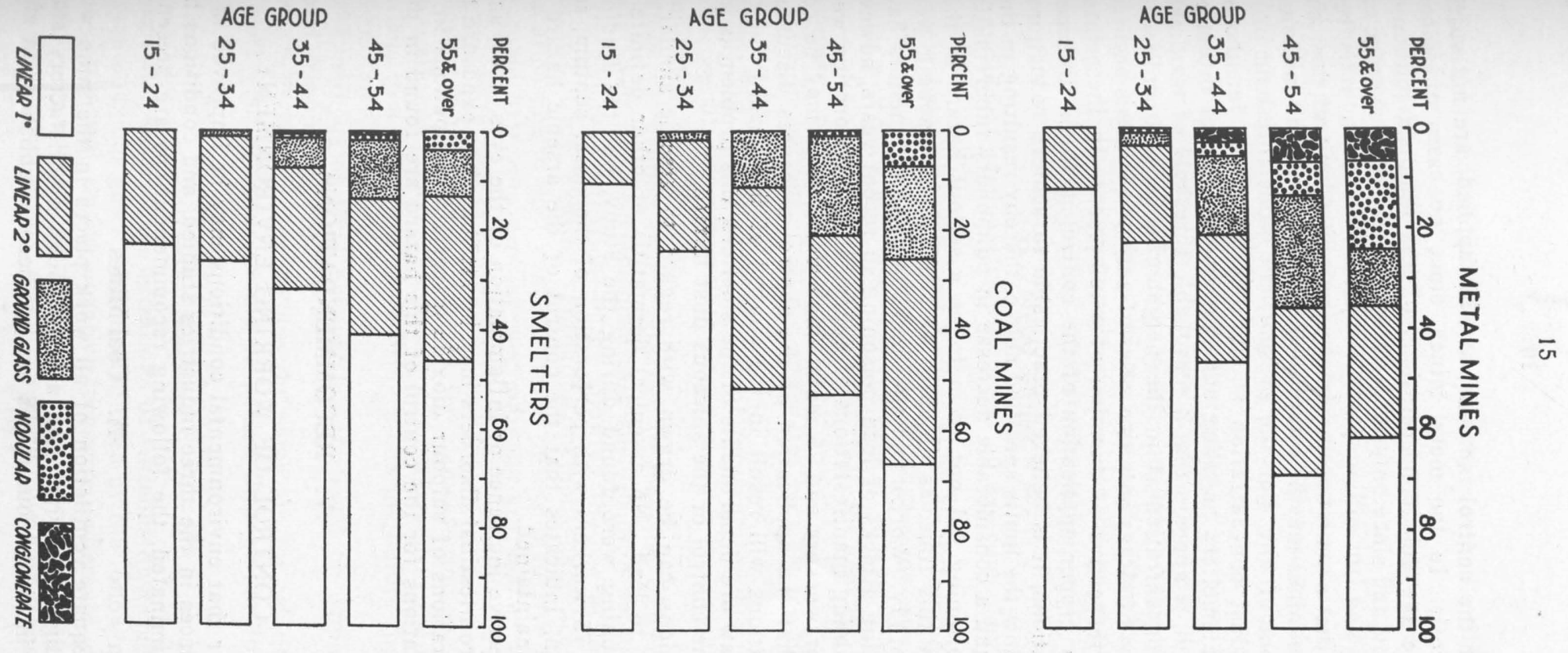

FIGURE A-A comparison of $X$-ray findings indicating degree of pulmonary fibrosis among workers in metal mines, coal mines, and smelters, classified by age. 
indicate that the control methods, as now applied, are not sufficient to prevent silicosis. In the metal mines, since no cases of silicosis were found in average dust concentrations of less than six million particles per cubic foot, and since only three cases occurred with average exposures between six and 10 million particles per cubic foot, it is reasonable to conclude that a tentative maximal permissible limit of dust concentra. tion for these mines may be established at from five to 10 million particles per cubic foot of air. For the present, the same threshold of maximal permissible dust concentration should be established for those departments in the smelters handling siliceous materials. For bituminous coal mines in Utah, it appears that a reasonable threshold of maximal permissible dust concentration is in the neighborhood of 20 million particles per cubic foot of air, as only two cases of anthraco-silicosis occurred below this level, irrespective of duration of employment. In these three industries, with a proper application of the control methods discussed in the recommendations, it is believed practicable to achieve reductions in dust exposure below the limits specified above, thereby resulting in the control of silicosis and a considerable decrease in pulmonary tuberculosis.

Lead poisoning did not seem to be a serious hazard in these three industries at this time, as no cases of acute lead poisoning were found during the study. Workers in the metal mines and smelters had experienced disabling attacks of lead poisoning in recent years, however. Clinical, nondisabling manifestations of abnormal lead absorption were found in 41 smelter workers and 75 metal mine workers. It may be concluded therefore, that the application of the control measures discussed in the recommendations will result in the control of this hazard. In the metal mines and raw ore departments of the smelters, this problem is intimately related to the control of the siliceous dust hazard.

Conclusions can be drawn with regard to arsenic similar to those with regard to lead. No arsenical dermatitis or other definite signs of arsenic poisoning were found during the study, but the finding in the smelters of 75 workers with perforation of the nasal septum, several of recent origin, indicates that the control of the arsenic hazard must be constantly maintained.

An excessive incidence of inflammation of the eyes, nose, and throat and of gastrointestinal disorders may be attributed to exposure to irritat ing concentrations of sulphur dioxide in certain occupations in smelters Recommendations for the control of this hazard are found in the follow ing section.

\section{RECOMMENDATIONS}

\section{CONTROL OF WORKING ENVIRONMENT}

In order that environmental conditions may be improved in the vari ous work places in the three industries studied, and conditions hazardou to health eliminated, the following recommendations are presented.

\section{A. Coal Mines}

1. Adequate ventilation of all work places in the mine would tend to replace dusty air with clean air. Although a satisfactory standard of air velocity in bituminous mines has not been established, an air velocity 
of at least 50 feet per minute seems desirable from the standpoint of eliminating dead ends.

2. One important source of silica dust in the haulageways is sand used to prevent slipping of the transport locomotives. Thorough wetting of the roadbed would minimize the dust hazard in the haulageways.

3. The greatest potential silica dust hazard was in sand drying operations when the dry sand was screened. The screens should be enclosed, and provided with an exhaust fan to carry away the dust generated during this activity.

4. In the working of low seams the amount of air should be greatly increased in order to remove the dust as quickly as possible.

5. Tipple operations generate excessive amounts of dust which might be lessened by a more thorough wetting of the coal before loading in the mine. However, a more satisfactory solution would be the installation of a wet-washing machine or local exhaust ventilation.

\section{B. Metal Mines}

1. Provision of adequate ventilation at all working places by means of mechanical ventilation.

2. Employment of proper wet drilling methods, including wet collaring, in all mechanical drilling operations. Arrangements should be made for supplying wet drills with water at the rate of at least one gallon per minute and drills should be so maintained that the leakage of air into the water stream is minimized.

3. Thorough wetting of all ore and waste rock (muck piles) before loading and during loading.

4. Sprinkling of haulageways and of faces before blasting.

5. The use of water curtains for preventing the promulgation of dust disseminated from blasting.

6. When wet drilling is not effective in reducing concentrations of dust to safe levels it is recommended that such drilling be supplemented by adequate general ventilation, or by allowing the use of local exhaust hoods or traps. Local exhaust ventilation methods have been shown to reduce the atmospheric dust concentrations to less than five million particles per cubic foot; the present wet methods are seldom effective in obtaining concentrations as low as five million.

7. Separate raises should be used for manways and for ore chutes.

8. A sufficient period of time should be allowed to reduce the dust concentrations to a safe limit after firing a charge, before the next shift is allowed to enter the mine.

9. Wet methods or local exhaust hoods should be employed in the bucking and crushing of ore.

10. Where it is necessary to use the same air for ventilating more than one work place, this air should be passed through settling chambers or air cleaners.

\section{Smeiters}

1. High atmospheric concénı́rations of siliceous cust, metallic dusts and fumes, and noxious gases rnày be eliminated by the following methods:

a. Enclosure under negative pressure, wherever possible, of sources of siliceous or ketallic dist, sich"as crushers, sampling machines, screens, conveyors, and ore feed, or tlue dust transfers. 
b. Use of local exhaust hoods at dust, fume, and gas sources which cannot be enclosed.

c. The use of screw conveyors, or some other enclosed convey. ing system, for the removal of dust from collection hoppers in flues, bag houses, and precipitators.

d. Use of vacuum cleaners for removing dust from girders, walls, and floor in sample mills, bucking rooms and crushing plants, and, wherever possible, the substitution of vacuum cleaning or wash. ing for the present practice of blowing off dust with compressed air jets.

e. When compressed air jets must be used for cleaning equip. ment this equipment should be provided with a system of exhaust hoods and ducts which will remove the dust from the working place during the blowing process.

f. Provision of mechanical general ventilation in all work places where natural ventilation is not dependable.

g. Provision of the proper type of personal respiratory protec tion for workers exposed to hazardous concentrations of dusts, fumes and gases, and the correct use and maintenance of these devices Respiratory protective devices should only be used against the typ of substance, and within the concentration limits of that substance for which its use has been approved by the U. S. Bureau of Mines No filter-type respirator will give protection against poisonous gases and no gas mask will protect a man in an atmosphere deficient i oxygen. Air-line respirators or oxygen breathing apparatus shoul be used wherever the possibility of an oxygen deficiency is suspected 2. The present safety program in the smelting industry should b intensified, and should receive more cooperation from both managemen and employees. Increased use of safety clothing, goggles, and hard shoe and hats is recommended.

3. Illumination levels should be raised in practically all departments

4. Maintenance of dust, fume, and gas control equipment merit the full-time attention of a division of the health and safety departmen in each smelter. The best control system is worse than none at all unles properly maintained and operated, since by giving a false sense of secur ity it may prevent the use of emergency forms of protection.

\section{General Recommendations for Engineering Control}

In addition to the methods of control recommended herein, certai other preventive methods have been found to be of practical value other industries presenting similar problems.

1. Dust should be controlled at its point of generation so as to prevent it from reaching the breathing zone of the workers or contaminating the general air. Thorough wetting by water is a general method of dust control at the point of origin. Material abatement of dust in the working environment may, be abtained by wet methods in almost all mining and processing operations.

2. The recommendations of the American Standards Association on general sanitation, as given in Code Z4.1, șould be adopted.

3. Periocic studies of the condition of the working environmen appear necessary to determine whether the control methods adopted ar 
really adequate. The work of inspection and review should be performed by persons trained for such studies.

4. The findings revealed by the sanitary survey indicate the necessity for proper sewage disposal in the communities adjacent to the industrial establishments investigated, and an improvement in the present unsafe methods of fecal disposal in the mines proper. Contaminated sources of water supply should be properly serilized. This applies especially to some of the privately owned water supplies.

\section{MEDICAL CONTROL OF OCCUPATIONAL DISEASES AND PROMOTION OF THE WORKER'S HEALTH}

1. In addition to the preemployment physical examination, a technically good roentgenogram should be made of every applicant seeking employment.

2. Annual medical examinations, including X-ray film of the chest, should be made to detect cases of active pulmonary tuberculosis in order that they may be placed under medical care, and to detect early silicotic changes in order to call attention to deficiencies in dust control. These physical examinations also enable the physician to practice preventive medicine in that he can detect other common aliments such as high blood pressure, nephritis, diabetes, syphilis, and heart disease during their incipient stages, and can advise the worker as to the means for avoiding the serious consequences of these diseases. He can also advise the worker at this time in the practice of personal hygiene and suggest corrective measures for various defects that may later cause serious physical impairments.

3. It is recommended that no worker be removed from work to which he is accustomed, and at which he is able to earn his living, merely because a diagnosis of simple silicosis has been made. Rather, the atmospheric dust in which he works can and should be brought within safe limits. If this is done his silicosis will not advance appreciably more rapidly than if he were made a clerk or given outdoor employment, and, if it is not done, removing him and putting a fresh man in his place will expose another worker to the same hazard. It is urged that the man be left and the dust removed, rather than that the dust be left and the man removed.

4. When active tuberculosis exists, it is another matter. Every tuberculous worker should be removed from a dusty industry, put under treatment, and not permitted to return. Any further exposure to silica will be harmful to him and he constitutes a danger to his fellow workers. Since infection is the main cause of serious progression of silicotic fibrosis, the adoption of those preventive measures which will materially reduce the possibility of contact with pulmonary infection may serve to postpone, if not actually stop, the progress of early changes (fibrosis) in the lung tissue. Furthermore, such preventive measures may and should be so efficient that no disability due to silicosis will develop in the usual working lifetime. It appears quite possible that the worker with a nondisabling simple silicosis will be safer continuing in a so-called dusty industry where the dust is properly controlled and from which tuberculous workers are carefully excluded, than if he were transferred to nondusty work with 
less attention paid to contact with fellow workers having active pulmonar tuberculosis.

5. Calcifications in chest roentgenograms indicating healed primar tuberculosis (complex) do not seem to be a contra-indication for employ. ment in a dusty trade.

6. Close medical supervision is recommended of all workers in dust trades in order to prevent common respiratory infections such as colds grippe, influenza, and pneumonia, as they seem to have more seriou after-effects in silicotic than in nonsilicotic persons, and even in nonsil cotic workers may leave damaged areas of lung tissue that will be unfavor ably affected by subsequent dust exposure. Workers convalescing from these diseases should be advised not to return to work until completel recovered.

7. It is poor hygienic practice to permit miners or smelter worker to leave the mines or other work places wearing work clothes wet wit perspiration and water from mining processes. This is particularly tru in inclement weather, as such exposures favor the acquisition of respir tory infections. It is recommended that all such industries provide chang houses with facilities for hot and cold shower baths and drying room and lockers for clothing, including provisions for both work and stree apparel. These change houses should be conveniently located to insur minimal exposure to weather after leaving the work place.

8. The essence of a medical program to prevent lead poisoning to minimize lead absorption and necessitates preemployment and period medical examinations. In departments or occupations with serious le exposure, these examinations should be made often enough to preven the occurrence of disabling lead poisoning. These examinations might wel include blood study with regard to reticulocyte counts and basophili stippling. In some instances, it may be desirable to supplement the laboratory tests with chemical determinations of the lead content of blo and excreta as an index of abnormal lead absorption.

9. All workers should be reexamined by the medical departme when reporting back to duty after absence on account of illness.

10. Employees should be encouraged to report all minor nondisa ling illnesses, particularly gastrointestinal, in order that the medic department may ascertain whether or not they are due to lead or oth toxic agents.

11. The plant physician should be familiar with various plant pr cesses and make periodic inspections of the plant. He should report the industrial hygiene or safety engineer the occurrence of "leadin in certain departments or occupations in order that proper preventi measures may be taken to prevent further injury to workmen.

12. Care should be required of the employee in personal cleanline and eating habits to avoid unnecessary ingestion and inhalation of le and other toxic agents.

13. It is recommended that silicosis, lead poisoning, arsenic poiso ing, and other occupational diseases be reported to the State Board Health.

The basic data revealed through this study evidences the importanc and need of a program, designed not only to prevent and control indus trial health hazards, but, at the same time, to render a complete healt 
service to the gainfully employed population of Utah. Such a program is a legal responsibility of the State and local health departments, and can be provided through the continuation of the State Industrial Hygiene Unit as it is now organized and functionce in this field and have had valuable training and a program effectively. Therefore, it is recommended:

That the Industrial Hygiene Unit be continued as a neutral, factfinding, and educational agency, designed to consult with and offer medical, engineering, and laboratory services to industry, labor, the Industrial Commission, the medical profession, and other interested groups, and work cooperatively with same in the solution of industrial hygiene problems.

That the industrial hygiene program be integrated with all other services of the State and local health departments, and serve as the medium or clearing house through which the entire public health program may be brought into the working places, homes, and communities of the gainfully employed workers.

That the various industrial groups of the State be utilized as "contact units for public health activity," just as our public schools are now being used as the chief medium or approach for promoting and protecting the health of children.

That among the more important and specific services which may be rendered by the official industrial hygiene division, the following should be emphasized:

1. Consultation with plant management regarding needed corrections of environmental conditions.

2. Advice to the management and medical supervisor as to the relative toxicity of materials or processes, and advice concerning new materials prior to their introduction into the industry.

3. Assistance in developing, maintaining, and analyzing absenteeism records.

4. Consultant service to medical supervisors, private physicians, compensation authorities, and other State agencies regarding illness affecting workers.

5. Provision of necessary laboratory service of both a clinical and physical nature.

6. Integration of the activities of other public health bureaus in their programs for workers; for example, the control of cancer, syphilis, and tuberculosis. 

VI. GENERAL PROCEDURE 


\section{ENVIRONMENTAL STUDY}

An important procedure in the search for major factors in the caus tion of disease of suspected occupational etiology is a detailed investig tion of the conditions under which the work is performed. In the presen study, investigations of the working environment consisted of an analys of the various operations and activities involved in the three industri studied (bituminous coal mining, nonferrous metal mining, and nonfer rous metal smelting), and the sampling and analysis of the atmospher dusts, fumes, and gases. In addition, certain data were obtained on ter perature, humidity, air movement, illumination, and sanitation faciliti in these industries. A sanitary survey of the communities surroundin the workplaces was also made.

\section{Nature and Scope}

Knowledge of potential hazards associated with each occupation coal mining, metal mining, and metal smelting, and the number so posed, was obtained from a preliminary survey conducted by the U. Public Health Service and the Utah State Board of Health (1). On t basis of information obtained during this survey, representative ente prises in each industry - three coal mines, three metal mining interprise and two smelters--were selected for detailed study. Insofar as possib the identity of individual mines or plants has not been disclosed in report, and data given relative to a specified mine field have been co sidered typical of all mines in that area. The location of the princip mining fields and the smelters is shown in Figure 1.

All three industries are subject to wide occupational fluctuatio With regard to each industry as a whole, these fluctuations depend market conditions. With regard to an individual enterprise, fluctuatio in employment will also be caused by changes in technology, and, in min by variations in the quality and location of the ore or coal. Each indiv ual mine has its life definitely limited by the extent of the mineral posits being worked. Moreover, the ore deposits of non-ferrous meta usually worked by shaft and drift methods, are seldom uniform or ce tinuous, and frequent decreases or increases in the number of employe are caused by the exhaustion of rich veins, or the discovery of new reserv respectively. Consequently, the time of study was so selected that avera environmental and employment conditions were obtained in each industr

The three coal mines selected for study were all located in the pri cipal coal mining district. They represented both hand and mechaniz operations as practiced in Utah.

The metal mines studied were operated by three different companie and were in three different mine fields. All were underground min extracting lead-copper or lead-silver ores, in which gold and zinc occasio ally occurred in sufficient amounts to be considered as supplementa ores. This study did not apply to the mining of iron, manganese, mercury ores existing as independent deposits. Compounds of iron, ma ganese, arsenic, cadmium, selenium, and mercury occurred in the cor mercial ores being mined, and both arsenic and cadmium were beir recovered in the smelting process, and were of hygienic significance the However, neither the medical nor the engineering data showed that the elements were occurring in sufficient concentrations in the mines studi to constitute a health hazard in the mining, crushing or wet concentr 


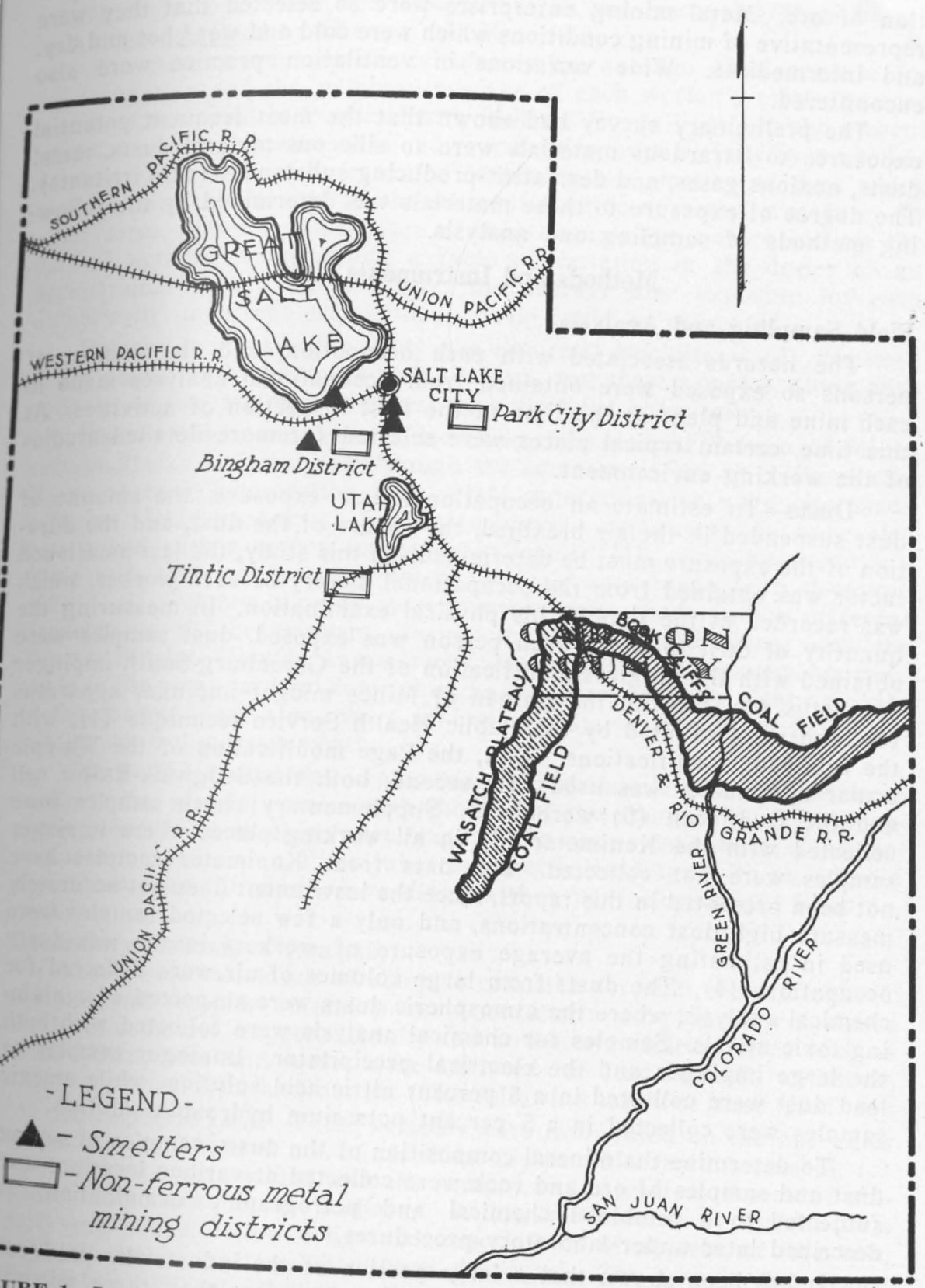

IGURE 1-Location of main coal mines, metal mines, and smelters in the State of
Utah. 
tion of ore. Metal mining enterprises were so selected that they wer representative of mining conditions which were cold and wet, ${ }^{1}$ hot and $\mathrm{dry}$ and intermediate. Wide variations in ventilation practice were als encountered.

The preliminary survey had shown that the most frequent potentia exposures to hazardous materials were to siliceous mineral dusts, metal dusts, noxious gases, and dermatitis-producing substances (skin irritants) The degree of exposure to these materials was determined by the follow. ing methods of sampling and analysis.

\section{Methods and Instruments Used}

\section{Field Sampling and Analysis}

The hazards associated with each occupation, and the number persons so exposed were obtained from occupational analyses made each mine and plant at the time of the first inspection of activities. this time, certain typical places were selected for more detailed studie: of the working environment.

Dusts - To estimate an occupational dust exposure, the amount dust suspended in the air breathed, the nature of the dust, and the dura tion of the exposure must be determined. In this study, the last-mentione factor was obtained from the occupational history of each worker, whic was recorded at the time of his physical examination. In measuring th quantity of dust to which each person was exposed, dust samples we obtained with the all-glass modification of the Greenburg-Smith imping apparatus (2), or with the Bureau of Mines midget impinger apparat (3), and were counted by the Public Health Service technique (4), wi the following modifications. First, the Page modification of the Whipp ocular micrometer was used (5); second, both the Sedgwick-Rafter ce and the Dunn cell (6) were used. Supplementary check samples we collected with the Konimeter (4) in all working places where impinge samples were not collected. The data from Konimeter samples ha not been presented in this report, since the instrument does not accurate measure high dust concentrations, and only a few selected samples we used in estimating the average exposure of workers in the less dus occupations (4). The dusts from large volumes of air were collected $f$ chemical analysis, where the atmospheric dusts were suspected of contai ing toxic metals. Samples for chemical analysis were collected with bo the large impinger and the electrical precipitator. Impinger samples lead dust were collected in a 5 percent nitric acid solution, while arsen samples were collected in a 5 percent potassium hydroxide solution.

To determine the mineral composition of the dusts, samples of settl dust and samples of ore and rock were collected at various locations a subjected to a combined chemical and petrographic examination, described later under laboratory procedures.

It has been shown that a large portion of the industrially produce dust particles suspended in the atmosphere are less than three micro in longest dimension, a size permitting access to the lung tissue Therefore, consideration was given to the size of the dust particles pended in the working atmosphere. This was done by taking portior

1 Wet mining refers only to ground water. Wet drilling was used in all Utah mines. 
of the dusts collected in the impinger tubes and measuring them by the technique dsecribed by Chamot and Mason (8).

The method employed in calculating the average dust exposure for an occupation and the weighted average of each worker's total exposure has been described in Public Health Bulletin No. 217 (4). In the present study, dust samples were obtained representing each activity in a number of dusty occupations, in order to determine the amount of dust which each activity contributed to the sum total of occupational exposure. In other cases, sampling times were of long enough duration to include the various activities constituting a cycle of variation in the duties of an occupational group. In this way, the average dust exposure for each numerically important occupational group could be estimated.

Fumes-In the smelter study, the electrical precipitator (9) was used in the collection of fumes as well as dusts, and these samples, along with portions of the impinger samples, were analyzed chemically.

Gases-Mine gases were collected in the standard Bureau of Mines vacuum flasks and analyzed through the courtesy of the U.S. Bureau of Mines at their laboratories (10). Field determinations were also made with an Orsat apparatus. Carbon monoxide concentrations were also determined with a carbon monoxide indicator (11), while hydrogen sulphide and hydrogen cyanide determinations were made with detectors (12) (13). Sulphur dioxide measurements were made in the different departments of the smelters, during the various operations, with the Thomas Sulphur Dioxide Autometer ${ }^{1}$ (14). Additional measurements were made in the plant yards to determine the concentrations of sulphur dioxide in the general plant atmosphere, and other tests were made in Salt Lake City as control measurements.

Other Determinations-Temperature and humidity readings were made at the working places with the aid of the standard sling psychrometer; ventilation readings were made with a vane anemometer, a thermoanemometer (15), or a Pitot tube; barometric readings with an aneroid barometer; and illumination readings with a photoelectric cell illuminometer.

\section{Laboratory Methods of Analysis}

There were two kinds of samples collected for analysis, atmospheric samples and samples of materials. Atmospheric samples were analyzed for lead, cadmium, copper, arsenic, and antimony, while samples such as settled dust, ores and rocks, were analyzed for lead, arsenic, antimony, cadmium, total silica and quartz. The following methods were used.

Atmospheric Lead-These samples were evaporated on the hot water bath down to about $5 \mathrm{ml}$. in platinum dishes. Five millimeters of $1: 1$ sulphuric acid were added and the sample was carried to fumes of sulphuric acid on a hot air radiator. A few millimeters of hydrofluoric acid were added, followed by small amounts of nitric acid, at intervals, until all organic material had been destroyed. The sample was transferred to a $250 \mathrm{ml}$. Phillips beaker and diluted to $200 \mathrm{ml}$. It was next treated with hydrogen sulphide and allowed to stand overnight. The sulphide precipitate was filtered off and dissolved into a $125 \mathrm{ml}$. Phillips

1 We are indebted to the American Smelting and Refining Company and to Dr. Moyer D. Thomas ing this apparatus. 
beaker with about $10 \mathrm{ml}$. of hot $1: 1$ nitric acid followed by hot water. The solution was boiled to get rid of any sulphur. It was then neutralized with sodium hydroxide solution. This was followed by acidifying with acetic acid. The solution was heated to boiling and lead was precipitated as the chromate by the addition of a potassium chromate solution. The precipitate was allowed to digest overnight on the steam table and after allowing to cool was collected on a filter paper and washed thoroughly with water. It was next dissolved with cold 1:9 hydrochloric acid and washed through the paper into the beaker in which the chromate precipitation was made.

Potassium iodide, not in too great excess (usually not over one-half gram), was then added and the liberated iodine was titrated with 0.005 $\mathrm{N}$ sodium thiosulphate using starch as an indicator (16).

In cases where the lead chromate was considerable, the following modified procedure was used: The lead chromate was filtered onto a Gooch crucible, washed, and then dried in the oven at $110^{\circ}$ and weighed.

Atmospheric Cadmium-The filtrates from the lead determinations were taken for the cadmium analyses. The excess chromate was first reduced with hydroxylamine hydrochloride. The samples were then treated with hydrogen sulphide. The precipitates were washed with 0.1 percent hydrochloric acid saturated with hydrogen sulphide, dissolved with hydrochloric acid followed by nitric acid where necessary. These solutions were next re-precipitated with hydrogen sulphide from acid solution. The precipitates were then treated with freshly prepared ammonium sulphide to dissolve out any of the arsenic group present.

The sulphide residue was dissolved with nitric acid and the solution was neutralized with ammonia. The presence of copper was now indicated by the blue color of the ammoniacal solution. Further traces of copper were tested with potassium ferrocyanide reagent. In the cases where copper was found present the sample was divided into two portions, one for the estimation of cadmium and the other for copper.

1. Determination of cadmium in the absence of copper.

The solution was acidified with sulphuric acid and cadmium sulphide was precipitated with hydrogen sulphide. The cadmium sulphide was converted to the sulphate and weighed as such (17).

2. Determination of cadmium in the presence of copper.

Potassium cyanide was added to the ammoniacal solution and cadmium sulphide precipitated upon treatment with hydrogen sulphide. The precipitate of cadmium sulphate was treated as in (1) above.

Atmospheric Copper-The portions of solution set aside from the cadmium analysis were acidified with nitric acid and the copper determined electrolytically.

After precipitation of the lead as chromate, as previously described, the filtrates were taken for subsequent analysis of copper. The sulphide was precipitated with hydrogen sulphide and dissolved in nitric acid. Sulphuric acid was added and the solution evaporated down to fumes of sulphuric acid. These sulphuric acid solutions, after dilution with water, were treated with metallic aluminum to deposit the copper by electro-deposition. The copper was redissolved in nitric acid and bromine water was added to oxidize any arsenic and antimony that might be pres- 
ent. The solutions were boiled to expel excess bromine and then evaporated almost to dryness. The copper nitrate residues were treated with sodium hydroxide solution until a slight permanent precipitate of cupric hydroxide formed. Acetic acid was now added, then potassium iodide and the liberated iodine was titrated with sodium thiosulphate using starch as an indicator (18).

Atmospheric Arsenic-These samples were obtained in 5 percent potassium hydroxide solution. They were chlorinated, treated with sulphuric acid and then taken down to fumes of sulphuric acid. Arsenic was then determined by the Gutzeit method (17).

Total Silica and Heavy Metals in Material Samples-These chemical analyses were carried out according to the standard methods of rock analysis (16) (19). Lead was weighed as the chromate; arsenic as the sulphide; antimony was titrated with potassium permanganate; and cadmium was weighed as the sulphate.

The free silica or quartz content of these samples was determined petrographically. A preliminary separation of the sample into fractions of approximately the same size was made by air elutriation. The Roller Particle Size Analyzer (20) was used for this purpose. The volume of sample necessary for such a fractionation is about $25 \mathrm{ml}$. and separations may be accomplished in about seven hours. The samples were separated arbitrarily into fractions of $0-5,5-10,10-20,20-40,40-80$, and $80+$ microns based on the specific gravity of quartz. According to the theory on which such separations are based, the sample is fractionated into portions whose particles are all the same weight. This being the case, the percentage of quartz particles in a given fraction by count should be equal to the percentage of these particles by weight. Thus, the quartz particles were identified with the petrographic microscope and counted (usually 200 particles in a fraction were counted) and the percentage of quartz was determined. A summation of the quartz content of all the fractions of the sample was made and in this way the percentage of quartz in the samples was obtained (21).

\section{References}

1. Page, R. T., and J. J. Bloomfield: Evaluation of the industrial hygiene problem of the State of Utah. U. S. Public Health Service Multilith Publication R-670. 1938.

2. DallaValle, J. M.: Note on comparative tests made with the Hatch and the Greenburg-Smith impingers. U. S. Public Health Reports 52: 1114-1118. 1937.

3. Schrenk, H. H., and F. L. Feicht.: Bureau of Mines midget impinger, U. S. Bur. Mines Information Circular 7076. 1939.

4. Bloomfield, J. J., and J. M. DallaValle: The determination and control of industrial dust. U. S. Public Health Bull. 217. Washington, Gov. Print. Off. 1935.

5. Page, R. T.: Note on a new ocular micrometer for use in dust counting. U. S. Public Health Reports 52: 1315-1316. 1937.

6. Dunn, K. L.: Note on an improved cell for dust counting. J. Ind. Hyg. Toxicol. 21: 202-203. 1939.

7. Bloomfield, J. J.: Size frequency of industrial dusts. U. S. Public Health Reports 48: 961-968. 1933. 
8. Chamot, E. M., and C. W. Mason: Handbook of chemical microscopy New York, John Wiley and Sons, Inc. 1930. p. 402.

9. Barnes, E. C., and G. W. Penny: An electrostatic dust weight sampler. J. Ind. Hyg. Toxicol. 18: 167-172. 1936.

10. Yant, W. P., and L. B. Berger: Sampling mine gases and use of the Bureau of Mines portable Orsat apparatus in their analysis. U. S, Bur. Mines Miners' Circular 34. Revised June 1936.

11. Katz, S. H., D. A. Reynolds, H. W. Frevert, and J. J. Bloomfield: Development and characteristics of carbon monoxide recorder. J. Amer. Soc. Heat. and Vent. Eng. 32: 349-374. 1926.

12. Littlefield, J. B., W. P. Yant, and L. B. Berger: A detector for quantitative estimation of low concentrations of hydrogen sulphide. U. S. Bur. Mines Report of Investigations 3276. 1935.

13. Report of Sub-Committee on Chemical Methods in Air Analysis: Sampling and sampling devices. Amer. Public Health Assoc. Year Book, 1939-40.

14. Thomas, M. D.: Determination of sulphur dioxide. Ind. and Eng. Chem., Anal. Ed. 4: 253-254. 1932.

15. Yaglou, C. P.: The heated thermometer anemometer. J. Ind. Hyg. Toxicol. 20: 497-510. 1938.

16. Fairhall, L. T.: Lead Studies: I. The estimation of minute amounts of lead in biological material. J. Ind. Hyg. Toxicol. 4: 9-20. 1922.

17. Hillebrand, W. F., and G. E. F. Lundell: Applied inorganic analysis. New York, John Wiley and Sons, Inc. 1929.

18. Fales, Harold, and Frederic Kenny: Inorganic quantitative analysis. New York. D. Appleton Century Co. 1939.

19. Scott, W. W.: Standard methods of chemical analysis. Ed. 5. Edited by N. H. Furman. In two volumes. New York, D. Van Nostrand Co., Inc. 1939.

20. Roller, P. S.: Size distribution of ceramic powders as determined by a particle-size air analyzer. J. Amer. Ceramic Soc. 20: 167. 1937.

21. Goldman, F. H.: Methods for the determination of quartz in industrial dusts. U. S. Public Health Reports 52: 1702. 1937. Reprint 1882. 
VI. GENERAL PROCEDURE 


\section{MEDICAL STUDY}

\section{Objectives}

The purpose of the medical observations was (1) to ascertain the incidence of silicosis, lead poisoning, and other occupational diseases in the three Utah industries; (2) to correlate the clinical findings with the environmental findings as determined by industrial hygiene engineers; (3) to appraise nonindustrial diseases or conditions of public health importance; and (4) to make recommendations for protecting and improv. ing the health of these workers.

\section{Procedure of Medical Examinations}

Workers were examined from three bituminous coal mines in Carbon County, Utah, from a metal mine of each of the three principal metal mining districts, and from a copper and lead smelter in Utah. An effort was made to examine every employed worker without selection. In the mines both underground and surface workers were included. About 80 percent (545) of employed coal mine workers and approximately 90 per. cent of metal mine (783) and smelter workers (1511) were examined. The remainder were either laid off temporarily, on vacation, ill, or were unwilling to be examined for various reasons. Their cooperation generally was excellent. In many cases the workers gave up their free time for the period of the examination.

Examinations were made and field laboratories were set up in the auditorium of the theater in one coal-mining town, in the recreation hall of another, and in the basement of a church in another. Temporary medical examination facilities for observation of metal mine workers were estab lished in the local Union headquarters, in a local grade school, and in a mining company's dispensary. The examinations of smelter workers were carried out in space provided by the plants. The operators supplied the necessary furniture, utilities, and heavy wiring installation for the X-ray equipment. Local officials of the United Mine Workers of America and International Union of Mine, Mill, and Smelter Workers delegated a committee to schedule the examinations and urge the men to report for examination. The management assisted materially in some locations by permitting workers to be examined on company time.

The coal workers and about half of the metal mine workers presented themselves during the off hours of the day or night shifts, and the smelter workers and half of the metal mine workers were examined during working hours. Three or more physicians and a dentist were present at all times, together with the laboratory staff. As they came in the men were assigned to the physicians for physical examination, the laboratory technicians for blood sampling, urinalysis, and X-ray, and to the dentist for dental examination, as expediency required. The complete examination usually required about one hour for each worker.

As the worker entered the examining booth, he was requested to strip to the waist, thus giving the physician ample opportunity while recording the history to observe any abnormalities or defects and to form a tentative opinion of the general physical condition of the man he was later to examine more thoroughly. A detailed occupational history was obtained from each man and care was taken to record the location of 
each occupation, that is, the State and general location within the State where the work had been done. This was particularly important in the history of those men who had worked in mines outside the State of Utah in determining the type of dust or other hazards to which they had been exposed. The specific occupations within the industry were also recorded, together with remarks concerning the industrial hazards to which the worker was exposed while engaged in such employment. The use and type of preventive measures were also noted. In short, the occupational history was a detailed chronological record of each man's employment from the time he began working to the present. A typical occupational history is shown in Figure 2. This form was essentially the same in all three studies. Names were not entered on these records in order to insure complete anonymity for all medical findings.

\section{U. S. Public Health Service and Utah State Bituminous Coal Study}

\section{4501 puwr $X Y Z$ Coal C. DATB Sefpt. I}

Hene

IAT 50 AGE BEGAN TORS

TEARS MORKN 35

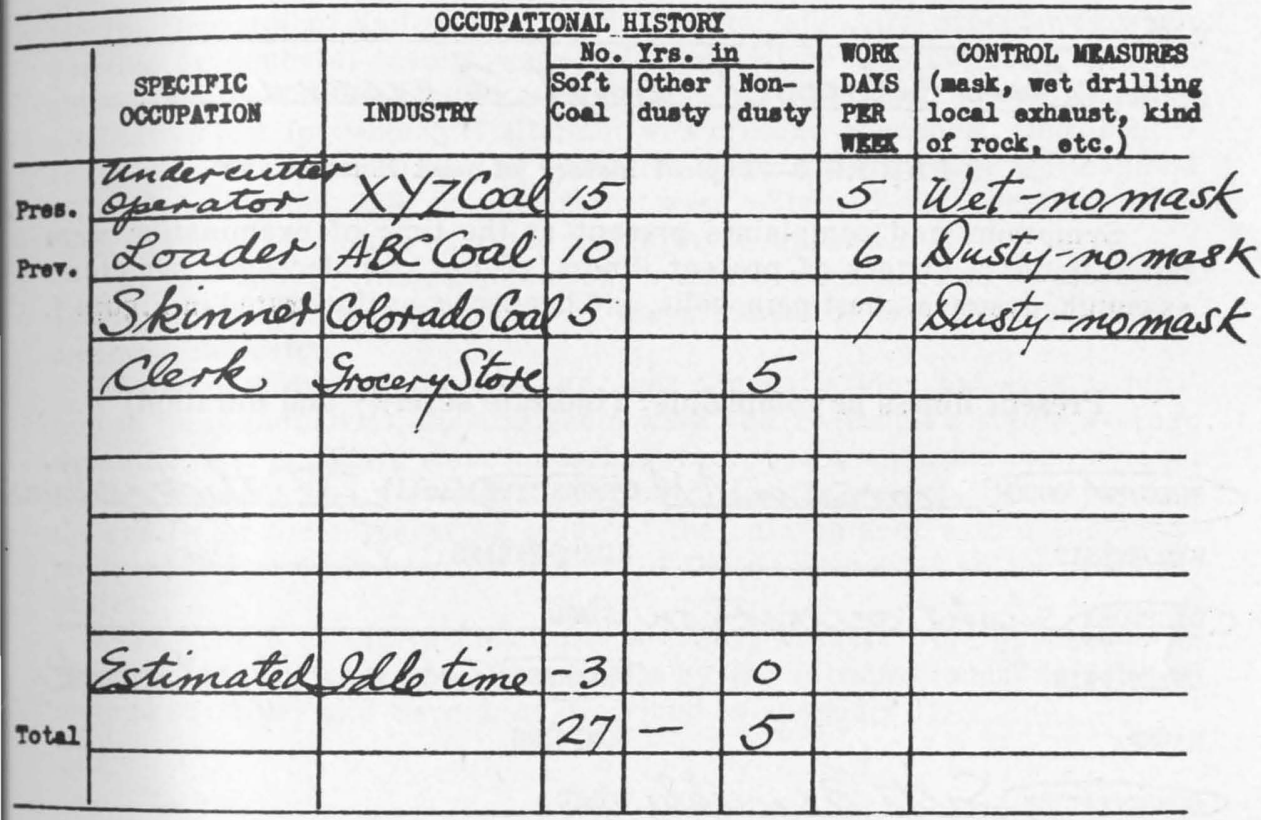

FIGURE 2-Typical occupation history.

The past medical history consisted of information concerning the exposure to and contraction of a number of common diseases and any sequelae resulting therefrom. Chronic complaints relating to the various systems such as respiratory and digestive, and from which the worker was now free were also recorded together with injuries and operations. A typical past medical history is shown in Figure 3. 
34

Past Medical: (Insert date, severity, and sequelae)

TUBERCILOSIS CONTACT Sistex-close contact lyx - 1908

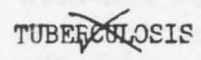

PNEUMONIA 1918 -sever embed 6 whes-nocomplication.

INFLUENZA

PLEXS(SY (dry - wet) not since pneumonia

BRONCHITIS) Frequent cough, moderate, past 2 y,

DISABLING COLDS

LOSS OF WEIGHT PAST YEAR 10 lb c - $30 \mathrm{lbs}$ in 5 years.

HEART DISORDERS DIGESTIVE DISTURBANCES mild in digestion following, moa $v \ngtr$. OTHER "Rundown" past 2 years

FIGURE 3-Typical history of past illnesses.

Symptoms and complaints present at the time of examination were noted under a history of present illness. These included such symptoms as cough, dyspnea, chest pain, colic, and headache, as illustrated in Figure 4

Present illness or complaints: (Indicate severity and duration)

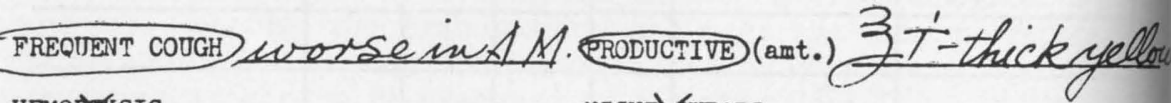
HEMOPSIS NIGH SWEATS

DYSPNOEA slight, on exertion AS'

CHESTXPAIN

NAD)
HEAKNESS tires easily at work TORI) ING

CONSTIPATION Salts, $3 \times$ weekly cont

METALS

HEAD $\triangle C H E$

NEUt IS

CHIS

ARTHrITIS

(sKIN) Acne over shoulder

OTHER Feels well, except tox above

FIGURE 4-Typical history of present illnesses or complaints. 
At this point, a thorough physical examination was performed with strict adherence to the method of well-established practice. Beginning with the close inspection of the head and continuing with the neck, thorax, abdomen, and extremities, special attention was given to the examination of the respiratory and cardiovascular systems. Examination of the abdomen, genitalia, and anal region was omitted unless indicated by the history. A simple neurologic examination was done and a rough estimation of the psyche was recorded. The procedure for the dental examination is described in the dental section. (See appendix I.)

The laboratory procedure included taking a single X-ray film of the chest and a fluoroscopic examination by one of the physicians. Most of the X-ray films were processed in the laboratories of the Division of Industrial Hygiene, National Institute of Health, at Bethesda, Maryland. The films were classified by a group of physicians, and then final diagnoses were made, taking into consideration the X-ray and physical findings, case histories and laboratory findings.

Sputum was collected from those in whom tuberculous lesions were suspected from the history and physical examination, and was examined by the State Health Department. Blood was drawn for examination for reticulocytes, hemoglobin (Newcomer), stipple cells, and a serodiagnostic test. The Kahn test for syphilis was performed routinely by the State Health Department and was checked by other standard procedures when positive or doubtful results were obtained. Urine was collected and examined by the sulphosalicylic acid method for albumin, and the Benedict qualitative test for sugar. If albumin was present, specimens were centrifuged and examined microscopically for casts and red and white blood cells. In addition, $250 \mathrm{cc}$ specimens were obtained for spectrographic determination of metals excreted as shown in appendix III.

At the end of the examination, workers were advised to seek the advice of their private physician if the presence of any physical impairments so indicated.

After determining the average dust concentrations for each occupation in these industries, the engineers were able to assign a single average weighted dust exposure value to each worker, based upon his occupational history, by a method previously mentioned, for the purpose of correlating the results of the engineering study of the environment with the medical study of the possibly harmful effects of the environment on the worker's health.

The effects of the various dusts to which workers were exposed were also studied with experimental animals by the intraperitoneal injectional method of Miller and Sayers, as described in appendix II. 

VII. COAL MINES 


\section{ENVIRONMENTAL STUDY}

\section{The Mining and Preparation of Bituminous Coal}

The Bureau of the Census of the United States Department of $\mathrm{C}_{0}$ n merce states that in the year 1929 there were 40 bituminous coal mine in operation in the State of Utah, and that these mines produced $\mathrm{m}_{0}$ than five million tons of coal. In the year 1930, 3,452 persons were engage in the coal mining industry (1).

\section{Geography of the Bituminous Field}

In the State of Utah, bituminous and semi-bituminous coal occurs 11 known fields, of which three or of commercial importance. The co which was produced from the portions of Book Cliffs field and Wasatch Plateau field, located in Carbon County accounted for more tha 85 percent of the total Utah production in 1936 (2).

The Book Cliffs field stretches from the Utah-Colorado line wes ward in a crude semicircle to Castlegate, Carbon County, where it merge into the Wasatch Plateau field (3). The dividing line between the two arbitrarily drawn at the point where the Cliffs change in direction fro east-west to north-south; this is at the bend west of Price River Canyor The general features of the two fields are very much alike. All of $t$ coal is in the Mesa Verde formation of the upper Cretaceous system. Book Cliffs are 1,000 to 2,000 feet high and the highest points on plateau are about 6,000 feet higher than the lowlands to the south. T Wasatch Plateau is a broad upland with long stretches of table land, b its eastern front is marked by sandstone cliffs rising 1,000 to 2,000 above the adjacent Castle Valley. The total relief between the plate top and Castle Valley is more than 5,000 feet. In places, the plateau fro is breached by deep canyons and the coal outcrop is generally diffic of access.

The coal beds in these two fields are comparatively flat with a ranging from 0-17 degrees. A white sandstone 5 to 60 feet thick normal marks the base of the coal. Above this standstone is a large number coal beds, some of which maintain workable thicknesses throughout co siderable areas. At no one place are all beds workable.

In parts of these fields, rocks are much faulted and at some localiti the faults seriously affect mining. The coal is bituminous in rank. D placement faults with throws varying in extent from a few to sever hundred feet are present in most of the mines. Want areas, often coverin acres, are islands where the coal bed has entirely disappared or is reduced in thickness that profitable mining is not possible. Such areas a frequently encountered in some of the coal beds (4). The floor of t want, and the mining conditions around it, are generally normal, the being no breaking or displacement of the strata. Burned areas where coal has been burned from the outcrop, at times extending 2,000 from the surface and under cover to the depth of $800 \mathrm{feet}$, are prese in these coal fields. A majority of the mines are affected with burnt are near the outcrop. While the presence of displacement faults, want ani burnt areas have often seriously interferred with the planning of t mine layout, they have not affected the method of mining. 
In each field the number and size of the veins vary. Often the larger veins are split by an intrusion of rock into two or more separate seams. Mining operations are carried on in some seams which are only four feet in thickness, but the bulk of the coal is obtained from seams varying from 8 to 30 feet.

Type of Mining

All of the mines in Carbon County are opened by slopes and the pillar and room system of mining is used. The slopes are usually driven down the dips with levels turned to the right or left on the strike of the bed about every 400 feet. From these levels, or cross entries, rooms are driven either directly up the pitch, or at an angle, to decrease the grade. Main slopes 14 feet wide in sets of two, three, and four, 40 to 80 feet apart, are advanced on the dip or raise of the coal bed, from which pairs of strike or room entries are turned.

Rooms 12 to 14 feet in width are generally turned from the entries. After advancing two or three cuts, or from 12 to 18 feet, they are made the standard room width (20 to 30 feet) and advanced for a distance ranging from 350 to 500 feet to the barrier pillar protecting the entry above. Room pillars vary in width.

The main entries are driven straight to reduce the flow resistance of the air used for ventilation purposes. At times the roofs are heavily timbered. This timber is not used to support the overlying strata, which at some places reaches a thickness of more than 2,000 feet, but to hold up the friable layers of coal and strata.

The main entry usually divides, or splits, at a point some distance from the portal. This split is called the main parting and gives access to other working areas. Parallel to the main slope, or entries, a return airway is driven at a distance of 30 to 40 feet. (A slope is an inclined tunnel.) The fresh air entering the main gangway is separated from the return airway by solid pillars of coal. However, at intervals of 75 to 200 feet crosscuts are driven to facilitate the circulation of air. Old crosscuts are closed progressively as mining proceeds. In rooms or entries these crosscuts are from 50 to 100 feet apart.

The thickness of the coal seams in the three mines showed considerable variation. Mine No. 1 worked a coal seam 26 feet thick; mine No. 2, a seam 16 feet thick; and mine No. 3, one seam four to five feet thick and another one six feet thick. In mines No. 1 and No. 2, the practice is to cut rooms or entries seven to eight feet in height. After this is done the top coal is drilled and dropped. However, not all of the top coal is recovered until the pillars are pulled, since three to four feet of the coal is left in place to furnish support for the roof. In mine No. 3 all of the coal is taken in the first operation and this necessitates using timber to help support a treacherous roof. The only timber required in mines No. 1 and No. 2 is that used to act as indicators. Any movement of the roof is transferred to the timbers and often they are bowed 10 to 12 inches out of line. Timbering, in any event, is only capable of giving protection against the immediate roof, probably a few feet overlying the coal bed.

\section{Loading Methods}

Three methods of loading are in common use in the coal fields in Carbon County: mobile mechanical loading machines, shaker or duckbill conveyors, and hand loading. 
Mobile loaders are of two general types: those employing the shovel principle, and those using the gathering principle. The shovel type loader forces a shovel underneath the coal, parallel to the mine floor, and as the shovel is located on a boom which can be revolved, the operator can guide the shovel to the coal car for emptying. The gathering loader is equipped with two claw-like arms attached to rotating disks which pull the coal onto the conveyor part of the machine. The discharge end of the conveyor is extendable so that it is possible to load cars while the gathering arms cover an extended area. Both types of machines are mounted on caterpillars, so that they can be readily moved, either on or off mine tracks.

Shaker or duckbill conveyors consist of sectional steel troughs which are fitted end to end as the working face progresses. To the end of the shaking conveyor is attached a shovel device with a flared mouth called a duckbill. The trough is operated by a series of gears and eccentrics which convert the rotary motion of an electric motor into a reciprocating motion. A slow forward motion is transmitted toward the car loading point, followed by a quick reverse motion which has the effect of joggling the coal along the trough. These troughs are hung from posts on either side, to allow horizontal movement.

\section{Robbing (Pulling Pillars)}

In primary or intial mining operations, pillars of coal are left to support the weight of the overlying strata. In one mine, secondary mining was carried on to recover these large pillars and also the top coal which had been left to help support the roof. The percentage of the total coal recovered in the initial operations is only 30 to 40 , while in robbing the pillar a total of 90 to 95 percent of the coal may be recovered. In removing the pillar and top coal, operations do not differ from ordinary room and pillar mining. However, more skill is required in this type of mining due to the bounces of coal from the face or roof. Numerous posts are required to furnish support and to indicate roof movement in this type of work. Only the most experienced and skillful miners are assigned to the hazardous task of robbing pillars. When as much coal is recovered as can safely be done in an area several hundred feet square, the props are pulled and the roof is caved in.

\section{Transportation}

All three mines in this study are electrified and do not use animals for hauling coal cars, although animals are occasionally used for moving supplies. Each contains extensive track systems over which empty cars are moved to the working faces and loaded cars are moved from the working face to the portal. With the exception of the few faces where duckbill conveyors are used, the tracks extend to all working faces. Loaded cars are taken from the rooms, or from the end of conveyors, to sidings, where a train of cars is made up and hauled to the portal. Empty cars are brought from the siding to the working places for loading.

Mine locomotives are of either the storage battery or overhead trolley type. Some locomotives of the overhead trolley type are equipped with cable drums for furnishing power beyond the limits of the trolley system.

On the steep inclines in the mines the cars are raised or lowered by means of a hoist. These hoists are run by electric motors. Usually the cars of coal are lowered down the incline and the drum of the hoist acts 
as a prake to check their speed. Empty cars are hauled up the incline to be filled with coal from the working faces on this level.

\section{Maintenance}

Since these three mines use mechanized equipment to a high degree, a large force of men is required to maintain the equipment. Transportation maintenance consists of track repairs and removal of material which accumulates along haulageways. Water is piped to all working faces to keep down the dust hazard and the water system must be maintained at all times. Since all machinery is run by electricity, motor repairs, battery charging, and wiring maintenance are frequently required. Most of the mines have good natural drainage and pumps are seldom necessary. Ventilation

Air movement in the mines under study is produced by large suction fans placed at surface openings. Air enters through the main haulageway in all cases, but there may be an additional opening through which air is also drawn. The air is drawn through the various gangways and workings to the return airways, which are joined together into a single duct leading to a fan.

The flow of air is directed by means of brattices and doors. In the rooms of one of the mines the brattice cloth is hung from a wire stretched along the top coal. This system permits carrying the cloth directly to the face, and during loading or blasting, moving back the cloth along the wire, like a curtain. After passing across the coal face, the air enters the return airways through crosscuts. Brattice men attend to hanging all cloth in two of the mines, while in the third mine, miners have this responsibility. Masons and stopping men erect permanent concrete brattices and concrete foundations for machinery.

\section{Superintendence}

The general supervision and direction of the underground working force is in charge of the mine foreman, who must be certified as such. The mine foreman is often assisted by an assistant mine foreman or haulage boss. Since it is impossible for the foreman to directly supervise all the varied operations in a mine, he maintains contact through sectional foremen, called face or pillar bosses, who are responsible for maintenance of scheduled output and safety practices in their workings.

Before workmen enter the mines in the morning, fire bosses test all working places and report any existing danger to the various miners who might be exposed to these conditions. In some mines where blasting is done during the working shift, fire bosses also act as shotfirers. After firing, it is their duty to investigate for gas and unsafe conditions.

\section{Conveyance to the Tipple}

In the mines under study the tipples, which clean and size the coal, are located some distance from the portal and at a lower elevation. With this layout, no energy is required to move the loaded trains from the portal to the tipple. In one mine, the trains were lowered by a hoist located at the portal. By this method, a minimum of power is used, since the loaded train being lowered acts as a counter weight in returning the empty cars to the portal. When the loaded train reaches the tipple the cars are uncoupled and, one at a time, released on the scales, where they are weighed, and, then by means of a rotary dumper, revolved sideways to empty into a large hopper. 


\section{Tipple}

After the coal is emptied from the cars into the hopper, it passes over a screen where all the large lumps are retained. The large lumps are caused to move forward by a reciprocating movement of the screen and fall into a crusher. Spiral-gravity separators, which are so constructed that the heavier material (rock) moves to the edge and falls out, are used. Shaking and vibrating screens separate different sizes as the coal passes along. Bony pickers are stationed along the sides of these screens to pick out pieces of bony (slate or shale) or lumps of coal which contain streaks of bony. A variety of sizes of coal may be prepared, depending upon the screens used.

\section{Loading of Railroad Cars}

Under the tipple are sloped railroad tracks. Empty railroad box cars or gondolas are lowered by gravity into position for loading different sizes of coal. Before shipping, carloads of coal are inspected.

\section{Other Outside Activities}

In order to maintain all equipment in working order, a group of men are engaged in numerous surface activities. Electricians repair electric locomotives and other electrical equipment, while armature winders rewind motors. Blacksmiths sharpen cutting drills, teeth for undercutters, and repair coal cars. Machinists and mechanics not only keep tipple machinery in working order, but also make repairs on machinery and mov. ing equipment brought out from the mines. Some special parts are made in the machine shop. Firemen attend stationary boilers which furnish power for the mines. Lampmen clean, charge, and test the miners' lamps. All of the clerical work, such as preparation of time, salary, and shipping sheets, is done in offices above ground.

\section{Occupational Analysis and Description of Chief Occupations}

An occupational analysis of the number of men employed at the coal mines is given in tables 1 and 2. The number of men recorded for each occupation shown in the tables is as of the time the study was made. This number is somewhat less than the peak employment, since the mines were just preparing for their maximum production for the year. The total of 986 workers employed by these three mines was greater than that shown in the medical study, which preceded the engineering study by about a month.

From the tables shown it is apparent that a great variety of occupations exist in the coal mines. It is possible to divide the total number of workers into two separate groups, those who are actually engaged in extraction of coal and those who are associated with auxiliary services required in mining operations. In mine No. 1, 27 percent of the employees were engaged in drilling, undercutting, loading, and firing; in mine No. 2, 31 percent, and in mine No. 3, 58 percent. The large percentage of men engaged in extraction of coal in the latter mine is due to the lack of mechanization in the loading processes. In mines No. 1 and No. 2, all loading is done by mechanical loaders or duckbill conveyors, while in mine No. 3 all loading is done by hand. In the three mines taken together, 41 percent of the workers are engaged in the extraction of coal. Undercutting, drilling, and loading operations generate most of the dust under ground. In order to give the necessary emphasis to this condition, ap 
TABLE 1-Occupational Analysis of Inside Force of Three Representative Utah Bituminous Coal Mines.

Section and Occupation

Coal Mining:

Undercutter operators and helpers.

Drillers and helpers.

Facemen, shovel operators and helpers

Hand loaders and coal diggers.

Conveyor operators and helpers.

Machine operators, miscellaneous 1

Shot firers and fire bosses.

TOTAL

Development Work:

Rock workers

Ventilation:

Brattice men

Masons and stopping men.

Sprinklers

Rock dusters (hand)

TOTAL

Transportation:

Motormen, car nippers, and rope riders

Hoistmen

Mule skinners and drivers.

Tool nippers and materialmen

TOTAL

Hoisting Water:

Pumpmen

Timbering:

Timbermen and helpers

Maintenance:

Trackmen and helpers.

Cleanup men and laborers.

Pipemen and helpers.

Mechanics and helpers, greasers

Electricians and helpers, wiremen. TOTAL

Superintendence:

Foremen, haulage bosses and face bosses

Miscellaneous:

Dummy makers

Dispatchers

TOTAL

GRAND TOTAL

1 This name was given to a special group of men in Mine No. 1 who did not only drilling, undercutting, loading but also shooting. 
TABLE 2-Occupational Analysis of Outside Force of Three Representative Utah Bituminous Coal Mines.

\begin{tabular}{|c|c|c|c|c|}
\hline \multirow{2}{*}{ Section and Occupation } & \multicolumn{4}{|c|}{ Number of Men } \\
\hline & $\begin{array}{l}\text { Mine } \\
\text { No. } 1\end{array}$ & $\begin{array}{l}\text { Mine } \\
\text { No. } 2 \\
\end{array}$ & $\begin{array}{l}\text { Mine } \\
\text { No. } 3 \\
\end{array}$ & Total \\
\hline \multirow{2}{*}{\multicolumn{5}{|c|}{ 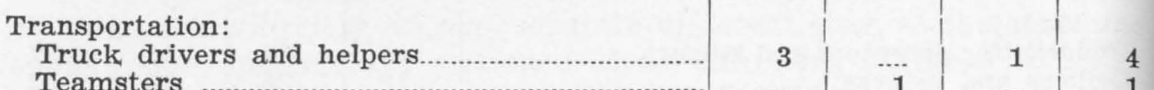 }} \\
\hline & 3 & .... & 1 & 4 \\
\hline Teamsters & $\cdots$. & 1 & $\cdots$. & 1 \\
\hline TOTAL & 3 & 2 & 1 & 6 \\
\hline \multicolumn{5}{|l|}{$\begin{array}{l}\text { Maintenance: } \\
\text { Repair foreman }\end{array}$} \\
\hline Repair foreman ...................... & 1 & 1 & 1 & 3 \\
\hline $\begin{array}{l}\text { Machinists and mechanics............................ } \\
\text { Car repairmen }\end{array}$ & 13 & 8 & 6 & 27 \\
\hline $\begin{array}{l}\text { Car repairmen } \\
\text { Blacksmiths and helpers, welders }\end{array}$ & 4 & 2 & 2 & $\begin{array}{l}6 \\
7\end{array}$ \\
\hline Electricians, armature winders and helpers.. & $\frac{2}{5}$ & $\begin{array}{l}3 \\
3\end{array}$ & $\begin{array}{l}2 \\
3\end{array}$ & $\begin{array}{r}7 \\
11\end{array}$ \\
\hline 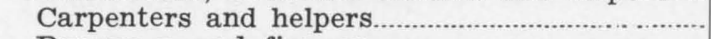 & 3 & 1 & $\ldots$ & 4 \\
\hline Pumpmen and firemen & 2 & 3 & 1. & 6 \\
\hline Plumbers, pipemen and helpers............................... & 2 & 1 & 2 & 5 \\
\hline Laborers & 5 & 1 & .... & 6 \\
\hline 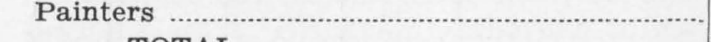 & 1 & .... & .... & 1 \\
\hline TOTAL ....................... & 38 & 23 & 15 & 76 \\
\hline \multicolumn{5}{|l|}{ Coal Preparation (tipple): } \\
\hline Tipple foremen and assistant foremen......... & 2 & 2 & 2 & 6 \\
\hline Weighmen and check takers & 1 & 4 & 2 & 7 \\
\hline & 1 & 2 & 2 & 5 \\
\hline $\begin{array}{l}\text { Couplers, rope tenders and switchmen } \\
\text { Tipple operators, crushers, starters and }\end{array}$ & 1 & 2 & 2 & 5 \\
\hline screeners & 5 & 6 & 4 & 15 \\
\hline Bony pickers & 27 & 14 & 22 & 63 \\
\hline Car droppers, and trimmers..................... & 5 & 11 & 4 & 20 \\
\hline 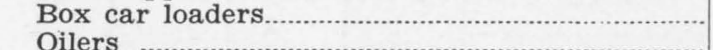 & 2 & 3 & .... & 5 \\
\hline Oilers .................................. & 0 & 3 & & 3 \\
\hline 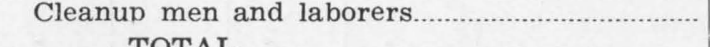 & 2 & $\ldots$. & 2 & 4 \\
\hline - & 46 & 47 & 40 & 133 \\
\hline \multicolumn{5}{|l|}{$\begin{array}{l}\text { Superintendence: } \\
\text { Superintendents }\end{array}$} \\
\hline Superintendents & 1 & 1 & 1 & 3 \\
\hline Cashiers, clerks and telephone operators.... & 5 & 4 & 4 & 13 \\
\hline Lampmen and fanmen ....................................... & $\begin{array}{l}4 \\
2\end{array}$ & $\begin{array}{l}3 \\
2\end{array}$ & $\dddot{1}$ & $\begin{array}{l}7 \\
5\end{array}$ \\
\hline Engineers and assistant engineers...... & 2 & 2 & 1 & 5 \\
\hline TOTAL .... & 12 & 10 & 6 & 28 \\
\hline \multicolumn{5}{|l|}{$\begin{array}{l}\text { Miscellaneous: } \\
\text { Material men } \\
\text { Janitors }\end{array}$} \\
\hline $\begin{array}{l}\text { Material men } \\
\text { Janitors }\end{array}$ & ... & 1 & .... & 1 \\
\hline $\begin{array}{l}\text { Janitors } \\
\text { Watchmen, guards and marshals } . . . . .\end{array}$ & 1 & & & 1. \\
\hline $\begin{array}{l}\text { Watchmen, guards and marshals ...... } \\
\text { Sand dryers }\end{array}$ & 2 & 1 & 1 & 4 \\
\hline Dummy makers & 1 & $\begin{array}{l}1 \\
2\end{array}$ & $\cdots \cdot$ & $\begin{array}{l}2 \\
2\end{array}$ \\
\hline Storekeepers and store clerks........... & 2 & 3 & 3 & 8 \\
\hline TOTAL & 6 & 8 & 4 & 18 \\
\hline GRAND TOTAL . & 105 & 90 & 66 & 261 \\
\hline
\end{tabular}


proximately half of the underground atmospheric samples were obtained for the important group of workers engaged in these activities.

Since there are so many different occupations in a coal mine, brief definitions giving the various duties associated with the more important occupations are listed in the following sections.

\section{Inside Force}

Undercutter operators and helpers set up and operate an electricallydriven coal cutting machine, which is used to cut a channel along the bottom of the working face, and also to make vertical shears in the face of the high coal, so that it may be blasted down without shattering the mass. Helpers shovel back fine cuttings (bug dust) from the end of the cutting bar. They also move the machine from one working face to another. Depending upon the type of machine used, undercutting crews consists of two to four men, who may rotate duties.

Drillers and helpers operate auger type electric drills and use either extension bits, or change bits as depth of hole increases. Horizontal holes are drilled in faces and vertical holes in top coal. These holes vary from 5 to 15 feet in depth. Helpers assist drillers and pick holes in face or roof of coal, to guide drills when starting holes. These men move drills from one working place to another after a sufficient number of holes are drilled. Before starting to drill each face, a drill post must be set and wedged firmly in position. Drillers also lubricate, adjust, and make minor repairs to machines.

Shovel and loader operators and helpers operate electrical loading machines. Facemen who pick down loose coal after blasting also act as helpers. By means of gathering arms, loading machines place the coal on the conveyor portion of the machine, which carries the coal into cars or onto a shaker conveyor. Operators, by means of levers, guide the gathering mechanism into the loose coal, and also the end of the conveyor over the cars to be filled. When rope shovels are used, the operator guides the shovel bucket, and moves the machine near the loose coal, by means of levers. Helpers assist operators in moving loading machines from one face to another, by clearing loose coal from the path of the caterpillar treads.

Hand loaders and coal diggers shovel coal blasted from the working face into cars, or onto conveyors, from which cars are loaded at some point away from the working face. These men extend track to the working face as the work progresses, and occasionally put in timber to hold up the roof.

Conveyor operators and helpers operate a loading machine of the shaker-conveyor type to mechanically transport coal from the working face and to load it into mine cars at some point removed from the face. They also extend conveyor sections to the working face as the work progresses. They clean, oil, and adjust conveyor sections and power units.

Machine operators miscellaneous is a classification given to a special group of workers in one seam in one mine. These men operate small electric undercutters, electric drills, and also use a duckbill conveyor for loading. Instead of having separate crews for each operation, one crew 
performs the various mining operations in rotation. In this instance, the same crew also charges the holes and shoots the charge during the shift.

Shot firers and fire bosses are grouped together because their duties overlap, although inherent exposures differ between the two occupations. Shot firers load and tamp the charges in the holes before firing the explosive to break down the face of the coal. In some instances, this is done between shifts and the room is left idle for several hours after firing. Fire bosses inspect working faces for presence of gas between the time of firing and the time when the miners enter the mines to begin work. In cases where firing is done on shift, shot firers frequently acted as fire bosses, and in some cases the shot firing was done by the miner and the inspection was made by the face or section boss. Fire bosses also make periodic inspection of abandoned workings.

\section{Development Work}

Rock workers are engaged in driving tunnels and airways through rock. This work consists of drilling holes with a Leyner drill, charging them with explosives, firing, and loading loose rock into cars.

\section{Ventilation}

Brattice men are engaged in erecting temporary cloth partitions for directing air currents toward the working faces.

Masons and stopping men erect permanent partitions of masonry for sealing off old workings or for directing mine air currents, and also put in foundations for transformer stations, hoists, and other installations.

Sprinklers spend full time wetting down working faces, and "bug dust" accumulations with water.

Rock dusters are employed to cover with rock dust the exposed walls near the face of the coal, as the work progresses, and also areas where the dust has dropped off due to falls of the roof and sidewalls. This dusting is hand work.

\section{Transportation}

Motormen operate electric locomotives of different types used in the transportation of the mine cars between the face and the tipple.

Car nippers, couplers and spraggers attend to track switches, couple and uncouple cars, and apply sprags to the car wheels, which act as brakes in checking the momentum of the cars on grade.

Rope riders are assigned to perform duties similar to car nippers on the inclined cableways.

Hoistmen operate electric hoists for winding or unwinding the cable used in lowering the full coal cars, and pulling up the empty cars on the inclines in the mines.

Skinners and drivers drive mules or horses to transport rails, pipes, and other material too difficult to load in mine cars.

Tool nippers and material men deliver and distribute tools and supplies to the various workings.

\section{Hoisting Water}

Pumpmen are employed to operate and maintain underground electric pumps used for moving water from low workings and for supplying water to working faces.

Timbering

Timbermen erect wooden brattices, and erect supporting timbers along 
haulageways and stulls in the workrooms, to hold up overlying coal and rock.

\section{Maintenance}

Trackmen and helpers lay and maintain rails used for haulage of cars in the mine. They also lay and remove temporary track to working faces, and remove old track from abandoned areas.

Greasers inspect and oil or grease idler rollers or pulleys over which cable passes along haulage slopes.

Cleanup men or laborers have no fixed duties, but are assigned to miscellaneous laboring tasks as needed.

Pipemen and helpers lay and maintain water pipes to the various faces, since all cutting operations are performed wet and water is needed for wetting down coal after blasting.

Mechanics install and maintain all mechanical equipment underground.

Electricians and wiremen are employed to erect and maintain trolley wire, telephone and signal wires, and string electric lights from transformer stations along main haulageways. They also make emergency repairs on electric motors and transformer stations.

\section{Superintendence}

Mine foremen and assistant mine foremen are responsible for all underground operations.

Face and pillar bosses are engaged in direct supervision of mining operations at the working faces.

\section{Miscellaneous}

Dummy makers are employed to make powder dummies by filling paper tubes. with sand.

Dispatchers operate electrical switches for mine railroads and also operate telephone switchboards which are connected with all crews working underground.

\section{Outside Force}

\section{Transportation}

The occupations listed for this section are self-explanatory.

\section{Maintenance}

The occupations listed for this section are also self-explanatory.

\section{Coal Preparation}

Tipple foremen and assistant foremen are in direct supervision of all operations at the tipple.

Weighman and check takers are engaged in weighing each car of coal from the mine before it is dumped at the tipple, and also taking the identifying check from the car, so that it may be credited to a specific group of coal workers.

Car dumpers are employed to operate a lever which turns the car of coal upside down, emptying the coal into the storage hopper at the tipple.

Car couplers, rope tenders and switchmen uncouple cars and drop them by gravity to car dumpers, while the switchmen receive the cars leaving the dumper and switch them to a siding for return to the mine. Rope tenders unfasten cables for cars of coal lowered by hoist, and fasten cables to the empty cars for return to the mine. 
Tipple operators, crusher operators, starters, and screeners are em. played to operate machinery in the tipple.

Bony pickers are employed to pick slate (bony), rock and other impurities from the coal as it passes by on a conveyor, shaking screen, or gravity incline, and to throw it into a waste pocket or bin.

Car droppers and trimmers run box and gondola cars down inclined tracks to designated points, for loading with coal from the tipple. Also, the loaded gondola cars are trimmed so that coal will not fall off in transit. After cars are loaded, brakes are released, and these cars are lowered down inclined grades to switching tracks to be picked up by switch engines.

Oilers keep tipple machinery oiled and greased.

Cleanup men and laborers are employed to keep the tipple clean and do odd jobs in their spare time.

\section{Superintendence}

Superintendents are directly responsible for all underground and surface activities.

The designations of cashiers, clerks, and telephone operators are self-explanatory.

Lampmen and fanmen maintain and have charge of all safety and electrical cap lamps and batteries. They also are responsible for running and maintenance of the ventilating fans.

Engineers and assistant engineers run line and grade for underground workings, calculate amount of excavations, and draw up maps showing all workings.

\section{Ventilation}

The underground workings in all mines are ventilated by large electric fans which draw air from the mines. There are one or more openings on the surface which are used as intakes. Generally, the principal air intakes are the main slope and the manway. Foul air is drawn from the mine at one or more points by an exhaust fan or fans and fresh air is drawn into the mine through openings located elsewhere. After the air enters the main entry, it is subdivided by a number of passageways so that it passes the faces of the different working places. Parallel to the gangways, serving as fresh air routes, are returns which act as passageways for the return air to be exhausted by the fans. By means of brattice cloth, the air is guided to the face of the coal, so that fumes or gases generated by blastings are replaced with clean air.

\section{TABLE 3-Ventilation Facilities in Three Bituminous Coal Mines.}

\begin{tabular}{l|c|c|c|c}
\hline & $\begin{array}{c}\text { Amount of air } \\
\text { moved by fans } \\
\text { (cubic feet per } \\
\text { minute) }\end{array}$ & $\begin{array}{c}\text { Number of } \\
\text { men employed } \\
\text { underground } \\
\text { per shift }\end{array}$ & $\begin{array}{c}\text { Number of } \\
\text { cubic feet per } \\
\text { minute per man }\end{array}$ & Remarks \\
\hline Mine No. 1 & 114,175 & 75 & 1522 & $\begin{array}{l}\text { Mine laws call for } \\
\text { Min cubic feet of } \\
\text { Mine No. 2 }\end{array}$ \\
Mine No. 3 & 179,680 & 125 & 1437 & $\begin{array}{l}\text { air per minute for } \\
\text { each underground } \\
\text { worker. }\end{array}$ \\
\hline
\end{tabular}

Adequate ventilation is one of the most important factors in guarding health and safety in a mine. The essential object is to dilute and render harmless various mine gases, such as methane, carbon monoxide, carbon dioxide, and hydrogen sulphide. The Industrial Commission of the 
State of Utah requires a minimum quantity of not less than 150 cubic feet per minute of air for each and every person in every gaseous coal mine (5). In table 3 , it will be noted that each mine studied affords ventilation facilities much in excess of the requirements of the Industrial Commission.

Although the initial volume of air that enters the mines from the surface is deemed sufficient, this volume gives no indication of the adequacy of the amount of air at the working face. In order to dilute gases immediately as they issue from the coal or rock, so as to render them harmless, a certain degree of turbulence in the air at the working face is necessary to assist in breaking up the body of gases and thereby furnish a larger surface to aid diffusion.

The velocities recorded at the working faces varied from less than 20 feet to 75 feet per minute. This variation depends upon many factors, such as distance from the face to main airways, the necessity for dead ends, and the efficiency of the brattice system used. However, there are no set standards for air movement at the working faces to remove the gases and dusts.

The dry bulb temperatures at the working face varied from 51 to 66 degrees Fahrenheit, averaging 60.2 degrees. Relative humidities were rather high, with an average of 85 percent, varying between 72 and 96 . From these readings, it can be seen that the working conditions are not uncomfortable when men are performing hard labor.

\section{Nature of Mine Air}

In table 4 , the average composition (percentage) is given for normal mine air, air at the working face immediately after blasting, and air in the return airways.

\section{TABLE 4-Gas Analyses of Different Types of Mine Air.}

\begin{tabular}{|c|c|c|c|c|c|c|c|c|c|c|c|c|c|c|c|c|}
\hline \multirow{2}{*}{ Type of air } & \multicolumn{15}{|c|}{ Percent Gas Concentrations } & \multirow{2}{*}{ 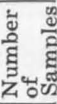 } \\
\hline & Max. & $\begin{array}{l}\mathrm{CO}_{2} \\
\text { Min.| }\end{array}$ & Ave. & Max. & $\begin{array}{l}\mathrm{O}_{2} \\
\mathrm{Min}\end{array}$ & $\mid A$ & Max. & $\begin{array}{l}\text { CO } \\
\text { Min.| }\end{array}$ & Ave. & Max. & $\begin{array}{l}\mathrm{CH}_{4} \\
\mathrm{Min} .\end{array}$ & Ave. & Max. & $\begin{array}{l}\mathrm{N}_{2} \\
\mathrm{Min} .\end{array}$ & Ave. & \\
\hline $\begin{array}{l}\text { Normal } \\
\text { mine air.... }\end{array}$ & 0.40 & 0.04 & 0.16 & 20.91 & 20.30 & 20.65 & 0.00 & 0.00 & 0.00 & 0.38 & 0.00 & 0.07 & 79.25 & 78.94 & 79.12 & 11 \\
\hline After firing & 1.00 & 0.08 & 0.36 & 20.78 & 20.06 & 20.61 & 0.28 & 0.00 & 0.08 & 1.34 & 0.05 & 0.41 & 78.99 & 77.25 & 78.54 & 5 \\
\hline Return air.. & 0.27 & 0.07 & 0.17 & 20.84 & 20.41 & 20.59 & 0.00 & 0.00 & 0.00 & 0.15 & 0.00 & 0.08 & 79.27 & 79.04 & 79.17 & 10 \\
\hline
\end{tabular}

It will be noted that in all three groups there is slight variation in the oxygen and nitrogen concentration. The oxygen content, with a minimum value of 20.06 for air after blasting, is only slightly lower than air at sea level. The maximum value of carbon dioxide is one percent and this is due to the products of combustion, which occurred after blasting. All carbon dioxide values are higher than normal at sea level ( 0.3 percent).

Carbon monoxide (called "white damp") was detected only in samples taken immeditely after blasting. This gas is not found in normal air, but is a product of incomplete combustion. In four of the five samples taken immediately after blasting, carbon monoxide was found present with a maximum value of 0.28 percent. Concentrations of carbon monoxide as low as 0.01 percent (one part in 10,000 ) may be considered harmful if the exposure is of sufficient duation (6). Methane $\left(\mathrm{CH}_{4}\right)$ was also found in the air samples. Methane is dangerous, not only because it may reduce 
the percent of oxygen, but also because if the concentration reaches 5 to 15 percent, with sufficient oxygen present in the air, there is danger of explosions. The Bureau of Mines recommends that the methane content of mine air be kept below 0.5 percent. In only one sample was the methane content greater than that amount (6).

Although some of the carbon monoxide and methane readings were of sufficient concentration to be considered dangerous if existing for somewhat lengthy durations, it must be remembered that these high values occurred in air samples taken immediately after blasting and were of only momentary duration. Since the readings at all other locations showed no carbon monoxide and little, if any, methane present due to a sufficient dilution of these gases with the incoming air, these results on mine gases may be considered to indicate safe conditions, so long as present rates of gas generation are not exceeded and adequate ventilation is maintaind.

\section{Atmospheric Dust}

\section{Nature of Dust.}

Fourteen samples of materials and settled dust were collected from the various operations in the mine. Some of these samples had settled out of the atmosphere at the breathing level of the workers. These samples were analyzed chemically for total silica and petrographically for quartz. An indication of the quartz exposure of the various workers in the mine may be obtained from the results presented in table 5 .

\section{TABLE 5-Occupational Exposure to Quartz and Total Silica in Bitu- minous Coal Mines.}

\begin{tabular}{|c|c|c|c|c|}
\hline \multirow{2}{*}{ Source of Sample } & \multirow{2}{*}{$\begin{array}{c}\text { No. of } \\
\text { Samples }\end{array}$} & \multicolumn{2}{|c|}{ Percent Silica } & \multirow{2}{*}{$\begin{array}{l}\text { Type of } \\
\text { Sample }\end{array}$} \\
\hline & & Total & Quartz & \\
\hline Traction sand in haulageways. & 2 & 81.0 & 69.0 & Material sample \\
\hline Dummy sand & 2 & 65.7 & 44.4 & Material sample \\
\hline Roof rock ........................................ & 2 & 77.4 & 51.4 & Material sample \\
\hline Rock dust ..................................... & 3 & 14.0 & 2.0 & Settled dust \\
\hline 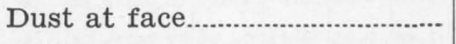 & 5 & $3.2-68.4$ & $<1.0-11.0$ & Material sample \\
\hline
\end{tabular}

It will be observed that the five samples obtained in the vicinity of face workers ranged in total silica content from 3.2 to 68.4 percent, while the quartz content of these samples varied from less than 1 to 11 percent. Face workers comprised the majority of underground employees, constituting 55 percent in the present study. It is obvious, therefore, that more than half of the underground workers in the mines under study were exposed to relatively small amounts of quartz. The results on traction sand employed in haulageways, dummy sand, and the other materials shown in table 5 , even though they are high, are not necessarily to be charged as exposures to the workers employing these various materials. It was found impracticable to obtain atmospheric dust samples in sufficient quantity for mineralogical analysis, so that no true indication of the quartz exposure of some of these workers is available. However, in the mines studied, only 11 such workers were employed in dummy making, at rock work, or in rock dusting. 


\section{Size of Dust}

From table 6, it may be seen that 17 percent of the dust was more than 5 microns in average dimension. Less than 3 percent of the particles were under 0.5 microns in size. Figure 5 shows that the median size, 1.94 microns, is somewhat larger than the size encountered in most industrial dusts (7).

\section{TABLE 6-Summary of Size-frequency Distribution of Dust Suspended in the Air of Three Bituminous Coal Mines.}

Immediately after blasing

Machine loading

General mine air

Erecting brattice cloth.

Conveyor men

TOTAL AVERAGE
Drilling coal

Dumping at tipple.

\begin{tabular}{|c|c|c|c|c|c|c|c|c|c|c|c|}
\hline \multirow[b]{2}{*}{ 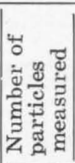 } & \multirow[b]{2}{*}{ 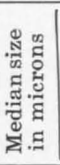 } & \multicolumn{10}{|c|}{$\begin{array}{c}\text { Percentage frequency of each particle-size } \\
\text { group (in microns) }\end{array}$} \\
\hline & & $\begin{array}{l}\stackrel{5}{+} \\
\vdots \\
0\end{array}$ & $\begin{array}{l}\text { क़ } \\
0 \\
1 \\
1 \\
\stackrel{5}{0}\end{array}$ & 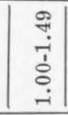 & 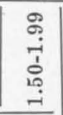 & 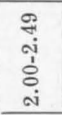 & $\begin{array}{l}\text { \& } \\
\text { ஸें } \\
\text { மे } \\
\text { i⿱ } \\
\text { i. }\end{array}$ & 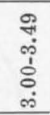 & 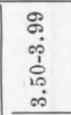 & $\begin{array}{l}+ \\
\stackrel{+}{+}\end{array}$ & 点 \\
\hline 400 & 1.80 & 3.5 & 19.3 & 21.5 & 9.5 & 11.5 & $5.2+$ & 4.5 & $4.2+$ & 20.8 & 100 \\
\hline 200 & 1.91 & 3.0 & 20.5 & 20.0 & 8.0 & 8.0 & 3.0 & 4.0 & 2.5 & 31.0 & 100 \\
\hline 400 & 1.94 & 2.8 & 16.8 & 20.2 & 11.5 & 7.2 & 4.0 & 4.8 & 6.0 & 26.7 & 100 \\
\hline 40 & 1.54 & 4.8 & 23.2 & 20.8 & 16.0 & 11.0 & 2.5 & 3.0 & 3.5 & $15.2+$ & 100 \\
\hline 200 & 2.81 & 1.0 & 6.5 & 18.0 & 12.0 & 7.5 & 8.0 & 8.5 & 7.0 & 31.5 & 100 \\
\hline 200 & 2.02 & 1.0 & 19.5 & 21.5 & 7.5 & 11.5 & 6.0 & 6.0 & 2.5 & 24.5 & 100 \\
\hline 200 & 2.48 & 1.5 & 9.5 & 15.0 & 9.5 & 15.0 & 6.5 & 8.0 & 5.0 & 30.0 & 100 \\
\hline 2000 & 1.94 & 2.8 & 17.5 & 20.0 & 11.1 & 10.2 & 4.7 & 5.1 & 4.4 & 24.2 & 100 \\
\hline
\end{tabular}

\section{Dust Concentrations by Occupation}

For the purpose of determining the amount of dust in the mine air, 168 samples were taken with the impinger apparatus.

Table 7 lists the number of men employed in each occupation, the number of samples taken to determine the dust concentration, and the number of millions of dust particles per cubic foot of air (weighted average). In occupations in which the activities did not vary or change locations, the numerical average of the dust samples taken was also considered as the weighted average. Bony pickers in the tipple are an example of this type of presentation. However, when the activitis and the location of the activities varied, the dust samples representing each activity were weighted according to the amount of time devoted to each activity, as already mentioned. Most of the dust concentrations for occupations underground were calculated by the latter method.

Undercutting - It may be seen in table 7 that workers engaged in undercutting and shearing coal are exposed to 33.6 millions of dust particles per cubic foot. Most of this dust is generated in undercutting or shearing the face of the coal, and, in some instances, remains suspended in the air while other activities are being carried on, such as changing teeth and moving undercutting machines. If measures are taken to reduce materially the dust associated with the cutting operations, the dust problem for this occupation would be solved. A more liberal application of water during cutting operations, and adequate ventilation at the face in order to dilute the dust, will reduce this exposure to a great extent, as will be shown later.

Drillers-In drilling operations, the following three activities, picking down, setting up the drill, and drilling, account for 93 percent of the 
percent

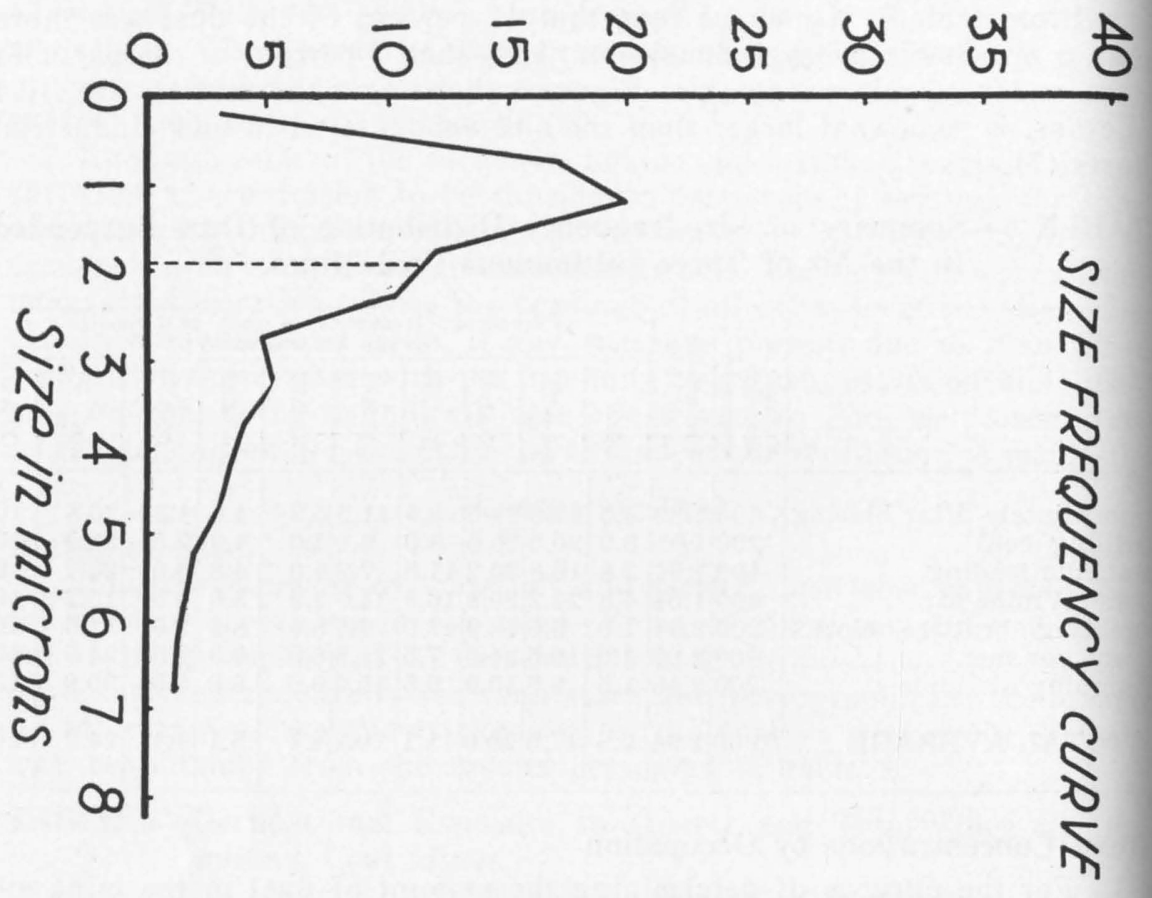

Percent less than Stated Size

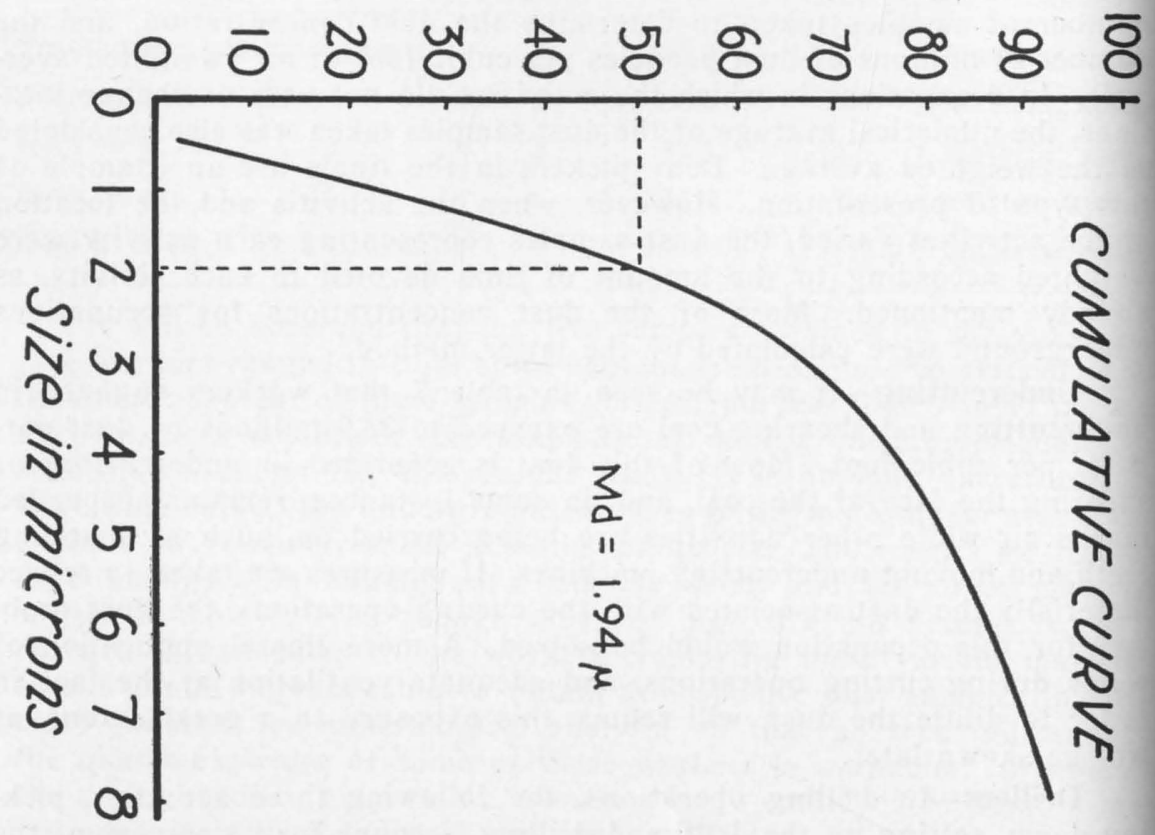

FIGURE 5-Particle-size distrbiution of coal mine dusts. 
TABLE 7-Summary of Occupational Dust Exposure of Workers in Three Representative Utah Bituminous Coal Mines.

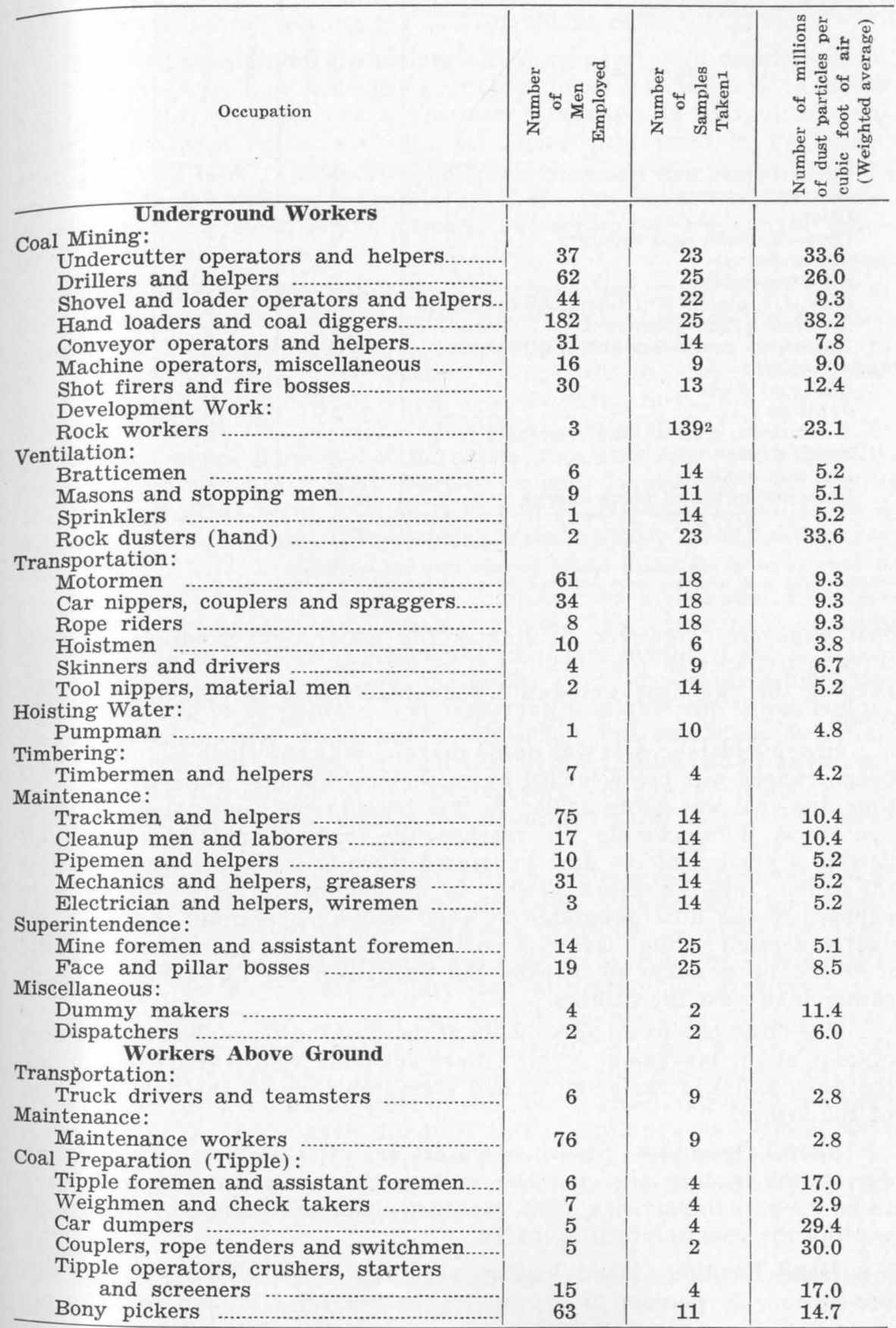


TABLE 7-Summary of Occupational Dust Exposure of Workers in Three Representative Utah Bituminous Coal Mines (Continued)

\begin{tabular}{|c|c|c|c|}
\hline Occupation & 总岁营 & 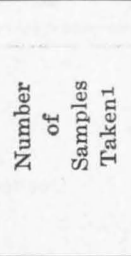 & 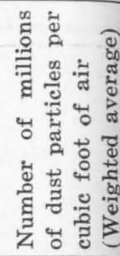 \\
\hline 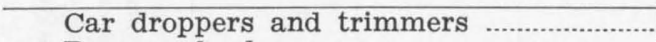 & 20 & 4 & 2.9 \\
\hline Box car loaders & 5 & 3 & 118.9 \\
\hline Oilers & 3 & 1 & 9.5 \\
\hline Clean-up men and laborers & 4 & 11 & 14.7 \\
\hline $\begin{array}{l}\text { Superintendence: } \\
\text { Superintendents }\end{array}$ & & & \\
\hline Superintendents & 3 & 25 & 5.1 \\
\hline Cashiers, clerks and telephone operators.. & 13 & 5 & 1.5 \\
\hline Lampmen and fanmen .................................... & 7 & 9 & 2.8 \\
\hline 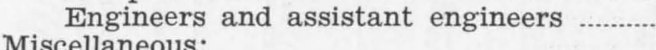 & 5 & 25 & 4.2 \\
\hline $\begin{array}{l}\text { Miscellaneous: } \\
\text { Material men }\end{array}$ & 1 & 5 & 1.5 \\
\hline Janitors & 1 & 9 & 2.8 \\
\hline 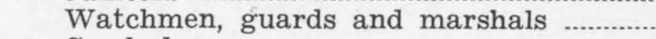 & 4 & 5 & 1.5 \\
\hline Sand dryers & 2 & 2 & 98.2 \\
\hline 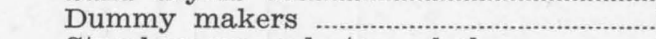 & 2 & 2 & 11.4 \\
\hline 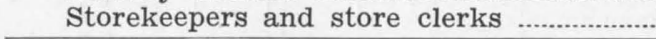 & 8 & 2 & 1.5 \\
\hline 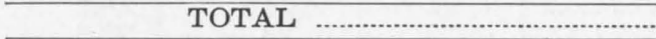 & 986 & & \\
\hline
\end{tabular}

IIn many instances one sample applied to more than one occupation.

2Samples for rock workers were obtained in metal mines in the State of Utah.

dust exposure. However, drilling is the major dust exposure of these three activities. In roof drilling it is difficult to use much water, but keeping the bug dust wet would undoubtedly help in reducing the dust count.

In some instances, it was noted that the top coal which had previously been dropped was being loaded by mechanical loaders, while, at the same time, top coal was being drilled farther back in the same room. In these operations the incoming air reached the loading operations first and carried a portion of the dust generated there over the dropped coal past the drillers into the return airway. In this manner, drillers were not only exposed to the dust generated by their drilling operations, but also the dust generated by the loading of coal. By spacing the operations properly, it would be possible to by-pass the dust-laden air through a crosscut rather than past the drillers.

The observations on air velocity at the working faces showed instances of only slight movement of air. More adequate ventilation would dilute the dust, assist in removing it, and measurably lessen the dust exposure of the drillers.

Shovel Operators-Shovel operators get their heaviest dust exposure during the loading process. The average dust concentration was found to be 9.3 million particles. This exposure could be lessened by thoroughly wetting the coal before it is loaded.

Hand Loading-Hand loading occurs in only mine No. 3. In this occupation, 84 percent of the dust exposure (38.2 million particles per 
cubic foot) occurs while shoveling. Since the seams in this mine are very low, there is not the volume of air in the immediate working vicinity to dilute the dust as in mines with large rooms and high roofs. In order to lower the dust count, the ventilation facilities should be improved and a very thorough job of wetting the coal should be done.

Miscellaneous Mining Operations-Development work requiring tunnelling through rock, or removing roof rock (brushing the roof) to secure haulage height, is sometimes a necessary operation in bituminous coal mining, but these operations were not being performed in the mines studied at this time. These operations are quite similar to the development operations employed in metal mines, and the dust control measures recommended for metal mines, namely, wet drilling and adequate ventilation, should be employed.

Transportation (underground)-The suggestion made previously in connection with hand loaders, namely, the wetting of the coal at the face prior to loading, also applies to transportation workers. In order to further allay the fine dust ever present in coal cars, the empty cars should be also treated with plenty of water before moving them into the mines. Forbes and Emery (8), in 1927, reporting on the source of dust in bituminous coal mines, showed that the dust concentrations were materially reduced when water was used liberally on both loaded and empty cars. These investigators were able to reduce the dust count from 14 to 2 million particles per cubic foot by using water on both loaded and empty. cars.

Transportation workers are also subjected to a potential silica exposure from the sand used to obtain traction. This exposure is greatest on grades and in starting and stopping. If that portion of the haulageways which is on the grades, and the places where the trains usually use sand in starting or stopping, are kept sprinkled, so that the siliceous dust which has accumulated would not be stirred up, this hazardous condition would be minimized. It would appear that by the correct use of additional water the dust count along the haulageways might be considerably reduced from the present finding of 9.3 million particles per cubic foot of air.

Tipple Workers-Tipple workers are exposed to a considerable amount of dust (see table 7), which might be somewhat lessened by a more thorough wetting of the coal before loading in the mines, as previously mentioned. However, the installation of wet-washing systems, or local exhaust ventilation, offer a more satisfactory solution to the dust problem.

Sand Dryers-There are only two sand dryers working at these mines, but their dust exposure is potentially as hazardous as any group of workers, due to both the high dust concentration and the amount of free silica contained in the sand. Most of the dust is generated when the sand is screened after it has been dried. If this operation were enclosed with an exhaust fan carrying the dust away, the silica dust hazard would be greatly reduced. Until such control is employed, the men should be protected by approved dust respirators.

\section{Summary}

Table 8 presents data on certain operations in coal mines under both controlled and uncontrolled working conditions. The controlled conditions 
were actually found in the mines under consideration. It may be seen from this table that by employing the control procedures shown in the remarks column, no dust exposure need exceed 10 million particles per cubic foot of air. Some of the reductions in dust concentrations shown in table 8 are very striking. For example, by the generous use of water on the coal during hand loading operations and by having sufficient air movement, especially in low seams, dust concentrations are reduced from 123 to 5 million particles. It is apparent from these results that the dust hazard in Utah coal mines may be greatly reduced by more intensive application of the very methods already employed in these mines.

\section{TABLE 8-Summary of Results Contrasting the Dust Exposure of Bitu- minous Coạl Mine Workers Under Controlled and Uncontrolled Working Conditions.}

\begin{tabular}{l|c|c|c|}
\hline \multicolumn{1}{c|}{ Operation } & $\begin{array}{c}\text { Average dust concentration } \\
\text { in millions of particles } \\
\text { per cubie foot of air }\end{array}$ & \multicolumn{1}{|c|}{ Remarks } \\
\hline Controlled & Uncontrolled & \\
\hline Undercutting coal & 5 & 56 & $\begin{array}{l}\text { Thorough use of water and } \\
\text { adequate ventilation at face } \\
\text { decrease dust concentration }\end{array}$ \\
\hline Drilling & 10 & 63 & $\begin{array}{l}\text { Wetting of bug dust essential } \\
\text { for low dust concentration }\end{array}$ \\
\hline Machine loading coal & 4 & 18 & $\begin{array}{l}\text { Wetting of coal to be loaded } \\
\text { reduces dust concentration }\end{array}$ \\
\hline Hand loading coal & 5 & 123 & $\begin{array}{l}\text { Wetting of coal and greater } \\
\text { air movement especially in } \\
\text { low seam necessary to reduce } \\
\text { dust }\end{array}$ \\
\hline Hauling coal in mine & 4 & 23 & $\begin{array}{l}\text { Wetting both coal and empty } \\
\text { cars reduces dust in haulage- } \\
\text { ways }\end{array}$ \\
\hline Preparation of coal & 2 & 34 & $\begin{array}{l}\text { Wet process or local exhaust } \\
\text { ventilation necessary to re- } \\
\text { duce dust concentration }\end{array}$ \\
\hline
\end{tabular}

\section{Atmospheric Lead Concentrations}

Atmospheric lead samples were collected from the return air from each mine, and in the tipples. None of these samples showed lead detectable by the analytical method used. Analyses of drinking water from the communities adjacent to these mines showed that all supplies contained less than 0.1 parts per million of lead and consequently complied with the U. S. Public Health Service standards for drinking water insofar as the lead content was concerned. These samples were collected to ascertain whether or not a lead hazard existed in the coal mines. The evidence did not show that this hazard existed.

\section{Sanitary Survey}

As indicated in the preceding section, on the nature and scope of the study, certain data were obtained on sanitary facilities, both at the various establishments and in the communities surrounding these establishments. At one of the three coal mines investigated, it was found that both the mine and town near it used the same company-owned water supply. A spring located above the town was found to be subject to occasional contamination. Some satisfactory kind of sterilization should be provided for this supply. 
The septic tank employed for the town sewage had no satisfactory disposal system for its effluent. In the mine itself the method of carrying drinking water in individual canteens or lunch buckets is satisfactory. However, there are no toilet facilities in the mine and fecal matter is deposited and covered on the mine floor. Box-type pail privies are used by the surface crew, but they are not removed regularly. The use of metal boxes placed conveniently and frequently limed and hauled to the surface at regular intervals would be a much more satisfactory arrangement. The fact that cases of typhoid fever and dysentery have occurred in this town indicates the necessity for the recommendations given.

At another coal mine, the workers carry individual canteens or water bottles filled with water from the company-owned water supply in the town. This method of handling drinking water in the mine may be considered satisfactory. River water is treated adequately at a filtration plant, but re-contamination occurs at the uncovered distribution reservoir.

The company-owned sewerage system discharges into a septic tank whose effluent is allowed to discharge into an isloated area. For the present this arrangement may be considered satisfactory, but plans should be made for proper treatment of the effluent. In the mine, no toilet facilities are provided and fecal matter is deposited promiscuously on the mine floor, usually in the exhaust ventilation tunnel. The use of metal boxes placed conveniently and frequently limed and hauled to the surface at regular intervals would be a more satisfactory arrangement. Cases of typhoid fever and recent dysentery have also occurred in this town.

The third coal mine, with a town adjacent to it, may be described as similar to the others, except that the treated water supply is quite satisfactory. The town, however, has no sewerage system. Sewage is handled by individual cesspools. Here, also, cases of typhoid fever and recent cases of dysentery have occurred.

It may be concluded from these findings that sanitary facilities with reference to water supply and sewage disposal are far from satisfactory, both at the mines proper and in the communities in which these mine workers are located.

\section{Summary}

This report on the working environment is based on a study of three representative bituminous coal mines in the State of Utah. The evaluation of the dust hazard constituted an important part of an investigation for the health of the workers in these mines.

An occupational analysis revealed, among other things, that 41 percent of the workers were employed at the face in getting out coal. These workers encountered the highest dust exposures. In addition to the dust determinations, ventilation readings were made in various places. Each mine was supplied with air much in excess of the 150 cubic feet per minute per man as required by the Industrial Commission of Utah. However, more than half of the working faces had air velocities of less than 40 feet per minute. The air movement in some working places was practically zero. The dry bulb temperatures were fairly constant during the period each mine was studied and averaged 60.2 degrees Fahrenhit. The relative humidity averaged 85 percent but varied considerably.

Samples of mine air for analyses were collected from 26 locations. Carbon dioxide, oxygen and nitrogen did not vary greatly from the usual 
concentrations found in the general outdoor atmosphere. Carbon monoxide occurred only in the samples taken immediately after blasting. Although a maximum of 0.28 percent was found present at that time it was of very short duration since other samples of normal mine air and return air gave zero readings. Methane occurred in samples taken of normal mine air, in air sampled immediately after blasting, and in return air. However, in only one sample did the concentration (1.34 percent) exceed the recommended maximum of the Bureau of Mines (less than 0.5 percent). Due to a sufficient dilution of methane $\left(\mathrm{CH}_{4}\right)$ with the incoming air all other samples were well within this recommendation.

Settled dust and material samples were analyzed petrographically for quartz content. These samples on analysis showed that the majority of the underground workers ( 55 percent) were exposed to dust containing small amounts of free silica in the form of quartz. In fact, the highest concentration found at the face was 11 percent. Most of the face workers were exposed to less than this amount.

Measurements of 2000 particles of dust, obtained by sampling the atmosphere in the breathing zone of the workers, showed that 83 percent of the particles were less than 5 microns in average diameter. Only 2.8 percent of the particles were less than 0.5 micron. The median size particle was 1.94 microns.

For determining the dust exposure in different occupations 168 atmospheric dust samples were obtained. A summary of the results of these determinations is given in Table 7 .

From this table it will be noted that in underground operations; hand loading, undercutting, rock dusting and drilling produce the dustiest working conditions. Hand loaders were exposed to a dust concentration of 38 , undercutters to 34 , rock dusters (hand) 34 and drillers 26 million particles per cubic foot of air. The dust exposures for other underground workers varied from four million particles per cubic foot of air for timbermen to 23 million particles for rock workers.

The dustiest occupations above ground were found in the tipple. Box car loaders with a dust concentration of 119 million particles per cubic foot of air greatly exceeded all other occupations. The next greatest concentrations in the tipple were for car dumpers and couplers, rope tenders and switchmen who were exposed to approximately 30 million particles per cubic foot of air.

The only occupation above ground, with the exception of the tipple, which had a high concentration of dust was sand dryers with 98 million particles. All other workers had an exposure of five million particles or less with the exception of dummy makers who had 11 million particles per cubic foot of air.

If all occupations are considered together irrespective of underground and surface workers, it is noted that only 24 percent of the workers are exposed to more than 30 million particles per cubic foot of air. The majority of the workers ( 59 percent) were exposed to concentrations varying from 5 to 29 million particles. The remaining 17 per cent of the workers had the negligible dust exposure amounting to less than five million particles.

Methods of reducing the dust hazards, directed at those activities which contributed the largest proportion of the workers' total dust exposure, have been presented. 


\section{Recommendations}

1. Dust should be controlled at its point of generation so as to prevent it from reaching the breathing zone of the workers or contaminating the general air. Thorough wetting by water is a general method of dust control at the point of origin. Material abatement of dust in the working environment may be obtained by wet methods in almost all coal mining and processing operations.

2. Adequate ventilation of all workplaces in the mine would tend to replace dusty air with clean air. Although a satisfactory standard of air velocity in bituminous mines has not been established, an air velocity of at least 50 feet per minute seems desirable from the standpoint of eliminating dead ends.

3. One important source of silica dust in the haulageways is sand used to prevent slipping of the transport locomotives. Thorough wetting of the roadbed would minimize the dust hazard in the haulageways.

4. The greatest potential silica dust hazard was in sand drying operations when the dry sand was screened. The screens should be enclosed, and provided with an exhaust fan to carry away the dust generated during this activity.

5. In the working of low seams, the amount of air should be greatly increased in order to remove the coal dust as quickly as possible.

6. Tipple operations generate excessive amounts of dust which might be lessened by a more thorough wetting of the coal before loading in the mine. However, a more satisfactory solution would be the installation of a wet-washing system or local exhaust ventilation.

7. Periodic studies of the condition of the working environment appear necessary to determine whether the control methods adopted are really adequate. The work of inspection and review should be performed by persons trained for such studies.

8. The findings revealed by the sanitary survey indicate the necessity for proper sewage disposal in the communities adjacent to the coal mines and an improvement in the present unsafe methods of fecal disposal in the mines proper. Contaminated sources of water supply should be properly sterilized. This applies especially to some of the privately owned water supplies.

\section{References}

1. U. S. Department of Commerce, Bureau of the Census. Fifteenth Census of the United States. Mines and Quarries: 1929. General Report and Report for States and Industries. Washington, Gov. Print. Off. 1933.

2. Keystone Coal Buyers Manual and Directory of Mines. New York, McGraw-Hill Publishing Co. 1939.

3. U. S. Department of the Interior, Bureau of Mines. Analysis of Utah coals. Technical Paper 345. Washington, Gov. Print. Off. 1925.

4. Tomlinson, Herbert: Falls of roof and coal in the Book Cliffs and Wasatch Plateau coal fields in Utah. U. S. Bur. Mines Report of Investigations 3189. 1932.

5. Utah Industrial Commission: General Coal Mine Safety Orders. July 1, 1937. 
6. Forbes, J. J., and G. W. Grove: Mine gases and methods for their detection. U. S. Bur. Mines Miners' Circular 33. Washington, Gov, Print. Off. 1937.

7. Bloomfield, J. J., and J. M. DallaValle: The determination and con. trol of industrial dust. U. S. Public Health Bull. 217. Washington, Gov. Print. Off. 1935.

8. Forbes, J. J., and Alden H. Emery: Sources of dust in coal mines. U. S. Bur. Mines Report of Investigations 2793. 1927. 
VII. COAL MINES 


\section{MEDICAL STUDY}

\section{Characteristics of the Coal Mining Population}

Comparison with Census Data - In this study, 545 male coal mine workers representing about 80 percent of all persons employed in three bituminous coal mines in the State of Utah were examined. These persons represent almost one-fifth of the 2,810 male coal mine operatives in Utah who were listed in the 1930 Census of population. ${ }^{1}$ Distribution by race is not available for the study population, but the Census shows that 50.7 percent were native white, 37.0 percent foreign-born white, 1.1 percent Negro, and 11.2 percent other races. It may be assumed that the group under investigation is composed primarily of white males either native or foreign born and that the proportion of other races is negligible.

Seasonal fluctuation in the number of coal mine workers must be taken into consideration since the study cases were those employed at the time of the field investigation. According to a Census of mines and quarries made in 1935 , there were nearly twice as many persons employed in the coal mines in Utah on December 15 th of that year as on July 15 th The present study was made during August and September when employ. ment was growing but had not yet reached its maximum.

\section{TABLE 9-Number and Percent of Coal Mine Workers According to Age for the United States, the State of Utah, and This Study.}

\begin{tabular}{|c|c|c|c|c|c|c|}
\hline \multirow{2}{*}{$\begin{array}{c}\text { Age } \\
\text { (years) }\end{array}$} & \multicolumn{3}{|c|}{ Number of workers } & \multicolumn{3}{|c|}{ Percent of workers } \\
\hline & $\begin{array}{c}\text { United } \\
\text { States } 1 \\
\end{array}$ & Utah 2 & $\begin{array}{l}\text { This } \\
\text { study }\end{array}$ & $\begin{array}{r}\text { United } \\
\text { States }\end{array}$ & Utah & $\begin{array}{l}\text { This } \\
\text { study }\end{array}$ \\
\hline All known ages & 621,195 & 2,804 & $545^{3}$ & 100.0 & 100.0 & 100.0 \\
\hline Under 25 & 130,071 & 509 & 79 & 20.9 & 18.2 & 14.5 \\
\hline $25-34$ & 154,947 & 756 & 177 & 25.0 & 27.0 & 32.5 \\
\hline $35-44$ & 159,811 & 870 & 154 & 25.7 & 31.0 & 28.2 \\
\hline $45-54$ & 114,938 & 503 & 99 & 18.5 & 17.9 & 18.2 \\
\hline 55 and over & 61,428 & 166 & 36 & 9.9 & 5.9 & 6.6 \\
\hline
\end{tabular}

1 15th Census of the United States, (1930), Population, Vol. V, pp. 118-119.

2 15th Census of the United States, (1930), Population, Vol. IV, p. 1626.

3 Includes 38 workers with mixed dust exposure.

As shown in Table 9, the known age distribution of coal mine operatives in the State of Utah and in the entire United States compares rather closely with the age distribution in this study. The present study has a slightly smaller percentage under 25 years of age, 14.5 compared with 18.2 in Utah and 20.9 in the United States. However, in the age group from 25-34 years, the percentages are $32.4,27.0$ and 25.0 , respectively, with the result that the total number under 35 years of age does not vary by as much as 2 percent. Similarly, the percentages of workers 45 years of age and over are 24.9 in the present study, 23.8 in Utah, and 28.4 in the United States.

Workers with Experience in Other Dusty Trades - Because of the possibility that past rather than present occupation might influence the medical findings it was decided to eliminate the 38 cases who had had an exposure in some dusty trade other than coal mining lasting for a period of more than two years. Work in some other non-dusty occupation

1 The number of workers is based on the 1930 census of population which is considerably smalle than the number shown in the engineering section which is based on the 1929 census of mines an quarries. A much more useful figure for comparative purposes should be available shortly when the results of the 1940 census are released. 
no matter for how many years, was not a cause for exclusion. All of the following tables will include only the 507 cases whose experience in a dusty trade was limited to bituminous coal mining.

Among the 38 cases excluded there were 22 who had worked principally in metal mines, six in smelters and ten in other dusty trades. There were six cases of silicosis representing 15.8 percent of this excluded group. The experience of these persons was as follows: a 55-year-old man with second stage silicosis had worked 25 years in coal and 12 years as a driller in an iron mine; a 52-year-old man with second stage silicosis had worked 19 years in coal and 14 years in iron and metal mines; a 46-year-old man with first stage silicosis had worked 19 years in coal and seven years as a driller in a copper mine; a 52-year-old man with second stage silicosis had worked 15 years in coal and seven years in hard rock in a metal mine; a 52-year-old man with first stage silicosis and minimal, apparently healed tuberculosis had worked 28 years in coal and six years in a quartz mine; and a 60-year-old man with second stage silicosis and minimal, apparently healed tuberculosis had worked 21 years in coal, nine years in a quartz mine, and seven years in a metal mine.

\section{TABLE 10-Number and Percent of Coal Mine Workers, with Employ- ment in Utah Only, and in Utah and Outside, According to Age.}

\begin{tabular}{|c|c|c|c|c|c|c|}
\hline \multirow[b]{2}{*}{ Age in years } & \multicolumn{3}{|c|}{ Number of workers } & \multicolumn{3}{|c|}{ Percent of workers } \\
\hline & Total & $\begin{array}{l}\text { Utah } \\
\text { only }\end{array}$ & $\begin{array}{c}\text { Utah and } \\
\text { outside }\end{array}$ & Total & $\begin{array}{l}\text { Utah } \\
\text { only }\end{array}$ & $\begin{array}{l}\text { Utah and } \\
\text { outside }\end{array}$ \\
\hline All ages & 507 & 442 & 65 & 100.0 & 100.0 & 100.0 \\
\hline $15-19$ & 7 & 7 & 0 & 1.4 & 1.6 & ........... \\
\hline $20-24$ & 72 & 72 & 0 & 14.2 & 16.3 & \\
\hline $25-29$ & 91 & 90 & 1 & 17.9 & 20.4 & 1.5 \\
\hline $30-34$ & 79 & 70 & 9 & 15.5 & 15.8 & 13.8 \\
\hline $35-39$ & 84 & 70 & 14 & 16.6 & 15.8 & 21.5 \\
\hline $40-44$ & 58 & 49 & 9 & 11.4 & 11.1 & 13.9 \\
\hline $45-49$ & 49 & 40 & 9 & 9.7 & 9.0 & 13.9 \\
\hline $50-54$ & 39 & 24 & 15 & 7.7 & 5.4 & 23.1 \\
\hline $55-59$ & 18 & 11 & 7 & 3.6 & 2.5 & 10.8 \\
\hline $60-64$ & 7 & 6 & 1 & 1.4 & 1.4 & 1.5 \\
\hline 65 and over & 3 & 3 & 0 & .6 & .7 & \\
\hline Average age & 36.5 & 35.2 & 44.8 & & & \\
\hline
\end{tabular}

Age Distribution - An age distribution by 5-year intervals is presented in Table 10. When compared with a study of anthracite coal miners (1) it appears that the present group is younger. For example, under 35 years of age there were 37.0 percent in the former study and 49.2 percent in the latter, while for those 55 years of age and over the percentages were 10.1 and 5.5, respectively. The average age for anthracite workers was 39.5 and for bituminous workers it was 36.5. Compared with a study of the pottery industry (2) there is a smaller proportion under 30 years as well as a smaller proportion 55 years and over, but in all the middle age groups there is an excess among the Utah coal miners. For all ages the average is 2.6 years more for pottery workers. Among the other industries studied by the Public Health Service the following had an average age greater than for the present study: iron and steel (3), granite cutting (4), fur cutting (5), post office and foundry (3). Those industries with a smaller 
average age included glass, cigar, gas, cement, rubber, chemical, garment (3), truck driving (6), and asbestos textiles (7).

Length of Employment - Years of employment are very closely correlated with the age distribution of the workers. Hence a study of the anthracite coal industry showed 72.4 percent of the workers with ten or more years of employment in the industry, while for the present study there were 58.7 percent. Pottery workers showed 50.1 percent, 10,000 industrial workers (3) 45.3 percent, and asbestos textile workers (7) 13.7 percent of all employees studied with ten or more years of exposure.

Employment Outside of Utah - It will be noted that Table 10 shows the age distribution for a group of 442 workers who had had their entire experience in the bituminous coal industry within the borders of the State of Utah. The remaining 65 workers had at some time in the past been employed for more than two years in coal mines located outside of Utah. In some instances this experience had even been outside of the United States. This later group was much older, having an average age of 44.8 years compared with 35.2 years for those working in Utah only. It will be observed that workers under 30 years of age represented 37.9 percent of the total among men having experience in Utah only and 1.5 percent among men with outside experience. A similar trend was found for years of employment in coal mines; for Utah only the average duration was 12.5 years and for Utah and outside it was double that time, or 25 years.

\section{Diagnosis and Symptomatology of Silicosis}

Earlier investigations, both in this country and abroad, have shown that the outstanding occupational disease occurring among workers in dusty trades is silicosis (4) (8). Inhalation of siliceous dust almost invariably results in silicosis if a certain combination of circumstances has prevailed during the working experience of a miner or workers in other dusty occupations. Among these circumstances are that the dust be of respirable size, that it be present in the atmosphere at the breathing level in concentrations exceeding five million particles per cubic foot on the average, that it be inhaled for a number of years, and that it contain silica in a free state, such as quartz. If respirable dust of very high quartz content is inhaled in high concentrations, the disease develops and causes disability in a shorter period of time than if the quartz content and atmospheric dust concentrations are low.

As silicosis was the principal occupational disease found in the examination of 545 coal miners, 783 metal miners, and 1511 smelter workers, the following general discussion will be of interest. These cases resemble in many respects those found by the Public Health Service in previous studies of anthracite miners (1), pottery workers (2), and pegmatite miners (9).

Silicosis has been defined by the Committee on Pneumoconiosis of the American Public Health Association (10) as "a disease due to breathing air containing silica $\left(\mathrm{SiO}_{2}\right)$, characterized anatomically by generalized fibrotic changes and the development of miliary nodulation in both lungs, and clinically by shortness of breath, decreased chest expansion, lessened capacity for work, absence of fever, increased susceptibility to tuberculosis (some or all of which symptoms may be present), and by characteristic X-ray findings." 
The diagnosis of silicosis was based upon three factors:

1. Characteristic lung-field markings as shown by a satisfactory X-ray film of the chest.

2. Symptoms and physical findings which supported the X-ray findings and excluded other diseases as being the cause of these X-ray changes.

3. An occupational history which revealed prolonged exposures to dust containing silica.

\section{X-ray Findings}

As a characteristic appearance in the lung-field markings of an X-ray film is the foundation for a diagnosis of silicosis, these films were studied with the greatest care. The X-ray films were interpreted independently of other findings and were classified by a group of physicians familiar with this disease, using a system developed in other recent investigations of the Public Health Service (1) (2) (9) as shown in Figure 6. In this figure is shown diagramatically the sequence of bilateral changes in the appearance of the lung-fields from a healthy chest to advanced silicosis, indicating increasing degrees of pulmonary fibrosis. The linear phases are characterized by the dominance of the peribronchial or linear pulmonic markings. Little or no exaggeration of these markings is normally found in healthy young adults, but they may become exaggerated normally in older persons due to such factors as arteriosclerosis, repeated bronchial infection, excessive smoking, exposure to irritating gases, and pulmonary congestion often associated with heart disease. Beading is often associated with these second-degree exaggerated linear markings. Such increased markings are also part of the sequence of dust-induced changes as shown in Figure 6, but may not be altogether attributable to such exposure. This degree of change is comparable to the classification more fibrosis than usual or commencing generalized fibrosis used by earlier investigators (11).

With increasing dust exposure, the lung-fields assume a diffuse granular or stippled appearance, of ten called ground-glass, which indicates the formation of the minute nodules characteristic of silicosis. Although diffusely disseminated, this granular appearance is more easily recognized in the middle thirds and infraclavicular regions, being rather indistinct in the bases and above the clavicles. The transition to the granular phase from the linear phase is gradual; when the film is distinctly granular but the linear markings still predominate, the film is classified as first-degree granular. This phase, if well established, is usually, but not always, consistent with a diagnosis of early silicosis. Many cases showing only this degree of change may be regarded as borderline silicosis.

As the minute nodules increase in size the linear markings are gradually obscured, especially in the middle thirds. This disappearance of the linear markings due to the increasing stippled or granular shadows has been likened by Irvine (11) to the growth of leaves on a tree which gradually obscures the branches. Eventually the majority of the linear markings are obscured, but of ten heavy peribronchial markings are seen to persist extending into the bases and sometimes the apices. This phase is characteristic of early silicosis.

As the nodules increase in size they may be observed as discrete, 


\section{SCHEME REPRESENTING THE SEQUENCE OF LUNG-FIELD MARKINGS IN A TYPICAL CASE OF UNCOMPLICATED SILICOSIS}

\begin{tabular}{l|l|l|l|l|} 
TORMAL LUNG MARKINGS \\
IST DEGREE EXAGGERATION \\
OF LINEAR PULMONIC MARK- \\
INGS.
\end{tabular}


separate nodules on the flat film. The change from the granular to the nodular phase is gradual but when many definite, discrete nodules can be identified the film is classed as nodular. These shadows, like the granular, are most easily observed in the middle thirds and infraclavicular regions. If the average size of the nodules tends to be $1 \mathrm{~mm}$ or less in size, the film is classified as first-degree nodular; if the nodules are predominantly larger than this, the film is classified as second-degree nodular. With increasing size of the nodules, radiolucency indicating emphysema is often observed in the bases. These distinctly nodular films present the classifical picture of silicosis provided it is shown that they are not attributable to pulmonary infection. There may be a tendency for the nodules to cluster in the outer zones of the infraclavicular regions and middle thirds of the lung-fields.

During the nodular phase, nodules may appear to coalesce to form conglomerate shadows, which are usually bilateral, and appear frequently in the middle thirds and infraclavicular region, and less of ten in the bases. They may range in size from $6 \mathrm{~mm}$ to an area occuping the entirety of one or more lobes. These conglomerate areas of ten increase in size and density. Films classified in this phase are usually consistent with a diagnosis of well-advanced silicosis. Compensatory emphysema is generally present in the bases in this phase, and areas of vicarious emphysema may be observed throughout the lung fields, and frequently in the apices. Pneumothorax, a severe complication in silicosis, is rarely seen in employed workers.

Infection, tuberculous or otherwise, may complicate the findings in any phase of this sequence of changes as reported by a committee on the roentgenological appearances in silicosis and underlying pathological lesions (12). It is generally characterized by asymmetrical distribution of shadows, localized discrete densities and/or string-like shadows, a mottling lacking uniform density and distribution with ill-defined borders, and massive shadows of homogeneous density not of pleural origin. These massive shadows of superimposed infection may be difficult to distinguish from the conglomerate shadows of silicosis, so that serial $X$-ray and clinical studies may be necessary over a period of time in order to identify the infection or exclude it as a complicating factor. It is thought that the conglomerate shadows of silicosis may be due to functional changes in areas of the lung impaired by a previous infection, and what is seen in the X-ray are residuals of this earlier infection.

Considerable care is necessary in the interpretation of massive shadows in advanced silicosis when tuberculosis or other infection is suspected. As stated by Pancoast, et al, in the report of this Committee (12) :

"The differentiation between these massive shadows of infectious origin and the conglomerate shadows of far-advanced simple silicosis is difficult and not always possible. Repeated reexamination of the patient for evidence of change in the roentgenographic appearance of the lesion, penetration of the massive areas by overexposure to analyze its internal structure, the clinical behavior of the patient, and repeated bacteriological examination of the sputum may all be necessary to determine whether an active infection is present."

\section{Symptoms and Physical Findings}

The symptoms and physical signs of cases of silicosis observed in this 
study are discussed in sections dealing with representative case historie and with relation to degrees of change of pulmonary fibrosis as show by the lung-field markings on the X-ray film. These are the same a found previously by the Public Health Service in studies of potter workers (2), anthracite miners (1), pegmatite workers (9), granite cutter (4), and others.

According to the Report on Medical Control of the National Silicosi Conference (13), the following signs and symptoms may be expectec frequently in cases of silicosis;

1. Shortness of breath, particularly upon exertion.

2. Cough, usually a dry cough. If the cough is productive it usually means infection, temporary when the result of acute respiratory infection if persistent, usually means long-standing, chronic bronchitis, active tuberculosis, bronchiectasis, etc. It is never a symptom of silicosis per se.

3. Chest pain, varying from the feeling of tightness in the chest to the sharp, excruciating pain typical of pleurisy. Simple silicosis rarely causes chest pain.

4. Hemoptysis. True hemoptysis is rarely offered as a complaint by the silicotic, and in such cases emphysema or infection may be demonstrated. In such cases the sputum may appear bloodstreaked following a severe coughing attack produced by excessive dust exposure or exertion This complication must always be considered as suggesting tuberculosi as a complication.

5. General complaints. Weakness, loss of weight, digestive disturb. ances, night sweats, insomnia, dizziness, and edema of the extremities are not characteristic of uncomplicated silicosis.

6. Chest expansion. Varies considerably with individuals. A decrease in chest expansion may be difficult to demonstrate except with advanced degrees of silicosis.

7. Prolonged expiration is a common finding, especially in association with emphysema. Breath sounds may not be appreciably changed until advanced stages of silicosis, unless complicated by infection. The are seldom absent, but there may be a relative decrease in intensity with advanced degrees of silicosis, especially with emphysema.

8. Rales. Subcrepitant rales which clear up following coughing ar occasionally heard in cases of simple silicosis. Wheezing or musical rales are frequently associated with simple silicosis and extensive emphysema

9. Fluoroscopic examination is of distinct advantage; particularly it is possible by such procedure to study diaphragmatic movement and note the presence of areas of increased density which, of course, are better shown in detail by film examination.

Infection, of course, may complicate the picture of silicosis at any time, usually being manifested by pleural pain, fever, night sweats, weigh loss, anorexia, weakness, and a cough producing large amounts of sputum or blood-tinged sputum. All of these factors must be evaluated in estimating the degree of disability, if any, in connection with the diagnosis of silicosis.

\section{Diagnosis}

In making a diagnosis of silicosis, or silicosis with superimposed infection, it is important from the administrative and medico-legal view point to classify silicotic workers into groups indicating the degree 
physical impairment or disability, based upon all available evidence, including symptoms, physical findings, X-ray changes, and laboratory tests. The group of physicians who classified these films later took all these factors into consideration in reaching a final diagnosis. For this purpose the cases observed were classified conveniently into three stages:

1. First stage silicosis or anthraco-silicosis - Slight but definitely characteristic X-ray changes with little or no evidence of physical disability. This does not imply, however, that there is not a potential disability. This does not imply, however, that there is not a potential disability in the individual's lessened resistance to pulmonary infection and further harmful dust exposures, or possibly his ability to do unusually strenuous work.

2. Second stage silicosis-Moderate to well-advanced X-ray changes with moderate disability.

3. Third stage silicosis-Well-advanced X-ray changes and well established or total disability. In some instances these individuals are capable of doing light work although incapable of heavy manual labor.

In addition to the three stages of silicosis as defined above, many workers showed early dust-induced changes on their X-ray films, but not sufficiently so to justify a diagnosis of silicosis. These were classified as borderline cases. Their lung-field markings were usually in an early phase of the granular type, and the workers with those markings showed no symptoms or present evidence of disability.

Pulmonary infection, particularly tuberculosis, may complicate any of these stages and must be taken into consideration in judging the degree of disability. For example, a worker may have X-ray evidence of what would otherwise be classified as first-stage silicosis, but shows signs of clinically active pulmonary tuberculosis in addition with moderate disability, so he would be classified as silicosis with infection, second-stage; also, he is unfit to work so long as the complicating infection remains active. On the other hand, a worker may show X-ray evidence of well advanced silicosis with massive shadows indicating infection, and yet be classified as second-stage silicosis with infection (quiescent) as there may be no clinical evidence of active infection and the disability may not be well marked.

As stated previously in making a diagnosis of silicosis, all available evidence must be taken into consideration to exclude other diseases which simulate the signs, symptoms and X-ray findings of silicosis. The X-ray appearance of miliary tuberculosis may be almost indistinguishable from that of the typical nodular phase of silicosis, but the silicotic case lacks the fever, prostration, rapid pulse, and wasting observed in miliary tuberculosis. Chronic fibroid tuberculosis may offer the greatest difficulty in differential diagnosis, especially when there has been a siliceous dust exposure. It is sometimes almost impossible, to differentiate cases of this type from a typical silicosis without extensive clinical study. If the findings tend to be unilateral with dense, irregular fibroid areas, with retraction of the mediastinal shadow, with coarse, fibrous strands extending into the bases, with pleural adhesions, and with symptoms or past history suggestive of infection, tuberculosis is likely. Perhaps the greatest difficulty is in establishing the presence of silicosis in a worker whose chest film shows evidence of chronic infection which all but obscures the 
possible presence of silicotic lesions. In some instances only small areas of nodules or nodulo-conglomerate areas may be distinguished where not obscured by dense masses and areas of compensatory emphysema. The occupational history and clinical study with serial X-ray films (including stereoscopic films) are invaluable aids in diagnosing these cases.

Cancer of the lung may simulate silicosis but the lesion usually appears in the root of the lung, is unilateral, produces changes in the mediastinum and diaphragm, and may of ten be confirmed by bronchos. copy and other clinical findings. Frank hemoptysis is a frequent symptom as opposed to the infrequent blood-streaked sputum of silicosis.

Carcinomatosis of the lungs may simulate the X-ray picture of sili. cosis but is usually accompanied by evidence of a primary tumor elsewhere as in the breast or kidney, and clinical findings of serious illness.

Numerous miliary calcifications scattered throughout the lung-fields which are seen not infrequently in X-ray films of agricultural workers may offer some difficulty in the diagnosis. These are thought to be caused by micro-fungi or mixed infections as discussed by Sayers and Meriwether (14) and Fawcitt (15). Lack of the characteristic findings of silicosis and cultural study of the sputum will aid in the identification of these infections.

\section{Symptoms and Signs in Relation to Lung-field Markings}

Although such cardinal symptoms of anthraco-silicosis as shortness of breath, weakness, cough, chest pain, and physical findings suggestive of pulmonary fibrosis were taken into account in making a diagnosis of anthraco-silicosis, it is of interest to observe the frequency of occurrence and severity of these and other symptoms in workers with anthraco. silicosis, and to note their relationship to the finer degrees of change in pulmonary fibrosis as indicated by the X-ray film. This relationship to the diagnosis of silicosis is shown in the description of the representative case histories on pages 86 to 107.

\section{TABLE 11-Number and Percent of Coal Miners who Reported Certain Symptoms, with Relation to Lung-field Markings.}

\begin{tabular}{|c|c|c|c|c|c|c|}
\hline \multirow[b]{2}{*}{ Symptom } & \multicolumn{3}{|c|}{ Percent } & \multicolumn{3}{|c|}{ Number } \\
\hline & $\begin{array}{l}\text { First } \\
\text { degree } \\
\text { linear }\end{array}$ & $\begin{array}{c}\text { Second } \\
\text { degree } \\
\text { linear }\end{array}$ & $\begin{array}{c}\text { Granular } \\
\text { and } \\
\text { Nodular } \\
\end{array}$ & $\begin{array}{c}\text { First } \\
\text { degree } \\
\text { linear }\end{array}$ & $\begin{array}{l}\text { Second } \\
\text { degree } \\
\text { linear }\end{array}$ & $\begin{array}{c}\text { Granular } \\
\text { and } \\
\text { Nodular }\end{array}$ \\
\hline Number in group & $\ldots$. & $\ldots$ & ( & 307 & 138 & 44 \\
\hline Average age & ..... & & & 33.6 & 39.4 & 47.5 \\
\hline Shortness of breath & 5.2 & 8.0 & 13.6 & 16 & 11 & 6 \\
\hline Frequent cough & 7.8 & 9.4 & 13.6 & 24 & 13 & 6 \\
\hline Productive cough & 6.8 & 8.7 & 13.6 & 21 & 12 & 6 \\
\hline Chest pain & 2.3 & .7 & 2.3 & 7 & 1 & 1 \\
\hline Weakness & 2.0 & 5.1 & 6.8 & 6 & 7 & 3 \\
\hline Neuritis & 4.2 & 4.3 & 6.8 & 13 & 6 & 3 \\
\hline Arthritis & 6.5 & 12.3 & 9.1 & 20 & 17 & 4 \\
\hline Night sweats & 2.6 & 2.2 & 2.3 & 8 & 3 & 1 \\
\hline Asthma & .3 & 1.4 & 4.5 & 1 & 2 & 2 \\
\hline
\end{tabular}

1 Only 3 cases with nodular markings.

Table 11 indicates the incidence of the more important symptom reported by these miners in relation to the degree of fibrosis observed 
on their X-ray films. As discussed previously, the first-stage linear group includes those miners with normal chest films. The granular and nodular group includes workers showing increased fibrosis characteristic of silicosis. In this group the films are not generally of the more advanced type seen in the silicotic smelter workers and metal miners. This group includes only three workers with nodular markings, and includes 26 workers with early granular markings, not sufficient to be classified as silicosis, but diagnosed as borderline cases. The second-degree linear group is an intermediate group showing exaggerated linear markings indicating slightly increased pulmonary fibrosis, not necessarily due to dust.

\section{Present Complaints}

On the whole, the coal miners examined offered but few symptoms of physical impairments. Shortness of breath was reported by 13.6 percent of the granular and nodular group as compared with 5.2 and 8 percent in the other groups. Frequent and productive cough was reported by a similar proportion in all three groups. Arthritis signifying pain and stiffness in the joints, and neuritis were reported by a small proportion in all groups. Complaints of asthma, general weakness, chest pain, and night sweats were reported infrequently. Other symptoms with no relation to pulmonary fibrosis were reported as follows: headaches, 6.9 percent; skin disturbances, 6.1 percent; constipation, 4.7 percent; nausea, 3.1 percent; colic, 3.0 percent; metallic taste, 1.2 percent; and chills and hemoptysis, less than 1 percent.

In comparing these coal workers with pottery and pegmatite workers previously examined (2) (9), it was found that in each lung-field marking group the incidence of complaints of shortness of breath, cough, and weakness was practically the same.

\section{TABLE 12-Number and Percent of Coal Miners Who Reported Certain} Past Illnesses, with Relation to X-ray Findings.

\begin{tabular}{|c|c|c|c|c|c|c|}
\hline \multirow[b]{2}{*}{ Past illness } & \multicolumn{3}{|c|}{ Percent } & \multicolumn{3}{|c|}{ Number } \\
\hline & $\begin{array}{c}\text { First } \\
\text { degree } \\
\text { linear }\end{array}$ & $\begin{array}{l}\begin{array}{l}\text { Second } \\
\text { degree } \\
\text { linear }\end{array} \\
\end{array}$ & $\begin{array}{c}\text { Granular } \\
\text { and } \\
\text { Nodular }\end{array}$ & $\begin{array}{l}\text { First } \\
\text { degree } \\
\text { linear }\end{array}$ & $\begin{array}{l}\text { Second } \\
\text { degree } \\
\text { linear }\end{array}$ & $\begin{array}{l}\text { Granular } \\
\text { and } \\
\text { Nodular } 1\end{array}$ \\
\hline Number in group & $\ldots$. & $\ldots$. & ........ & 307 & 138 & 44 \\
\hline Average age & $\ldots$ & & & 33.6 & 39.4 & 47.5 \\
\hline Pleurisy & 11.1 & 13.8 & 15.9 & 34 & 19 & 7 \\
\hline Pneumonia & 16.0 & 11.6 & 15.9 & 49 & 16 & 7 \\
\hline Bronchitis & 6.8 & 6.5 & 6.8 & 21 & 9 & 3 \\
\hline Disabling colds & 10.7 & 13.0 & 15.9 & 33 & 18 & 7 \\
\hline Tuberculosis contact & 2.6 & 2.9 & 2.3 & 8 & 4 & 1 \\
\hline Influenza & 46.9 & 39.1 & 40.9 & 144 & 54 & 18 \\
\hline Loss of weight & & & & & & \\
\hline (6 lbs. or more) & 11.1 & 10.1 & 9.1 & 34 & 14 & 4 \\
\hline Digestive disturbances & 18.9 & 18.8 & 18.2 & 58 & 26 & 8 \\
\hline
\end{tabular}

1 Only 3 cases with nodular markings.

\section{Past Medical History}

No significant differences are observed in the past medical history between coal miners classified by degree of pulmonary fibrosis as shown in Table 12. A history of influenza which usually occurred during the pandemics was the most common finding, being reported by 40 percent of all workers. Digestive disturbances were reported by one-fifth of all the 
miners, and pleurisy, pneumonia and disabling colds were reported less frequently. Loss of weight (6 pounds or more in past year) was reported by 10 percent of these miners and bronchitis by about 7 percent. It is interesting to compare the history of illnesses of these bituminous miners with the anthracite miners in an earlier study of the Public Health Service (1). Of the 1,193 anthracite miners who were free of anthraco-silicosis, 5.7 percent gave a history of tuberculosis contact, a rate almost double that of the bituminous miners. Fewer of these anthracite miners had experienced attacks of pleurisy ( 7.5 percent), pneumonia (10.2 percent), influenza (26.6 percent), and bronchitis ( 5.8 percent) than the Utah bituminous coal miners as shown in Table 12 .

In general, however, Utah coal miners had enjoyed good health and had had but few illnesses sufficiently severe to prevent their working full time.

\section{Physical Findings with Relation to X-ray Findings}

A summary of the more important physical findings with relation to the degree of pulmonary fibrosis revealed by the X-ray films is shown in Table 13. As a group the coal miners were in a good general state of health in comparsion with other industrial populations.

TABLE 13-Number and Percent of Workers Classified According to Degree of Pulmonary Fibrosis as Shown by X-Ray Findings, Who Were Found to Have Certain Abnormalities on Physical Examination.

\begin{tabular}{|c|c|c|c|c|c|c|}
\hline \multirow[b]{2}{*}{ Physical finding } & \multicolumn{3}{|c|}{$\begin{array}{l}\text { Percent of workers } \\
\text { Lung-field markings }\end{array}$} & \multicolumn{3}{|c|}{$\begin{array}{l}\text { Number of workers } \\
\text { Lung-field markings }\end{array}$} \\
\hline & $\begin{array}{c}\text { First } \\
\text { degree } \\
\text { linear }\end{array}$ & $\begin{array}{l}\text { Second } \\
\text { degree } \\
\text { linear }\end{array}$ & $\begin{array}{l}\text { Ground- } \\
\text { glass and } \\
\text { nodular } \\
\end{array}$ & $\begin{array}{l}\text { First } \\
\text { degree } \\
\text { linear }\end{array}$ & $\begin{array}{l}\text { Second } \\
\text { degree } \\
\text { linear }\end{array}$ & $\begin{array}{l}\text { Ground- } \\
\text { glass and } \\
\text { nodular }\end{array}$ \\
\hline Number of workers & 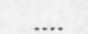 & 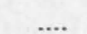 & ....... & 307 & 138 & 44 \\
\hline Average age & & & & 33.6 & 39.4 & 47.5 \\
\hline Cachectic appearance & 3.9 & 2.9 & 4.5 & 12 & 4 & 2 \\
\hline Underweight more & & & & & & \\
\hline than 5 percent & 41.0 & 44.9 & 43.2 & 126 & 62 & 19 \\
\hline Pallor & 4.9 & 2.2 & 4.5 & 15 & 3 & 2 \\
\hline Chest expansion less & & & & & & \\
\hline than $5 \mathrm{~cm}$. & 5.2 & 8.0 & 11.4 & 16 & 11 & 5 \\
\hline Retracted fossae & 12.1 & 14.5 & 15.9 & 37 & 20 & 7 \\
\hline Impaired mobility & 1.0 & 3.6 & 9.1 & 3 & 5 & 4 \\
\hline Dullness, percussion & 9.1 & 4.3 & 11.4 & 28 & 6 & 5 \\
\hline Hyperresonance, & & & & & & \\
\hline percussion & 3.3 & 8.7 & 4.5 & 10 & 12 & 2 \\
\hline Abnormal breath sounds & 16.6 & 21.0 & 43.2 & 51 & 29 & 19 \\
\hline Rales & 8.8 & 8.7 & 18.2 & 27 & 12 & 8 \\
\hline Dyspnoea & 3.6 & 4.3 & 6.8 & 11 & 6 & 3 \\
\hline Clubbed fingers & 9.1 & 12.3 & 13.6 & 28 & 17 & 6 \\
\hline Restricted movement, & & & & & & \\
\hline diaphragm & 4.2 & 5.8 & 20.5 & 13 & 8 & 9 \\
\hline Adhesions, diaphragm & 3.9 & 4.3 & 11.4 & 12 & 6 & 5 \\
\hline
\end{tabular}

It is observed that nearly all the miners presented either an average or robust general appearance as only about 4 percent appeared to be cachectic or in a general state of ill health or malnutrition, while 37.6 percent appeared robust, or above the average.

Slightly more than 40 percent of the miners were more than 5 percent underweight compared to average values for men of their height and 
age, compiled by the Association of Life Insurance Medical Directors and the Actuarial Society of America (16). This proportion of coal miners weighing under the average is somewhat greater than that found in a study of truck drivers (6) (30.5 percent) and among a group of hatters ${ }^{1}$ (34.1 percent) (17).

TABLE 14-Distribution of Percentage Weight Deviations for Coal Mine Workers Classified by Diagnosis of Silicosis.

\begin{tabular}{|c|c|c|c|c|}
\hline \multirow{3}{*}{$\begin{array}{l}\text { Percentage } \\
\text { weight } \\
\text { deviation }\end{array}$} & \multicolumn{4}{|c|}{ Percent of workers } \\
\hline & \multirow[b]{2}{*}{$\begin{array}{l}\text { All coal } \\
\text { mine workers }\end{array}$} & \multicolumn{3}{|c|}{ Diagnosis of silicosis } \\
\hline & & $\begin{array}{l}\text { 1st and 2nd } \\
\text { stage }\end{array}$ & Borderline & Non-affected \\
\hline Total & 5041 & 16 & 25 & 463 \\
\hline-35 & .2 & $\ldots$. & $\ldots$. & .2 \\
\hline-25 to 34 & .6 & & ..... & .7 \\
\hline-15 to 24 & 7.7 & 25.0 & 8.0 & 7.1 \\
\hline-5 to 14 & 34.5 & 37.5 & 28.0 & 34.8 \\
\hline+5 & 33.1 & 18.8 & 44.0 & 33.0 \\
\hline+5 to 14 & 15.1 & 12.5 & 12.0 & 15.3 \\
\hline+15 to 24 & 5.8 & 6.2 & 8.0 & 5.6 \\
\hline+25 to 34 & 1.8 & .... & .... & 1.9 \\
\hline+35 to 49 & .6 & .... & ..... & .7 \\
\hline+50 & .6 & & .... & .7 \\
\hline Average 2 & -1.5 & -6.2 & -1.6 & -1.3 \\
\hline Standard deviation & 12.7 & 13.2 & 10.2 & 12.8 \\
\hline
\end{tabular}

Percentage weight deviation for 3 workers is unknown.

2 Averages represent the percentage the workers fell below or above the average for life insurance applicants of comparable age and height.

As shown in Table 14,16 coal miners with anthraco-silicosis weigh 6.2 percent less than the expected normal value, on the average, although the borderline cases and non-affected group closely approximate the normal value.

Pallor was observed in a small proportion of all groups, and in no instance was the pallor of the degree observed in metallic poisoning.

The physical findings from the chest examination showed several trends with X-ray evidence of increasing pulmonary fibrosis. Men with chest expansion of less than 5 centimeters ( 2 inches) were found twice as often (11.4 percent) in the group with ground-glass markings as in the first-degree linear group (5.2 percent), and impaired resonance, retracted fossae, impaired mobility, dull percussion note, and rales were likewise recorded more frequently in the ground-glass group. Abnormal breath sounds showed the greatest correlation wtih X-ray changes ranging from 16.6 percent in first-degree linear group to 43.2 percent in the ground-glass group.

Workers showing shortness of breath or difficulty in breathing after exercise comprised a small proportion of all groups ( 3.6 to 6.8 percent). Clubbed fingers, or abnormally curved nails, sometimes associated with pulmonary fibrosis, was found somewhat more frequently in the groundglass group (13.6 percent) than in the normal group (9.1 percent).

Fluoroscopic examination of the chest showed one-fifth of the workers with ground-glass or nodular markings to have some restriction, usually slight, of the movement of the diaphragm, while occurring infrequently in the other groups ( 4.2 to 5.8 percent). Adhesions of the diaphragm 
were noted in 11.4 percent of the ground-glass group films, as compared with about 4 percent in the other groups.

In comparing the incidence of such physical signs as abnormal breath sounds, dullness on percussion, and clubbed fingers (abnormal curving of nails) with pottery workers examined in a previous study (2), it was found that there is fairly good correspondence between similar groups by lung-field markings.

Miscellaneous Physical Findings - Other physical findings were recorded and tabulated which bore no relationship to pulmonary fibrosis. Inspection of the eyes revealed 20 percent of the miners had some injection of the conjunctivae (bloodshot eyes), a condition frequently associated with eyestrain, irritating atmospheric contaminants, inadequate or glaring illumination, and loss of sleep. While this condition occurred less frequently than among truck drivers (6) (51 percent), it was more frequently observed than among hatters (2.8 percent) (17). It seems probable that the necessarily low illumination level in coal mines may be a factor in causing such an incidence of conjunctival injection. On the other hand, no typical case of miners' nystagmus was observed, such as described by Legge (18) and other earlier investigators, especially in English mines. There were, however, seven cases observed with slight lateral nystagmus, which caused no apparent symptoms, found among haulageway workers in four cases, and in a shot firer, a coal digger, and an undercutter operator. These workers averaged 25 years in the coal mines, and their average age was 44 years. Two of these men had firststage anthraco-silicosis, and one was considered a borderline case. Six of these seven workers showed some clubbing of the fingers, and four were underweight. Irregular and unequal pupils, as well as evidences of previous eye injuries were observed infrequently. Chronic inflammation of the nose or throat, usually slight, was observed in 9.4 percent of the men examined.

Skin diseases were relatively infrequent $t_{2}$ acne or boils occurring in 14 cases (2.7 percent) and dermatitis of common types occurring in seven cases. Amputations, usually of a finger or two, were recorded in 24 cases (4.7 percent), while other deformities, usually due to accidental injuries of the hands and arms, were observed in 13 cases ( 2.6 percent). Increased knee-jerks were observed in 7.6 percent of the miners and decreased kneejerks were observed in 5.1 percent. Visible tremor of the hands, usually fine, was observed in 12.4 percent, an incidence less than that of truck drivers (6) and hatters (17) previously studied. Other abnormalities such as bursitis, enlarged thyroid, or other neurologic changes occurred too infrequently to merit tabulation.

Among the 476 urinalyses performed on these workers, there were 33 tests ( 6.9 percent) showing more than a trace of albumin by the sulphosalicylic acid method, and seven tests ( 1.5 percent) which showed only a trace. This figure is somewhat less than that reported by Blatherwick (18) (10.7 percent) from 13,000 employees of a life insurance company. Of these 40 tests showing some albumin, 11 workers ( 2.3 percent) showed a significant number of red cells in their urine, and 21 (4.4 percent) showed white or pus cells. Casts were found, however, in only three instances. Only four urinalyses revealed more than a trace of sugar by the Benedict method, and two revealed a trace. 
It appears from these findings that the bituminous coal miners observed in this study enjoy good health as a group. Forty-four workers with significantly increased pulmonary fibrosis indicated by the X-ray film showed a slight increase in signs and symptoms associated with such fibrosis, but little apparent disability was noted.

Syphilis-Kahn blood tests for syphilis were reported to be positive (4 plus) in ten cases of the 552 blood specimens so examined, an incidence of 1.8 percent. This rate compares closely with that of smelter workers (1.8 percent), but is almost double that of metal miners ( 0.8 percent). These rates correspond with those of storage battery workers (2.2 percent) (34), compressed air workers (2.7 percent) (35), hatters (1.0 percent) (17), and other industrial groups studied recently by the Public Health Service.

In addition to the ten workers with a 4 plus test, one worker was found to show a 2 plus reaction with other evidence of syphilis, and one had a 2 plus reaction but showed no evidence of syphilis. It therefore appears that there were presumably 11 cases of syphilis in this group of coal workers, an incidence of 2 percent. The average age of this group was 45 years, including only four men under the age of 40 years. Six men showed physical signs which supported a diagnosis of syphilis, including one with well developed aortitis, and a case with circinate lesions of the skin. Two of the workers gave a history of syphilis and two others gave a history of gonorrhea. No well developed syphilis of the central nervous system was observed.

\section{Anthraco-Silicosis Among Bituminous Coal Miners}

Sixteen cases of anthraco-silicosis were found among 507 miners whose only occupational dust exposure had been in bituminous mines; six had exposure only in Utah, and ten had exposure in Utah and also in other sections of the United States. These cases were not advanced or seriously disabled as shown by representative case histories (p. 85). Only one case of moderately advanced (second-stage) anthraco-silicosis was found (Figure 14), and no well advanced (third-stage) case was observed. No case was found that presented the typical picture of welladvanced anthraco-silicosis with bilateral, massive, conglomerate shadows as found by the Public Health service in a study of 2,711 anthracite miners (1), but these cases presented changes in their films similar to those observed in anthracite miners with early anthraco-silicosis. Twentysix workers were diagnosed as borderline cases of anthraco-silicosis because their X-ray films showed an early, diffuse, granular infiltration throughout the lung-fields, but the changes observed and the signs and symptoms were not sufficient to justify a diagnosis of anthraco-silicosis. The explanation for the lack of advanced cases is shown by the fact that the dust exposures were considerably less in the bituminous mines studied here than in the anthracite mines, both in dust concentration and in free silica content.

Although no specimens were obtained in this investigation for pathologic study, extensive descriptions have been given of the coal miner's lung by Miller (1), Cummins and Sladden (20), and Gardner (21). It has been recognized generally that silica must be present in atmospheric dust to cause disabling pulmonary fibrosis, whether it reaches the breath- 
ing zone from the natural coal content, bony or rock encountered, rock dust, or possibly from the dispersion of fine sand used in the haulageways. It is expected that the occurrence of silicosis would vary considerably from one coal mining area to another, depending to a large extent on the free silica content of the dust in the breathing zone of the miners as pointed out by Cummins and Sladden (20), who said:

"Our observations lead us to the conclusion that anthracosis, defined as a fibrosis of lungs accompanied by heavy impregnation with coal-dust, is a sepcial form of industrial disease occurring in coal miners chiefly and to a less extent in others who labor with coal. A further deduction appears fully warranted, that a preceding condition essential to anthracotic fibrosis is the inhalation of silica. When the exposure to silica-dust is great, as with hard-heading workers and repairers, the fibrosis becomes intense and the pulmonary disability correspondingly serious. We believe that in the absence of the silica factor there would be, under modern mining conditions, no serious degree of anthracosis, that in fact anthracosis is essentially a special variety of silicosis depending upon the simultaneous or subsequent accumulation of coal-dust in the silica-damaged lung. We recognize the importance of the experimental work of Haldane, Mavrogordato and others on the rapid elimination of carbon particles from the normal lung. These observations lend point to our finding that coaldust is retained in the lung when the lymph drainage has been impaired by the action of silica."

They further stated:

"From a not inconsiderable experience of post-mortem examinations on coal miners we draw the conclusion that out of the general classification 'pulmonary diseases' given as the cause of death in coal miners, a very important proportion consists essentially of fibrosis of lung complicated often with bronchitis, not seldom with tuberculois, and frequently terminating in pneumonia. The basic damage to the lung by fibrotic changes may well underlie the increased incidence recorded under these other headings. Doctors working in the colliery areas are unanimous in declaring that coal miners as a class resist pneumonia and influenza badly. We are told that coal miners when affected by pulmonary fibrosis state they feel better below ground than 'on top,' and for this and other reasons they often remain at work although hampered by partial pulmonary disablement."

Whether this occupational disease of coal miners is termed anthracosilicosis as in an earlier Public Health Service report (1), silico-anthracosis as used by British investigators, or anthracosis as used in the pathologic sense $^{1}$ by Cummins and Sladden and earlier investigators, the pathology appears to be essentially a modified form of silicosis, the modification depending largely on the amount of free silica experience in relation to carbon dust. The sources of siliceous dust exposure in the present study is discussed in the Engineering Section.

1 The recent trend in pathologic classifications is to restrict the term "anthracosis" to merely pigmentation of the lung by coal dust, soot, or smoke, with little or no fibrosis (22). 


\section{Relation of Anthraco-Silicosis to Dust Concentration and Duration of Employment}

Table 15 shows a distribution of anthraco-silicosis and borderline anthraco-silicosis cases according to years employed in coal mining and weighted average atmospheric dust concentration. ${ }^{1}$ It will be noted that no case of anthraco-silicosis is found with less than ten years' experience in coal mines. Only two cases are found who had been exposed to an average atmospheric dust concentration of less than 20 million particles per cubic foot. These had worked for $38^{2}$ and 21 years in coal mines. Three out of the four coal miners who had worked more than 30 years in a dust concentration of 30 million particles and over, showed evidence of anthraco-silicosis, and included the only second-stage case found.

If dust concentration is considered, irrespective of years employed in coal mining, it will be observed that 0.6 percent are affected with anthraco-silicosis in the exposure groups below 20 million particles, 5.9 percent in the group from $20-29$ million particles, and 9.2 percent in the group above 30 million particles per cubic foot. Among those affected the weighted average dust concentration did not exceed 37 million particles per cubic foot of air.

The influence of years of employment in coal mines is more marked than dust concentration. For less than 10 years there are none affected with anthraco-silicosis, from 10-19 years there are 1.7 percent, from 20-29 years there are 5.1 percent, and for 30 years and over 22.5 percent. Of those affected in the last group, six had worked in coal from 30-39 years and three from 40-45 years. When borderline silicosis cases are added to the anthraco-silicosis cases the percent affected for the corresponding periods of employment is 0.5 percent, 5.6 percent, 16.5 percent, and 45.0 percent.

In the group of persons with coal mining experience outside of the State of Utah the incidence of anthraco-silicosis was 15.4 percent compared with 1.4 percent for those who had worked in Utah only. In Table 16 an occupational history is given for each of the 10 anthraco-silicosis cases with out-of-State mining experience. It will be observed that these men spent an average of 16.2 years in Utah and 17.6 years in eleven other States. Two men had worked in English coal mines. In general, arrival in Utah did not cause a change in the particular type of coal mining work which had previously been followed. Most of the men had been engaged for the greater part of their working life in the digging, cutting, or loading of coal. The working conditions which prevailed in States other than Utah cannot be determined, but since such experience was usually several years ago, it is possible that the former dust exposure was greater than the present. Siliceous dust exposures in coal mining operations vary from region to region, depending on the nature of the coal deposits and associated rock and slate formations. It is not unlikely that miners work-

The method of determining weighted average dust concentration exposure values for each worker is the same as that described in Public Health Bulletin No. 221 (1), and is shown in appendix IV, However, this case, with an average weighted dust exposure of less than 10 million particles per cubic foot, had worked for 24 years hauling coal in Iowa where the dust concentration was unknown. 
TABLE 15-Number of Coal Mine Workers in Utah with Anthraco-Silicosis and Borderline Anthraco-Silicosis According to Years Employed in Coal Mines and Dust Concentration.

\begin{tabular}{|c|c|c|c|c|c|c|}
\hline \multirow{2}{*}{$\begin{array}{c}\text { Dust concentration, } \\
\text { million particles } \\
\text { per cubic foot }\end{array}$} & & \multicolumn{5}{|c|}{ Years employed in coal mines } \\
\hline & & $\begin{array}{c}\text { Less than } \\
10\end{array}$ & $10-19$ & $20-29$ & $\begin{array}{c}30 \text { and } \\
\text { over }\end{array}$ & Total \\
\hline O-9.9 & $\begin{array}{l}\text { Number exposed } \\
\text { Number with anthraco-silicosis } \\
\text { Number with borderline authraco-silicosis }\end{array}$ & $\begin{array}{r}74 \\
0 \\
0\end{array}$ & $\begin{array}{r}65 \\
0 \\
2\end{array}$ & $\begin{array}{r}28 \\
0 \\
3\end{array}$ & $\begin{array}{l}9 \\
1 \\
1\end{array}$ & $\begin{array}{r}176 \\
1 \\
6\end{array}$ \\
\hline $10.0-19.9$ & $\begin{array}{l}\text { Number exposed } \\
\text { Number with anthraco-silicosis } \\
\text { Number with borderline authraco-silicosis }\end{array}$ & $\begin{array}{r}73 \\
0 \\
0\end{array}$ & $\begin{array}{r}57 \\
0 \\
2\end{array}$ & $\begin{array}{r}18 \\
1 \\
1\end{array}$ & $\begin{array}{r}11 \\
0 \\
4\end{array}$ & $\begin{array}{r}159 \\
1 \\
7\end{array}$ \\
\hline $20.0-29.9$ & $\begin{array}{l}\text { Number exposed } \\
\text { Number with anthraco-silicosis } \\
\text { Number with borderline authraco-silicosis }\end{array}$ & $\begin{array}{r}33 \\
0 \\
0\end{array}$ & $\begin{array}{r}28 \\
1 \\
0\end{array}$ & $\begin{array}{r}16 \\
1 \\
3\end{array}$ & $\begin{array}{l}8 \\
32 \\
2\end{array}$ & $\begin{array}{r}85 \\
5 \\
5\end{array}$ \\
\hline 30.0 and over & $\begin{array}{l}\text { Number exposed } \\
\text { Number with anthraco-silicosis } \\
\text { Number with borderline authraco-silicosis }\end{array}$ & $\begin{array}{r}27 \\
0 \\
0\end{array}$ & $\begin{array}{r}23 \\
1 \\
2\end{array}$ & $\begin{array}{l}11 \\
2^{2} \\
2\end{array}$ & $\begin{array}{l}4 \\
31 \\
0\end{array}$ & $\begin{array}{r}65 \\
6 \\
4\end{array}$ \\
\hline $\begin{array}{l}\text { Exposure } \\
\text { not } \\
\text { determined }\end{array}$ & $\begin{array}{l}\text { Number exposed } \\
\text { Number with anthraco-silicosis } \\
\text { Number with borderline authraco-silicosis }\end{array}$ & $\begin{array}{l}2 \\
0 \\
1\end{array}$ & $\begin{array}{l}6 \\
1 \\
1\end{array}$ & $\begin{array}{l}6 \\
0 \\
0\end{array}$ & $\begin{array}{l}8 \\
2 \\
2\end{array}$ & $\begin{array}{r}22 \\
3 \\
4\end{array}$ \\
\hline
\end{tabular}

1 Includes one second-stage anthraco-silicosis case with nodular lung-field markings.

2 Includes one case with nodular lung-field markings. 
ing in other States were in some instances exposed to dusts with a larger proportion of free silica.

\section{Incidence of Anthraco-Silicosis By Principal Occupation}

Anthraco-silicosis was found in this study in six undercutter operators, four coal diggers, and hand loaders, two shot firers and tampers, two trackmen, one driller, and one driver. As shown in Table 17, there are many occupations in the coal mines studied which did not reveal a case of anthraco-silicosis or borderline anthraco-silicosis. Indeed, none of these persons whose principal occupation was above ground showed any evidence of anthraco-silicosis. Surface workers included persons having to do with transportation, maintenance and supervision, as well as the dusty occupation of tipple operation.

Underground workers sometimes had experience in more than one type of job below the surface. In order to take into account this shifting of employment within broad groups, the records of those persons to whom no definite principal occupation had been assigned, were re-examined and so far as possible classified into underground or surface workers. Significant differences were noted between the two groups. The average age for underground workers was 38.0 years, while for surface workers it was 32.6 years; the average years of employment in coal for these groups were 15.7 and 10.4 ; and the average dust concentrations were 18.3 and 10.9 million particles per cubic foot, respectively. Not only were the underground workers older, but also they had been employed in coal mining for a longer time and had been exposed to higher concentration of dust.

In considering the finer degrees of change in pulmonary fibrosis as indicated by the lung-field markings on the X-ray film, further differences are evident between surface and underground workers, taking into consideration years of exposure, as shown in Table 18 and Figure 7. In both occupational groups the proportion of workers with increased fibrosis is greater with employment for 10 years and more than for shorter periods. It is observed, however, that the proportion of workers showing increased pulmonary fibrosis is greater in underground workers in each group by years of employment. There are no nodular or groundglass cases among surface workers. On the other hand, underground workers show ground-glass markings with less than 10 years of exposure, while nodular markings are found among those with more than 20 years of employment.

Summary - Sixteen cases of anthraco-silicosis were found among 348 underground bituminous-coal miners, an incidence of 4.6 percent. The proportion of miners with anthraco-silicosis or borderline anthraco-silicosis increased regularly with increasing dust concentrations and increasing lengths of employment. Anthraco-silicosis was found among miners whose principal occupations were coal diggers, loaders, under-cutter operators, shot firers, trackmen, drivers, and drillers. Anthraco-silicosis was not found among workers whose principal occupation was at the surface.

The cases of anthraco-silicosis were early, showing but slight disability in all but one case. In addition, six cases of silicosis were found, four of which were moderately advanced; in the group that had had considerable previous siliceous dust exposure in metal mines. 


\section{TABLE 16-Occupational History of 10 Coal Mine Workers Affected by Anthraco-Silicosis with Coal Mining Experience Both in Utah and Outside of Utah.}

\begin{tabular}{|c|c|c|c|c|c|c|c|c|}
\hline \multirow{2}{*}{ Case } & \multirow{2}{*}{ Age } & \multicolumn{2}{|c|}{ Mining experience in Utah } & \multicolumn{2}{|c|}{ Mining experience outside Utah } & \multirow{2}{*}{$\begin{array}{l}\text { Lung-field } \\
\text { marking }\end{array}$} & \multirow{2}{*}{$\begin{array}{l}\text { Stage of } \\
\text { Anthraco- } \\
\text { Silicosis }\end{array}$} & \multirow{2}{*}{ Remarks } \\
\hline & & Occupation & $\begin{array}{c}\text { Years } \\
\text { Employed }\end{array}$ & Occupation & $\begin{array}{c}\text { Years } \\
\text { Employed }\end{array}$ & & & \\
\hline 1 & 35 & Machine operator & 4 & $\begin{array}{l}\text { Machine operator } \\
\text { Demonstrator } \\
\text { Coal cutter }\end{array}$ & $\begin{array}{r}12 \\
2 \\
3 \\
\end{array}$ & G G 2 & Stage 1 & Primary tbc \\
\hline 2 & 48 & $\begin{array}{l}\text { Motorman } \\
\text { Loading and hauling coal }\end{array}$ & $\begin{array}{l}5 \\
9\end{array}$ & Hauling coal & 24 & G G 1 & Stage 1 & \\
\hline 3 & 49 & $\begin{array}{l}\text { Shot firer } \\
\text { Trackman }\end{array}$ & $\begin{array}{r}14 \\
2\end{array}$ & Digging and hauling coal & 19 & G G 2 & Stage 1 & \\
\hline 4 & 50 & $\begin{array}{l}\text { Hoistman } \\
\text { Digger }\end{array}$ & $\begin{array}{l}4 \\
2\end{array}$ & Digger & 25 & G G 2 & Stage 2 & \\
\hline 5 & 52 & $\begin{array}{l}\text { Trackman } \\
\text { Loader }\end{array}$ & $\begin{array}{l}5 \\
3\end{array}$ & Loader & 9 & G G 2 & Stage 1 & \\
\hline 6 & 53 & Machine man & 14 & $\begin{array}{l}\text { Machine man } \\
\text { Skinner } \\
\text { Tamper }\end{array}$ & $\begin{array}{l}6 \\
9 \\
4\end{array}$ & G G 2 & Stage 1 & Primary tbc \\
\hline 7 & 54 & Machine man & 19 & Machine man & 3 & G G 2 & Stage 1 & \\
\hline 8 & 57 & $\begin{array}{l}\text { Inspector } \\
\text { Shot firer } \\
\text { Digger }\end{array}$ & $\begin{array}{r}10 \\
7 \\
10\end{array}$ & Miner & 15 & G G 2 & Stage 1 & \\
\hline 9 & 58 & $\begin{array}{l}\text { Track layer } \\
\text { Timberman } \\
\text { Loader }\end{array}$ & $\begin{array}{r}4 \\
3 \\
12 \\
\end{array}$ & Loader & 15 & G G 2 & Stage 1 & Primary tbc \\
\hline 10 & 60 & Machine man & 11 & Machine man & 30 & Nod. 1 & Stage 1 & \\
\hline
\end{tabular}




\section{TABLE 17-Coal Mine Workers in Utah, by Principal Occupation Accord- ing to Years Employed in Coal Mines, and Diagnosis of anthraco-silicosis.}

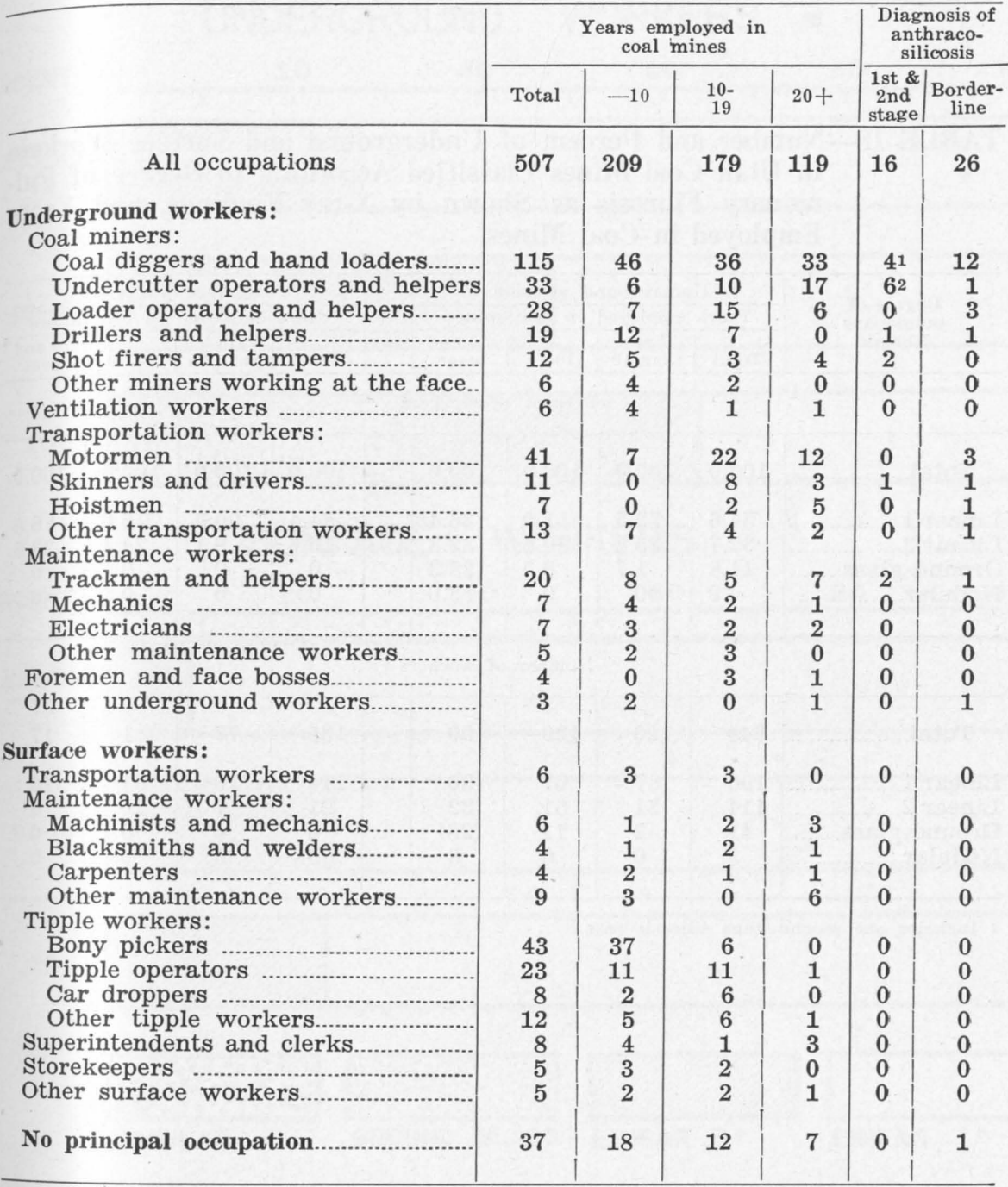

1 Includes 1 case with nodular lung-field markings and 1 second-stage anthraco-silicosis case.

2 Includes 2 cases with nodular lung-field markings. 
TABLE 18-Number and Percent of Underground and Surface Workers in Utah Coal Mines Classified According to Degree of Pulmonary Fibrosis as Shown by X-ray Findings, and Years Employed in Coal Mines.

\begin{tabular}{|c|c|c|c|c|c|c|c|c|}
\hline \multirow{3}{*}{$\begin{array}{l}\text { Degree of } \\
\text { pulmonary } \\
\text { fibrosis }\end{array}$} & \multicolumn{4}{|c|}{ Underground workers } & \multicolumn{4}{|c|}{ Surface workers } \\
\hline & \multirow{2}{*}{\begin{tabular}{|l|} 
Years \\
Total
\end{tabular}} & \multirow{2}{*}{$\begin{array}{c}\text { employed } \\
\text { Less } \\
\text { than } 10\end{array}$} & \multirow{2}{*}{$\begin{array}{l}\text { in coal } \\
10-19\end{array}$} & \multirow{2}{*}{$\begin{array}{l}\text { mines } \\
\begin{array}{c}20 \text { and } \\
\text { over }\end{array}\end{array}$} & \multirow{2}{*}{\begin{tabular}{l|} 
Years \\
Total
\end{tabular}} & \multirow{2}{*}{$\begin{array}{c}\text { employed } \\
\text { Less } \\
\text { than 10 }\end{array}$} & \multirow{2}{*}{\begin{tabular}{|c|} 
in coal \\
$10-19$
\end{tabular}} & \multirow{2}{*}{\begin{tabular}{|c|}
$\begin{array}{c}20 \text { and } \\
\text { over }\end{array}$ \\
\end{tabular}} \\
\hline & & & & & & & & \\
\hline \multicolumn{9}{|c|}{ Percent of workers } \\
\hline Total.. & 100.0 & 100.0 & 100.0 & 100.0 & 100.0 & 100.0 & 100.0 & 100.0 \\
\hline Linear $1 .$. & 54.6 & 72.5 & 51.9 & 36.4 & 84.4 & 90.9 & 75.6 & 76.5 \\
\hline Linear $2 \ldots \ldots \ldots \ldots$ & 32.7 & 25.8 & 39.6 & 32.3 & 15.6 & 9.1 & 24.4 & 23.5 \\
\hline Ground-glass......... & 11.8 & 1.7 & 8.5 & 28.3 & 0 & 0 & 0 & 0 \\
\hline Nodular........................... & .9 & 0 & 0 & 3.0 & 0 & 0 & 0 & 0 \\
\hline \multicolumn{9}{|c|}{ Number of workers } \\
\hline Total... & 348 & 120 & 129 & 99 & 135 & 77 & 41 & 17 \\
\hline Linear 1. & 190 & 87 & 67 & 36 & 114 & 70 & 31 & 13 \\
\hline Linear $2 \ldots$ & 114 & 31 & 51 & 32 & 21 & 7 & 10 & 4 \\
\hline Ground-glass......... & 41 & 2 & 11 & 281 & 0 & 0 & 0 & 0 \\
\hline Nodular..................... & 3 & 0 & 0 & 3 & 0 & 0 & 0 & 0 \\
\hline
\end{tabular}

1 Includes one second-stage silicosis case. 


\section{UNDERGROUND WORKERS}
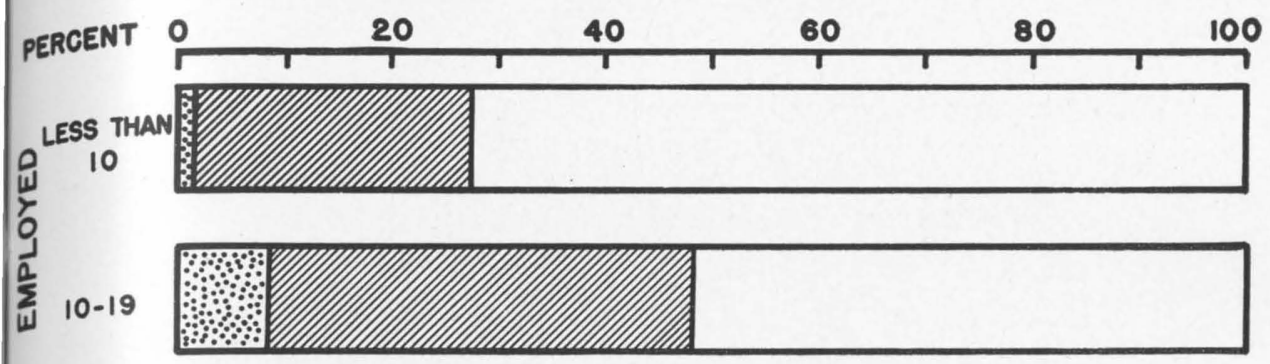

$20+$

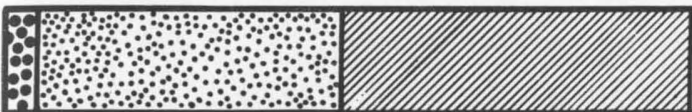

\section{SURFACE WORKERS}
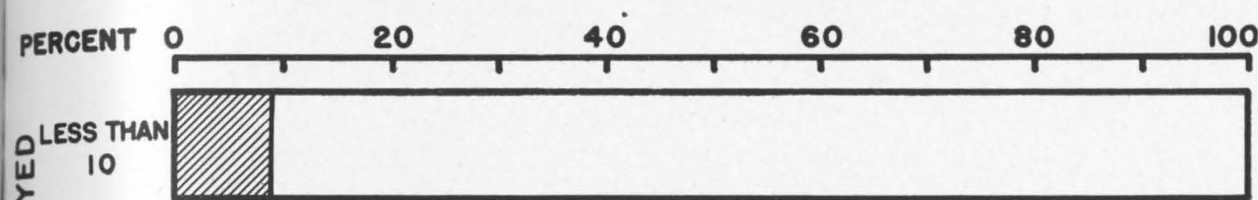

$10-19$

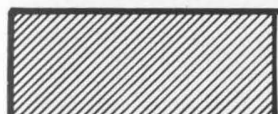

$20+$

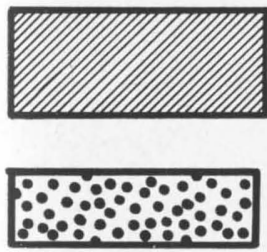

NODULAR
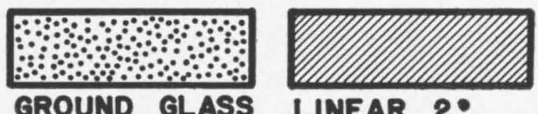

LINEAR $2^{\circ}$

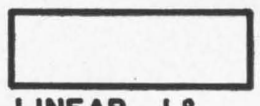

FIGURE 7 -Underground and surface workers who had certain $X$-ray findings indicating degree of pulmonary fibrosis, classified by duration of employment in coal mines. 

REPRESENTATIVE CASE HISTORIES 


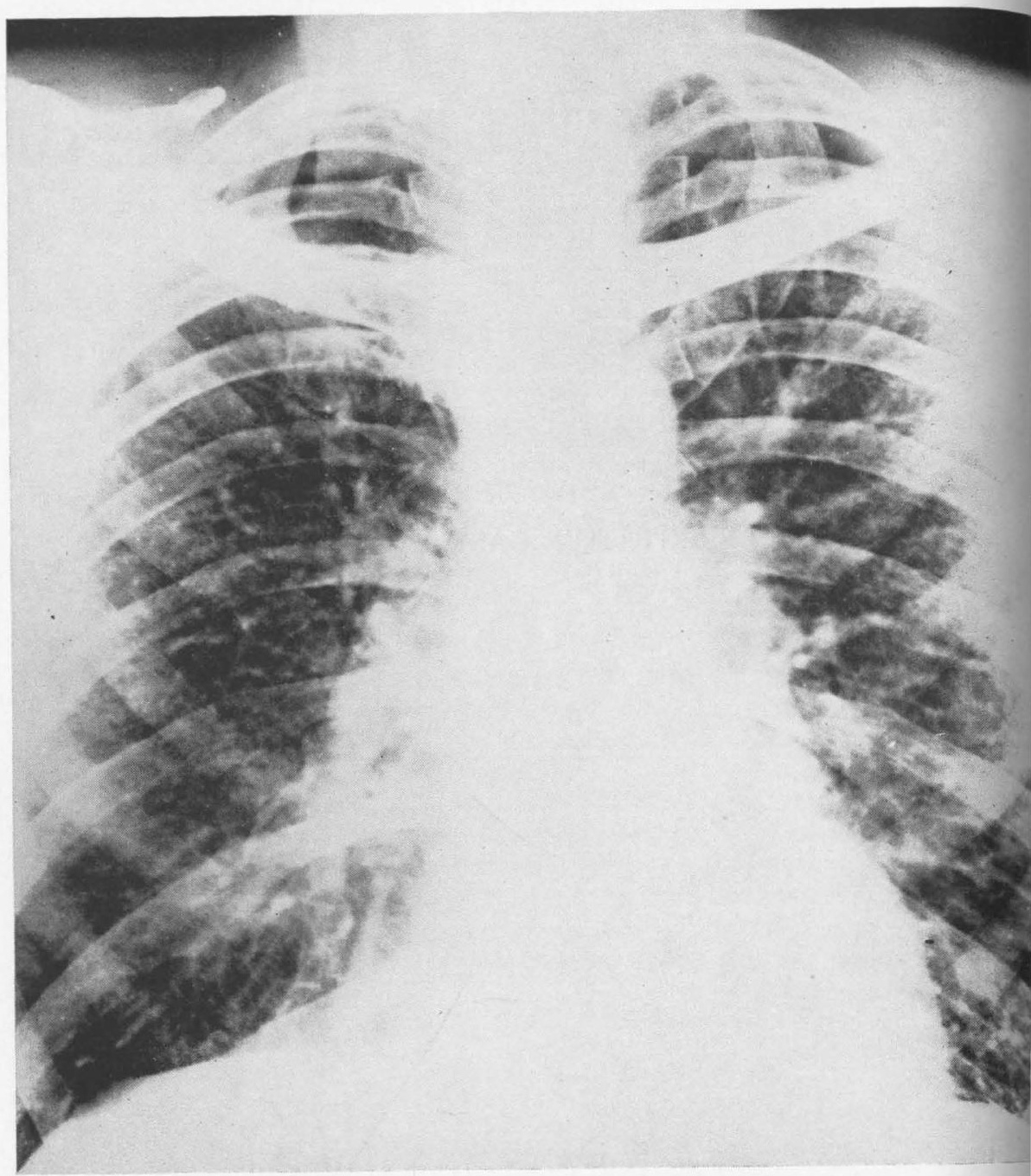

FIGURE 8-Coal digger, male, age 59. 


\section{Figure 8-Case History}

Occupational history-Lamp house man, seven years; wrecker, two years; yard foreman, seven years; face boss, one year; coal digger, 22 years; teamster, nine years. Idle, three years. Total, 16 years, top work; 32 years, underground, in soft coal mines in Utah.

Estimated dust exposure-Weighted average, 22 million particles per cubic foot.

Past medical history-Pneumonia, 1890. Influenza, several mild attacks. Mild attack of dry pleurisy in 1934 .

Complaints-Morning cough for about the past 10 years, raising about one teaspoon of purulent sputum. Moderate shortness of breath for two years. Occasional metallic taste. Left knee stiff and painful for six months.

Physical examination-Average appearance, $68 \mathrm{I} / 2$ inches; weight, 164 pounds. Chest expansion, $4 \mathrm{~cm}$. Chest examination, retracted fossae. Rubs palpated over middle and lower chest. Breath sounds are very rough throughout. No rales. Blood pressure, 118/76. Heart rate, 84; after exercise, 80. Respiratory rate, 20; same after exercise. No dyspnoea observed. Heart examination, negative.

Fluoroscopic examination-Slight impairment of movement of diaphragm.

X-ray film-Fine nodules, diffusely scattered throughout lung field. Small calcification in both hila. First degree nodular phase. losis.

Diagnosis-Anthraco-silicosis early, with healed childhood tubercu-

Comment-Little disability is observed in this 59-year-old coal miner who has spent 16 years above ground and 32 years in the mines. 


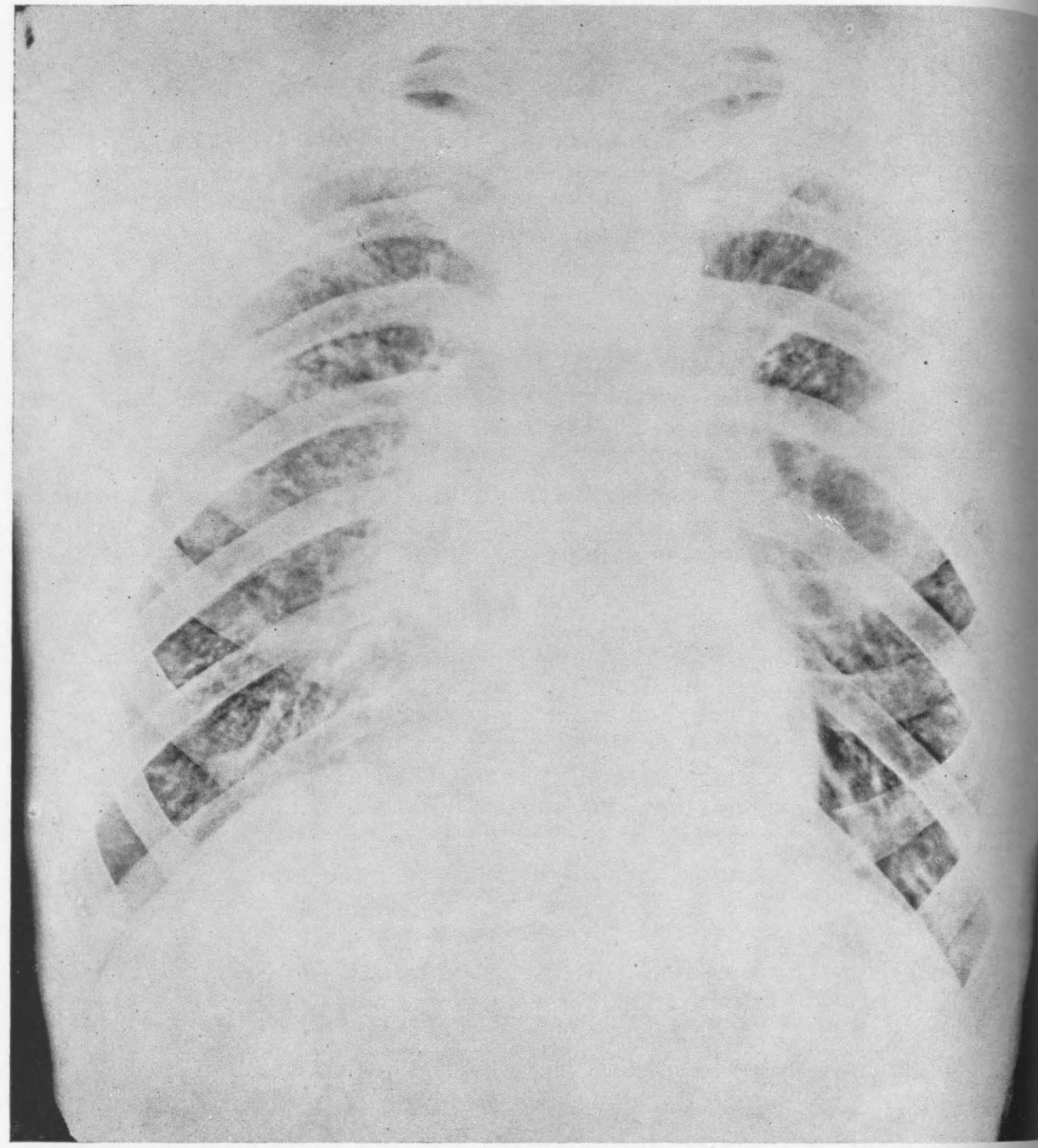

FIGURE 9-Cutting machine operator, male, age 48. 


\section{Figure 9-Case History}

Occupational history-Cutting machine operator in Utah soft coal mines for past 21 years. Prior to that, had spent seven years in non-dusty trades.

Estimated dust exposure-Weighted average, 34 million particles per cubic foot.

Past medical history-Essentially negative.

Complaints-None.

Physical examination-Average appearance. Height, 67 inches; weight, 120 pounds. Chest expansion, $7 \mathrm{~cm}$. Chest examination, negative. Blood pressure, 120/85. Slight arteriosclerosis. Heart rate, 72 ; respiratory rate, 18. No change after exercise. No dyspnoea observed. Kahn test, $2+$.

Fluoroscopy-Movement of diaphragm not restricted. Increased pulmonary fibrosis.

X-ray film-Soft, diffuse, nodular infiltration throughout both lung fields; more easily observed in the middle thirds and infraclavicular regions. Moderate emphysema of bases and possibly of apices.

Diagnosis-Anthraco-silicosis early, and possible syphilis, latent.

Comment-Although this worker has no aparent disability, the X-ray film suggests a well developed case of anthraco-silicosis. It was not possible to recheck the blood test for further information concerning possible syphilis. His only underground experience had been in Utah soft coal mines. 


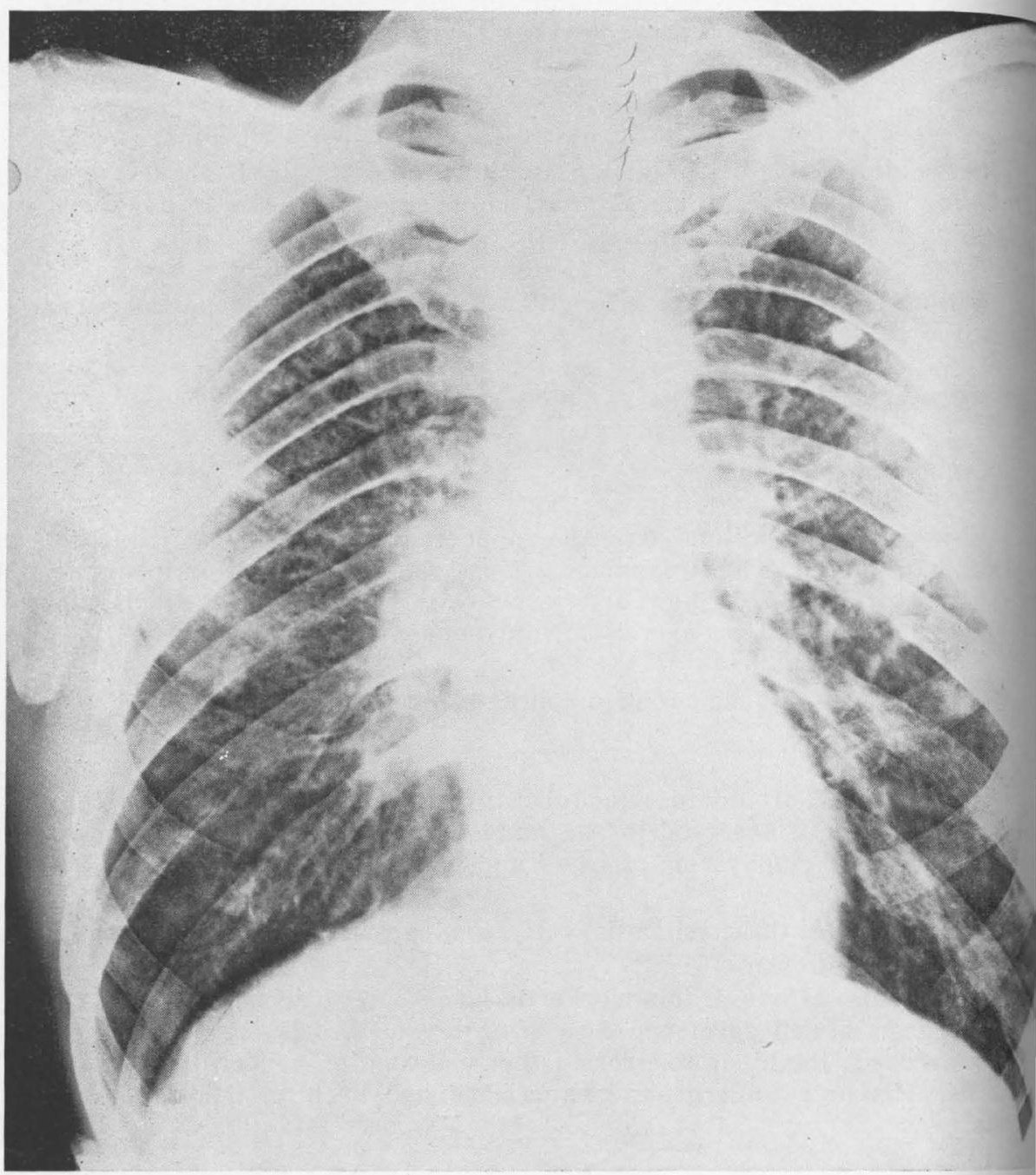

FIGURE 10-Driller, male, age 41. 


\section{Figure 10-Case History}

Occupational history-Driller in soft coal mine in Utah for past 17 years. Laborer in brick yard, six years.

Estimated dust exposure-Weighted average, 21 million particles per cubic foot.

Past medical history-Typhoid fever, 1925, severe, no sequellae. Spit blood two years ago, with sever cold. Slight attack of bronchitis last year.

Complaints-Occasional pain and stiffness in legs.

Physical examination-Average appearance; height, 68 inches; weight, 130 pounds. Chest expansion, $9 \mathrm{~cm}$. Chest examination, negative. Blood pressure, 136/96. Heart rate, 88; after exercise, 108. Heart examination, systolic murmur heard in the mitral area after exercise. Respiratory rate, 16 and 20 before and after exercise. No dyspnoea noted.

Fluoroscopy-Movement of diaphragm slightly restricted.

X-ray film--Diffuse, fine, granular appearance with obliteration of linear markings. Emphysema at bases. Calcified lesion in middle lung field under second rib, right. Small calcifications in both hila.

Diagnosis-Anthraco-silicosis, early, and healed reinfection tuberculosis, minimal. Possible rheumatic heart disease.

Comments-No apparent disability is shown by this case with 17 years' exposure to soft coal dust. The tuberculous lesion appears to be well healed. 


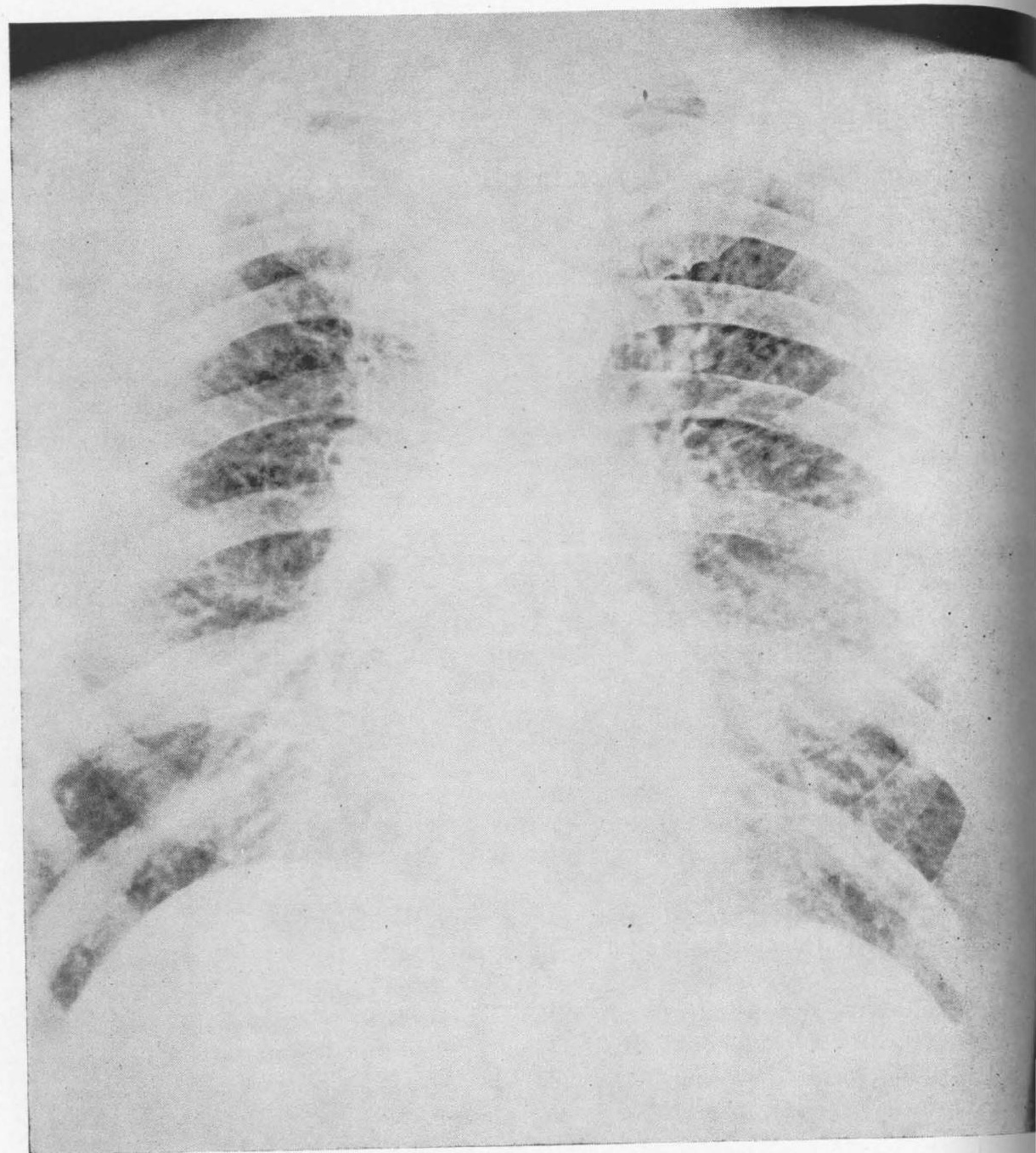

FIGURE 11-Shot firer, male, age 49. 


\section{Figure 11-Case History}

Occupational history-Shot firer, seven years; trackman, six months; roller greaser, two years; shot firer, seven years, in soft coal mines in Utah. Prior to that, had worked in coal mines in Yorkshire, England, as a coal digger for seven years; haulage boy and pony driver for 12 years.

Estimated dust exposure - Weighted average, unknown.

Past medical history-Essentially negative.

\section{Complaints-None.}

Physical examination-Appearance slightly cachexic. Height, 67 inches; weight, 139 pounds. Eyes, slight lateral nystagmus. Chest expansion, $6 \mathrm{~cm}$. Chest examination, negative. Blood pressure, 132/74. Heart rate, $96 ; 100$ two minutes after exercise. Respiratory rate, $20 ; 24$ after exercise. Slight dyspnoea observed after exercise. Slight clubbing of fingers. Coarse tremor of hands.

Fluoroscopy-Movement of diaphragm not restricted. Slight increase of fibrosis.

X-ray film-Diffuse, coarse, granular appearance throughout, almost obliterating linear markings. Questionable emphysema in left upper lung field. No other pathology observed.

Diagnosis-Anthraco-silicosis early.

Comment-The relative importance of 19 years in coal mines at Yorkshire, England, and $161 / 2$ years in Utah coal mines is not known. This is one of the very few cases who revealed a slight degree of nystagmus. 


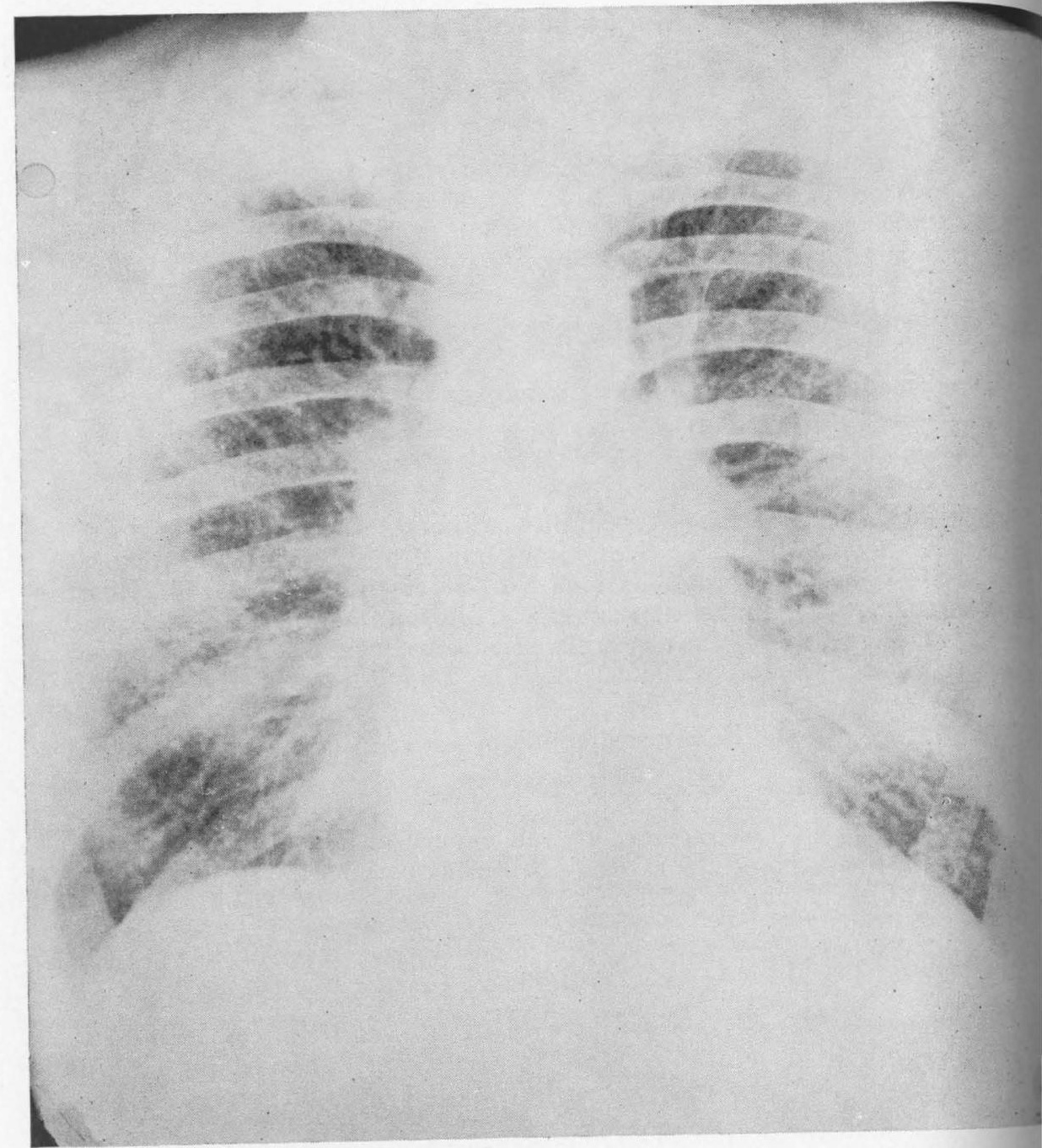

FIGURE 12-Cutting machine operator, male, age 60. 
Figure 12-Case History

Occupational history-Operated cutting machine and loading machine for 11 years in Utah. Previously, had operated a cutting machine for two years in Pennsylvania, 20 years in Ohio, six years in West Virginia, and two years in Kentucky, all in soft coal mines, making a total of 41 years. No other dust exposure.

Estimated dust exposure.-Weighted average, 35 million particles per cubic foot.

Past medical history-Essentially negative.

Complaints--None, except occasional attacks of sciatica in right leg.

Physical examination-Average appearance. Height, 63 inches; weight, 140 pounds. Chest expansion, $6 \mathrm{~cm}$. Chest examination, breath sounds distant in right base; no rales. Blood pressure, 200/100; was later rechecked and found to be $165 / 95$. Heart rate, $68 ; 72$ after mild exercise. Respiratory rate, $20 ; 24$ after mild exercise. Moderate dyspnoea after exercise. Heart enlarged to left. Moderate clubbing of fingers. Urinalysis, negative.

Fluoroscopy-Movement of diaphragm not restricted.

X-ray film-Minute discrete nodules scattered diffusely throughout both lung fields, with obliteration of linear markings. Questionable emphysema in bases. The character of the nodulation is such as to give a pigskin appearance to the lung field markings on the flat film.

Diagnosis-Anthraco-silicosis early. Hypertensive heart disease, moderate.

Comment-It is not know to what extent the 30 years spent in soft coal mines in other sections of the country have modified this film. However, the degree of fibrosis is very similar to that shown in Figure 8, who had worked only in Utah coal mines. 


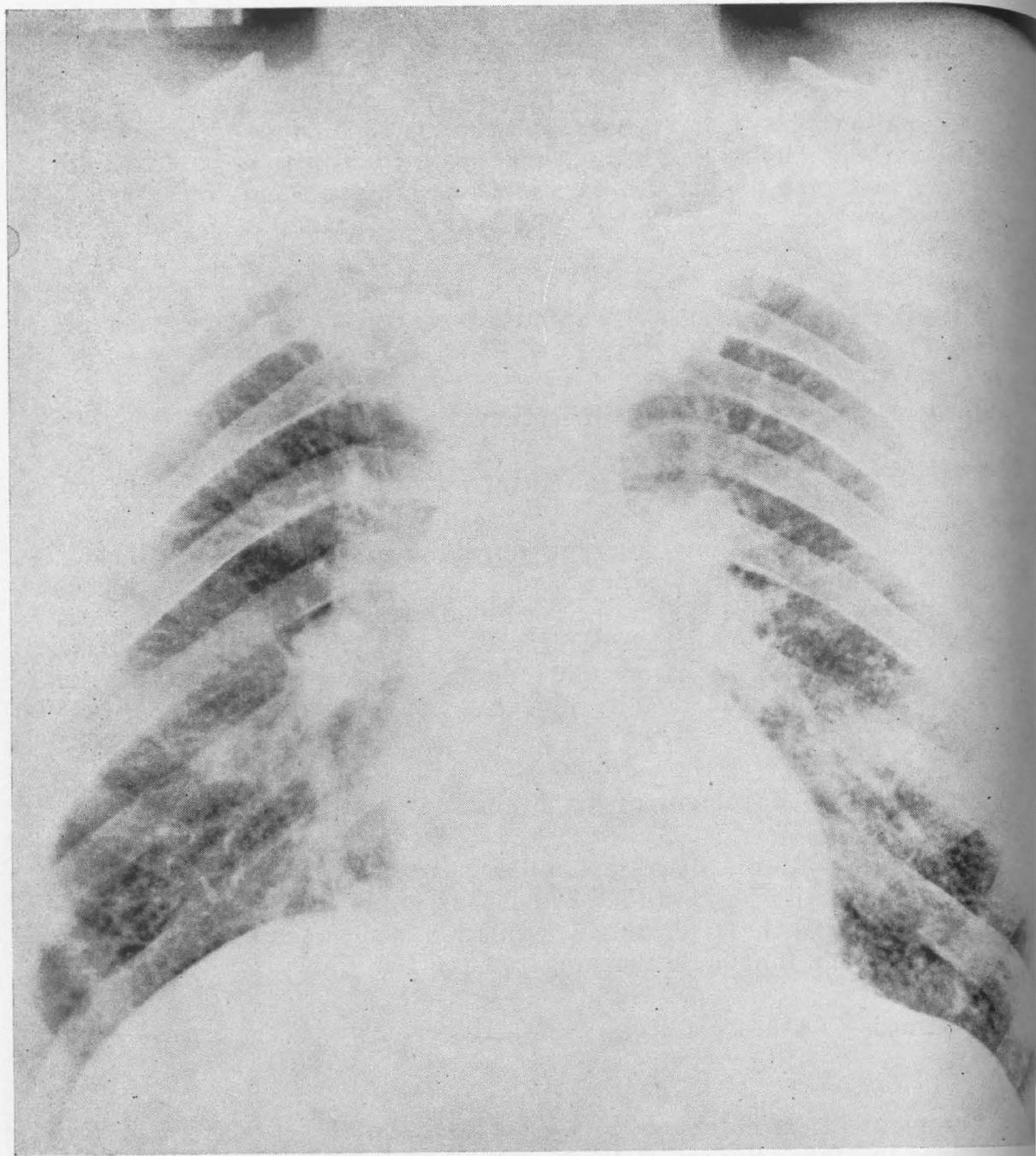

FIGURE 13-Track layer, male, age 58. 


\section{Figure 13-Case History}

Occupational history-Track layer, four years; timberman, three years; coal loader, 12 years, in soft coal mines in Utah. Prior to that had loaded coal for 11 years in Washington and four years in Illinois, making a total of 34 years in soft coal mines. No other dusty exposure.

Estimated dust exposure-Weighted average, 35 million particles per cubic foot.

Past medical history-Frequent attacks of sore throat and severe colds. Appendectomy, 10 years previously.

\section{Complaints-None.}

Physical examination-Average appearance; height, 67 inches; weight, 160 pounds. Chest expansion, $8 \mathrm{~cm}$. Chest examination, negative. Blood pressure, $130 / 95$. Heart rate, 74 ; respiratory rate, 18 , with no increase two minutes after exercise. Slight ateriosclerosis. No dyspnoea observed. Heart examination, negative.

Fluoroscopy-Movement of diaphragm not restricted.

X-ray film-Diffuse granular appearance throughout, with obliteration of linear markings. Several calcifications in right hilum. Apices somewhat hazy.

Diagnosis-Anthraco-silicosis early, with healed childhood tuberculosis.

Comment-No apparent disability is shown by this early case of anthraco-silicosis, who has spent 34 years in soft coal mines in three states. 


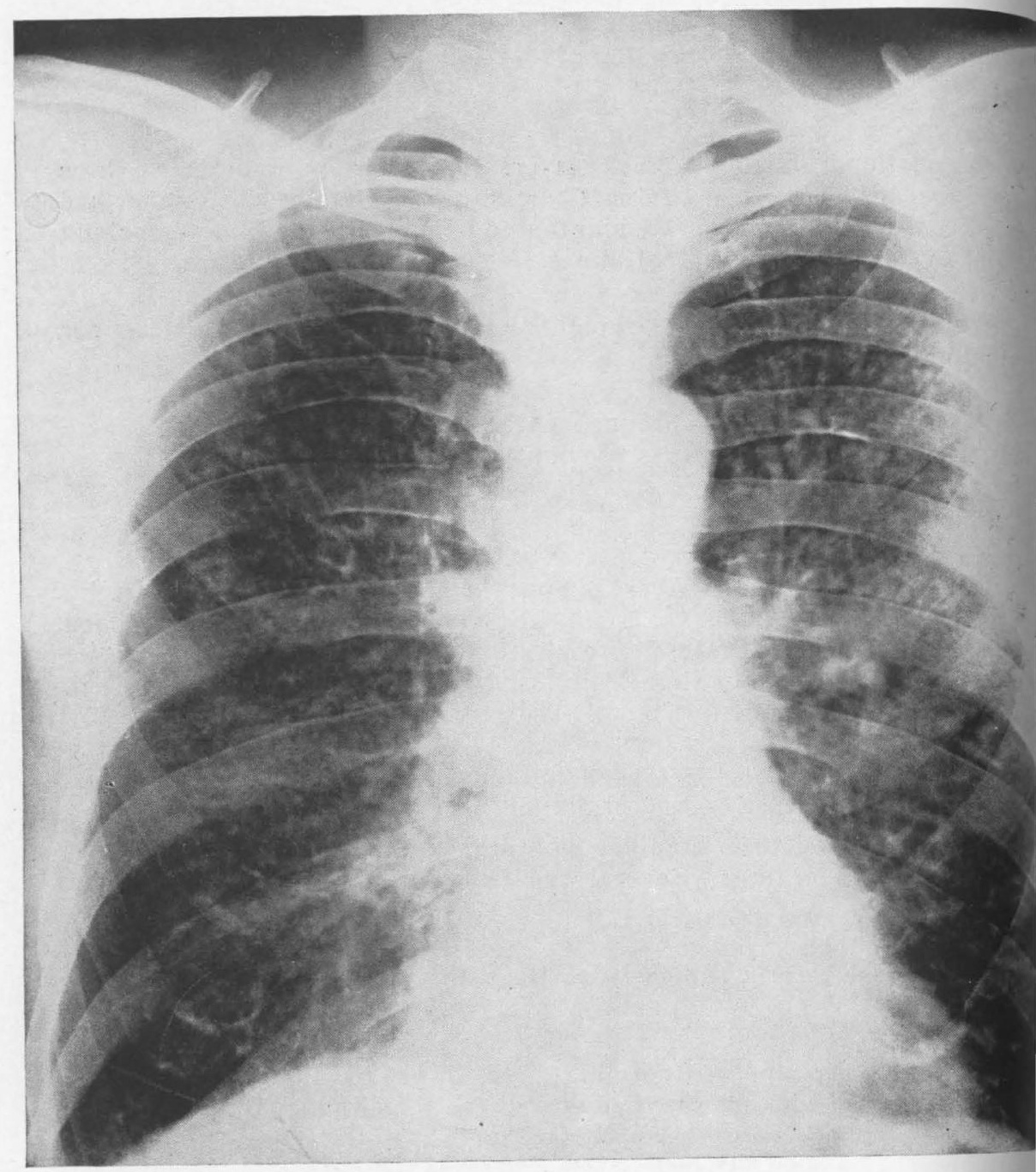

FIGURE 14-Coal digger, male, age 50. 


\section{Figure 14-Case History}

Occupational history-Coal digger and hoistman for six years in Utah, and coal digger in Illinois for seven years; in Colorado for 11 years, and in Pennsylvania for seven years, making a total of 31 years in soft coal mines. Prior to that, had spent six years in non-dusty occupations.

Estimated dust exposure-Weighted average, 24 million particles per cubic foot.

Past medical history-Influenza, moderate, in 1919. Severe attack of pneumonia in 1931, followed by bronchitis which has persisted. Frequent attacks of epigastric pain during past two years. Gonorrhea, 30 years previously.

Complaints-Frequent cough, past eight years, raising about two ounces of sputum a day. Shortness of breath on exertion and tires easily. Frequent pains in the pit of the stomach. Frequent slight pains in arms and legs.

Physical examination-Average appearance. Height, 70 inches; weight, 160 pounds. Chest expansion, $5 \mathrm{~cm}$. Dullness on percussion in the left base and right middle third. Breath sounds decreased throughout. Coarse, scattered rales, persistent in nature. Blood pressure, 160/80. Heart rate, 84 ; after exercise, 76 . Respiratory rate, 16 ; after exercise, 14 . No ateriosclerosis. No dyspnoea. Slight clubbing of fingers. Kahn test, 4 plus.

Fluoroscopy-Movement of diaphragm slightly restricted. Increased pulmonary fibrosis.

X-ray film-Diffuse granular appearance throughout chest, almost obliterating linear markings. Slight emphysema of bases and apices. Markings in bases suggest bronchiectasis. latent.

Diagnosis-Anthraco-silicosis, moderate, with bronchiectasis. Syphilis,

Comment-This miner appears to show a moderate degree of disability in connection with his silicosis, although the signs and symptoms are undoubtedly altered by bronchiectasis which may have followed his pneumonia and is frequently observed in advanced silicosis. Likewise, emphysema is an important factor in producing disability. Excepting the blood test, there is no clinical evidence of syphilitic activity. 


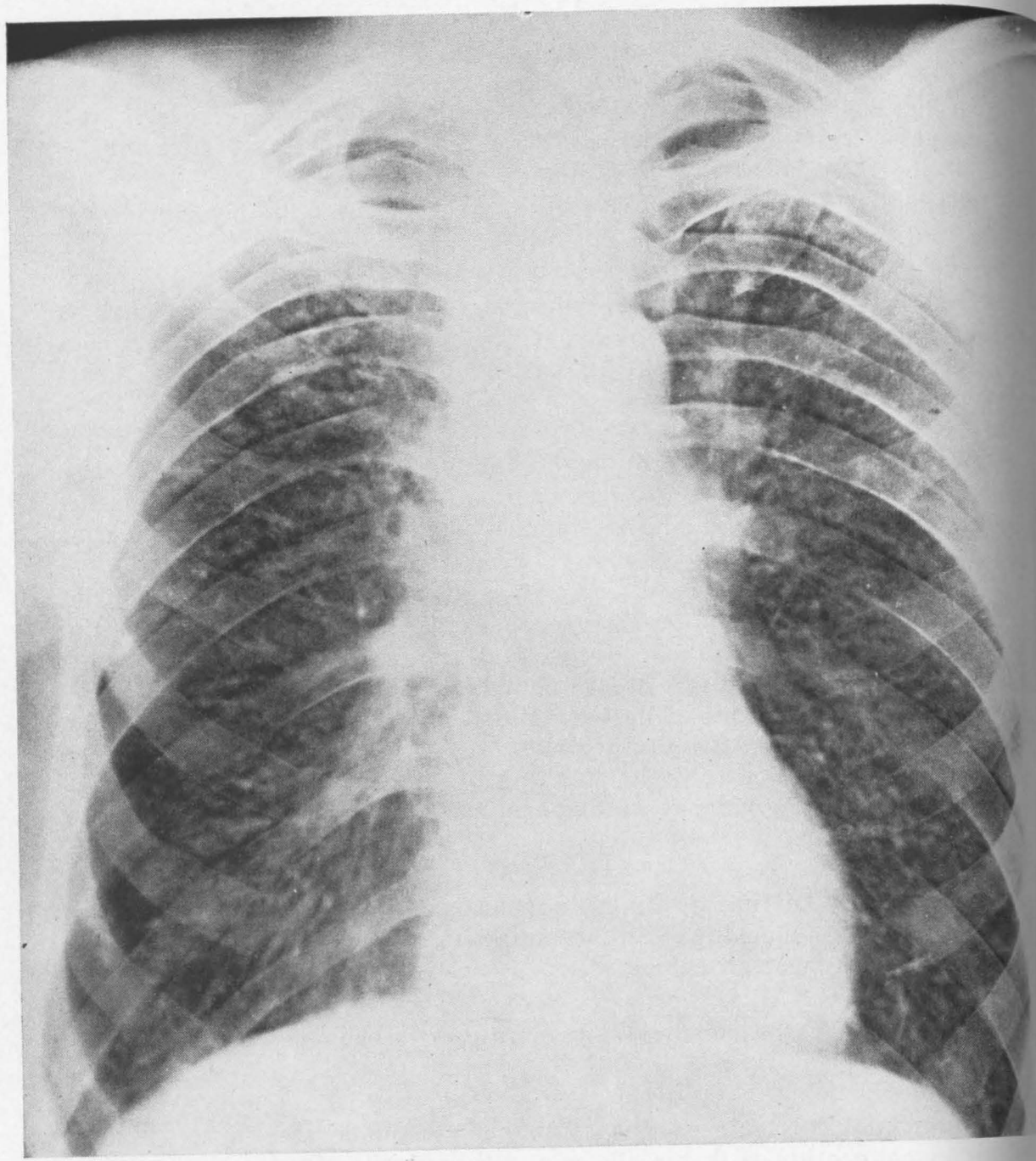

FIGURE 15-Trackman, male, age 52. 


\section{Figure 15-Case History}

Occupational history-Trackman for 15 years, and coal loader for three years in Utah bituminous coal mines. Coal loader for 12 years in various mines in Colorado, New Mexico, and Wyoming. Prior to that had spent nine years as a laborer on construction jobs. During his 30 years in coal mines, he estimated that he had been idle approximately one-third of the time.

Estimated dust exposure - Weighted average, 24 million particles per cubic foot.

Past medical history-Essentially negative. Lost three pounds of weight in the past year.

\section{Complaints-None.}

Physical examination-Average appearance. Height, 68 inches; weight, 130 pounds. Chest expansion, $5 \mathrm{~cm}$. Breath sounds, decreased and distant throughout. Few fine, dry, persistent rales throughout entire chest. Blood pressure, $125 / 75$. Heart rate, 72 ; respiratory rate, 18 , with no increase two minutes after exercise. Slight enlargement of heart. Slight arteriosclerosis. No dyspnoea observed.

Fluoroscopy-Movement of diaphragm not restricted. Increased pulmonary fibrosis.

X-ray film-Diffuse granular appearance throughout, with linear markings almost obliterated. Questionable emphysema.

Diagnosis-Anthraco-silicosis, early.

Comment-This worker shows slight X-ray changes and few physical findings after 30 years as a trackman and loader in soft coal mines. $\mathrm{He}$ estimates, however, that he was idle about one-third of this time. 


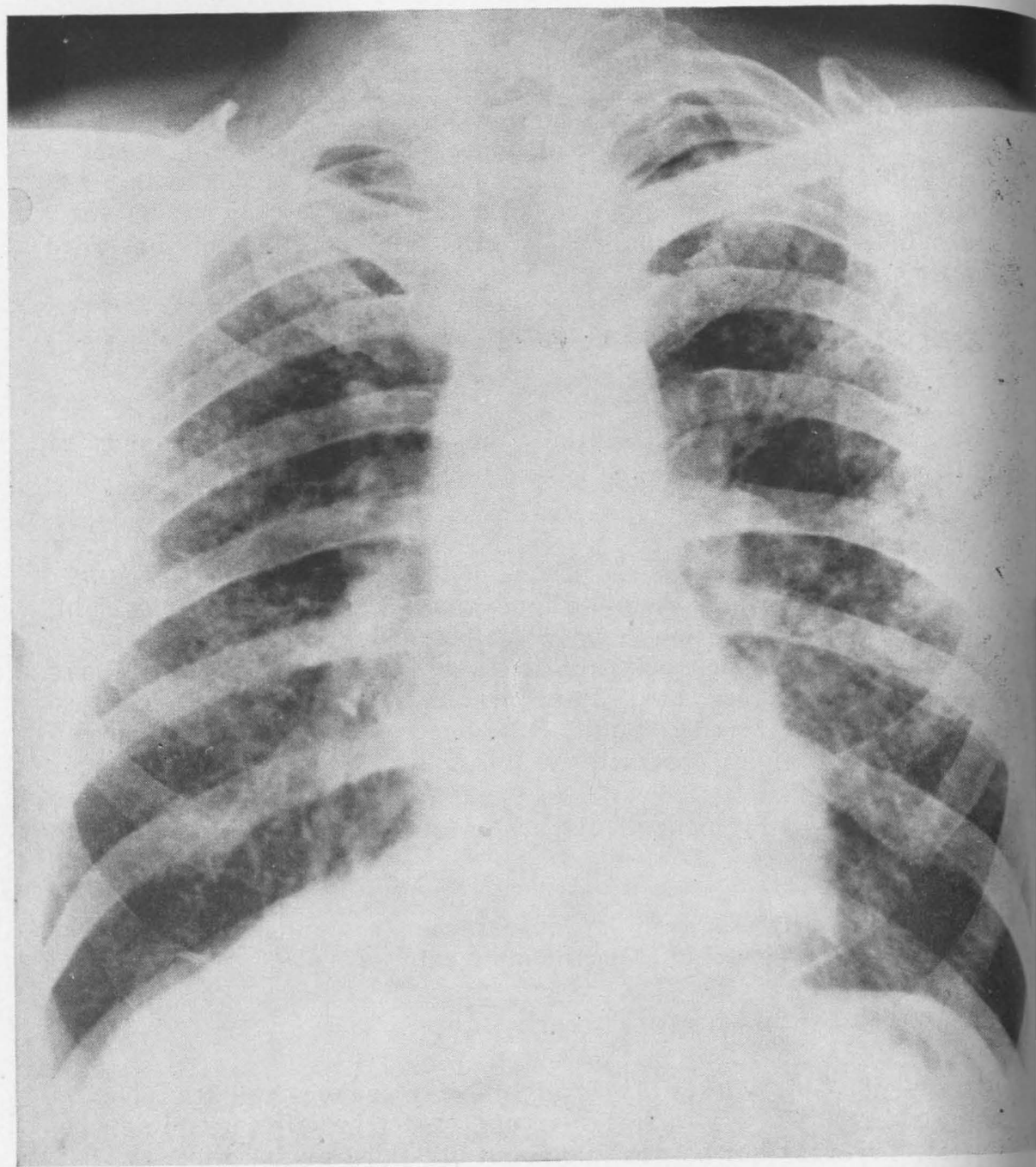

FIGURE 16-Coal digger, male, age 55. 


\section{Figure 16-Case History}

Occupational history-Coal digger in Utah for 18 years; coal digger in Nevada, one year; Ohio, six years. Prior to that, a driller in iron mines for 12 years. He had been idle for about $4 \frac{1}{2}$ years during that time, leaving about 22 years in soft coal mines and $101 / 2$ years in iron mines.

Estimated dust exposure-Weighted average, unknown.

Past medical history-Essentially negative.

\section{Complaints-None.}

Physical examination-Average appearance. Height, 66 inches; weight, 130 pounds. Chest expansion, $4 \mathrm{~cm}$. Inspection and palpation of the chest revealed impaired mobility throughout. Occasional dry rales in right middle third. Few sibilant rales in left lower. Blood pressure, 149/100. Marked arteriosclerosis. Heart rate, 88; after exercise, 120. Respiratory rate, 28; after exercise, 20. No dyspnoea observed. Moderate tremor of the hands.

Fluoroscopy-Movement of the diaphragm slightly restricted. Moderate pulmonary fibrosis.

X-ray film-Nodular infiltration throughout lung fields, with early conglomerate areas in the upper third and outer zones of the lung fields. Moderate emphysema of the bases, and possibly of the apices.

Diagnosis - Silicosis, moderate, and hypertensive heart disease, early.

Comment-This case represents the results of a mixed exposure; 22 years in soft coal mines and $101 / 2$ years in iron mines. From a review of the coal miners with only coal mine exposure, it would seem that the iron mine exposure would be the more important in producing this case of silicosis. Cases such as this are excluded from the tabulation of anthraco-silicosis occurring in coal miners. 


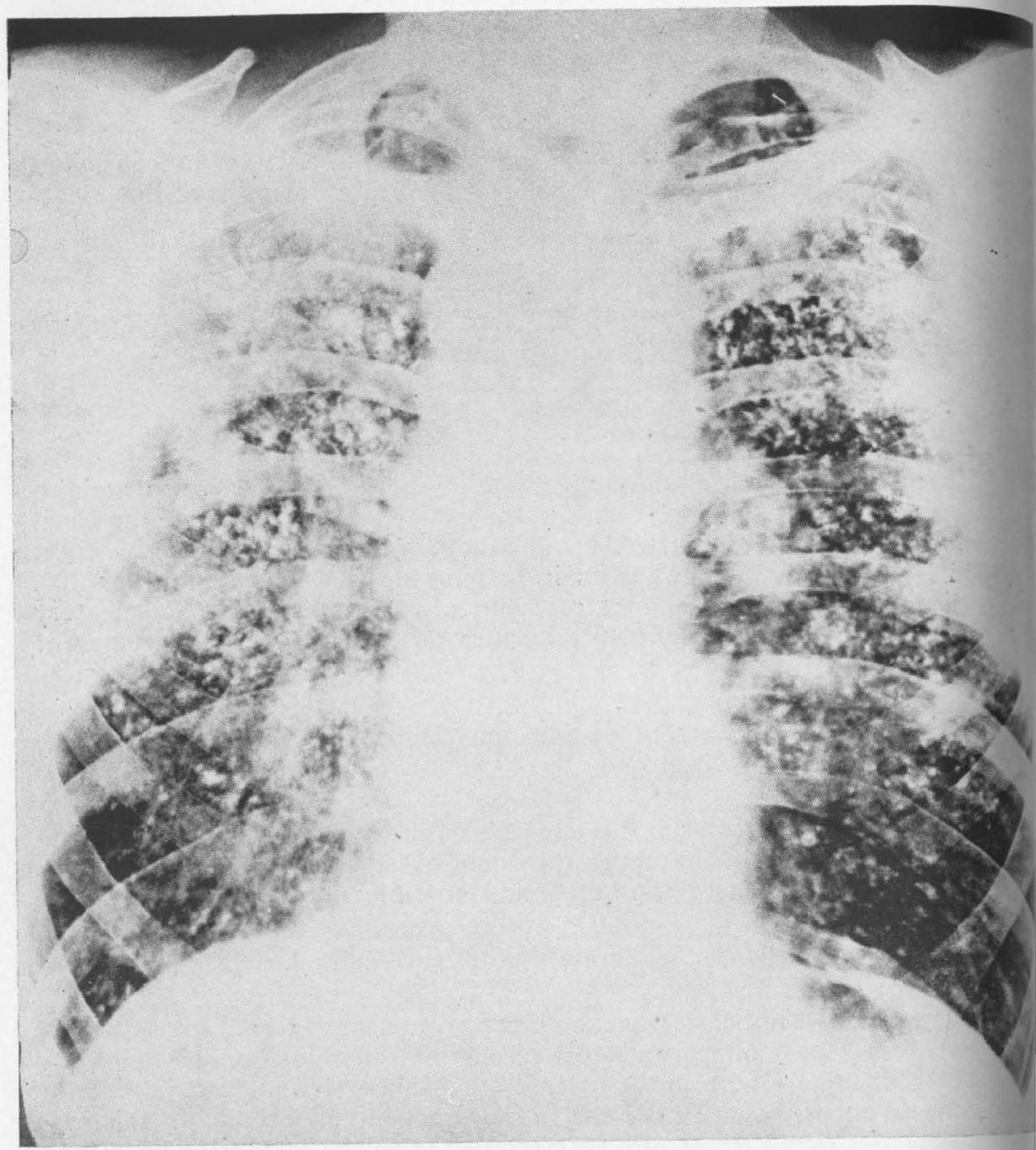

FIGURE 17-Coal hauler, male, age 52. 


\section{Figure 17-Case History}

Occupational history-Coal hauler, two years, and cement mixer, driller, and timberman for 17 years, in Utah soft coal mines. Prior to that had worked as a shift boss for four years and as a timberman and miner for eight years in non-ferrous metal mines, and as a miner for two years in iron mines. Had spent four years at non-dusty occupations.

Estimated dust exposure.-Weighted average, unknown.

Past medical history-Influenza, 1919; no complications. Has lost 20 pounds since serious injury several months ago.

Complaints-Morning cough, raising thick, yellowish sputum of ten tinged with blood, $11 / 2$ ounces daily. Short of breath on exertion, but not as bad as several years previously. Frequent pains in arms.

Physical examination-Average appearance. Height, 72 inches; weight, 148 pounds. Chest appeared normal. Chest expansion, $8 \mathrm{~cm}$. Breath sounds, decreased in the bases and distant in the right upper. Fine, dry, persistent rales in the right upper, anteriorly, and in middle thirds, posteriorly. Blood pressure, 125/90. Heart rate, 96. Respiratory rate, 18. Not exercised because of injuries. Slight arteriosclerosis. No dyspnoea observed. Kahn test, doubtful.

Flouroscopy-Movement of diaphragm not restricted. Lung fields have nodular, conglomerate appearance. Aorta, moderately enlarged.

X-ray film-Multiple calcified nodules, scattered diffusely throughout chest, tending to conglomerate in the upper thirds, and particularly in the outer zones. Moderate emphysema of the bases, apices, and the middle third left. Diaphragm appears normal. Aortic shadow, widened moderately. Calcified glands in both hila. Areas suggestive of cavitation in right upper third in the outer zone and an area suggestive of infection in the same area on the left side.

Diagnosis-Anthraco-silicosis, moderate (healing), with active pulmonary tuberculosis. Aortitis, probably syphilitic.

Comment-The blood tinged sputum, physical findings, and $\mathrm{x}$-ray film suggest active pulmonary tuberculosis, superimposed upon the other pathology observed in this film. The history of the case suggests that this worker received his greatest siliceous dust exposure more than 19 years previously. It seems probable that he developed typical nodular silicosis at that time and that during the 19 years in the coal mines, witha relatively low grade exposure, calcium has been deposited in the silicotic lesions in an attempt at healing. This phenomenon has been known to occur frequently in animals, but is observed rarely in human beings with silicosis. (Refer to Case 18.)

The width of the aortic shadow and the doubtful Kahn reaction suggest syphilitic aortitis. This worker should have the benefit of repeated sputum examinations and serial X-ray study, as well as repeated blood examinations. 


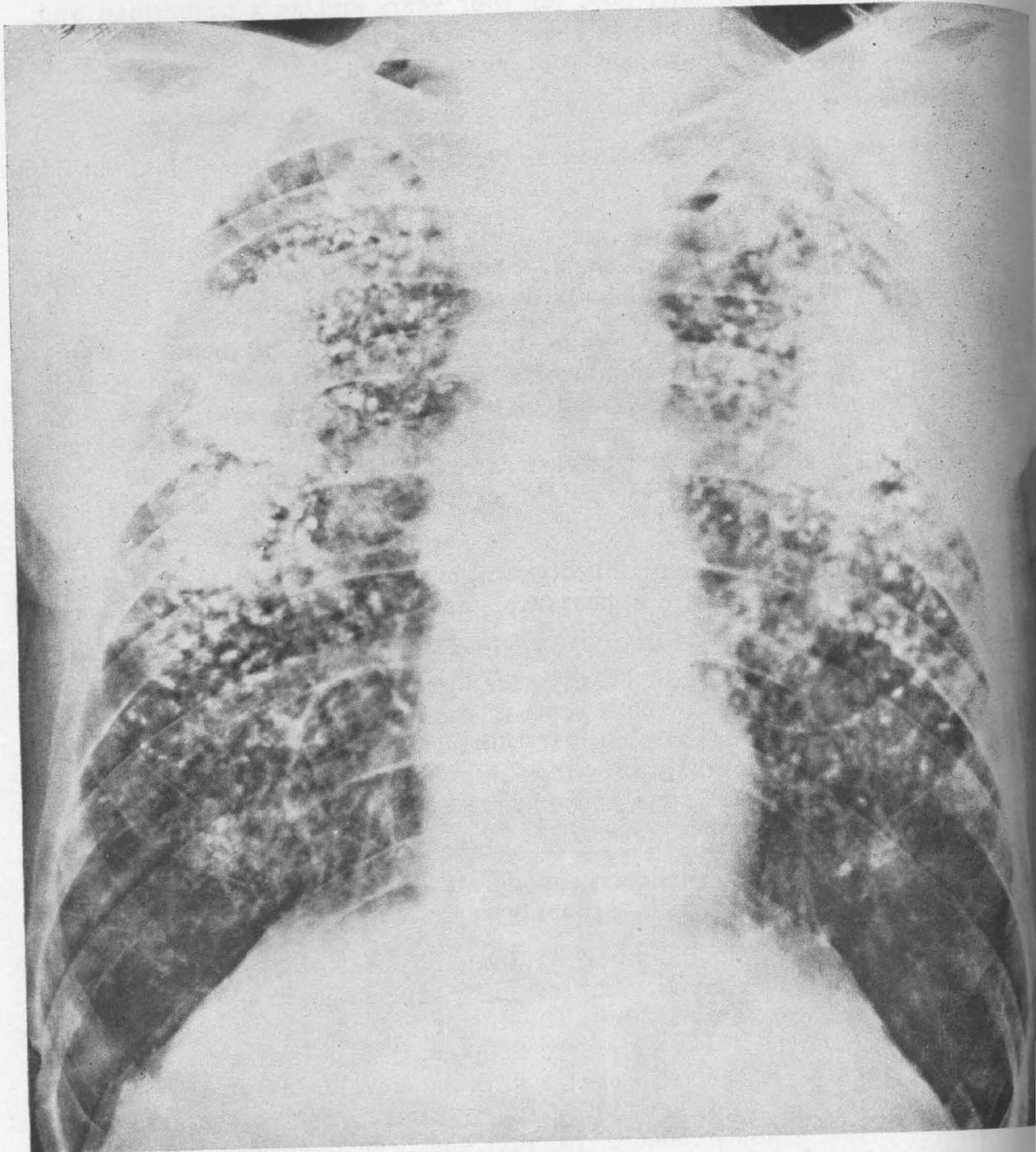

FIGURE 18-Pennsylvania coal miner, age 60. 


\section{Figure 18-Case History}

"A. O., an Italian by birth, worked with a jackhammer in sandstone entries in a coal mine in Germany from the age of 12 to 30 years. At the age of 30 he emigrated to America and worked continuously in a bituminous mine in western Pennsylvania until age of 60 . The silica content of the atmosphere in the western Pennsylvania mine could be considered negligible. The patient had discontinued his occupation only a few days before this film was made, and died several weeks after the film was made of some condition which was not associated with pulmonary pathology."

(Personal communication from Paul G. Bovard, M.D., of Tarentum, Pennsylvania.)

Comment-This case, detected by Dr. Bovard by a routine industrial examination, closely resembles the preceding case in the X-ray findings, both presenting unusual features. Both had a substantial siliceous dust exposure many years previously, during which a moderately advanced silicosis had developed. Both then spent the rest of their working lives in soft coal mines with relatively little exposure to silica, and it is assumed that the old silicotic lesions underwent a healing process with deposition of calcium. The former case showed clinical evidence of tuberculosis but this case showed no physical signs except shortness of breath. Neither worker was seriously incapacitated by silicosis. 


\section{Pulmonary Tuberculosis Among Bituminous Coal Miners}

Two broad classifications of pulmonary tuberculous disease are gen. erally recognized; primary or childhood tuberculosis, and the adult or reinfection type of tuberculous lesion (23).

A healed primary lesion as seen in the x-ray film is usually characterized by the appearance of small, usually dense, opacities in the lymph nodes of the hilus, or at the site of the original infection in the lung parenchyma as described by McPhedran (24). This infection occurs chiefly during early life, but might appear later in those persons not exposed to the disease until after adolescence. Usually no symptoms are noted in the development of this pulmonary lesion and the patient is neither dis. abled nor likely to transfer the disease to others in the community, pro. vided that the infection is arrested at this point and becomes encapsu. lated.

The adult or reinfection type of tuberculosis may or may not be preceded by a demonstrable primary lesion. It is recognized by its anatomic distribution and peculiarities of its appearance on the X-ray film. It is possible for an infection of this kind to precipitate no recognizable symptoms and to become arrested or quiescent while the worker is performing his usual activities. Very frequently, however, the disease progresses, the patient is disabled and he becomes a source of tuberculous infection to his family, fellow workers, and the community.

In the analysis of the examination records made in this study, the diagnosis of tuberculosis was reached only after careful consideration and review by several physicians and in the same manner as that described previously in the diagnosis of silicosis. All questionable cases with insufficient clinical evidence to reach a decision were regarded as essentially negative.

The classification of the cases studied according to the activity of the disease is more or less arbitrary since only one film was available for each man examined. Nevertheless the classification is dictated by certain rather well established standards of X-ray interpretation. The lesions in cases classified as active appeared as soft, infiltrating shadows in the lung parenchyma accompanied by symptoms of tuberculosis elicited in the history or signs revealed by the physical examination. The lesions in apparently healed cases were more sharply defined, usually with some evidence of scarring, and accompanied by no symptoms or signs referable to tuberculous infection. The cases in the unknown group consist of those with the X-ray appearance of a tuberculous lesion, the status of which could not be determined from the information at hand. The healed cases include those of the adult or reinfection type which revealed definite evidence of scarring and were accompanied by no signs or symptoms of tuberculous disease.

Table 19 shows the distribution of these various tuberculous lesions in 507 coal miners according to the above classification. It is observed that there are 13 workers with adult type pulmonary tuberculosis, of whom three have active lesions, nine have apparently healed lesions, and one has a lesion the activity of which is unknown. Healed primary lesions 


\section{TABLE 19-Classification of 65 Primary or Reinfection Tuberculous Lesions Occurring in 507 Coal Mine Workers According to Degree of Activity.}

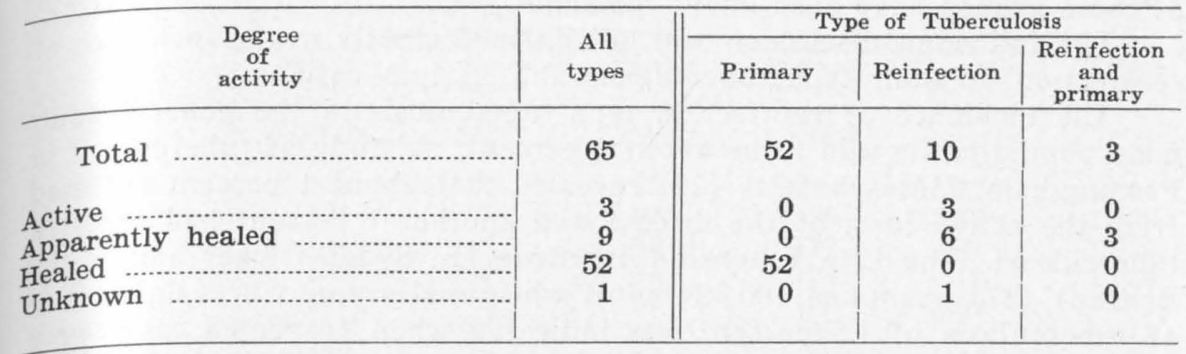

are found in 55 workers, three of whom have apparently healed reinfection type lesions.

There is fair general agreement that calcified pulmonary nodules are of no clinical significance at any age. Calcified tracheobronchial lymph nodes in young adults indicate severe exposure to tuberculosis in childhood, but there is no incontrovertible evidence that such persons are particularly liable to tuberculosis in later life.

Fellows, in a serial chest roentgenological study (25) of 3,179 office employees covering a period of 12 years from 1926 to 1938, found no significant difference in the development rate of pulmonary tuberculosis in this group whose first roentgenogram of the chest was classified as average, healthy or negative chest when compared to a similar group, whose first roentgenogram showed a healed primary complex. In a study of pottery workers (2) there was evidence adduced to show that calcified primary lesions should not prevent a person from working at a dusty trade.

Table 20 shows the number and percent of coal miners with tuberculosis, grouped according to age and including all types and degrees of activity of tuberculosis. It is seen that 10.3 percent of the 507 coal miners have evidence of a primary lesion as shown by X-ray. This figure is slightly less than those of Utah smelter workers (13.8 percent) and Utah metal miners (16 percent). In a group of 801 male office workers, Fellows found 87 or 10.9 percent with healed primary tuberculosis, which corresponds closely with the coal miners. In both studies the incidence of

TABLE 20-Number and Percent of Coal Mine Workers with Tuberculosis, By Age.

\begin{tabular}{|c|c|c|c|c|c|}
\hline & \multirow{3}{*}{$\underset{\text { workers }}{\text { All }}$} & \multicolumn{4}{|c|}{ Workers with tuberculosis } \\
\hline & & \multicolumn{2}{|c|}{ Primary } & \multicolumn{2}{|c|}{ Reinfection 1} \\
\hline & & Number & Percent & Number & Percent \\
\hline All ages. & 507 & 52 & 10.3 & 13 & 2.6 \\
\hline $15-24$ & 79 & 6 & 7.6 & 1 & 1.3 \\
\hline $25-34$ & 170 & 10 & 5.9 & 1 & .6 \\
\hline $35-44$ & 142 & 17 & 12.0 & $\mathbf{5}$ & 3.5 \\
\hline $45-54$ & 88 & 15 & 17.0 & 5 & 5.7 \\
\hline 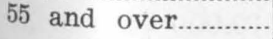 & 28 & 4 & 14.3 & 1 & 3.6 \\
\hline
\end{tabular}

1 Reinfection or adult type including those with primary lesions. 
primary lesions increases with age and in no instance is the difference between the two comparative age groups of any statistical significance, sc it would seem that the chances for past exposure to tuberculous infection of these groups have been about the same.

The following discussion will be confined chiefly to the incidence of reinfection or adult type tuberculosis and its implications.

The incidence of reinfection type tuberculosis in the general adul male population is said to be about 2 percent. A study of tuberculosis in Framingham, Massachusetts (26) revealed that about 1 percent suffered from the active form of the disease and another 1 percent had arreste tuberculosis. The Life Extension Institute (E. Sydenstricker and R. H Britten) (27) examined 100,924 adult white males and a prevalence rate of tuberculosis of 1.5 percent was indicated when suspected cases wer included. In a study of 10,000 male industrial workers (3) the U. S. Publi Health Service found 2.5 percent affected with pulmonary tuberculosis

In the Utah studies, 5.4 percent of 1,391 smelter workers showed tuberculous lesions by X-ray, while only 2.5 percent of 727 metal miners revealed adult type tuberculosis, a proportion similar to that of coa miners (2.6 percent).

The incidence of adult type tuberculosis in coal workers according to occupation reveals little that is of significance due to the scattering of the cases throughout the various occupations and the small number of cases in each occupational group. Six of the 13 cases were found in diggers and loaders, two each in tipple workers and haulage men, and one each among drillers, shot firers, and shovel operators. Only one tuberculous lesion, which was minimal and apparently healed, occurred among the 16 anthraco-silicosis cases, a 41 -year-old driller with first-stage anthraco-silicosis. Two tuberculosis cases, also classified as minimal and healed, were found among the 26 borderline cases of anthraco-silicosis

It is emphasized that all 13 tuberculosis cases were considered minimal, and of these only three cases showed signs of activity. It therefore appears that tuberculosis is not a serious hazard among the bituminous coal miners examined in Utah.

\section{Blood Pressure}

\section{Cardiovascular Findings}

Systolic and diastolic blood pressure determinations were made on each worker while in a sitting position with his arm lying relaxed on the examining table. The auscultory method was used with a mercury sphygmomanometer. These readings were made after the taking of the occupational and medical history, so that the workers had had a reasonable length of time to rest and to overcome the first feeling of nervous excitation caused by the examination procedures. As this same method was followed in other studies by the Public Health Service, the results should be strictly comparable, making allowance for the fact that blood pressure increases normally with age.

As shown in Table 21 , the average blood pressure values for bituminous coal miners compare very closely, although a few points lower, with those for similar age groups in a previous study of 10,000 industrial male workers (3). The difference between these groups tends to become greater with increasing age, signifying that the increase of average blood 
TABLE 21-Average Systolic and Diastolic Blood Pressures of Coal Mine Workers, By Age, as Compared with 10,000 Male Industrial Workers.

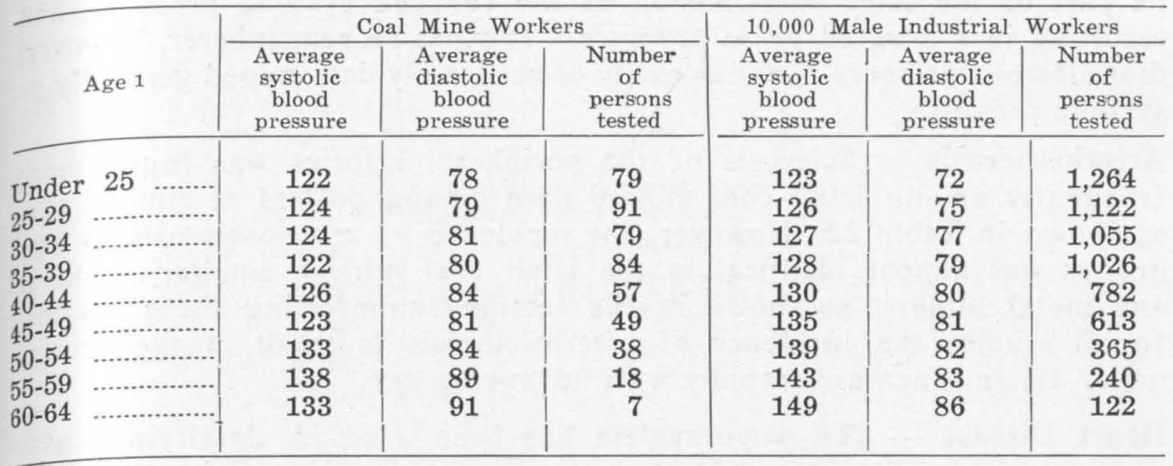

1 Three persons over 65 years of age were excluded from the tabulations for coal mine workers, and 78 for 10,000 male industrial workers.

pressure of coal miners with age is not so rapid as found in previous workers. These values also correspond very closely to those for smelter workers and metal miners examined in Utah. All three Utah studies indicate slightly lower average blood pressures than previous studies, including pottery workers (2), truck drivers (6), as well as the 10,000 industrial workers (3). The cause of this slightly lowered systolic blood pressure cannot be explained, but the altitude at which Utah workers live and work may be an important factor.

Arterial Hypertension, defined as systolic pressure averaging more than $150 \mathrm{~mm} \mathrm{Hg}$ was also observed less of ten among all Utah workers than among pottery workers, and the 10,000 industrial workers as shown in the section summarizing these studies. Hypertension occurred in less than 3 percent of the coal miners under 50 years of age and in about one-fifth of the workers between 50 and 70 years, an incidence slightly less than in the other two Utah studies and considerably less than in previous studies.

TABLE 22-Number and Percent of Coal Mine Workers Who Were Found To Have Arteriosclerosis, Classified By Age, and Compared with Pottery Workers.

\begin{tabular}{|c|c|c|c|c|c|}
\hline \multirow{3}{*}{ Age } & \multicolumn{3}{|c|}{ Coal Mine Workers } & \multicolumn{2}{|c|}{ Pottery Workers } \\
\hline & \multirow{2}{*}{$\begin{array}{l}\text { Number in } \\
\text { age group }\end{array}$} & \multicolumn{2}{|c|}{$\begin{array}{c}\text { With } \\
\text { arteriosclerosis }\end{array}$} & \multirow{2}{*}{$\begin{array}{l}\text { Number in } \\
\text { age group }\end{array}$} & \multirow{2}{*}{$\begin{array}{l}\text { Percent with } \\
\text { arterio- } \\
\text { sclerosis }\end{array}$} \\
\hline & & Percent & Number & & \\
\hline All ages & 507 & 10.3 & 52 & 1,627 & 6.0 \\
\hline Under 25 & 79 & 2.5 & 2 & 350 & \\
\hline $25-34 \quad \ldots \ldots \ldots$ & 170 & 2.4 & 4 & 549 & 0.6 \\
\hline $35-44 \quad \ldots$ & 142 & 5.6 & 8 & 370 & 1.2 \\
\hline …................. & 88 & 25.0 & 22 & 221 & 13.7 \\
\hline $55-64$ & 25 & 56.0 & 14 & 115 & 36.2 \\
\hline 65 and over.......... & 3 & 66.7 & 2 & 22 & 85.8 \\
\hline
\end{tabular}


Diastolic blood pressure, however, averages three to four points more than the values for the 10,000 industrial workers. These differences are fairly constant in all age groups, and cannot be readily explained, but may be part of the same phenomenon as the reduced systolic pressure, and resulting in a lowered pulse pressure. ${ }^{1}$ It must be rememberer, however, that diastolic pressure is not as easily or accurately determined generally as systolic pressure.

Arteriosclerosis - Sclerosis of the peripheral arteries was found more frequently among Utah coal miners than among potters of similar age, as shown in Table 22. However, the incidence of arteriosclerosis by age groups was almost identical in the Utah coal miners, smelter workers, and metal miners, as shown in the section summarizing these studies. In all studies the incidence of arteriosclerosis is small in age groups under 45 , and increases rapidly with advancing age.

Heart Disease - The same system has been used in classifying cases of heart disease found in this study as discussed in the study of pottery (2) workers and other recent studies of the Public Health Service (6) (17) (9), which classifies heart disorders under the broad, etiological headings in accordance with the scheme prepared by the Heart Committee of the New York Tuberculosis and Health Association (26), and which has been discussed by Hedley (27). As shown in previous studies, Table 23 indicates that the arteriosclerotic-hypertensive group of heart diseases leads the other groups in the number of persons affected, and the incidence increases with advancing age. Table 23 shows that 5.7 percent of coal miners are so affected, the incidence rising from about 2 percent in workers under 45 years of age, and 11.4 percent in the age group of 45 to 54 years, to 35.7 in the group over 55 years of age. These figures correspond very closely to those observed in a study of pottery workers (2) and probably reflect the normal age trend. The incidence in coal miners is only slightly less than among metal miners and smelter workers, the difference probably not being significant. Arterial hypertension ${ }^{2}$ was the outstanding finding in many of these cases, with or without an enlarged heart, arteriosclerosis, and other evidence of hypertensive heart disease. Evidence of myocardial degeneration ("myocarditis") due to coronary sclerosis was observed infrequently save in the oldest age group. The majority of these cases was in an incipient or latent period from the clinical viewpoint and showed but few symptoms or evidence of disability.

Rheumatic Heart Disease - Heart disease of the rheumatic type was observed in 14 coal workers (2.8 percent), constituting a small proportion of all age groups, and being found somewhat more frequently in men over 35 years of age. The coal miners compared closely with metal miners in this regard (2.3 percent), but both groups showed more rheumatic heart disease than the smelter workers who corresponded closely with pottery workers (1.0 percent and 0.6 percent). Viko (30) has reported the incidence of rheumatic heart disease to be higher in Utah than many other sections of the country. Most of these cases showed evidence of valvular deformities due to past attacks of acute rheumatic fever, the mitral valves usually being affected. A few of these cases showed evidence of moder-

1 Pulse pressure $=$ systolic pressure - diastolic pressure.

2 Systolic pressure over $150 \mathrm{~mm} \mathrm{Hg.,} \mathrm{or} \mathrm{diastolic} \mathrm{pressure} \mathrm{over} 100 \mathrm{~mm} \mathrm{Hg}$. 
TABLE 23-Incidence of Heart Disease Among Coal Mine Workers Classified According to Age and Compared with Pottery Workers.

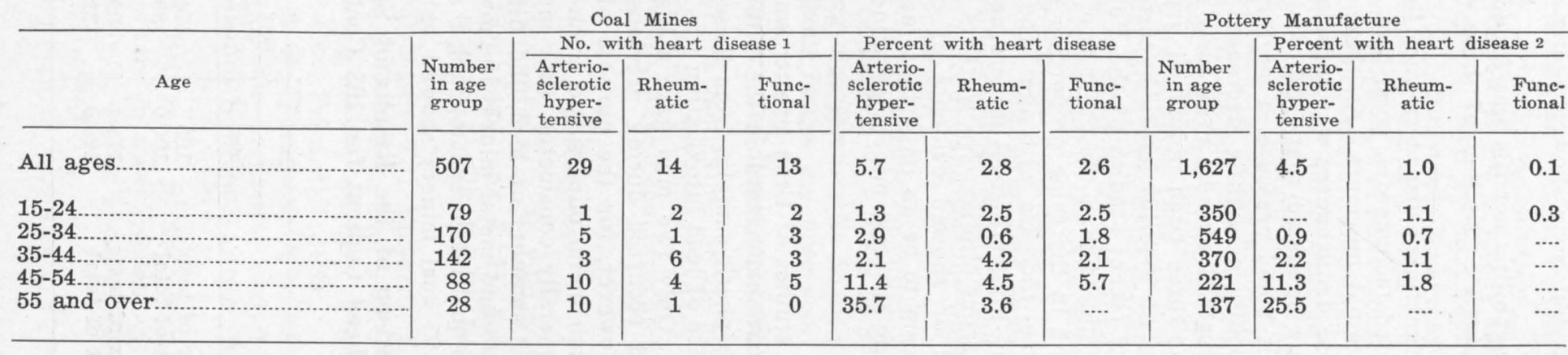

1 One case of syphilis of heart or aorta and one of toxic heart disease were also found among coal mine workers.

2 Three cases of syphilis of heart or aorta and one of toxic heart disease were also found among pottery workers. 
ate myocardial damage, but none showed evidence of cardiac decompen. sation.

Only one case of syphilitic aortitis was found, and one case of post. scarletinal myocardial disease. Neither of these workers had yet experienced serious disability.

Thirteen cases of functional disorders were found, the manifestations of which usually included tachycardia, persisting after exercise, frequent extrasystoles, or functional murmurs. As there was no other evidence of disease, none of these disturbances was considered significant.

In summary, it may be stated that Utah coal miners tended to have a slightly lower systolic blood pressure, a slightly higher diastolic blood pressure, and consequently a slightly decreased pulse pressure, on the average, than most industrial workers previously examined by the Public Health Service, but the three Utah industrial groups are similar in this respect. The incidence of arteriosclerotic-hypertensive heart disease is similar to that in other recent studies of the Public Health Service and is slightly less in coal miners than the other two Utah industrial groups. Arteriosclerosis is found in the same proportion of all three Utah industries and shows a normal increase with age. The incidence of rheumatic heart disease is slightly higher in coal miners and metal miners than in smelter workers and earlier studies. No workers with heart disease were seriously incapacitated or showed evidence of cardiac decompensation. Occupation does not seem to be an important factor in relation to cardiovascular disease among the coal miners examined.

\section{Other Health Hazards}

As opposed to the studies of Utah smelter workers and metal miners, lead was not an occupational hazard in the bituminous coal mines. $\mathrm{N}_{0}$ lead was found in atmospheric samples from these mines (see engineering section), and no evidence of lead intoxication was observed in the examination of these miners. Only two men gave a history of lead poisoning, and these assacks had occurred during previous work in metal mines. Data are presented, however, for the purpose of comparison with leadexposed workers in Utah metal miners and smelter workers.

Although it is generally considered that most persons absorb and excrete normally small amounts of lead, the difference in this respect between the coal miners and metal miners is shown in Table 24 , where it is seen that in a semi-qualitative spectographic analysis of urine specimens, 89 percent of 195 coal miners showed only a faint trace of lead

TABLE 24-A Comparison of the Results of Spectrographic Tests for Urinary Lead Content for 195 Coal Miners and 178 Metal Miners.

\begin{tabular}{|c|c|c|c|c|c|}
\hline \multirow{2}{*}{\multicolumn{2}{|c|}{ Study }} & \multicolumn{4}{|c|}{ Urinary lead concentration } \\
\hline & & Total & $\begin{array}{l}\text { Faint } \\
\text { trace }\end{array}$ & Moderate & Heavy \\
\hline $\begin{array}{l}\text { Coal mines } \\
\text { ( } 507 \text { workers) }\end{array}$ & $\begin{array}{l}\text { Number of tests } \\
\text { Percent of total }\end{array}$ & $\begin{array}{l}195 \\
100.0\end{array}$ & $\begin{array}{l}174 \\
89.2\end{array}$ & $\begin{array}{l}20 \\
10.3\end{array}$ & $\begin{array}{l}1 \\
0.5\end{array}$ \\
\hline $\begin{array}{l}\text { Metal mines } \\
(727 \text { workers })\end{array}$ & $\begin{array}{l}\text { Number of tests } \\
\text { Percent of total }\end{array}$ & $\begin{array}{l}178 \\
100.0\end{array}$ & $\begin{array}{l}39 \\
21.9\end{array}$ & $\begin{array}{c}136 \\
\quad / 6.4\end{array}$ & $\begin{array}{l}3 \\
1.7\end{array}$ \\
\hline
\end{tabular}


in the urine as compared with 22 percent of 178 metal mine workers of whom 78.1 percent show a higher concentration.

Increased reticulocyte counts are generally considered to be an index of abnormal lead absorption. The average reticulocyte count for coal miners ( 0.73 percent) was slightly less than that of metal miners $(0.82$ percent) and that of smelter workers $(0.80$ percent $)$. This difference becomes more significant when it is observed that only 20 percent of the coal miners had reticulocyte counts of more than 1 percent, as compared with 26 percent for metal miners and 28 percent for smelter workers.

Basophilic stippling, a phenomenon often associated with abnormal lead absorption and increased reticulocyte counts, was only observed in 40 coal miners ( 8.2 percent) of the 486 , whose blood was so examined. None of these values was above 60 stippled cells per 100,000 red cells, Of the 40 workers showing stippled cells, 12 had reticulocyte counts of more than 1 percent. Falconer (31), Teleky (32), and Kehoe (33) have discussed the occurrence of stippled cells in non-leaded individuals.

Hemoglobin determinations by the Newcomer method showed the average value for coal miners to be the same as that of metal miners (13.4 and $13.6 \mathrm{Gm}$. respectively), both averaging somewhat less than smelter workers (14.3 Gm.). Alubuminuria occurred somewhat less frequently in the metal miners ( 5.6 percent) and smelter workers (2.6 percent) than among coal miners (6.9 percent).

There was no evidence of arsenic poisoning or other metallic intoxication among coal miners. A few shot firers complained of headaches in connection with blasting operations. No evidence of ill effects from carbon monoxide or nitrous fumes was observed.

\section{Summary and Recommendations}

A section dealing with a summation of the medical findings on bituminous coal mine workers, and recommendations for the protection and preservation of their health, have been presented in a previous section of this report.

\section{References}

1. Sayers, R. R., J. J. Bloomfield, J. M. DallaValle, R. R. Jones, W. C. Dreessen, D. K. Brundage, and R. H. Britten: Anthraco-silicosis among hard coal miners. Public Health Bulletin No. 221, 114 pp. 1936.

2. Flinn, R. H., W. C. Dreessen, T. I. Edwards, E. C. Riley, J. J. Bloomfield, R. R. Sayers, J. F. Cadden, and S. C. Rothmann: Silicosis and lead poisoning among pottery workers. Public Health Bulletin No. 244. Washington, Gov. Print. Off. 1939.

3. Britten, R. H., and L. R. Thompson: A health study of ten thousand male industrial workers. Statistical analysis of surveys in ten industries. Public Health Bulletin No. 162. Washington, Gov. Print. Off. 1926.

4. Russell, A. E., R. H. Britten, L. R. Thompson, and J. J. Bloomfield: The health of workers in dusty trades. II. Exposure to siliceous dust (granite industry). Public Health Bulletin No. 187. Washington, Gov. Print, Off. 1929.

5. Neal, P. A., R. R. Jones, J. J. Bloomfield, J. M. DallaValle, and T. I. 
Edwards: A study of chronic mercurialism in the hatters' fur-cutting industry. Public Health Bulletin No. 234. Washington, Gov. Print. Off. 1937.

6. Jones, B. F., R. H. Flinn, E. C. Hammond, W. H. Wulfeck, R. H. Lee, D. D. Donahue, H. Specht, H. D. Baernstein, R. C. Channell, J. W. Hough, R. R. Jones, and R. R. Sayers: Fatigue and hours of service of interstate truck drivers. Public Health Bulletin ..... Washington, Gov. Print. Off. In press.

7. Dreessen, W. C., J. M. DallaValle, T. I. Edwards, J. W. Miller, R. R. Sayers, H. F. Easom, and M. F. Trice: A study of asbestosis in the asbestos textile industry. Public Health Bulletin No. 241. Wash. ington, Gov. Print. Office. 1938.

8. Middleton, E. L.: Industrial pulmonary disease due to the inhalation of dust with special reference to silicosis. Lancet. 231: 1-9, 59-64. 1936.

9. Dreessen, W. C., J. M. DallaValle, T. I. Edwards, R. R. Sayers, H. F. Easom, and M. F. Trice: Pneumonconiosis among mica and pegmatite workers. Public Health Bulletin No. 250. Washington, Gov. Print. Off. 1940.

10. Committee on Pneumoconiosis and Committee on Standards. Report of Am. Pub. Health Assn., Annual Meeting. 1932-33 Year Book. Nov. 1932.

11. Irvine, L. G., and W. Stewart: The radiology and symptomatology of silicosis. Silicosis. Records of the International Conference held at Johannesburg 13-27 August, 1930. International Labour Office, Geneva. 1930.

12. Pancoast, H. K., E. P. Pendergrass, A. R. Riddell, A. J. Lanza, Wm. J. McConnell, R. R. Sayers, H. L. Sampson, and L. U. Gardner: Roentgenological appearances in silicosis and the underlying pathological lesion. U. S. Public Health Reports, Vol. 50, pp. 989-996. August 2, 1935. Reprint No. 1696 from the Public Health Reports.

13. Report on Medical Control. Final Report of the Committee on the Prevention of Silicosis through Medical Control. Bulletin No. 21, Part 1. National Silicosis Conference. Div. of Labor Standards, U. S. Department of Labor. 1938. Washington, Gov. Print Off., price 15 cents.

14. Sayers, R. R., and F. V. Meriwether: Miliary lung disease due to an unknown cause. Amer. Journ. Roentgenol. 27: 337, 1932. (Also Reprint No. 1431 from Public Health Reports)

15. Fawcitt, Richard: Occupational diseases of the lungs in agricultural workers. Brit. J. Radiol. 11: 378. 1938.

16. Medico-Actuarial Mortality Investigation. Vol. 1. Statistics of height and weight of insured persons. The Actuarial Society of America, and The Association of Life Insurance Medical Directors, New York, 1912.

17. Neal, P. A., R. H. Flinn, T. I. Edwards, W. H. Reinhart, J. W. Hough, J. M. DallaValle, F. H. Goldman, and D. W. Armstrong, and A. S. Gray, A. L. Coleman, and B. F. Postman: Mercurialism and its control in the felt hat industry. Public Health Bulletin No. 263. Washington, Gov. Print. Off. 1940. 
18. Legge, Sir Thomas: Industrial Maladies. Oxford Univ. Press, London: Humphrey Milford. 1934.

19. Blatherwick, N. R.: The Kingsbury-Clark method for albumin and the Benedict picrate method for sugar. Journal-Lancet 53: 57-59. 1933.

20. Cummins, S. L., and A. F. Sladden. Coal-Miner's Lung; Investigation into Anthracotic Lungs of Coal Miners in South Wales. Jour. of Path. and Bacteriol. 33, Oct. 1930, pp. 1095-1132.

21. The Health of Workers in Dusty Trades. Public Health Bulletin No. 208, 1933. Washington, Gov. Print. Off.

22. Cooke, W. E.: Silicosis in British Coalfields. Tubercle 19: 289. 1938.

23. Diagnostic Standards; Tuberculosis of the Lungs and Related Lymph Nodes. National Tuberculosis Association, New York. Tentative Edition 1938.

24. McPhedran, F. M.: Tracheobronchial lymphadenitis and its associated lesions. Penn. Med. Jour. 32: 228-233. 1929. Also in 21st Ann. Rpt. Henry Phipps Inst.

25. Fellows, H. H.: Serial chest roentgenograms of 3179 office employees, 1926-1938. J. Ind. Hyg. \& Tox. 22: 157. May 1940.

26. Framingham Community Health \& Tuberculosis Demonstration. National Tuberculosis Assoc., Framingham Monograph No. 10, July, 1924, p. 69.

27. Sydenstricker, E., and R. H. Britten: The physical impairments of adult life. Amer. J. of Hygiene 11: 89, 1930.

28. Bainton, J. H., A. C. DeGraff, R. L. Levy, and H. E. B. Pardee: Criteria for the classification and diagnosis of heart disease. New York Tuberculosis and Health Association, Inc. Heart Committee. 3d ed., 1932. Approved by the American Heart Association.

29. Hedley, O. F.: Studies of heart disease mortality. An analysis of the accuracy of deaths recorded as being due to heart disease in Washington, D. C., during 1932, with a discussion of the defects of the present method of tabulating deaths and suggestions for a new system based upon etiological factors. Public Health Bulletin No. 231. 49 pp. 1936.

30. Viko, L. E.: Heart disease in the Rocky Mountain region. Amer. Heart J. 6: 264-273. 1930-31.

31. Falconer, E. H.: The clinical significance of punctate basophilia in the erythrocyte. Ann. Internal Med. 12: 1429-1441, 1939.

32. Teleky, L.: Lessons from the history of lead poisoning. A review of international experience. Indust. Med. 9: Ind. Hyg. Section, pp. 17-20, Jan., 1940. Abst. in J. I. H. and T. 22: 119-121, June 1940.

33. Kehoe, R. A.: Discussion of recent studies with summary of analytical results correlated with chemical data and suggested methods of plant control. Proceedings of Industrial Hygiene Sessions of 15th Annual Convention of National Battery Manufacturers Association, Oct., 24-25, 1939, pp. 51-59.

34. Dreessen, W. C., T. I. Edwards, W. H. Reinhart, R. T. Page, S. H. Webster, D. W. Armstrong, and R. R. Sayers: The control of the lead hazard in the storage battery industry. Public Health Bulletin No. 262, 1940. Washington, Gov. Print. Office.

35. Report concerning caisson disease among compressed air workers. To be published as a Public Health Bulletin. 
36. Occupation and Health Series. Brochures entitled "Silicosis" and "Pneumoconiosis." International Labour Office, Geneva. (Copies may be obtained from International Labour Organization, 734 Jack. son place, Washington, D. C.)

37. Silicosis. Proceedings of the International Conference held in Geneva from 29 August to 9 September, 1938. International Labour Office Geneva, 1940. 
VIII. METAL MINES 


\section{ENVIRONMENTAL STUDY}

A study of working conditions in a metal mine is quite different from a study of working conditions in a factory, since the former necessitates a study of a constantly changing environment, while the environment in the latter, from a static physical viewpoint, may generally be considered uniform. Moreover, in metal mines, unlike coal mines, it is the usual practice to use the same air for ventilating several working places, and since the mineralogical composition of the rock and ore in any two stopes, or between two faces in the same stope, may differ considerably, it is obvious that the chemical composition of the dust breathed by an individ. ual worker may be quite different than the composition of the dust which he is generating.

In 1937, at the time of the preliminary survey (1), the Utah State Industrial Commission had a record of 56 separate active non-ferrous metal mining enterprises employing five or more persons. Under this heading of separate enterprises were included, as one mine, all interconnected mining operations owned by one company, even if portions of the mine were being operated under mining lease permits by independent operators. While no accurate data on the number of workers were available, it was assumed that the total employment in the state had practically returned to the 1929 level. The U. S. Census Bureau showed 49 copper, lead and silver enterprises operating 55 mines and employing 8,182 persons in 1929 (one zinc and three lode gold enterprises were also reported but no data on employment were given) (2). Twenty-three of these mining enterprises (including 30 mines employing 5,390. persons) were visited during the preliminary survey. Two of these enterprises, employing approximately 1,900 persons, were open pit mines. These two mines were eliminated from further consideration at this time, and the detailed study was limited to shaft or adit mines (underground mining operations). Three representative mining enterprises were selected for study from the 21 underground enterprises surveyed.

\section{Geography and Geology of Utah Ore Deposits}

The principal ores mined in Utah are lead and copper ores mixed with ores of zinc and the precious metals. Ries and Watson (3) state, "the group of lead and zinc ores carrying more or less gold and silver as well as some copper and iron is found chiefly in the Rocky Mountains, and is not only of complex character, but differs in form and origin from the eastern deposits. Quartz is the common gangue material, while arsenic, antimony, and iron are common impurities." With regard to copper deposits, they say, "Copper ore exists as disseminated bodies of sulphides deposited by magmatic waters, in igneous rocks or schists, either in connection with the contact metamorphic deposits or alone... The country rock is more or less fractured, and the low grade disseminated ore is sometimes present in large amounts. Its commercial value is due to secondary enrichment, and over it there is a leached capping of variable thickness ... Vein deposits of mixed character, in which the copper is associated with lead, zinc, gold or silver are worked at a number of points in the Rocky Mountains."

Metal mining is conducted in over half of the 29 counties of Utah. In many of the counties the mines are small, little more than prospects, 
with only a few employees doing prospecting or irregular development.

Approximately 97 percent of the metal mine production of the State comes from three mining sections known as the Bingham District, the Park City District, and the Tintic District. The location of these areas is shown in Figure 1.

In 1929 , approximately 72 percent of the metal ore produced in Utah came from the Bingham District, 14 percent from the Park City District, and 11 percent from the Tintic District (4). However, open pit mines from which most of the low grade copper ore is mined were not included in the present study. On the basis of the production of lead and silver metal, the approximate relative percentages of production were Tintic, 36 percent; Park City, 35 percent; Bingham, 26 percent; all other areas, 3 percent.

The relative proportion of the metals secured from the more important ores is shown in Table 25. Obviously, the relative percentages of total production will have yearly variations, but the 1929 figures are a fair measure of capacity production at the present time. During the life of a mine, the percentage of carbonate and oxide ores will decrease and the percentage of sulphide ores will increase. This table has been presented to emphasize the wide variety of metal ores occurring in Utah metal mines, and to show that any analysis of Utah ores or rock can only be considered as representative of the immediate location sampled. Wide deviations from any estimated average ore analyses may be expected at different working faces.

\section{TABLE 25-Proportional Part of Utah Metal Production Derived from Principal Ore Minerals.}

\begin{tabular}{|c|c|c|}
\hline Metal & Ore & $\begin{array}{l}\text { Percent Utah } \\
\text { production } \\
\text { derived from } \\
\text { each (1929) }\end{array}$ \\
\hline \multirow{5}{*}{ Silver } & Cerargerite (silver chloride). & 11 \\
\hline & Argentite (silver sulphide) & 57 \\
\hline & Argentojabosite (basic sulphate of silver and iron).. & 11 \\
\hline & Native silver (dry siliceous ore) & 30 \\
\hline & 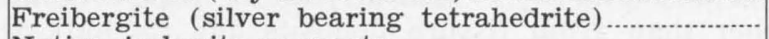 & 1 \\
\hline \multirow[t]{2}{*}{ Gold } & Native, in barite or quartz & 96 \\
\hline & Sylvenite (gold-silver teluride) ........ & 4 \\
\hline \multirow[t]{2}{*}{ Lead } & 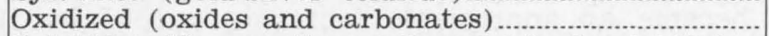 & 22 \\
\hline & \begin{tabular}{|l} 
Sulphides \\
(Jamesonite-antimonial lead sulphide) \\
(Plumboparosite-basic lead ferric sulph- \\
ate) \\
(Wulfenite-lead molybdate) \\
(Anglesite-lead sulphate)
\end{tabular} & 78 \\
\hline \multirow[t]{9}{*}{ Copper } & Boronite (copper iron sulphide) & 61 \\
\hline & Chalcopyrite (copper iron sulphide) ..................... & 2 \\
\hline & Enargite (copper arsenic sulphide) & \\
\hline & Tetrahedrite (copper antimony sulphide). & 7 \\
\hline & Malachite (basic copper carbonate) ........... & 11 \\
\hline & Chalcocite (copper sulphide) & \\
\hline & Chalcanthite (hydrated copper sulphate) & 16 \\
\hline & $\begin{array}{l}\text { Cuprite (copper oxide) } \\
\text { Azurite (copper carbonate) }\end{array}$ & \\
\hline & $\begin{array}{l}\text { Azurite (copper carbonate) } \\
\text { Native copper }\end{array}$ & 3 \\
\hline
\end{tabular}


One of the primary purposes of the engineering study was to deter. mine the exposure of the various workers to silica and toxic metal dusts. While no attempt will be made to describe the geology of the areas in detail, a brief review of the literature will illustrate the occurence of widespread, but non-uniform sources of these materials.

Park City District - Boutwell, in describing the ore deposits of the Park City District (5), reported that the sediments of this district are limestones, sandstones, quartzites and shales. The more important of these, from the point of view of ore deposits, are the Park City limestone, and the Thaynes formation, comprising limestones, sandstones, and shales, The strata have been arched forming part of the Park City anticline which has been broken by many faults. These sediments were intruded by diorite and diorite-porphyry magmas which metamorphosed them and caused the deposition of metallic sulphides. Subsequent fracturing occurred and permitted renewed deposition of sulphides. Further faulting presumably gave access of surface waters to the primary ore bodies, causing oxidation of the sulphides. This faulting also caused some displacement of the ore bodies. Ores are both lode and bedded replacement type. Lode ores occur in both quartzite and limestone, while replacement ores are restricted to certain members of the two formations occurring at different horizons. The most valuable and productive deposits occurred in a limestone bed in the Park City formation about 100 feet from the Weber quartzite. Another very productive horizon was on the contact of the Weber quartzite and the Park City limestone. As the richer ore deposits are depleted it becomes necessary to go deeper into the quartzite to find commercial ore.

Average mill feed ores from this area contain about 15 percent lead sulphide and 60 percent non-metallic gangue (45 percent quartz and 15 percent carbonate) (6).

Early returns from mining in this area were high from the time of its location in 1869 until 1884 when, after the bonanzas had been exploited, the so-called "bedded" deposits were worked. Yield from these deposits declined until 1900, when the effect of gradual depletion of high grade ore was partly offset by the development of relatively large bodies of lower grade ore at depth. By 1908 nearly all of the ore tonnage was from "bedded" rather than from fissure deposits and its bulk was made up of sulphides with little of the richer oxidized material. With improved milling, zinc became an appreciable factor in output by 1910 and the yield of this metal has increased, particularly since 1925. Few bodies of high grade ore have been discovered in the past two decades (7).

The decrease in the amount and proportion of oxidized ore produced, and the decrease in grade of lead ore should tend to diminish the amount and toxicity of lead dust produced per ton of ore mined. However, since the sulphide ores tend to occur more frequently in the quartzite or sandstone, while the carbonate and oxide ores occur more frequently in the limestone deposits, the general trend through the years has been to increase the silicosis hazard, which probably has only partly been counterbalanced by an increase in the efficiency of control measures during this time.

Bingham District - Less information has been published about the geology of the Bingham district than about the other two districts, and most of this has dealt with the large deposits of low grade copper ore 
being worked by open cut methods. However, Fulton (8) and Lyons (9) show that, except that the lead-copper ores are more common than the lead-zinc ores, the history and geology of the field is very similar to that at Park City. Ore was discovered at approximately the same time, the lens-shaped deposits of oxidized ores in the limestone have been practically exhausted, and the ore now being mined is the deep sulphide ore which occurs either as beds between the limestone and quartzite or in fissures in the quartzite.

Tintic District - Ore discoveries were made in the Tintic district in 1869 and developments were started in the western and southern parts of the district. Developments in the eastern part of the district did not start until about 1900, after the discovery of commercial ore bodies from 500 feet below the surface downward, but with no surface outcrops. Since 1918, the principal producing mines have been in this eastern part of the district. The geology of this district has been described in detail (10). While the geological history of this area differs from the other two districts, the present picture is nearly the same from the industrial hygiene viewpoint. High- and low-grade lead-silver ores exist as intrusions and large replacements in the limestones, adjacent to faulted faces of the shales and quartzites. Both ores are completely oxidized to 1,000 feet below the surface; for the next 500 feet the sulphide content of the ore increases until the ores are practically all sulphides. At the lower levels the ore frequently occurs between hanging walls of shales and limestones and footwalls of quartzite. Extensive postmineral faulting has brecciated a large part of this ore into fine sandy material intermixed with masses of heavy lead ore. The hanging wall shales have been altered by mineralizating solutions to a soft grey clayey material and the limestone areas over the ore bodies are altered by the introduction of silica and magnesium silicates.

The individual ore bodies, when adjacent to the quartzite fault faces, have steep dips ranging from 45 degrees to vertical; when distant from the quartzite fault faces, they are tabular replacements of flat lying limestone beds. The tabular commercial ore bodies range in height from six to 200 feet.

A typical geological section through the Tintic district is shown in Figure 19.

Only a small proportion of the ore mined in the Tintic district can be classed as "gold and silver ore," which Henderson and Dunlop have defined as "dry and siliceous ores" ${ }^{1}$ but both metals occur as impurities in base ores.

\section{Mining Methods ${ }^{2}$}

There are many standard methods of mining metal ore, and several of these methods, or modifications of them, may be used in the same mining operation. The methods encountered have been described briefly

1 Silica rich ores worked for the precious metals, with gold and silver usually free milling, and associated with relatively little metalliferous minerals, are called "dry and siliceous ores" by smeltermen.

"A 'dry' ore is one that carries so little lead or copper that by itself in quantity it would not satisfy the requirements for the smelting charge in lead smelting or copper smelting, respectively .... Siliceous (silica in excess of iron) gold, gold-silver, and silver ores containing too little copper, lead or zine to be classfied as copper, lead, zinc, or mixed ores are called 'dry' ores regardless of the ratio of concentration...." (11)

Metal Mine Practice by Jackson and Hedges has been used as a basis for this section (12). 


\section{SECTIONS OF OPHIR FORMATION TINTIC DISTRICT}

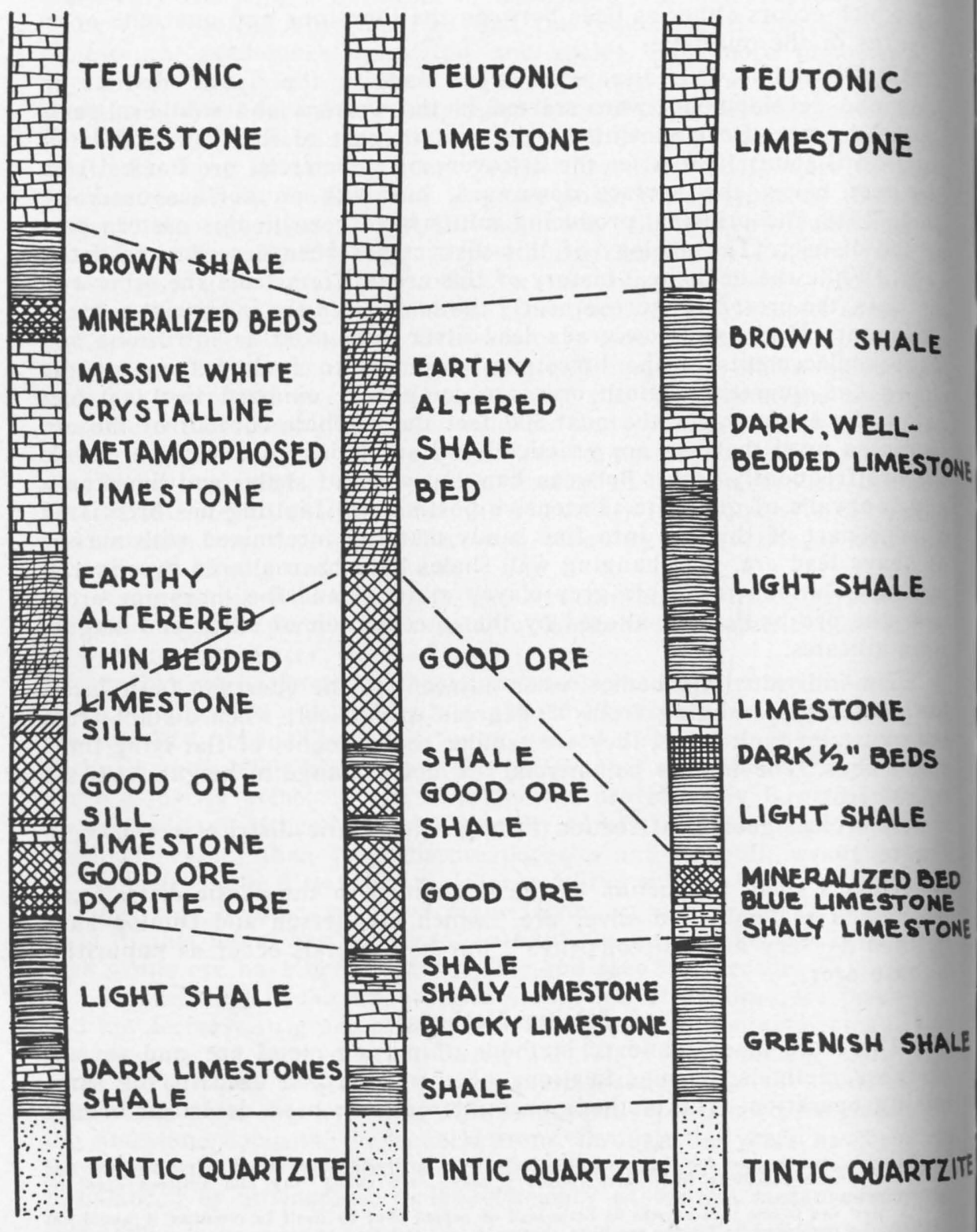

FIGURE 19-Typical sections through the Ophir formation in the Tintic mining district. (Reprinted from Bureau of Mines Information Circular 6360) 
in the following paragraphs, but no attempt has been made to give precise technical details. Underground mining operations may be roughly classified as follows: (a) Mine development and exploration, (b) stoping, and (c) transportation of ore and waste. Other underground operations, such as maintenance and construction, are essential but can be considered as supplemental to the actual mining of the ore.

\section{Mine Development and Exploration}

Jackson and Hedges (12) have stated that: "The term "mine development' is employed to designate the operations involved in preparing a mine for ore extraction. These operations include tunneling, shaft sinking, crosscutting, drifting, and raising."

In most mines, both exploration and development continue after ore extraction by stoping has begun, and often nearly to the end of the life of the mine. Although all of the mines studied had been operating over 20 years, and some of them for as long as 70 years, both exploration and development were being continued. The development system in one Utah metal mine is shown in Figure 20.

Shafts and Adits - Both shafts and adits (haulage tunnels to the outside) are used for bringing ore to the surface. Since most Utah mines occur in areas of high relief where much of the deposit lies above surface drainage, it has been possible in many cases to use the same tunnel for drainage and haulage. However, in most of these cases, the original development was by shaft, and later the adits were driven to a level station. Mines studied included mines with shaft collars at the surface, mines having both shafts and tunnels opening at the surface, and mines having anderground shafts at the end of tunnel adits. Two of the mines studied were in the process of sinking new shafts, or deepening present shafts.

The usual shaft is vertical and of such dimensions, inside the timber, as to provide for two hoisting compartments and a ladder pipeway. Ore is hoisted, in balance, in cars on cages or in skips. Inclined shafts are used in some cases, especially for underground shafts used for lifting ore to main haulage levels from sub-levels. In inclined shafts, or winzes, skip hoisting through a single hoist compartment is the most common procedure.

A landing, or shaft station, is provided at each haulage level. These levels are seldom less than 100 feet or more than 200 feet apart after the shaft has penetrated the ore body. Except in those cases where the adit or drainage tunnel is on the lowest level, a sump is usually provided at the lowest shaft station, into which all water seeping into the mine is drained, and from which it is pumped.

Adits or haulage tunnels are similar to main haulage drifts. Their size is governed by the rate of production and the size of the mine car used. In general, they are high enough to permit suspension of the trolley wires well above the head of a man standing upright, and of sufficient width to allow for a manway on one side of the track and a drainage ditch on the other. Most of the mines studied had at least two openings to the surface serving as ventilation shafts or tunnels, although in several cases at least one of these openings was also used for haulage. Drifts, Crosscuts, and Raises - Drifts or haulageways are driven from the shaft stations through the ore, or through the footwall under the ore. These drifts are connected by crosscuts on the same level, and the drifts 
$\frac{1}{\frac{1}{4}}$

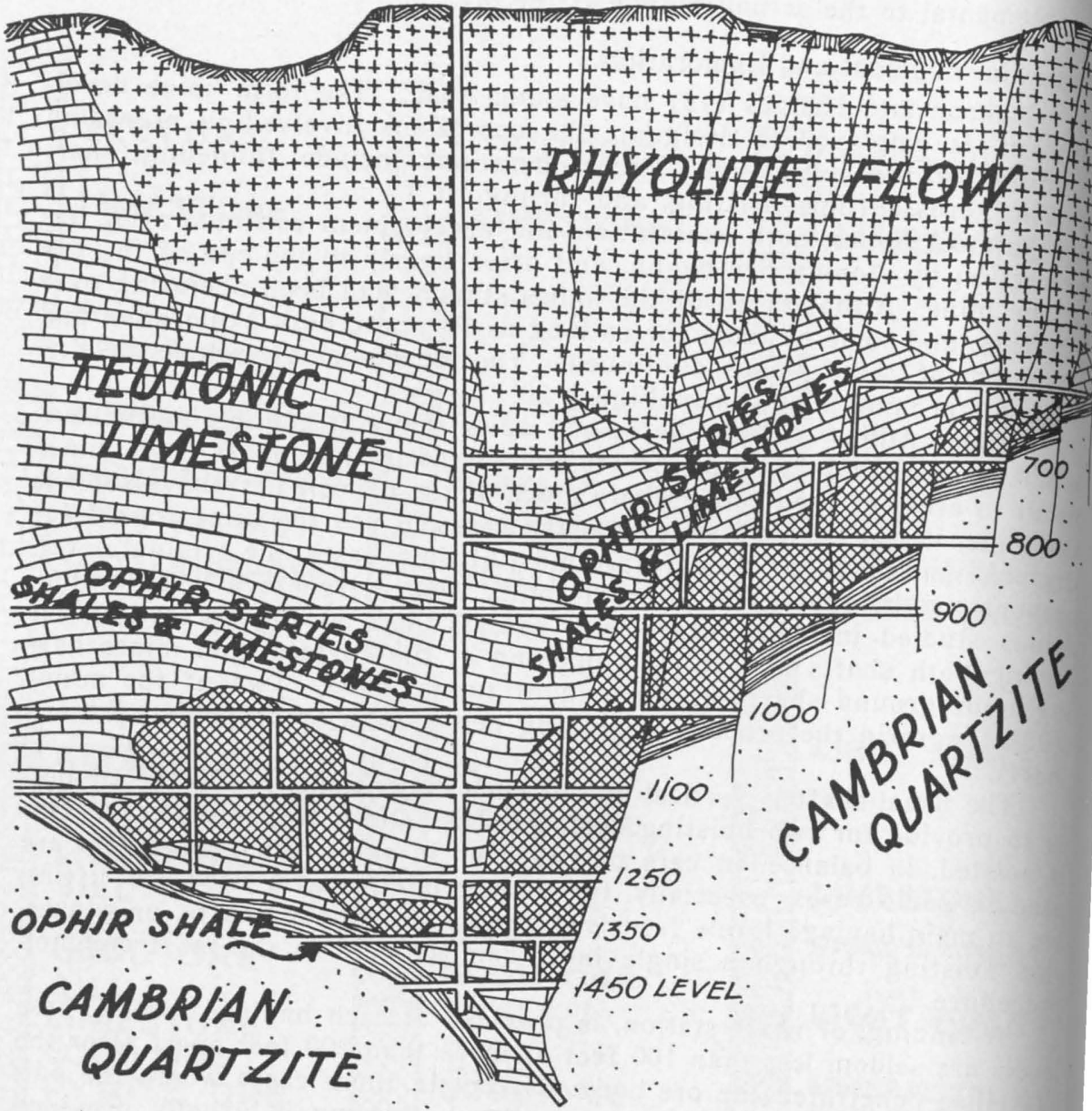
FIGURE 20- Development system in a Utah metal mine. (Reprinted from Bure
of Mines Information Circular 6360.)

on different levels are connected by vertical or inclined raises. Drifts, crosscuts, and raises are driven to facilitate the removal of the ore from the mine and are usually driven in the native rock, although they may be driven in ore or along ore fissures.

In a typical system of tunnels, drifts, and crosscuts, openings were six feet wide and eight feet high. The roof was arched where possible, and in heavy ground (brecciated rock which is not self-supporting) 10 inch by 10 inch timber sets were used with six foot spacing. Drilling and shoveling was done simultaneously, the crew in the heading consisting of a miner and one or two muckers, depending on the tramming distance. 
The miner stood on the muck pile to put in the top round of holes (cuts, relievers and back holes). Shovelers loaded broken rock into cars and trammed them to chutes for filling, to a switch station, or to the shaft station for hoisting. When the muck pile had been removed the miner drilled his lifter holes while the shovelers laid a platform of lagging to receive the next round. Timbering was done by a separate crew; but when the ground was so heavy that immediate timbering was necessary, the miner did his own timbering. The track and the air and water pipe were advanced by a special crew, and a third crew advanced and cared for the ventilation pipe. Draw cut rounds were drilled with a jack-hammer, or if the ground was too hard for a jack-hammer, the miner used a Leyner machine mounted on a horizontal bar. In some of the mines, drilling and mucking were performed on alternate shifts.

Raises, and the raising method, varied considerably in the different mines. In some sections raises required little timbering, while in others standard square sets completely lagged were necessary. In this case the raises were usually two sets wide, one set being used for a manway, a timberway, and for air, water and ventilation piping, while the other side was used as an ore chute. A miner, using a stoper drill, and a mucker worked together in driving the raise, and kept the chute lined to within two sets of the top.

\section{Stoping}

The subject of stoping has been discussed in detail by Jackson and Gardner (13) and summarized by Jackson and Hedges (12). The following discussion is drawn from these references but the reader is respectfully eferred to the original publications for detailed technical discussions.

The term "stoping" is applied in a broad sense to the operation of excavating ore by means of a series of horizontal, vertical, or inclined workings in veins, or large irregular bodies of ore; or by rooms in flat deposits. It covers the breaking of ore and its removal from underground workings, except those driven for exploration and development, and the timbering or filling of the stopes for the purpose of support.

Various methods of stoping have been devised for extracting ore safely and economically from deposits of different types. The stoping method, or methods, applied to a given ore body depend on the requirements for support of the stope-the maximum area or span of back and walls that will be self supporting during the removal of the ore; the nature, size and interval between supports required to maintain the backs and walls of the excavations; and the requirements for permanently supporting the overlying and surrounding country rocks and overburden to prevent their movement and subsidence.

The following classifications of stoping methods based upon method of support was adopted by the Mining Division of the U. S. Bureau of Mines in 1928:

A. Stopes naturally supported.

1. Open stoping.

a. Open stopes in small ore bodies.

b. Sublevel stoping.

2. Open stopes with pillar supports.

a. Casual pillars.

b. Room (or stope) and pillar (regular arrangement). 
B. Stopes artifically supported.

3. Shrinkage stoping.

a. With pillars.

b. Without pillars.

c. With subsequent waste filling.

4. Cut-and-fill stoping.

5. Stulled stopes in narrow veins.

6. Square-set stoping.

C. Caved stopes.

7. Caving (ore broken by induced caving).

a. Block caving; including caving to main levels and caving to chutes or branched raises.

b. Sublevel caving.

8. Top slicing (mining under a mat that, together with the caved capping, follows the mining downward in successive stages).

D. Combinations of supported and caved stopes. (As shrinkage stoping with pillar caving, cut-and-fill stoping with top slicing of pillars, etc.)

Practically all of these methods, and many modifications of them, were encountered during the study. Modifications of the square-set stoping method were most frequently encountered. In this method the ore is excavated in small rectangular blocks, one block at a time. After each block is removed its place is taken by a set of framed timber which serves as a temporary support to the surrounding ground. As best employed, square-set timbering is not used to permanently support the stope for it cannot hold great pressures. As soon as possible, waste filling is put in for permanent support. Stoping is commonly carried upward from a drift, or laterally from a raise, or both. In one mine where open stopes, a shrinkage stoping method, and a modified square-set method had been tried and found unsuitable, a regular square-set and back fill method had been adopted. This required the driving of a vertical square-set raise from the footwall at the level where the stope was to be started to the level above. This raise was the place where the stope was started and through which waste was dumped from the level above when filling was wanted. In this mine, ore was trammed in small ore cars from the active sets to ore chutes. These chutes lead to ore pockets in the main haulage drift or crosscut on the lower level. In another mine where combinations of horizontal square-set stoping and sublevel caving or top slicing were used, the ore was moved to the loading chutes with dragline scrapers (slushers). Stulled stopes, which might or might not subsequently be filled with waste, were developed in some mines. Many other modifications of standard stoping methods are also used in Utah metal mines. An example of stringer-set stope timbering is shown in Figure 21.

\section{Transportation of Ore and Waste}

Transportation concerns the operations involved in the transportation of ore and waste from the face or stope where it is broken to the surface, or the transportation of waste to a stope for gobbing (filling), but not the handling of the ore in the stopes, which has been discussed under "Stoping." It includes loading cars from chutes on the haulageways and intermediate levels, handtramming, animal and locomotive haulage, scraper 
transportation, operation of main transfer raises between levels, dumping into shaft pockets, the operation of skip loading devices, the caging of cars, and the hoisting of ore in cages or skips.

The transportation facilities which must be provided when under. ground work is begun may or may not be retained as mine development expands and ore production begins.

Hand tramming is widely used in small mines, and as an adjunct to mechanical haulage systems. For tramming small tonnages of rock and ore short distances on the main levels, for short transfers on sublevels, and in some types of stopes, it may be the most practical method. It is particularly adapted to prospects and small-scale operations, such as those conducted by "leasers" (lessees). Small cars of 12 to 20 cubic foot capacity, of either the end- or side-dumping type, are usually employed.

Mules and horses were extensively used for haulage in the past, but are being replaced by mechanical haulage methods.

Mechanical haulage in the metal mines studied was of two types: (a) Locomotive, and (b) scraper or slusher.

Locomotives for underground use were electric powered, and either of the trolley or storage-battery type. For long hauls and heavy trains, the trolley type was used, while for gathering service from a number of loading points to a main haulageway or shaft station, the storage-battery type was preferred. Small storage-battery locomotives of the "trammer" type that could be run on the mine cage, and transferred quickly from one level to another, were used in mines where the ore came from scattered areas and several horizons.

Scrapers powered by electric, or compressed air motors, ordinarily were employed underground as mucking and loading machines; but they were also employed as conveying machines, and in some instances, were used to transport ore and rock several hundred feet from the face to chutes or mine cars.

Gravity usually is employed, wherever possible, to move broken ore from stopes to the haulage levels; and ore-passes from the stopes terminate at the bottom in chutes, by means of which the flow of ore into cars can be controlled. Loading chutes are constructed in various ways and consist essentially of a framework of timber, steel, or concrete with gates or other means provided for holding back the column of broken ore in the raise above. Chute gates are of many different types (14), but from the industrial health viewpoint, they are all apt to be sources of dust dissemination unless a satisfactory dust control method is employed.

Ore- and waste-passes are simply vertical or inclined openings for the transfer of broken ore to the haulage system, and of waste rock to the mined stopes. They may be cut in the ore or in the walls of the deposit, or be timbered openings through old or filled stopes. From a health viewpoint, the combination of an ore pass and a manway in the same opening, even if they are separated by stulls and lagging, may cause serious dust exposures for men who must use the manways during or immediately after ore movement.

Hoisting in Cages and Skips - Both cage hoisting and skip hoisting were employed in the mines studied. Arrangements for caging cars at the shaft stations varied. In some mines, stations were cut on both sides of the shaft. The loaded cars were pushed onto the cage from one side 
and the empty cars pushed off on the other. In other mines, the station was cut only on one side of the shaft so that the empty car had to be pulled back off the cage before the loaded car could be pushed on. Switches and crossovers were provided for pulling the empties off to one side to allow caging the loaded cars.

Skip hoisting was employed for moving ore from sublevels to main haulage levels at a higher elevation. Single compartment, skip-hoists with self dumping skips were used in winzes or shafts. Muckers dumped the ore directly from small tram cars to the skip buckets. The skip buckets either dumped directly into large tram cars, or dumped to car loading pockets. Skip hoisting was also employed in some main shafts, in which case storage pockets and loading chutes were provided at the shaft stations. At two of the mines studied, ore was hoisted or lowered in the main shaft to a tunnel haulage level. At this level station, trains of ten to thirty cars were made up and hauled by trolley locomotives to the outside. Where skip hoisting was used, this required the loading of cars from ore pockets opening at this level station.

Hoisting in cages is considerably slower than hoisting with skips, due to the smaller net load that can be hoisted in a shaft of the same size, and to the time required for caging cars at the shaft stations and on the surface, and usually requires more labor. However, cage hoisting reduces the number of ore transfers, and every ore transfer is a potential source of dust dissemination.

A typical shaft "cage" consists of a double deck platform with boiler plate side shields and doors, and a steel canopy, the latter affording protection from debris and falling objects when men are raised and lowered in the shaft. The cages move along fixed guide rails and are provided with safety devices to prevent falling in case a hoisting cable breaks. The hoisting cables are strung over sheave wheels, mounted on the shaft head frame, and are connected to large driving drums located in a hoist house adjacent to the shaft.

\section{0ther Underground Operations}

Maintenance-A large force of men is required to maintain the electrical, pumping, piping, and transportation services, and to maintain timbering in shafts and haulage drifts. The electrical services in a mine include lighting, telephone lines, signal systems, power wiring, motor installation and repair, and battery charging. Water pumps may be necessary to remove ground water, or water which seeps into the mine. There are also piping systems for compressed air and water. Transportation maintenance consists of track repair work, clearing drainage ditches, and the removal of rock and ore which accumulates along the main haulageways. In some dry mines, it is also necessary to sprinkle haulageways with water to reduce the dust concentrations.

Ventilation-Only one of the mines studied had made any planned attempt to secure adequate mine ventilation by mechanical means. The other mines depended upon natural ventilation through shafts, adits, drifts, crosscuts and raises supplemented, in a few cases, by small fans or blowers supplying air to the stopes; and, in other cases, by the exhaust from compressed air drills, or from open valves in the compressed air lines. Where planned ventilation systems are used, air movement is produced by large surface fans working from the suction (or return air) 


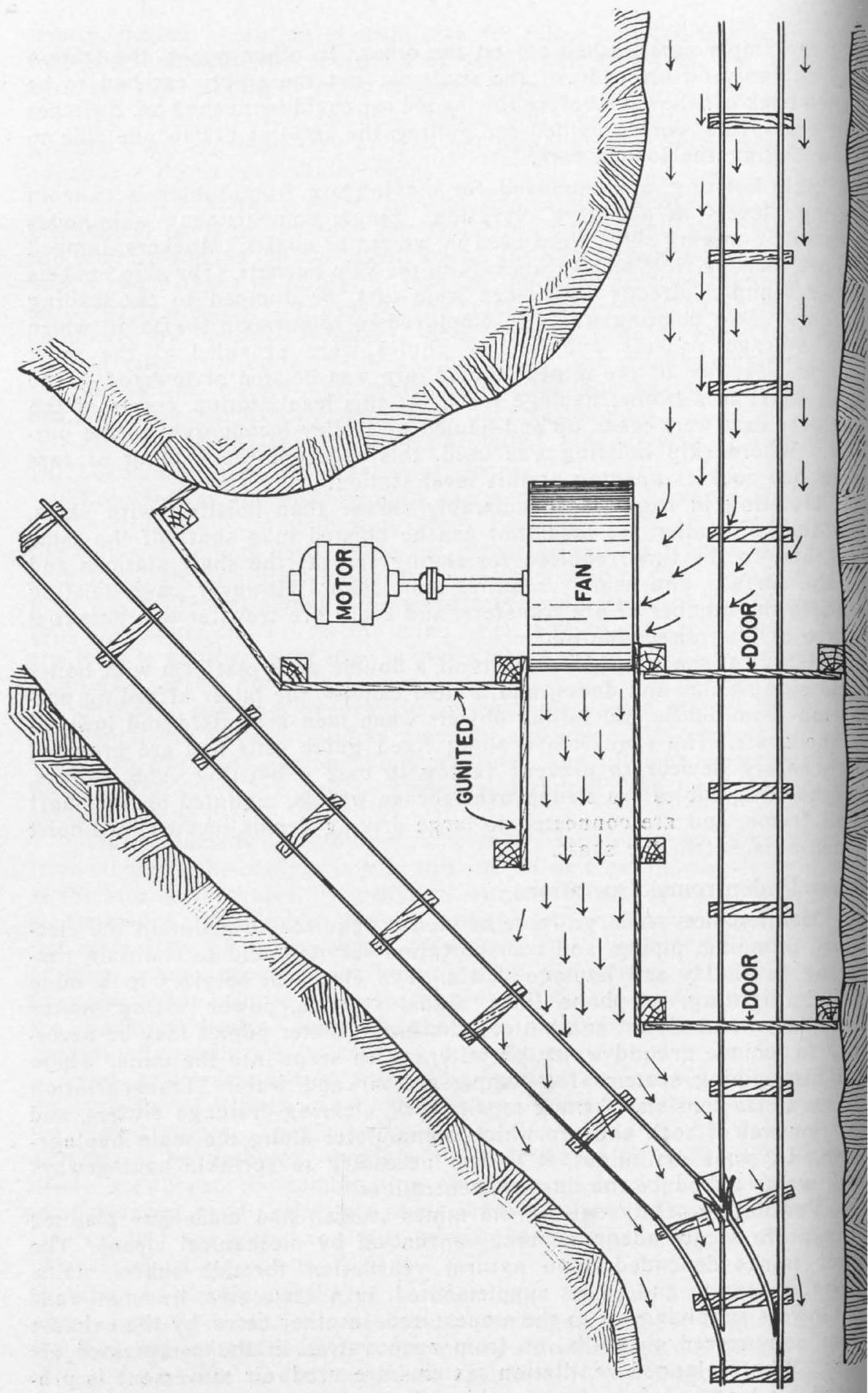


side, and located at the collar of a ventilation shaft, or by underground fans located in a ventilation tunnel (Figure 22). Air enters the mines through other shafts, or adits, and flows through drifts and raises to the stopes; and then, preferably, from the stopes to ventilation drifts which are brought together into a single airway leading to the exhaust shaft. The direction of air currents in the mine is controlled by brattice doors and partitions, and the velocity of the currents may be increased by supplementary booster fans (Figure 23). Small auxiliary fans and ventilation ducts are also required for ventilating blind stopes and dead ends.

Superintendence-The mine foreman has general supervision of all underground activities. Since it is impossible for him to personally supervise all the varied operations, he maintains contact with the miners through shift bosses and level foremen, who are responsible for the maintenance of scheduled output and all matters of safety in the sections of the mine under their jurisdiction. In some mines, they act as timekeepers, and also keep other records.

\section{Outside Activities}

Surface Transportation-Ore coming to the surface through shafts in skip buckets is usually dumped directly into shipping pockets or ore docks. Ore reaching the surface in caged cars is hand trammed, and ore from the adits is hauled to the top of the docks and dumped. The railroad siding is usually beside the ore dock, and railroad cars can be loaded directly through chutes from the ore bins. In some mines, the topography prevents building a railroad line near the shaft location, in which case the ore is transported from the ore bins at the shaft head to the loading docks by means of an aerial tramway.

Other Outside Activities-Surface maintenance crews repair portable mine equipment and may do emergency repair work in the mine. Carpenter shops or saw mills in which timbers to be used in the mine can be cut and framed, electrical repair shops, and blacksmith shops for repairing ore cars and sharpening drill steel are essential. The present tendency is to use detachable bits, and to sharpen bits or steel in automatic sharpening machines.

Most metal mines employ the services of an assayer who makes chemical and fire analyses of ore samples.

\section{Occupational Analysis and Description of Chief Occupations}

An occupational analysis of the workers employed in 21 Utah underground metal mining operations in 1937, and of the workers employed in the three mining operations studied in 1939, is given in Table 26. The number of men recorded for each occupation shown in the table is an average figure for the stated time. The metal mining industry is subject to abrupt fluctuations in employment caused by changes in the state of the market, and in the quantity and quality of ore available.

From Table 26 it is apparent that there is a great diversity of occupations to be found in metal mining. The occupations may be classified on the basis of underground and surface workers, although many of the persons classified in the latter group spend part of their time in the mine. The occupations may also be classified into two other broad groups, namely, those associated with the actual extraction of the ore, and the indirect labor required in the mining operations. In the mining operation 


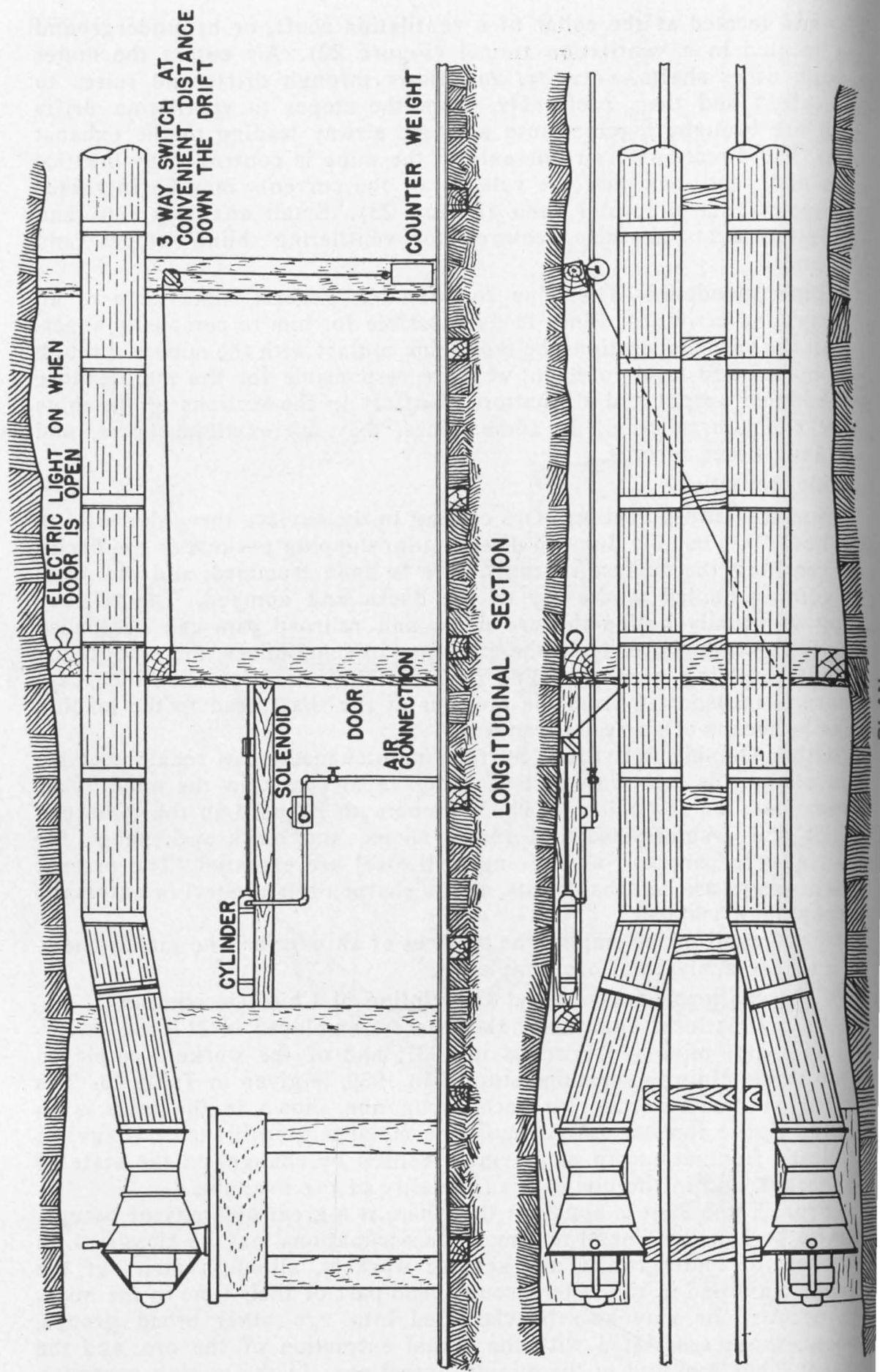

FIGURE 23-Air door and secondary fan installation. (Reprinted from Bureal of Mines Information Circular 6360.) 


\section{TABLE 26-Occupational Analysis of Employees of Three Metal Mining Operations Studied in 1939 Compared with Occupational Analysis of 21 Operations Surveyed in 1937. ${ }^{1}$}

Section and Occupation

Office and General Supervision

Superintendent, assistant superintendent, general foreman, manager

Engineer, mining, civil, safety, surveyor and geologist

Office worker, timekeeper, clerk, etc.

Face Operations, Underground.

Foreman, mine boss, shift boss, level boss.

Miner, machine driller, machine man, driller.

Mucker, hand miner, laborer, mucker and

trammer

Sampler

Transportation, Underground

Mule skinner, horse tender, trammer.

Motorman, motorman's helper

Hoistman, winze hoistman, slusher man,

tuggerman

Station tender, carman

Cager, cage rider

$\mathrm{Ni}_{\mathrm{r}}$ per, tool nipper, supply man, material man.

Powderman

Bin tender (car loaders)

Maintenance and Construction, Underground.

Timberman, tunnel maintenance man

Shaftman

Pipeman

Trackman, track-and-pipeman

Ventilation man

Wireman, electrician

Mechanic, repairman, oiler

Sanitation man, inspector, general utility man

Compressor man, underground

General labor, miscellaneous labor

Transportation, Surface

Hoistman

Top carman, topman

Tram motorman, tramway operator

Waste dumpman, trackman

Bin man, ore loader, ore dumper, yard laborer.

Truck driver, truck driver's helper.

Tractor operator

Teamster

Maintenance and Construction, Surface

*Compressorman

Painter

*Electrician

Blacksmith, tool dresser, steel sharpener

Welder

Tinsmith, boilermaker

Cable maker

\begin{tabular}{|c|c|c|c|c|}
\hline 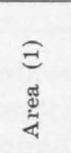 & 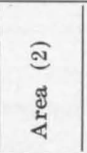 & 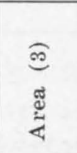 & 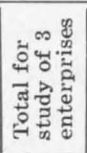 & 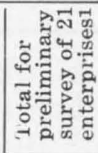 \\
\hline (5) & (10) & (16) & (31) & \\
\hline 1 & 2 & 2 & 5 & \\
\hline 1 & 6 & 7 & 14 & \\
\hline 3 & 2 & 7 & 12 & \\
\hline 38) & (154) & (177) & (399) & $(197$ \\
\hline & 11 & 7 & 21 & \\
\hline 30 & 56 & 87 & 173 & \\
\hline 35 & 87 & 81 & 203 & 982 \\
\hline & & 2 & 2 & \\
\hline (29) & (45) & (37) & (111) & (40 \\
\hline 12 & & & 12 & \\
\hline 5 & 11 & 18 & 34 & \\
\hline 6 & 31 & & 37 & \\
\hline 4 & … & 2 & 6 & \\
\hline & & 6 & 6 & \\
\hline 1 & 1 & 2 & 4 & \\
\hline 1 & & 9 & 10 & \\
\hline & 2 & .... & 2 & \\
\hline (29) & $(55)$ & (47) & (131) & $(490$ \\
\hline & 48 & 38 & 106 & $\left\{\begin{array}{r}366 \\
19\end{array}\right.$ \\
\hline 2 & & .... & 2 & \\
\hline 2 & 5 & .... & 7 & \\
\hline .. & $\cdots$. & 4 & 4 & \\
\hline & $\cdots$. & .... & $\cdots$ & \\
\hline 2 & $\cdots$. & $\cdots$ & 2 & \\
\hline & 2 & 5 & $\begin{array}{l}5 \\
2\end{array}$ & \\
\hline 3 & .... & .... & 3 & \\
\hline (20) & (2) & (26) & (48) & \\
\hline & $\ldots$. & 3 & 7 & \\
\hline 10 & .... & 12 & 15 & \\
\hline 13 & $\cdots$. & .... & 13 & \\
\hline & & $\cdots$ & $\cdots$ & \\
\hline & 2 & 2 & 4 & \\
\hline & $\cdots$. & 9 & 9 & \\
\hline & … & … & $\cdots$. & \\
\hline (14) & (25) & (52) & (91) & \\
\hline & .... & 3 & 6 & 13 \\
\hline . & $\ldots$. & 3 & 3 & \\
\hline & & & 5 & \\
\hline 7 & 5 & 5 & 17 & 6 \\
\hline … & $\cdots$. & 1 & 1 & \\
\hline & $\cdots$. & 1 & 1 & \\
\hline & & & & \\
\hline
\end{tabular}




\section{TABLE 26-Occupational Analysis of Employees of Three Metal Mining Operations Studied in 1939 Compared with Occupational Analysis of 21 Operations Surveyed in $1937 .{ }^{1}-$ (Continued)}

\begin{tabular}{|c|c|c|c|c|c|}
\hline Section and Occupation & 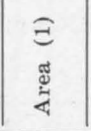 & ब్ర & 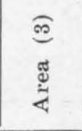 & 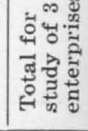 & 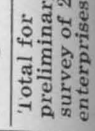 \\
\hline *Machinists, mechanics .................... & \multirow[t]{2}{*}{2} & \multirow[t]{3}{*}{5} & \multirow{2}{*}{$\begin{array}{l}4 \\
1\end{array}$} & \multirow{2}{*}{$\begin{array}{r}11 \\
4\end{array}$} & \multirow{2}{*}{$\begin{array}{r}44 \\
4\end{array}$} \\
\hline * Pumpinen, pipemen, plumbers & & & & & \\
\hline $\begin{array}{l}\text { Carpenters, timber framers, saw mill operators. } \\
\text { Firemen, stationary engineers }\end{array}$ & $\begin{array}{r}2 \\
\ldots .\end{array}$ & & $\begin{array}{l}9 \\
3\end{array}$ & $\begin{array}{r}14 \\
3\end{array}$ & $\begin{array}{l}43 \\
14\end{array}$ \\
\hline $\begin{array}{l}\text { Firemen, stationary engineers } \\
\text { General laborer }\end{array}$ & \multirow{2}{*}{$\ldots .}$. & \multirow{2}{*}{$\begin{array}{r}9 \\
\ldots .\end{array}$} & \multirow{2}{*}{$\begin{array}{l}17 \\
\ldots .\end{array}$} & \multirow{2}{*}{26} & \\
\hline *Battery man ............................................ & & & & & \\
\hline Milling Operations & \multirow{2}{*}{$(0)$} & (0) & $(0)$ & $(0)$ & \multirow{2}{*}{$(30)$} \\
\hline Concentration mill foreman & & \multirow{2}{*}{$\ldots}$. & \multirow{2}{*}{$\begin{array}{l}\ldots . . \\
\cdots . . \\
\end{array}$} & .... & \\
\hline Concentration mill operator (dry crushing). & \multirow{3}{*}{$\begin{array}{l}\ldots . \\
\ldots . . \\
\ldots .\end{array}$} & & & … & \multirow{2}{*}{26} \\
\hline Concentration mill operator (wet flotation) .... & & .... & .... & $\cdots$. & \\
\hline Concentration mill repairman & & $\cdots$. & ..... & $\cdots$. & 3 \\
\hline Assaying ............................ & \multirow{2}{*}{$\begin{array}{c}(2) \\
2\end{array}$} & $(0)$ & \multirow{2}{*}{$\begin{array}{c}(9) \\
5\end{array}$} & \multirow{2}{*}{$\begin{array}{c}(11) \\
7\end{array}$} & $(24)$ \\
\hline Chemist, assayer & & .... & & & \\
\hline Bucker ..................................... & \multirow{2}{*}{$\begin{array}{l}\cdots . . \\
(0)\end{array}$} & .... & 4 & 4 & \\
\hline Miscellaneous …............................ & & (4) & (4) & (8) & (49) \\
\hline 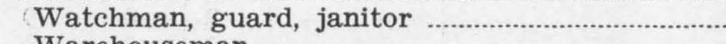 & .... & 3 & 1 & 4 & \\
\hline Warehouseman ............................... & $\cdots$ & 1 & 3 & 4 & 5 \\
\hline Cook, waiter, store clerk ..... & ... & -... & .... & $\cdots$. & 9 \\
\hline TOTAL & (167) & (295) & $(368)$ & $(830)$ & $(3480)$ \\
\hline
\end{tabular}

* Duties may necessitate underground work.

1 Data from the files of the Unemployment Compensation Division of the L'tah Industrial Commission showed that at the time of the preliminary survey there were approximately 56 active metal mining operations in the State. Of these, 23 were surveyed and found to employ 5390 persons. Two were open pit mines employing 1910 persons which left 3480 in underground mining operations.

in area 1, 40 percent of the total number of employees were miners and muckers; in area two, 49 percent, and in area three, 46 percent were thus employed. In the 21 mining operations previously surveyed, 54 percent of the 3,480 employees were classified as miners or muckers. Since the actual mining of the ore engages the direct attention of approximately half the total force, and since the drilling, blasting, and loading of the ore causes the generation of most of the dust in the mine, the chief interest is with those occupations which are directly engaged in drilling and loading ore, or closely associated with it. The sampling locations for atmospheric dust were so chosen that a representative picture of the various environmental conditions was obtained, samples being proportioned to the various occupations on the basis of the number of persons in each occupation, the estimated dustiness of the occupation, and the variation in exposure associated with the occupation.

In order to show the various duties involved in different occupations, it seems appropriate to give brief definitions of the more important occupations in the industry. Such a list of definitions follows: 


\section{Office and General Supervision}

The superintendent, assistant superintendent, general foreman, and/or general manager are responsible for all surface and underground operations. However, they usually spend a minor portion of their time underground.

The mining engineer, geologist, safety engineer, civil engineer and surveyor perform the engineering duties inherent to their profession and may spend from one-fourth to one-half of their time underground.

The classification of office worker has been given to all those occupations, such as executives, clerks, timekeepers, telephone operators, physicians, draftsmen, etc., whose duties do not require them to spend any appreciable part of their working time outside the main offices of the mine.

\section{Face Operations, Underground}

Mine foreman, shift boss, and level boss are occupations requiring the supervision of all underground operations. They also require the assumption of responsibility for safety and health conditions underground.

Miners, in the operations studied, were practically all machine men operating jack-hammers, Leyner drills, stopers, or drifters. While some differences in the amount of dust generated by these different drills have been shown, the individual miner's occupational histories showed no clearcut differentiation in the type of work done. In most Utah mines, a miner and a mucker work as partners and alternate jobs. The only apparent difference between a miner and a mucker was that the miner was the most experienced man and was permitted to charge holes and fire explosives. Miners barred down overhang, did a large part of the timbering in the stopes or drifts in which they worked, laid track and pipe, and even assisted in hand tramming ore cars to the switch stations.

Muckers assist miners in setting up drills, and may also operate drills and jack-hammers. They also bar-down overhang (loose roof-rock left after blasting); hand load ore into cars with shovels, or operate mechanical mucking machines; tram the loaded cars to the nearest switch, hoist, or dumping station; and tram the empty cars back to the stope.

Samplers collect specimens of rock and ore from each working face and send these samples to the assay office for analysis. Sampling may also be done by the geologist, foreman, miner, or the ore handler at the shaft station or bins.

\section{Transportation, Underground}

The movement of the ore cars from the face to the hoist may be accomplished by hand tramming, by mule train, or by hauling trains with electric locomotives. In this study, a differentiation between hand trammers and muckers was not practicable.

Mule skinners, also known as drivers or horse trammers, drive mules or horses used for moving ore cars and supplies between the shaft stations and the active working faces. Only one of the mines studied used animals for tramming, and in this mine they were rapidly being replaced by tram locomotives.

Motormen operate electric locomotives (called motors) which are either of the trolley or storage battery type. These locomotives are not only used to move trains along the haulage drifts on the various mine 
levels, but in adit or tunnel mines, are also used to haul ore from the inside shaft station to the outside railroad siding. Motormen are assisted by motorman's helpers who couple and uncouple cars at the switch sta. tions, open brattice doors, and act as tool nippers by delivering steel, bits, timber, and wedges to the various stopes and headings.

Underground hoistmen operate electric hoists in sub-shafts and winzes; and operate compressed air hoists at temporary hoisting stations, or for operating tuggers, slushers, or drag-line scrapers. In some mines, the main shaft collar is at the inside end of a haulage tunnel, or adit, which makes the main hoist operator an underground hoistman. The loca. tion and duties of each hoistman were considered in weighting his dust exposure.

Station tenders act as signal men at the various shaft stations and may be responsible for the routing of ore cars and supplies. They are assisted by carmen, who place loaded mine cars on the hoist cages and remove empty cars from these cages. They also couple and uncouple mine trains at the hoist stations. In skip hoisting, they may act as skip loaders or skip tenders.

Cagers or cage riders load hoist cages with tools, steel, timber and other miners' supplies. They may ride up and down with these cages and unload the materials at the proper stations. They act as signal men in the hoisting of ore, and as cage tenders in the hoisting of men.

Nippers, Tool nippers, supply men or material men deliver tools and supplies to the active working faces.

Powdermen deliver explosives, percussion caps and fuses to the active working faces. The actual loading and firing is done by the miners at the end of each shift.

Bin tenders, car loaders or skip tenders operate the gates on underground storage bins for ore or waste rock, which may be loaded into either mine cars or skip buckets.

\section{Maintenance and Construction, Underground}

Timbermen and timberman's helpers erect timbers and braces for supporting the roof in mined areas. The amount of timber required in the different mines, and in the different geological formations in the same mine, varied enormously. In general, the miners did their own timbering in stopes, while the timbermen did the timbering in permanent haulageways and did difficult jobs in stopes, drifts and raises.

Shaftmen are expert timbermen assigned to shaft construction and maintenance.

Pipemen extend water and compressed air lines to within a short distance of the working faces. In the mines studied, these duties were frequently assumed by miners, trackmen, or by pipemen assigned to surface maintenance crews.

Trackmen maintain main haulage lines and lay new track. The extension of temporary track in the stopes may be done by the miners and muckers.

Ventilation men install and maintain ventilation fans, pipes, flexible ventilation tubing, brattice doors, and brattice walls.

Wiremen or electricians do underground wiring. Ordinarily electric lighting is used only at shaft stations and in hoist houses (where it is 
required by law) and electric trolley wires are used only in the main drifts and tunnels. In the mines studied, this classification was not used and electrical maintenance was done by repair mechanics or surface maintenance men.

Mechanics, repairmen, and oilers service and maintain underground equipment. In many mines, this is done by men detailed from the surface maintenance crews.

Sanitation men, inspectors, or general utility men are responsible for the care and maintenance of underground latrines and toilets.

Compressormen operate electrically driven air compressors. While this occupation is occasionally encountered underground, air compressors are usually located on the surface.

General labor or miscellaneous labor includes such construction or maintenance jobs as timber handling, concrete construction work, and guniting; and also includes relief men who replace all men except miners and muckers.

\section{Transportation, Surface}

Hoistmen operate the machinery for lifting the cages, or skips, in the main shafts. Electric hoists were used in the mines studied, although auxiliary steam hoists were sometimes available.

Top carmen or topmen remove the loaded ore cars from the cages at the shaft collar, tram them to the ore bin dumping station, dump them, and return the empty cars to the cage station.

Surface motormen haul trains of ore from the inside shaft collar through the entrance adit or tunnel to the outside. These men were usually carried on the company payroll as inside motormen.

Tramway operators operate aerial cable-car tramways for conveying ore from the mine portal to a railroad siding located at some distance down the mountain. Duties consisted of loading cable cars, dumping cars, and operating control switches.

Waste dumpmen and dump trackmen maintain track on waste rock dumps, and dump cars of waste rock. This occupational designation did not occur in the mines studied, although waste rock was dumped by top trammers in some instances.

Binmen, ore loaders, ore dumpers, and yard labor have been grouped together since they all had similar duties in these mines, and were primarily engaged in the storage and the loading of ore into railroad cars.

Truck drivers and truck driver's helpers operate and load automobile trucks used in delivering supplies to the mine.

Tractor operators and teamsters are self-explanatory occupations, which did not happen to occur in the mines studied.

\section{Maintenance and Construction, Surface}

This section contains several occupations, the duties of which may necessitate that the worker spend part of his time underground.

Electricians maintain surface electrical wiring and motors. They also act as emergency repairmen or wiremen underground, and may make repairs on underground motors, although such repair work is usually done on the surface. 
Timber framers are employed in cutting and preparing timber for use underground. Carpenters may act as timber framers, but also do sur. face construction and repair.

Batterymen charge and maintain the electric storage batteries used in cap lamps, and/or the heavy duty batteries used in the tram locomo. tives.

The remaining occupations listed in this section appear to be selfexplanatory.

\section{Milling Operations}

Crushing and concentrating mills are frequently operated in conjunction with mines, as well as with smelters, or independently, since the crushing and concentrating of ore is an intermediate step between mining and smelting. None of the mines studied were carrying on milling operations at the time of the study, but a sufficient number of employees had had previous employment in ore mills to make the consideration of the dust exposure in these mills significant. A more detailed discussion of the milling of ore is contained in the section of this report on the health of workers in the Utah smelting industry. The broad occupational classifications used in this section appear to be self-explanatory.

\section{Assaying}

The assayer or chemist makes fire and chemical analyses of the pulverized ore samples to determine their mineral content. In the smaller assay offices he may also assume the duties of a bucker.

Buckers grind and quarter the samples and prepare them for analysis. Miscellaneous

The occupations listed in this section are self-explanatory.

\section{Typical Miner's, Mucker's, and Timberman's Activities}

In order to give a more complete picture of the activities of miners, muckers, and timbermen during the course of a day's work, the following tabular descriptions are presented. These show the average time consumed in performing the fundamental operations in two different types of mining which were practiced in one mine. These estimates were made for the U. S. Bureau of Mines (15) in a Utah mine which was not one of the mines included in this environmental study. Wide variations from these average figures for this mine can be expected for any individual worker on any one day, and the data are not directly applicable to similar mining operations in other mines. The operational-routine analyses used in estimating the average daily dust exposures of miners and muckers is more general in scope than those shown in Tables 27 and 28 .

It will be noted that all of the above activity estimates are based on a period of $61 / 4$ hours at the face. It is a Utah State law that no mine worker may spend more than eight hours per day underground, this being the time between entering and leaving the mine shaft or adit. Consequently, in mines covering large areas, a man may spend as much as $11 / 2$ hours in reaching and returning from his working place. He also spends at least one-half hour eating lunch (usually leaving the stope or heading and going to a less dusty location during this period). In hot mines, it was standard practice to take rest periods for at least 40 percent of the time at the face. These rest periods were usually secured by alternating at mucking. In soft land, enough ore was broken by one round 
TABLE 27-Routine of Operations in a Tunnel Using Crossbar for Leyner Drill. Hand Mucking and Tramming to a Switch at a Maximum Distance of 200 Feet Proceeded Simultaneously with Drilling.

\begin{tabular}{|c|c|c|}
\hline Miner & Mucker & Time \\
\hline Bar down. & Clean scattered rock in rear. & 15 minutes \\
\hline $\begin{array}{l}\text { Set up machines, fill water } \\
\text { tank and connect hose. }\end{array}$ & Shovel or to car, and tram. & 1 hour \\
\hline Drill top round. & Shovel or to car, and tram. & 3 hours \\
\hline $\begin{array}{l}\text { Tear down and remove ma- } \\
\text { chines }\end{array}$ & Shovel or to car, and tram. & 30 minutes \\
\hline $\begin{array}{l}\text { Drill lifters after all muck is } \\
\text { removed from face. }\end{array}$ & $\begin{array}{l}\text { Get powder and prepare } \\
\text { primers. }\end{array}$ & 45 minutes \\
\hline Load holes. & $\begin{array}{l}\text { Remove machine and equip- } \\
\text { ment to safe place in rear. }\end{array}$ & 30 minutes \\
\hline $\begin{array}{l}\text { Cut fuses and prepare to } \\
\text { blast. }\end{array}$ & $\begin{array}{l}\text { Lay blasting sheets or plank } \\
\text { lagging at the face. }\end{array}$ & 15 minutes \\
\hline Shoot round. & Shoot round. & \\
\hline
\end{tabular}

\section{TABLE 28-Routine of Operations in Square-set-and-fill Adaptation of Rill Stope Using Scrapers for Handling Ore.}

\begin{tabular}{|c|c|c|c|}
\hline Miner & Timberman & Mucker & Time \\
\hline Barring down. & Laying floor. & $\begin{array}{l}\text { Rigging scraper and } \\
\text { tail block }\end{array}$ & 30 minutes \\
\hline $\begin{array}{l}\text { Setting up machine } \\
\text { and connecting hose. }\end{array}$ & Getting timber. & $\begin{array}{l}\text { Cleaning up scattered } \\
\text { muck. }\end{array}$ & 45 minutes \\
\hline Drilling. & $\begin{array}{l}\text { Standing and block- } \\
\text { ing timber. }\end{array}$ & Scraping. & 3 hours \\
\hline $\begin{array}{l}\text { Tearing down and } \\
\text { removing machine. }\end{array}$ & $\begin{array}{l}\text { Lagging sets and } \\
\text { raising chute. }\end{array}$ & Scraping. & 1 hour \\
\hline $\begin{array}{l}\text { Getting powder and } \\
\text { loading holes. }\end{array}$ & $\begin{array}{l}\text { Lagging sets and } \\
\text { raising chute. }\end{array}$ & $\begin{array}{l}\text { Removing scraper and } \\
\text { tail block to safe } \\
\text { place. }\end{array}$ & 1 hour \\
\hline Blasting. & Blasting. & Blasting. & \\
\hline
\end{tabular}

of explosive to require two mucking shifts before another drilling shift could be started. Consequently, in mines which worked two shifts per day, each crew might drill only every other day.

\section{Ventilation, Temperature and Humidity}

Ventilation observations were made in some of the stopes, drifts, and shaft stations to determine the existing atmospheric conditions. In one mining field the air and rock temperatures were quite low, and the ore 
and rock were very wet; in another field, the air and rock temperatures were between $60^{\circ}$ and $70^{\circ} \mathrm{F}$. and part of the workings were comparatively dry; while, in the third area, air and rock temperatures were very high, and both the ore and rock were extremely dry. In the first two of the areas studied, the primary cause of air movement in the mines was natura] ventilation, although this was occasionally supplemented by air from compressed air lines, or from booster fans, supplying stopes and blind-end drifts. In most of the mines in these areas, there was no evidence of any systematic attempt to control the flow of air through the drifts and crosscuts. In the third area, the high temperature and the presence of mine gases, had made the use of systematic mechanical ventilation abso. lutely essential.

Natural ventilation depends upon the differential chimney effects of two shafts, or of a shaft and an adit having surface openings at different levels; upon the temperature difference between the mine air and the outside air; upon barometric pressure changes; and upon wind direction. The last three of these factors are subject to daily and seasonal variations, and, consequently, the ventilation determinations made at the time of the study are not necessarily representative of either extreme or average conditions in the mines. Natural ventilation is never depend able, and always should be supplemented by mechanical methods of ventilation, if all working faces are to be continually active. This is especially true in Utah mines, which are subject to inflows of rock-strata gases (see section on metal mine gases). Some dead-end headings and blind stopes were ventilated by small fans driven by either direct-connected alternating-current motors or compressed air motors. Galvanized iron pipe and flexible canvas tubing were used as ducts to carry the air from the fan to the working face. In other "naturally ventilated" mines the air exhaust from the compressed air drills was the only available method for emergency ventilation of a working place. In these mines, it was common practice for the miners to open the valves on the compressed air lines before blasting at the end of the shift. By allowing the compressor to run for an hour after the shift had left the mine, and starting it again an hour before the next shift entered the mine, it was possible to disseminate and dilute the blasting fumes and other mine gases. It was also observed that many miners used air from the high pressure lines to supplement natural ventilation while mucking ore and timbering.

Mechanical ventilation practice varies, but usually the foul air is drawn from the mine at one or more points by large fans capping ventilation shafts, and pure air flows into the mine through intake shafts located elsewhere. After reaching the mine, the air is bled off at various shaft stations and distributed to many points through the various drifts, crosscuts, and raises. It then flows upward or downward through the stopes, and then out through other drifts to the exhaust shaft. Air flow is controlled by the use of ventilation doors, airbridges, brattice walls and booster fans. In some mines, air is blown into the air-entries, and in other mines, a combination positive and negative pressure fan system is used. It is not the custom in metal mines to provide separate air-ways and haulageways, as is done in coal mines. Consequently, most air-ways also serve as haulageways, and dust generated in the air-entries by hauling 
may be carried through the working stopes, while dust generated in the stopes may be carried to other stopes and to haulageways which are used as return air-ways.

Frequent complaints of "bad air" in metal mines were usually found to be due to physical conditions instead of the presence of noxious gases.

Proper distribution of air to where it was needed was uncommon in most mines, and many working faces did not have sufficient air movement to be detected even by close observation of the deflection of a match flame.

It has been shown (16) that low air velocities, high temperature, high humidity, and the vitiation of air by increase of carbon dioxide and decrease of oxygen have an influence on the comfort and presumably on the health of underground workers.

No specific optimum values for the air velocity, or volume of fresh air, required in a working place can be given, since both depend upon the type of stope, or heading, and the rate of contamination by dust or gases. Moreover, the determination of the actual volume of air supplied to a working place is extremely difficult because of the irregularities of the stopes and the difficulty in distinguishing between useful and turbulent air currents. Section 39 of the General Safety Orders Covering Underground Metal Mining Operations made effective August 1, 1931, by the Industrial Commission of Utah states:

"The operator of every mine, whether operated by shaft, slope, tunnel, adit, level, or drift, shall provide and maintain for every such mine a good and sufficient amount of ventilation for such men and animals as may be employed therein, and shall cause an adequate quantity of pure air to circulate through and into all the shafts, winzes, levels, and all working places in such mine, and, except in case of an emergency, no man shall be allowed to work in an atmosphere injurious to health."

It will be noted that no specific recommendations are made as to either the volume or velocity of air required. McElroy (17) has reported:

"If air conditions are normal and general blasting is confined to the end of each shift, $50 \mathrm{c}$. f. $\mathrm{m}$. per man ordinarily would be satisfactory for operating concentrated working places two shifts with a long interval between shifts, but if the working places are scattered widely requirements would approach $100 \mathrm{c}$. f. m... Extensive timbering, moderate production of gas, such as usually accompanies work in sulphide ore, or moderately high temperatures would individually increase requirements 50 to $100 \mathrm{c}$. f. m. per man. Except under extreme high-temperature conditions, the requirements will seldom exceed 500 c. f. m. per man, but under such conditions as much as 1000 c. f. m. per man might be required for satisfactory results."

The volume of air entering a mine affords no information concerning the amount of air furnished at any particular working place. This is especially true in those workplaces at a great distance from the main air courses in mines depending upon natural ventilation. Two mines, in the same area, have mechanical ventilation, supplied 78,000 and 70,000 c. f. m. of air, respectively, to their workings, while a naturally ventilated mine in another area, employing approximately the same number of men per shift, had an inflow of approximately $20,000 \mathrm{c}$. f. m. It is a well-established 
fact that mechanically ventilated mines usually supply more air per worker than those depending upon natural ventilation, and are not subject such severe seasonal fluctuations in ventilation. The observations of actual ventilation conditions in typical working places are summarized in Table 29. This table shows that dry-bulb air temperatures ranged from $43^{\circ}$ to $99^{\circ} \mathrm{F}$. Considerable seasonal variation in mines having natural ventila tion can be expected, but the records of a company operating a mechanically ventilated mine having an air temperature of $84^{\circ} \mathrm{F}$. at the bottom of the main shaft at the time of the study, when the outside air temper. ature was $84^{\circ} \mathrm{F}$., only dropped to $79^{\circ} \mathrm{F}$. when the outside temperature dropped to $28^{\circ} \mathrm{F}$. Relative humidities were constantly high, ranging from 40 to 96 percent and averaging 82 percent. Lower relative humidities can be expected in winter, especially in mines having mechanical ventilation.

\section{TABLE 29-Ventilation Observations in Utah Metal Mines.}

\begin{tabular}{l|c|c|c|c}
\hline \multicolumn{1}{c|}{$\begin{array}{c}\text { Mining } \\
\text { area }\end{array}$} & $\begin{array}{c}\text { Dry bulb } \\
\text { temperature } \\
\left({ }^{\circ} \mathrm{F}\right)\end{array}$ & $\begin{array}{c}\text { Relative } \\
\text { humidity } \\
\text { (percent) }\end{array}$ & $\begin{array}{c}\text { Air } \\
\text { velocity } \\
(\mathrm{ft} / \mathrm{min})\end{array}$ & $\begin{array}{c}\text { Effective } \\
\text { temperature } \\
\left({ }^{\circ} \mathrm{F}\right)\end{array}$ \\
\hline Area I & & & & \\
Maximum....... & 46 & 97 & 190 & 46 \\
$\quad$ Minimum....... & 43 & 66 & 20 & 37 \\
Area II & 71 & 99 & 105 & 71 \\
Maximum....... & 60 & 86 & 20 & 56 \\
Minimum........ & & & & \\
Area III & 99 & 82 & 750 & 94 \\
Maximum........ & 78 & 40 & 25 & 65 \\
Minimum......... & & & & \\
\hline
\end{tabular}

A wide range of air velocities was disclosed in studying the air movement of typical work-places. These velocity studies indicated many readings in the order of 10 to 20 feet per minute (practically still air) and several as high as 800 feet per minute. This variation depends on such factors as the type of ventilation, location and type of stope, and the necessity of conducting mining operations in "dead end headings" while driving development tunnels, until airways have been created by connection with other passages. More than 50 percent of the air velocity observations were found to be less than 50 feet per minute, and the average in some mines was considerably lower than this. At the present time, there are no standards for the degree of air movement necessary in mine work-places for the removal of noxious gases and dusts, nor is it possible to make specific recommendations in a general study of this type. As has been previously stated, the amount of ventilation necessary will vary under different conditions, and should be determined by a competent ventilation engineer for each working place in each mine. 
Effective temperatures ${ }^{1}$ both above and below the comfort range of men performing hard work were observed (18).

Low effective temperatures can be compensated for by the use of additional clothing. High effective temperature can be decreased by reducing the relative humidity of the air or increasing its velocity. Usually the last procedure is the most practicable.

In instances where it was impossible to reduce the effective temperatures to comfort limits, it was noted that men were allowed frequent rest periods in cooler or better ventilated locations, and that salt tablets were used to prevent excessive reduction in the water-salt balance of the body with the resulting heat cramps.

Where wide differences exist between inside and outside temperatures, and men are removed rapidly through shafts or adits, the rapid temperature change may have a severe effect on the worker. When the shaft or haulageway is also used as a ventilation way, and the direction of travel is opposed to the normal direction of air motion, the worker may be severely chilled in transit, even though protected by heavy clothing. In such a case, this becomes another reason for the use of enclosed man cars, although from the safety viewpoint they are always preferable.

At all mines studied, modern change houses with showers and clothing drying racks or "dryers" were provided.

\section{Illumination}

Adequate industrial illumination is advisable not only as a means of lessening eystrain and saving sight, but also because it increases working efficiency and decreases the accident rates from such causes as falls, moving machinery, etc. The lighting of mines presents special problems. Permanent installations of incandescent lights at all shaft stations and in all hoisting rooms are required by Utah State law. The lighting at the working surfaces is by either carbide or electric lamps worn on the cap. The average intensity of illumination at shaft stations was approximately 10 foot candles, with a variation from five to 30 foot candles. The light from carbide lamps gave an illumination varying from less than one to a maximum of about 2.5 foot candles at a distance of three feet, while electric cap lamps gave an illumination of from 7 to 14 foot candles at the same distance. These variations were caused by differences in reflecting power of different ores, and by the condition of the lamps. Owings (19) has reported that the illumination on the working surface in coal mines is low, a few tenths of a foot-candle. However, in coal mines, the difficulties of seeing are further increased by the low reflecting power of the black coal surface, probably less than 5 percent. In England, miners' nystagmus is prevalent among coal miners and is generally attributed to the poor conditions of illumination under which they work. This disorder is not common in the United States, and no typical cases were found among Utah coal miners, all of whom used electric cap lamps, and no cases of miners' nystagmus were reported in Utah metal miners, even when they had been using carbide lamps for many years.

Effective temperature may be defined as that temperature of saturated air which, moving at a velocity of 15 to 25 feet per minute would produce the same sensation of warmth or cold as that produced by the combination of temperature, humidity, and air motion under observation. 
There are no standards for the illumination of working faces in mines, although every possible means should be used to keep above the minimum level of three foot candles recommended in the Code of Lighting of Factories, Mills and Work Places (20) drawn up by the Illuminating Engineering Society and approved by the American Standards Association.

There is a feeling that better illumination and less eyestrain results from the use of electric cap lamps. It is also obvious that their use decreases the fire hazard in timbered mines. However, it has been neces. sary for the Utah State Mine inspector to restrict their use to mines hav. ing a fan system of general ventilation. This restriction is necessary since atmospheres deficient in oxygen may occur in most Utah mines, and, if carbon monoxide is not present, a man may retain consciousness for several minutes in an atmosphere containing insufficient oxygen to sup. port an acetylene flame. The failure of a flame cap lamp may serve as sufficient warning to enable the miner to return to a safe place, while a miner using an electric lamp might continue into bad air until he lost consciousness. However, this is not a condemnation of the electric cap lamp, but it is an indication that mechanical ventilation should be required in these mines. At best, the acetylene cap lamp is a poor index of oxygen deficiency since it requires only slightly more oxygen to remain ignited than a man needs to retain consciousness. Moreover, the acetylene cap lamp will not show the presence of carbon monoxide gas. In naturally ventilated mines, where oxygen deficiencies are known to exist, the combined use of electric cap lamps and mine safety lamps, as used in coal mines, should be considered.

\section{Atmospheric Dust}

As previously indicated, the principal factors to be considered in evaluating the hazard of dust inhalation are the nature and concentration of the dust in question, and the duration of exposure. The duration of exposure was determined from a comprehensive occupational history of each worker. It is now fairly well established that nearly all atmospheric industrial dust is of a size capable of gaining ready access to the lung tissue. However, a limited number of dust particles, collected from the air of metal mines, were measured to show that these dusts were present in the expected size ranges. The following section of the report on working environment presents the results of a study of the nature, size, and concentration of the dust associated with the various occupations involved in the mining of lead-zinc-copper-silver ores.

\section{Siliceous Content of Dust}

Sixteen samples of dust settled out at the breathing level in different working places, or collected in atmospheric dust collectors, were obtained for the purpose of determining the silica content of the dust to which metal mine workers are exposed. These samples were supplemented by eight samples collected in concentrating plants and sampling mills of smelters processing Utah ores. Table 30 presents a summary of the sources of the samples obtained and of the results of the analyses.

Total silica values were determined by chemical analysis while the percentage of free silica (quartz) in each sample was determined by 
TABLE 30-Silica Content of Utah Metal Mine Dusts.

\begin{tabular}{|c|c|c|c|c|c|c|c|}
\hline \multirow{2}{*}{ Location } & \multirow{2}{*}{$\begin{array}{c}\text { Number } \\
\text { of } \\
\text { samples }\end{array}$} & \multicolumn{3}{|c|}{ Total Silica } & \multicolumn{3}{|c|}{ Free Silica } \\
\hline & & Maximum & Minimum & Average & Maximum & Minimum & Average \\
\hline ore milling processes* & 12 & 62.1 & 9.5 & 31.8 & 43.0 & 1.0 & 18.7 \\
\hline Mine airways... & 4 & 58.7 & 23.9 & 43.6 & 37.0 & 8.6 & 22.6 \\
\hline Mine development... & 4 & 99 & 24.1 & 57.9 & 99.0 & 2.0 & 41.3 \\
\hline $\begin{array}{l}\text { Stoping (Ore } \\
\text { breaking) }\end{array}$ & 4 & 75.7 & 32.3 & 54.4 & $45: 0$ & 1.0 & 23.4 \\
\hline
\end{tabular}

Eight of these samples were collected in ore sampling mills, bucking rooms, and crushing mills operated in conjunction with concentration mills or smelters.

petrographic analysis. The methods of analysis are discussed in the section on laboratory procedures.

It may be seen from Table 30 that the free silica content of the dusts to which the workers are exposed may vary from less than 1 percent to more than 99 percent. This is to be expected when we remember that the ore deposits may lie in quartzite, in siliceous limestone, or in carbonate limestone, and may vary from narrow veins of ore to large bedded deposits. In general, the more massive the ore deposit, the lower the free silica content of the dust will be. Since the same crew of miners may drive a development drift in quartzite, a development raise through ore and limestone, and then work out a stope in the ore deposit between the quartzite and limestone, it is impossible to attribute a definite average free silica content to the dust to which any individual worker is exposed during his working life.

It must also be remembered that the average silica content of the atmospheric dusts will vary in different mines.

The settled dust samples collected in ore milling processes showed a lower average free silica content (18.7 percent) than those collected in stopes (23.4 percent), while the samples collected in drift and crosscut headings showed the highest average content (41.3 percent). Drifts and crosscuts are frequently driven through the native rock while stopes always contain a high portion of ore. The ore and waste rock are separated in the stope, whenever this is possible, and the rock is left underground for filling. Since the rock usually contains a higher percentage of quartz than does the ore, the quartz content of the dust generated tends to decrease as the ore concentration progresses.

On the basis of these data, which are substantiated by previously published analyses of ore and rock from these areas, it appears that the average underground worker is exposed to atmospheric dusts containing between 20 and 40 percent free silica, but it is also obvious that any specific worker may have been exposed to atmospheric dust containing either a higher or lower percentage of free silica.

\section{Size of Dust}

Particle-size determinations were made on four impinger samples representing the dust actually suspended in the atmosphere at the breathing level of the workers. The method of making these measurements 
has been dsecribed previously (21). The results of the measurements are summarized in Table 31 .

From Table 31 and Figure 24, in which the percentage of particles is shown by size groups, it may be seen that half the dust suspended in the different working places in the mines was less than one micron $^{1}$ in average diameter and 96 percent were less than four microns. ${ }^{2}$

The median ${ }^{3}$ particle size was 0.94 micron. It is apparent, therefore, that the dust particles are of a size capable of gaining access to the lungs.

\section{Dust Concentration of Siliceous Dusts}

In studying the exposure of miners and muckers, 139 dust samples were evaluated. The large number of samples for these two occupations seemed necessary for the following reasons: (a) Miners and muckers com. prised 45 percent of all workers in metal mines; (b) with the exception of two minor operations, they are exposed to the greatest amount of dust, as will be shown later; and (c) the different methods of mining and types of ore encountered in metal mines necessitated a large number of samples for the purpose of determining the average exposure in these occupations.

\section{Summary of Occupational Dust Exposures}

A summary of the results of the determinations of the dust exposure in each occupation is given in Table 32. It is evident from the data in this table that the underground occupations of chute tenders, miners, muckers, timbermen, slushermen, and the surface occupations of bucker and railroad carloader are the most important from the viewpoint of dust exposure. Moreover, those underground maintenance and service occupations which require work in active stopes may also result in comparatively high exposures. The sources of dust exposure and the methods for their control are discussed below:

\section{Occurence of Dust}

This section of the report considers the occurrence of dust in terms of number of particles per cubic foot of air, which is the customary way of evaluating the hazard from a pneumoconiosis-producing dust. The metal content of these dusts is considered in succeeding sections. However, it appears that if the dust concentrations in all working places are kept below the suggested minimum concentration which will produce silicosis, the hazard from dusts of toxic metals will also be eliminated; atmospheric gas contamination will be reduced, and the general quality of the mine air will be improved.

The sources of dust in metal mines are: (a) Sources of generation, such as drilling, blasting, and ore breaking, mucking, dumping, or trans. ferring, which are definable as to time and place of occurrence, and (b) the return of settled dust to the air by timbering, tramming, maintenance, and stray air currents. The sources contributing to the various occupational exposures were as follows:

11 micron $=0.001$ millimeters $=0.00004$ inches.

2 The impinger sampling method, the light-field counting technique, and the method used for determining particle size give accurate results for the atmospheric dust particles having an average diameter greater than 0.5 micron. Below this limit the sampling efficiency of the impinger decreases rapidly with decreasing particle size, and the microscopic system used renders visible only a small portion of the smaller particles actually collected.

3 The median is the middle term in an array, and may be strictly defined as a point on the abscissal scale of a frequency distribution with 50 percent of the items on either side. 
TABLE 31-Summary of Size-Frequency Distribution of Dust Suspended in the Air of Utah Metal Mines.

\begin{tabular}{|c|c|c|c|c|c|c|c|c|c|c|c|c|c|c|}
\hline \multirow[b]{2}{*}{$\begin{array}{l}\text { Description } \\
\text { of sample }\end{array}$} & \multirow{2}{*}{$\left|\begin{array}{c}\text { Number } \\
\text { of } \\
\text { particles } \\
\text { measured }\end{array}\right|$} & \multirow{2}{*}{$\begin{array}{c}\text { Median } \\
\text { size } \\
\text { (microns) }\end{array}$} & \multicolumn{12}{|c|}{ Percentage frequency of each particle-size group (in microns) } \\
\hline & & & $\begin{array}{c}0 \\
\text { to } \\
0.49\end{array}$ & $\begin{array}{c}0.50 \\
\text { to } \\
0.99\end{array}$ & $\begin{array}{c}1.00 \\
\text { to } \\
1.49 \\
\end{array}$ & $\begin{array}{c}1.50 \\
\text { to } \\
1.99 \\
\end{array}$ & $\begin{array}{c}2.00 \\
\text { to } \\
2.49 \\
\end{array}$ & $\begin{array}{l}2.50 \\
\text { to } \\
2.99 \\
\end{array}$ & $\begin{array}{c}3.00 \\
\text { to } \\
3.49 \\
\end{array}$ & $\begin{array}{c}3.50 \\
\text { to } \\
3.99 \\
\end{array}$ & $\begin{array}{c}4.00 \\
\text { to } \\
4.49 \\
\end{array}$ & $\begin{array}{c}4.50 \\
\text { to } \\
4.99 \\
\end{array}$ & $\begin{array}{l}5.00 \\
\text { or } \\
\text { more }\end{array}$ & Total \\
\hline $\begin{array}{l}\text { Development work-head- } \\
\text { ing drift through rock... }\end{array}$ & 200 & 0.97 & 8.5 & 44.5 & 25.0 & 8.5 & 3.5 & 2.5 & 1.5 & 1.0 & 0 & 1.0 & 4.0 & 100.0 \\
\hline $\begin{array}{l}\text { Skip dumping pocket at } \\
\text { shaft collar }\end{array}$ & 200 & 1.10 & 12.0 & 31.5 & 29.5 & 10.0 & 7.5 & 4.5 & 3.5 & 0.5 & 0 & 0 & 1.0 & 100.0 \\
\hline Mucking in stope... & 200 & 0.96 & 10.5 & 43.0 & 22.5 & 6.0 & 4.0 & 1.5 & 2.0 & 3.0 & 3.0 & 1.0 & 3.5 & 100.0 \\
\hline Haulageway ..... & 200 & 0.80 & 19.5 & 51.5 & 16.5 & 4.0 & 4.0 & 2.0 & 0 & 1.0 & 0.5 & 0 & 1.0 & 100.0 \\
\hline TOTAL .. & 800 & ....... & ....... & ....... & ....... & ....... & ....... & ....... & ....... & ....... & ....... & ....... & ....... & ......... \\
\hline AVERAGE .................... & ....... & 0.94 & 12.6 & 42.7 & 23.4 & 7.3 & 4.7 & 2.4 & 1.7 & 1.4 & 0.9 & 0.5 & 2.4 & 100.0 \\
\hline
\end{tabular}




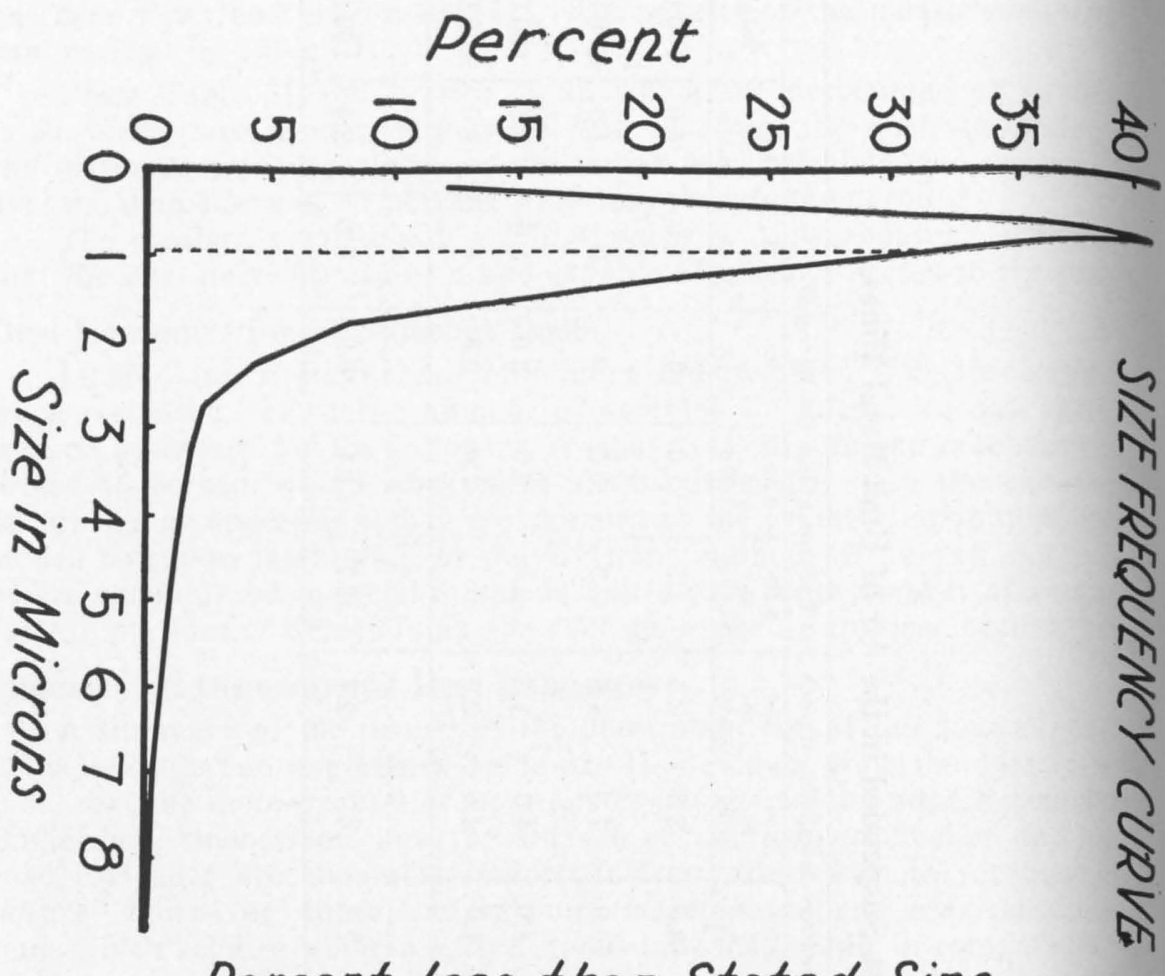

Percent less than Stated Size

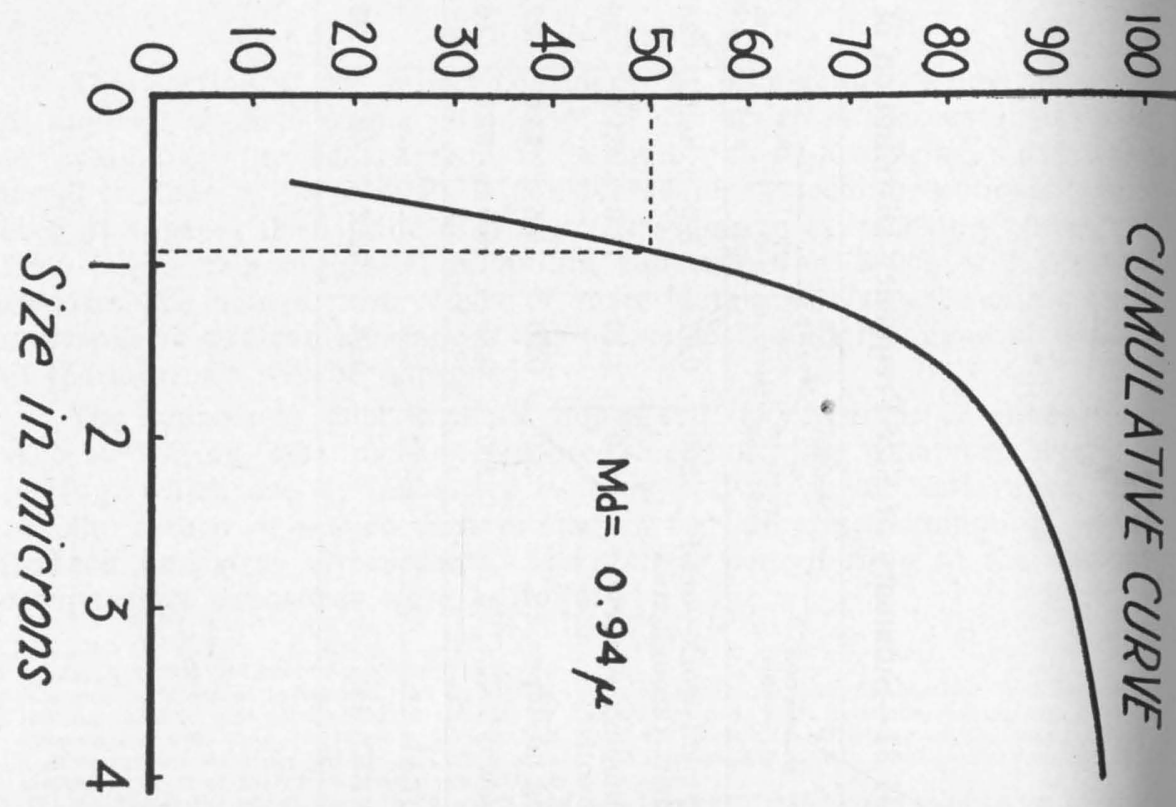

FIGURE 24-Particle-size distribution in metal mine dusts. 


\section{TABLE 32-Summary of Occupational Dust Exposure in Three Repre- sentative Utah Metal Mining Operations.}

\begin{tabular}{|c|c|c|c|}
\hline Section and Occupation & $\begin{array}{l}\text { Number } \\
\text { of men } \\
\text { employed }\end{array}$ & $\begin{array}{l}\text { Number of } \\
\text { samples } \\
\text { taken }\end{array}$ & $\begin{array}{c}\text { Number of } \\
\text { millions of } \\
\text { dust particles } \\
\text { per cubic } \\
\text { foot of air } \\
\text { (weighted } \\
\text { average) }\end{array}$ \\
\hline $\begin{array}{l}\text { Office and General Supervision: } \\
\text { Superintendent, assistant superintendent, gen- } \\
\text { eral foreman, manager, engineer, and geo- } \\
\text { logist }\end{array}$ & $\begin{array}{l}19 \\
12\end{array}$ & $\begin{array}{r}20^{3} \\
9^{3}\end{array}$ & $\begin{array}{l}4.0 \\
2.5\end{array}$ \\
\hline $\begin{array}{l}\text { Face Operations, Underground: } \\
\text { Foreman, mine boss, shift boss, level boss....... }\end{array}$ & \multirow{3}{*}{$\left.\begin{array}{r}21 \\
173 \\
203 \\
2\end{array}\right\}$} & \multirow[t]{2}{*}{17} & \multirow[t]{2}{*}{10.5} \\
\hline Miners, drillers, machine men........................ & & & \\
\hline $\begin{array}{l}\text { Muckers, handminers, hand trammers........... } \\
\text { Samplers }\end{array}$ & & $\begin{array}{r}139 \\
1\end{array}$ & $\begin{array}{l}23.1 \\
10.5\end{array}$ \\
\hline Transportation, Underground: & \multirow{6}{*}{$\begin{array}{r}12 \\
34 \\
18 \\
19 \\
6 \\
6\end{array}$} & \multirow{6}{*}{$\begin{array}{c}3 \\
11 \\
2 \\
7 \\
62 \\
4\end{array}$} & \multirow{6}{*}{$\begin{array}{r}7.7 \\
10.5 \\
7.5 \\
18.2 \\
3.8 \\
3.8\end{array}$} \\
\hline $\begin{array}{l}\text { Mule skinner, horse tender, trammers } \\
\text { Motorman, motorman's helper }\end{array}$ & & & \\
\hline $\begin{array}{l}\text { Motorman, motorman's helper } \\
\text { Hoistman, winze-hoistman }\end{array}$ & & & \\
\hline $\begin{array}{l}\text { Hoistman, winze-hoistman } \\
\text { Hoistman, slusherman }\end{array}$ & & & \\
\hline $\begin{array}{l}\text { Hoistman, slusherman } \\
\text { Station tender, carman }\end{array}$ & & & \\
\hline Cager, cage rider.................. & & & \\
\hline Nipper, tool nipper, material man and & \multirow{2}{*}{$\begin{array}{r}14 \\
2\end{array}$} & \multirow{3}{*}{$\begin{array}{c}171 \\
4\end{array}$} & \multirow{2}{*}{$\begin{array}{l}15.2 \\
37.5\end{array}$} \\
\hline $\begin{array}{l}\text { Bin tender, carloader, chute gate tenders........... } \\
\text { Maintenance and Construction. Underground: }\end{array}$ & & & \\
\hline $\begin{array}{l}\text { Maintenance and Construction, Underground: } \\
\text { Timberman, tunnel maintenance man and }\end{array}$ & \multirow[b]{2}{*}{$\begin{array}{r}106 \\
18\end{array}$} & & \multirow[b]{2}{*}{$\begin{array}{l}18.9 \\
15.2\end{array}$} \\
\hline $\begin{array}{l}\text { shaftman } \\
\text { All others }\end{array}$ & & \multirow{2}{*}{$\begin{array}{l}25 \\
171\end{array}$} & \\
\hline $\begin{array}{l}\text { Transportation, Surface: } \\
\text { Hoistman }\end{array}$ & \multirow{5}{*}{$\begin{array}{r}7 \\
15 \\
13 \\
4\end{array}$} & & \multirow[b]{2}{*}{3.8} \\
\hline 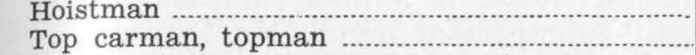 & & 1 & \\
\hline 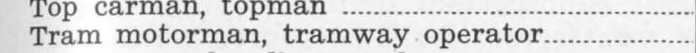 & & 4 & 9.4 \\
\hline 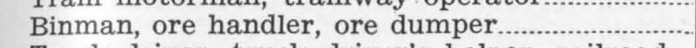 & & $\begin{array}{l}3 \\
8\end{array}$ & $\begin{array}{r}6.0 \\
17.1\end{array}$ \\
\hline $\begin{array}{l}\text { Truck driver, truck driver's helper, railroad } \\
\text { car loaders }\end{array}$ & & \multirow[t]{2}{*}{$9^{3}$} & \multirow{2}{*}{2.5} \\
\hline Maintenance and Construction, Surface: & \multirow{3}{*}{$\begin{array}{l}6 \\
3\end{array}$} & & \\
\hline $\begin{array}{l}\text { Compressor man } \\
\text { Painter }\end{array}$ & & $\begin{array}{l}1 \\
93\end{array}$ & $\begin{array}{l}3.8 \\
2.5\end{array}$ \\
\hline Carpenter, timber framer, saw mill & & \multirow{3}{*}{$\begin{array}{l}1 \\
9^{3} \\
8\end{array}$} & \multirow{3}{*}{$\begin{array}{l}5.5 \\
2.5 \\
9.8\end{array}$} \\
\hline Fireman, stationary engineers. & \multirow{2}{*}{$\begin{array}{r}14 \\
3 \\
65\end{array}$} & & \\
\hline All others & & & \\
\hline Milling Operations: & \multirow{5}{*}{$\begin{array}{l}\cdots . . \\
\cdots . . \\
\cdots . .\end{array}$} & \multirow[b]{2}{*}{5} & \multirow[b]{2}{*}{4.5} \\
\hline Concentrating mill foreman & & & \\
\hline $\begin{array}{l}\text { Dry crusher operator. } \\
\text { Flotation mill operator. }\end{array}$ & & 5 & 14.3 \\
\hline Flotation mill operator & & 5 & 4.5 \\
\hline $\begin{array}{l}\text { Concentrating mill repairman.... } \\
\text { Assaying: }\end{array}$ & & 5 & $14 . \hat{~}$ \\
\hline $\begin{array}{l}\text { Assaying: } \\
\text { Chemist, assayer }\end{array}$ & \multirow{3}{*}{$\begin{array}{l}7 \\
4\end{array}$} & \multirow{3}{*}{$\begin{array}{l}5^{4} \\
4\end{array}$} & \\
\hline Bucker & & & $\begin{array}{r}5.8 \\
57.9\end{array}$ \\
\hline Miscellaneous: & & & \\
\hline Watchman, guard, janitor and warehouseman. & 8 & $9^{3}$ & 2.5 \\
\hline TOTAL & 830 & 6 & \\
\hline
\end{tabular}

1 Includes 5 Konimeter samples.

2 Includes 2 Konimeter samples.

${ }^{3}$ Includes 5 Konimeter samples.

4 Includes 3 impinger samples from smelter assay office.

5 All samples from concentrating plants included in smelter study.

Samples were frequently representative of more than one activity, hence no total is given in this column. 
Office and General Supervision-The exposures of workers in gen. eral supervisory and engineering capacities were received during the performance of their duties underground. An average exposure of $4.0 \mathrm{mil}$. lion particles per cubic foot was estimated for these occupations. Workers whose duties were mainly confined to of fice work had an average exposure of 2.5 million particles per cubic foot at the time of this study. This exposure is abnormally high-the average exposure of office workers usually being less than one million particles per cubic foot-but can be accounted for by the fact that this study was made during the dry sum. mer season and the office air was contaminated by road and yard dust as well as dust from ore bins.

Face Operations, Underground-Miners and muckers comprised the largest portion of this group, and were found to have an average exposure of 23.1 million particles per cubic foot. Most of the exposures of underground bosses and samplers were received during the time they were in active stopes and headings, but since a large portion of their time was spent in travel between different workings, their average exposure was only 10.5 million particles per cubic foot.

Wide variations were found between the amounts of dust created by different miners and muckers in performing their duties. These variations were due to several factors, including (a) differences in the ore and rock being worked, (b) differences in drilling and mucking practice, (c) the number of simultaneous operations being performed in a stope or heading, (d) the amount of fresh air being supplied to the working place, and (e) the quality of this air. These factors will be discussed in the section on control of the dust hazard.

Transportation, Underground-Bin or chute gate tenders had the highest average exposure in this section, 37.5 million particles per cubic foot, but this was a numerically unimportant occupational group. Any point where ore is dumped or transferred is a dust source which should be controlled.

The exposures of motormen and helpers were highest during loading under chutes or scraper loading stations. Another source contributing to their exposure was the frequent occurrence of drifts used both for tramming and returning vitiated air to upcast shafts. The exposure of mule skinners and horse trammers was slightly lower than that for motormen (7.7 and 10.5 million particles per cubic foot, respectively). Nippers and powdermen had an average exposure of 15.2 million particles per cubic foot, partly received in the stopes and partly while riding in empty mine cars.

Slushermen, or scraper loader operators might be classed as face operators. Their high average exposure (18.2 million particles per cubic foot) was due to their locations above ore dumps or bins at the foot of inclined stopes where dry ore was handled.

The exposures in the other occupations in this group were not significantly high.

Maintenance and Construction, Underground-Timbermen were found to have an average exposure of approximately 19 million particles per cubic foot. Timbermen are exposed to the dust generated during drilling and mucking, and also to previously settled dust thrown into the air while erecting and wedging timber. 
Most of the other occupations in this section were grouped together and given an average exposure based on the mean of all samples representing these maintenance operations.

Transportation, Surface-The only occupations in this section having significantly high exposures were topmen and binmen. The workers in both these occupations were engaged in handling ore, either dumping it from ore cars to bins or operating chutes from bins to railroad cars, or both.

Maintenance and Construction, Surface-While several of the occupations in this group had an average exposure of nearly 10 million particles per cubic foot, these were primarily shop exposures to dusts having a very low free silica content. The application of the average exposure for this group to individual cases must be made with extreme caution.

Milling Operations-The average exposures assigned to occupations in this group are based on the study of concentration mills operated in conjunction with smelters, since no concentrating mills were being operated at the mines studied.

Assaying-Workers in these occupations are subject to the exposures typical of a chemical laboratory, and also to considerable dust where ore samples are pulverized in dry grinders. Dust respirators were used in the bucking rooms studied, and both rooms were equipped with local exhaust systems. However, due to the high dust concentrations associated with these operations, it was obvious that the control systems were not efficient, so data on these systems have not been included in this report.

\section{Methods of Minimizing the Silica Dust Hazard}

The analysis of dust counts according to occupation suggests the lines along which attempts to minimize the dust hazard could be most effectively directed. These suggestions will be presented in the same order as was followed in the discussion of dust counts according to occupation, but will be given only for those occupations having significant dust exposures, or which are primary causes of air dustiness.

\section{Face Operations}

Previous studies by the U. S. Public Health Service (22) and the U. S. Bureau of Mines (23) have shown that drilling, mucking, and blasting are the most important primary sources of atmospheric dust contamination in mines. Utah metal mines are required to use hollow drill steel and wet methods in all drilling operations, and this practice has been in common use for at least 15 years. That this method of dust control has borne results is attested by the estimated average dust exposure of 23 million particles per cubic foot for miners and muckers. In a recent study of the health of pegmatite workers (24) it was shown that dry drilling caused an average dust concentration of 76 to 760 million particles per cubic foot, while wet drilling caused an average concentration of only 15.5 million particles per cubic foot. Blasting in Utah metal mines, was not a primary source of dust exposure when all blasting was done at the end of the shift, and from two to 16 hours elapsed before the next shift entered the workings. However, where stopes or headings were poorly ventilated, the fine dust generated or dispersed by blasting settled close to the face and was redispersed by mucking or timbering operations, unless it was thoroughly wetted down. One mine made a policy of washing down the walls and roof upon entering a heading, and thor- 
oughly soaking the muck pile with water before starting mucking whenever, thereafter, that the muck appeared dry. Another mine had been sprinkling their muck piles for about six months. While wet drilling and sprinkling will not eliminate the dust problem, they will definitel decrease it, and the proper use of wet methods supplemented by adequate ventilation should reduce dust concentrations to safe limits. However, even with proper control measures, occasions will occur where high dus concentrations will be unavoidable for short periods. In these cases, filter respirator of a type approved by the U. S. Bureau of Mines for use against silica and lead dust should be furnished to the worker, and used by him. Respirators were furnished for this purpose by some operators, but their use was of questionable value since the worker seldom had one with him when it was needed.

Recommendations for improving the ventilation in stopes and head. ings, if followed, should reduce the dustiness by dilution or by flushing the workings with air. Improved ventilation should be supplemented by better control of the dust at its source. The Bureau of Mines has shown that increasing the water flow through the drill steel of drills in common use in the United States will reduce dust concentrations during drilling, and should be at least one gallon per minute (25). They explain this as follows:

"In most pneumatic rock drills air passes through the drill steel with the water. Ordinarily some of the high-pressure air supplied to the drill for its operation escapes into the back end of the drill steel, even when the operating throttle is not in the blowing position, and travels up to the face of the hole being drilled. The amount of water escaping is affected by the water flow through the drill steel; as the water flow through the drill steel increases, the air flow decreases. Mining officials in South Africa concluded that such air leakage, although probably facilitating removal by the water of the cuttings from the hole, was responsible for entrapping fine dust and blowing it into the air during drilling (26). Consequently they have devoted much attention to designing drills that permit the minimum practical air leakage through the drill steel and have established regulations on the use of such drills. Canada is also doing much work along this line, and recent reports state that such drills are practical and produce about one-fourth the dust concentration of corresponding drills without the 'dustless-head' features (27)."

While it makes very little difference to the practical operator whether reduction in dust concentration is caused by increased water flow or by decreased air leakage, they will be interested in knowing that they can reduce dust concentrations, resulting from drilling, by increasing the water flow through the drill steel, either by increasing water pressure or by the use of water tubes of larger inside diameter.

Where water is scarce, and insufficient water is available for adequate dust control, the use of dust traps and local exhaust hoods should be permitted (28).

Transportation, Underground -- The high exposures of slusher operators and chute tenders were due to the handling of dry ore. These exposures can be controlled by thorough sprinkling of the ore, by location of chute tender's or slusher operator's stations on the fresh air side 
of the ore transfers, by the use of personal respiratory protective devices, or by a combination of these three methods. The exposures of motormen and mule skinners at transfer points can also be reduced by such measures. Their exposures should be further reduced by sprinkling both loaded and empty ore cars before transit, and by eliminating the dual use of drifts for haulage and return airways, as is done in coal mines.

Naintenance and Construction, Underground - It is probable that proper ventilation, and a more general application of wet control methods to processes other than drilling, will decrease the dust exposures in these occupations, but respirators should be used on dusty jobs until such exposures are reduced.

Surface Operations - Bucking rooms should be provided with both local exhaust ventilation and general ventilation. Chemical analyses producing toxic dusts and gases should be performed under hoods.

Top trammers, bin tenders and railroad carloaders should be provided with respirators unless their dust exposure can be decreased by use of water sprays or by mechanization of dumping and loading processes.

The methods of controlling dust in ore concentrating plants are discussed in the engineering section of the smelter study.

Summary - Table 33 summarizes the results obtained under controlled and uncontrolled working conditions. The controlled conditions were found in certain places in the mines studied. It is apparent that the dust hazard may be greatly lessened and in some instances adequately controlled, by the extension of methods already employed in the mines.

\section{TABLE 33-The Effect of Good and Poor Practice on the Dust Concen- trations to Which Metal Mine Workers are Exposed.}

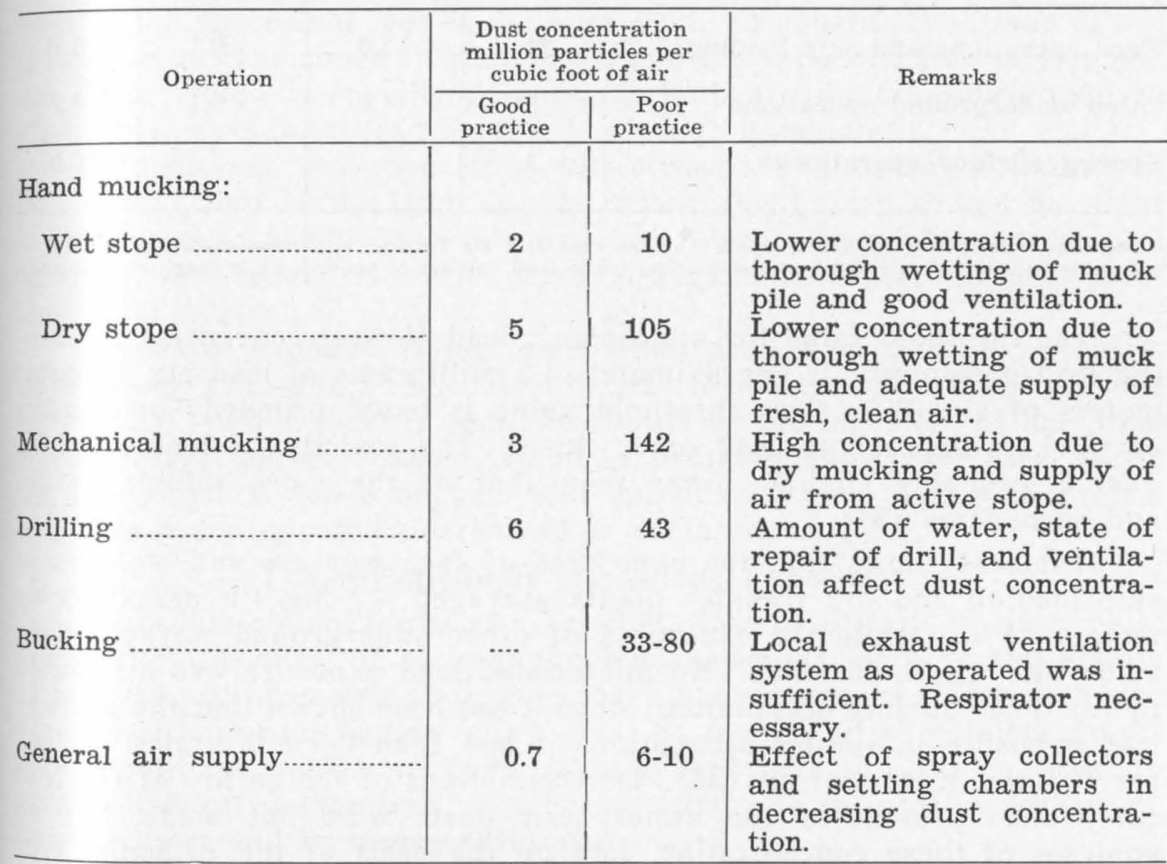




\section{Evaluation of the Lead Hazard}

Attention has previously been called to the occurrence of cases of occupational lead poisoning in the metal mines of Utah (29) as discussed in the following section. Since all of the mines studied were producers of lead ore, and most of the ore extracted contained some lead compounds, the need for a study of atmospheric lead concentrations was apparent. However, since both the time and funds avialable for the study were limited, and since an extensive engineering investigation was not justified by evidence of existing cases of lead poisoning, the study of lead expo. sures was limited to analyses of drinking water samples collected from the mine water supplies, and the collection and analysis of 30 impinger samples and four precipitator samples of atmospheric dust at representative locations in the different metal mines. All but one of these samples were collected underground. One sample was collected at an obviously hazard. ous location in a machine shop. Other potentially hazardous surface occupations were considered comparable to similar occupations in concentrating mills, bucking rooms and ore docks operated in conjunction with Utah smelters, and the data from the study of environmental conditions in smelters were applied to them.

The atmospheric lead concentrations, shown by analysis of these samples, are presented in Table 34 .

\section{TABLE 34-Atmospheric Lead Concentrations to Which Metal Mine Workers are Exposed.}

\begin{tabular}{|c|c|c|c|c|}
\hline \multirow{2}{*}{ Operation } & \multirow{2}{*}{$\begin{array}{c}\text { Number } \\
\text { of } \\
\text { Samples }\end{array}$} & \multicolumn{3}{|c|}{$\begin{array}{l}\text { Lead exposure, in milligrams of } \\
\text { lead per } 10 \text { cubic meters of air }\end{array}$} \\
\hline & & Maximum & Minimum & Mean \\
\hline Face operations and skip loading. & 24 & 13.5 & $<0.1$ & 3.7 \\
\hline Other underground operations . & 81 & 1.0 & $<0.1$ & 0.2 \\
\hline Special surface operations ${ }^{2} \ldots$ & 1 & .... & .... & 6.5 \\
\hline
\end{tabular}

1 Includes 4 samples collected in main haulageways and air returns with electrostatic precipitator. 2 Sample collected beside lathe operator using white lead cutting compound while machining threads,

The threshold value for atmospheric lead (lowest concentration causing lead poisoning), is approximately 1.5 milligrams of lead per 10 cubic meters of air (30). This threshold value is based primarily on studies of workers exposed to lead oxide dusts. The toxicity of lead sulphide dust is probably slightly lower than that of the more soluble oxides and carbonates (31).

Table 34 shows that the exposures of face workers and workers at skip loading and ore transfer points averaged $3.7 \mathrm{mg} \mathrm{Pb}$ per 10 cubic meters of air, while the exposures of other underground workers were below the threshold value. No appreciable lead exposure was attributed to less dusty surface occupations, since it has been shown that the average lead exposure in similar occupations is less than 0.3 milligrams of lead per 10 cubic meters of air (32). Determinations of the nature of the lead compounds present in the atmospheric dusts were not made, but an analyses of these concentration data on the basis of the principal type 
of lead ore being mined, presented in Table 35, shows that the average lead concentration was higher in carbonate and oxide stopes than in sulphide stopes.

\section{TABLE 35-Variations in Atmospheric Lead Concentration with Respect To Type of Ore Being Mined and Type of Operation.}

\begin{tabular}{|c|c|c|c|c|}
\hline \multirow{2}{*}{ Location } & \multirow{2}{*}{$\begin{array}{l}\text { Number } \\
\text { of } \\
\text { Samples }\end{array}$} & \multicolumn{3}{|c|}{$\begin{array}{l}\text { Lead concentrations in milligrams } \\
\text { per } 10 \text { cubic meters of air }\end{array}$} \\
\hline & & Maximum & Minimum & Average \\
\hline Sulphide ore & & & & \\
\hline $\begin{array}{l}\text { Face operations } \\
\text { Skip loading }\end{array}$ & $\begin{array}{r}16 \\
3\end{array}$ & $\begin{array}{l}9.3 \\
5.2\end{array}$ & $<0.1$ & 2.7 \\
\hline $\begin{array}{l}\text { oxide or carbonate ore } \\
\text { Face operations }\end{array}$ & 6 & 13.5 & $<0.1$ & 6.1 \\
\hline $\begin{array}{l}\text { General haulageways and shaft } \\
\text { stations } \\
\text { Air entries }\end{array}$ & 2 & $<0.1$ & $<0.1$ & $<0.1$ \\
\hline Air returns to surface... & 6 & 1.0 & $<0.1$ & 0.3 \\
\hline Bucking rooms ${ }^{1}$ & & 76.4 & 3.0 & 34.4 \\
\hline Ore crushing 1 & & 7.4 & 3.7 & 5.5 \\
\hline
\end{tabular}

1 From smelter study.

Wide variations in the percentage of lead in the ore are experienced, even within short distances in the same vein. In general, the grade of ore is lower than that mined in past years, and the ratio of oxide to sulphide ore being mined is steadily decreasing; both are factors which tend to diminish the potential lead hazard, but not to eliminate it.

Occupational lead poisoning will always be a potential hazard in lead mining, but in the Utah mines studied, this hazard should be slight if the siliceous dust problem is controlled. Wet drilling, adequate general and local ventilation, and strict personal hygiene, will keep the lead problem under control.

The water supplies of the mines studied all showed lead concentrations lower than the Public Health Service maximum tolerance of 0.1 p.p.m. (33). While there is some possibility of the ingestion of lead dust which has settled on lunches, common drinking cups, and water bags; the use of metal lunch buckets and individual water bags with protective caps has eliminated this hazard in some mines.

\section{Other Potentially Hazardous Exposures}

Atmospheric quartz dust as a possible cause of silicosis in Utah metal mines, the possibility of occupational lead poisoning, and the bad effects of adverse psychrometric conditions, have been discussed. There are also other environmental factors which must be considered as possible causes of occupational morbidity. These include exposures to noxious gases; to toxic metals other than lead; to skin irritants; and to infectious diseases. These factors will be discussed briefly. 


\section{Noxious Gases}

Several detailed studies have been made of the noxious gases occur. ring in Utah metal mines. These studies have shown that the presence of toxic concentrations of these gases are indications of abnormal conditions, and that injury resulting from exposure to these concentrations is usually acute and accidental. However, the possibility of chronic effects from continued exposures to low concentrations of these gases must be considered.

Harrington and Denny (34) report that methane has been found in a number of metal mines and explosions have been caused by this gas. Some metal mine atmospheres contain appreciable amounts of highly explosive hydrogen. Carbon dioxide flows into the mines in some regions, while in other regions high temperature gases containing a mixture of gases of sulphur $\left(\mathrm{SO}_{2}, \mathrm{H}_{2} \mathrm{~S}, \mathrm{SO}_{3}\right)$, carbon dioxide and nitrogen have been found at the working faces. The hydrogen sulphide concentration may be in lethal proportions at blasting time in some high sulphide metal mines. Carbon monoxide constitutes a decidedly dangerous hazard in connection with metal mine blasting, because of the heavy charges of dynamite employed, and the use of fuse which in burning gives off this gas. All of the above gases, as well as volatile compounds of some toxic metals, may be produced in mine fires, by the slow oxidation of the ores, or by other chemical reactions.

The results of gas analyses are shown in Table 36. These samples were supplemented by tests for carbon monoxide made with the carbon monoxide indicator (35), and for hydrogen sulphide with the lead acetate tube indicator (36). Significant concentrations of these gases were not found in the workings investigated, although the odor of hydrogensulphide was noticed on several occasions, and the presence of dangerous concentrations in some worked out sections and drainage tunnels was known.

The normal or average percentage compositon of the air is shown in the International Critical Tables to be 0.03 percent $\mathrm{CO}_{2}, 20.75$ percent $\mathrm{O}_{2}, 77.08$ percent $\mathrm{N}_{2}, 0.01$ percent $\mathrm{H}_{2}, 0.98$ percent Argon, and 1.2 percent water vapor, the last factor being extremely variable and causing proportional changes in the other constituents. The corresponding partial pressures, and percentages of dry volume at sea level, are shown in Table 36. It will be noted that the percentage composition of the gas samples collected did not vary appreciably from these normal values, but that, since all mine workings were between 5000 and 9000 feet above sea level, the partial pressures were considerably less. In the absence of appreciable amounts of toxic gases, the most serious hazard is oxygen deficiency, especially in the presence of excess carbon dioxide. It is known that acclimitization to the lowered partial pressure of oxygen encountered at high altitude is accompanied by a decrease in alveolar carbon dioxide tension, but even in persons who have become so adapted, a sudden decrease in atmospheric oxygen pressure, an increase in carbon dioxide pressure, or the presence of small amounts of carbon monoxide will cause a severe, or even fatal anoxemia.

Haldane (37) has shown that a man may advance for some distances into an atmosphere deficient in oxygen before he begins to be seriously affected; for the temporary increase in the breathing may at first prevent 
TABLE 36-Summary of Analyses of Mine Air Samples for Gaseous Composition.

\begin{tabular}{|c|c|c|c|c|c|c|c|c|c|}
\hline \multirow[b]{3}{*}{ Location } & \multirow{3}{*}{$\begin{array}{c}\text { Number } \\
\text { of } \\
\text { samples }\end{array}$} & \multirow{3}{*}{$\begin{array}{l}\text { Baro- } \\
\text { metric } \\
\text { pressure } \\
(\mathrm{mm} \mathrm{Hg})\end{array}$} & \multicolumn{7}{|c|}{ Results of gas analyses 1} \\
\hline & & & \multicolumn{4}{|c|}{ Partial pressures of component gases } & \multicolumn{3}{|c|}{ Percent total dry volume } \\
\hline & & & $\begin{array}{c}\text { Carbon } \\
\text { dioxide } \\
(\mathrm{mm} \mathrm{Hg})\end{array}$ & $\begin{array}{l}\text { Oxygen } \\
\text { (mm Hg) }\end{array}$ & $\begin{array}{l}\text { Nitrogen2 } \\
\text { (mm Hg) }\end{array}$ & $\begin{array}{c}\text { Water } \\
\text { vapor } \\
(\mathrm{mm} \mathrm{Hg})\end{array}$ & $\begin{array}{l}\text { Carbon } \\
\text { dioxide } \\
\text { Percent }\end{array}$ & $\begin{array}{l}\text { Oxygen } \\
\text { Percent }\end{array}$ & $\begin{array}{l}\text { Nitrogen } \\
\text { Percent } 2\end{array}$ \\
\hline Normal air at sea level3 & \multirow{5}{*}{7} & $(760)$ & $(0.2)$ & (156.7) & $(594.0)$ & $(9.1)$ & $(0.03)$ & $(20.93)$ & $(79.04)$ \\
\hline $\begin{array}{l}\text { A-Results tabulated on an } \\
\text { operational basis irrespective } \\
\text { of mining area } \\
\text { Development work }\end{array}$ & & (1,00) & & & & & & & \\
\hline Average & & 617 & 1.7 & 122.7 & $47 \% .5$ & 15.1 & 0.28 & 20.36 & 79.36 \\
\hline Maximum & & 648 & 5.7 & 128.8 & 500.0 & 28.0 & 0.92 & 20.83 & 80.12 \\
\hline Minimum & & 555 & 0.3 & $\mathbf{1 1 4 . 7}$ & 433.8 & 4.9 & 0.05 & 18.96 & 79.02 \\
\hline Stoping & \multirow[t]{4}{*}{8} & & & & & & & & \\
\hline 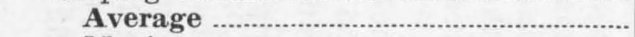 & & 611 & 3.3 & 119.3 & 475.5 & 12.9 & 0.57 & 19.94 & '79.49 \\
\hline 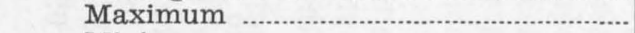 & & 652 & 12.3 & 133.5 & 510.8 & 29.3 & 2.12 & 20.75 & 80.01 \\
\hline Minimum & & 576 & 0.4 & 103.2 & 452.7 & 7.4 & 0.06 & 19.38 & 79.15 \\
\hline Haulageways ............. & \multirow[t]{4}{*}{5} & & & & & & & & \\
\hline Average & & 632 & 1.2 & $12 \% .1$ & 488.6 & 15.2 & 0.20 & 20.62 & 79.18 \\
\hline 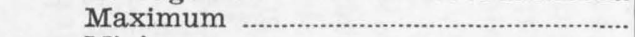 & & 649 & 3.4 & 132.0 & 504.0 & 21.8 & 0.59 & 20.80 & 79.31 \\
\hline Minimum & & 578 & 0.5 & 116.1 & 458.4 & 7.4 & 0.11 & 20.10 & 79.12 \\
\hline Abandoned dead-end raise & \multirow{3}{*}{1} & \multirow{3}{*}{633} & \multirow{3}{*}{4.2} & \multirow{3}{*}{105.9} & \multirow{3}{*}{506.0} & \multirow{3}{*}{16.5} & \multirow{3}{*}{0.68} & \multirow{3}{*}{17.17} & \multirow{3}{*}{82.15} \\
\hline near junction with drift ......... & & & & & & & & & \\
\hline $\begin{array}{l}\text { B-Results tabulated on basis } \\
\text { of mining area irrespective } \\
\text { of operation }\end{array}$ & & & & & & & & & \\
\hline Area 1 -Average & \multirow[t]{3}{*}{8} & 585 & 3.3 & 115.9 & 459.3 & 6.9 & 0.58 & $\mathbf{2 0 . 0 5}$ & 79.37 \\
\hline Maximum & & 652 & 12.3 & 113.5 & 510.8 & 7.4 & 2.12 & 20.83 & 80.01 \\
\hline Minimum & & 555 & 0.4 & 103.2 & 433.8 & 4.9 & 0.06 & 17.87 & 79.02 \\
\hline Area 2 -Average & \multirow[t]{3}{*}{4} & 627 & 4.1 & 116.0 & 492.3 & 15.0 & 0.67 & 18.92 & 80.41 \\
\hline Maximum & & 633 & 5.7 & 120.8 & 506.0 & 16.5 & 0.92 & 19.86 & 82.15 \\
\hline Minimum & & 621 & 3.1 & 105.9 & 483.3 & 12.4 & 0.51 & 17.17 & 79.58 \\
\hline Area 3-Average & \multirow[t]{3}{*}{9} & 645 & 0.6 & 129.2 & 494.8 & 20.7 & 0.10 & 20.76 & 79.21 \\
\hline Maximum & & 649 & 0.9 & 132.0 & 504.0 & 29.3 & 0.15 & 20.84 & 79.38 \\
\hline 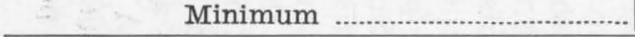 & & 637 & 0.3 & 127.2 & 489.9 & 11.9 & 0.05 & 20.57 & 79.11 \\
\hline
\end{tabular}

1 Methane, carbon monoxide, and hydrogen reported absent in all samples.

3 International Critical Tables. 
an appreciable fall in the alveolar oxygen pressure. When the breathing begins to quiet down again the effects of the atmosphere will develop fully and it may then be too late to turn.

Rosenau (38) states that the limit at which life may be sustained is about 26,000 feet (barometric pressure of the air is $251 \mathrm{~mm}$ and partial pressure of oxygen $52 \mathrm{~mm}$, equivalent to 6.8 percent of the oxygen at sea level), but that dyspnea is common above 12,000 feet, and as the altitude increases, headache, muscular weakness, apathy, and psychic disorders occur. Twelve thousand feet altitude is equivalent to a normal barometric pressure of approximately $485 \mathrm{~mm}$, and a partial oxygen pressure of $102 \mathrm{~mm}$. It is the partial pressure which exerts physiological effects, and it will be noted that the pressure of oxygen in several of these samples had been reduced to nearly dangerous levels.

The U. S. Bureau of Mines (39) has reported the presence of rock. strata gases in the East Tintic mining district and have stated that fatal. ities from such rock gases have occurred in the Park City district and elsewhere (34). The present study confirmed these reports and showed that these gases, presumably formed by the absorption of oxygen by sulphide ores, or its conversion to carbon dioxide by oxidizing ore or decomposing timber, were present in all mines studied, although seldom in serious amounts. In the Tintic district this absence of rock strata gases in large quantities is partly due to the use of mechanical ventilation, and partly due to the fact that this study was made in July, August, and September when sudden barometric changes are unusual.

McElroy states (39):

"A study of individual inflows in the mines affected shows that the time and amount of gas inflows is determined by variations of barometric pressure and that the inflows are caused by rapid and extreme decreases in pressure. Since such decreases are quite prevalent from November to April, and quite rare from May to September, gas inflows are also quite frequent during the winter months and happen rarely or not at all during the summer months."

Gases have been reported that contained more than 60 percent carbon dioxide, whereas other gases were almost pure nitrogen and so hot that they accumulated in raises. It is expected that air containing a high percentage of carbon dioxide will flow to the lowest level of a mine. It is the accepted theory that these heavy gases settled down through the porous and shattered quartzite and rest, presumably, on water at an unknown depth. A decrease in the barometric pressure causes an increase in volume of this large body of gas contained in the quartzite and as the body is confined on the sides and bottom, the increase in volume tends to raise the level of the gas.

Since field observations have shown heavy inflows only from shattered and fissured zones, it is concluded that the rate of penetration of gas into the porous quartzite is so much slower than the rate of increase in volume that the excess is pushed up through shattered zones and may rise to working levels where an inflow to mine openings results. As barometric pressure rises the increase in pressure causes a contraction of the gas body and the level of the gas in the shattered zones recedes.

A minor example of this type of inflow was given by two samples collected in a raise heading at 9:20 and 11:40 a.m., respectively. During this period the barometer fell from $652 \mathrm{~mm}$ to $576 \mathrm{~mm}$, the carbon 
dioxide content of the air increased from 0.06 to 0.75 percent, the nitrogen content from 79.2 to 79.9 percent, and the oxygen content decreased from 20.8 percent to 19.4 percent. In another case air in a worked out area, as sampled through a bulkhead, showed 8 percent carbon dioxide and only 12 percent oxygen content.

The presence of blasting gases in metal mines must always be considered. The oxides of nitrogen and carbon monoxide are extremely hazardous. The occurrence and control of these gases have been investigated by Gardner (40). Control of this hazard embodies proper choice of an explosive, correct blasting technic, adequate ventilation, and use of water in spraying muck piles. Occurrence of "powder headaches" is prima facie evidence of insufficient control of blasting fumes.

\section{Skin Irritants and Sources of Infection}

Many of the materials handled in metal mining may be irritating to the skin. In most cases, the use of protective clothing, and proper personal hygiene will eliminate the trouble from this source. The common policy of wearing work-clothes continuously until they are "worn out," is unhygienic. The provision of laundry facilities at the mines should be considered. Engineering data on skin irritants is necessarily limited, and the reader is respectfully referred to the medical section of this report.

The high humidities and absence of sunlight in underground workings make them theoretically ideal environments for the transmission of air-borne bacteria. Unfortunately, data on the transmission of bacteria in mines are not available, and fortunately, no crowding in working places occurs. However, due to these factors, and to the known hypersusceptibility of silicotics to pulmonary infections, workers should not enter mines when suffering from an acute respiratory infection.

Infections transmitted by contact are a constant nuisance in mining camps. Athlete's foot, trench mouth or Vincent's angina, and other infections, may be eliminated by proper hygienic methods.

\section{0ther Toxic Metals}

Spectrographic analyses of settled dust samples showed the presence of copper, silver, manganese, mercury, arsenic, antimony, and selenium in some, or all, samples, but analyses of atmospheric dust samples did not show that any of these metals were present in toxic quantities. In the absence of definite clinical signs of present or past intoxication from these metals, it seems probable that no poisoning will occur if the atmospheric contamination is kept at the low level which will result from adequate control of the silica and lead dust hazards. This statement applies only to the type of metal mines studied and would probably be untrue for mines producing commercial manganese or mercury ore, where other factors would have to be considered.

\section{Sanitary Survey}

A sanitary survey made in the metal mines studied, and in the adjacent towns, showed that conditions which may be detrimental to health existed.

The drinking water supply for the workmen in one of the mines, and for the residents of the camp adjacent to this mine, originates in an 
abandoned mine tunnel and in a diamond drill hole. This supply appears to be protected satisfactorily against contamination at the source, but slant-jet bubblers should be provided for mine workmen at drinking water stations, where hose bibs or open pipes are now used. At another mine, all of the mine's water supply and some of the municipal supply comes from a bulkheaded mine drift. The remainder of the municipal supply comes from two mine tunnels and a spring. Consequently, while the mine's supply will require only protection against contamination at the inlet pipe, the municipal water supply will not be satisfactory until sterilization equipment has been installed. In this mine the workmen fill their individual canteens or jugs from a tap or from the bulkhead overflow.

At the third mine, shaft seepage is used for drinking water. One shaft is subject to contamination by dust-laden return air. Water is made available to the workmen at chilled water taps, where they also fill water bags with artificial ice and chilled water. These bags are carried into the workings where they become dirty with continued use. Each worker should have his own container and keep it clean. The source of contamination of the water supply should be discovered and eliminated. The water supply of the adjacent town should also be studied since occasional contamination has been reported.

Waste disposal in some mines and mining towns is unsatisfactory. The use of open flumes in mine tunnels for the deposition of human wastes permits the exposure of workmen and the pollution of streams. The use of chemical cans or boxes, with proper precautions for preventing odors and keeping all wastes covered, is more satisfactory. Full boxes are hoisted to the surface and dumped. Frequent emptying of such boxes, and the proper disposal of their contents are essential.

Municipal sewage disposal in metal mine camps consisted of either the use of septic tanks or the dumping of raw sewage to nearby streams. Improved methods of municipal waste disposal should be adopted.

Cases of dysentary and typhoid fever occurred recently in some of these camps.

Housing facilities seem overcrowded.

\section{Summary}

Engineering studies were made of the working environment in three metal mining enterprises: (1) to identify the nature of the materials and conditions to which the workers were exposed, (2) to measure dust concentrations, lead concentrations and gas concentrations in the several operations and assign exposure values to individual workers, and (3) after locating the sources of generation and dispersal of hazardous substances, to formulate practicable methods of reducing the exposure of workers to safe limits.

In the three main Utah mining areas, Park City, Bingham and Tintic, lead-copper or lead-sliver ores containing gold, zinc and other metals are mined by shaft and drift mining methods. Some oxidized ore and brecciated sulphide ore can be removed from the stopes by pick-and-shovel methods, but the major portion of the ore tonnage is secured by fine breaking of massive ore deposits with heavy explosive charges in pneumatic drill holes. Wet methods are employed with jack-hammers, Leyner drills, drifters and stopers, and in collaring. No uniformity of drilling 
practice was applied, and such lack of uniformity was undoubtedly caused by the wide variations in hardness and composition of the ore.

Ore and rock varied from limestone containing no detectable free silica to quartzite consisting of over 99 percent free silica. Since all miners had worked in various locations, it was not possible to distinguish between those who had had high or low free silica exposures. Consequently, for statistical purposes it was assumed that all underground workers had been exposed to atmospheric dusts having an average free silica content of $30 \pm 10$ percent.

Particle size determinations showed that the atmospheric dusts had a median diameter of 0.9 microns and that over 96 percent of all atmospheric dust particles were of a size which might readily reach the smallest air sacs in the lungs.

Of the 830 persons working in the metal mining enterprises studied, less than 1 percent were exposed to average dust concentrations higher than 30 million particles per cubic foot, at the time of the study; 711 or approximately 86 percent were exposed to dust concentrations between 6 and 30 million particles per cubic foot of air and about 13 percent were exposed to less than six million particles. High dust exposures were usually associated with the drilling, breaking and handling of ore, but the use of vitiated air for ventilation also increased the dust concentrations in some stopes.

Examples of good mining practice with regard to control of the principal sources of dust contamination show that the dust can be reduced to concentrations below six million particles per cubic foot in all regular mining operations by advantageous use of present control measures; namely: Wet methods, adequate ventilation, air cleaners or settling chambers, and local exhaust ventilation. Until these control measures are universally adopted, and in special cases even after adoption, the use of approved respirators is recommended.

The presence of toxic gases, or atmospheres deficient in oxygen, in metal mines, has been shown by previous studies. Gas analyses made during this study showed that such conditions are of a temporary nature when adequate ventilation is maintained, and that accidents from this cause can be prevented by constant supervision and investigation of all working places.

Extremely high and low temperatures, rapid temperature changes, dusts of toxic metals, illumination, and poor sanitary facilities were found to merit consideration, and recommendations have been made for the improvement of some existing conditions.

\section{Recommendations}

Specific recommendations for the control of environmental health hazards are included in the general recommendations at the beginning of this report.

\section{References}

1. Page, R. T., and J. J. Bloomfield: Evaluation of the industrial hygiene problem of the State of Utah. U. S. Public Health Service Multilith Publication R-670. 1938.

2. U. S. Department of Commerce, Bureau of the Census. Census of Mines and Quarries, 1929. Washington, Gov. Print. Off. 1930. 
3. Ries, H., and T. L. Watson: Engineering geology. Ed. 4, Chapter 18 New York, John Wiley and Sons, Inc. 1931.

4. Murray, A. L.: Sanitary survey of the coal mining, metal mining, and smelting towns of Utah. U. S. Bur. Mines Report of Investigations 3184. 1932 .

5. Boutwell, J. M.: Geology and ore deposits of the Park City district, Utah. U. S. Geological Survey Prof. Paper 77. 1912.

6. Head, R. E., et al: Detailed statistical microscopic analysis of the ore and mill products of the Silver King flotation concentrator, Park City, Utah. U. S. Bur. Mines Report of Investigations 3236. 1934.

7. Corry, A. V., and O. E. Kiessling: Mineral technology and output per man studies; grade of ore. W. P. A. and Bureau of Mines Cooperative Report No. E-6. 1938.

8. Fulton, C. H.: The ores of copper, lead, gold, and silver. U. S. Bur. Mines Technical Paper 143. 1916.

9. Lyons, D. A.: Metallurgical treatment of the low-grade and complex ores of Utah. U. S. Bur. Mines Technical Paper 90. 1914.

10. Wade, J. W.: Mining methods and costs at Tintic Standard Mine, Tintic district, Utah. U .S. Bur. Mines Information Circular 6360. 1930.

11. Henderson, C. W., and J. P. Dunlop. Gold and silver. Minerals Year. book, 1937. U. S. Bur. Mines. 1937.

12. Jackson, C. F., and J. H. Hedges: Metal mining practice. U. S. Bur. Mines Bull. 419. 1939.

13. Jackson, C. F., and E. D. Gardner: Stoping methods and costs. U. S. Bur. Mines Bull. 390. 1936.

14. Jackson, C. F., and J. B. Knaebel: Underground chute gates in metal mines. U. S. Bur. Mines Information Circular 6495. 1931.

15. Hewitt, E. A.: Mining methods and costs at the Park Utah Mine, Park City, Utah. U. S. Bur. Mines Information Circular 6290. 1930.

16. Harrington, Daniel: Underground ventilation at Butte. U. S. Bur, Mines Bull. 204. 1923.

17. McElroy, G. E.: Engineering factors in the ventilation of metal mines, U. S. Bur. Mines Bull. 385. 1935.

18. Houghten, F. C., et al: Heat and moisture losses from men at work and application to air conditioning problems. Heating, Piping and Air Conditioning 3: 493-504. 1931.

19. Owings, C. W.: Some mine-lighting practices in the United States. Trans. Illum. Eng. Soc., New York, 29: 47-63. 1934.

20. U. S. Department of Labor, Division of Labor Statistics: Code of lighting: Factories, mills and workplaces. No. 556. 1930.

21. Bloomfield, J. J., and J. M. DallaValle: The determination and control of industrial dust. U. S. Public Health Bull. 217. Washington, Gov. Print. Off. 1935.

22. Sayers, R. R., et al: Anthraco-silicosis among hard coal miners. U. S. Public Health Bull. 221. Washington, Gov. Print. Off. 1936.

23. Brown, C. E., and H. H. Schrenk: Control of dust from blasting by a spray of water mist. U. S. Bur. Mines Report of Investigations 3388. 1938. 
24. Dreessen, W. C., et al: Pneumoconiosis among mica and pegmatite workers. U. S. Public Health Bull. 250. Washington, Gov. Print. Off. 1940.

25. Brown, C. E., and H. H. Schrenk: Relation of dust dissemination to water flow through rock drills. U. S. Bur. Mines Report of Investigations 3393. 1938.

26. Veasey, J. H.: Preventing the creation of fine (or phthisis-producing) dust when drilling rock with air-operated machine drills of "Leyner" type. J. South African Institute of Engineering 22:153-168. 1924.

27. Dust from "Dustless Drifters." The Miner (Canadian) 10:31-33. 1937.

28. Mechin, R. J.: Practical control of drill dust in mines. Amer. Inst, Mining and Metallurgical Engineers Technical Publication 637, Class A, Metal Mining, 60. 1935.

29. Murray, A. L.: Lead poisoning in the mining of lead in Utah. U. S. Bur. Mines Technical Paper 389. 1926.

30. Dreessen, W. C., et al: The control of the lead hazard in the storage battery industry. U. S. Public Health Bull. 262. Washington, Gov. Print. Off. 1940.

31. Fairhall, L. T., and R. R. Sayers: The relative toxicity of lead and some of its common compounds. U. S. Public Health Bull. 253. Washington, Gov. Print. Off. 1940.

32. Bloomfield, J. J., and H. S. Isbell: The presence of lead dust and fumes in the air of streets, automobile repair shops, and industrial establishments. J. Ind. Hyg. 15:3 pp. 144-149. 1933.

33. U. S. Public Health Service: Report of Advisory Committee on Official Water Standards. U. S. Public Health Reports 4: 15. 1925.

34. Harrington, Daniel, and E. R. Denny: Gases that occur in metal mines. U. S. Bur. Mines Bull. 347. 1931.

35. Katz, S. H., D. A. Reynolds, H. W. Frevert, and J. J. Bloomfield: Development and characteristics of carbon monoxide recorder. J. Amer. Soc. Heat. and Vent. Eng. 32: 5. 1926.

36. Littlefield, J. B., W. P. Yant and L. B. Berger: A detector for quantitative estimation of low concentrations of hydrogen sulphide. U. S. Bur. Mines Report of Investigations 3276. 1935.

37. Haldane, J. S., and J. G. Priestley: Respiration. New Haven, Yale University Press. 1935.

38. Rosenau, M. J.: Preventive medicine and hygiene. Ed. 6. New York, D. Appleton-Century Co., Inc. 1935.

39. McElroy, G. E.: Rock-strata gases in mines of the East Tintic mining district, Utah. U. S. Bur. Mines Reports of Investigations 2275. 1921.

40. Gardner, E. C., S. P. Howell, and G. W. Jones: Gases from blasting in tunnels and metal-mine drifts. U. S. Bur. Mines Bull. 287. 1927. 

VIII. METAL MINES 


\section{MEDICAL STUDY}

\section{Characteristics of the Metal Mining Population}

Comparison with Census Data - This study includes schedules obtained from 783 male workers who represent approximately 90 percent of all persons employed in three Utah metal mines. When compared with the 1930 Census count of copper, gold, silver, lead, and zinc mine operatives, the present sample represents 23 percent of the total metal mine workers in Utah. ${ }^{1}$ The racial distribution as found in the 1930 Census shows 60 percent native white, 23 percent foreign-born white, and 17 percent other races. Similar information is not available for the mines studied, but it is the opinion of the examining physicians that the proportion of other races is low.

Table 37 shows the known age distribution of metal mine workers in this study compared with those in the State of Utah and in the entire United States. It will be observed that there is almost the same broad age distribution in the first two population groups.

TABLE 37-Number and Percent of Metal Mine Workers According to Age for the United States, the State of Utah, and This Study.

\begin{tabular}{|c|c|c|c|c|c|c|}
\hline \multirow[b]{2}{*}{ Age in years } & \multicolumn{3}{|c|}{ Number } & \multicolumn{3}{|c|}{ Percent } \\
\hline & $\begin{array}{l}\text { United } \\
\text { States } 1\end{array}$ & Utah 2 & $\begin{array}{c}\text { This } \\
\text { study } 3\end{array}$ & $\begin{array}{l}\text { United } \\
\text { States }\end{array}$ & Utah & $\begin{array}{l}\text { This } \\
\text { study }\end{array}$ \\
\hline All known ages & 65,197 & 3,379 & 783 & 100.0 & 100.0 & 100.0 \\
\hline Under 25 & 11,554 & 768 & 83 & 17.7 & 22.7 & 10.6 \\
\hline $25-34 \quad \ldots \ldots$ & 16,770 & 1,005 & 335 & 25.7 & 29.7 & 42.8 \\
\hline $35-44$ & 15,951 & 837 & 189 & 24.5 & 24.8 & 24.1 \\
\hline 45-54 & 11,920 & 513 & 122 & 18.3 & 15.2 & 15.6 \\
\hline 55 and over & 9,002 & 256 & 54 & 13.8 & 7.6 & 6.8 \\
\hline
\end{tabular}

1 15th Census of the United States (1930), Population Vol. V, pp. 118-119.

2 15th Census of the United States (1930), Population Vol. IV, p. 1626.

3 Includes 56 workers with mixed dust exposure.

NOTE: U. S. Census figures include copper mine operatives, gold and silver mine operatives, lead and zine mine operatives.

For example, under 35 years of age there are 53.4 percent in the present study and 52.4 percent in the entire State; $35-44$ years there are 24.1 and 24.8 percent, respectively; and 45 years and over there are 22.5 and 22.8 percent. At the extremes of the age distribution there is a slightly larger proportion in the State of Utah group. When workers in the United States are compared with the present study there is a smaller percentage under 35 years of age, about the same percentage in the middle-aged group, and a greater percentage in the older group.

Workers with Experience in Other Dusty Trades - A group of 56 persons who were working in metal mines at the time of the study had previously worked more than two years in some other dusty trade. They are therefore excluded from all the following tabulations because of the possibility that their physical condition might be affected by their nonmetal mine experience. Among these 56 metal mine workers 23 had also worked in coal mines, 24 had worked in smelters, four had worked in both of those industries, and five had worked at other dusty jobs such as stone

1 The number of workers is based on the 1930 census of population which is considerably smaller than the number shown in the engineering section which is based on the 1929 census of mines and quarries. A much more useful figure for comparative purposes should be available shortly when the results of the 1940 census are released. 
cutting, pottery manufacture, and quartz mining. These persons were older than the average for industrial workers, only 28.6 percent being under 35 years of age. Because of their older age and varied experience with respect to dust, it is not surprising that the percent with silicosis is high. Among this group 25.0 percent had silicosis, while for those 45 vears of age and over the percentage was 40.7. All but one of these 14 silicosis cases were 43 years of age or over. Only two had less than nine years' experience in metal mines, and six had 20 or more years' experience.

The six persons who had second-stage silicosis had the following experience: A 43-year-old man with possibly active, moderately advanced tuberculosis had worked two years as a metal miner and three years as a laborer in the construction of Boulder Dam; a 43-year-old man had worked 24 years as a metal miner, three years as a coal miner, and one year as a quartz miner; a 47-year-old man with active, moderately advanced reinfection tuberculosis had worked 19 years as a metal miner, and five years in a coal mine; a 47-year-old man had worked 29 years as a metal miner and three years in a smelter; a 54-year-old man with quiescent, moderately advanced reinfection tuberculosis had worked 28 years as a metal miner and 13 years as a coal miner, part of the time in France; and a 56-year-old man with quiescent, moderately advanced reinfection tuberculosis had worked 30 years as a metal miner, and six years as a coal miner in England. In most of the above cases the metal mine experience would appear to have been the predominating influence in bringing about silicosis.

Age Distribution - As shown in Table 38, the average age for the remaining 727 metal mine workers in this study is 36.0 years, which is nearly the same as for Utah coal mine workers, 36.5 years, but younger than for smelter workers, 39.1 years. The proportion of workers under 35 years of age is nearly the same for this study as for the study of pottery workers made by the U. S. Public Health Service (1). The former showed 55.9 percent, whereas the latter showed 55.3 percent. However, the pottery study showed more in the older age group, 50 years and older, which represented 14.7 percent, compared with 12.0 for metal mine workers. Of the studies made in recent years by the U. S. Public Health Service, workers in the following industries showed an average age greater than for metal mines: anthracite coal mines (2), pottery (1), iron and steel, granite cutting, fur cutting, post office, and foundry $(3,4,5)$. Workers in the following industries showed a lower average age: glass, gas, cigar, cement, rubber, chemical, garment (5), and asbestos textile (6).

Length of Employment-The average number of years employed in the Utah metal mines was 11.1, whereas in the Utah coal mines it was 14.1. Since the average age in these two industries has been shown to be nearly the same, the shorter length of employment for metal mine workers indicates that these workers did not enter their present industry at as early an age as did the coal mine workers. From an examination of the work histories it would appear that a considerable group of metal mine workers spent a portion of their adult working life in agriculture before engaging in industrial employment. The percentage of workers with 10 years or more of employment was 45.8 for metal mine workers, which is nearly the same as for the 10,000 industrial workers (5) who had 45.3 percent in this group. A larger proportion of the workers with 10 years 
or more of employment was found among pottery workers, 50.1 percent Utah coal mine workers, 58.7 percent, and anthracite coal miners, 72.4
percent.

Employment Outside of Utah - Of the 727 metal mine workers studied there were 41 who at some time in the past had been employed more than two years in metal mines located outside the State border of Utah. As shown in Table 38 , this group had an average age of 44.2 years compared with an average of 35.3 years for those working in Utah only.

TABLE 38-Number and Percent of Metal Mine Workers with Employ.
ment in Utah Only and in Utah and Outside, According to ment in Utah Only and in Utah and Outside, According to Age

\begin{tabular}{|c|c|c|c|c|c|c|}
\hline \multirow[b]{2}{*}{ Age in years } & \multicolumn{3}{|c|}{ Number of workers } & \multicolumn{3}{|c|}{ Percent of workers } \\
\hline & Total & Utah only & $\begin{array}{c}\text { Utah and } \\
\text { outside }\end{array}$ & Total & Utah only & $\begin{array}{c}\text { Utah and } \\
\text { outside }\end{array}$ \\
\hline All ages ... & 727 & 686 & 41 & 100.0 & 100.0 & 100.0 \\
\hline $15-19$ & 3 & 3 & 0 & 0.4 & 0.4 & \\
\hline $20-24 \ldots \ldots \ldots \ldots \ldots$ & 80 & 80 & 0 & 11.0 & 11.7 & \\
\hline $25-29$ & 169 & 166 & 3 & 23.3 & 24.2 & 7.3 \\
\hline 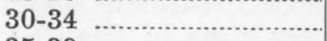 & 154 & 151 & 3 & 21.2 & 22.0 & 7.3 \\
\hline 35-39 & 98 & 92 & 6 & 13.5 & 13.4 & 14.6 \\
\hline 40-44 & 74 & 64 & 10 & 10.2 & 9.3 & 24.4 \\
\hline $45-49$ & 61 & 53 & 8 & 8.4 & 7.7 & 19.5 \\
\hline $50-54$ & 43 & 37 & 6 & 5.9 & 5.4 & 14.7 \\
\hline 55-59 & 27 & 22 & 5 & 3.7 & 3.2 & 12.2 \\
\hline 60-64 …… & 17 & 17 & 0 & 2.3 & 2.5 & \\
\hline 65 and over & 1 & 1 & 0 & 0.1 & 0.2 & \\
\hline Average age & 36.0 & 35.3 & 44.2 & & & \\
\hline
\end{tabular}

With respect to length of employment in metal mines, the average for the 41 workers was 21.6 years as compared with 10.5 years for workers with mining experience in Utah only.

\section{Diagnosis and Symptomatology of Silicosis}

Besides evidence that a worker has been exposed to dust in effective dosage, the diagnosis of silicosis was based on characteristic lung-field markings as seen in the chest X-ray film and symptoms and signs supporting these roentgenographic signs and excluding other diseases. These diagnostic criteria as well as differential diagnosis of silicosis are discussed in the previous section giving results of medical findings of coal mine workers. (Page 64).

\section{Symptomatology in Relation to Lung-Field Markings and Silicosis}

\section{Present Complaints}

With respect to silicosis, the cardinal symptoms of dyspnea, frequent cough, productive cough, chest pain, and weakness were complained of in the order listed. This checks well with the symptomatology reported in investigations of a similar nature by the Public Health Service (2), (7), as well as those reported by other investigators $(8,9,10)$.

It is well to remember that seldom have all of these symptoms occurred at a single time in any individual worker, but they have often appeared in two's and three's and in combination with other less frequent complaints. As is to be expected, the occurrence of symptoms is highest in those workers having the most severe degree of lung involvement 
(page 67). The prevalence of the various symptoms in those with conglomerate lung-field markings is three to four times that of the workers with no appreciable pulmonary fibrosis (linear 1 and 2). This difference hetween nonaffected and affected workers is also shown in Table 39 wherein the men have been classified according to diagnosis of silicosis. The influence of pulmonary tuberculosis aggravating symptoms such as cough and chest pain is also shown. The quartz content of dust in these metal mines is generally 20 to 40 percent (page 147), and for this reason it would be expected that the symptomatology and other medical findings should parallel those found in workers in other dusty trades $(1,3)(7)$ having this degree of quartz exposure. Certain details on symptomatology are presented in the description of representative case histories on pages 183 to 191 .

\section{TABLE 39-Number and Percent of Metal Mine Workers Classified on Basis of Diagnosis of Silicosis and Reinfection Pulmonary Tuberculosis, Who Complained of Certain Symptoms.}

\begin{tabular}{|c|c|c|c|c|c|c|c|c|c|}
\hline Symptoms & Total & \multicolumn{2}{|c|}{$\begin{array}{c}\text { Essentially } \\
\text { negative }\end{array}$} & \multicolumn{2}{|c|}{ Borderline } & \multicolumn{2}{|c|}{ Silicosis } & \multicolumn{2}{|c|}{$\begin{array}{l}\text { Silicosis with } \\
\text { reinfection } \\
\text { tuberculosis }\end{array}$} \\
\hline \multirow[t]{2}{*}{ Number of workers ......... } & 727 & \multicolumn{2}{|c|}{619} & \multicolumn{2}{|c|}{42} & \multicolumn{2}{|c|}{57} & \multicolumn{2}{|c|}{9} \\
\hline & Number & No. & |Percent & No. & |Percent & No. & |Percent & No. & |Percent \\
\hline Dyspnea ................ & 138 & 93 & 15.0 & 16 & 38.0 & 25 & 43.9 & 4 & 44.4 \\
\hline Frequent cough ... & 142 & 100 & 16.2 & 15 & 35.7 & 22 & 38.6 & 5 & 55.6 \\
\hline Productive cough ... & 114 & 82 & 13.2 & 8 & 19.0 & 21 & 36.8 & 3 & 33.3 \\
\hline Chest pain .............................. & 56 & 43 & 6.9 & 4 & 9.5 & 7 & 12.3 & 2 & 22.2 \\
\hline Weakness & 30 & 19 & 3.1 & 2 & 4.8 & 8 & 14.0 & 1 & 11.1 \\
\hline
\end{tabular}

\section{Past Medical History}

Pleurisy, pneumonia, and bronchitis were reported almost twice as frequently by workers with advanced pulmonary fibrosis, as shown by $\mathrm{X}$-ray findings, than by those showing first- and second-degree linear or normal markings. The percentages for the affected group were found to be: pleurisy, 32 percent; pneumonia, 29 percent; and bronchitis, 18 percent. The percentages for the relatively non-affected group were 22 , 17 , and 11 , respectively. Respiratory conditions of this type have shown a similar percentage increase in recent investigations of other dusty trades. It brings up again the question as to whether they may not be interchangeably related with both cause and effect of fibrotic changes in the lung tissues.

Although no consistent attempt was made to elicit the appendicitis and appendectomy experience of these workers, it was demonstrated that appendiceal disease has been quite prevalent. The percent of workers giving a positive history ranged from approximately 11 in one to 13 and 14 in the other two mines. In the smelters the percent was about 17. The disabling lead poisoning experience of metal mine workers is discussed on page 194 .

\section{Physical Findings}

As regards general appearance, these 727 metal miners were, for the most part, normal healthy men, but in thirty instances the examiners were impressed by their unhealthy or cachectic appearance. Nine of the 
30 were affected with silicosis or borderline silicosis, of whom all but one had silicosis complicated by pulmonary infection. The remaining 21 show. ing cachexia were scattered among those not affected with silicosis, but affected with such conditions as cardiovascular disease, latent lead poison. ing, hand infections, syphilis, and nontuberculous lung infections. As would be expected, most of the 30 were underweight.

Weight Deviation-The percent deviation of each worker's weight from the average for men of comparable height and age was calculated from data compiled by the Association of life Insurance Medical Directors and the Actuarial Society of America (11). Arbitrarily, plus or minus $( \pm)$ 5 percent deviation from this insurance average has been considered normal. As seen in Table 40, those figures marked minus (-) represent the percent weight deviation below this "normal," whereas those marked plus ( + ) designate the percent of weight deviation above "normal." For comparison, similar data on 877 truck drivers (12) recently examined by the Public Health Service are shown in the right-hand column. It was observed that 43.9 percent of the men having first- or second-stage silicosis were underweight for age-height compared with 32.4 percent of the non-affected group and 30.6 percent of 877 truck drivers.

\section{TABLE 40-Distribution of Percentage Weight Deviations for Metal Mine Workers, Classified by Diagnosis of Silicosis, and Compared with Truck Drivers.}

\begin{tabular}{|c|c|c|c|c|c|}
\hline \multirow{3}{*}{$\begin{array}{l}\text { Percentage } \\
\text { weight } \\
\text { deviation }\end{array}$} & \multicolumn{5}{|c|}{ Percent of workers } \\
\hline & \multirow{2}{*}{$\begin{array}{c}\text { All metal } \\
\text { mine workers }\end{array}$} & \multicolumn{3}{|c|}{ Diagnosis of silicosis } & \multirow{2}{*}{$\begin{array}{c}\text { Truck } \\
\text { drivers }\end{array}$} \\
\hline & & $\begin{array}{l}\text { 1st and 2nd } \\
\text { stage }\end{array}$ & Borderline & $\begin{array}{l}\text { Non- } \\
\text { affected }\end{array}$ & \\
\hline \multicolumn{6}{|l|}{ Number of } \\
\hline workers & 727 & 66 & 42 & 619 & 877 \\
\hline$-25 \ldots \ldots \ldots \ldots \ldots$ & 0.6 & 4.5 & $\ldots$. & 0.2 & 0.3 \\
\hline-15 to $24 \ldots \ldots$. & 5.5 & 7.6 & 23.8 & 5.6 & 6.2 \\
\hline-5 to $14 .$. & 27.0 & 31.8 & 45.3 & 26.6 & 24.1 \\
\hline$+5 \ldots \ldots \ldots \ldots$ & 37.1 & 31.8 & 21.4 & 37.2 & 29.2 \\
\hline + 5 to $14 \ldots$ & 20.3 & 15.2 & 7.1 & 20.8 & 22.1 \\
\hline+15 to 24 & 7.3 & 9.1 & 2.4 & 7.1 & 10.3 \\
\hline+25 to 34 . & 1.4 & $\ldots$. & $\ldots$. & 1.5 & 4.4 \\
\hline+35 to $49 \ldots$ & 0.4 & .... & $\ldots$. & 0.5 & 2.5 \\
\hline$+50 \ldots \ldots \ldots \ldots$ & 0.4 & $\ldots$. & $\ldots$. & 0.5 & 0.9 \\
\hline \multirow{2}{*}{\multicolumn{6}{|c|}{$\begin{array}{l}\text { Average } 1 \\
\text { Standard }\end{array}$}} \\
\hline & & & & & \\
\hline deviation & 11.7 & 12.4 & 9.8 & 11.8 & 14.5 \\
\hline
\end{tabular}

1 Averages represent the percentage the workers fell below or above the average for life insurance applicants of comparable age and height.

As a group, the silicotics fell 2.7 percent below, and the non-affected 0.6 percent above, the average weight of life insurance applicants of comparable age and height. The group of borderline cases was significantly heavier on the average than the first- and second-stage cases. When the borderline cases are compared with the non-affected group, no important differences can be seen from inspection. This is confirmed by a statistical test. But, on the whole, all metal mine workers considered together have weights almost identical to those of life insurance applicants.

Physical Findings in Relation to X-ray Findings-In Table 41 are summarized the more important physical findings in relation to degree 
of pulmonary fibrosis as shown by X-ray findings. Abnormally shaped chests were rarely observed. In the 25 workers with barrel-shaped chests, the abnormality was nearly four times as frequent among workers with advanced pulmonary fibrosis as in the group with first- and second-degree linear markings. The table also shows that altered breath sounds were observed in approximately one-fifth of the workers with relatively clear chests and in slightly more than half of those showing positive changes in the chest on X-ray examination. Impaired or restricted diaphragm action, as observed on fluoroscopy, was noted in 23.8 percent of the normal workers, in 42.2 percent of workers with ground-glass markings, and in 65.8 percent with nodular and conglomerate markings. Change from normal percussion note, impaired chest mobility, dyspnea, curved or clubbed finger nails, and decreased chest expansion were other findings of importance for a diagnosis of silicosis. Nonpersistent rales, chest lag, pleural rubs, and retracted supra- and infraclavicular fossae, while of assistance in the diagnosis of individual cases, did not show a high degree of correlation with the degree of lung involvement and are not shown in the table. The occurrence of a combination of these findings in individual workers is presented in selected case records (page 183).

\section{TABLE 41-Number and Percent of Metal Mine Workers Classified Ac- cording to Degree of Pulmonary Fibrosis as Shown by X-ray Findings, Who Were Found to Have Certain Abnormalities on Physical Examination.}

\begin{tabular}{|c|c|c|c|c|c|c|}
\hline \multirow[b]{2}{*}{ Physical finding } & \multicolumn{3}{|c|}{ Percent of workers } & \multicolumn{3}{|c|}{ Number of workers } \\
\hline & $\begin{array}{c}\text { First- and } \\
\text { second } \\
\text { degree } \\
\text { linear }\end{array}$ & $\begin{array}{c}\text { Ground } \\
\text { glass }\end{array}$ & $\begin{array}{c}\text { Nodular } \\
\text { and } \\
\text { conglom- } \\
\text { erate }\end{array}$ & \begin{tabular}{|c} 
First- and \\
second \\
degree \\
linear
\end{tabular} & $\begin{array}{r}\text { Ground } \\
\text { glass }\end{array}$ & $\begin{array}{c}\begin{array}{c}\text { Nodular } \\
\text { and } \\
\text { conglom- } \\
\text { erate }\end{array} \\
\text { erate }\end{array}$ \\
\hline Number of workers & \multirow{4}{*}{19.8} & \multirow[b]{4}{*}{42.2} & \multirow[b]{4}{*}{71.1} & \multirow{4}{*}{$\begin{array}{l}617 \\
34.4 \\
122\end{array}$} & \multirow{4}{*}{$\begin{array}{l}64 \\
43.5 \\
27\end{array}$} & \multirow{4}{*}{$\begin{array}{l}38 \\
48.8 \\
27\end{array}$} \\
\hline $\begin{array}{l}\text { examined } \\
\text { Average age }\end{array}$ & & & & & & \\
\hline 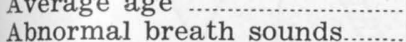 & & & & & & \\
\hline $\begin{array}{l}\text { Apnormal oreach sounds........ } \\
\text { Restricted movement }\end{array}$ & & & & & & \\
\hline 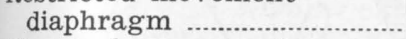 & \multirow[t]{2}{*}{23.8} & \multirow[t]{2}{*}{42.2} & \multirow[t]{2}{*}{65.8} & \multirow[t]{2}{*}{147} & \multirow[t]{2}{*}{27} & \multirow[t]{2}{*}{25} \\
\hline Change from normal & & & & & & \\
\hline 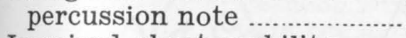 & 8.8 & 26.6 & 44.7 & 54 & 17 & 17 \\
\hline Impaired chest mobility.......... & 3.2 & 17.2 & 10.5 & 20 & 11 & 4 \\
\hline 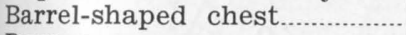 & 2.4 & 7.8 & 13.2 & 15 & 5 & 5 \\
\hline 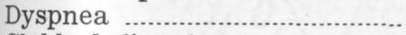 & 5.2 & 14.1 & 21.1 & 32 & 9 & 8 \\
\hline 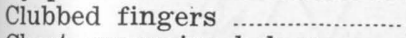 & 7.8 & 14.1 & 28.9 & 48 & 9 & 11 \\
\hline Chest expansion below & & & & & & \\
\hline $6 \mathrm{~cm}$ & 18.5 & 31.2 & 26.3 & 114 & 20 & 10 \\
\hline
\end{tabular}

It is apparent from these data that not only a smaller proportion of workers are affected with silicosis, but less severely, than has been found in certain other investigations of metal mine workers, as in the Tri-State (10) and South Africa (13) investigations. Some of the factors relating to this are discussed in the following section.

\section{Incidence of Silicosis}

\section{Relation of Silicosis to Dust Concentration and Duration of Employment}

The incidence of silicosis among workers in the Utah metal mines 


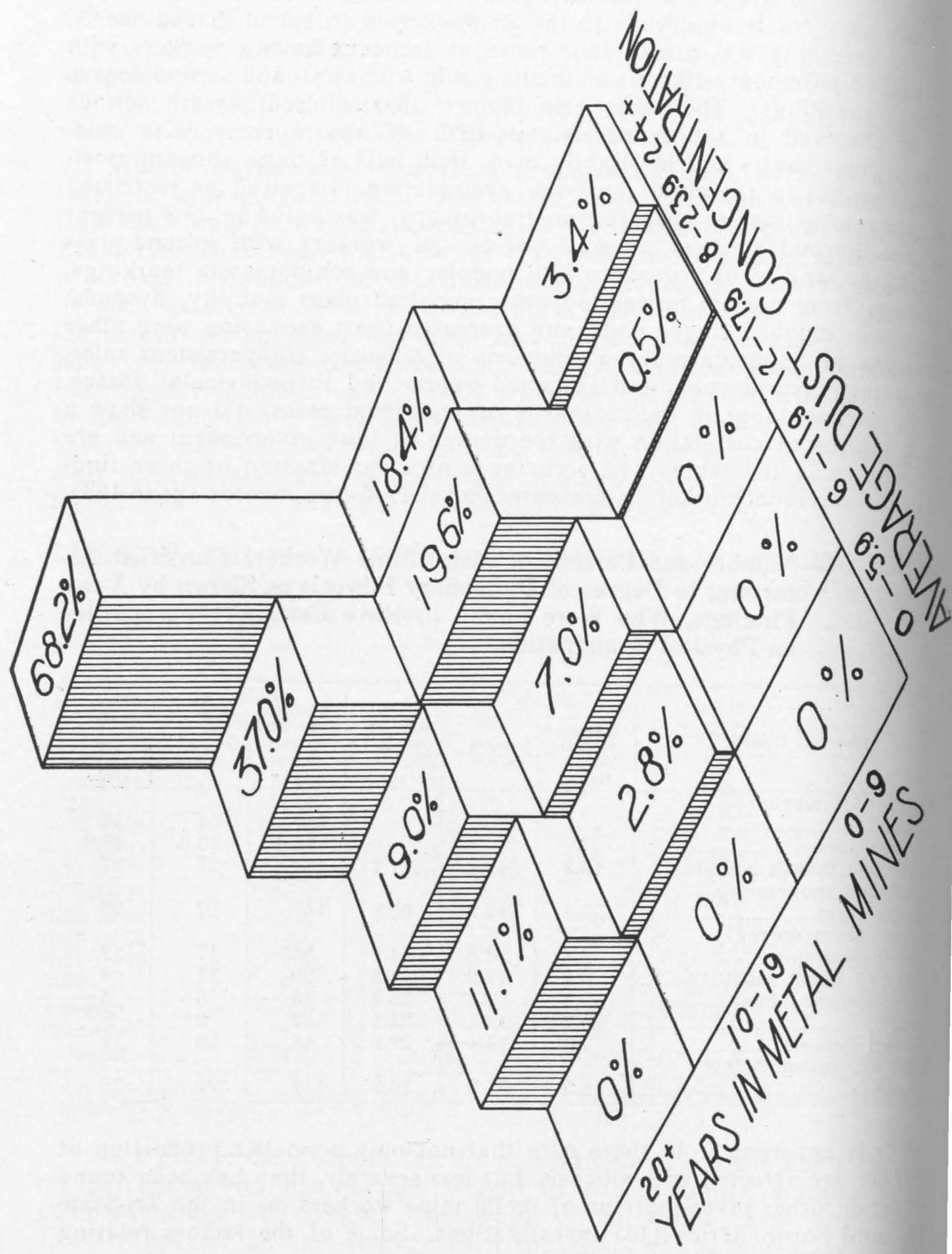

FIGURE 25-Relation of average dust concentration and duration of employment in the metal mines to the percentage of workers found to have silicosis (first and second stage). 
is related both to the length of their employment in that industry and to the average dust concentration to which they have presumably been exposed during all their working years in metal mines. Since the procedures employed in determining weighted average dust concentrations have been described in Appendix IV, they do not need to be repeated here.

Table 42 and Figure 25 show the result of grouping the 727 metal mine workers according to weighted average dust concentration in arbitrary intervals of six million particles per cubic foot of air. Each of these five groups is subdivided into three durations of employment in metal mines, namely, less than 10 years, 10-19 years, and 20 years and over. A total of 66 cases of silicosis was found on examination of these men. Forty-two were first-stage and 24 second-stage silicosis. No third-stage cases were observed. Forty-two others were diagnosed as borderline silicosis.

\section{TABLE 42-Number and Percent of Metal Mine Workers in Utah with Silicosis According to Years Employed in Metal Mines and Dust Concentration.}

\begin{tabular}{|c|c|c|c|c|c|}
\hline \multirow{2}{*}{$\begin{array}{l}\text { Dust concentra- } \\
\text { tion, million } \\
\text { particles per } \\
\text { eubic foot }\end{array}$} & & \multirow[b]{2}{*}{ Total } & \multicolumn{3}{|c|}{ Years employed in metal mines } \\
\hline & & & $\begin{array}{c}\text { Less } \\
\text { than } 10\end{array}$ & $10-19$ & $\begin{array}{c}20 \text { and } \\
\text { over }\end{array}$ \\
\hline \multirow{4}{*}{$0-5.9$} & Number exposed ................. & 39 & 17 & 11 & 11 \\
\hline & Number with silicosis....... & 0 & 0 & 0 & 0 \\
\hline & Percent with silicosis... & & & & \\
\hline & Number exposed .................. & 98 & 44 & 36 & 18 \\
\hline \multirow[t]{3}{*}{$6.0-11.9$} & Number with silicosis.... & 3 & 0 & 1 & 2 \\
\hline & Percent with silicosis........ & 3.1 & & 2.8 & 11.1 \\
\hline & Number exposed ................... & 115 & 51 & 43 & 21 \\
\hline \multirow{2}{*}{$12.0-17.9$} & Number with silicosis....... & 7 & 0 & 3 & 4 \\
\hline & $\begin{array}{l}\text { Percent with silicosis... } \\
\text { Number exposed }\end{array}$ & 6.1 & 189 & 7.0 & 19.0 \\
\hline \multirow{3}{*}{$18.0-23.9$} & $\begin{array}{l}\text { Number exposed ............... } \\
\text { Number with silicosis....... }\end{array}$ & 22 & 109 & 56 & 27 \\
\hline & $\begin{array}{l}\text { Number with sillcosis........ } \\
\text { Percent with silicosis....... }\end{array}$ & 8.1 & 0.5 & 11.6 & 10 \\
\hline & 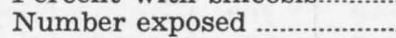 & 187 & 89 & $\begin{array}{l}19.0 \\
76\end{array}$ & $\begin{array}{l}37.0 \\
22\end{array}$ \\
\hline \multirow[t]{3}{*}{24.0 and over } & Number with silicosis........ & 32 & 3 & 14 & 15 \\
\hline & Percent with silicosis......... & 17.1 & 3.4 & 18.4 & 68.2 \\
\hline & Number exposed ....................... & 727 & 394 & 228 & 105 \\
\hline \multirow{2}{*}{$\begin{array}{l}\text { All dust con- } \\
\text { centrations } 1\end{array}$} & Number with silicosis........... & 66 & 4 & 30 & 32 \\
\hline & Percent with silicosis............ & 9.1 & 1.0 & 13.2 & 30.5 \\
\hline
\end{tabular}

1 Includes two cases of silicosis among 16 workers with unknown dust concentration.

From the table it is observed that in concentrations of less than six million particles of dust there was no case of silicosis even for those working the longest period. However, there were only seven underground workers in this group, two of whom were face workers with one year's experience each. Among those employed for less than 10 years there was no case of silicosis in the first three dust concentration groups; there was one case in the 18.0 to 23.9 dust group; and there were three cases or 3.4 percent in the 24.0 million particles and over dust concentration group. In the 10-19 year employment group, the percent affected rose from 2.8 in the 6.0 to 11.9 dust concentration group to 19.6 percent in the 18.0 to 23.9 dust group. Those with the longest employment, 20 years and over, showed a much larger proportion affected in each dust group, 
reaching 68.2 percent among those having the greatest weighted average dust exposure. This tendency for silicosis incidence to increase, both with increasing length of employment and with increasing dust concentration has been observed in other studies made by the U. S. Public Health Service in such dusty trades as anthracite coal mining (2), asbestos textile manu. facture (6), pottery manufacture (1), and mica and pegmatite mining (7) X-ray Findings of Silicosis Cases - The increasing severity of silicosis with increasing years of employment in metal mines is shown in Table 43. Ground-glass lung-field markings represent the maximum de. gree of involvement found in cases with less than 10 years of employment. Half of the cases show nodular markings when the employment is 10 to 14 years, whereas conglomerate markings are not found until the 15 to 19 year group. It will be noted that after 14 years there is a steady decrease in the percentage of silicosis cases showing ground-glass markings and a corresponding increase in both the percentage showing nodular and the percentage showing conglomerate markings. The latter increases more rapidly with lengthening duration of employment, as has been shown in other studies of silicosis. In addition to the expected increase with duration of employment, another factor that probably played a part among the older workers was the practice of dry drilling until about 1924. Nevertheless, 14 cases of silicosis, five of them with nodular markings, were found among workers with less than 15 years' exposure. This and the results of the engineering study indicate that the control methods in present use are not sufficient to prevent silicosis.

\section{TABLE 43-Number and Percent of First- and Second-stage Silicosis Cases Among Metal Mine Workers with Specified X-ray Findings According to Years Employed in Metal Mines.}

\begin{tabular}{|c|c|c|c|c|c|c|c|c|}
\hline \multirow{2}{*}{$\begin{array}{l}\text { Years employed } \\
\text { in metal mines }\end{array}$} & \multicolumn{4}{|c|}{ Number of workers } & \multicolumn{4}{|c|}{ Percent of workers } \\
\hline & Total & $\begin{array}{c}\text { Ground } \\
\text { glass }\end{array}$ & Nodular & $\left|\begin{array}{c}\text { Conglom } \\
\text { erate }\end{array}\right|$ & Total & $\begin{array}{c}\text { Ground } \\
\text { glass }\end{array}$ & Nodular & $\begin{array}{l}\text { Conglom- } \\
\text { erate }\end{array}$ \\
\hline Total ...... & 66 & 28 & 24 & 14 & 100 & 42.4 & 36.4 & 21.2 \\
\hline Under 5 & 0 & 0 & 0 & 0 & 100 & & $\ldots$. & .... \\
\hline 5-9 ………........ & 4 & 4 & 0 & 0 & 100 & 100.0 & & .... \\
\hline $10-14 \ldots \ldots \ldots \ldots \ldots$ & 10 & 5 & 5 & 0 & 100 & 50.0 & 50.0 & \\
\hline 15-19 ……….... & 20 & 9 & 7 & 4 & 100 & 45.0 & 35.0 & 20.0 \\
\hline $20-24$ & 11 & 4 & 4 & 3 & 100 & 36.4 & 36.4 & 27.2 \\
\hline 25 and over...... & 21 & 6 & 8 & 7 & 100 & 28.6 & 38.1 & 33.3 \\
\hline
\end{tabular}

Employment Outside of Utah - In the group of silicosis cases just described, there were 13 men who had worked in metal mines outside of Utah for more than two years at some time in the past. A portion of their dust exposure was obtained from this experience, although the exact amount cannot be ascertained. They also had considerable experience in Utah alone, only one for less than 10 years, and eight for more than 20 years. On the other hand, only two had outside experience for more than 10 years. When the incidence of silicosis is computed for those working outside of Utah, the percent affected is found to be 31.7. Some of this excess in rate may be accounted for by the older age distribution of men who have worked both in Utah and outside. The percent of persons over 40 years of age in this group is 70.8 compared with 28.3 percent for those who had worked in Utah only. However, the percent affected in the 40-59 
year age group was 37.9 percent and 20.5 percent, respectively, so there apparently still remains an excess of silicosis among those working outside. This may be due to less effective dust control methods, a greater proportion of free silica, or other factors.

\section{Silicosis By Principal Occupation}

Any account of silicosis incidence in the metal mines is incomplete unless attention is directed to occupational differences. As shown in Table 44, silicosis cases and borderline silicosis cases are concentrated in a few occupations while many occupations show no persons affected. It will be observed that there were only one silicosis case and five boderline cases found among the entire group of persons whose work experience has been principally above ground, milling operations excepted. This single first-stage silicosis case had worked as a blacksmith for 23 years and during that time possibly had been exposed to free silica during the sharpening of miner's tools. Cases of silicosis are found in six different underground occupations, namely, face workers, mule skinners, powdermen, pipemen, shift bosses, and timbermen.

\section{TABLE 44-Metal Mine Workers in Utah by Principal Occupation Accord- ing to Years Employed in Metal Mines, and Diagnosis of Silicosis.}

\begin{tabular}{|c|c|c|c|c|c|c|}
\hline \multirow{3}{*}{ Principal occupation } & \multicolumn{4}{|c|}{ Number employed } & \multirow{2}{*}{\multicolumn{2}{|c|}{$\begin{array}{c}\text { Number affected } \\
\begin{array}{c}\text { Diagnosis of } \\
\text { silicosis }\end{array}\end{array}$}} \\
\hline & \multicolumn{4}{|c|}{$\begin{array}{l}\text { Years employed in } \\
\text { metal mines }\end{array}$} & & \\
\hline & Total & $\begin{array}{c}\text { Under } \\
10\end{array}$ & $\begin{array}{l}10- \\
19\end{array}$ & $\begin{array}{c}20 \text { and } \\
\text { over }\end{array}$ & $\begin{array}{c}\text { 1st and } \\
\text { 2nd stage }\end{array}$ & $\begin{array}{l}\text { Border- } \\
\text { line }\end{array}$ \\
\hline Total & 727 & 394 & 228 & 105 & 66 & 42 \\
\hline 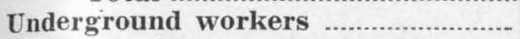 & 513 & 321 & 143 & 49 & 52 & 27 \\
\hline Face workers & 385 & 253 & 104 & 28 & 43 & 21 \\
\hline Trasportation workers: & & & & & & \\
\hline Motormen & 20 & 18 & 2 & 0 & 0 & 0 \\
\hline Hoistmen ............ & 19 & 11 & 4 & 4 & 0 & 1 \\
\hline Mule skinners & 11 & 4 & 4 & 3 & 1 & 0 \\
\hline Cagers & 6 & 0 & 5 & 1 & 0 & 1 \\
\hline Other transportation workers.. & 8 & 2 & 2 & 4 & 1 & 1 \\
\hline Maintenance workers: & & & & & & \\
\hline 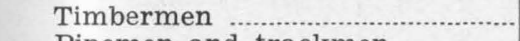 & 37 & 26 & 8 & 3 & 4 & 0 \\
\hline Pipemen and trackmen................ & 6 & 2 & 4 & 0 & 1 & 1 \\
\hline Sanitation and ventilation men.. & 5 & 1 & 3 & 1 & 0 & 1 \\
\hline Other maintenance workers ...... & 8 & 4 & 2 & 2 & 0 & 0 \\
\hline Supervisors and shift bosses........ & 8 & 0 & 5 & 3 & 2 & 1 \\
\hline Surface workers & 115 & 41 & 48 & 26 & 1 & 5 \\
\hline Superintendents and engineers.... & 17 & 12 & 2 & 3 & 0 & 0 \\
\hline Blacksmiths & 13 & 3 & 7 & 3 & 1 & 0 \\
\hline 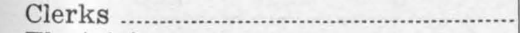 & 11 & 2 & 7 & 2 & 0 & 0 \\
\hline 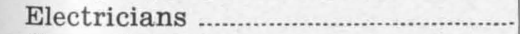 & 10 & 4 & 3 & 3 & 0 & 1 \\
\hline 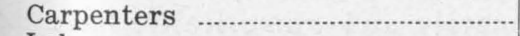 & 10 & 3 & 5 & 2 & 0 & 0 \\
\hline Laborers & 8 & 3 & 5 & 0 & 0 & 0 \\
\hline Machinists and mechanics............... & 8 & 0 & 4 & 4 & 0 & 0 \\
\hline Top car men & 6 & 2 & 3 & 1 & 0 & 1 \\
\hline Hoistmen …................... & 5 & 0 & 1 & 4 & 0 & 1 \\
\hline Chemists ..................... & 5 & 2 & 3 & 0 & 0 & 0 \\
\hline Truck drivers ……...................... & 5 & 4 & 1 & 0 & 0 & 0 \\
\hline Other surface workers & 17 & 6 & 7 & 4 & 0 & 2 \\
\hline Milling operations & 13 & 2 & 4 & 7 & 1 & 1 \\
\hline No principal occupation & 86 & 30 & 33 & 23 & 12 & 9 \\
\hline
\end{tabular}


Table 45 shows the incidence of silicosis and borderline silicosis, by years in metal mines, for three broad occupational groups. The persons affected with silicosis represent 11.2 percent of the face workers (i.e drillers, miners, and muckers), 7.0 percent of the underground workers and 0.9 percent of the surface workers. Only for face workers were there cases of silicosis among persons with less than 10 years in metal mines For face workers and for other underground workers, the percent af fected was 22.1 and 10.3, respectively, among those who had worked 10-19 years, 55.0 percent and 23.1 percent among those in the $20-29$ year group, and 62.5 percent and 25.0 percent in the 30 years and over group. When borderline silicosis is included, the percent affected rises to 33.6 for face workers and 15.4 for other underground workers in the group who had worked 10-19 years, and 75.0 percent and 38.5 percent in the group who had worked $20-29$ years.

\section{TABLE 45-Number and Percent of Metal Mine Workers in Utah with Silicosis According to Broad Occupational Group and Years of Employment}

\begin{tabular}{|c|c|c|c|c|c|c|c|}
\hline \multirow{3}{*}{$\begin{array}{l}\text { Principal occupation } \\
\text { and years in metal mines }\end{array}$} & \multirow{3}{*}{$\begin{array}{l}\text { Number } \\
\text { exposed }\end{array}$} & \multicolumn{3}{|c|}{ Number affected } & \multicolumn{3}{|c|}{ Percent affected } \\
\hline & & \multicolumn{3}{|c|}{ Silicosis } & \multicolumn{3}{|c|}{ Silicosis } \\
\hline & & Total & \begin{tabular}{|l|}
1 st and \\
2d stage
\end{tabular} \mid & $\begin{array}{l}\text { Border- } \\
\text { line }\end{array}$ & Total & $\begin{array}{l}\text { 1st and } \\
\text { 2d stage }\end{array}$ & $\begin{array}{l}\text { Border- } \\
\text { line }\end{array}$ \\
\hline \multicolumn{8}{|l|}{ Total } \\
\hline Face workers & 385 & 64 & 43 & 21 & 16.6 & 11.2 & 5.4 \\
\hline $\begin{array}{l}\text { Other underground } \\
\text { workers }\end{array}$ & & & & & & & \\
\hline Surface workers & 115 & 6 & 1 & 5 & 5.2 & 0.9 & $\begin{array}{l}4.1 \\
4.3\end{array}$ \\
\hline \multicolumn{8}{|l|}{ Under 10 years } \\
\hline Face workers ........... & 253 & 8 & 4 & 4 & 3.2 & İ.6 & 1.6 \\
\hline $\begin{array}{l}\text { Other underground } \\
\text { workers }\end{array}$ & 68 & 1 & 0 & 1 & 1.5 & 0 & 1.5 \\
\hline Surface workers ....... & 41 & 0 & 0 & 0 & 0 & 0 & 0 \\
\hline \multicolumn{8}{|l|}{ 10-19 years } \\
\hline Face workers & 104 & 35 & 23 & 12 & 33.6 & 22.1 & 11.5 \\
\hline $\begin{array}{l}\text { Other underground } \\
\text { workers }\end{array}$ & 39 & 6 & 4 & 2 & 15.4 & 10.3 & 51 \\
\hline Surface workers & 48 & 5 & 0 & 5 & 10.4 & 0 & 10.4 \\
\hline \multicolumn{8}{|l|}{ 20-29 years } \\
\hline $\begin{array}{l}\text { Face workers .......... } \\
\text { Other underground }\end{array}$ & 20 & 15 & 11 & 4 & 75.0 & 55.0 & 20.0 \\
\hline workers & 13 & 5 & 3 & 2 & 38.5 & 23.1 & 15.4 \\
\hline Surface workers ........ & 18 & 0 & 0 & 0 & 0 & 0 & 0 \\
\hline \multicolumn{8}{|l|}{30 years and over } \\
\hline $\begin{array}{l}\text { Face workers } \\
\text { Other underg..... }\end{array}$ & 8 & 6 & 5 & 1 & 75.0 & 62.5 & 12.5 \\
\hline $\begin{array}{l}\text { Other underground } \\
\text { workers }\end{array}$ & 8 & 3 & 2 & 1 & 37.5 & 25.0 & 12.5 \\
\hline Surface workers .......... & 8 & 1 & 1 & 0 & 12.5 & 12.5 & 0 \\
\hline
\end{tabular}

Since face workers, both proportionately and numerically, have the greatest problem of silicosis, this occupation will be examined in more detail. Of the 385 workers in this group, 88.2 percent were exposed to a dust concentration of 20 million particles and over, compared with 24.8 percent for other underground workers and 4.3 percent for surface workers. Samples of dust collected at the face showed a free silica content of approximately 20 to 40 percent (page 147). This should be remem bered along with the fact that the average dust concentration for face 
workers was 23.6 million particles. As shown in Figure 26, this combination of a heavy dust concentration and a high silica content resulted in a silicosis incidence which affected nearly a fourth of those who had worked in metal mines for over six years, and all four workers who had been employed for 34 years and more. The increase in the percent affected is especially great when those with over 13 years' employment are compared with those having over six years. Since the population exposed to risk is rather small for those working more than 20 years, not too much dependence should be placed on the percent affected for these particular groups, but the trend toward an increasingly serious problem is unmistakable. Whereas conglomerate lung-field markings were not present in any of those affected when the duration of employment was less than 15 years, these markings indicating marked pulmonary fibrosis included 55 percent among those with experience of 20-29 years.

Figure 27 , in which the width of the bar is proportionate to the number exposed, emphasizes the importance of the group of face workers who have been employed 10-19 years in metal mines, and shows an incidence of silicosis of 22.1 percent, and of silicosis and borderline silicosis 22.1 percent, and of silicosis and borderline silicosis combined, 33.6 percent. These account for 23 cases of silicosis compared with 16 cases for all longer durations.

The above data should be considered a minimum estimate of the actual incidence of silicosis produced by work at the face of the metal mines. Of the 23 cases with silicosis who were classified as other than face workers, 78 percent had worked at the face at some time in the past, five for less than five years, seven for 5-9 years, and six for 10 years and over. It is evident that many of these had a serious dust exposure while working at the face, although they might have spent many years at other and less dusty occupations.

There appears to be a tendency for persons affected with silicosis to be placed in jobs requiring less strenuous work. For example, a tabulation of silicosis cases by present occupations shows a markedly different picture than for principal occupation. Instead of 43 cases classed as face workers, there are now 29 , and instead of one surface worker there are now 11, showing that many former face workers have been transferred to the surface. 


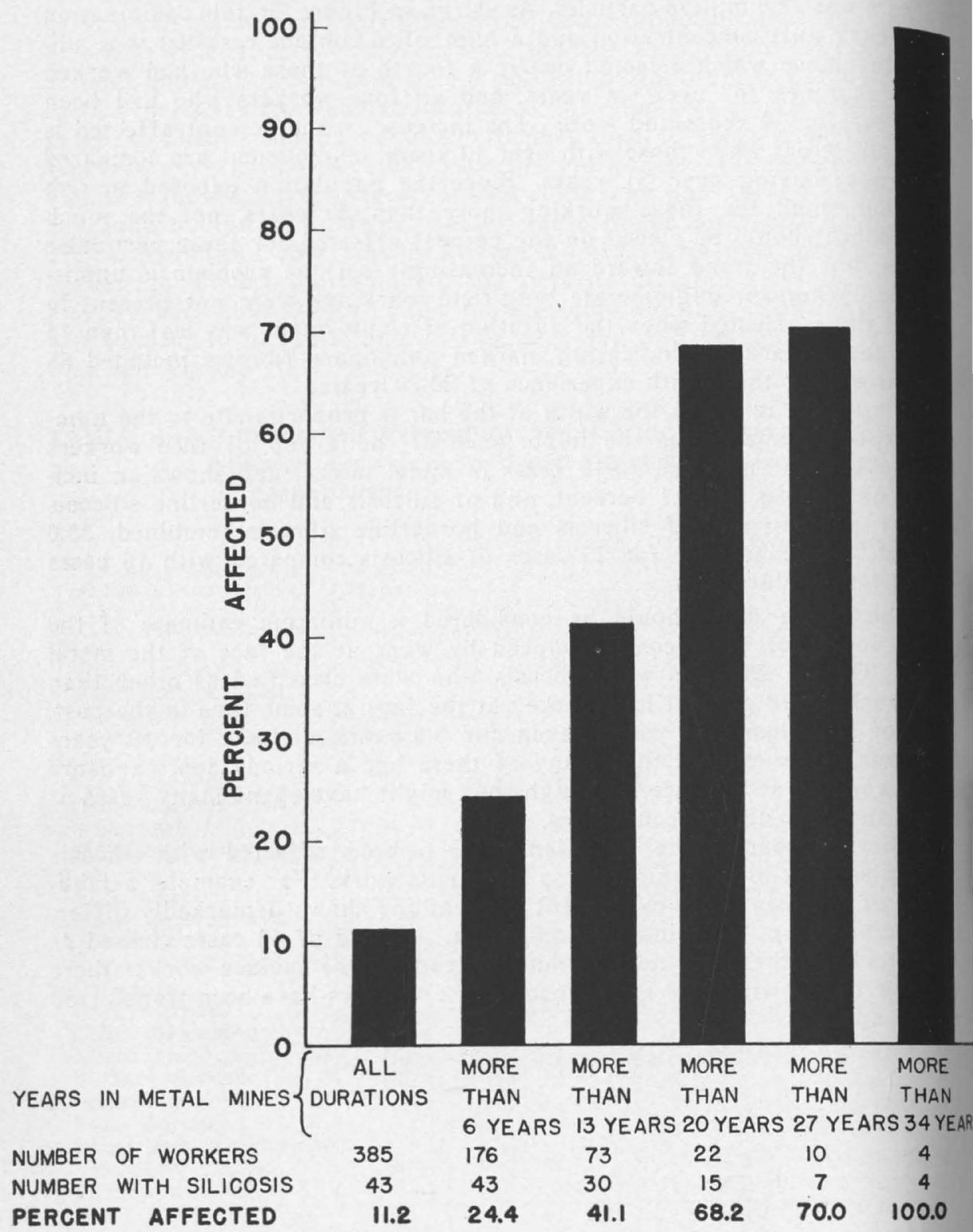

FIGURE 26-Percentage of face workers found to have first- and secondstage silicosis, classified by duration of employment in metal mines. (Numbers of workers are cumulated downward.) 


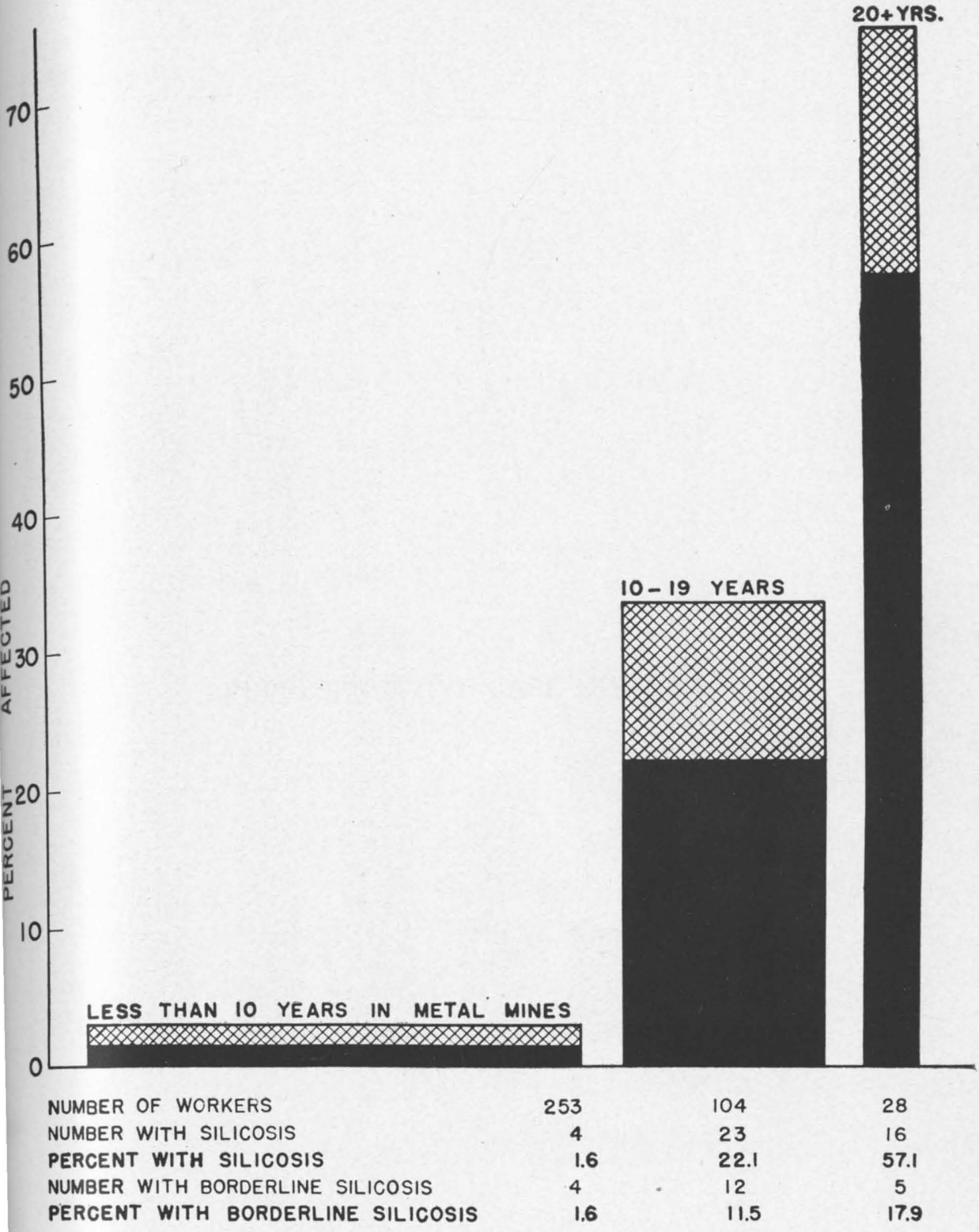

SILICOSIS BORDERLINE SILICOSIS

FIGURE 27-Percentage of face workers found to have silicosis, classified by duration of employment in metal mines. (Width of bar is proportionate to the total number of workers for the given periods.) 

REPRESENTATIVE CASE HISTORIES 


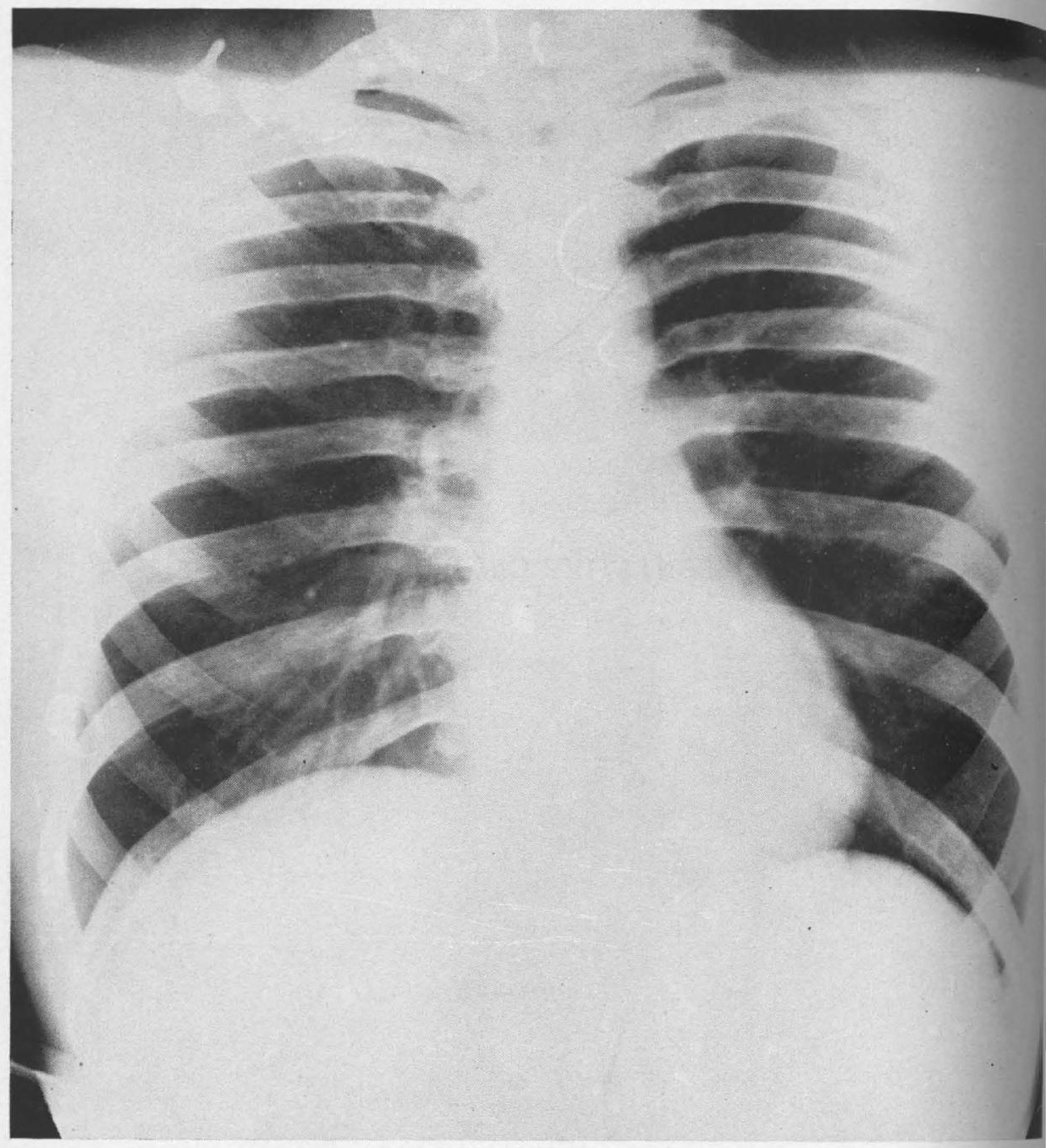

FIGURE 28-Normal chest, white male, age 29. 


\section{Figure 28-Case History}

Occupational history-Mine of fice clerk, five years; farming six years.

Estimated dust exposure-Three million particles per cubic foot (weighted average).

Past medical history-Influenza, 1923; appendectomy, 1938.

Present complaints-None.

Physical examination-Robust appearance; height, 66 inches; weight, 142 pounds; chest expansion, 7 centimeters.

Fluoroscopy-Apices clear, diaphragm regular, and no restriction in motion; hilar shadows of usual size and density.

Film-Normal linear markings present in both lungs. Heart, negative.

Diagnosis-Essentially negative.

Comment-This roentgenogram has been reproduced for comparative purposes. It shows the type of lung-field markings observed in the chest of a normal young adult. With increasing age the linear pulmonic markings usually become accentuated, but do not show granular, nodular, or nodulo-conglomerae markings characteristic of silicosis. 


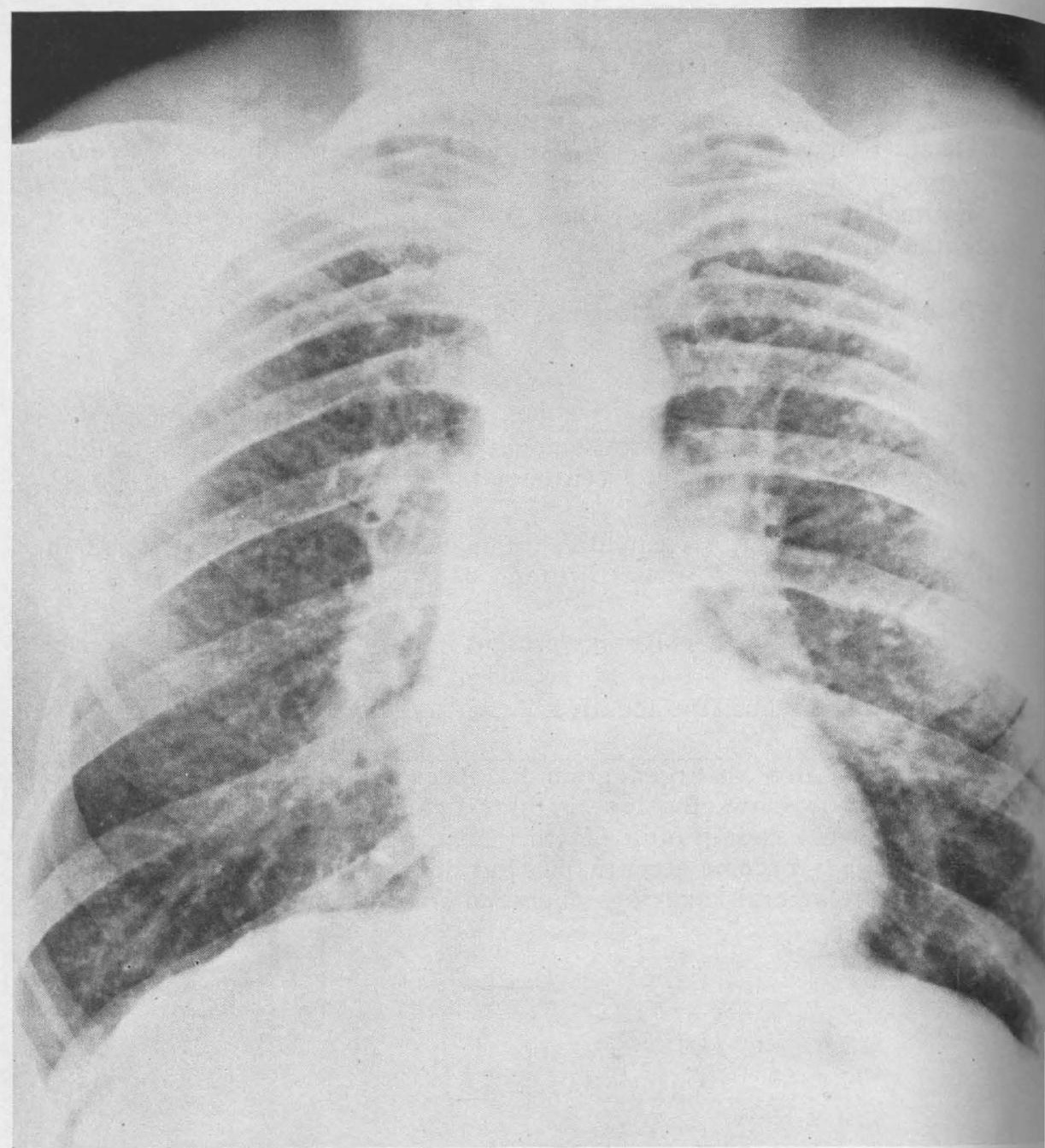

FIGURE 29-First-stage silicosis, white male, age 32. 


\section{Figure 29-Case History}

Occupational history-Top car man, five years; contract miner, onehalf year; station tender, one year; and mucker, six years.

Estimated dust exposure-Sixteen million particles per cubic foot (weighted average).

Past medical history-Pneumonia in childhood; frequent colds in past few years. Weight loss in past six months, six pounds. Otitis media with drainage, 1916; occasional sinusitis; tonsillectomy, 1925.

Present complaints-Frequent colds with sinusitis for past four years.

Physical examination-Average appearance; height, $681 / 2$ inches; weight, 160 pounds; chest expansion, 10 centimeters; chest findings, negative.

Fluoroscopy - Soft granular appearance with almost complete obliteration of linear markings throughout both lungs. Movement of diaphragm not restricted.

Film-Diffuse granular appearance, linear markings obliterated. Slight emphysema in the bases; right cardiophrenic angle slightly obliterated; both costophrenic angles shallow.

Diagnosis-First-stage silicosis.

Comment-This film demonstrates a well-defined first-stage of simple silicosis. The past history and present complaints are fairly typical. The physical findings in the chest are negative. The film, however, has a fairly heavy and uniform infiltration of granular markings which are becoming nodular in the periphery of the upper halves of both lungs. 


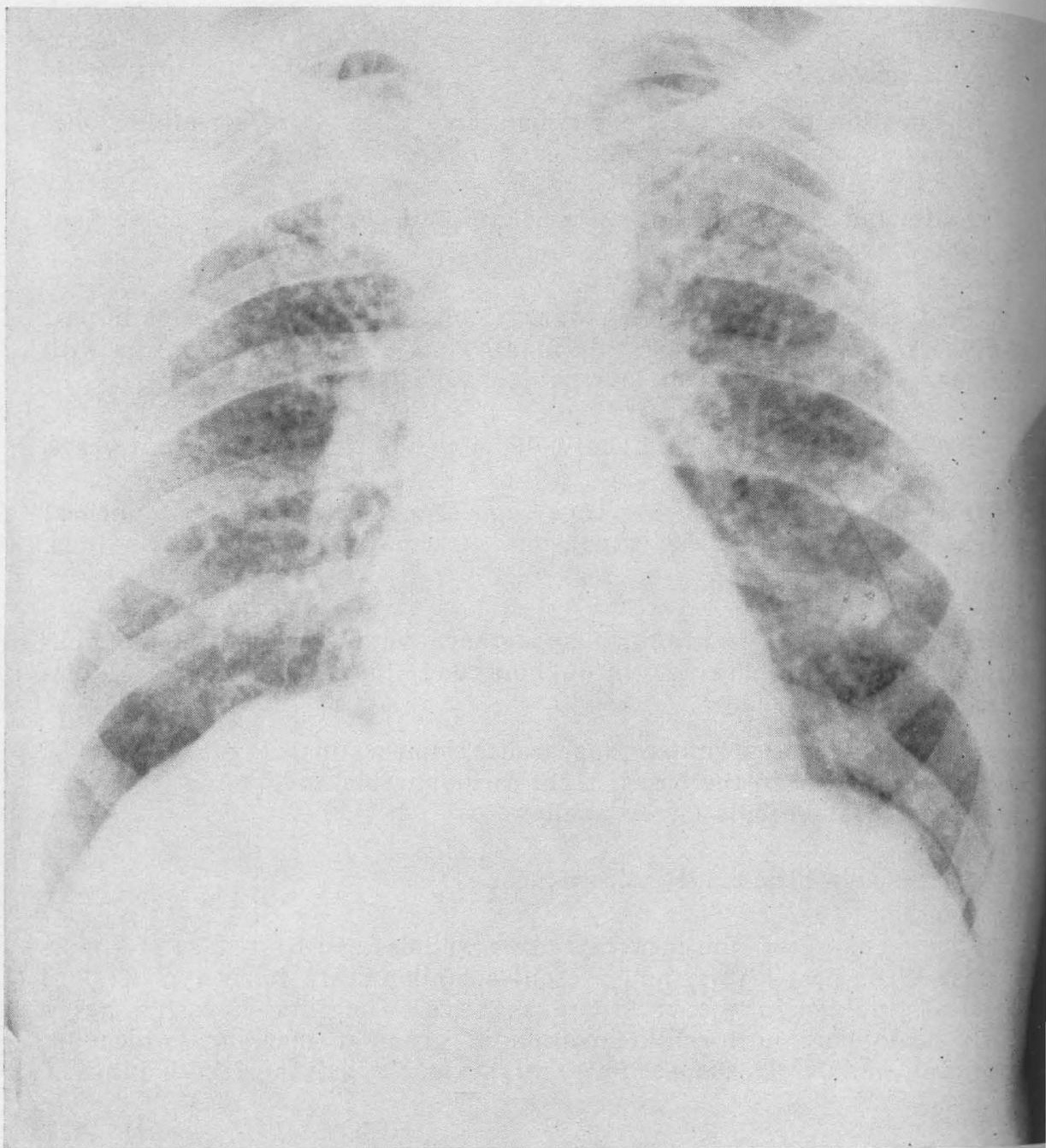

FIGURE 30-Second-stage silicosis, white male, age 63 . 


\section{Figure 30-Case History}

Occupational history-General mining, 16 years; sheep herding, 30 years; farming, four years.

Estimated dust exposure - Thirty-one million particles per cubic foot (weighted average).

Past medical history-Appendectomy, 1919; influenza in 1934, 1936, and 1937; occasional abdominal cramps, 1938.

Present complaints-Mild shortness of breath for the past year on exertion.

Physical examination-Average appearance; height, 64 inches; weight, 134 pounds; chest expansion, 6 centimeters; breath sounds, rough; wet, coarse, nonpersistent rales in the right middle lobe anterior.

Fluoroscopy-Early nodulo-conglomerate markings throughout both lungs. Movement of diaphragm moderately restricted.

Film-Shows diffuse nodular shadows throughout both lungs and beginning coalescence of nodular markings in both the upper thirds. Linear markings are obliterated. Slight emphysema in bases.

Diagnosis-Second-stage silicosis.

Comments-The past history and dyspnea are suggestive of a more chronic condition. Rales are often found in this stage of involvement because of the associated bronchitic or bronchiolitic changes. The above findings, together with the heavy mottled appearance in the roentgenogram and fairly long exposure, give a good description of this stage of involvement. 


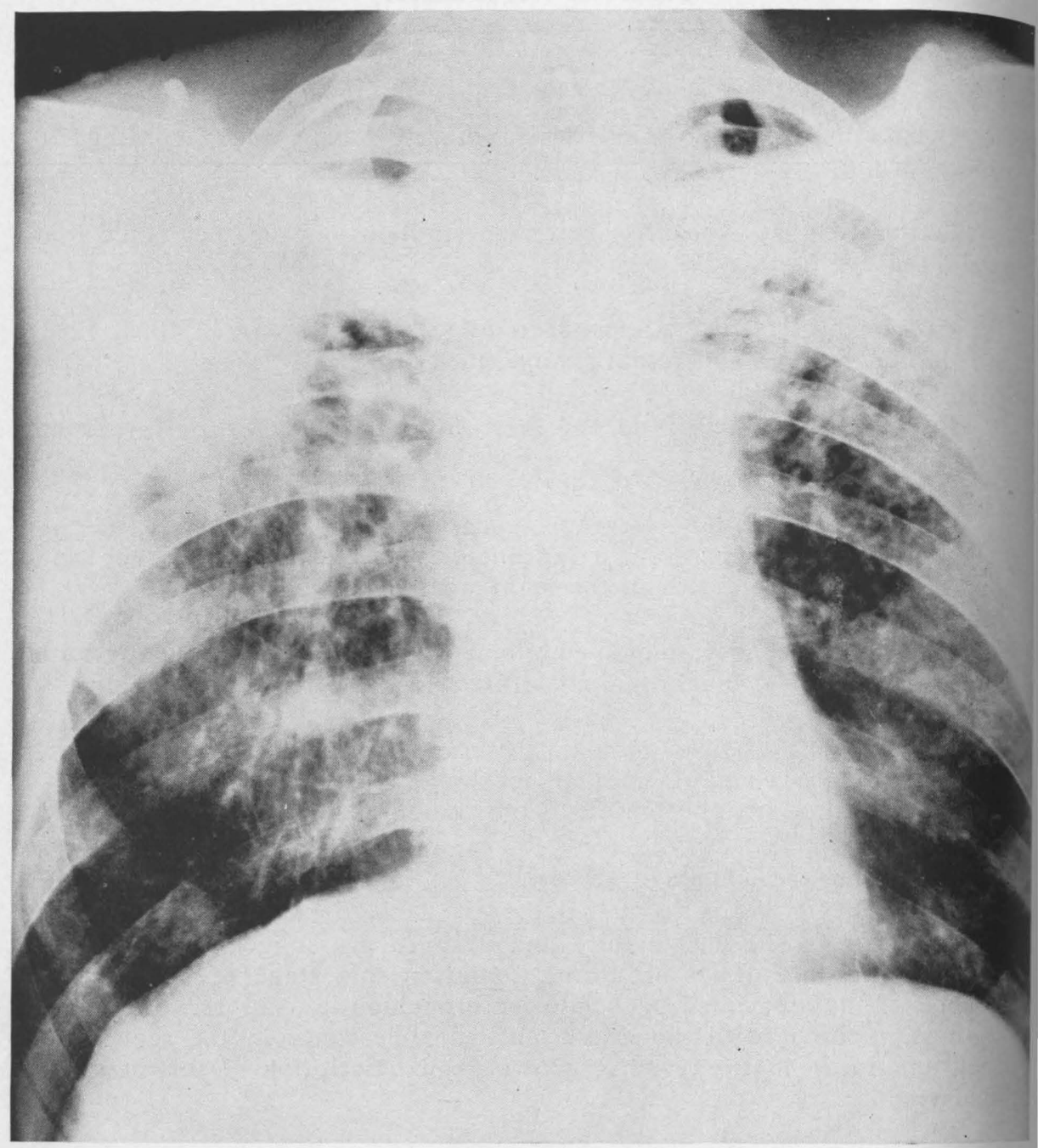

FIGURE 31-Second-stage silicosis with infection, white male, age 47 . 
Figure $31-$ Case History

Occupational history-Timberman, 121/2 years; mucker, 141/2 years.

Estimated dust exposure - Twenty-nine million particles per cubic foot (weighted average).

Past medical history-Pneumonia of the right base, 1925; severe cold, 1936.

Present complaints-None.

Physical examination-Cachectic appearance; height, 69 inches; weight, 160 pounds; chest expansion, 8 centimeters; retracted fossa on inspection; interscapular dullness; breath sounds rough in interscapular region.

Fluoroscopy-Coalescing nodular shadows throughout both lungs. Movement of the diaphragm moderately restricted.

of nodular marking in the left upper third. Large irregular dense infiltration in the right infraclavicular region. Moderate emphysema present at both bases, especially the right. There is mediastinal distortion with heavy bands pulling on both diaphragms.

Diagnosis-Second-stage silicosis plus infection.

Comment-This case is similar to that of other metal miners who have worked over twenty years at timbering and mucking. The irregular fibroid areas, soft nodulation, and long shadows in the right base, the mediastinal distortion, and asymmetry of markings, together with the history and physical examination, all suggest an infective condition with well-advanced silicosis. 


\section{Pulmonary Tuberculosis Among Metal Mine Workers}

Two broad classifications of pulmonary tuberculous disease are gen. erally recognized by X-ray: the healed (or healing) primary or child. hood type of tuberculosis, and the adult or reinfection type of tuberculous lesion (14).

A primary lesion in the adult is usually characterized by the appearance of small, often dense, opacities in the lymph nodes o f the hilus, or at the site of the original infection in the lung parenchyma (15). This infection occurs chiefly during early life, but might appear later in those persons not exposed to the disease until after adolescence. Usually no symptoms are noted in the development of this pulmonary lesion and the patient is neither disabled nor likely to transfer the disease to others in the community, provided that the infection is arrested at this point and becomes encapsulated.

The adult or reinfection type of tuberculosis may or may not be preceded by a demonstrable primary lesion. It is recognized by its anatomic distribution and peculiarities of its appearance on the X-ray film. It is possible for an infection of this kind to precipitate no recognizable symptoms and to become arrested or quiescent while the patient is performing his usual activities. Very frequently, however, the disease progresses, the patient is disabled, and he becomes a source of tuberculous infection to his fellow workers and others in his community.

In the analysis of the examination records made of this study, the diagnosis of tuberculosis was reached only after careful consideration and review by several physicians, and in the same manner as that described previously in the diagnosis of silicosis. All questionable cases with insufficient clinical evidence were regarded as essentially negative.

Reinfection Tuberculosis - Table 46 shows the distribution of both primary and reinfection tuberculous lesions in 727 metal mine workers, according to age. It is noted that 18 mine workers have reinfection tuberculosis, an incidence of 2.5 percent. This prevalence is about the same as that observed in 507 Utah coal mine workers (2.6 percent) but less than half that found in 1,391 Utah smelter employees (5.4 percent). This incidence figure for metal mine workers approximates that reported for the general adult male population. A study of tuberculosis in Framing. ham, Massachusetts (16) revealed that about 1 percent suffered from the active form of the disease and another 1 percent had arrested tuberculosis. The Life Extension Institute (17) examined 100,924 adult white males and a prevalence rate of tuberculosis of 1.5 percent was indicated when suspected cases were included. In a study of 10,000 male industrial workers (5), the Public Health Service found 2.5 percent affected with pulmonary tuberculosis. In the Tri-State district for the year 1929 (10), the incidence of tuberculosis was 3.8 percent.

Table 46 also shows an appreciable age trend in the case of reinfection tuberculosis. From the standpoint of diagnosis of silicosis (Table 47) it becomes apparent that the percent affected with reinfection tuberculosis is directly proportional to the degree of lung involvment due to dust. The 1 percent incidence of reinfection tuberculosis in the 619 mine workers not affected with silicosis is as low or lower than in the general population. The borderline group has a percentage seven times as high, and of the workers classified as having first- and second-stage silicosis 13.6 percent 


\section{TABLE 46-Number and Percent of Cases of Primary and Reinfection Tuberculosis Found on Examination of Metal Mine Workers, Classified By Age.}

\begin{tabular}{|c|c|c|c|c|c|}
\hline \multirow[b]{2}{*}{ Age } & \multirow{2}{*}{$\begin{array}{l}\text { Number of } \\
\text { workers in } \\
\text { age group }\end{array}$} & \multicolumn{2}{|c|}{ Primary tuberculosis } & \multicolumn{2}{|c|}{ Reinfection tuberculosis 1} \\
\hline & & $\begin{array}{c}\text { Number of } \\
\text { workers }\end{array}$ & $\begin{array}{c}\text { Percent of } \\
\text { workers }\end{array}$ & $\begin{array}{c}\text { Number of } \\
\text { workers }\end{array}$ & $\begin{array}{l}\text { Percent of } \\
\text { workers }\end{array}$ \\
\hline All ages & 727 & 116 & 16.0 & 18 & 2.5 \\
\hline $15-24$ & 83 & 11 & 13.3 & $\cdots$ & … \\
\hline 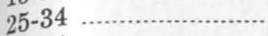 & 323 & 40 & 12.4 & 2 & .6 \\
\hline$\ldots \ldots \ldots \ldots \ldots$ & 172 & 24 & 14.0 & 2 & 1.2 \\
\hline $45-54$ & 104 & 30 & 28.8 & 9 & 8.7 \\
\hline 55 and over & 45 & 11 & 24.4 & 5 & 11.1 \\
\hline
\end{tabular}

Reinfection or adult type including those with primary lesions.

have reinfection tuberculosis, or nearly fourteen times the percentage of the non-affected group.

The classification of the cases studied according to the degree of activity is more or less arbitrary since only one film was available for each man examined. Nevertheless, the classification is dictated by certain rather well-established standards of X-ray interpretation. In the cases classified as active the lesions appeared as soft, infiltrating shadows in the lung parenchyma accompanied by symptoms of tuberculosis elicited in the history or signs revealed by the physical examination. In the quiescent, apparently healed or arrested cases the lesions were more sharply defined, usually with some evidence of scarring, and accompanied by no symptoms or signs referrible to tuberculous infection. With reference to the degree of tuberculous lung involvement, 14 were minimal and four moderately advanced. The four who had moderately advanced tuberculosis were thought to show activity on the basis of physical findings and X-ray; they also had silicosis. The other 14 were quiescent, apparently arrested or healed.

TABLE 47-Incidence of Reinfection Tuberculosis Among Metal Miners, Classified by Diagnosis of Silicosis.

\begin{tabular}{|c|c|c|c|}
\hline \multirow{2}{*}{ Diagnosis of silicosis } & \multirow{2}{*}{$\begin{array}{c}\text { Number of } \\
\text { workers }\end{array}$} & \multicolumn{2}{|c|}{ With reinfection tuberculosis } \\
\hline & & Number & Percent \\
\hline Total & 727 & 18 & 2.5 \\
\hline Non-affected & 619 & 6 & 1.0 \\
\hline Borderline & 42 & 3 & 7.1 \\
\hline First stage …………… & 42 & 4 & 9.5 \\
\hline Second stage & 24 & 5 & 20.8 \\
\hline
\end{tabular}

Primary Tuberculosis - There is fair general agreement that calcified pulmonary nodules are of no clinical significance at any age. Calcified tracheobronchial lymph nodes in young adults indicate severe exposure to tuberculosis in childhood, but there is no incontrovertible evidence that such persons are particularly liable to tuberculosis in later life. Fellows (18) found no significant difference in the development rate of pulmonary tuberculosis in a serial chest roentgenological study of 3,179 office employees from 1926 to 1938 , whose first roentgenogram of the chest was classified as average, healthy, or negative chest when compared to a similar group whose first roentgenogram showed a healed primary complex. 
Table 46 also shows the number and percent of metal mine worke with healed primary tuberculosis, grouped according to age. It is seen tha 16 percent of the metal mine workers have evidence of a primary lesion shown by X-ray. In a group of 801 male office workers, Fellows foun 87 or 10.9 percent with healed primary tuberculosis. The incidence of primary lesions has a tendency to increase with age (Table 46.) A similar age trend was observed by Fellows (18). Previous dust investigations made by the Public Health Service (1) (7) also show this age trend. The findings in the present investigations as well as earlier Public Health studies indicate that a healed primary complex does not appear to be a contraindication for employment in a dusty trade.

\section{Lead Poisoning Among Metal Mine Workers}

\section{Past History of Lead Poisoning}

Lead poisoning has been known to be an industrial disease of the metal mine workers in Utah for a number of years. Murray's studies (19) demonstrated the frequency of the disease and showed that the incidence of disabling plumbism was related to the type of ore mined. The inci. dence in lead mines is lowest in those workings where lead sulphide ore is being extracted and highest in lead carbonate ores. This finding is in conformity with general opinion (20).

On the basis of the information in the past medical histories of all metal mine workers examined in the summer of 1939, it is apparent that lead poisoning is still an industrial health problem among the personnel employed in this group of mines. The number of cases giving a history of lead poisoning, according to the time of occurrence of disabling acute episode and the present age of the individual, is shown in table 48. Of the 727 metal mine employees ${ }^{1}$ examined, 102 (table 48) gave a history of acute episodes of lead intoxication. Nineteen mine workers reported that they had had acute episodes within the past four and one-half years (1935. 1939). In a few of these cases the period of disability was recent, antedating the study by only a few months. The majority of the acute episodes as the table shows, occurred among workers under 30 years of age. This high prevalence in the younger age groups is comparable to experience elsewhere (21).

\section{TABLE 48-Number of Cases Giving History of Lead Poisoning According to Present Age and Date of Disability.}

\begin{tabular}{|c|c|c|c|c|c|c|c|}
\hline \multirow[b]{2}{*}{ Present age } & \multicolumn{7}{|c|}{ Time of occurrence of acute lead episode } \\
\hline & $\begin{array}{c}\text { Prior to to } \\
1915\end{array}$ & $\begin{array}{l}1915- \\
1919\end{array}$ & $\begin{array}{l}1920- \\
1924\end{array}$ & $\begin{array}{l}1925- \\
1929\end{array}$ & $\begin{array}{l}1930- \\
1934\end{array}$ & $\begin{array}{l}1935- \\
19391\end{array}$ & Total \\
\hline $20-29$ & $\ldots .$. & $\ldots$. & & 3 & 6 & 10 & 19 \\
\hline 30-39. & ..... & .... & 3 & 11 & 15 & 5 & 34 \\
\hline $40-49$ & 2 & 3 & 4 & 5 & 11 & 4 & 29 \\
\hline $50-59$ & 3 & 1 & 2 & 5 & 5 & .... & 16 \\
\hline 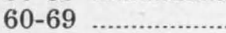 & & & 2 & & 2 & .... & 4 \\
\hline Total & 5 & 4 & 11 & 24 & 39 & 19 & 102 \\
\hline
\end{tabular}

1 Only part of 1939.

1 Of the 56 miners with a mixed occupational exposure (p. 168), eight gave a history of acute episodes of lead poisoning. One of these was convalescing at the time of examination. 
The duration of the disability in recent years seldom exceeded two months and in most instances lasted only two or three weeks. The disabling symptoms were predominantly of a gastrointestinal nature. According to Belknap (22), this is the most common type of industrial lead poisoning. It is manifested by typical lead constipation and violent abdominal pain which is called lead colic. Associated with these gastrointestinal symptoms, there is a corresponding rise in stippled cell count and related erythrocytic changes. No instances of lead palsy or encephalopathy were reported in these past medical histories.

As Kehoe, et al (23) has shown, there are safe levels of lead intake. With the recently introduced and more refined methods of lead analysis (24) (25) of biological specimens, it has become increasingly apparent that even the so-called normal nonexposed individual may have measurable amounts of lead in his blood and excreta. The lead intake of nonexposed individuals has been shown to be somewhat less than $0.5 \mathrm{mg}$ per day and probably is about 0.2 to $0.3 \mathrm{mg}$ per day $(23,26)$. The so-called threshold limit of intake before clinical plumbism ordinarily develops in industrial workers is $1.5 \mathrm{mg}$ of lead per $10 \mathrm{~m}^{3}$ of air (25). This threshold is approximately the same as that determined by Legge and Goadby in Great Britain (27). Table 49 shows that nearly one-half of the workers were exposed at the time of the study to lead concentrations exceeding the above threshold. This table also shows that the great proportion of mine employees having this exposure also had a high weighted average dust exposure, and suggests that the lead problem, like the dust problem, is essentially one of face workers.

\section{TABLE 49-Relation of Weighted Silica Dust Concentration to Present Lead Exposure.}

\begin{tabular}{|c|c|c|c|c|c|c|c|c|}
\hline \multirow{3}{*}{$\begin{array}{l}\text { Dust concentration, million } \\
\text { particles per cubic foot }\end{array}$} & \multicolumn{6}{|c|}{ Lead exposure, $\mathrm{mg}$ of lead per $10 \mathrm{cu} . \mathrm{m}$. of air } & \multirow{2}{*}{\multicolumn{2}{|c|}{ Total }} \\
\hline & \multicolumn{2}{|c|}{ Less than 0.3} & \multicolumn{2}{|c|}{$0.3-1.5$} & \multicolumn{2}{|c|}{ More than 1.51} & & \\
\hline & No. & Percent & No. & Percent & No. & Percent & No. & Percent \\
\hline Total ...... & 104 & 100.0 & 266 & 100.0 & 355 & 100.0 & $725^{2}$ & 100.0 \\
\hline $0-5.9 \ldots$ & 21 & 20.2 & 13 & 4.9 & 4 & 1.1 & 38 & 5.2 \\
\hline $6.0-11.9$ & 44 & 42.3 & 44 & 16.6 & 9 & 2.5 & 97 & 13.4 \\
\hline $12.0-17.9$ & 25 & 24.1 & 65 & 24.4 & 25 & 7.1 & 115 & 15.9 \\
\hline $18.0-23.9 \ldots \ldots . .$. & 7 & 6.7 & 94 & 35.3 & 171 & 48.2 & 272 & 37.5 \\
\hline 24.0 and over... & 5 & 4.8 & 42 & 15.8 & 140 & 39.4 & 187 & 25.8 \\
\hline 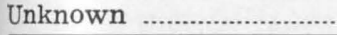 & 2 & 1.9 & 8 & 3.0 & 6 & 1.7 & 16 & 2.2 \\
\hline
\end{tabular}

Average exposure for group centers about 3.7.

2 Excludes two workers with known dust concentration but with unknown lead exposure.

\section{Estimate of Present Incidence of Abnormal Lead Absorption}

Only actively employed persons were examined. Out of the total of 727 mine employees, the case records of 141 were selected for intensive study because of some sign or symptom indicative of abnormal lead absorption. While, according to the past medical histories, a few instances of acute episodes had occurred amongst this population within a few months prior to the investigation, no man had a combination of signs or symptoms that warranted a diagnosis of lead intoxication causing disability or lost time. In only 75 of these 141 did a diagnosis of latent plumbism (abnormal lead absorption) seem justified. The sense of well being of these men was unaffected, but each of these cases had a combination of 
at least three of the symptoms or signs associated with abnormal lead absorption.

The subjective and objective signs and laboratory findings, noted in the 75 metal mine workers affected with abnormal lead absorption (latent plumbism), are shown in table 50 . It will be observed that metallic gum line, constipation, and other gastrointestinal complaints were the most common signs. Basophilic stippling was observed in 77 percent of the blood films. It will also be observed that no one sign is common to all those affected.

\section{TABLE 50-Frequency of Occurrence of Certain Signs and Laboratory Findings Among 75 Metal Mine Workers With Abnormal Lead Absorption.}

\begin{tabular}{|c|c|c|}
\hline Signs and laboratory findings & $\begin{array}{l}\text { Percent of } \\
\text { workers }\end{array}$ & $\begin{array}{c}\text { Number of } \\
\text { workers }\end{array}$ \\
\hline Number of workers affected.. & & 75 \\
\hline Metallic line 1 ............................... & 35.5 & 22 \\
\hline Loss of weight & 32.0 & 24 \\
\hline Constipation and other gastrointestinal complaints... & 30.7 & 23 \\
\hline 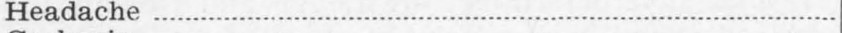 & 24.0 & 18 \\
\hline 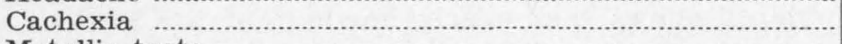 & 8.0 & 6 \\
\hline Metallic taste ...... & 6.7 & 5 \\
\hline Weakness & 6.7 & 5 \\
\hline Tremor & 6.7 & 5 \\
\hline Arthralgia …….................................... & 5.3 & 4 \\
\hline 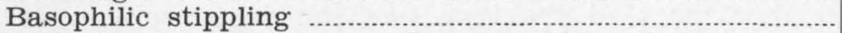 & 77.3 & 58 \\
\hline 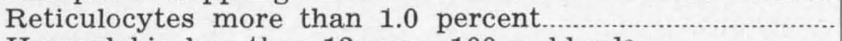 & 32.0 & 24 \\
\hline Hemoglobin less than $12 \mathrm{~g}$ per $100 \mathrm{cc}$ blood $^{2} \ldots \ldots \ldots \ldots \ldots \ldots$ & 17.4 & 12 \\
\hline Urinary lead more than $0.05 \mathrm{mg}^{3} \ldots \ldots \ldots \ldots \ldots$ & 50.0 & 10 \\
\hline Albuminuria & 5.3 & 4 \\
\hline History of previous attacks of lead poisoning.. & 14.7 & 11 \\
\hline
\end{tabular}

\footnotetext{
1 Percentage is based on 62 workers; 13 were found with full dentures.

2 Hemoglobin values were known for 69 workers.

3 Quantitative urinary lead analyses were made on 20 workers.
}

Two-thirds of these 75 cases were employed at the face and about one-third were employed as timbermen, transportation, and maintenance personnel. Isolated cases occurred in mechanics, carpenters, blacksmiths, and bosses. One case ${ }^{1}$, a machine man of 32 years of age, was apparently convalescing from a mild episode. He suffered with constipation, metallic taste, acid eructations, slight evidence of bone marrow irritation (one percent reticulocytes, 40 stippled cells per 100,000 red blood cells, hemoglobin, $12 \mathrm{~g}$ (Newcomer)), and had a urinary lead concentration of $0.04 \mathrm{mg}$ per liter. This was the most severe form of toxic lead involvement encountered.

Two of four cases of nystagmus observed among the metal mine workers have a past history of lead poisoning.

Some measure of the lead exposure and the degree of lead absorption of these workers may be observed in table 51, wherein the results of the lead content of the urine of metal mine workers are compared with those of coal miners who had no industrial lead exposure. It is observed that all workers, even coal miners, showed lead in their urine. The important finding, however, is that 78.1 percent of the metal mine workers showed

1 Another similar case was observed in the mixed occupational exposure group. 
moderate and heavy amounts of lead in their urine, whereas 10.8 percent of the coal miners showed more than faint traces. Attention is called to the fact, however, that urine was obtained for spectrographic analysis on only 178 or about 24 percent of the metal mine employees examined (see Appendix III).

\section{TABLE 51-A Comparison of the Results of Spectrographic Tests for Urinary Lead Content.}

\begin{tabular}{|c|c|c|c|c|c|}
\hline \multirow[b]{2}{*}{ Study } & & \multicolumn{4}{|c|}{ Urinary lead concentration } \\
\hline & & Total & $\begin{array}{l}\text { Faint } \\
\text { trace }\end{array}$ & Moderate & Heavy \\
\hline $\begin{array}{l}\text { Coal mines } \\
(507 \text { workers })\end{array}$ & 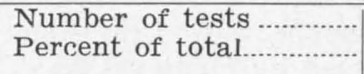 & $\begin{array}{l}195 \\
100.0\end{array}$ & $\begin{array}{r}174 \\
89.2\end{array}$ & $\begin{array}{l}20 \\
10.3\end{array}$ & $\begin{array}{l}1 \\
0.5\end{array}$ \\
\hline $\begin{array}{l}\text { Metal mines } \\
(727 \text { workers })\end{array}$ & $\begin{array}{l}\text { Number of tests .. } \\
\text { Percent of total.... }\end{array}$ & $\begin{array}{l}178 \\
100.0\end{array}$ & $\begin{array}{l}39 \\
21.9\end{array}$ & $\begin{array}{l}136 \\
76.4\end{array}$ & $\begin{array}{l}3 \\
1.7\end{array}$ \\
\hline
\end{tabular}

It is apparent that the lead hazard in metal mines, based on these observations, is less severe than it was 20 to 25 years ago. This improved incidence and severity rate is probably related to the use of wet mining methods in the past 20 years, improved ventilation, more abundant mining of sulphide instead of carbonate ores, personal respiratory protection, and probably closer medical supervision of the personnel.

\section{Dermatologic Conditions}

Dermatitis and other dermatologic conditions were observed in 61 metal mine workers. These skin affections, in general, were of minor character, and were not extensive or prone to be disabling. Irritative and contact dermatitis, some of which were thought to be "sulphide rashes" were observed in 14 men, all of whom were face workers. Acne vulgaris was observed in 19 men and psoriasis in eight men. Other skin affections observed included such conditions as scabies, pityriasis rosae, urticaria, impetigo, and furunculosis.

\section{Headaches}

Complaints of headaches were much more frequent among metal mine workers than among coal mine and smelter workers, the percentages being 16.0, 6.9, and 7.0, respectively. However, surface workers and all underground workers, except those working at the face in metal mines, did not show appreciably greater incidence of headaches than that found for the other Utah industries studied. In these groups between 5 and 10 percent complained of headaches.

Among metal mine workers occupied at the face, the percent with headaches was 23.7. This excess at the face suggests the possibility of inadequate ventilation which allows the accumulation of gases, dust, and fumes after blasting (p. 158). "Powder" headaches were often reported by metal mine workers. Although working conditions were somewhat different in the three mines studied, the percent of face workers complaining of headaches was nearly the same, varying from 21 to 27 percent.

\section{Disease of the Heart and Vascular System}

Table 52 shows that 149 (20.5 percent) of the mine workers examined 
were 45 years of age or older. This older age group presents a special health problem which cannot be divorced from age, and the one disease that stands out prominently on statistical analysis is cardiovascular disease of the arteriosclerotic-hypertensive type. As Steiglitz (28) has stated, "of all the diseases to which adult man is heir, the cardiovascular-renal dis. eases are the most frequent cause of death today. Heart disease is very often but a part of a generalized hypertensive arterial disease, and renal failure, likewise, is not uncommonly secondary to arterial disease."

Table 52 shows the frequency distribution of certain forms of heart disease, by age, compared with 1,627 white male potters. The cases were classified under broad, etiological headings in accordance with a scheme prepared by the Heart Committee of the New York Tuberculosis and Health Association (29) which was sponsored by the American Heart Asso. ciation, and as modified and discussed by Hedley (30).

As in other studies by the Public Health Service, it is the arteriosclerotic-hypertensive group of heart diseases which is the most prevalent. As Hedley (30) points out, this is a more heterogeneous group than any of the others, involving the interplay of a number of factors. The structural change of arteriosclerosis and the physiological alteration of increased arterial tension, resulting in a greater load on the myocardium, each play a part. Frequently it is impossible to ascribe to each its relative significance. It includes (a) the so-called "chronic myocarditis" in which myo. cardial degeneration due to coronary arteriosclerosis is accompanied by impaired cardiac function, usually by well-marked beading of the peripheral arteries and sometimes by arterial hypertension. At present (31) almost all of these degenerative diseases of the heart that were termed "chronic myocarditis" a generation ago are known to have as their basis disease of the coronary arteries or their branches. This disease of the coronary arteries leads to gradual or sudden impairment of the coronary circulation and to necrosis of smaller or larger areas of the muscle fibers, with resulting fibrosis and scarring. The term "myocardosis" has been suggested to distinguish myocardial degeneration from inflammatory conditions. Other forms of heart disease included under the general etiological heading of arteriosclerotic-hypertensive heart disease include (b) hypertensive heart disease, in which well-established, persistent arterial hypertension is associated with enlarged heart and in which there may or may not be discernible arteriosclerosis; (c) essential hypertension with no other signs of organic disease; and (d) less frequently, valvular heart disease due to sclerotic changes in the valve cusps and ring (usually of the aortic valve) with no demonstratable evidence of syphilis.

The rheumatic group of heart diseases, on the basis of these data, is slightly more prevalent among metal mine workers than among potters. This finding is consistent with Hedley's studies on heart mortality among persons five to 24 years of age (32). The mortality rate for rheumatic heart diseases in this age group is much higher in Utah than for other States in the United States registration area. Viko in his study of 1,000 cases (33) also observed that although the Rocky Mountain States of Utah, Idaho, and Wyoming have a relatively low cardiac mortality rate, the incidence of rheumatic heart disease was higher in these States than in the remainder of the United States. Those observed in the older age groups of metal mine workers probably represent persons who have survived acute 
TABLE 52-Incidence of Heart Disease Among Metal Mine Workers, Classified According to Age, and Compared With Pottery Workers.

\begin{tabular}{|c|c|c|c|c|c|c|c|c|c|c|c|}
\hline \multirow[b]{3}{*}{ Age } & \multicolumn{7}{|c|}{ Metal mines } & \multicolumn{4}{|c|}{ Pottery manufacture } \\
\hline & \multirow[b]{2}{*}{$\begin{array}{l}\text { Number } \\
\text { in age } \\
\text { group }\end{array}$} & \multicolumn{3}{|c|}{ Number with heart disease 1} & \multicolumn{3}{|c|}{ Percent with heart disease } & \multirow[b]{2}{*}{$\begin{array}{l}\text { Number } \\
\text { in age } \\
\text { group }\end{array}$} & \multicolumn{3}{|c|}{ Percent with heart disease 2} \\
\hline & & $\begin{array}{l}\text { Arterio- } \\
\text { sclerotic } \\
\text { hyper- } \\
\text { tensive }\end{array}$ & Rheumatic & Functional & $\begin{array}{l}\text { Arterio- } \\
\text { sclerotic } \\
\text { hyper- } \\
\text { tensive }\end{array}$ & Rheumatic & Functional & & $\begin{array}{l}\text { Arterio- } \\
\text { sclerotic } \\
\text { hyper- } \\
\text { tensive }\end{array}$ & Rheumatic & Functional \\
\hline All ages ............................. & 727 & 49 & 17 & 14 & 6.7 & 2.3 & 1.9 & 1,627 & 4.5 & 1.0 & 0.1 \\
\hline $15-24$ & 83 & 4 & 2 & 1 & 4.8 & 2.4 & 1.2 & 350 & $\ldots . .$. & 1.1 & 0.3 \\
\hline $25-34$ & 323 & 4 & 6 & 6 & 1.2 & 1.9 & 1.9 & 549 & 0.9 & 0.7 & $\ldots$. \\
\hline 35-44 …............................. & 172 & 13 & 4 & 1 & 7.6 & 2.3 & 0.6 & 370 & 2.2 & 1.1 & .... \\
\hline $45-54$ & 104 & 14 & 4 & 5 & 13.5 & 3.8 & 4.8 & 221 & 11.3 & 1.8 & $\cdots$. \\
\hline 55 and over & 45 & 14 & 1 & 1 & 31.1 & 2.2 & 2.2 & 137 & 25.5 & .... & $\ldots$. \\
\hline
\end{tabular}

1 One case of syphilis of heart or aorta, and one of toxic heart disease were also found among metal mine workers.

2 Three cases of syphilis of heart or aorta and one case of toxic heart disease were also found among pottery workers. 
cardiac phenomena of adolescence, but still present clinically demonstra. ble cardiac residuals.

The 14 cases classified under the functional type included several with cardiac murmurs and premature contractions. One man with a clinical history of infection, treatment, and positive serology showed roentgeno. graphic evidence of luetic aortitis. One case was classified as toxic heart disease-toxemia apparently being due to thyroid disease. No frankly decompensated cases were observed among these 727 mine workers.

On the whole, cardiovascular diseases do not seem more prevalent in Utah metal mine workers than in potters (1) and in other large groups of employed industrial workers who have been studied by the Public Health Service (5). It is of interest to note that metal mine workers, as well as the comparison group of potters, have some degree of exposure to lead or its compounds, and to siliceous dusts. When compared with coal mine workers of Utah who have a low siliceous dust or no lead exposure, the data reveal a close agreement in incidence rates. A similar finding is observed when cardiovascular diseases of these metal mine workers are compared with those of truck drivers. Thus it would appear, on the basis of these findings, that dust and lead exposure of these metal mine workers has no particular influence on cardiovascular diseases.

\section{Cardiovascular Signs}

Among the signs used in arriving at a diagnosis of heart disease were enlarged heart, systolic arterial tension in excess of $150 \mathrm{~mm}$ of mercury, diastolic arterial tension in excess of $100 \mathrm{~mm}$ of mercury, arteriosclerosis, poor response to test exercise, abnormal cardiac rhythm, and cardiac murmurs. In the diagnosis of individual cases, symptoms and past medical history aided in deciding on the etiology of the cardiovascular impairment. Owing to their relatively high prevalence, hypertension and arteriosclerosis are two findings which will be presented in some detail.

Blood Pressure - Average systolic blood pressures for workers classified into five-year-age groups (Table 53) are slightly but consistently lower among metal mine workers than other industrial workers $(1,5)$ examined by the Public Health Service. On the other hand, average diastolic blood pressures are slightly above the averages observed in these other investigations for particular age groups.

\section{TABLE 53-Average Systolic and Diastòlic Blood Pressures of Metal Mine Workers, By Age, and Compared with 10,000 Male indus- trial Workers (5)}

\begin{tabular}{|c|c|c|c|c|c|c|c|}
\hline \multirow{2}{*}{\multicolumn{2}{|c|}{ Age }} & \multicolumn{3}{|c|}{ Metal mine workers } & \multicolumn{3}{|c|}{10,000 male industrial workers } \\
\hline & & $\begin{array}{l}\text { Average } \\
\text { systolic } \\
\text { blood } \\
\text { pressure }\end{array}$ & $\begin{array}{l}\text { Average } \\
\text { diastolic } \\
\text { blood } \\
\text { pressure }\end{array}$ & $\begin{array}{c}\text { Number } \\
\text { of } \\
\text { persons } \\
\text { tested }\end{array}$ & $\begin{array}{l}\text { Average } \\
\text { systolic } \\
\text { blood } \\
\text { pressure }\end{array}$ & $\begin{array}{l}\text { Average } \\
\text { diastolic } \\
\text { blood } \\
\text { pressure }\end{array}$ & $\begin{array}{c}\text { Number } \\
\text { of } \\
\text { persons } \\
\text { tested }\end{array}$ \\
\hline Under & $25 \ldots \ldots \ldots \ldots \ldots \ldots$ & 124 & 78 & 82 & 123 & 72 & 1,264 \\
\hline $25-29$ & .................. & 123 & 78 & 167 & 126 & 75 & 1,122 \\
\hline $30-34$ & …................... & 122 & 77 & 151 & 127 & 77 & 1,055 \\
\hline $35-39$ & ............... & 122 & 78 & 98 & 128 & 79 & 1,026 \\
\hline $40-44$ & …………..... & 127 & 84 & 74 & 130 & 80 & 782 \\
\hline $45-49$ & 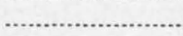 & 127 & 83 & 61 & 135 & 81 & 613 \\
\hline $50-54$ & 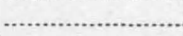 & 132 & 85 & 43 & 139 & 82 & 365 \\
\hline 55 and & over 1 ............... & 138 & 88 & 45 & 147 & 84 & 440 \\
\hline
\end{tabular}

1 Includes one person over 65 years of age. 
Hypertension - The arbitrary standards of arterial systolic tension in excess of $150 \mathrm{~mm}$ of mercury and diastolic tension in excess of $100 \mathrm{~mm}$, which have been used to define hypertension, agree closely with those suggested by Stieglitz and others (28) (34). In spite of differences in occupational exposure of employees in three Utah industries of coal mining, metal mining, and smelting, the percentage of workers with hypertension in the specific age groups is nearly the same, as shown in the table in Appendix V. When compared with pottery and other industrial workers, the percentage of workers in Utah metal mines showing hypertension is consistently lower. A similar observation was made for Utah coal mine and smelter employees. It is of interest to note in this connection that in the examinations (35) of drafted men during the World War, Utah was found to rank very low among States in the proportion of men rejected on account of arteriosclerosis and hypertension.

Arteriosclerosis - Seventy-one of the metal mine workers, or 9.8 percent, were found to have arteriosclerosis. This proportion was approximately the same as that found for Utah coal mine and smelter workers, the percentages being 10.3 and 12.9 , respectively. Table 54 shows that there is essentially no difference between metal mine workers and coal mine workers in the prevalence of arteriosclerosis when age is taken into account. The severe grades of vessel involvement are present in only the older age groups.

\section{TABLE 54-Number and Percent of Metal Mine Workers Who Were Found to Have Arteriosclerosis, by Age, and Compared With Coal Mine Workers.}

\begin{tabular}{|c|c|c|c|c|c|c|}
\hline \multirow{3}{*}{ Age } & \multicolumn{3}{|c|}{ Metal mine workers } & \multicolumn{3}{|c|}{ Coal mine workers } \\
\hline & \multirow{2}{*}{$\begin{array}{l}\text { Number } \\
\text { in age } \\
\text { group }\end{array}$} & \multicolumn{2}{|c|}{$\begin{array}{l}\text { With } \\
\text { arteriosclerosis }\end{array}$} & \multirow{2}{*}{$\begin{array}{l}\text { Number } \\
\text { in age } \\
\text { group }\end{array}$} & \multicolumn{2}{|c|}{$\begin{array}{c}\text { With } \\
\text { arteriosclerosis }\end{array}$} \\
\hline & & Percent & Number & & Percent & Number \\
\hline All ages . & 727 & 9.8 & 71 & 507 & 10.3 & 52 \\
\hline $15-24 \ldots \ldots$ & 83 & & 0 & 79 & $\overline{2} .5$ & 2 \\
\hline $25-34$ & 323 & 3.4 & 11 & 170 & 2.4 & 4 \\
\hline 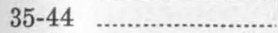 & 172 & 6.4 & 11 & 142 & 5.6 & 8 \\
\hline $45-54$ & 104 & 24.0 & 25 & 88 & 25.0 & 22 \\
\hline 55 and over................... & 45 & 53.3 & 24 & 28 & 57.1 & 16 \\
\hline
\end{tabular}

\section{Syphilis}

A State-wide survey (36) made by the physicians of Utah in 1936 placed the number of syphilitics in Utah at 10,000 . On the basis of estimated population of 521,000 for that year, this would indicate an incidence rate of about 2 percent. Using positive serodiagnostic tests as an index, the incidence in the metal mine workers was even lower, 0.8 percent, though the rate for coal mine and smelter workers was 1.8 and 1.9 percent, respectively, or almost identical to the rate for the State as a whole.

Five of the six positive Kahn tests noted in metal mine workers were four-plus reactions and the other was a three-plus. Since no open lesions were observed, all of these cases are regarded as latent syphilis. These positive tests occurred only in men more than 40 years of age. A diagnosis of leutic aortitis (p. 200) was made in one case and another showed questionable widening of the aorta. 


\section{Summary and Recommendations}

A summation of the medical findings on nonferrous metal mine workers and recommendations for the protection and preservation of their health are included in the general summary and recommendations at the beginning of this report.

\section{References}

1. Flinn, R. H., W. C. Dreessen, T. I. Edwards, E. C. Riley, J. J. Bloom. field, R. R. Sayers, J. F. Cadden, and S. C. Rothmann: Silicosis and lead poisoning among pottery workers. Public Health Bull. 244 Washington, Gov. Print. Off. 1939.

2. Sayers, R. R., J. J. Bloomfield, J. M. DallaValle, R. R. Jones, W. C Dreessen, D. K. Brundage and R. H. Britten: Anthraco-silicosis among hard coal miners. Public Health Bull. 221. Washington, Gov. Print. Off. 1936.

3. Russell, A. E., R. H. Britten, L. R. Thompson, and J. J. Bloomfield: The health of workers in dusty trades. II. Exposure to siliceous dust (granite industry). Public Health Bull. 187. Washington, Gov. Print. Off. 1929.

4. Neal, P. A., R. H. Flinn, T. I. Edwards, W. H. Rheinhart, J. W. Hough, J. M. Dallavalle, F. H. Goldman, and D. W. Armstrong, and A. S Gray, A. L. Coleman, and B. F. Postman: Mercurialism and its control in the felt hat industry. Public Health Bull. 263. Washington, Gov. Print. Off. 1940.

5. Britten, R. H., and L. R. Thompson: A health study of 10,000 male industrial workers. Public Health Bull. 162. Washington, Gov. Print. Off. 1926.

6. Dressen, W. C., J. M. DallaValle, T. I. Edwards, J. W. Miller, R. R. Sayers, H. F. Easom, and M. F. Trice: A study of asbestosis in the asbestos textile industry. Public Health Bull. 241. Washington, Gov. Print. Off. 1938.

7. Dreessen, W. C., J. M. DallaValle, T. I. Edwards, R. R. Sayers, H. F. Easom, and M. F. Trice: Pneumoconiosis among mica and pegmatite workers. Public Health Bull. 250. Washington, Gov. Print. Off. 1940.

8. Sayers, R. R., Silicosis among miners. Bureau of Mines, Technical Paper 372. 1925.

9. Betts, W. B.,: Chalicosis pulmonum or chronic interstitial pneumonia. J. Amer. Med. Assoc. 34: 70-74. 1900.

10. Sayers, R. R., F. V. Meriwether, A. J. Lanza, and W. W. Adams: Silicosis and tuberculosis among miners of the tri-state district of Oklahoma, Kansas, and Missouri. Part 1.-Bureau of Mines, Technical Paper 545, 1933. Part II-Bureau of Mines Technical Paper $552,1933$.

11. Assoc. Life Insurance Medical Directors and Actuarial Society of America: Medico-acturial mortality investigations. Vol. I. Introduction. Statistics of height and weight of insured persons. Compiled and published by the Assoc. Life Ins. Med. Dir. and the Actuarial Soc. of America, New York. 1912.

12. Jones, B. F., R. H. Flinn, E. C. Hammond, W. H. Wulfeck, R. H. Lee, D. D. Donahue, Heinz Spetcht, H. D. Baernstein, R. C. Channell, J. W. Hough, R. R. Jones, and R. R. Sayers: Fatigue and hours of 
service of interstate truck drivers. Public Health Bull. Washing, Gov. Print. Off. In press.

13. Irvine, L. G., A. Mavrogordato, and Hans Pirow: A review of the history of silicosis on the Witwatersrand goldfields. Silicosis, Studies and Reports, Series F (Industrial Hygiene), No. 13, 178-208. International Labour Office, Geneva. 1930.

14. National Tuberculosis Association: Diagnostic standards-Tuberculosis of the lungs and related lymph nodes. Tentative edition, 1938.

15. McPhedran, F. M.: Tracheobronchial lymphadenitis and its associated lesions. Penn. Med. Jour. 32: 228-233. 1929. Also in 21st Ann. Rpt. Henry Phipps Inst.

16. National Tuberculosis Association: Framingham community health and tuberculosis demonstration. Framingham Monograph No. 10, July, 1924.

17. Sydenstricker, Edgar, and R. H. Britten: The physical impairments of adult life. Amer. J. of Hyg. 11: 89 and 100. 1930.

18. Fellows, H. H.: Serial chest roentgenograms of 3,179 of fice employees, 1926-1938. Jour. Ind. Hyg. Toxicol. 22: 157-168. 1940.

19. Murray, A. L.: Relation of lead poisoning in Utah to mining. U. S. Bureau of Mines, Reports and Investigations 2274. Washington. 1921.

20. Hamilton, Alice: Industrial poisons in the United States. New York, The Macmillan Company. 1929.

21. Legge, Thomas: Industrial maladies. London, Oxford University Press. 1934.

22. Belknap, E. L.: The actual control of poisons in industry. Discussion of industrial accidents and diseases. U. S. Division of Labor Standards Bull. 35. Washington, Gov. Print. Off. 1940.

23. Kehoe, R. A., Frederick Thamann, and Jacob Cholak: On the normal absorption and excretion of lead. I. Lead absorption and excretion in primitive life. J. Ind. Hyg. Toxicol. 15: 257-288. 1933.

24. Willoughby, C. E., and E. S. Wilkins: The lead content of human blood. J. Biol. Chem. 124: 639-657. 1938.

25. Dreessen, W. C., T. I. Edwards, W. H. Reinhart, R. T. Page, S. H. Webster, D. W. Armstrong, and R. R. Sayers: The control of the lead hazard in the storage battery industry. Public Health Bull. 262. Washington, Gov. Print. Off. In press.

26. Monier-Williams, G. W. Lead in food. Report on Public Health and Medical Subjects No. 88. Ministry of Health. London, H. M. Stationery Office. 1938.

27. Legge, T. M., and K. W. Goadby: Lead poisoning and lead absorption. New York, Longmans, Green and Co. 1912.

28. Stieglitz, E. J.: Abnormal arterial tension. New York, National Med. Book Co., Inc. 1935.

29. Bainton, J. H., A. C. DeGraff, R. L. Levy, and H. E. B. Pardee: Criterion for the classification and diagnosis of heart disease. New York Tuberculosis and Health Association, Inc. Heart Committee. 3d ed. 1932. Approved by the American Heart Association.

30. Hedley, O. F.: Studies of heart disease mortality. An analysis of the accuracy of deaths recorded as being due to heart disease in Washington, D. C., during 1932, with a discussion of the defects of the 
present method of tabulating deaths and suggestions for a new system based upon etiological factors. Public Health Bull. 231. Washington, Gov. Print. Off. 1936.

31. Lanza, A. J., and J. A. Goldberg: Industrial Hygiene (by various authors). New York, Oxford Univ. Press. 1939. Page 135.

32. Hedley, O. F.: Trends, geographical and racial distribution of mortality from heart disease among persons 5 to 24 years of age in the United States during recent years (1922-1936). Public Health Re. ports 54: 2271-2297. 1939.

33. Viko, L. E.: Heart disease in the Rocky Mountain region. Amer. Heart J. 6: 264-273. 1930-31.

34. White, P. D.: Heart disease. New York, Macmillan Co. 2d ed. 1938.

35. Love, A. G., and C. B. Davenport: Defects found in drafted men, Washington, Gov. Print. Off. 1920.

36. Utah State Board of Health: Biennial report, July 1, 1936-June 30, 1938. 
IX SMELTERS 


\section{ENVIRONMENTAL STUDY}

\section{Description of the Working Environment During the Preparation and Smelting of Complex Lead and Copper Ores (1) (2)}

It is not the purpose of this discussion to give a technical description of the metallurgy and the difficulties involved in the smelting of various copper and lead ores. The purpose is to acquaint the reader, who is not familiar with the general principles and processes in use in the preparation and smelting of lead and copper ores, with the methods used in the plants being studied. In brief, the fundamental operations consist of re ceiving the ore from the mines, usually in railroad cars, unloading these cars, crushing the ore, concentrating by flotation, then roasting, smelting purifying, casting, and shipping. The bullion produced is shipped to refineries, since at present refining is not being done at either of the two plants studied. Other operations are necessary, however, such as sampling, assaying, maintenance, supervisory, and clerical. Supplementary departments are operated to transform by-products into marketable forms, such as the arsenic plant, the cadium plant, the acid plant, and the sulphur plant. These various operations and departments are shown on the flow sheet in figure 32, and are discussed briefly in the following paragraphs.

\section{Ore Unloading}

The bulk of the ore coming into these smelters is mined in Utah, but as both of the plants handle a large percentage of custom ores, shipments also are received from the surrounding States, and sometimes from foreign countries. Most of the crude ore is shipped to the smelters in open, swing bottom railroad cars, and is dumped into ore pits, or into the bins leading to the sample mill, by dropping the bottoms of the cars. After the bulk of the ore has fallen into the pits, men climb into the cars to sweep down the remaining portions that adhere to the cross members and undercarriage of the cars. Compressed air is used to remove the last bit of ore before winding up the car bottoms and shunting the cars on down the track. This blowing down of the cars sends more dust into the atmosphere than any of the other phases of car unloading. It was noted that one group of men used brushes and cleaned the cars without the use of compressed air, with a resulting lower dust concentration in the atmosphere. Ores travelling great distances, and ores of great value are sometimes shipped in box cars, and these shipments are unloaded by handshovelling. Crews work in the cars, sometimes with wheelbarrows, and other times, shovelling the ore from the ends of the car to the door, and then shovelling it into the bins. This operation is dusty.

Concentrates coming into the plant from the concentrating mills are too wet and stick to be handled by the sampling mill, and, at one plant, special machines called Martin Sampling Machines have been constructed to unload and sample this material. Each Martin sampling machine consists of an overhead crane, operating a clam-shell bucket which is dropped into the open railroad cars, the ore is picked up, carried over the housing of the machine, and dropped into a system of heated rolls. These heated rolls dry and sample the concentrates. The small portion of ore in the car that cannot be picked up with the clam-shell bucket is shovelled out by hand. After a representative portion has been removed through slots 


\section{FLOW SHEET OF A COMBINED LEAD AND COPPER SMELTER}

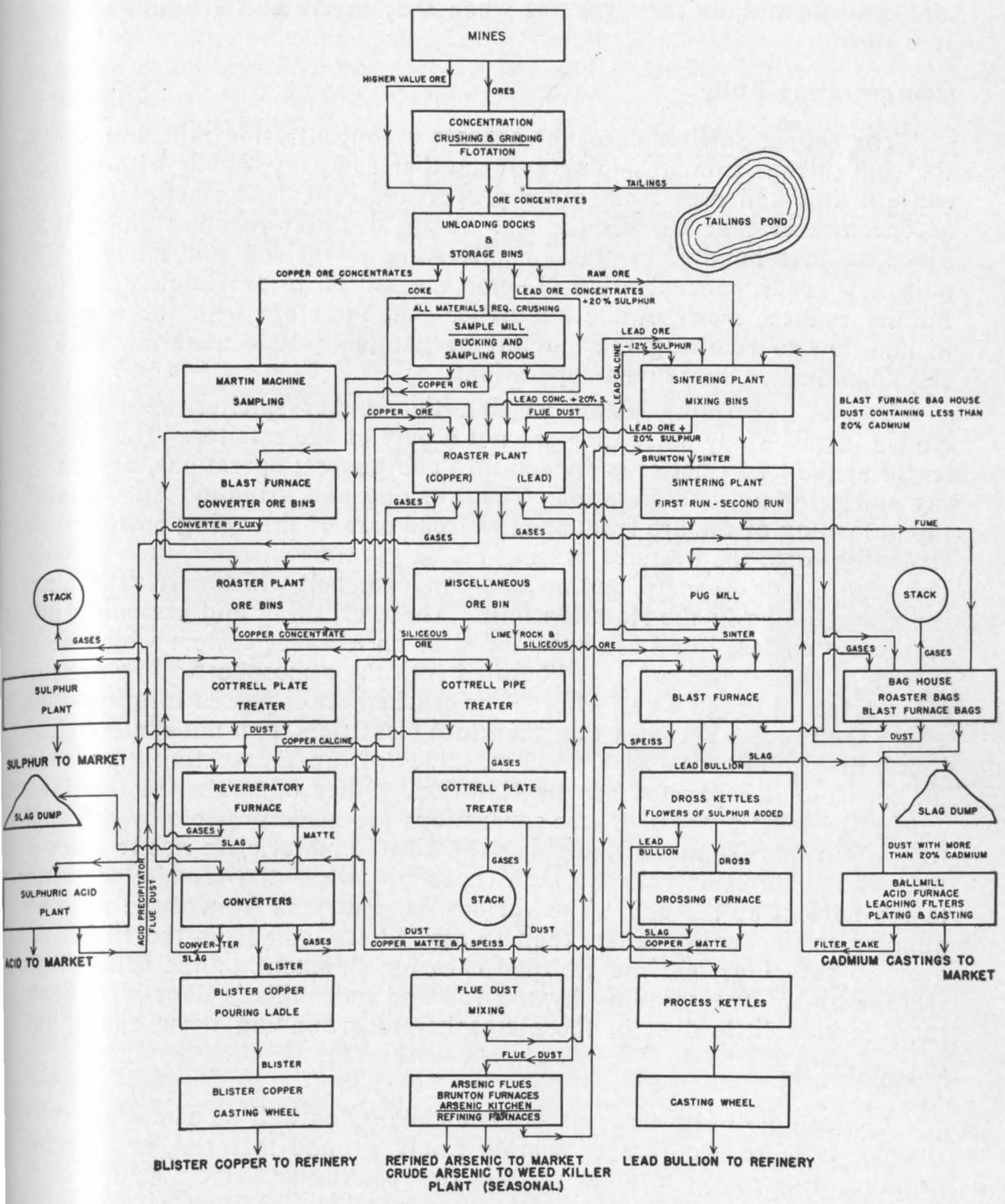

FIGURE 32-Flow sheet.

in the rolls for a sample, the remainder is carried by conveyor belts to ore storage bins. Another product received at one of the plants is called "precipitate." This is a wet material that is precipitated from water used in the mining processes of one of the copper mines. It is shovelled out of the cars by hand, every fifth shovelful being thrown to the sample, which 
is later mixed, dried, and prepared in the bucking room. The quantity received does not justify the use of a Martin sampling machine. Practi. cally no dust is in evidence around the unloading of these precipitates and concentrates, as they are wet when they arrive and are unloaded betore they dry.

\section{Concentrating Mills}

The copper smelter does not operate a concentration mill, but smelts the concentrate from two plants of another company, along with custom concentrates and ores from other properties. The lead smelter operates a concentrator that has been in use as an all-flotation plant since 1926 . Since the ores handled by these smelters are so variable and many are of quite low grade, concentration of some is essential to profitable operation. Milling reduces many of the impurities that interfere with the smelting, in addition to reducing the amount of gangue (waste material, such as clay) handled in subsequent operations.

The concentrating plants serving the copper smelter were not included in this study since they are not a part of the smelter. The concentrator at the lead smelter is divided into two general operations, dry crushing and grinding, and flotation. The crushing and grinding mill included the unloading of the ore from open railroad cars of the swing bottom type, screening, with the oversize passing int oa gyratory crusher, then through two sets of roll crushers, and on to a conveyor belt which carried it up to the storage bins in the flotation unit. These crushing and screening processes are enclosed and are provided with an exhaust system which helps to reduce the amount of dust liberated into the atmosphere. The exhaust air is passed through a bag filter. The crushed ore is passed into rod-mills, where the process becomes wet, then into classifiers, ball mills, more classifiers, then to minerals separation machines of the subaeration type where the lead ore is separated out by flotation. Other minerals are separated out by the same process. These separations are made possible by the addition of various chemicals that cause the desired material to rise to the surface of the flotation cells, to be scraped off, while the remainder settles to the bottom of the cell. The various concentrates from these cells are pumped to thickening tanks, then to disc filters, and from the filters are dropped into bins, or into railroad cars for shipment to the concentrate storage bins. The grinding by the rod and ball mills is done wet, hence there is very little dust in the atmosphere surrounding these operations.

\section{Sample Mills}

The sample mills serve as crushing plants as well as sampling units, since it is more accurate to sample finely ground material, and as this grinding is necessary in other steps in the roasting and smelting processes. The ore enters through a chute or conveyor belt, and passes through a series of crushers and rolls, and portions of these ore streams are diverted to the sample. The sample is further divided, and the rejected portions rejoin the ore through the mill, while the sample is sent to the bucking rooms for further dividing and crushing. The ground ore, from which the sample has been removed, is carried by conveyor belts to ore storage bins, or is sent to the roasters. In the storage bins special machines called "trippers" are used to spread the ore thinly over the stock pile, as they 
travel up and down the length of the ore bin. This form of bedding the ore is used to secure a uniform charge for the subsequent operations, as the cars are loaded with vertical sections through these beds. After each different batch of ore is sampled, the rolls, crushers, and conveyors in the sample mill must be cleaned, so that contamination will be avoided. This cleaning is done with compressed-air jets and great quantities of dust are thrown into the atmosphere during this process. The rolls and crushers in one of the sample mills are enclosed and provided with exhaust ventilation, but in cleaning the machinery the covers are removed and the dust blown out, contributing to the dustiness of the atmosphere. The Martin sampling machines, described under "Ore Unloading," are used for sampling copper concentrates.

\section{Roasting}

The purpose of roasting is to reduce the sulphur content of the ore and to volatize some of the components, such as arsenic, and to convert the bulk of the ore to oxides and sulphates. $X$ This process is carried out in mechanically raked furnaces of the Wedge, MacDougall, and Herreschoff types. All of these furnaces are of the same general type, that is, multiplehearth furnaces with revolving arms. There is a central shaft to which the rabble arms, for stirring the ore, are attached. The ore is fed upon the upper hearth, which, being warmed by the heat generated in the roasting operation, serves to dry the material. The ore passes from the outer edge across the upper hearth and falls through a slot upon hearth No. 1. It passes across this hearth to a slot near the periphery and there drops through onto hearth No. 2 and thus in a zig-zag fashion through the furnace, and drops finally into a larry car beneath the furnace, liberating considerable dust and sulphur dioxide.

A large amount of flue dust is made as the hot ore drops from hearth to hearth and is stirred by the rabble arms. The flue dust and the sulphur dioxide gases are carried upward through the furnace to the flues, where the dust settles out, or is collected by electrical precipitators, or bag houses. Some of the sulphur dioxide is used in the acid plant to prepare sulphuric acid, and in the experimental sulphur plant it is used to produce free sulphur. For most rough roasting, once the ore is ignited, the reaction furnishes enough heat to make the process a continuous one, but for ores that are difficult to roast or are lower in sulphur, gas burners are used to supply the necessary heat for the processes.

In the roasting of lead ores, the sulphide ore is rough roasted in a Wedge or MacDougal multiple-hearth furnace, then this calcine is given a finishing roast in a Dwight-Lloyd (D \& L) straight-line machine. The heat generated by the burning of the sulphur will raise the temperature of the mass, melting the lead sulphide into matte and retarding the roast. It is necessary with high sulphur ores to start the reaction, then, before the melting temperature is reached, chill the cake, grind it, and feed it again to the sintering machine, thereby reducing the sulphur the desired amount without melting the lead in this process. The Dwight-Lloyd machines are of the continuous down-draft type, and consist of an endless system of grates. These grates hold the charge during the roasting process. Underneath the train of grates is a suction box connected with a fan which induces a down draft through the perforated bottom and through the ore charge. 
Mounted above and near the feed end of the machine is an ignition box for furnishing the heat to start the roast. When the grate has passed over the suction box and comes to the curved guides at the end of the track, it slides down these guides and hits the preceding grate. This jars the sinter cake loose, and it falls into a car waiting below. The cycle of operations is as follows: An oncoming grate passes under the feed hopper, where it is covered with a mixture of moistened ore and flux. It next passes under the gas-fired ignition furnace, where the top surface of the charge is kindled. Next it passes out over the suction box, where a steady current of air is drawn through the charge, completely sintering it. The cake is discharged as described above, and the grate returns under the suction box to be loaded again. Fine particles are drawn through the charge bed, and collect in the bins below. These bins must be cleaned out frequently. Since the D \& L machines operate under negative pressure, most of the gases, fumes, smoke, and dust are drawn in to the machine and then into the flues without being allowed to escape, yet some dusts, gases, and fumes are released.

\section{Smelting}

Lead Blast Furnace - The roasted ore with suitable proportions of coke and fluxes, is charged into the blast furnace. Air admitted through the tuyeres burns the fuel and furnishes heat for the process. The lead sulphide reacts with the lead oxide and sulphate to produce metallic lead. Lead oxide is also reduced by the coke and the carbon monoxide produced in the process. If the ore contains gangue in the form of oxides and silicates of iron, calcium, and aluminum, these unite with the silica of the charge to form a fusible slag which will not dissolve metallic lead. If there is any sulphur present, it will form a matte with copper, iron, zinc, and other base metals. These three-lead, slag, and speiss-are of different specific gravities, are not soluble in each other, and are easily separated. The precious metals which are present enter the lead matte and are recovered later in the refining process. The charge is dropped from charge cars into the top of the furnace through swinging doors, the molten lead bullion runs to the bottom of the crucible, and the slag forms on top of the bullion. The slag is tapped by knocking out the fire-clay plug which closes the tap hole and allows the slag and speiss to flow into a settler, where the speiss collects. The slag overflows into a granulator, and is carried by an elevator to a storage bin. This bin is emptied into trains of slag cars which are hauled to the slag dump and emptied. The speiss is tapped from the settler into pans, allowed to cool, and is shipped to zinc refineries. The lead bullion is tapped from the well into ladles which are carried to the drossing kettles by an overhead crane. The settler, called a "boat," is hooded, as are the lead bullion tap and the ladle while filling, and the fumes are carried through flues to a bag house.

Reverberatory Furnace - The reverberatory furnace used in copper smelting is in reality a huge melting furnace. It is built of refractory brick, is fired from one end, the charge is dropped from larry cars, part of the charge entering the furnace from the top and part from the sides. The charging is done near the firing end, and as the charge melts the matte settles to the bottom of the furnace and the slag rises to the surface. The slag is tapped at the flue end of the furnace and flows into slag cars, 
which are pulled in trains out to the slag dump and emptied. The matte is tapped from the side of the furnace, and the matte flows into ladles. These ladles are covered with hoods that are connected with the flues, and the fumes are collected by the electrical precipitators. The ladles of matte are carried and poured into the converters by the overhead cranes. Slag from the converters is poured back into the reverberatory furnaces to extract the remaining copper. Hot calcined ore forms most of the charge, but some raw ores, along with flue dusts, and fluxing materials are added. These reverberatory furnaces are fired with natural gas.

Waste Heat Boilers-The waste gases passing out of the reverberatory furnaces have a very high temperature, and to reclaim some of this heat the gases are passed through large water tube boilers, which act as heat exchangers, producing the steam for power generation. As these gases carry considerable dust, it is necessary to clean frequently the deposit from the tubes in these boilers.

\section{Purifying}

Dross Kettles and Furnace - The lead bullion from the blast furnace is carried by crane to the drossing kettles, which are large pots set in the floor, into which the bullion is poured. Various materials are added for the purpose of "cleaning" the lead, or removing those substances that are undesirable in the bullion. A mechanical stirrer is lowered over the kettle and the bullion is stirred until the dross rises to the surface. During this agitation and during the skimming operation a hood, connected with an exhaust ventilation system, is swung over the kettles to trap the dust and fumes, carrying them to a bag house. At the completion of the stirring, the dross is skimmed off by means of a large suspended shovel, placed in a ladle which is carried by the crane, and emptied into the top of the dross furnace, (a small reverberatory furnace). In this furnace the lead is separated from the slag and the copper matte. This lead is returned to the dross kettles, and the copper matte is shipped to a copper smelter. When the lead has been cleaned, it is pumped or piped to the casting wheel.

Converters-Converters are used in the copper smelter and consist of a shell, lined with refractory material. At one end of the converter is a large gear and pinion by means of which the converter can be tilted for inspection and pouring. There is a wind box along the front, supplying air to the tuyere pipes. These converters are provided with a charging device (silica gun) in the end of the converter barrel, so that siliceous flux can be added without tipping the converter. Air is blown through the tuyeres, and when the air strikes the copper matte, the sulphur is oxidized and driven off. The iron in the matte unites with the silica to form a slag, then the oxygen in the blast converts the free sulphur and the sulphur in the copper sulphide to sulphur dioxide. Some of the other metals that might be present, such as arsenic, antimony, bismuth, and lead, are volitalized as oxides. The converters are provided with hoods that fit over the mouth. These hoods serve two purposes: first, to keep the fume and dust out of the converter aisle and provide better working conditions for the operators; second, to save this flue dust and fume for treatment, since the flue dust contains valuable by-products. The precious metals are contained in the blister copper that is poured from the converter into ladles, and carried by the cranes to the casting ladle. The slag from the convert- 
ers is emptied into ladles and poured back into the reverberatory furnaces by the cranes.

\section{Casting}

Lead Casting-The lead that flows from the drossing kettles is poured into molds that are placed around the circumference of a casting wheel. This wheel revolves, and as the lead is poured into a mold, the wheel ro. tates and a man sprays water on the casting, quenching it, and another uses a die and a hammer to identify the pig. Pin ejectors in the bottoms of the molds eject the pigs as the wheel reaches the discharge position. The pigs are placed on hand trucks, and pushed into railroad cars for shipment to the refinery

Copper Casting-The blister copper is poured from the converters into the casting ladle, then into molds on the copper casting wheel. The molds are sprayed with a wet material to prevent the copper from sticking to the mold, then the blister copper is poured into the molds as the wheel is rotated by an operator. The pig is quenched, and the mold is tilted up so that the pig is dumped out on a conveyor, and then is dumped on the landing floor. Then the mold is sprayed and is ready for the next pouring. These molds are cast alongside the casting wheel and are made from raw copper, that is, copper matte that has not been completely treated in the converter. When the molds wear out, they are placed back in the converters, and are then poured with the blister copper. Samples of the blister copper are collected by placing a small mold in the stream of blister copper as it is poured from the ladle, then quenching the mold and knocking out the sample. After the pigs are dumped on the landing floor, they are trucked into railroad cars and shipped to the refinery.

\section{Reclamation from Flue Gases}

Dusts, fumes, and gases are the materials that were once lost up the stack, but they are now in a large part being recovered. This recovery is made possible both by long flues leading to the stacks, and by electrical precipitators or bag houses, placed in the flow of the flue products to remove these materials before the gases pass up the stacks. The long flues permit much of the flue-dust to settle out before reaching the filtering or precipitating units. Regularly spaced openings along the hopper bottoms of these flues, equipped with sliding doors, are provided for cleaning the flue dust out of the flues. This dust is dumped into larry cars and carried back to the various processes to reenter the flow of material through the plants at the proper place. The dust that is filtered out of the bags in the baghouses is deposited in the bottoms of the hoppers by shaking the bags, then the dust is loaded into larry cars and placed back in the processes. Mechanical shakers are provided for the bags in the bays handling the gases from the blast furnace and the roasters in the lead smelter, but the bags in the bays handling the products from the drossing kettle, dross furnace, blast furnace boat, and blast furnace matte tapping, are shaken by hand. This necessitates going into these bays, grasping these bags near the bottoms and shaking them vigorously. The atmosphere surrounding the workmen is extremely dusty during this operation. Periodic inspections and repairs are made to all of the bags. This necessitates entering the bays, looking for holes, loose connections, 
and shortening the bags to eliminate the holes, or replacing the bags entirely if they are worn out. The general repairs are made during periods when the smelter is not operating, and gases are not passing through the bays. However, there is an occasional bag failure during regular operation, which makes it necessary to cut out the bay by means of bypass dampers, opened up for periods ranging from half an hour to an hour, while the bag is repaired or replaced, after which the bay is put back into operation.

Cottrell precipitators or treaters remove the particles of dust and fume by imparting a negative electrical charge to the particle, causing it to adhere to metal strips, plates, or tubes, surrounding the wire or rod carrying a high voltage current. When the coating of particles has accumulated to a sufficient thickness, the current is shut of f for a moment and the tube, plate, or strip is tapped mechanically, causing the flue dust to dislodge and fall into the bottom part of the chamber, where it may be Lrawn off for treatment. This type of flue dust recovery is used at the copper smelter.

At the copper smelter, sulphur dioxide was being reclaimed in the sulphuric acid plant, and in the free sulphur experimental plant. Sulphuric acid was being made by the contact method. As the free sulphur work was experimental, methods and technique had not been established. The sulphur dioxide being used in the acid plant, and in the sulphur plant, was being reclaimed from the Herreschoff roaster flue gases.

\section{By-Products}

Arsenic-Flue dusts, rich in arsenic, from the lead roasters, are transported by larry cars to Brunton arsenic furnaces where they are heated with coke fires. The arsenic sublimes, and is condensed in large brick rooms, or flues, called "arsenic kitchens." This first product is called crude arsenic. The remaining sinter in the furnace is carried back to the sintering plant, where it is mixed with other sinter charges. The gases that emerge from the arsenic condensers, or kitchens, go through flues back to the roaster flues and to the bag house. The crude arsenic can either be refined by another sublimation process, or as is done in this case, employed in the manufacture of a product that does not require pure arsenic. The crude arsenic is stored until early spring and is then made into a preparation used as a weed killer. This material is marketed as a liquid. The weed-killer plant was not in operation during the study.

Cadmium-Cadmium builds up in the flue dust from the lead blast furnace, since this dust is continually being returned to the furnace. When the cadmium concentration of the flue dust exceeds 20 percent by weight, the dust is conveyed to the cadmium plant and dumped into a storage bin. Then it is ground in a ball mill and screened before being placed in a mixing box and mixed with sulphuric acid. This mixing is done by the operators using a long-handled hoe. When thoroughly mixed the bin is pushed under a hood so that the fumes will be carried into the flue system. After several hours, this mixture is shoveled into the flue-end of two small reverberatory furnaces, and is gradually paddled forward by the furnace operator. Upon reaching the front end of the furnace, the cadmium sulphate roast is removed from the furnace, ground and screened, then neutralized with hydrated lime in an agitator. The 
solution is then filtered in a pressure filter, the filter cake going back to the pug mill at the bag house, to return to the roasters. The filtrate is placed in electrolytic cells, and the cadmium is plated out. This cadmium is scraped from the plates, melted under oil in a melting kettle and poured into pigs. These pigs are later remelted and cast into various forms for market.

Sulphuric Acid-A portion of the sulphur dioxide from the Hereschoff roasters in the copper smelter is used in the preparation of sulphuric acid by the contact method. The gases were passed through an electrical precipitator for cleaning purposes, and the resulting flue-dust is returned to the reverberatory furnace. The sulphuric acid is sent to market. This is merely a pilot plant, and much more acid could be prepared if all of the sulphur dioxide generated in the roasting process were to be used.

Sulphur-Another portion of sulphur dioxide from the Hereschoff roasters was being used in an experimental plant to produce sulphur.

\section{Other Operations}

Maintenance-Both smelters had the normal complement of maintenance departments, such as a boiler shop, blacksmith shop, carpenter shop, electrical shop, machine shop, paint shop, pipe shop, and warehouse. Power houses were operated by each of the plants to generate electricity, and the copper smelter operated a foundry that made grey iron castings, and some brass castings for replacements in the plant. The men working in repair, such as brick masons, electricians, painters, carpenters, and machinists, naturally worked throughout the plant, as well as in their respective shops.

Chemical Research and Control-Assay laboratories were in operation to maintain a control on the various operations in both smelters, with both chemical and fire assaying playing important roles. Chemical research was also in progress.

Administrative and Clerical-This group included those persons located within the plant. Both smelters have the bulk of their clerical offices in Salt Lake City, and these were not included in this study. The personnel includes the plant superintendents, safety and employment personnel, first-aid workers, and bookkeepers, timekeepers, and clerks.

\section{Occupational Analysis and Description of Chief Occupations}

Table 55 presents an occupational analysis of the workers employed in the four Utah lead and copper smelters at the time of the 1937 preliminary survey, and the two smelters studied in 1939 (3). The lists of employees as furnished by the companies in 1939 were not broken down into all of the operations, and could only be given by departments, and sometimes in groups of departments. In one plant, the lead blast furnace department, drossing department, and casting department were grouped together, and no figures were given for the cadmium plant, and flue cleaners were not listed separately. The number of men recorded for each occupation shown in the table will vary with the market demands for the metals, but it is felt that these figures represent a fair average of the number of workers employed in the smelting industry in Utah.

In order to show the various duties performed by the many different occupations shown in table 55 , it seems appropriate to give brief 
TABLE 55-Occupational Analysis of Employees of Two Utah Smelters.

Departments and occupations

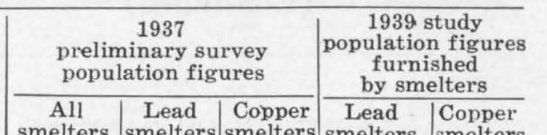

Totals ........................................................................

Administrative and supervisory personnel:

Superintendents and plant engineers.

Safety personnel, draftsmen, office engineers, physician, clerical, timekeepers, bookkeepers

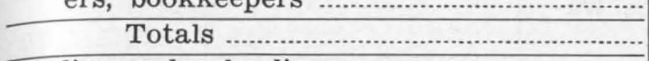

Loading and unloading:

Martin machine operators, helpers and laborers

Coal dock tenders, weighmasters, unloading foremen, unloaders, cranemen, and ore bin feeders

Yard loading and unloading, foremen, locomotive engineers, firemen, switchmen, tractor operators, cranemen, motormen, track repairmen, brakemen and conductors ...............................................

smelters smelters smelters smelters smelters

\begin{tabular}{|r|r|r|r|r}
2,591 & 440 & 1,250 & 564 & 838 \\
\hline \hline 26 & 2 & 10 & & \\
& & & & \\
118 & 15 & 56 & & \\
\hline 144 & 17 & 66 & 33 & 12 \\
\hline & & & & \\
9 & & 9 & & 12
\end{tabular}

Concentrator:

Dry: Unioaders, crushermen, rolls operators, screenmen, conveyormen

Wet: Binmen, reagentmen, thickenermen tankmen, feeders, flotation cell operators, filtermen, concentrate loaders, pumpmen, dikemen, clean up men, rod and ballmill men, classifiermen.

Foremen

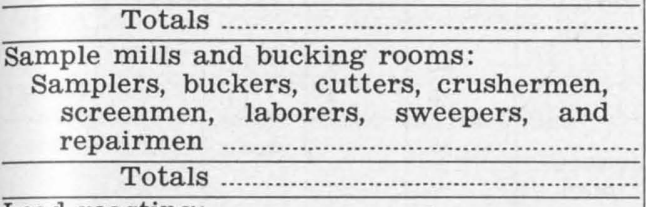

Lead roasting:

Wedge roasting-Foremen, furnacemen and helpers .

D. \& L. roasting-Foremen, furnacemen, burnermen, scalers, binmen, trippermen, finesmen, crushermen, fanmen, oilers, larrymen and gratemen..

Totals ....................................................

\section{Copper roasting:}

Foremen, binmen, larrymen, firemen, feeders, oilers, laborers, switchmen, conveyor tenders, repairmen..

\begin{tabular}{l}
\hline Totals ...................................................... \\
Lead blast furnace:
\end{tabular}

Charge floor-Foremen, weighmen, furnace tenders, larrymen, binmen, scrap iron men, hoistmen, switchmen, laborers and conveyor tenders.

Tapping floor-Tappers, slag motormen, slag switchmen, settlers, blast furnace operators, laborers, matte motormen, and helpers and matte hoistmen.................

Totals .....................................................


TABLE 55-Occupational Analysis of Employees of Two Utah Smelters.
(Continued)

Departinents and occupations

Reverberatory furnace:

Foremen, skimmers, tappers, helpers, laborers, feeủers, weighmen, larrymen and slag motormen

Waste heat boilers-Boiler tenders, water tenders, flue cleaners

Totals

Lead drossing kettles and drossing furnace:

Foremen, skimmers, loaders, crane operators, furnacemen

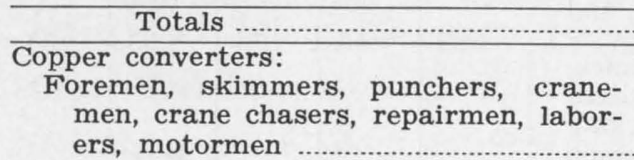

Lead casting:

Moulders, casters, car loaders, stampers, checkers Totals

Copper casting:

Foremen, wheelmen, samplers, landers, sample sawers, and truckmen.

\section{Flue cleaning:}

Roaster flues, arsenic flues, converter and reverberatory flues, flue dust collectors

\section{Bag houses:}

Totals ...................................................

Roaster, blast furnace, blast furnace boat, and dross kettle bays - dust men, baghousemen, pug mill operators and dumpers

\section{Totals}

\section{Electrical precipitators:}

Converter, reverberatory furnace, roaster and acid plant treaters-Operators, helpers and flue dust contractors.

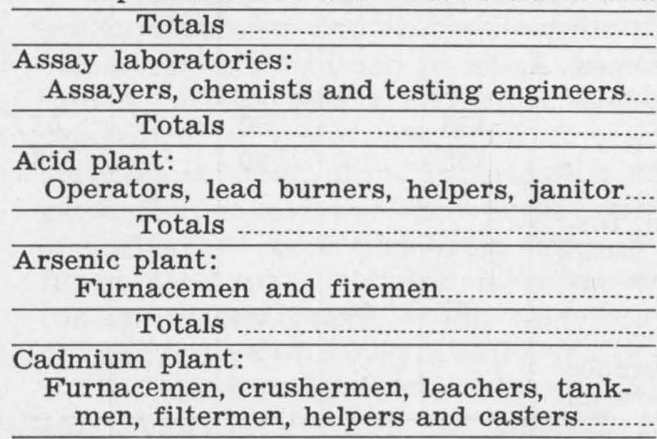

\section{7}

preliminary survey

population figures

\begin{tabular}{c|c|c|c|c|c|c|}
\hline $\begin{array}{c}\text { All } \\
\text { smelters }\end{array}$ & $\begin{array}{c}\text { Lead } \\
\text { smelters }\end{array}$ & $\begin{array}{c}\text { Copper } \\
\text { smelters }\end{array}$ & $\begin{array}{c}\text { } \\
\text { smelters } \\
\text { by smelters }\end{array}$ \\
$\begin{array}{c}\text { Leapper } \\
\text { smelters }\end{array}$ \\
\hline
\end{tabular}

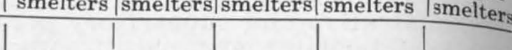

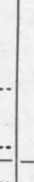

\begin{tabular}{r|r|r|}
\hline 145 & & 121 \\
\hline 41 & 27 & \\
\hline 41 & 27 & \\
\hline
\end{tabular}

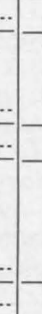

\begin{tabular}{r|r|r}
\hline 41 & 27 \\
\hline & & \\
\hline 157 & & 98 \\
\hline
\end{tabular}

\begin{tabular}{r|r|r|}
\hline 157 & & 98 \\
\hline 13 & 6 & \\
\hline 13 & 6 &
\end{tabular}

\begin{tabular}{l|l}
\hline & \\
\hline & \\
& 103 \\
\hline & 103 \\
\hline
\end{tabular}

...

.

\begin{tabular}{r|r|r}
\hline 13 & 6 & \\
\hline 25 & & 25 \\
\hline 25 & & 25 \\
\hline
\end{tabular}

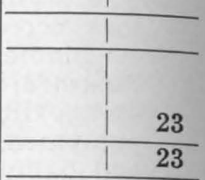

\begin{tabular}{|c|c|c|c|c|}
\hline 28 & 4 & 11 & & 6 \\
\hline 28 & 4 & 11 & & 6 \\
\hline 22 & 9 & & 16 & \\
\hline 22 & 9 & & 16 & \\
\hline 27 & & 18 & & 18 \\
\hline 27 & & 18 & & 18 \\
\hline 69 & 10 & 26 & 21 & 6 \\
\hline 69 & 10 & 26 & 21 & 6 \\
\hline 18 & & 18 & & 9 \\
\hline 18 & & 18 & & 9 \\
\hline 12 & 6 & & 7 & \\
\hline 12 & 6 & & 7 & \\
\hline 20 & 14 & & & \\
\hline 20 & 14 & & & \\
\hline
\end{tabular}


TABLE 55-Occupational Analysis of Employees of Two Utah Smelters. (Continued)

\begin{tabular}{|c|c|c|c|c|c|}
\hline \multirow[t]{2}{*}{ Departments and occupations } & \multicolumn{3}{|c|}{$\begin{array}{c}1937 \\
\text { preliminary survey } \\
\text { population figures }\end{array}$} & \multicolumn{2}{|c|}{\begin{tabular}{|c}
1939 study \\
population figures \\
furnished \\
by smelters
\end{tabular}} \\
\hline & \begin{tabular}{c|c|} 
All \\
smelters
\end{tabular} & $\begin{array}{c}\text { Lead } \\
\text { smelters }\end{array}$ & $\begin{aligned} \begin{array}{c}\text { Copper } \\
\text { smelters }\end{array} \\
\text { smel }\end{aligned}$ & $\begin{array}{c}\text { Lead } \\
\text { smelters }\end{array}$ & $\begin{array}{c}\text { Copper } \\
\text { smelters }\end{array}$ \\
\hline $\begin{array}{l}\text { Power house: } \\
\text { Firemen, engineers, pumpmen, oilers, } \\
\text { boiler tenders, and janitors.............................. }\end{array}$ & 41 & 9 & 15 & 10 & 15 \\
\hline 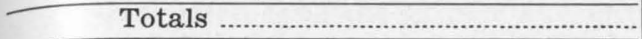 & 41 & 9 & 15 & 10 & 15 \\
\hline $\begin{array}{l}\text { Maintenance: } \\
\text { Boiler shop-Welders, layout men, boil- } \\
\quad \text { ermakers, punchers and apprentices........ }\end{array}$ & \multirow{3}{*}{$\begin{array}{r}144 \\
29 \\
77\end{array}$} & 17 & 97 & 19 & 52 \\
\hline $\begin{array}{l}\text { Blacksmith shop-Blacksmiths and } \\
\text { helpers.. }\end{array}$ & & 28 & 15 & & \\
\hline 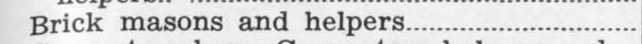 & & 4 & 37 & 7 & 19 \\
\hline $\begin{array}{l}\text { Carpenter shop-Carpenters helpers and } \\
\text { pattern makers }\end{array}$ & $\begin{array}{r}121 \\
48\end{array}$ & $\begin{array}{r}16 \\
6\end{array}$ & $\begin{array}{l}75 \\
22\end{array}$ & $\begin{array}{r}19 \\
7\end{array}$ & $\begin{array}{l}31 \\
17\end{array}$ \\
\hline $\begin{array}{l}\text { Electrical shop-Electricians and helpers .. } \\
\text { Foundry-Molders, helpers, coremakers, } \\
\text { cupolatenders, cranemen and handy- } \\
\text { men }\end{array}$ & \multirow{2}{*}{$\begin{array}{l}36 \\
39\end{array}$} & \multirow{2}{*}{\multicolumn{2}{|c|}{$\begin{array}{l}36 \\
39\end{array}$}} & \multirow{4}{*}{36} & \multirow{2}{*}{$\begin{array}{l}16 \\
12\end{array}$} \\
\hline 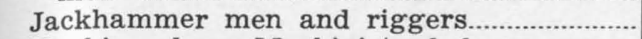 & & & & & \\
\hline $\begin{array}{l}\text { Machine shop-Machinists, helpers, mo- } \\
\text { tor and car repair, and auto mechanics. }\end{array}$ & \multirow{2}{*}{$\begin{array}{r}147 \\
17\end{array}$} & \multirow[t]{2}{*}{25} & \multirow{2}{*}{$\begin{array}{l}64 \\
10\end{array}$} & & \multirow{2}{*}{$\begin{array}{r}34 \\
9\end{array}$} \\
\hline Paint shop-Painters and helpers.................... & & & & & \\
\hline $\begin{array}{l}\text { Pipe shop-Pipe fitters, helpers and ap- } \\
\text { prentices }\end{array}$ & \multirow{2}{*}{$\begin{array}{r}42 \\
7\end{array}$} & \multirow[t]{2}{*}{5} & \multirow{2}{*}{$\begin{array}{r}33 \\
5\end{array}$} & & \multirow{2}{*}{$\begin{array}{r}27 \\
5\end{array}$} \\
\hline 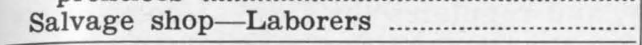 & & & & & \\
\hline 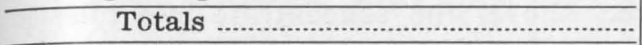 & 707 & 77 & 433 & 92 & 233 \\
\hline Yard laborers: & \multirow{3}{*}{197} & \multirow{3}{*}{53} & \multirow{3}{*}{111} & & \multirow{3}{*}{38} \\
\hline 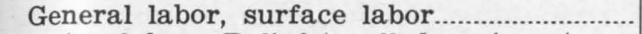 & & & & 40 & \\
\hline Extra labor-Relief to all departments....... & & & & 12 & \\
\hline Totals & 197 & 53 & 111 & 52 & 38 \\
\hline Miscellaneous: & & & & & \\
\hline $\begin{array}{l}\text { Watchmen, warehousemen, janitors, fire- } \\
\text { chief and gardner }\end{array}$ & 34 & & 21 & 26 & 19 \\
\hline 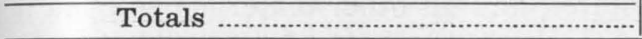 & 34 & & 21 & 26 & 19 \\
\hline
\end{tabular}

1 Employees in the lead blast furnace department, lead drossing kettles, drossing furnaces, and lead casting were reported as one group.

descriptions of the more important occupations in the industry. Such a list of definitions follows:

\section{Administrative and Supervisory Personnel}

Only the plant personnel is considered in this study, as both plants have their main offices in Salt Lake City, and these were not included in the study. The superintendents had the responsibility of plant supervision, and spent a portion of their time out in the plants, but were considered primarily as office workers. Plant engineers were in charge of the technical direction of the various departments, and were working to improve the mechanical operation in the plant. Office engineers do designing, estimating, and other engineering duties at the direction of the plant engineers, and they do some plant enginering. Draftsmen do mechanical drawing and tracing. 
Safety personnel are employed in studying methods of preventing accidents, conducting educational campaigns on safety, and inspecting safety equipment installed throughout the plant. They also keep personnel records, and do some welfare work.

Physicians are employed on part-time and full-time basis to do emergency work, as well as physical examinations, and an X-ray is included in the plant equipment in one of the smelters. Hospital facilities, and more complete medical facilities are provided outside the plant, and the work in the plant is concerned primarily with first aid, physical examinations, and operating a dispensary.

Timekeepers are employed to keep the work records of the men and to make up the payrolls.

Bookkeepers keep records of the plant transactions.

Clerical workers do typing, filing, and other office work.

\section{Foremen}

Practically every department has a foreman who is in direct charge of the work being done in that department. The larger departments have assistant foremen, who at times act as foremen on their respective shifts. To avoid repetition, these foremen will not be listed for each department.

\section{Loading and Unloading}

Martin machine operator is the term applied to the craneman who operates the Martin machine.

The Martin machine helper works inside the Martin machine housing, keeps the rolls operating properly, and regulates the flow of concentrate through the machine. The laborers shovel the concentrate into piles in the cars as it becomes more difficult for the clam-shell bucket to pick it up, and finally shovel out the remaining portion that is impractical for the bucket to pick up.

Weighmasters weigh and keep records of the weight of materials entering the plant, and different products leaving and entering the various departments.

Unloaders dump cars of ore, sinter, and all other materials shipped to the unloading docks.

Coal dock tenders unload coal that is used in firing boilers.

Ore bin feeders bar down the ore from the storage bins into larry cars that transport the ore to the roasters, furnaces, or converters.

\section{Yard Crews}

Locomotive engineers and firemen run and fire the locomotives that are used for transferring the railroad cars around the plants.

Switchmen operate track switches, and assist in placing the railroad cars in the desired locations. Helpers assist on the ore trains, clean up ores and help switch the cars.

Cranemen operate steam and electric cranes which load and unload ores on stock piles, cleaning up along tracks, loading and unloading scrap iron, and other materials. Crane firemen operate the boilers on the steam cranes, and assist the cranemen.

Track repairmen keep the railroad tracks repaired, replacing ties, and tracks, as needed.

Tractor operators drive tractors around the plant which handle ore, build roads and plow snow. Tractor helpers assist the tractor operators. 


\section{Concentrator Mill}

The concentration of the crude ores consists of two general processes, dry and wet.

\section{Dry}

Unloaders, dump cars of ore, clean ore from the under-carriage of the cars, sweep out the cars, and roll them down the track.

Crushermen, and rolls operators tend the gyratory and roll crushers that reduce the size of the pieces of ore entering the mill.

Screenmen tend the grizzly and other screens that separate the undersize and oversize ores, and make sure that these screens do not become clogged.

Conveyormen tend the belt conveyors and elevators that transport the ore through the mill and remove foreign particles, such as wood, wire, and tramp iron.

Repairmen, machinists, and helpers do general repair work in the entire mill, both dry and wet sides.

Cleanup men recover spilled ore with vacuum cleaners, and tend the baghouse that filters the air emerging from the dust control stystem in this department.

\section{Wet}

Binmen tend to the storage of dry ore prior to its being fed to the rod and ball mills.

Rod and ball mill men operate rod mills and ball mills which further grind the ore. This grinding is done under water.

Classifier men operate separators for sizing the ore, so that the larger particles can be put through the rod and ball mill again.

Flotation cell operators tend the cells in which the metals are separated from the gangue by means of agitation after the addition of various chemicals.

Feeders regulate the flow of the ore to the mills and cells.

Thickener tankmen tend the pumps that convey the concentrates into the thickeners, and when the correct amount of water has been removed, pump the thickened material to the filter vats.

Filtermen operate and repair the rotating disc vacuum filters, adjusting both the speed of the filter and the amount of vacuum.

Reagentmen mix all of the reagents for flotation processes as needed. liquid.

Pumpmen operate the pumps in the mill operations, both air and

Concentrate loaders prepare the railroad cars, spot the cars, and drop the concentrate from the bins into the cars so that it can be sent to the smelter yard. mill.

Samplers collect samples from the ores and various processes in the

Cleanup men keep the floors, aisles, and conveyor tracks clean.

Dikemen take care of the dikes around the ponds into which the tailings from the mill flow.

\section{Sample Mills}

Crushermen operate jaw and roll crushers to reduce the size of the pieces of ore coming into the plant. 
Mill operators and repairmen keep crushers, rolls, mills, and conveyors in repair.

Laborers and sweepers clean up around the mill, tend conveyor belts, and remove foreign material from the ore.

Slag dump laborer is the term applied to a man that takes samples of slag from the slag dump and sends them to the assay laboratory.

Car samplers take samples of materials from the railroad cars as they arrive, and send these samples to the bucking room, assay laboratory, and moisture house.

\section{Bucking and Parting Rooms}

Cutters dump the samples that come from the sample mill on to the floor, mix the sample with shovels, and divide it into portions. Part is retained for further treatment and the remainder is placed back in the flow of ore through the plant.

Buckers grind the retained portion after drying it on steam tables, divide it still further, mix it again, and repeat this process until a small portion of the ore is retained that is truly representative of the shipment of ore being sampled.

Moisture men take samples of the ore as it comes into the plants, and as it is weighed, then determine the moisture in the ore.

\section{Roasters}

The occupations in the Herreschoff, Wedge, MacDougal, and Brunton furnaces are very similar and will be discussed together.

Binmen unload ores and furnace charges from receiving bins into larry cars, or on to conveyor belts.

Larrymen run the larry cars that carry the charges to the furnace feed-or charge-floors, and dump these charges.

Feeders keep the feeding machinery clear and regulated, and adjust the speed of the feed to the furnaces.

Firemen adjust the burners, or add the amount of fuel to give the necessary amount of heat to continue the reaction, in those cases where the heat generated by the burning of the sulphur is not sufficient to maintain the process.

Laborers assist in the firing, feeding, and cleaning of the furnaces, and clean up around the department.

Repairmen clean out the furnaces and repair the rabble arms and linings of the furnaces.

The Dwight and Lloyd sintering machines are operated by men with different classifications and these are listed below.

Binmen maintain the storage bins, and regulate the hoppers feeding the charge on to the conveyors.

Scalers regulate the feed of raw lead, silver ore, first run sinter and other materials making up the charge to the machines.

Trippermen operate a tripper machine that discharges materials into feed bins from the conveyor belt.

Burnermen operate the burners that ignite the charge as it moves on to the rotating grates. The charge is ignited on the surface just before the pallets reach the suction box.

Gratemen clean the travelling grates and keep them in repair. 
Crushermen operate the crusher that crushes the sinter after its first run over the machines, before it is mixed with a new charge and sintered again.

Finesmen handle collections of fine dust and that settle on the floor of the crusher, conveyors, and clean out the accumulations in the wind boxes of the machines.

Fanmen operate the electric fans which exhaust the fumes, gases and dusts from the machines, while creating a draft through the sinter bed.

Cleanup men do general cleaning in the roasting plant.

\section{Lead Blast Furnace}

Binmen take care of the bins in which ores are stored for furnace feeding.

Scalers or weighmen weigh materials in making up charges for the furnace.

Scrap iron men load and weigh scrap iron for the furnace charge.

Larrymen operate larry cars that are used for hauling the charge to the furnace and dump the cars.

Feeders operate the swing doors that allow the charge to enter the furnace, and watch the level of the charge in the furnace, keep records of draft and temperatures.

Furnace operators direct the charging of the furnace, and have charge of the operations.

Tappers knock out the fire clay plugs and allow the slag to flow through the slag port, and also open the tap that allows the matte to flow into the ladles. They replace the fireclay plugs to stop the flow of slag or matte, and keep the ports clear during tapping.

Slag motormen operate the electric motors pulling the cars of granulated slag out to the slag dump. Slag switchmen assist the motormen and help fill and dump the cars.

Matte cranemen use overhead cranes to lift and transport ladles of matte from the blast furnace to the drossing kettles, carry dross from the kettles to the furnace, and lead back from the dross furnace to the kettles.

\section{Reverberatory Furnace}

Larrymen operate the larry cars that bring the calcine from the roasters, the raw ore from the storage bins, and other materials that make up the charge for the furnaces. They also dump these cars during the charging of the furnaces, and fill the cars when picking up their loads.

Weighmen weigh the calcine as it leaves the roasters for the reverberatory furnace charge.

Furnacemen direct the larrymen in dumping the charge into the furnace, and supervise the charging operation.

Skimmers open the slag port and allow the slag to flow down into slag cars. As these cars fill the train is pulled forward and the next car is filled. When all the cars in the train are full, or when the slag in the furnace has reached the desired level, the skimmer plugs the port with a fireclay plug, by placing the plug on the end of a long steel rod and then pushing the plug into the port. The slag launderers in the lead smelter are not covered and the fumes are not collected by exhaust hoods. 
Tappers' duties are similar to the skimmers, except that they tap the sides of the furnace and draw off the matte into large ladles. These ladles are hooded during the filling operation and the fumes and gases are drawn into the flues. They also plug the ports with fireclay at the conclusion of the tapping operation. The matte launderers in the copper smelter are covered and the fumes and gases are drawn back into the furnace.

Furnace helpers assist with the skimming and tapping.

Laborers sweep up calcines from the top of furnaces, clean slag tunnels, matte launderers, and slag launderers.

Slag motormen operate the electric motors that haul the slag cars to and from the slag dump. Slag switchmen spot the slag cars during skimming, and help empty the cars on the slag dump.

\section{Waste Heat Boilers}

Boiler tenders tend boilers operated by heat from waste gases from the reverberatory furnaces.

Water tenders are responsible for maintaining the proper water level in the waste heat boilers.

Tube cleaners blow and scrape flue dust from the boiler tubes, using long-handled scrapers and blowers inserted through small doors in the sides of the boilers.

\section{Dross Kettles and Furnace}

Cranemen are described for this operation under lead blast furnace.

Skimmers shovel off the dross from the surface of the lead in the drossing kettles. This is done with a long-handled swing shovel. The dross is placed in a ladle to be carried to the drossing furnace.

Furnacemen charge the dross into the top of this small reverberatory furnace, tap matte, slag, and lead.

\section{Copper Converters}

Cranemen operate overhead travelling cranes to transport ladles of matte, slag, blister copper, and other heavy material in the converterreverberatory building. Crane chasers are stationed on the ground to direct the operations desired of the cranemen, and they connect the crane hooks to the ladles and other material to be picked up, and unhook them when they are replaced on the ground. The cranemen and crane chasers alternate jobs during the shift.

Converter operators, or skimmers, operates levers causing the converter to rotate to pour off slag, blister copper, or to receive ladles of matte, or to observe the color of the flame. These men are responsible for the proper treatment of the matte to convert it into blister copper. They also operate the silica guns that shoot the silica into the charge with compressed air.

Punchers keep the tuyere openings clear by punching a rod through them periodically to prevent their being sealed over by slag.

Silica motormen transport siliceous and high grade ores in dump cars from unloading-dock bins to converter feed bins, to be fed into the converters by the skimmer.

Repairmen keep the cranes and converters in repair.

Laborers assist around the converters and keep the floors clean. 


\section{Lead Casting}

Molders, or casters draw molten lead from the heating kettles, introduce it into molds on a rotating wheel, and quench the cast pigs with water.

Stampers number the pigs with a metal die and hammer, marking them with identifying symbols.

Car loaders or truckers lift pigs from molds and truck them to railroad cars.

Checker keeps a record of the number of pigs and weight shipped.

\section{Copper Casting}

Wheelmen operate wheel caster. Blister copper is poured into molds on the rim of the casting wheel by tipping the ladle. These operations are controlled by the wheelman by levers in his shack.

Samplers dip samples from pigs as they are poured. These samples are collected in a spoon and are quenched, then taken to the sawer. The sample sawer operates a motor-driven saw that cuts these sample molds into segments that are used for chemical analyses.

Landers remove the blister copper pigs from the conveyor, keeping them from piling up, and the truckers use hand trucks to move the pigs into railroad cars.

\section{Flue Cleaning}

The roasters in both plants, the arsenic furnaces in the lead smelter, and the converters and the reverberatory furnaces in the copper smelter, have flues leading from them that collect flue dust, and have to be cleaned out by hand. The men that clean these flues are called flue dust collectors. They open the slide doors at the bottom of the hopper-bottomed flues and let the dust fall into larry cars. They also sweep up the dust that falls on the tracks. This dust is then carried back and placed in the various processes.

\section{Bag Houses}

Dusts, that do not settle out as flue products, travel toward the stacks in the lead smelter, along with the fumes in these flue products, and are removed in the bag houses. Sections of these houses, or separate houses, handle flue products from different processes, such as roasters, blast furnace, the vents from the blast furnace boats (or settlers), dross kettles, and dross furnace. However, the following occupations apply to all of the houses, and the same crews work in all of the bag houses.

Bag housemen shake the bags, repair the bags, and replace bags that are worn out.

Dust men clean out the hoppers, clean out the cellars under the bays, and load this dust into larry cars.

Most of the bag house flue dust is carried to the pug mill, where the operator regulates the amount of water to be mixed with the dust. After mixing, the pugged material is carried by a conveyor to a railroad car, and is then returned to the plant processes.

\section{Electrical Precipitators}

Dusts that do not settle out as flue products travel toward the stacks 
in the copper smelter, along with the fumes in these products, and are removed by the electrical precipitators. The products from the following flues pass through different precipitators: converters, reverberatory furnace, roaster, and acid plant. The following men operate these precipitators:

Operators have charge of the treater floors and adjust the amount of current flowing through the plates. Helpers assist the operators and knock the treater plates when the current has been turnd off so that the dust will fall into the hoppers.

Flue dust contractors empty the dust from these hoppers into larry cars and transport it to the plant processes.

\section{Assay Laboratories}

Chemists and assayers test the various ore samples by chemical methods and fire assaying.

Testing engineers collect smoke samples and make chemical analyses of smokes in the smoke laboratory.

\section{Acid Plant}

The sulphuric acid plant has operators in charge who control the processes, check the various chart readings, and test the products. A lead burner is employed to repair the pipes and linings in the plant. The janitor keeps the floor and equipment clean.

\section{Arsenic Plant}

In the arsenic plant the arsenic flue dust is brought to the furnace charge floor in a larry car, and is slowly fed into the top of the furnace by the furnaceman, and the fireman below shovels coke into the firebox of the furnace. The men working on these two jobs alternate their work on alternate days. At the time the study was made, the arsenic was not being used in the weed-killer plant, nor was it being refined, so that these operations were not observed.

\section{Cadmium Plant}

In the cadmium plant the furnacemen, leachers, tankmen, filtermen, and helpers alternate jobs irom day to day. In other words, all men in the department change jobs except the men in the casting department, in which the casters remelt the sponge and cadmium that is scraped from the plates in the tankroom and pour the melted cadmium into bars, balls, and other forms for shipment. The operations in the cadmium plant performed by the men mentioned above are discussed under the section on Processes.

\section{Power Houses}

Engineers operate steam-powered air compressors and steam-driven electric generators.

Pumpmen oil and repair the compressor pumps.

Oilers are responsible for the lubrication of the power house equipment, and for keeping the equipment clean.

Boiler tenders, or Firemen, regulate the stokers feeding coal to the boilers, regulate the water in the boilers, and clean the tubes in the boilers. 
The lead smelter operates these boilers in connection with the power house, while the copper smelter uses the steam from the waste heat boilers to operate the power house.

Janitors do the general cleaning in the power houses.

\section{Maintenance}

Boiler Shop-The boiler shops in both plants are primarily welding shops, with welders doing both arc and acetylene welding. Layout men mark steel for welding and cutting; boilermakers do general steel fabricating and erection work; punch machine men operate motor-driven machines to punch holes in boiler plate. The apprentices assist with the various jobs. The men in the maintenance department work in the plant as well as in their particular shop.

Blacksmith Shop-Blacksmiths do general forge work, heating, shaping, sharpening, and cutting of metals. Helpers assist the blacksmiths.

Carpenter Shop-Pattern makers cut out, glue, sand, and paint wooden patterns to be used in the foundry to make molds for casting. Carpenters do general carpentery, using band saws, planers, mechanical sanders, and other equipment for carpentry and cabinet work. In addition to this shop work, these men do repair and construction work throughout the plant.

Brick Masons - The primary duty of the brick masons and helpers is to repair, reline, or even construct furnaces, roasters, converters, and ladles. Practically all of the mason's work is in the various departments in the plant. They sometimes work on reclaiming brick from furnaces and linings that are being dismantled, so that these brick can be used in the reconstruction. Much of this work is done with silica brick.

Electrical Shop-Electricians work in the shop, winding armatures, repairing motors and switches, in addition to installing these motors and other appliances in the plant. They are responsible for the installation and maintenance of all of the electrical equipment. The helpers assist the electricians in this work.

Foundry-Molders make sand molds, assist in the pouring of molten metal into their molds, and help shake the castings out of the sand. Molder helpers assist the molders, condition the sand by shovelling it into piles, mixing it, and breaking up the lumps.

Core makers mix the core sand with the binders, mold the cores, and bake these cores.

Cupola tenders fire and charge the cupola.

Cranemen operate an overhead travelling crane used to carry ladles of molten iron, and to transport heavy castings across the floor. These men also clean the castings with pneumatic chippers.

Handymen assist with the various operations, condition sand, and clean up the shop.

Jackhammer Operators and Riggers-Jackhammer operators are employed in repair work, in removing concrete, breaking out baffle walls, and linings.

Riggers handle and place heavy machinery and erect steel work.

Machine Shop-Machinists, apprentices, and helpers operate lathes, milling machines, and the other equipment found in general machine shop work. Slag motor repairmen repair locomotives for hauling slag. Railroad 
car repairmen repair cars, engines, and cranes in the round house. Auto mechanics repair company automobiles and trucks. All of these men do not work in the machine shop itself, but do similar work.

Paint Shop-Painters and their helpers do general painting throughout the entire plant, as well as mixing paints and storing their equipment in the paint shop, where they also paint signs.

Pipe Shop-Pipe fitters, helpers and apprentices cut, thread, install pipe, and connect various machines with pipes for steam, air, water, and other liquids.

Salvage Shop-Salvage laborers reclaim waste materials from the plant.

Yard Labor-Yard laborers do general labor around the plant, digging ditches, cleaning grounds, and general work required around the plant.

Miscellaneous-Watchmen are stationed at various gates to permit only employees or persons on business to enter the plants, and also to make periodic inspections of departments when they are not in operation.

Warehousemen maintain stocks of supplies, and issue these materials to the men as needed.

\section{TABLE 56-Lead, Arsenic, Selenium, and Antimony in Settled Dust Samples.}

\begin{tabular}{|c|c|c|c|c|}
\hline Source of sample & $\begin{array}{c}\text { Percentage } \\
\text { of } \\
\text { lead }\end{array}$ & $\begin{array}{l}\text { Percentage } \\
\text { of } \\
\text { arsenic }\end{array}$ & $\begin{array}{l}\text { Percentage } \\
\text { of } \\
\text { selenium }\end{array}$ & $\begin{array}{l}\text { Percentage } \\
\text { of } \\
\text { antimony }\end{array}$ \\
\hline 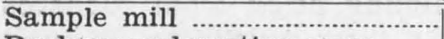 & 0.9 & 2.1 & .......... & \\
\hline Bucking and parting room.... & $0.4)$ & …... & ........ & ......... \\
\hline & 16.0) & ….. & …...... & …...... \\
\hline \multirow{2}{*}{\multicolumn{5}{|c|}{$\begin{array}{l}\text { D. and L. Roasters: } \\
\text { Conveyors }\end{array}$}} \\
\hline & & & & \\
\hline 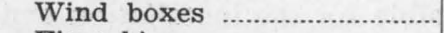 & 38.6 & ....... & .......... & .......... \\
\hline 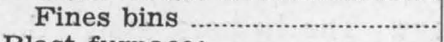 & 33.4 & ....... & ......... & ......... \\
\hline \multicolumn{5}{|l|}{ Blast furnace: } \\
\hline \multirow{2}{*}{\multicolumn{3}{|c|}{ Charge floor }} & $\cdots \cdots \cdots$ & \\
\hline & $\begin{array}{l}34.0) \\
14.3)\end{array}$ & 0.1 & (n...... & (....... \\
\hline \multicolumn{5}{|l|}{ Drossing furnace charge } \\
\hline floor & 15.7 & …... & …..... & \\
\hline \multicolumn{5}{|l|}{ Lead casting....................... } \\
\hline \multicolumn{5}{|l|}{$\begin{array}{c}\text { Copper casting sample } \\
\text { sawing }\end{array}$} \\
\hline \multirow{2}{*}{\multicolumn{5}{|c|}{$\begin{array}{l}\text { Flue cleaning: } \\
\text { Arsenic flues }\end{array}$}} \\
\hline Arsenic flues ................... & 19.0 & 2.2 & & \\
\hline Roaster flues ..................... & ....... & 0.2 & 0.056 & \\
\hline \multicolumn{5}{|l|}{ Bag house: } \\
\hline $\begin{array}{l}\text { Roaster bays ............... } \\
\text { Blast furnace bays..... }\end{array}$ & $\begin{array}{r}1.1 \\
11.4\end{array}$ & 7.3 & ......... & \\
\hline $\begin{array}{l}\text { Blast furnace bays................. } \\
\text { Dross kettle bays.................... }\end{array}$ & 21.9 & ….. & ….... & $\begin{array}{l}\text { 1race } \\
2.7\end{array}$ \\
\hline $\begin{array}{l}\text { Dross kettle bays................. } \\
\text { Blast furnace boat bays..... }\end{array}$ & 16.6 & $\cdots \cdots .$. & (.......... & 0.6 \\
\hline Pug mill & $6.3)$ & 10.3) & $\ldots \ldots . . .$. & 1.8) \\
\hline \multirow{2}{*}{\multicolumn{4}{|c|}{ Electrical precipitator }} & 1.6) \\
\hline hoppers & 36.8 & 1.3 & & \\
\hline \multicolumn{5}{|l|}{ Arsenic plant: } \\
\hline Feed floor & …... & 5.4 & ......... & \\
\hline Firing floor & …... & 1.6 & ......... & ....... \\
\hline \multicolumn{5}{|l|}{ Acid plant: } \\
\hline Precipitator flue dust.............. & …... & ….. & 0.040 & \\
\hline
\end{tabular}


Janitors clean offices, buildings and residences in the plant.

Gardener does experimental gardening and landscaping.

Firechief is in charge of fire prevention and checks on fire extinguishers and other fire-fighting equipment.

\section{Nature of Dust}

\section{Atmospheric Dusts}

Samples of dust settled out near the breathing level in different working places were collected, and 24 of these samples were analyzed for lead and/or arsenic, selenium, or antimony content. Table 56 lists the sources of these samples and the percentage of lead, arsenic, selenium and antimony found by chemical tests made.

Thirteen of the settled dust samples were analyzed chemically for total silica and petrographically for quartz content. In addition to these 13 samples, six additional samples were examined petrographically only for the amount of quartz. In Table 57 the sources of these samples are listed by department, and the percentages of total silica and free silica are shown. Those departments in which workers were exposed to dust with more than 10 percent quartz were the sample mills, the loading and unloading docks, and the bucking and parting rooms. On the basis of quartz alone, the dusts in the sample mills, the loading and unloading docks, and the bucking and parting rooms have the greatest potential silica hazard, while the dusts in the crushing and grinding (or dry side of the concentrator) contain slightly less free silica.

\section{TABLE 57-Silica Content of Settled Dust Samples.}

\begin{tabular}{|c|c|c|c|}
\hline \multirow{2}{*}{ Source of sample } & \multicolumn{3}{|c|}{ Percentage of silica } \\
\hline & \multicolumn{2}{|c|}{ Total } & Free \\
\hline Chemical and pertographic analyses & \multirow{3}{*}{$\begin{array}{l}17.8) \\
34.2)\end{array}$} & \multirow{2}{*}{26.0} & \multirow{2}{*}{$\begin{array}{l}14.7) \\
17.1)\end{array}$} \\
\hline Loading and unloading docks........... & & & \\
\hline Concentrator & & 45.3 & \multirow{5}{*}{$\begin{array}{lr} & 8.9 \\
23.5) & 21.5 \\
18.6) & \\
12.9) & 11.6 \\
10.4) & \end{array}$} \\
\hline Sample mill & \multirow{3}{*}{$\begin{array}{l}32.5) \\
31.7) \\
33.5) \\
23.1)\end{array}$} & 70.0 & \\
\hline & & \multirow{3}{*}{28.3} & \\
\hline Bucking and parting rooms.... & & & \\
\hline Roasters: & \multirow{6}{*}{\multicolumn{2}{|c|}{$\begin{array}{r}8.6 \\
8.6 \\
16.3 \\
13.9 \\
20.9\end{array}$}} & \\
\hline Feed floor & & & Less than 1.0 \\
\hline D. \& L. conveyor & & & $\begin{array}{l}\text { Less than } 1.0 \\
\text { Less than } 1.0\end{array}$ \\
\hline Reverberatory furnace charge floor....... & & & 4.6 \\
\hline Flue cleaning (roaster flues) & & & $1-2$ \\
\hline Maintenance - Foundry & & & 4.6 \\
\hline Petrographic analysis only & & & \multirow{4}{*}{$\begin{array}{l}\text { Less than } 1.0 \\
\text { Less than } 1.0 \\
\text { Less than } 1.0\end{array}$} \\
\hline Lead blast furnace charge floor $. . . \ldots \ldots \ldots . . . .$. & & & \\
\hline Dross furnace charge floor.................................... & & & \\
\hline Flue cleaning (arsenic flues) .......................... & & & \\
\hline Bag house: & & & \multirow{3}{*}{$\begin{array}{l}\text { None } \\
\text { None }\end{array}$} \\
\hline Roaster bays & & & \\
\hline Pug mill ........................... & & & \\
\hline Electrical precipitators & & & \multirow[b]{2}{*}{ None } \\
\hline Converter flue hoppers & & & \\
\hline
\end{tabular}


Upon classifying the workers on the basis of their quartz exposure, it is found that approximately 20 percent are exposed to dusts containing more than 10 percent quartz. Loaders and unloaders and those workers in the sampling mills and bucking and parting rooms are so exposed.

\section{Size of Dust}

Particle-size measurements were made on 200 dust particles in each of four impinger samples collected from the breathing zone of smelter workers. The size distribution of these 800 particles is shown in Figure 33 and in Table 58. Half of the particles were less than 1 micron and fourfifths were less than 2 microns in average length. These dusts are similar in size to industrial dusts that have been encountered in other studies of dusty trades, (4) and it is apparent that the dust particles are of a size capable of gaining access to the lungs.

\section{Dust Concentration}

For determination of the amount of dust to which smelter workers were exposed, 257 atmospheric dust samples were obtained with the Greenburg-Smith and midget impingers. These samples were allotted on the basis of the number of workers in each occupation or department, the importance of the occupations from the standpoint of the amount of dust exposure, and the amount of variation found to exist in the operating conditions. The following departments and operations were assigned more samples than average: unloading docks, the dry side of the concentrator, the sample mills, the bucking and parting rooms, the flue cleaning, the bag houses, the electrical precipitators, and the foundry. In the cases of the unloading docks, the crushing and grinding and unloading in the concentrator, the sample mills, and the bucking and parting rooms, it is evident that with the varied ores, concentrates, precipitates, and other materials being handled, it is important to take samples during the treatment of the various materials. A great difference in dustiness is found, for example, in the air during the unloading of wet, sticky concentrate or precipitate and the unloading of a dry crude ore.l Since the different flues were collecting materials from different operations, different bays of the bag houses collected dust from different operations, and the electrical precipitators in the different flues collected dusts from different operations, it was felt that each of these units should be studied so that representative exposures could be determined. In the foundry, not only were there several types of occupations in the one department, but on different days of the week, the operations were different. For example, approximately three and a half days each week were devoted to molding, conditioning sand, core making, and cleaning castings; twice a week a half day was required to pour the castings; and two half-days were devoted to shaking out the castings. In other words, it was necessary to take three sets of samples to represent this cycle of operations.

In most of the smelter operations or departments, the samples taken were representative of the exposure of all men in the department. This was due to the fact that the departments were usually housed in the same room, or building, that was not partioned, or that men alternated positions resulting in equal exposures over a period of time. In these departments the samples taken were applied to all of the occupations working in the 
TABLE 58-Summary of Size Frequency Distribution of Atmospheric Dusts in Utah Smelters.

\begin{tabular}{|c|c|c|c|c|c|c|c|c|c|c|c|c|c|c|c|c|c|c|}
\hline \multirow[b]{2}{*}{$\begin{array}{l}\text { Location of } \\
\text { sampling station }\end{array}$} & \multirow{2}{*}{$\begin{array}{c}\text { Number } \\
\text { of } \\
\text { particles } \\
\text { measured }\end{array}$} & \multicolumn{17}{|c|}{ Percentage distribution of each particle-size group (in microns) } \\
\hline & & $<0.49$ & $\begin{array}{c}0.50 \\
\text { to } \\
0.99\end{array}$ & $\begin{array}{c}1.00 \\
\text { to } \\
1.49\end{array}$ & $\begin{array}{c}1.50 \\
\text { to } \\
1.99\end{array}$ & $\begin{array}{c}2.00 \\
\text { to } \\
2.49\end{array}$ & $\begin{array}{c}2.50 \\
\text { to } \\
2.99\end{array}$ & $\begin{array}{c}3.00 \\
\text { to } \\
3.49\end{array}$ & $\begin{array}{c}3.50 \\
\text { to } \\
3.99\end{array}$ & $\begin{array}{c}4.00 \\
\text { to } \\
4.49\end{array}$ & $\begin{array}{c}4.50 \\
\text { to } \\
4.99\end{array}$ & $\begin{array}{c}5.00 \\
\text { to } \\
5.49\end{array}$ & $\begin{array}{c}5.50 \\
\text { to } \\
5.99\end{array}$ & $\begin{array}{c}6.00 \\
\text { to } \\
6.49\end{array}$ & $\begin{array}{c}6.50 \\
\text { to } \\
6.99\end{array}$ & $\begin{array}{c}7.00 \\
\text { to } \\
7.49\end{array}$ & $\begin{array}{c}7.50 \\
\text { to } \\
7.99\end{array}$ & $<8.0$ \\
\hline Sample mill & 200 & 8.5 & 40.0 & 29.0 & 8.0 & 7.5 & 3.0 & 2.5 & 2.5 & 1.5 & .... & 0.5 & 0.5 & 0.5 & .... & 0.5 & 0.5 & .... \\
\hline Sample mill …........... & 200 & 9.5 & 33.0 & 21.5 & 13.5 & 6.5 & 3.0 & 2.0 & 0.5 & 2.5 & 3.5 & 0.5 & 0.5 & 0.5 & .... & 0.5 & 0.5 & 2.0 \\
\hline Concentration mill . & 200 & 13.5 & 41.5 & 22.5 & 6.5 & 4.5 & 4.5 & 0.5 & 1.0 & 3.0 & 1.5 & .... & .... & .... & .... & .... & ..... & 0.5 \\
\hline Concentration mill & 200 & 9.0 & 46.0 & 24.0 & 4.5 & 5.5 & 3.0 & 4.0 & .... & 0.5 & .... & 0.5 & 0.5 & 0.5 & 1.0 & 0.5 & $\ldots$. & 0.5 \\
\hline Total & 800 & .... & .... & .... & .... & .... & .... & .... & .... & .... & .... & .... & .... & .... & .... & $\ldots$. & .... & .... \\
\hline Average distribution & & 10.1 & 40.1 & 23.0 & 8.1 & 6.0 & 3.4 & 2.2 & 1.0 & 1.9 & 1.3 & 0.4 & 0.4 & 0.4 & 0.2 & 0.4 & 0.2 & 0.9 \\
\hline
\end{tabular}


Dercent

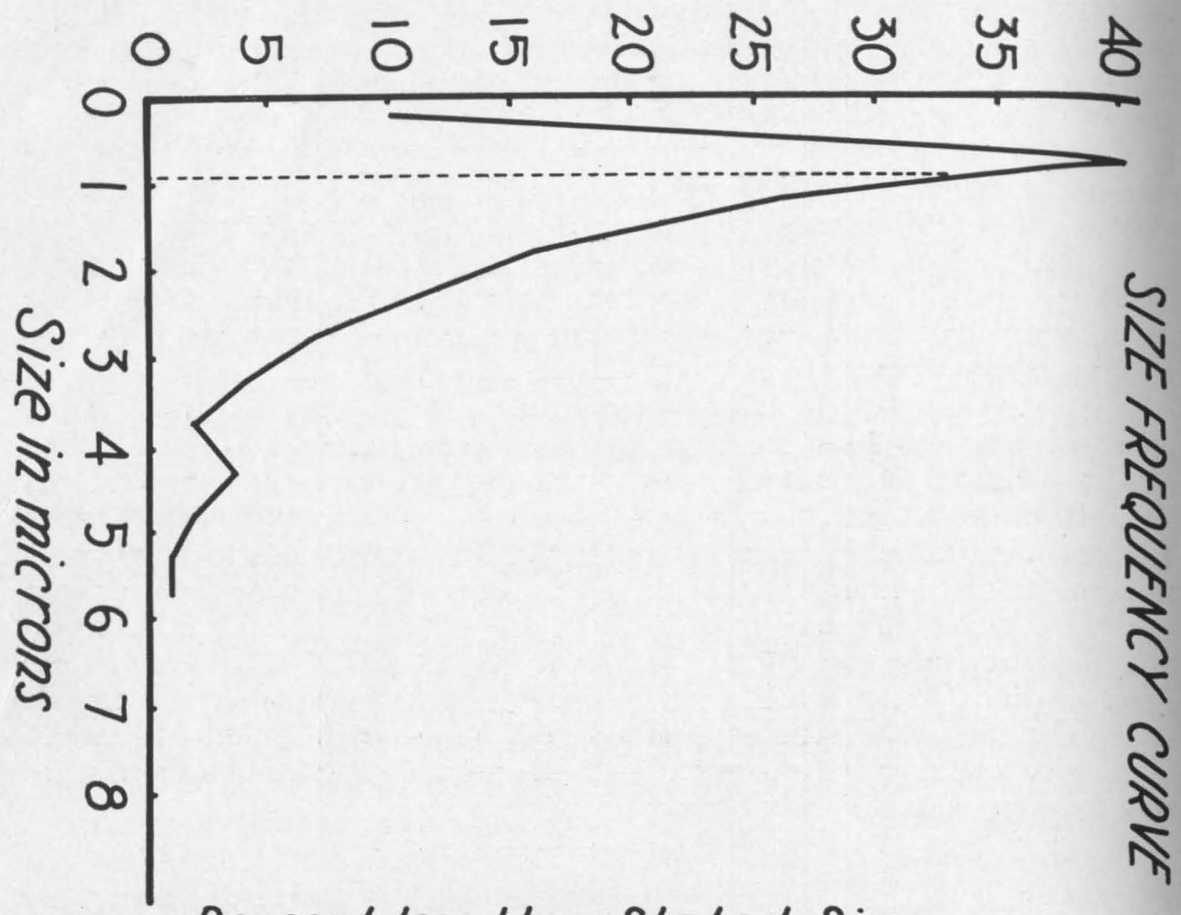

Percent less than Stated size

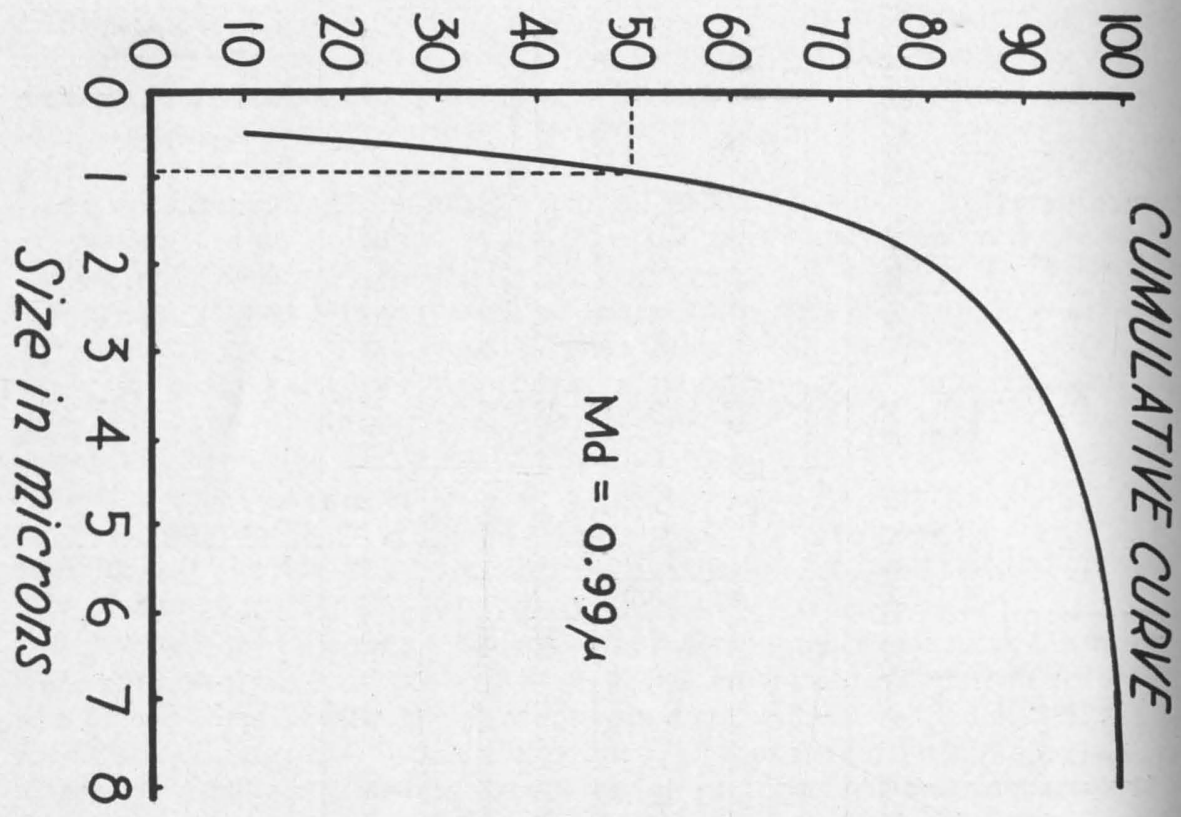

FIGURE 33-Particle-size distribution of smelter dusts. 
department. In some departments, however, there were distinctly different exposures in different rooms, or workers were separated widely enough so that the exposures would not be the same, and the men did not alternate on the jobs. This was true in the unloading department, and the conditions surrounding the unloading docks, the Martin machines, and the engines and cranes operated by the yard crews, were quite different. Other instances of departments that needed subdividing for the purpose of considering dust exposures to the men working in the departments were the concentrater, lead roasting, lead blast furnace, reverberatory furnace, electrical precipitator, and cadmium departments. These departments were subdivided into groups of occupations that are in the same locality or have similar exposures.

Since the amount of quartz in the dust and the concentration of the dust in the atmosphere are both of great importance in evaluating the hazard to health in breathing these dusts, data are presented showing the concentrations of dusts in departments from which the settled dust samples were found to contain more than 10 percent quartz (table 59). In table 60 dust concentrations in departments whose settled dust showed less than 10 percent quartz are shown. In tables 59 and 60 , in addition to the average dust concentrations found, the maximum and the minimum concentrations found are also shown, along with the number of samples taken and the percentage of quartz found in the department. It should be pointed out that the highest percentage of quartz and dust concentration was found in the sample mills.

\section{TABLE 59-Concentrations of Dusts Containing More Than 10 Percent Quartz.}

\begin{tabular}{|c|c|c|c|c|c|}
\hline \multirow{2}{*}{ Location } & \multirow{2}{*}{$\left|\begin{array}{c}\text { Number } \\
\text { of } \\
\text { samples }\end{array}\right|$} & \multirow{2}{*}{$\begin{array}{c}\text { Percentage } \\
\text { of } \\
\text { quartz }\end{array} \mid$} & \multicolumn{3}{|c|}{$\begin{array}{l}\text { Millions of particles } \\
\text { per cubic foot of air }\end{array}$} \\
\hline & & & Average & Maximum & Minimum \\
\hline Unloading & 15 & 17.1 & 34.7 & 203.7 & 0.2 \\
\hline Sample mills. & 27 & 21.05 & 72.7 & 206.2 & 3.0 \\
\hline Bucking and parting rooms.. & 25 & 11.6 & 34.1 & 112.9 & 2.8 \\
\hline
\end{tabular}

\section{TABLE 60-Concentration of Dusts Containing Less Than 10 Percent Quartz.}

\begin{tabular}{|c|c|c|c|c|c|}
\hline \multirow{2}{*}{ Location } & \multirow{2}{*}{$\begin{array}{c}\text { Number } \\
\text { of } \\
\text { samples }\end{array}$} & \multirow{2}{*}{$\begin{array}{c}\text { Per- } \\
\text { centage } \\
\text { of } \\
\text { quartz }\end{array}$} & \multicolumn{3}{|c|}{$\begin{array}{l}\text { Millions of particles } \\
\text { per cubic foot of air }\end{array}$} \\
\hline & & & Average & Maximum & Minimum \\
\hline \multicolumn{6}{|l|}{$\begin{array}{l}\text { Roasters } \\
\text { Sintering }\end{array}$} \\
\hline 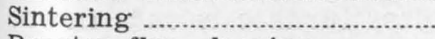 & 11 & Trace & 15.7 & 47.2 & 1.2 \\
\hline Roaster flue cleaning.... & 4 & $1-2$ & 597.9 & $1,491.9$ & 151.1 \\
\hline Reverb charge floor & 4 & 4.6 & 8.7 & 23.4 & 2.4 \\
\hline Foundry & 21 & 4.6 & 47.5 & 385.0 & 3.7 \\
\hline \multicolumn{6}{|l|}{ Concentrator: } \\
\hline Dry crushing and grinding. & 18 & 8.9 & 14.3 & 35.1 & 2.6 \\
\hline
\end{tabular}


Table 61 lists the number of workers in each department or occupation in the two smelters, the number of samples collected to determine the dust concentration in each department or occupation, the average dust concentration by department or occupation, and the weighted average dust concentrations in each. As has been stated previously, some departments have operations that differ both in type and location, so that some depart. ments are broken down into smaller groups. In most cases it was felt that the samples collected were representative of the operations and in the correct proportion, so that the numerical average of the dust counts was also the weighted average of the concentration of dust in the atmos. phere. However, there were exceptions and these averages were weighted by considering the amount of time the worker spent in a location or in a particular phase of the operation.

It may be seen from an examination of Table 61 that the dust concentrations range from negligible amounts, in the neighborhood of less than 1 million particles for such occupations as maintenance workers, to extremely high amounts in the neighborhood of 400 million particles for certain bag house workers. However, in order to interpret these dust concentrations it is necessary to take into consideration the nature of the dusts themselves. It has already been shown that certain workers in sample mills, although not exposed to as high dust concentrations as those in the bag house were exposed to dusts containing relatively high concentrations of quartz, whereas the bag house dust was found to contain but traces of this material.

\section{Atmospheric Concentrations of Metals}

As has been previously stated, the ores come to these smelters from many sources, and are of a very complex nature. Many metals occur in varying proportions through a wide range of chemical combinations in the ores handled, and while a complete analysis of each sample collected was not attempted, the outstanding metals of interest and significance were evaluated chemically. Emphasis was placed on those metals that were being separated or changed chemically in any process within the departmental operations, and on the metals of possible health significance, instead of attempting complete chemical analyses of every sample collected.

\section{Antimony}

Table 62 lists the number of samples used and the amount of antimony in the atmosphere in the various departments. A study of this table reveals the fact that the highest atmospheric concentrations of antimony were found in the bag houses, with the blast furnace bays having a concentration of 130 milligrams of antimony per 10 cubic meters of air. The samples collected in the bag houses for this series of samples were taken during the Saturday bag repairs. It is a general practice to make repairs on the bags on Saturday morning, when the blast furnace is shut down, and the bays are opened up and aired out before the men enter to do the repair work. The samples from the roaster bays and the dross kettle bays were also collected inside the bays during the bag repairing operation. No antimony was detected in the samples from the concentrator crushing plant or the D \& L roasters, but it must be realized that as differ- 
TABLE $61-$ Summary of Average Dust Exposures by Departments and Occupations in Utah Smelters.

\begin{tabular}{|c|c|c|c|}
\hline Departments and occupations & $\begin{array}{c}\text { Number } \\
\text { of } \\
\text { workers }\end{array}$ & $\begin{array}{l}\text { Number } \\
\text { of } \\
\text { samples }\end{array}$ & $\begin{array}{c}\text { Weighted } \\
\text { average dust } \\
\text { exposure } \\
\text { (millions of } \\
\text { particles per } \\
\text { cubic foot of air) }\end{array}$ \\
\hline Totals & 1402 & 257 & \\
\hline Office and supervisory personnel................... & 45 & ....... & 3.0 \\
\hline \multicolumn{4}{|l|}{ Loading and unloading: } \\
\hline Martin machine operators & 12 & 2 & 2.7 \\
\hline Unloading docks & 113 & 17 & 33.5 \\
\hline Yard crews & 50 & 6 & 3.8 \\
\hline \multirow{2}{*}{\multicolumn{4}{|c|}{$\begin{array}{l}\text { Concentrator: } \\
\text { Car dumping, crushing, and }\end{array}$}} \\
\hline & & & \\
\hline 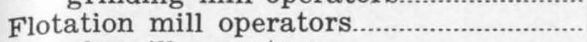 & 501 & $\begin{array}{l}18 \\
10\end{array}$ & $\begin{array}{r}14.3 \\
4.5\end{array}$ \\
\hline 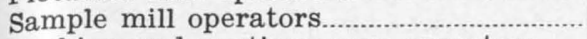 & 76 & 27 & 72.7 \\
\hline Bucking and parting room operators... & 40 & 28 & 33.4 \\
\hline \multicolumn{4}{|l|}{ Lead roasting: } \\
\hline Wedge furnace operators......................... & 16 & 4 & 31.7 \\
\hline 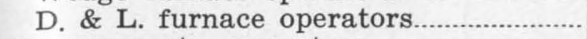 & 55 & 11 & 15.7 \\
\hline Copper roaster operators.............................. & 53 & 3 & 7.5 \\
\hline \multicolumn{4}{|l|}{ Lead blast furnace: } \\
\hline Charge floor operators....... & 12 & 3 & 61.6 \\
\hline Tapping floor operators.... & $24^{2}$ & 2 & 1.1 \\
\hline \multicolumn{4}{|l|}{ Reverberatory furnace: } \\
\hline Furnace operators & 85 & 9 & 9.5 \\
\hline Waste heat boiler operators & 19 & 2 & 3.0 \\
\hline \multicolumn{4}{|l|}{$\begin{array}{l}\text { Lead drossing kettle and furnace: } \\
\text { Operators }\end{array}$} \\
\hline 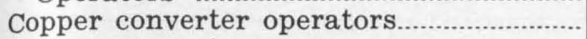 & $84^{3}$ & 5 & $\begin{array}{l}1.0 \\
2.9\end{array}$ \\
\hline Copper converter crane men $\ldots . . . \ldots \ldots \ldots \ldots . . . . . .$. & $19^{3}$ & 2 & 14.6 \\
\hline Lead casting wheel operators.......... & 72 & 1 & 1.3 \\
\hline Copper casting wheel operators.... & 23 & 3 & 3.5 \\
\hline Flue cleaners .............................................. & 6 & 9 & 107.4 \\
\hline Bag house operators ........ & 16 & 16 & 371.2 \\
\hline \multicolumn{4}{|l|}{ Electrical precipitators: } \\
\hline Operators & $6^{4}$ & 4 & 1.5 \\
\hline Hopper cleaners ……….......................... & $12^{4}$ & 5 & 55.8 \\
\hline 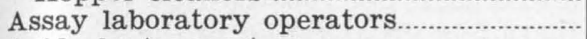 & 27 & 4 & 5.6 \\
\hline Acid plant operators................................. & 9 & 1 & 0.3 \\
\hline 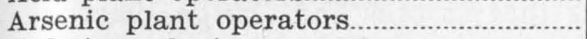 & 7 & 2 & 10.6 \\
\hline Cadmium plant: & & & \\
\hline $\begin{array}{l}\text { Furnace, mill, leaching and } \\
\text { tank room operators.............. }\end{array}$ & 5 & 4 & \\
\hline Casting room operators............ & 5 & 1 & $\begin{array}{l}0.4 \\
1.4\end{array}$ \\
\hline 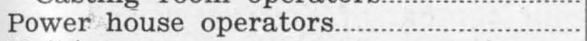 & 25 & 3 & 0.8 \\
\hline \multicolumn{4}{|l|}{ Maintenance: } \\
\hline Boiler shop ............. & 71 & 6 & 6.0 \\
\hline 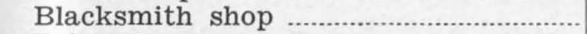 & 15 & 4 & 2.4 \\
\hline Brick masons ………………………… & 26 & 6 & 46.3 \\
\hline 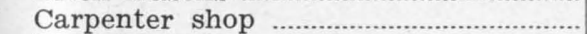 & 50 & 2 & 15.9 \\
\hline 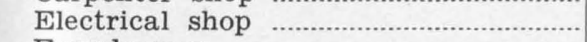 & 24 & 3 & 0.7 \\
\hline Foundrymen & 16 & 21 & 24.8 \\
\hline Jackhammer men and riggers............... & 12 & 2 & 60.9 \\
\hline 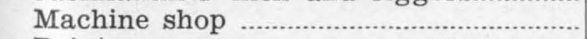 & 70 & 5 & 2.7 \\
\hline Painters & 9 & $\ldots$ & 6.0 \\
\hline 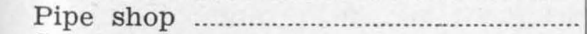 & 27 & 1 & 0.8 \\
\hline Salvage shop ……………… & 5 & 1 & 6.0 \\
\hline Yard laborers & 78 & ..... & 6.0 \\
\hline \multicolumn{4}{|l|}{ Extra labor (relief to all } \\
\hline $\begin{array}{l}\text { Miscellaneous-Watchman, } \\
\text { janitor, etc. }\end{array}$ & & & \\
\hline janitor, etc. …………… & 45 & 1 & 2.4 \\
\hline
\end{tabular}

1 All employees in the concentrator were reported together and this breakdown is based on the ratio shown in the preliminary survey.

2 All employees in the lead plant were reported together and this breakdown is based on the ratio shown in the preliminary survey.

3 Converter operators and cranemen were reported together and this breakdown is based on the ratio shown in the preliminary survey.

4 Precipitator operators and hopper cleaners were reported together and this breakdown is based on the ratio shown in the preliminary survey.

5 No employees were reported in the cadmium department. 
ent ores, containing varying amounts of antimony, are handled by these departments, the amounts of antimony in the air will vary.

\section{TABLE 62-Distribution of Antimony in the Atmosphere by Department.}

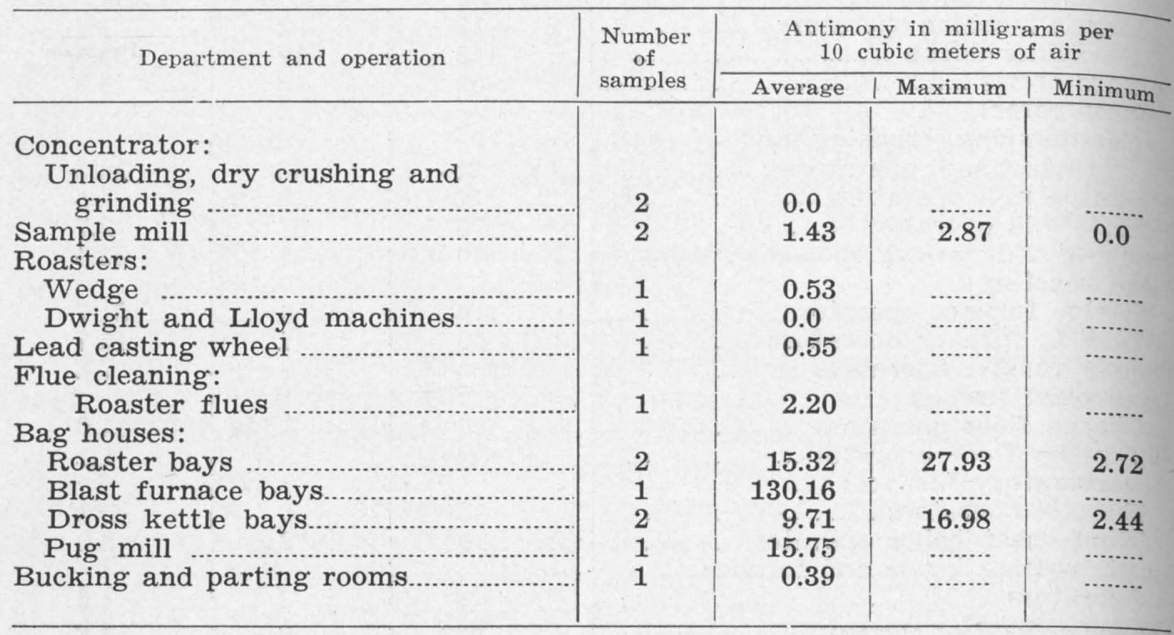

Arsenic

The concentrations of arsenic found in the atmosphere are shown, by department, in Table 63. The values range from zero in the samples collected at the unloading docks, the dross kettle bays of the bag houses, the bucking and parting rooms, and the general air in the plant yard, to 956 milligrams per 10 cubic meters of air in the roaster flue cleaning operation. It is to be noted also that there is a great range in the samples within a single department, indicating that as ores and charges vary, the concentration of arsenic in the atmosphere varies. There is some variation in dust counts in these same departments and operations, but the dust range would not account for the great range of arsenic concentrations unless there was a change in the arsenic content of the charge and dust also. One of the samples (0.09) taken on the arsenic furnace charge floor was during a period that arsenic flue dust was not being fed to the furnace, while the other sample (94.5) was during the charging operation.

\section{Cadmium}

Thirty-six samples were analyzed to determine the atmospheric concentrations of cadmium, by departments, as shown in Table 64. Again the atmosphere in the blast furnace bays was found to have the highest concentration, 809 and 373 , or an average of 591 milligrams of cadmium per 10 cubic meters of air for the two samples. The concentrations that were next in magnitude were found near the ball mill in the cadmium plant, and in the roasting department. Some of the samples of crude ore being treated in the sample mill caused a detectable cadmium concentration in the atmosphere, while others gave negative results. This fact indicates that fluctuating cadmium values in the ores received will cause the cadmium concentrations in the atmospheres surrounding the various processes treating these ores to fluctuate, but it is apparent there is a build-up 


\section{Copper}

Table 65 shows the departmental distribution of 88 samples that were analyzed to determine the atmospheric concentrations of copper in the various departments in these two plants. By far the greatest concentrations were found in operations handling flue dusts, that is, cleaning the roaster flues, and in working inside the bag house that filters out the dusts from the drossing operation. In noting that there is a wide range in the copper concentrations for a particular department, it must be re membered that the findings for similar operations were combined for the two plants wherever possible. This fact will account for some of the roaster samples showing zero milligrams of copper per 10 cubic meters of air, while others show as high as 243 milligrams of copper in the same amount of air. This is also true in the case of roaster flue cleaning, where the range is from 44 to 2221 milligrams of copper per 10 cubic meters of air. While much of the lead ore being handled in the lead smelter contains some copper, it is obvious that the ores higher in copper value will be sent to a copper smelter. The reverse is true in the case of lead values, and it is generally found that the concentrations of lead in the atmosphere in the lead smelter are greater than those found in the copper smelter. High concentrations of copper are found in the atmosphere surrounding operations in the dross kettle bays, as the drossing operation is the point at which the copper is separated from the lead, and the point where copper from large quantities of ore is accumulated.

\section{Lead}

The atmospheric concentrations of lead found by department are shown in Table 66. Since inhalation of lead-laden air plays such an important role in the causation of lead poisoning (5) it is apparent that hazards exist in many of the departments. The flue dust operations, roasting departments, and sample mills were found to have the highest concentrations. It was observed that men working in these departments wore respirators.

\section{Zinc}

Zinc was found in only one of the three atmospheric samples analyzed, and this analysis indicated an atmospheric concentration in the blast furnace bays of the bag house of 309 milligrams of zinc per 10 cubic meters of air. Two samples collected near the tapping operations of the blast furnace failed to reveal any zinc, although it is known that the "speiss" being collected in the settlers is rich in zinc. However, a hood with a local exhaust system was in position over the settlers to remove the fumes, and since zinc was detected in the bag house handling the gases from this settler, while none was found in the atmosphere surrounding the tapping operation, credit must be given to the control system installed.

\section{Other Metals}

Two samples collected during reverberatory furnace operations, one during the tapping of slag, and the other during the tapping of matte failed to show any selenium, as did a sample collected near the copper converters, and one near copper casting. Selenium was found in the settled 
TABLE 65-Distribution of Copper in the Atmosphere by Department.

\begin{tabular}{|c|c|c|c|c|}
\hline \multirow{2}{*}{ Department and operation } & \multirow{2}{*}{$\begin{array}{c}\text { Number } \\
\text { of } \\
\text { samples }\end{array}$} & \multicolumn{3}{|c|}{$\begin{array}{l}\text { Copper in milligrams per } \\
10 \text { eubic meters of air }\end{array}$} \\
\hline & & Average & Maximum & Minimum \\
\hline Concentration mill: & \multirow{6}{*}{$\begin{array}{l}2 \\
2 \\
4 \\
9\end{array}$} & \multirow{6}{*}{$\begin{array}{l}0.20 \\
0.0 \\
3.22 \\
9.90\end{array}$} & \multirow{3}{*}{0.41} & \multirow{3}{*}{0.0} \\
\hline 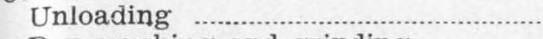 & & & & \\
\hline Dry crushing and grinding..... & & & & \\
\hline Unloading & & & 8.59 & 0.0 \\
\hline 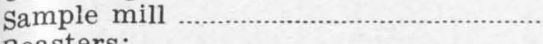 & & & 46.46 & 0.0 \\
\hline \multicolumn{3}{|l|}{ Roasters: } & & \\
\hline Roasting & 8 & 85.91 & $24 \hat{z} .93$ & 0.0 \\
\hline Sintering & \multirow[t]{2}{*}{7} & \multirow[t]{2}{*}{8.22} & \multirow{2}{*}{43.75} & \multirow{2}{*}{0.41} \\
\hline $\begin{array}{l}\text { Furnaces: } \\
\text { Blast }\end{array}$ & & & & \\
\hline Reverberatory & \multirow{2}{*}{$\begin{array}{l}5 \\
6\end{array}$} & \multirow{2}{*}{$\begin{array}{l}0.0 \\
4.54\end{array}$} & \multirow[t]{2}{*}{15.80} & \multirow{2}{*}{0.0} \\
\hline Converters (including reberberatory & & & & \\
\hline converter cranes) & \multirow[t]{2}{*}{6} & \multirow[t]{2}{*}{4.99} & \multirow[t]{2}{*}{13.47} & \multirow[t]{2}{*}{1.52} \\
\hline Drossing: & & & & \\
\hline Kettles .. & \multirow{5}{*}{$\begin{array}{l}2 \\
2 \\
1 \\
1\end{array}$} & \multirow{5}{*}{$\begin{array}{c}6.61 \\
0.0 \\
0.0 \\
10.36\end{array}$} & \multirow{2}{*}{12.62} & \multirow{2}{*}{2.60} \\
\hline Furnace ..... & & & & \\
\hline Lead casting ........................... & & & .......... & .......... \\
\hline Copper casting ..... & & & ........... & ........... \\
\hline Flue cleaning: & & & \multirow{3}{*}{$2,221.21$} & \\
\hline Roaster & \multirow{4}{*}{$\begin{array}{l}1 \\
1\end{array}$} & \multirow{4}{*}{$\begin{array}{r}1,132.60 \\
5.50 \\
703.54\end{array}$} & & 44.00 \\
\hline Arsenic & & & & -......... \\
\hline Reverb …........ & & & .......... & .......... \\
\hline Electrical precipitators: & & & & \\
\hline Converter hoppers & 1 & 1.34 & ......... & -......... \\
\hline Reverb and roaster hoppers... & 1 & 152.53 & …..... & ......... \\
\hline Acid plant hoppers........................ & 1 & 37.06 & …..... & .......... \\
\hline 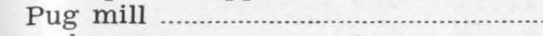 & 1 & 0.0 & ......... & ......... \\
\hline Bag houses: & & & & \\
\hline Roaster bays .............. & 2 & 0.0 & ......... & ......... \\
\hline Blast furnace bays... & 2 & 0.0 & & \\
\hline 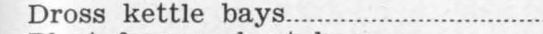 & 2 & $1,743.02$ & $2,022.64$ & $1,463.41$ \\
\hline Blast furnace boat bays.............. & 2 & 0.0 & $\ldots \ldots$ & ........... \\
\hline Pug mill ................................. & 1 & 40.94 & & \\
\hline Bucking rooms & 5 & 10.05 & 29.29 & 0.51 \\
\hline Parting rooms ……………………… & 2 & 0.25 & 0.51 & 0.0 \\
\hline Assay laboratory & 2 & 0.0 & .......... & \\
\hline Acid plant .................... & 1 & 0.0 & & \\
\hline Arsenic plant .............. & 2 & 1.52 & 2.52 & 0.53 \\
\hline Cadmium plant & 5 & 0.0 & & \\
\hline
\end{tabular}

dust samples in the room used for sawing up the blister copper samples, and in flue dusts from the roasters and acid plant (Table 56). Since the selenium is in the flue dust, and in the final product in one of the smelters, it indicates a source of atmospheric contamination that should be kept in mind. It is known that the ores entering these plants contain many other metals, such as silver, gold, bismuth, manganese, and mercury, but as these were of little health significance or present in very low concentrations, analyses were not made for these materials in atmospheric dust samples.

\section{Atmospheric Concentrations of Toxic Gases}

\section{Sulphur Dioxide}

Sulphur dioxide is one of the by-products in the roasting and smelting of sulphide ores, and 96 samples of air were sampled in the vicinity 
TABLE 66-Distribution of Atmospheric Lead by Departments.

\begin{tabular}{|c|c|c|c|c|}
\hline \multirow{2}{*}{ Department and operation } & \multirow{2}{*}{$\begin{array}{c}\text { Number } \\
\text { of } \\
\text { samples }\end{array}$} & \multicolumn{3}{|c|}{$\begin{array}{l}\text { Lead in milligrams per } \\
10 \text { cubic meters of air }\end{array}$} \\
\hline & & Average & Maximum & Minimum \\
\hline \multicolumn{5}{|l|}{ Concentration mill: } \\
\hline $\begin{array}{l}\text { Unloading } \\
\text { Dry crushing and grinding }\end{array}$ & 2 & 5.3 & 6.1 & 4.5 \\
\hline $\begin{array}{l}\text { Dry crushing and grinding..... } \\
\text { Unloading (car dumping and }\end{array}$ & 2 & 5.5 & 7.4 & 3.7 \\
\hline blowing) & \multirow{3}{*}{$\begin{array}{l} \pm \\
9\end{array}$} & 32.4 & \multirow{3}{*}{$\begin{array}{r}118.4 \\
69.1\end{array}$} & \multirow{3}{*}{$\begin{array}{l}0.0 \\
0.5\end{array}$} \\
\hline 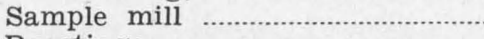 & & \multirow{2}{*}{$\begin{array}{l}32.4 \\
27.2\end{array}$} & & \\
\hline & & & & \\
\hline $\begin{array}{l}\text { Roasters } \\
\text { Sinterers }\end{array}$ & \multirow{2}{*}{$\begin{array}{l}7 \\
8\end{array}$} & \multirow{2}{*}{$\begin{array}{r}22.1 \\
194.2\end{array}$} & \multirow{2}{*}{$\begin{array}{r}95.1 \\
1,234.4\end{array}$} & \multirow{2}{*}{$\begin{array}{r}0.5 \\
13.8\end{array}$} \\
\hline Furnaces: & & & & \\
\hline $\begin{array}{l}\text { Blast } \\
\text { Reverberatory }\end{array}$ & \multirow{2}{*}{$\begin{array}{l}2 \\
6\end{array}$} & \multirow{2}{*}{$\begin{array}{l}0.5 \\
8.4\end{array}$} & \multirow{2}{*}{$\begin{array}{r}1.1 \\
23.8\end{array}$} & \multirow{2}{*}{$\begin{array}{l}0.0 \\
0.0\end{array}$} \\
\hline Converters (including cranes in & & & & \\
\hline reverb.-converter building) & \multirow[t]{2}{*}{6} & \multirow[t]{2}{*}{1.4} & \multirow[t]{2}{*}{2.1} & \multirow[t]{2}{*}{0.5} \\
\hline $\begin{array}{l}\text { Drossing: } \\
\text { Kettles }\end{array}$ & & & & \\
\hline $\begin{array}{l}\text { Kettles } \\
\text { Furnace }\end{array}$ & \multirow{2}{*}{2} & \multirow{2}{*}{2.1} & 4.3 & 0.0 \\
\hline Casting: & & & & 0.0 \\
\hline Lead casting wheel.... & 1 & 0.0 & 0.0 & 0.0 \\
\hline Copper casting wheel.. & 1 & 2.1 & ........... & \\
\hline Flue cleaning: & & & & \\
\hline Roaster flues ....................... & 2 & 996.8 & $1,976.9$ & 16.7 \\
\hline Reverb flues & 1 & 14.6 & $\quad \ldots \ldots$. & …...... \\
\hline Arsenic flues & 1 & 136.2 & ......... & .......... \\
\hline Electrical precipitators-Cleaning & & & & \\
\hline 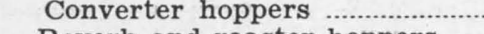 & 2 & 54.4 & 102.7 & 6.2 \\
\hline Reverb and roaster hoppers...... & 1 & 25.3 & -.......... & .......... \\
\hline $\begin{array}{l}\text { Acid plant hoppers.................. } \\
\text { Pug mill }\end{array}$ & 1 & 74.7 & ….. & ..... \\
\hline Bag houses: & 1 & 4.7 & & \\
\hline 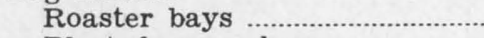 & 3 & 224.0 & 277.1 & 152.7 \\
\hline Blast furnace bays........................ & 2 & 484.3 & 509.5 & 459.1 \\
\hline Dross kettle bays & 2 & $5,962.0$ & $7,680.5$ & $4,243.4$ \\
\hline Blast furnace boat bays............... & 2 & 77.4 & 100.0 & 54.8 \\
\hline 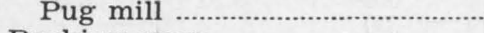 & 1 & $1,550.8$ & & \\
\hline Bucking room & 5 & 34.4 & 76.4 & 3.0 \\
\hline Parting room & 2 & 87.8 & 97.0 & 78.6 \\
\hline Assay furnace room & 2 & 6.0 & 6.6 & 5.5 \\
\hline Acid plant ................................... & 2 & 1.0 & 2.0 & 0.0 \\
\hline $\begin{array}{l}\text { Arsenic furnace } \\
\text { Cadmium plant: }\end{array}$ & 2 & 9.7 & & \\
\hline $\begin{array}{l}\text { Cadmium plant: } \\
\text { Ball mill }\end{array}$ & 1 & 61.1 & 17.9 & 1.6 \\
\hline Furnace, leaching, tank room.. & 3 & 0.0 & 0.0 & 0.0 \\
\hline Casting & 1 & 2.7 & .......... & ......... \\
\hline General air & 1 & 0.0 & -......... & ......... \\
\hline
\end{tabular}

of the various operations and in the plant yards. Two samples of air near the State capitol building in Salt Lake City were analyzed for the purpose of controls on the tests in the two plants. The results of these sulphur dioxide tests are shown in Table 67.

It should be stated that the concentrations of sulphur dioxide found at any location within the plant depend upon many variable factors. The direction and velocity of the wind are big factors, as is the location of the sampling station with reference to the wind-direction. The atmospheric 
conditons also play an important role in the concentrations found in the plant atmosphere, for on a cloudy, foggy day, with very little wind, the gas generated will hang in the atmosphere in the vicinity of the plant much longer than it will on a bright day with a moderate or strong breeze blowing. Due to the fact that these variables influence the conditions, many samples were found to be necessary to arrive at a fair average concentration in such departments as the roasters, reverberatory furnace, and converters. In most cases, extremely high concentrations of sulphur dioxide are temporary, and are decreased by diluting wind currents, or a change in the conditions creating the high concentration. In very few instances is it necessary for a worker to remain in the immediate vicinity of these concentrations, as it is usually possible by walking a few steps to get out of the cloud, returning when the cloud has been dispersed. One of the exceptions to this case is the crane operators in the reverb-converter building. These men cannot leave the crane on these occasions, and it is often impossible for them to move the crane as they will be pouring a ladle of molten metal. Larrymen are sometimes subjected to extreme conditions when charging the reverberatory furnaces, or when loading the larry cars under the roasters.

It will be observed from examining Table 67 that the average sulphur dioxide concentrations in the plants varied from approximately 0.02 p.p.m. to as high as 12 p.p.m., found near the convertors and cranes. It has been well established that sulphur dioxide may be detected by the layman when the concentration is approximately 3 p.p.m. Concentrations in excess of 10 p.p.m. are severely irritating and those exposed will tend to leave the location. Every effort should be made to protect workmen who are forced to encounter concentrations in excess of 10 p.p.m., and it was observed that in one of the plants some of the men were furnished with respiratory protective devices.

\section{TABLE 67-Sulphur Dioxide Concentrations by Department.}

\begin{tabular}{|c|c|c|c|c|}
\hline \multirow{2}{*}{ Department and operation } & \multirow{2}{*}{$\begin{array}{c}\text { Number } \\
\text { of } \\
\text { samples }\end{array}$} & \multicolumn{3}{|c|}{$\begin{array}{l}\text { Sulphur dioxide in parts per } \\
\text { million parts of air }\end{array}$} \\
\hline & & Average & Maximum & Minimum \\
\hline \multicolumn{5}{|l|}{ Roasting: } \\
\hline Roasters & 13 & 4.68 & 14.99 & 0.20 \\
\hline Sinterers & 9 & 3.31 & 11.25 & 0.57 \\
\hline \multicolumn{5}{|l|}{ Furnaces: } \\
\hline \multirow{2}{*}{\multicolumn{4}{|c|}{ Reverberatory and waste }} & 0.01 \\
\hline & 28 & 11.26 & 98.00 & 0.20 \\
\hline \multicolumn{5}{|l|}{ Converters and cranes.. } \\
\hline \multicolumn{5}{|l|}{ Drossing } \\
\hline \multicolumn{5}{|l|}{ Casting } \\
\hline Bag houses ................. & 2 & 0.91 & 1.10 & 0.72 \\
\hline \multicolumn{5}{|l|}{ Assay laboratory } \\
\hline Foundry & 4 & 0.81 & 1.17 & 0.58 \\
\hline \multicolumn{5}{|l|}{ Maintenance: } \\
\hline Blacksmith shops & 5 & 0.30 & 0.40 & 0.21 \\
\hline Brick masons & 1 & 2.00 & & \\
\hline General air in plant yard.... & 6 & 0.025 & 0.12 & 0.021 \\
\hline Controls (Salt Lake City). & 2 & 0.004 & 0.006 & 0.002 \\
\hline
\end{tabular}




\section{Carbon Monoxide}

Forty-six tests were made for carbon monoxide concentrations in the smelters. It may be seen from Table 68 that in only one department was carbon monoxide present, that being the foundry. However, even here the average concentrations cannot be considered as excessive. The highest average concentration was in connection with the pouring operation, while the next highest was associated with cupola charging. The fan in use with the cupola was observed to be shut off until the firing and charg. ing of the cupola had been in progress for some time. Steps should be taken to exhaust any carbon monoxide that may escape from the charge opening, especially during the periods of "back draft."

\section{T ABLE 68-Carbon Monoxide Concentrations by Department.}

\begin{tabular}{|c|c|c|c|c|}
\hline \multirow{2}{*}{ Department and operation } & \multirow{2}{*}{$\begin{array}{l}\text { Number } \\
\text { of } \\
\text { samples }\end{array}$} & \multicolumn{3}{|c|}{$\begin{array}{l}\text { Carbon monoxide in parts per } \\
\text { million parts of air }\end{array}$} \\
\hline & & Average & Maximum & Minimum \\
\hline \multicolumn{5}{|l|}{ Roasting: } \\
\hline Roasters & 3 & 0.0 & & \\
\hline Sinterers ... & 3 & 0.0 & & \\
\hline \multicolumn{5}{|l|}{ Furnaces: } \\
\hline Blast & 1 & 0.0 & & \\
\hline \multicolumn{5}{|l|}{ Reverberatory and waste } \\
\hline 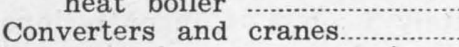 & $\begin{array}{l}6 \\
5\end{array}$ & 0.0 & & \\
\hline Drossing & 2 & 0.0 & ........ & \\
\hline Casting & 3 & 0.0 & $\ldots . . .$. & \\
\hline Assay laboratory .......................... & 1 & 0.0 & & \\
\hline \multicolumn{5}{|l|}{ Foundry: } \\
\hline Crane level during pouring.... & 4 & 15 & 20 & 0 \\
\hline Pouring floor during pouring & 3 & 37 & 40 & 30 \\
\hline 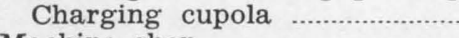 & 6 & 25 & 150 & 0 \\
\hline Machine shop & 1 & 0.0 & .......... & \\
\hline Blacksmith shop .............. & 4 & 0.0 & & \\
\hline
\end{tabular}

\section{Other Toxic Gases}

Tests were made for hydrogen cyanide in the air during the hardening of steel in the blacksmith shop, and for hydrogen sulphide in the sulphur plant, but these tests did not nidicate the presence of either gas in toxic concentrations.

\section{Control Measures}

Mechanical devices are in use in a number of the processes in these plants to remove dusts and gases that would normally contaminate the atmosphere. Some enclosed processes were employed, preventing the escape of contaminating materials, while other processes were hooded and these hoods were connected with exhaust systems to remove dusts, fumes or gases. Experimental work was in progress in one of the plants to determine the most effective hoods, exhaust system, and air cleaning devices for their particular needs.

Wet methods were not in general use as control measures, since it was believed that many of the processes would be hindered by wet mate- 
rials, such as crushing, grinding and screening. Water was being used to wet down the accumulated flue dust before shovelling it out of a reverberatory flue. Long water pipes were pushed into the banks of dust, and when the dust was wet thoroughly it was shoveled into trucks and hauled out of the flue. The wetting down of this flue dust enabled it to be moved with comparatively little contamination of the atmosphere, while without the use of water, the dust concentration would have been as high as in other flue cleaning operations. The flue products pass through a water spray before entering the bag houses, but this was to cool the gases, extinguish any sparks that might be present and to reduce the fire hazard. Sulficient water cannot be added to control the dust in these products, since a dampening of the bags would increase the resistance to the flow of gases through the bags.

Personal protection was provided in the forms of respirators, masks, and protective clothing. Many different types of respirators were observed in the plants, ranging from the U.S. Bureau of Mines approved types, to handkerchiefs tied over the nose and mouth. Some of the men wore the respirator whenever they were doing work that created large amounts of dust. Others had the respirators around thei rnecks and only wore them when the dust concentrations made breathing difficult without this protection. Gas masks were used by men entering the bag house bays for emergency repairs, when the bays had not been "aired" long enough to remove the carbon monoxide and other gases present.

Employees in the cadmium plant, arsenic plant, bag houses, and pug mill department were all furnished work clothing. The outer garment was a white coverall with a hood attached which covered the back of the man's neck and his head. The men in the bag houses and pug mill, and the flue cleaners in one plant placed thick layers of absorbent cotton over their noses and mouths, then laid a heavy cotton cloth over this cotton and tied it back of their heads. They believed that this type of respirator filtered out the dusts effectively. Rubber boots were provided when the men were required to work in materials which would effect the feet, and wooden shoes were used by men standing on hot floors. The samplers on the copper casting wheel were provided with asbestos gloves and aprons, and all men working with molten metals were furnished goggles.

General application, to all similar sources of contamination, of some of these methods for reducing the concentration of atmospheric contaminants, will appreciably reduce the industrial health hazards in the smelting industry. Moreover, some of the control devices now used will give better results if they are properly applied and maintained. Complete control of atmospheric contaminants requires the application of specific recommendations for control of each source of dust, fume, or gas. Such specific recommendations are beyond the scope of this report, but the following suggestions for reducing the atmospheric contamination by dusts, fumes, and gases, discussed by department, are of sufficient general interest to merit consideration.

\section{Loading and Unloading Docks}

The use of compressed-air jets to clean the undercarriage and wheels of the ore cars created dustiness in excess of the amount found where this cleaning operation was done with brushes. It is suggested that the 
use of compressed air for this purpose be discontinued. To reduce the amount of dry sweeping necessary in cleaning up the docks along the tracks, it is suggested that industrial vacuum cleaners be used, mounted on a car that can be moved along the entire length of the docks. Sweeping of this material creates a dust cloud, not only for the sweeper, but also for the men working in the ore pits who are below the track level filling larry cars with ore.

\section{Car Dumping, Crushing and Grinding in the Concentrator}

The use of vacuum cleaners on the concentrator unloading docks, as they are now employed in one mill, would reduce the amount of sweeping necessary, with a resulting lowering of the amount of dust dispersed. In crushing and grinding mills where local exhaust systems were used, maintenance of the dust control systems should be emphasized, as openings were observed in the casings enclosing the crushing processes, allowing dust to escape into the surrounding atmosphere.

\section{Sample Mills}

Dust control in the sample mills is important, since the study showed that the highest concentrations of dusts containing more than 10 percent free silica were found in these mills. Enclosing the crushing and grinding equipment with provision for local exhaust ventilation is highly desirable, and local exhaust hoods or enclosures should be provided on ore transfers and ore chutes. Here again, emphasis must be placed on the maintenance of dust control systems that are installed, as it was observed in one of the plants that several of the casings enclosing the crushing and grinding operations were loose, permitting the escape of quantities of dust into the atmosphere. A substitute should be found for the present method of cleaning the equipment with compressed air after running a batch of ore through the mill. One mill had enclosures and a local exhaust system on all of the processes in the sampling mill. However, much of the advantage normally gained by such a control system was lost by opening up these enclosures and blowing out the equipment with compressedair jets. This operation dispersed large amounts of dust which remained suspended in the atmosphere for long periods of time. As this dust settled to the floors, ledges, and sills, a man picked it up with a vacuum cleaner, but some method of cleaning the equipment without liberating the dust into the atmosphere would be a material aid in reducing the atmospheric concentrations.

The use of a vacuum cleaner for cleaning in the other mill would be a less dusty method than the present practice of blowing the dust from the floors, sills, and beams from the top of the mill to the basement, then shoveling up the dust in the basement. It should be pointed out that accumulated dust on floors, sills, and machinery is often dispersed into the air by winds, or by vibration of the equipment, or by men in walking over the floors. Good housekeeping is one of the most important control measures in any plant, and can be practiced with very little additional effort.

\section{Bucking and Parting Rooms}

The highest atmospheric concentrations of dusts in this department 
were found during the bucking, parting, and grinding operations. When these ores are being handled, the operator should be working in front of an exhaust hood, so that the dust created will be drawn away from him, and into a collecting system. Again, vacuum cleaning is desirable and compressed air should be used as little as possible in cleaning out the equipment.

\section{Lead Roasting and Sintering}

The feed bins contributed the greatest dust exposure in the Wedge roaster department, while the fines bins, cleaning of the windboxes, and the feed conveyors dispersed the most dust into the atmosphere surrounding the D. \& L. sintering machines. It was also noted that roaster operators received an appreciably high dust exposure during the manual emptying of nearby flue hoppers. The use of enclosed screw conveyors for moving dust from collecting hoppers to pug mills is strongly recommended. The control during the cleaning of wind boxes and of feed conveyors requires detailed specific recommendations for each installation. Local exhaust hoods and enclosure of processes will help to solve these problems, but more specific recommendations are beyond the scope of this report.

\section{Copper Roasting}

The use of a vacuum cleaner for cleaning the floors would reduce the amount of dust created in this department, as would a method of eliminating the surges of calcine into the larry cars. If a method could be developed for discharging the calcine from the roasters uniformly, much of the billowing of the dust would be eliminated. Some method of breaking the fall of the material, such as a flexible metal tubing that could be attached to the bottom of the roaster and extend into the larry car, would decrease the amount of dust disseminated into the atmosphere. Every effort should be made to decrease the amount of sulphur dioxide liberated into the atmosphere in this department. An exhaust system should be installed to remove as much of the sulphur dioxide as possible during the loading of the larry cars with calcine, and the roasting equipment should be kept in repari to further help reduce the amount of this gas liberated.

\section{Lead Blast Furnace Charge Floor}

The dust is liberated in this department during the dropping of the charge into the furnace from the larry cars. If it were possible to drop this charge in small quantities, or in a steady stream, instead of dropping the entire carload instantaneously, billowing would be prevented, and less dust emitted.

\section{Reverberatory Furnace}

It was noted that larry cars of calcine were dumped into the reverberatory furnaces creating dust concentrations ranging from 4.3 to 23.4 millions of particles per cubic foot of air. The fact that some cars were dumped with a small concentration of dust being created illustrates the fact that it is possible, and every effort should be made to dump these cars with a minimum of dust dispersion. High concentrations of sulphur 
dioxide were noted on this charge floor. It would be desirable to trap this gas as it emerges from the furnace, and convey it to the flues or to another exhaust system. Sweeping of the floor and tracks with a broom was observed. This cleaning could be done more efficiently with a vacuum cleaner, and with less dust being created. Covers over the slag launderers, similar to the covers in use over the matte launderers, with connections to the flue, would take away considerable quantities of sulphur dioxide that are now escaping into the atmosphere surrounding the reverberatory furnaces.

\section{Converters and Cranes}

The cover of the hood for each converter was lifted when the converter was rotated for observation, or to pour molten material into or out of the converter. During the periods that the converters were in the position for pouring or observing the batch, some of the fumes escaped the hoods and were released into the building. These fumes then drifted into the cranes. An extension of these hoods, that would trap these fumes being given off by the converters during pouring or charging, would help to keep the atmosphere surrounding the cranes clear. One crane was closed-in and was air conditioned, and it was stated by the management that their intention was to close and air condition the other two cranes.

\section{Flue Cleaning}

To reduce the amount of dust created in cleaning flues, it is suggested that conveyors be attached to the bottoms of the flues to convey the dust to a central point; and then load the larry cars at this central point, rather than at a number of points in each flue. At this central loading point on each flue an exhaust hood could be provided. Mechanical rapping could be employed on the sides of the flues to shake the dust down, or if it were necessary for the dust to be loosened in the flues with a rod, raised platforms could be provided so that the men could work from the sides or top of the flues, and would not have to stand underneath the flues, where the dust falls around them. A vacuum cleaner should be used to clean up the tracks under the flues.

\section{Bag Houses}

Mechanical shakers should be placed on all of the bag houses to eliminate the necessity of the men entering these bag house bays to shake the bags. Conveyors should be installed so that flue dusts would be emptied into larry cars at one point for each bay, and a control system should be used, as discussed under Flue Cleaning. In the blast furnace and roaster bag houses, it is suggested that a conveyor be installed to run from the hoppers under these bays to the pug mill, and that the loading of the larry cars with this dust and the dumping of this dust at the pug mill be eliminated. The bags should be shaken well, mechanically, before the men enter the bays to make repairs to the bags, and they should not enter until the bays have been well aired, and sufficient time has elapsed for most of the dust to have settled out of the atmosphere in the bays. 


\section{Electrical Precipitators}

The suggestions made in the section relating to Flue Cleaning with respect to loosening the dust on the sides of the flues would apply also to the precipitator hopper cleaning.

\section{Cadmium Plant}

It is suggested that the mixing of the sulphuric acid with the flue dust be done under the exhaust hood. The highest dust concentration in the cadmium plant was found near the ball mill. This operation could be enclosed and exhausted.

\section{Brick Masons and Other Repairmen}

When brick masons, or other repairmen, are required to enter a closed compartment, as in the relining of a furnace, roaster, converter, flue, or other enclosed space, provisions should be made for a supply of clean fresh air to these men. The use of air line respirators is suggested.

\section{Foundry}

The cleaning of castings should be done in a separate room, from the other foundry operations. Cleaning of the castings with pneumatic chippers should be done in front of, or under an exhaust hood. An operation that produced more dust than the cleaning operation, however, was the shaking out of the castings. As liberal use of water as is practical should be employed, wetting down the molds and floor before the castings are broken out, after the flasks are dumped, and after castings are removed from the sand altogether. Flasks and bottom boards should not be thrown around needlessly. In the case of small castings it is recommended that a central shakeout table be constructed, and provided with an exhaust ventilation system to control the dust liberated by the shaking out process.

It is recommended that the blower fan provided on the charge floor of the cupola be turned on when the charging of the cupola begins, since it was found that some carbon monoxide is liberated in the surrounding atmosphere during the firing and charging period of the cupola, and this condition will vary as the atmospheric conditions vary. Open windows, with good circulation of this air should be sufficient. No attempt has been made to discuss fully control measures for this department since this has been done extensivel yin recent foundry studies. (6)

\section{Personal Protection}

Respirators were observed in many parts of the plants, and as has been stated previously, many different types were in use. It is suggested that care be taken to see that respirators used in the various departments are suited to the needs of that particular environment. It is well known that respirators bearing the U. S. Bureau of Mines seal of approval for the removal of dusts are not necessarily effective in removing fumes from the air being breathed. Competent supervision should be given the issuance of respirators to the men in the various departments, and responsibility should be placed for the maintenance of these respirators. When a respirator becomes damaged or insanitary, men will cease to wear it, 
and unless these respirators are repaired, sterilized, and placed back in use, they will have lost their value. A careful supervision of the maintenance of the respirators will result in an increase in their use in those places where the wearing of a respirator is necessary or desirable. The use of respirators cannot be justified in many locations where they are now worn, and consideration should be given to the use of air-line helmets, or of positive control measures such as enclosure or local exhaust ventilation.

\section{Results of Sanitary Survey}

A sanitary survey of two smelters and of three immediately adjacent towns, was conducted to determine the other factors which may affect the health of smelter workers. Since the Utah smelters are located in the most heavily populated section of the State, and within commuting distance of Salt Lake City, the towns included in this portion of the survey represent the residences of a minority of the smelter workers, but probably represent average living conditions.

The smelter towns surveyed have populations of approximately 2,000 , 3,000 and 4,000 , respectively. In one town, the water supply is owned by a smelting company. The source of water is a number of drilled wells supplying a concrete reservoir. This supply is adequately protected. This same water supply is used in the adjacent smelter. In another smelter town, the water supply is municipally owned, and originates at the mouth of a canyon eight miles from the town. This supply is shared by three towns, and is a combination of spring and creek water. It is treated with an improvised drip-feed chlorinator at the point of division to the three towns, and the supply of the town surveyed is stored in covered, concrete reservoirs. Bacteriological examinations of this water show that this improvised chlorination is inadequate. An approved type sterilization plant should be installed. Previous histories of typhoid were reported in the case of 30 individuals in this town, and 14 individuals reported recent attacks of dysentery.

In a company-owned town, near another smelter, where many smelter employees resided, the company operates a satisfactory water supply system serving all homes and furnishing drinking water to the smelter.

Only one of these towns has a sewerage system and this system is connected to 377 homes, or 72 percent of the homes visited in this town. This sewage is carried in an outfall line to a point outside the town, where it is settled in a septic tank. The tank effluent flows several hundred feet through swampy ground to a small stream, into which it is discharged without further treatment. This method of disposal cannot be regarded as entirely satisfactory and will require improvement in the future. The remaining houses in this town, and all those in the other two towns, dispose of sewage by means of septic tanks, cesspools, and pit privies. Many of the cesspools overflow from time to time.

The water supply of one smelter was unsatisfactory, as stated above, while the supply to the other smelter seemed satisfactory. At one plant, the water fountains are of the vertical bubbler type, many of which have been constructed at the plant and consist of a short vertical pipe inside a bowl. These should be replaced by the more sanitary "slant-jet" fountains, which were in use in some places in the other smelter. 
Toilets and urinals are conveniently located throughout the plants. Change rooms are provided with well-ventilated steel lockers. Shower and dressing room floors are disinfected daily with a creosote compound.

Smelter sewage disposal is generally to septic tanks, from which the untreated effluent flows into a small river or to Great Salt Lake; in the latter case, entering in the vicinity of bathing beaches. A more detailed study of this method of disposal is desirable, before specific corrections are recommended.

\section{Summary}

Engineering studies were made of the working environment in two non-ferrous metal smelters (1) to identify the nature of the materials and the conditions to which the workers were exposed; $(2)$ to measure dust, heavy metal and toxic gas concentrations in the atmosphere surrounding the various operations, and to assign exposure values to individual workers; and (3) after locating the sources of the hazardous substances, to formulate practical recommendations for reducing the exposure of workers to safe limits.

Copper and lead are the main products of Utah smelters. Final refining of these metals was not done at the smelters studied. By-product processes included the manufacture of sulphuric acid, sulphur, arsenic, and cadmium. Other metal concentrates were separated from the ores by flotation processes and shipped to smelters in other States.

Precious metals contained in the ore were not being refined at these smelters during this study, but were containd in the pig-lead and blistercopper shipped to Eastern refineries.

Atmospheric dusts were found to contain an average quartz concentration varying from 21.5 to less than 1 percent, being highest in the departments handling raw ore, and very low in the other departments. The median diameter of atmospheric dust particles was approximately 1.0 micron, and 97 percent of the particles were less than 5.0 microns, showing that practically all this dust is of a size which can readily penetrate to the deep lung tissue.

The dust concentrations ranged from negligible amounts to approximately 400 million particles per cubic foot for certain bag house operations. However, in order to interpret the significance of these dust concentrations it is necessary to consider the nature of the dusts. Certain workers in sample mills, and other departments handling raw ore, although not exposed to dust concentrations as high as those in the bag house, were exposed to relatively high percentages of quartz, whereas the bag house dust contained only traces of this material.

Appreciable concentrations of some toxic metals, especially lead, arsenic, cadmium, and antimony, occurred in some departments. The significance of these exposures will be discussed in the following medical section of this report. Of special significance were the atmospheric lead concentrations which ranged from practically none, at some well controlled locations, to an average of nearly $6000 \mathrm{mg}$. of lead per 10 cubic meters of air in some bag house operations. These latter operations, fortunately, are of short duration.

The investigation of gas contamination showed that toxic concentrations of carbon monoxide might occur during furnace charging opera- 
tions, and that sulphur dioxide was present in many departments and at times reaches extremely irritating concentrations.

The results of a sanitary survey of the two smelters and three adjacent towns have been presented, and recommendations have been made for improving water supplies and waste disposal in these locations.

Specific suggestions for minimizing the hazards from dusts, fumes and gases have been made. General recommendations, applicable to all Utah smelters, for improving the worker's environment are included in the general recommendations at the beginning of this report.

\section{References}

1. Bray, J. L.: The Principles of Metallurgy. Ginn \& Co., Boston (1929).

2. Metallurgy of Lead and Zinc, Vol. 121, Transactions of the American Instiute of Mining and Metallurgical Engineers, New York, 1936.

3. Page, R. T., and Bloomfield, J. J.: Evaluation of the industrial hygiene problem of the State of Utah. Division of Industrial Hygiene, National Institute of Health, Washington, D. C. 1938.

4. Bloomfield, J. J.: The size distribution of industrial dusts. Supplement No. 115 to the Public Health Reports. 1935.

5. Hamilton, Alice: Industrial Toxicology. Harper \& Brothers, New York. p. 21. 1934.

6. Trice, M. F.: The foundry dust hazard and its control. Amer. J. Pub. Health 30: 760-765. 1940.

7. American Standards Association: Safety Code for Industrial Sanitation in Manufacturing Establishments. Z4. 1, 1935. 
IX SMELTERS 
MEDICAL STUDY

\section{Characteristics of the Workers in Smelting Plants}

Comparison With Census Data - This study includes schedules obtain. ed from 1,511 male workers who were employed in a lead and in a copper smelter in Utah. An examination of the U. S. Census figures for 1930 shows 2,729 males in Utah engaged in metal industries, except iron and steel. ${ }^{1}$ Smelter workers are not shown separately although they form a large part of the above group. Table 69 shows a comparison of the age distribution of the smelter workers in this study with the age distribution of all copper factory and lead and zinc factory workers in the United States. It appears that a much smaller percent are under 25 years of age in the present study, with a corresponding excess in the percent for each age group from 25 to 55 years of age. In the oldest age group, 55 years of age and over, the percentages are nearly the same.

\section{TABLE 69-Number and Percent of Smelter Workers According to Age for the United States and This Study.}

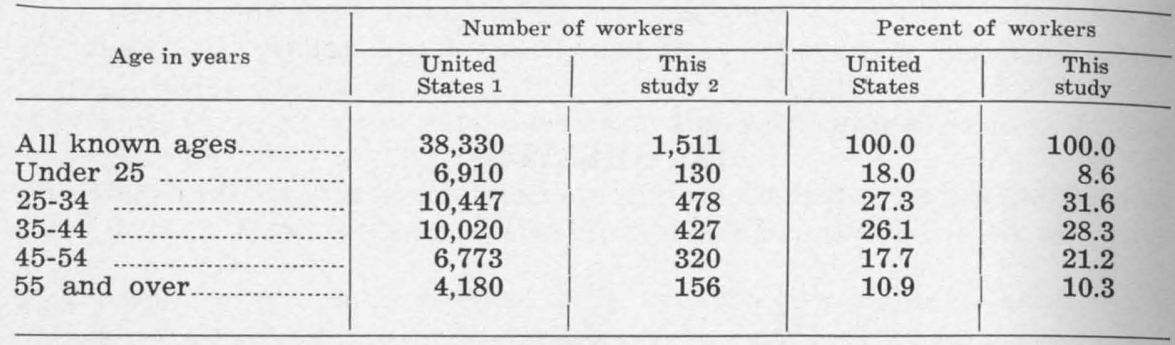

1 Fifteenth Census of the United States (1930). Vol. V, pp. 408-409. Includes copper factories, and lead and zine factories.

2 Includes 120 workers with mixed dust exposure.

Workers With Experience in Other Dusty Trades - A group of 120 persons who were working in the smelters at the time of the study had previously worked more than two years in some other dusty trade. They are therefore excluded from all the following tabulations because of the possibility that their physical condition might be affected by their nonsmelter experience. Of the three Utah industries investigated, namely, coal mines, metal mines, and smelters, the latter had the largest proportion of persons with exposure in more than one dusty trade. The close association between metal mining and smelting is apparently the reason for this. Of the 120 mixed exposure cases, 94 had had metal mine experience, 30 coal mine experience, and four experience in other dusty trades. Eight of those with metal mine experince had also had coal mine experience and are counted under both groups.

This excluded group is very much older than the remainder of the smelter workers. Only 16.7 percent were under 35 years of age and 50.0 percent were 45 years and over; consequently it is not surprising that the frequency of silicosis, 12.5 percent, is greater than that for other smelter workers. From an examination of the employment histories of the 15 persons with silicosis, it is observed that eight had also worked in metal mines,

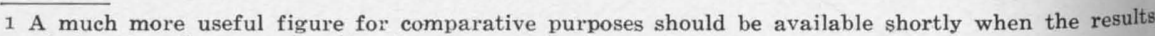
of the 1940 Census are released. 
in nearly every instance for ten or more years; four had worked in coal mines; two had worked in quartz mines; and one person who was 39 years of age had worked in fire clay for ten years. Twelve of the cases had firststage silicosis and three had second-stage silicosis. The latter were 49 , 56 , and 59 years of age with 14,32 , and 38 years of employment in the smelter industry and additional experience of 19 years in metal mines, eight years in metal mines, and three years in coal mines, respectively. Only one silicosis case also had reinfection tuberculosis. All silicosis cases had more than ten years in a dusty trade and five cases had more than 38 years.

Age Distribution - As shown in Table 70, the average age of smelter workers is 39.1 years, which is somewhat higher than that for Utah coal miners, 36.5 years, or metal miners, 36.0 years. The percentage of smelter workers under 35 years of age is 42.3 . Studies made by the U. S. Public Health Service of pottery workers (1), 10,000 industrial workers (2), mica and pegmatite workers (3), and asbestos textile workers (4), showed a considerably larger proportion of persons under 35 years of age. Anthracite coal miners (5) had a smaller proportion in this age group. When the age distribution for smelter workers is compared with that for Utah metal and coal miners, it is observed that the percentage for each age group beginning with $40-44$ years is greater. Thus, age 55 years and over accounts for 9.8 percent of the smelter workers but only 5.5 percent of the coal miners, and 6.1 percent of the metal miners. The pottery study (1), which had an excess of young persons when compared with the smeltters, had nearly as large a percent of old workers.

TABLE 70-Number and Percent of Smelter Workers With Employment In Utah Only, and in Utah and Outside, According to Age.

\begin{tabular}{|c|c|c|c|c|c|c|}
\hline & \multicolumn{3}{|c|}{ Number of workers } & \multicolumn{3}{|c|}{ Percent of workers } \\
\hline & Total & $\begin{array}{l}\text { Utah } \\
\text { only }\end{array}$ & $\begin{array}{l}\text { outside } \\
\text { Utah and }\end{array}$ & Total & $\begin{array}{l}\text { Utah } \\
\text { only }\end{array}$ & $\begin{array}{c}\text { Utah and } \\
\text { outside }\end{array}$ \\
\hline All ages & 1,391 & 1,371 & 20 & 100.0 & 100.0 & 100.0 \\
\hline $15-19$ & & 5 & 0 & 0.4 & 0.4 & .... \\
\hline $20-24$ & 125 & 125 & 0 & 9.0 & 9.1 & .... \\
\hline $25-29$ & 232 & 232 & 0 & 16.7 & 16.9 & .... \\
\hline 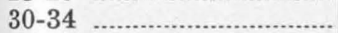 & 226 & 225 & 1 & 16.2 & 16.4 & 5.0 \\
\hline 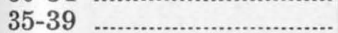 & 201 & 199 & 2 & 14.5 & 14.5 & 10.0 \\
\hline $40-44$ & 186 & 184 & 2 & 13.4 & 13.4 & 10.0 \\
\hline $45-49$ & 145 & 140 & 5 & 10.4 & 10.2 & 25.0 \\
\hline $50-54$ & 134 & 130 & 4 & 9.6 & 9.5 & 20.0 \\
\hline $55-59$ & 70 & 66 & 4 & 5.0 & 4.8 & 20.0 \\
\hline $60-64$ & 44 & 42 & 2 & 3.2 & 3.1 & 10.0 \\
\hline 65 and over & 23 & 23 & 0 & 1.6 & 1.7 & .... \\
\hline 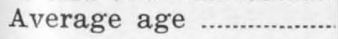 & 39.1 & 38.9 & 49.8 & & & \\
\hline
\end{tabular}

Length of Employment -- The average number of years of employment in smelters was 12.8 , which is more than for metal mines, 11.1 years, but less than for coal mines, 14.1 years. This is not the result one would expect from a knowledge of the age distribution in these industries. Although smelter workers are older than coal miners, they have not worked as long on the average in their occupation. Apparently smelter workers were more frequently engaged in other non-dusty occupations in their 
youth, whereas coal miners entered their occupation at an earlier age and remained more steadily in the same industry. Of all the smelter workers, 53.4 percent had worked in that industry for ten or more years. The corresponding figures for Utah coal miners were 58.7 percent and for metal miners 45.8 percent.

Employment Outside of Utah - Of the 1,391 smelter workers ${ }^{1}$ there were 20 who at some time in the past had been employed more than two years in smelters located outside the State border of Utah. These represented only 1.4 percent of the total study group, compared with 5.6 percent for metal miners and 13.0 percent for Utah coal miners. Smelter workers are evidently much less likely to migrate from similar employment in other States to the State of Utah. The group who had worked outside were older, having an average age of 49.8 years, compared with an average of 38.9 for those working in Utah only. For the average number of years employed in smelters, the difference was much greater, the two groups showing 25.5 years and 12.6 years, respectively.

\section{Diagnosis and Symptomatology of Silicosis}

Silicosis was the outstanding occupational disease found in the medical examination of 1,391 smelter workers. This was also the case in the study of workers in the Utah bituminous coal mines and in the metal mines. The method of arriving at a diagnosis of silicosis was identical in all three studies and a detailed discussion of the diagnosis, sympomatology and interpretation of pulmonary changes observed has already been presented in a previous section. (See the Report of the Medical Study of the Utah Bituminous Coal Mine Workers). (p. 64).

\section{Clinical Findings in Silicosis}

Table 71 shows the number and percent of smelter workers classified according to the degree of pulmonary fibrosis as shown by X-ray, who were found to have certain abnormalities on physical examination. Almost

TABLE 71-Number and Percent of Smelter Workers Classified According to Degree of Pulmonary Fibrosis as Shown by X-ray Findings, Who Were Found to Have Certain Abnormalities on Physical Examination.

\begin{tabular}{|c|c|c|c|c|}
\hline \multirow[b]{2}{*}{ Physical findings } & \multicolumn{2}{|c|}{ Percent of workers } & \multicolumn{2}{|c|}{ Number of workers } \\
\hline & $\begin{array}{l}\text { First } \\
\text { and } \\
\text { second } \\
\text { degree } \\
\text { linear }\end{array}$ & $\begin{array}{l}\text { Ground- } \\
\text { glass, } \\
\text { nodular } \\
\text { and con- } \\
\text { glomerate }\end{array}$ & $\begin{array}{l}\text { First } \\
\text { and } \\
\text { second } \\
\text { degree } \\
\text { linear }\end{array}$ & $\begin{array}{l}\text { Ground- } \\
\text { glass, } \\
\text { nodular } \\
\text { and con- } \\
\text { glomerate }\end{array}$ \\
\hline Number of workers examined. & & & 1,295 & 891 \\
\hline Average age & & & 38.5 & 48.1 \\
\hline 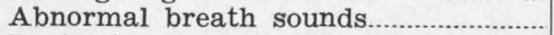 & 10.7 & 16.9 & 138 & 15 \\
\hline Restricted movement diaphragm....... & 5.3 & 19.1 & 69 & 17 \\
\hline Change from normal percussion note. & 4.6 & 5.6 & 60 & 5 \\
\hline Impaired mobility & 1.5 & 2.2 & 19 & 2 \\
\hline 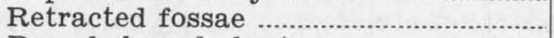 & 3.7 & 5.6 & 48 & 5 \\
\hline 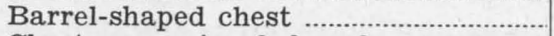 & 3.8 & 13.5 & 49 & 12 \\
\hline Chest expansion below $6 \mathrm{~cm}$................... & 18.8 & 30.3 & 244 & 27 \\
\hline 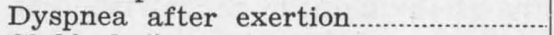 & 2.2 & 12.4 & 29 & 11 \\
\hline 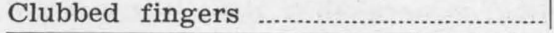 & 2.3 & 5.6 & 30 & 5 \\
\hline
\end{tabular}

1 Includes 10 workers with nodular and four with conglomerate markings.

1 One hundred twenty workers wtih mixed dust exposure have been excluded. 
without exception the silicosis cases are limited to those workers showing ground glass or more severe grades of lung-field markings. According to table 71 , the most significant clinical findings in those affected (with silicosis and borderline silicosis) are restricted movement of the diaphragm by fluoroscopy; dyspnea after exertion; barrel-shaped or emphysematous chest; a chest expansion below $6 \mathrm{cms}$.; and abnormal breath sounds. The other impairments listed do not occur with an appreciable difference in frequency in the affected as compared with the non-affected workers.

\section{TABLE 72-Percent of Smelter Workers Classified According to Diagno- sis of Silicosis, Who Complained of Certain Symptoms.}

\begin{tabular}{|c|c|c|c|c|}
\hline \multirow[b]{2}{*}{ Symptom } & \multirow{2}{*}{$\begin{array}{c}\text { All } \\
\text { workers }\end{array}$} & \multicolumn{3}{|c|}{ Diagnosis of silicosis } \\
\hline & & $\begin{array}{c}\text { Non- } \\
\text { affected }\end{array}$ & $\begin{array}{c}\text { Border- } \\
\text { line }\end{array}$ & $\begin{array}{c}\text { 1st and 2nd } \\
\text { stage 1 }\end{array}$ \\
\hline Number of workers....... & 1,391 & 1,289 & 65 & 37 \\
\hline Dyspnea ..................... & 6.4 & 6.3 & 9.2 & 5.4 \\
\hline Frequent cough & 7.1 & 6.8 & 7.7 & 16.2 \\
\hline Productive cough & 6.6 & 6.3 & 7.7 & 16.2 \\
\hline Chest pain & 2.1 & 1.9 & 3.1 & 5.4 \\
\hline Weakness & 1.4 & 1.3 & .... & 8.1 \\
\hline
\end{tabular}

1 Included in this group are six cases of reinfection tuberculosis which tend to increase the percent of workers complaining of productive cough and weakness.

Table 72 shows the percentage of workers, classified on the basis of diagnosis of silicosis, who complained of certain subjective symptoms. Although the percent of workers complaining of a listed symptom rises to a peak in those diagnosed as silicosis, the increased incidence of these symptoms in those affected is probably significant only in the case of frequent and productive cough and weakness.

From data compiled by the Association of Life Insurance Medical Directors and the Actuarial Society of America (6), the deviation of each worker's weight from the average for men of his height and age was calculated in percentage.

Table 73 shows the distribution of percentage weight deviations for smelter workers classified by diagnosis of silicosis. It will be observed that smelter workers not affected with silicosis had nearly the same weights, on the average, as life insurance applicants. Smelter workers diagnosed as affected with first and second stage silicosis fell 5.1 percent below the average, while those with borderline silicosis were 4.1 percent above the average weight for life insurance applicants.

It is evident that the vagueness and paucity of the above clinical findings and complaints or symptoms preclude the possibility of disclosing a majority of silicosis cases by these means. The most certain method of discovering silicosis is by X-ray, coupled with a good occupational history. Subjective and objective signs, however, are essential adjuncts in evaluat- 
TABLE 73-Distribution of Percentage Weight Deviations for Smelter Workers Classified by Diagnosis of Silicosis.

\begin{tabular}{|c|c|c|c|c|}
\hline \multirow{3}{*}{ Percentage weight deviation } & \multicolumn{4}{|c|}{ Percent of workers } \\
\hline & \multirow{2}{*}{$\begin{array}{c}\text { All } \\
\text { smelter } \\
\text { workers }\end{array}$} & \multicolumn{3}{|c|}{ Diagnosis of silicosis } \\
\hline & & $\begin{array}{c}\text { 1st and } \\
\text { 2nd stage }\end{array}$ & $\begin{array}{c}\text { Border- } \\
\text { line }\end{array}$ & $\begin{array}{c}\text { Non- } \\
\text { affected }\end{array}$ \\
\hline Total & 1,3881 & 37 & 65 & 1,286 \\
\hline-35 & .1 & & & \\
\hline-25 to 34 & 1.2 & 5.4 & 3.1 & 1.0 \\
\hline-15 to 24 & 8.6 & 18.9 & 3.1 & 8.5 \\
\hline - 5 to 14 & 28.3 & 32.5 & 23.1 & 28.5 \\
\hline \pm 5 & 32.1 & 13.5 & 26.1 & 32.9 \\
\hline$\mp 5$ to 14 & 18.9 & 24.3 & 21.5 & 18.7 \\
\hline+15 to 24 & 7.2 & 5.4 & 15.4 & 6.8 \\
\hline+25 to 34 & 2.6 & .......... & 4.6 & 2.6 \\
\hline+35 to 49 & .9 & .......... & 3.1 & .8 \\
\hline+50 & .1 & $\ldots \ldots . .$. & & .1 \\
\hline Average $^{2}$ & -.4 & -5.1 & +4.1 & -.5 \\
\hline Standard deviation & 12.9 & 14.2 & 15.5 & 12.7 \\
\hline
\end{tabular}

1 Percentage weight deviation for three workers is unknown.

2 Averages represent the percentage the workers fell below or above the average for life insurance applicants of comparable age and height.

\section{TABLE 74-Number of Smelter Workers in Utah with Silicosis, Accord- ing to Years Employed in Smelters and Weighted Average Dust Concentration.}

\begin{tabular}{|c|c|c|c|c|c|}
\hline \multirow{2}{*}{$\begin{array}{l}\text { Dust-con- } \\
\text { centration, } \\
\text { million } \\
\text { particles } \\
\text { per cubic foot }\end{array}$} & & \multicolumn{4}{|c|}{ Years employed in smelters } \\
\hline & & $0-9$ & $10-19$ & 20-29 & $\begin{array}{l}30 \text { and } \\
\text { over }\end{array}$ \\
\hline \multirow{3}{*}{$0-4.9$} & Number exposed & 84 & 67 & 33 & 22 \\
\hline & With 1st and 2nd stage silicosis ${ }^{1} \ldots \ldots$ & 0 & 0 & 1 & 1 \\
\hline & With borderline silicosis........................... & 0 & 4 & 2 & 0 \\
\hline \multirow{3}{*}{$5.0-9.9$} & Number exposed ............... & 223 & 160 & 72 & 25 \\
\hline & With 1st and 2nd stage silicosis.......... & 1 & $3^{2}$ & 2 & 2 \\
\hline & With borderline silicosis.......................... & 3 & 7 & 5 & 5 \\
\hline \multirow{3}{*}{$10.0-19.9$} & 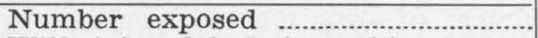 & 115 & 89 & 29 & 15 \\
\hline & With 1st and 2nd stage silicosis..... & 0 & 4 & 0 & 1 \\
\hline & 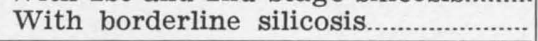 & 1 & 5 & 3 & 3 \\
\hline \multirow{4}{*}{$20.0-39.9$} & 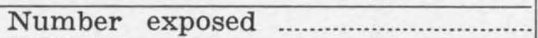 & 96 & 67 & 17 & 7 \\
\hline & With 1st and 2nd stage silicosis.... & 0 & 4 & 32 & $i$ \\
\hline & 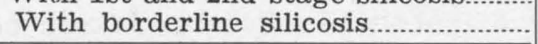 & 1 & 4 & 3 & 2 \\
\hline & 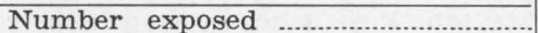 & 125 & 82 & 31 & 11 \\
\hline \multirow{2}{*}{$\begin{array}{l}40.0 \text { and } \\
\text { over }\end{array}$} & 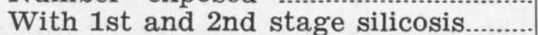 & 0 & 72 & 5 & 2 \\
\hline & 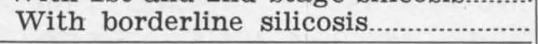 & 2 & 7 & 6 & 0 \\
\hline \multirow{6}{*}{ Total $^{3}$} & 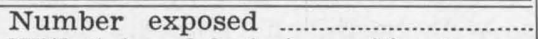 & 643 & 465 & 182 & 80 \\
\hline & With 1st and 2nd stage silicosis... & 1 & 18 & 11 & 7 \\
\hline & (Percent with 1st and 2nd stage & & & & \\
\hline & 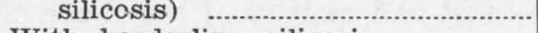 & 0.2 & 3.9 & 6.0 & 8.8 \\
\hline & With borderline silicosis....................... & 7 & 27 & 19 & 10 \\
\hline & (Percent with borderline silicosis) $\ldots$ & 1.1 & 5.8 & 10.4 & 12.5 \\
\hline
\end{tabular}

1 No third-stage cases were observed.

2 Includes one second-stage silicosis case.

3 Exclusive of two borderline silicosis cases in a group of 21 workers with unknown dust exposure. 
ing the severity of silicotic disease in individual cases and in excluding other respiratory diseases as the cause of these markings. (See p. 261-269).

\section{Incidence of Silicosis}

\section{Relation of Silicosis to Dust Concentration and Duration of Employment}

Among the group of 1,391 smelter workers, there were only 37 persons who showed evidence of silicosis and 65 persons who were considered borderline ${ }^{1}$ cases. The percentage affected with silicosis was 2.7, compared with an incidence of 3.2 percent among Utah coal mine workers and 9.1 per cent among Utah metal mine workers. Although this incidence seems low, still there is a genuine problem of silicosis among smelter workers, which becomes clearer when the data are subjected to a more detailed analysis.

Table 74 shows silicosis in relation to years of employment in the smelter industry and to weighted average concentration ${ }^{2}$ in million particles per cubic foot of air. As observed in other studies made by the U. S. Public Health Service, there is a general trend for the incidence of silicosis to increase with intensity and duration of exposure. However, this trend is not so well defined in the smelter industry, especially with respect to intensity of dust concentration, as in the coal mining and metal mining industries. Irrespective of the number of years employed in the smelter industry, incidence of silicosis rises from 1.0 percent in the dust concentration group of $0-4.9$ million particles to 5.6 percent for a concentration of 40.0 million particles and over. Each of these groups shows a slight increase in the percent affected over the group preceding it. In the dust concentration group with less than 10 million particles per cubic foot are found 27 percent of all the silicosis cases which were observed in the smelter industry. There was only one silicosis case in these dust concentration groups among coal miners, and two cases among metal miners. The highest weighted average dust concentration for persons with silicosis was 92 million particles.

Other factors are apparently at work which obscure the influence of dust concentration in the smelter industry. In the first place, dust exposures are extremely variable in the same occupation at different times, as shown in the engineering report. Secondly, there is much rotation from job to job within the industry, and, finally, free silica content of dust in occupations with high counts is not necessarily as great as that in occupations with low counts.

One case of silicosis and seven borderline silicosis cases were found among the group of workers who had had less than ten years of employment in smelters. This compares with data from the coal mine industry for the same employment period which shows no case of silicosis and only one borderline case. Among metal mine workers, where the incidence of silicosis was higher, it was found that 13.6 percent of the silicosis and borderline silicosis cases had been employed less than ten years, while the eight cases in the smelter industry represent 21.6 percent.

In the duration group, 10-19 years, there are 3.9 percent affected with silicosis; in the 20-29 year group there are 6.0 percent affected; and in the 30 years and over group, there are 8.8 percent. Not only do smelter

1 See Diagnosis and Symptomatology in section giving results of coal mine study. (p. 64)

2 See discussion of weighted average dust concentration in Appendix IV. 
workers have a lower incidence of silicosis for each given period of employ. ment than do metal mine workers, but also they do not show such a rapid increase with increasing duration of exposure. It should be remembered that these three Utah studies included only persons actually on the company payrolls at the time the medical examinations were made and do not take into account those persons who have left their employment for various reasons.

When borderline cases are combined with the silicosis cases, the percentage affected shows the same trends with dust concentration and years employed in the smelter industry as did the silicosis cases alone.

In contrast to the coal and the metal mining studies, there were no persons with silicosis in the smelter industry who had worked for more than two years in that industry outside of the boundaries of Utah. Hence, all cases must be attributed entirely to working conditions within the State. One person diagnosed as a borderline silicosis case had been employed for three years in a Montana smelter.

X-ray Findings of Silicosis Cases - X-ray findings showed a more severe pulmonary fibrosis among persons with silicosis as years of employment in smelters increased. While 58.3 percent of the silicotics with less than 20 years' employment showed nodular or conglomerate lung-field markings, 72.7 percent of those who had worked 20 years of more showed similar markings. Corresponding percentages for silicosis-affected workers in metal mines were 47.1 and 68.7 percent. Although smelter workers were less commonly affected with silicosis than metal miners, yet a slightly larger percent showed nodular and conglomerate lung-field markings which might indicate that silicosis when acquired is no less severe among smelter workers.

\section{Silicosis By Principal Occupation}

It will be observed from table 75 that with the exception of workers in the concentrating department, the distribution of cases of silicosis is scattered throughout a number of occupations, no one of which shows as many as four cases. Occupations in which silicosis cases are found include unloading dock workers, yard crews, Martin machine operators, sample mill operators, flotation mill operators, bucking room operators, grinding mill operators, lead and copper roasting workers, blast furnace charge floor operators, reverberatory furnace operators, machine shop workers, boiler shop workers, brick masons, pipe shop workers, foundrymen, and blacksmith shop workers. No silicosis or borderline silicosis cases were found among blast furnace tapping floor operators, reverberatory furnace waste heat boiler operators, lead-drossing kettle operators, copper converter cranemen, lead casting wheel operators, electrical precipitator hopper cleaners and operators, assay laboratory operators, acid plant operators, cadmium plant operators, carpenter shop workers, extra laborers, jackhammer men, painters, or office and supervisory personnel. It is apparent from the above that silicosis incidence is concentrated among those workers who are exposed to dust from the ore before it is processed in the furnaces.

When attention is centered on the group of operators in the concentrating department, including sample mill, flotation mill, bucking and parting room, and crushing and grinding mill workers, the problem of 
TABLE 75-Smelter Workers in Utah, by Principal Occupation, According to Years Employed in Smelters, and Diagnosis of Silicosis

\begin{tabular}{|c|c|c|c|c|c|c|}
\hline \multirow{3}{*}{ Principal occupation } & \multicolumn{4}{|c|}{ Number employed } & \multirow{2}{*}{\multicolumn{2}{|c|}{$\begin{array}{l}\text { Number affected } \\
\text { Diag. of silicosis }\end{array}$}} \\
\hline & \multicolumn{4}{|c|}{ Years employed in smelters } & & \\
\hline & Total & $\begin{array}{c}\text { Less } \\
\text { than } 10\end{array}$ & $10-19$ & $\begin{array}{l}20 \text { and } \\
\text { over }\end{array}$ & $\begin{array}{l}\text { 1st and } \\
\text { 2d stage }\end{array}$ & $\begin{array}{c}\text { Border- } \\
\text { line }\end{array}$ \\
\hline All occupations .................. & 1,391 & 649 & 471 & 271 & 37 & 65 \\
\hline Loading and unloading: & & & & & & \\
\hline Unloading docks .............. & 97 & 50 & 31 & 16 & 2 & 8 \\
\hline Yard crews .............................. & 23 & 2 & 11 & 10 & 1 & 0 \\
\hline Martin machine operators.... & 6 & 2 & 4 & 0 & 1 & 0 \\
\hline Concentrator: & & & & & & \\
\hline Sample mill operators............. & $\begin{array}{l}89 \\
45\end{array}$ & $\begin{array}{l}40 \\
13\end{array}$ & $\begin{array}{l}37 \\
20\end{array}$ & $\begin{array}{l}12 \\
12\end{array}$ & 11 & $\begin{array}{l}8 \\
3\end{array}$ \\
\hline Bucking and parting room & & 13 & 20 & & & 3 \\
\hline operators & 24 & 9 & 12 & 3 & 1 & 1 \\
\hline $\begin{array}{l}\text { Car dumping, crushing and } \\
\text { grinding mill operators...... }\end{array}$ & 18 & & & & & \\
\hline Lead and copper roasting............. & 117 & $\begin{array}{r}4 \\
58\end{array}$ & $\begin{array}{l}11 \\
37\end{array}$ & $\begin{array}{r}3 \\
22\end{array}$ & $\begin{array}{l}5 \\
1\end{array}$ & $\begin{array}{l}4 \\
4\end{array}$ \\
\hline Lead blast furnace: & & & & & & 4 \\
\hline Tapping floor operators......... & 16 & 1 & 6 & 9 & 0 & 0 \\
\hline Charge floor operators............ & 15 & 0 & 8 & 7 & 1 & 1 \\
\hline Reverberatory furnace: & & & & & & \\
\hline Furnace operators & 80 & 43 & 16 & 21 & 3 & 2 \\
\hline Waste heat boiler operators... & 6 & 3 & 2 & 1 & 0 & 0 \\
\hline Lead drossing kettle and & & & & & & \\
\hline & $\begin{array}{r}5 \\
82\end{array}$ & $\begin{array}{r}1 \\
58\end{array}$ & $\begin{array}{r}3 \\
18\end{array}$ & $\begin{array}{l}1 \\
6\end{array}$ & $\begin{array}{l}0 \\
0\end{array}$ & $\begin{array}{l}0 \\
2\end{array}$ \\
\hline $\begin{array}{l}\text { Copper converter operators........ } \\
\text { Copper converter cranesmen.... }\end{array}$ & 13 & 3 & 9 & 1 & 0 & $\begin{array}{l}2 \\
0\end{array}$ \\
\hline Lead casting wheel operators....... & 4 & 0 & 2 & 2 & 0 & 0 \\
\hline Copper casting wheel operators... & 18 & 8 & $\mathbf{5}$ & 5 & 0 & 4 \\
\hline Flue cleaners & 20 & 7 & 11 & 2 & 0 & 1 \\
\hline Baghouse operators & 19 & 9 & 8 & 2 & 0 & 1 \\
\hline Electrical precipitators: & & & & & & \\
\hline $\begin{array}{l}\text { Hopper cleaners } \\
\text { Operators }\end{array}$ & $\begin{array}{r}10 \\
8\end{array}$ & $\begin{array}{l}4 \\
2\end{array}$ & 5 & $\begin{array}{l}1 \\
0\end{array}$ & $\begin{array}{l}0 \\
0\end{array}$ & $\begin{array}{l}0 \\
0\end{array}$ \\
\hline 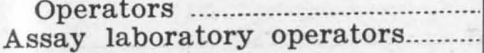 & $\begin{array}{r}8 \\
39\end{array}$ & $\begin{array}{r}2 \\
17\end{array}$ & $\begin{array}{r}6 \\
15\end{array}$ & $\begin{array}{l}0 \\
7\end{array}$ & 0 & $\begin{array}{l}0 \\
0\end{array}$ \\
\hline Acid plant operators....................... & 24 & 14 & 7 & 3 & 0 & 0 \\
\hline Arsenic plant operators & 10 & 2 & 2 & 6 & 0 & 1 \\
\hline Cadmium plant operators......... & 6 & 3 & 3 & 0 & 0 & 0 \\
\hline Power house operators.................. & 23 & 2 & 8 & 13 & 0 & 3 \\
\hline Maintenance: & & & & & & \\
\hline Machine shop & 89 & 39 & 29 & 21 & 1 & 3 \\
\hline Boiler shop & 54 & 20 & 23 & 11 & 2 & 4 \\
\hline 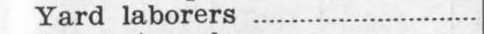 & 53 & 36 & 10 & 7 & 0 & 3 \\
\hline Carpenter shop & 30 & 9 & 14 & 7 & 0 & 0 \\
\hline Extra laborers & 22 & 10 & 3 & 9 & 0 & 0 \\
\hline 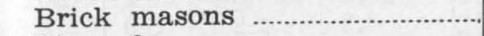 & 21 & 6 & 8 & 7 & 2 & 3 \\
\hline 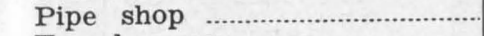 & 19 & 7 & 7 & $\mathbf{5}$ & 1 & 3 \\
\hline Foundry men & 17 & 8 & 6 & 3 & 2 & 1 \\
\hline Electrical shop & 12 & 2 & 6 & 4 & 0 & 2 \\
\hline Blacksmith shop & 11 & 2 & 6 & 3 & 1 & 0 \\
\hline Jackhammer men and riggers. & 11 & 5 & $\mathbf{5}$ & 1 & 0 & 0 \\
\hline 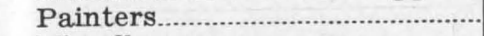 & 5 & 3 & 1 & 1 & 0 & 0 \\
\hline 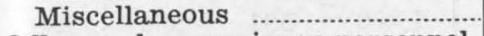 & 12 & 5 & 3 & 4 & 0 & 0 \\
\hline Office and supervisory personnel. & 65 & 34 & 20 & 11 & 0 & 0 \\
\hline Not classified & 153 & 108 & 33 & 12 & 1 & 2 \\
\hline
\end{tabular}

silicosis assumes importance. It will be seen from table 76 that 13.8 percent of those engaged principally in this department for 10-19 years show 
evidence of silicosis, while for those with 20 or more years of experience there are 22.6 percent affected. In this occupation smelter workers have almost as high an incidence of silicosis as was found for all occupations among metal mine workers. The latter group showed 13.2 percent affected with 10-19 years' exposure and 30.5 percent affected with more than 20 years.

TABLE 76-Incidence of Silicosis ${ }^{1}$ in the Concentrating Department Compared With the Incidence in All Other Departments, Accord. ing to Years Employed in Smelters.

\begin{tabular}{|c|c|c|c|c|c|c|}
\hline \multirow{3}{*}{$\begin{array}{l}\text { Years employed in } \\
\text { smelter industry }\end{array}$} & \multicolumn{3}{|c|}{ Concentrating department 2} & \multicolumn{3}{|c|}{ All other departments } \\
\hline & \multirow{2}{*}{$\begin{array}{c}\text { Number } \\
\text { of } \\
\text { workers }\end{array}$} & \multicolumn{2}{|c|}{ With silicosis } & \multirow{2}{*}{$\begin{array}{c}\text { Number } \\
\text { of } \\
\text { workers }\end{array}$} & \multicolumn{2}{|c|}{ With silicosis } \\
\hline & & Number & Percent & & Number & Percent \\
\hline Total & 176 & 18 & 10.2 & 1,215 & 19 & 1.6 \\
\hline Less than 9. & 65 & 0 & 0 & 584 & 1 & 0.2 \\
\hline $10-19$ & 80 & 11 & 13.8 & 391 & 7 & 1.8 \\
\hline 20 and over... & 31 & 7 & 22.6 & 240 & 11 & 4.6 \\
\hline
\end{tabular}

1 First and second stage silicosis.
2 Includes workers in sample mill, flotation mill, bucking and parting room, and crushing and grinding mill.

All smelter workers except those in the concentrator show an incidence of silicosis which reaches a maximum of 4.6 percent at 20 years and over.

\section{TABLE 77-Smelter Workers in the Concentrating Department Compared With Workers in All Other Departments, Classified Accord- ing to Years Employed in the Smelter Industry and Lung- field Markings.}

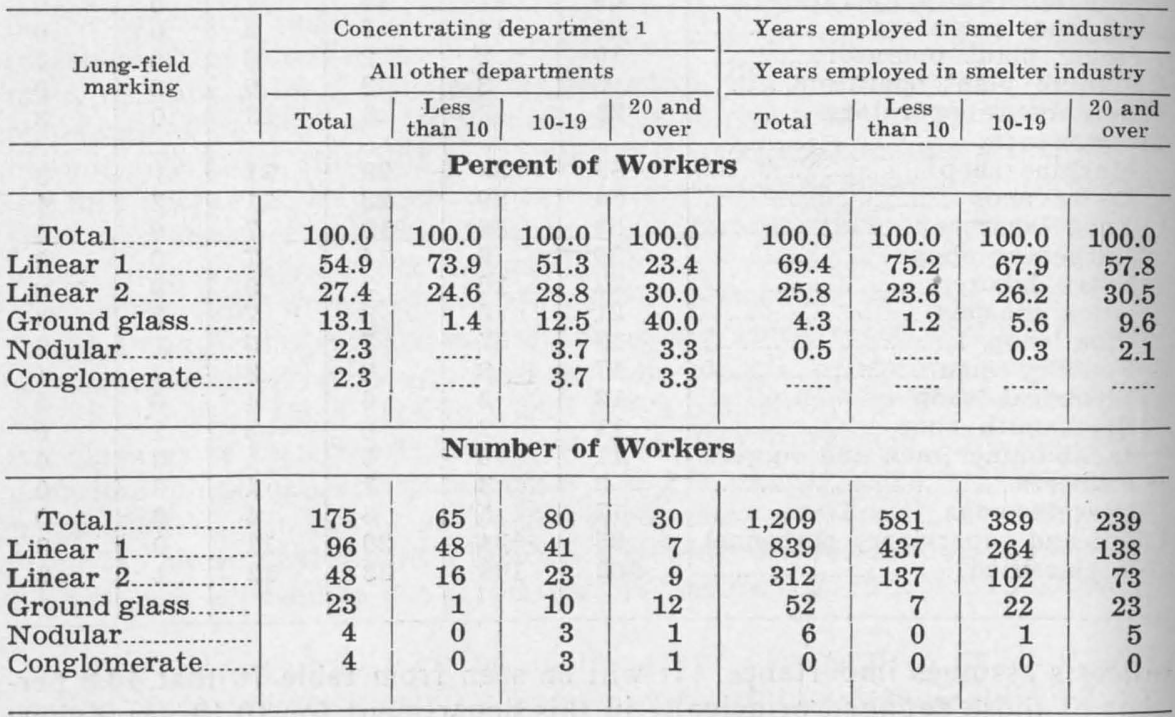

1 Includes workers in sample mill, flotation mill, bucking and parting room, and crushing and grinding mill. 
Many of these, although they could not be classified as concentrator workers according to principal occupation, had worked for several years in that department during their experience in the smelter industry.

Additional evidence of the harmful influence of the dust encountered in the concentrating department is offered by a study of lung-field markings as shown on the X-ray film. By this means it is possible to describe finer degrees of change in pulmonary fibrosis. Table 77 and figure 34 show that the percent of ground glass, nodular and conglomerate markings are much greater for all duration periods among workers in the concen-

\section{CONCENTRATING DEPARTMENT}

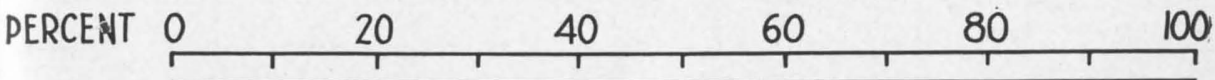

Less
than 10

$10-19$
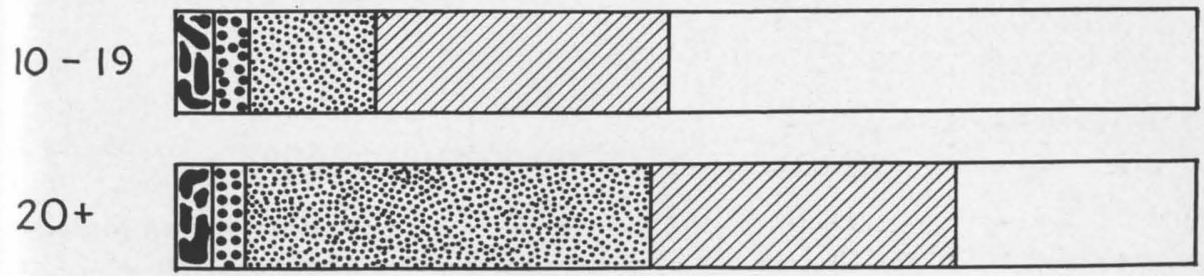

\section{ALL OTHER DEPARTMENTS}

DERCENT $0,20, \quad 40,60,80,80,100$

Less than 10

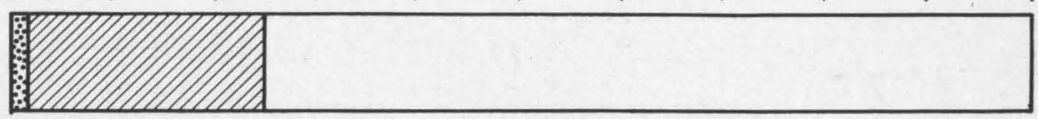

$10-19$

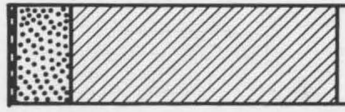

$20+$

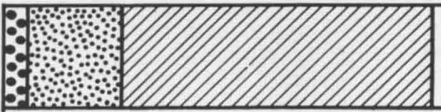

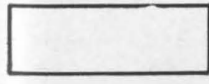

LINEAR $1^{\circ}$

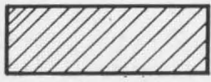

LINEAR $2^{\circ}$

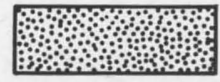

GROUND GLASS

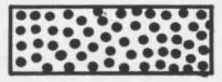

NODULAR

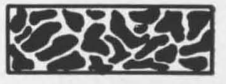

CONGLOMERATE

FIGURE 34-Smelter workers in the concentrating department and in all other departments who had certain $\mathbf{X}$-ray findings indicating degree of pulmonary fibrosis, classified by duration of employment in smelters. 
trating department than among workers in other departments of the smelter plants. After 20 years of employment four of the former group, but none of the latter, show conglomerate lung-field markings. The total percent showing ground-glass, nodular, or conglomerate markings, is 19.9 for concentrator workers with 10-19 years of exposure, and 5.9 percent for other smelter workers with the same period of exposure. Among the group with 20 or more years of exposure, the corresponding percentages are 46.6 and 11.7. 
REPRESENTATIVE CASE HISTORIES 


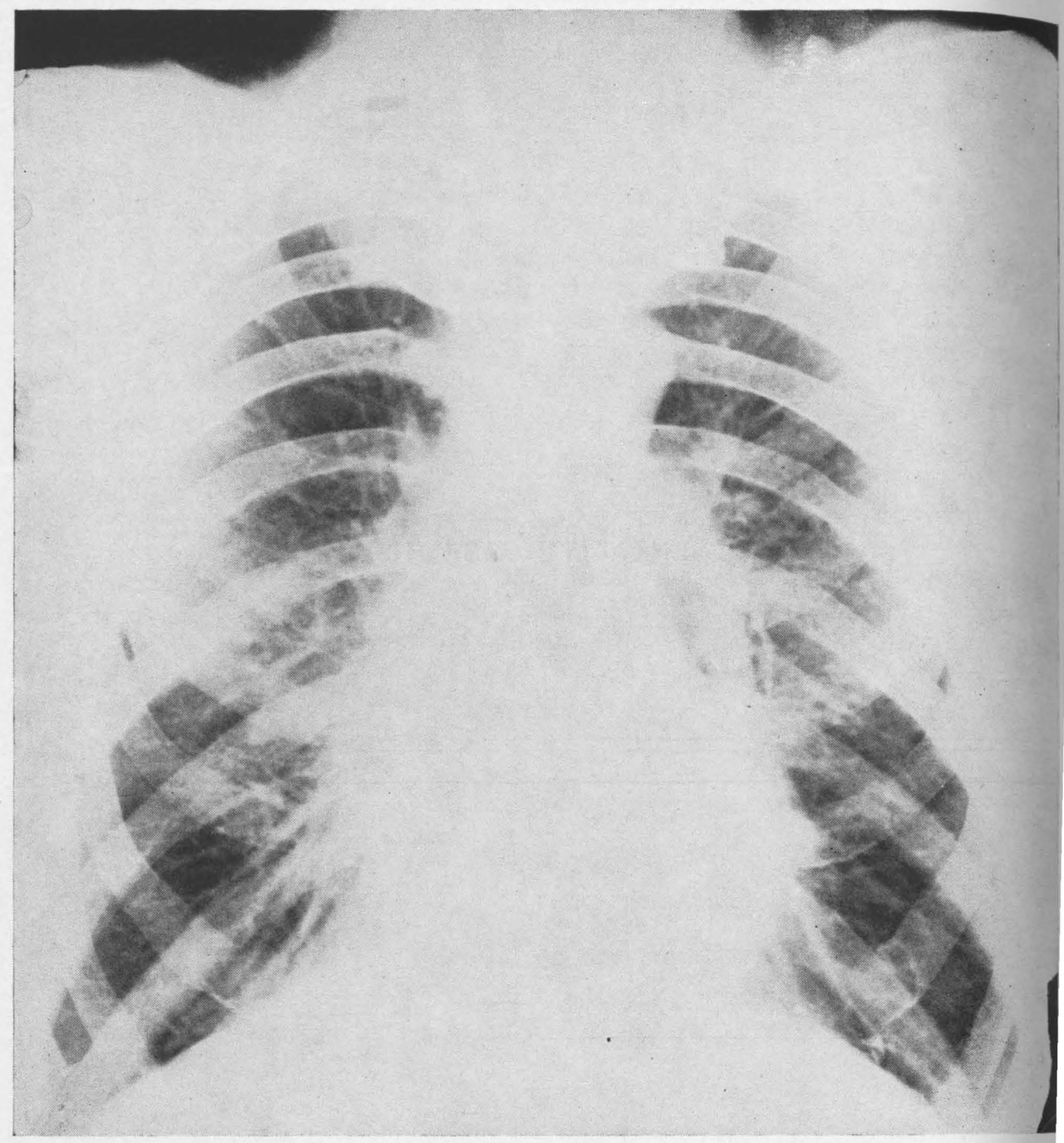

FIGURE 35-Borderline silicosis, white male, age 55. 
Figure 35-Case History

Occupational History-Brick mason in smelter, 17 years; brick mason in general construction work, 22 years.

Estimated Dust Exposure-Seven million particles per cubic foot (weighted average).

Past Medical History-Recalls no serious illnesses; no operations; has lost five pounds weight in past two years.

Present Complaints-Slight constipation for five years.

Physical Examination-Average appearance; height $721 / 2$ inches; weight 158 pounds; mild, acute inflamation of the nose and throat; perforation of the nasal septum; slight enlargement of thyroid; chest expansion, 4.5 $\mathrm{cm}$; chest findings negative; cardiovascular system normal. Blood pressure, $130 / 70$. No dyspnea.

Fluoroscopy-Reveals a slight increase in the normal linear markings. Movement of diaphragm not restricted.

X-ray-Second degree linear exaggeration with beading, and early granular appearance, but linear shadows predominate.

Comment-This film has been presented to show minimal dust-induced changes, hardly sufficient to justify a diagnosis of silicosis. For this reason it is classified as borderline silicosis. There is no apparent disability. 


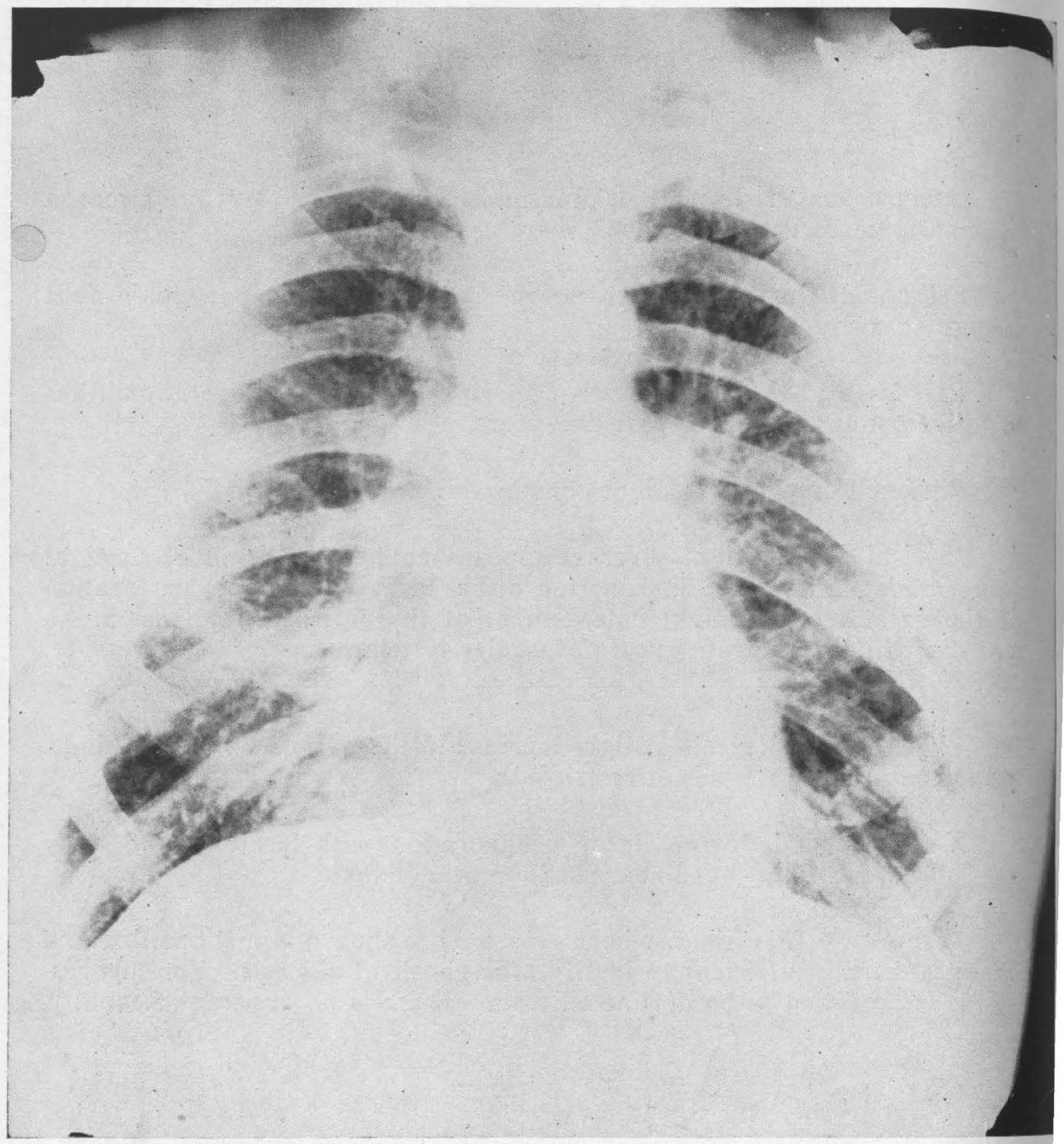

FIGURE 36-Simple first-stage silicosis, white male, age 37. 
Figure 36-Case History.

Occupational History-Employed in following occupations in a smelter: Repairman in sample mill, $3 \frac{1}{2}$ years; switchman, $1 \frac{1}{2} 2$ years; Martin machine operator, $31 / 2$ years; flue dust cleaner, one year; and painter's helper, one year. General laborer in coal plant, one year. Stoker in gas and coke plant, $4 \frac{1}{2}$ years. Idle four years.

Estimated Dust Exposure--Thirty-three million particles per cubic foot (weighted average).

Past Medical History-Slight contact with sister who had pulmonary tuberculosis. Recalls no serious illnesses; no operations.

Present Complaints-Has deep-seated chest pain on lung inspiration.

Physical Examination-Average appearance; mild, acute inflamation of eyes, nose, and throat; chest expansion, $8 \mathrm{~cm}$; chest findings, negative; cardiovascular system, normal.

Fluoroscopy-No restriction of diaphragmatic movement.

X-ray-This roentgenogram was interpreted as first-degree diffuse nodulation with slight emphysema.

Comment-On account of his employment outside of smelters, this man was excluded from regular statistical analysis, but considering his years of employment in smelters and weighted average dust exposure, his smelter exposure seems to be largely responsible for his pulmonary fibrosis (see coal section). 


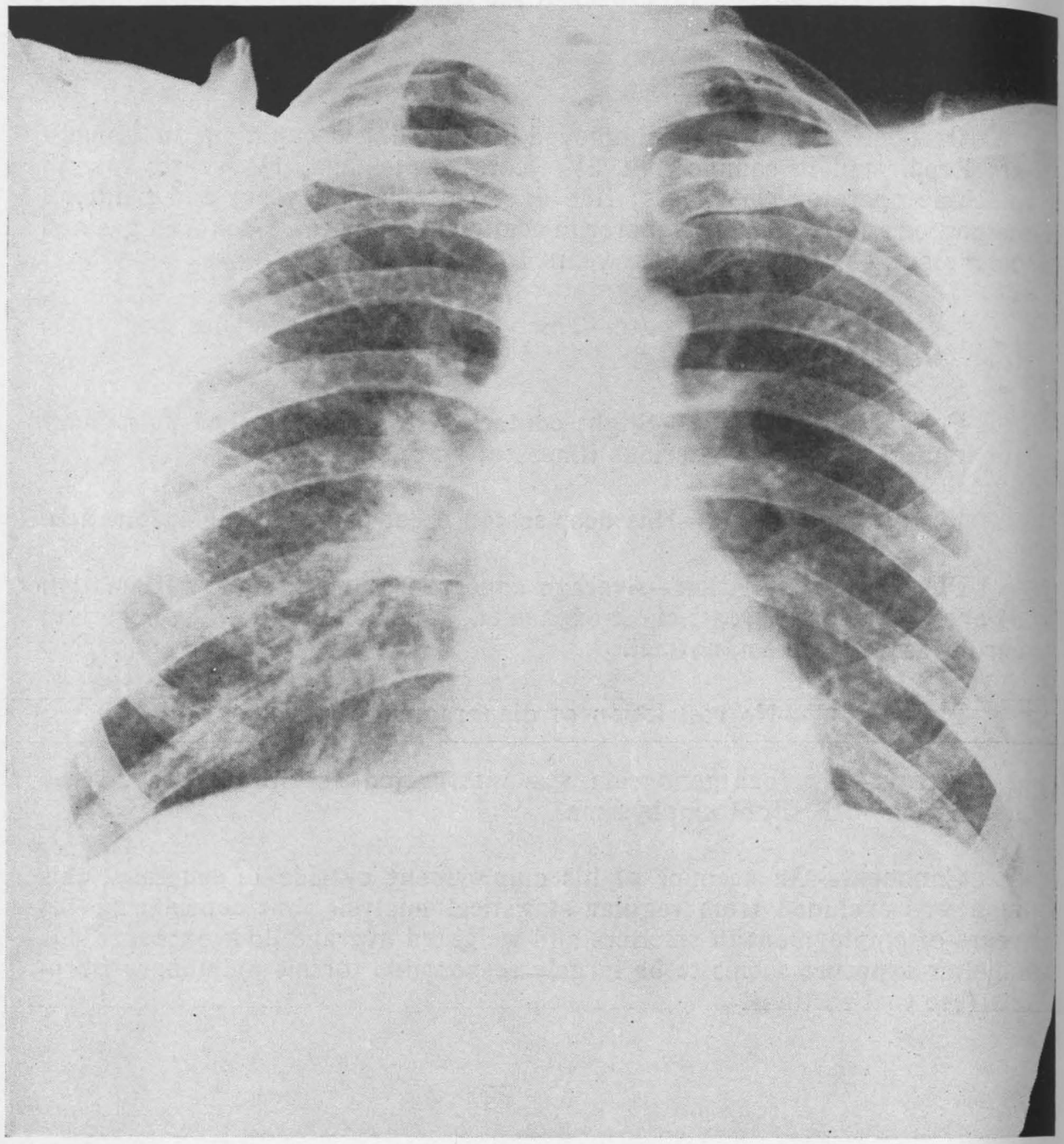

FIGURE 37 -Simple first-stage silicosis, white male, age 32 . 
Figure 37-Case History.

Occupational History-Feeder in reverberatory furnaces, 11 years; sampler in sample mill, one month; and repairman in flotation mill, ten years. (No other smelter employment). Laborer in municipal water works, three years; odd jobs, two years; idle, two years.

Estimated Dust Exposure - Eight million particles per cubic foot (weighted average).

Past Medical History-Pneumonia, no sequellae; dry pleurisy, about one week's duration, several times; has hemorrhoids which bleed slightly on occasion; loss of weight, 20 pounds in past year.

\section{Present Complaints-None.}

Physical Examination-Average appearance; height, 67 inches; weight, 147 pounds; chest expansion, $8.5 \mathrm{~cm}$; chest findings, negative; cardiovascular system, normal; blood pressure, 110/76.

Fluoroscopy-No restriction of diaphragmatic movement.

Comment-This case illustrates that complaints are not infrequently absent or inconsequential in first-degree silicosis. A good roentgenogram is essential for diagnosis in this stage. Except for loss of weight, there were no findings of disability at the time of this man's examination. 


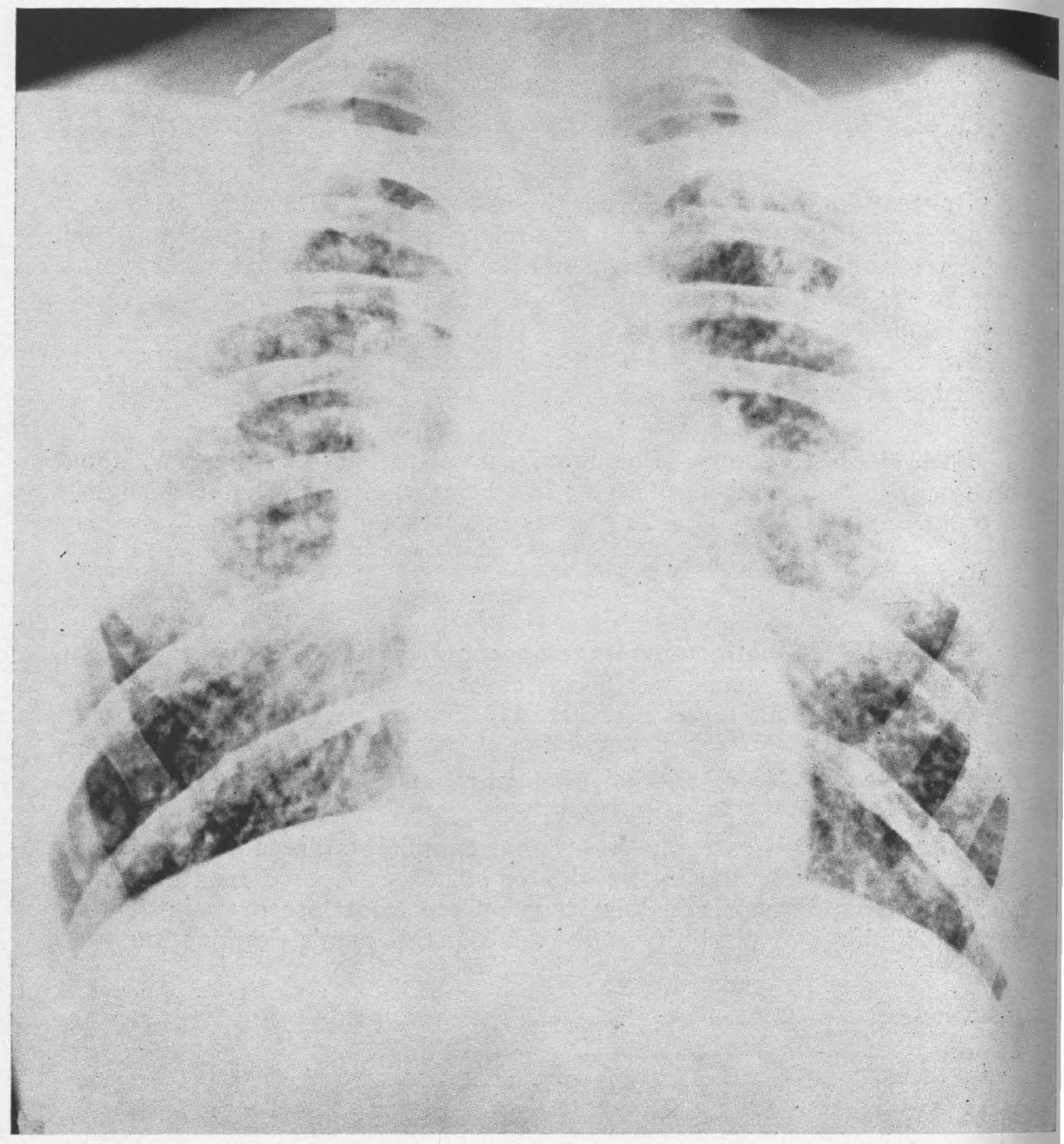

FIGURE 38-Second-stage silicosis, white male, age 39. 
Figure 38-Case History.

Occupational History - Slag switchman, two years; larryman, 11 months; and furnaceman's helper, one year-all in reverberatory furnace department. Crusher in copper concentrate mill ten years. General laborer in non-dusty trades, 11 years.

Estimated Dust Exposure - Forty million particles per cubic foot (weighted average).

Past Medical History-Tonsillectomy, 1923; unilateral inguinal herniorrhaphy, 1929. Recalls no serious illnesses.

\section{Present Complaints-None.}

Physical Examination--Average appearance; height 65 inches; weight, 129 pounds (underweight) ; shape of chest, normal; chest expansion, $8 \mathrm{~cm}$; retracted fossae; other findings in chest aparently normal. Cardiovascular system, normal. Blood pressure, 112/70. Shows slight clubbing of the fingers.

Fluoroscopy-Moderately increased hilar shadows. Movement of diaphragm not restricted.

X-ray-The figure shows early nodulo-conglomerate markings which are essentially coalescent nodules in the upper two-thirds of each lung field and most dense near the periphery. Slight emphysema present in base of each lung.

Comment-The coalescing shadows and slight asymmetry of markings are suggestive of an infective element complicating the silicotic process. This roentgenogram illustrates the amount of pulmonary fibrosis a worker may have without suffering appreciable symptoms. He may be considered as having moderate disability on account of these X-ray markings and physical findings.

It would seem that this man's most significant dust inhalation occurred as a crusher in a concentrating mill. Fixation of diaphragm, large conglomerate area of fibrosis, emphysema, and associated changes would be provocative of more symptoms and signs and hence disability. Cases showing early conglomerate changes should be X-rayed annually because of the likelihood that the pulmonary fibrosis will progress rapidly if infection is present. 


\section{Pulmonary Tuberculosis Among Smelter Workers}

Two broad classifications of pulmonary tuberculous disease are generally recognized by X-ray; the primary or childhood type tuberculosis, and the adult or reinfection type of tuberculous lesion (7).

A healed primary lesion as seen in the X-ray film is usually characterized by the appearance of small, often dense, opacities in the lymph nodes of the hilus, or at the site of the original infection in the lung parenchyma as described by McPhedran (8). This infection occurs chiefly during early life, but might appear later in those persons not exposed to the disease until after adolescence. Usually no symptoms are noted in the development of this pulmonary lesion and the patient is neither disabled nor likely to transfer the disease to others in the community, provided that the infection is arrested at this point and becomes encapsulated.

The adult or reinfection type of tuberculosis may or may not be preceded by a demonstrable primary lesion. It is recognized by its anatomic distribution and peculiarities of its appearance on the X-ray film. It is possible for an infection of this kind to precipitate no recognizable symptoms and to become arrested or quiescent while the patient is performing his usual activities. Very frequently, however, the disease progresses, the patient is disabled and he becomes a source of tuberculous infection in his community.

In the analysis of the examination records made during this study, the diagnosis of tuberculosis was reached only after careful consideration and review by several physicians and in the same manner as that described previously in the diagnosis of silicosis. All questionable cases with insufficient clinical evidence were regarded as essentially negative.

The classifications of the cases studied, according to the degree of activity, is more or less arbitrary since only one film was available for each man examined. Nevertheless, the classification is dictated by certain rather well-established standards of X-ray interpretation. The cases classified as active appeared as soft, infiltrating shadows in the lung parenchyma accompanied by symptoms of tuberculosis in the history or signs revealed by the physical examination. The apparently healed or arrested lesions were more sharply defined, usually with some evidence of scarring, and accompanied by no symptoms or signs referable to tuberculous infection. The cases of undetermined activity consist of those with the X-ray appearance of a tuberculous lesion, the status of which could not be determined by the information at hand. The healed cases include the primary lesions and those of the adult or reinfection type which revealed definite evidence of scarring and were accompanied by no signs or symptoms of tuberculous disease.

Table 78 shows the distribution of these various tuberculous lesions in 1,391 smelter workers according to the above classification.

It should be emphasized at this point that of the 75 cases of reinfection tuberculosis only 11 were designated as active. These, almost without exception, were considered to be lesions of minimal extent, as defined by the Committee on Diagnostic Standards of the National Tuberculosis Association (7).

There is a fair general agreement that calcified pulmonary nodules are of no clinical significance at any age. Calcified tracheobronchial lymph nodes in young adults indicate severe exposure to tuberculosis in 
TABLE 78-Classification of Primary and Reinfection Tuberculosis Occurring in Smelter Workers According to Degree of Activity.

\begin{tabular}{|c|c|c|c|c|}
\hline Degree of activity & All types & $\begin{array}{c}\text { Number with } \\
\text { primary }\end{array}$ & $\begin{array}{c}\text { Number with } \\
\text { reinfection } \\
\text { type }\end{array}$ & $\begin{array}{l}\text { Number with } \\
\text { reinfection } \\
\text { and primary }\end{array}$ \\
\hline Total .............. & 267 & 192 & 39 & 36 \\
\hline Active ..................... & 11 & 0 & 9 & 2 \\
\hline Apparently healed & 11 & 0 & 6 & 5 \\
\hline Healed ... & 227 & 192 & 9 & 16 \\
\hline Unknown ......... & 28 & 0 & 15 & 13 \\
\hline
\end{tabular}

childhood, but there is no incontrovertible evidence that such persons are particularly liable to tuberculosis in later life. Fellows (9), in a study of serial chest roentgenograms of 3,179 office employees covering a period of 12 years, found no significant difference in the development rate of pulmonary tuberculosis in this group, whose first roentgenogram of the chest was classified as average, healthy, or negative chest when compared to a similar group whose first roentgenogram showed a healed primary complex.

Table 79 shows the number and percent of smelter workers with tuberculosis, grouped according to age and including all types and stages of tuberculosis. It is seen that 13.8 percent of the 1,391 smelter workers have evidence of a primary lesion as shown by X-ray. In a group of 801 male office workers, Fellows found 87 or 10.9 percent with a healed primary tuberculosis. In both studies the incidence of primary lesions increases with age and in no instance is the difference between the two comparative age groups of any statistical significance.

\section{TABLE 79-Number and Percent of Smelter Workers with Tuberculosis By Age Groups.}

\begin{tabular}{|c|c|c|c|c|c|c|c|c|}
\hline \multirow{3}{*}{ Age } & \multirow{2}{*}{\multicolumn{2}{|c|}{ All workers }} & \multicolumn{4}{|c|}{ With tuberculosis } & \multirow{2}{*}{\multicolumn{2}{|c|}{$\begin{array}{l}\text { Essentially } \\
\text { negative }\end{array}$}} \\
\hline & & & \multicolumn{2}{|c|}{ Primary } & \multicolumn{2}{|c|}{ Reinfection 1} & & \\
\hline & Number & Percent & Number & Percent & Number & Percent & Number & Percent \\
\hline All ages & 1,391 & 100.0 & 192 & 13.8 & 75 & 5.4 & 1,124 & 80.8 \\
\hline $15-24 \ldots \ldots \ldots$ & 130 & 100.0 & 11 & 8.5 & 2 & 1.5 & 117 & 90.0 \\
\hline $25-34 \quad \ldots \ldots \ldots$ & 458 & 100.0 & 55 & 12.0 & 11 & 2.4 & 392 & 85.6 \\
\hline $35-44$ & 387 & 100.0 & 53 & 13.7 & 20 & 5.2 & 314 & 81.1 \\
\hline $45-54 \ldots$ & 279 & 100.0 & 46 & 16.5 & 24 & 8.6 & 209 & 74.9 \\
\hline $55-64 \ldots$ & 114 & 100.0 & 21 & 18.4 & 16 & 14.0 & 77 & 67.6 \\
\hline 65-74 …....... & 23 & 100.0 & 6 & 26.1 & 2 & 8.6 & 15 & 65.3 \\
\hline
\end{tabular}

1 Reinfection or adult type including those with primary lesions.

In consideration of the above, therefore, the discussion following will be confined chiefly to the incidence of reinfection or adult type tuberculosis and the implications thereof. 
The incidence of reinfection tuberculosis in the general adult male population is said to be about two percent. A study of tuberculosis in Framingham, Massachusetts (10), reveals that about 1.0 percent suffered from the active form of the disease and another 1.0 percent had arrested tuberculosis. The Life Extension Institute (11) examined 100,924 adult white males and a prevalence rate of tuberculosis of 1.5 percent was indicated when suspected cases were included. In a study of 10,000 male industrial workers, the U. S. Public Health Service (2) found 2.5 percent affected with pulmonary tuberculosis.

The incidence of reinfection tuberculosis in 1,391 smelter workers was found to be 5.4 percent. This compares unfavorably with the observations above, and also those noted in the study of 507 coal mine workers and 727 metal mine workers of Utah which showed an incidence of reinfection tuberculosis of 2.6 and 2.5 percent, respectively.

The incidence of reinfection tuberculosis in smelter workers according to occupation reveals little that is of statistical significance due to the scattering of the cases throughout the plant population and the small number of cases in each occpational group. This is realized when it is seen that 75 cases of reinfection tuberculosis are spread over some 30 occupations. Nor can the cases be grouped according to wage level because of the frequent fluctuation of plant operation and consequently the temporary overlapping of the economic status of the various occupational wage level groups.

The incidence of reinfection tuberculosus lesions in smelter workers, when tabulated according to age groups, shows the same trend as similar tabulations in other industries. The incidence increases with age and shows a preponderance of cases in men over 30 years of age.

A generally recognized cause for an increased incidence in the rate of tuberculosis in smelter workers is their exposure to siliceous dust. The Report of the Committee on the Prevention of Silicosis Through Medical Control of the National Silicosis Conference (12) indicates a close correlation between the development of silicosis and the incidence of tuberculosis in those affected.

Table 80 shows the incidence of adult or reinfection type tuberculosis among smelter workers classified by diagnosis of silicosis.

\section{TABLE 80-Incidence of Reinfection Tuberculosis Among Smelter Work-} ers, classified by Diagnosis of Silicosis.

\begin{tabular}{|c|c|c|c|}
\hline \multirow{2}{*}{ Diagnosis of silicosis } & \multirow{2}{*}{$\begin{array}{c}\text { Number } \\
\text { of } \\
\text { workers }\end{array}$} & \multicolumn{2}{|c|}{ With reinfection tuberculosis } \\
\hline & & Number & Percent \\
\hline All workers & 1,391 & 75 & 5.4 \\
\hline First and second stage... & 37 & 6 & 16.2 \\
\hline Borderline ... & 65 & 6 & 9.2 \\
\hline Nonaffected .. & 1,289 & 63 & 4.9 \\
\hline
\end{tabular}

It will be seen that the nonaffected group has an incidence of 4.9 percent of tuberculosis. The borderline group has a percentage almost 
twice as high, and of the workers classified as having silicosis 16.2 percent have tuberculosis, or slightly more than three times the percentage of the nonaffected group.

The exposure to siliceous dust, therefore, is an important factor, but it appears that other factors also play a part in producing the higher incidence of reinfection tuberculosis among smelter workers. When attention is limited to the group which is free from silicotic or pre-silicotic change there remains an excess of reinfection tuberculosis, the percent affected being 4.9 percent for smelter workers, 2.2 percent for coal mine workers, and 1.0 percent for metal mine workers. Table 81 shows that this difference cannot be attributed to variation in the age distribution of the three industrial groups. The method employed in preparing this table is to apply the percent with reinfection tuberculosis in a specified age group among smelter workers (column 3 ) to the number of workers exposed in the corresponding age groups for coal miners and metal mine workers (column 4 and column 6). The resulting figures indicate the number of persons who would have had reinfection tuberculosis in the metal mines and in the coal mines if these industries had the same rate of infection as the smelter industry. Actually the number of cases observed (column 5 and column 7 ) was much less than the expected rate, showing that reinfection tuberculosis was less common in the coal mine and metal mine industries. In the former industry approximately onehalf as many cases were found as expected, and in the latter industry only one-fourth as many were found.

\section{TABLE 81-Number of Cases of Reinfection Tuberculosis Among Work- ers Not Affected by Silicosis in Coal Mines and Metal Mines That Could be Expected if the Rates for Smelter Workers Had Prevailed.}

\begin{tabular}{|c|c|c|c|c|c|c|c|c|c|}
\hline \multirow[b]{3}{*}{ Age } & \multicolumn{3}{|c|}{ Smelters } & \multicolumn{3}{|c|}{ Coal mines } & \multicolumn{3}{|c|}{ Metal mines } \\
\hline & \multirow{2}{*}{ 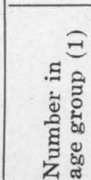 } & \multirow{2}{*}{ 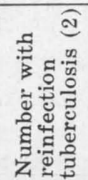 } & \multirow{2}{*}{ 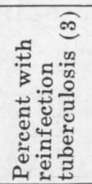 } & \multirow{2}{*}{ 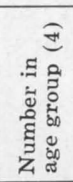 } & \multicolumn{2}{|c|}{$\begin{array}{l}\text { Reinfection } \\
\text { tuberculosis }\end{array}$} & \multirow{2}{*}{ 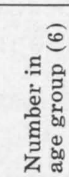 } & \multicolumn{2}{|c|}{$\begin{array}{c}\text { Reinfection } \\
\text { tuberculosis }\end{array}$} \\
\hline & & & & & 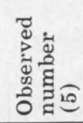 & 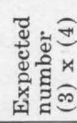 & & 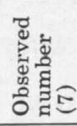 & 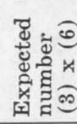 \\
\hline & 130 & 2 & 1.5 & 79 & 1 & 1.2 & 83 & 0 & 1.2 \\
\hline $15-24$ & 451 & $1 \overrightarrow{1}$ & 2.4 & 167 & 1 & 4.0 & 311 & 2 & 7.5 \\
\hline $25-34$ & 358 & 16 & 4.5 & 125 & 3 & 5.8 & 132 & 0 & 5.9 \\
\hline $35-44$ & 237 & 19 & 8.0 & 71 & 4 & 5.7 & 66 & 3 & 5.3 \\
\hline $45-54$ & 113 & 15 & 13.3 & 19 & 1 & 2.5 & 27 & 1 & 3.6 \\
\hline 55 and over. & 1,289 & 63 & & 465 & 10 & 19.2 & 619 & 6 & 23.5 \\
\hline
\end{tabular}

Another environmental factor of possible importance in smelters is the presence of irritating gases (13), including sulphur dioxide, which are encountered rarely in coal and metal mines. A comparison of two groups of nonsilicotic smelter workers with dissimilar exposure to sulphur dioxide, however, failed to show a difference in the incidence of tuberculosis. If the irritant action of sulphur dioxide is of importance, it 
is probably only one of several factors involved in connection with the slightly increased incidence of tuberculosis among smelter workers.

\section{The Lead Hazard in Utah Smelter Industry}

\section{Estimate of the Present Incidence of Abnormal Lead Absorption}

A total of 41 smelter workers was found to exhibit two or more generally accepted signs of latent plumbism. Six of these cases were selected on the basis of basophilic stippling, 16 by urinary lead content of $0.2 \mathrm{mg}$ per liter or more, and 19 by the presence of gingival metallic line. In addition to these criteria, each case was required to reveal at least one other indication of abnormal lead absorption.

When the reticulocyte percent values for the lead affected group of 41 workers are compared with the relatively nonaffected group, striking differences are observed. Among the workers with latent plumbism, 51.3 percent showed reticulocyte values in excess of 1.0 percent or more, while among the nonaffected only 8.2 percent. With respect to hemoglobin, the mean value for the affected group was found to be 13.2 grams per 100 cc of blood (Newcomer) while for the nonaffected group it was 14.3 grams.

The occupations or departments in which these 41 workers were employed at the time of examination include D. \& L. roasters-11, unloading - eight, lead plant-six, maintenance-five, flotation-three, and one each in the baghouse, wedge furnace, charge floor, arsenic plant, warehouse, sample mill, bucking room, and one laborer. Each of these cases, although considered at present to exhibit latent plumbism, might be looked upon as potential lead intoxication, since the supervention of one or more predisposing factors is capable of precipitating an acute attack of plumbism.

It should be noted at this point that no cases of acute plumbism were observed during the course of this study. Neither were cases observed which presented residual paralyses commonly attributable to lead poisoning, nor any neurological or encephalopathic manifestation sometimes noted following severe cases of plumbism. That acute attacks of lead poisoning do occur is evidenced by examination of the past history of the present personnel of these smelters.

\section{Past History of Lead Poisoning}

A total of 14 workers gave a history of an acute attack of lead poisoning at some time during th past five years (table 82). Three of these suffered more than one attack at intervals beyond the five years and one worker reported an attack within the past year. Information is not available for all as to length of their disability, but for those cases in which it was known the average was about one month. The clinical findings on these men at the time of examination during the present study were: two with generalized weakness, four with constipation, two with gingival metallic lines, one with pallor, and three with fine tremor. The distribution of occupations at the time of the last attack included: wedge roasters - five, D. \& L. roasters-four, maintenance-two, dross furnace-one, flue cleaning - one, and yard crew (surface laborer)-one.

One of these 14 men can be considered as convalescing from an acute attack of lead poisoning which occurred several months before the present study was undertaken. He was employed as a helper on the D. \& L. roasters and emptied the "fines box" when necessary. After three weeks of 
this work an acute attack of lead poisoning occurred which lasted 35 days. At the time of the present examination he had not yet recovered his weight loss but was not noticeably underweight. He still complained of moderate constipation and generalized weakness. Physical examination revealed a gingival metallic line, mild gingivitis, a fine tremor, and a rather excitable disposition. His erythrocytes showed no stippling and the reticulocyte count was 0.9 percent.

TABLE 82-Smelter Workers Giving a Past History of Acute Plumbism, Classified by Occupation, at the Time of Their Last Attack.

\begin{tabular}{|c|c|c|}
\hline \multirow[b]{2}{*}{ Occupation } & \multicolumn{2}{|c|}{ Histroy of lead poisoning } \\
\hline & $\begin{array}{c}\text { Within past } \\
5 \text { years }\end{array}$ & $\begin{array}{l}\text { More than } \\
5 \text { years ago }\end{array}$ \\
\hline Surface laborer ..... & \multirow{14}{*}{$\begin{array}{c}6 \\
4 \\
1 \\
1 \\
1 \\
1 \\
\ldots . . \\
\ldots . \\
\ldots . \\
\ldots . \\
\ldots . \\
\ldots . \\
\ldots . \\
\ldots . \\
\end{array}$} & \multirow{14}{*}{$\begin{array}{r}1 \\
3 \\
1 \\
\cdots \\
2 \\
8 \\
2 \\
3 \\
3 \\
1 \\
1 \\
1 \\
1 \\
1\end{array}$} \\
\hline D. \& L. sintering & & \\
\hline Dross furnace & & \\
\hline Flue cleaner-reverb. ... & & \\
\hline 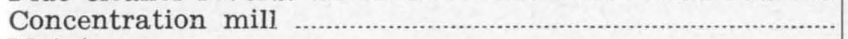 & & \\
\hline Maintenance $^{1}$ & & \\
\hline Sample mill & & \\
\hline Blast furnace & & \\
\hline 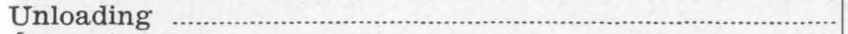 & & \\
\hline Converter & & \\
\hline 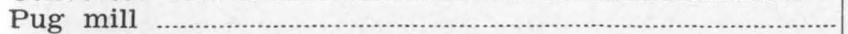 & & \\
\hline 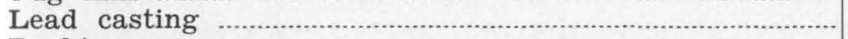 & & \\
\hline Bucking …-1-1) & & \\
\hline Not classified & & \\
\hline Total & 14 & 28 \\
\hline
\end{tabular}

1 Those in maintenance group include two carpenters and one each of boilermaker, mason, machinist, janitor, power plant operator, and general supervision.

Those who gave a history of lead poisoning occurring more than five years ago numbered 28 , as shown in table 82 .

Four of these workers experienced more than one attack. In the group reporting plumbism five or more years ago three cases of lead poisoning were noted among workers in the blast furnaces, but in the group reporting acute attacks within the past five years no cases were noted. This is probably associated with the fact that the establishment of the concentration mill in 1926 and the gradual improvement in its operation has reduced the necessity of operating more than one blast furnace at the present time. Although the roasting processes are fairly well controlled, there are few operations in which the worker is exposed to fumes and dust of high lead content. Among these is the emptying of the "fines boxes" in the D. \& L. sinterer. The decreased occurrance of acute plumbism in the maintenance group can be related to the decrease in the number of blast furnaces.

\section{Criteria Indicative of Abnormal Lead Absorption}

Basophilic Stippling-Of the 1,391 smelter workers examined, 82 revealed basophilic stippling ${ }^{1}$. Only four of these showed 100 to 500 stippled cells per 100,000 erythrocytes.

1 In addition 14 of the 120 workers excluded because of mixed dust exposure showed basophilic stippling. 
Table 83 classifies the smelter workers who were found to have baso. philic stippling according to present lead exposures. The number of those exposed to less than $1.5 \mathrm{mg}$ of lead per 10 cubic meters of air is 888 . Of this number 41 or 4.6 percent revealed basophilic stippling, whereas among the 256 workers exposed to more than $1.5 \mathrm{mg}$ of lead 23 or 9.0 percent showed basophilic stippling or almost twice as many.

\section{TABLE 83 - Smelter Workers, Classified by Present Lead Exposure, Whose Blood Showed Basophilic Stippling.}

\begin{tabular}{|c|c|c|c|}
\hline \multirow{2}{*}{$\begin{array}{l}\text { Present } \mathrm{Pb} \text { exposure- } \mathrm{Mg} \mathrm{Pb} \text { per } 10 \\
\text { cubic meters of air }\end{array}$} & \multirow{2}{*}{$\begin{array}{c}\text { Number of } \\
\text { workers } \\
\text { exposed }\end{array}$} & \multicolumn{2}{|c|}{ Workers with stippled cells } \\
\hline & & Number & Percent \\
\hline Total ...... & 1,391 & 82 & 5.9 \\
\hline Less than 0.1 . & 406 & 14 & 3.4 \\
\hline $0.1-1.4$ & 482 & 27 & 5.6 \\
\hline $1.5-9.8$ & 198 & 16 & 8.1 \\
\hline 9.9 and over & 58 & 7 & 12.1 \\
\hline Unknown & 247 & 18 & 7.3 \\
\hline
\end{tabular}

Little correlation appeared to exist between the elevation of the stippled cell count and other laboratory and clinical findings. Only six of these 82 workers presented one or more additional signs or symptoms indicative of abnormal lead absorption at the time of the study.

Dependence upon an elevated stippled cell count in detecting plumbism is general throughout industrial practice but not as much as is supposed since the industrial physician has the additional advantage of the periodic examination and continued observation of the worker. The preexposure level is usually known for each worker and the average normal count during the exposure to lead can be determined. Momeover, a sharp rise from the average normal count is usually accompanied by one or more clinical signs or symptoms not noted or regarded as insignificant during a single physical examination. Less importance should therefore be placed on stippled cell counts in estimating the degree of abnormal lead absorption in workers examined during a health survey of the type on which this report is based when the examiner has but one opportunity to see the worker.

Metallic Line-One of the criteria used in this study was the presence of a gingival metallic line, which, according to Teleky (14), was described by Burton in 1840 as follows:

"The lead line presents a slaty gray, from light to dark blue, discoloration of the line of the gums. Frequently it forms a line about one $\mathrm{mm}$ wide; in other cases it gradually fades towards the mucous membrane which covers the jaw. Frequently it is found only at the edge of separate teeth, if these protrude somewhat prominently in the jaw. Where a tooth is out and the gum has healed over the destroyed alveolar process, no lead line is found, and so for this reason, we miss the line in the toothless jaw. Often too, bluish gray spots are found on the gingiva and on the mucous membranes of the cheek and lips, especially where the latter approach the lead line." 
Nineteen smeltre workers presented a well-defined gingival metallic line. ${ }^{1}$ Four of these men showed basophilic stippling, and 14 showed a reticulocyte count of 0.70 percent or more. Nine men had a hemoglobin value of $13 \mathrm{gms}$ (Newcomer) or less per $100 \mathrm{cc}$ of blood. The lowest value was 11.5 and this occurred in only one instance. The test for urinary albumin in all of these cases proved to be negative, indicating that kidney damage was minimal or absent. Semi-qualitative spectrographic urinalyses were performed on all of these workers. One was recorded as showing a faint trace of lead, 14 showed a moderate amount, and four showed more than a moderate amount. With respect to physical impairments and complaints associated with lead absorption or intoxication, all presented one or more of the following: loss of weight, gastrointestinal disturbances, headache, depression, excitability, weakness in arms or legs, tremor, and constipation.

Urinary Lead Content-A quantitative spectrographic analysis ${ }^{2}$ was performed on the urine samples of 80 smelter workers. These samples were selected because of the appearance of one or more indications of abnormal lead absorption. Twenty urine specimens of this group of 80 were found to contain $0.2 \mathrm{mg}$ or more of lead per liter. Only two were found to be as high as $0.8 \mathrm{mg}$ per liter of urine. Of this group of 20 men, 18 showed one or more additional indications of abnormal lead absorption. Two of these cases are included in the list showing a gingival metallic line.

Related Hematologic Findings-The reticulocyte count was of minor assistance in the selection of those men considered to reveal evidence of latent plumbism. The mean value for all smelter workers is 0.80 percent, which is the same as that given by Orten (15) as the approximate mean value for men with a range from 0.01 to 2.0 percent. Only 25 smelter workers showed a reticulocyte count of 2.0 percent or more. The 41 men in the lead affected group, however, had a higher proportion (51.3 percent) of reticulocyte counts above one percent, than men in the non-affected group (8.2 percent).

A comparison of the three studies conducted in Utah shows that about 20 percent of the coal mine workers had reticulocyte values of more than 1.0 percent, while the percent for the metal mine workers was 26.0 and for smelters, 28.0. Furthermore, the mean value of reticulocyte percent in the coal mine workers was 0.73 while in the metal mine and smelter workers it was 0.82 and 0.80 percent, respectively. This stands as inferential data to conclude that some factor such as lead exposure in the metal mines and smelters was operating to cause this difference, but was absent in the coal mines.

The mean hemoglobin values showed little difference when the results of all three studies were compared, although the amount of hemoglobin per $100 \mathrm{cc}$ of blood was somewhat higher in the smelter workers than in either the coal or metal mine workers. A lower rate was found in one of the two smelters investigated, and this was probably due to the increased lead content of the ore handled.

\footnotetext{
1 In addition two of the 120 workers who were excluded because of mixed dust exposure showed a metallic line.

2 See section in Appendix describing the technique of qualitative spectographic urinalyses.
} 
Gastrointestinal Disorders-Although a critical review of the histories and examinations of the smelter workers fails to reveal a large number of cases of latent plumbism, the importance of the lead hazard should not necessarily be minimized. The change and development of new processes demands an unrelenting vigilance in the search for possible lead exposure. It is also possible that an accurate estimate of abnormal lead absorption and intoxication is only approximated by current clinical and laboratory methods. A hint in this direction is evidenced by the large number of digestive complaints volunteered by the workers during the recording of the past and present medical history. Of the 1,391 smelter workers examined, 412 or about 30 percent complained of digestive disturbances, compared to 19.2 percent among coal mine workers. Also, the incidence of appendectomy, or appendicitis requiring surgical intervention, was found to be 15 percent in one smelter and 19 percent in another, although this question was not always specifically asked. The question is raised as to the probability of the high incidence of digestive disturbances and appendectomies being due to unrecognized lead intoxication.

Other causes for this high incidence of gastrointestinal disorders are possible. The various fumes and gases encountered throughout the plants, particularly sulfur dioxide and arsenic fumes, may be causative factors. The fact that shifts are changed every three to four weeks probably accounts for a certain percentage of the symptoms noted. In the presence of a definite lead exposure hazard, plumbism should be kept in mind.

\section{Sulphur Dioxide}

Sulphur dioxide, which is produced in large quantities in the smelting of sulphide ores, is listed by Henderson and Haggard as one of the common respiratory irritants. Contact with the moist surfaces of the respiratory tract and conjunctiva oxidizes it to sulphurous acid. This is of course, immediately neutralized and the resulting salts are nontoxic. "Although the action of sulfur dioxide is mainly in the upper respiratory tract, severe exposure causes inflammation of the bronchi and occasionally edema of the lungs" (16). However, acute poisoning from inhalation of sulphur dioxide is rare because lethal concentrations are so irritating to the eyes and respiratory tract that such an atmosphere is almost irrespirable and relief is sought at once.

Very rarely, if ever, are such high concentrations encountered in the smelter, but the workers are exposed to lower concentrations which may induce a mild degree of sulphur dioxide poisoning. McNally (17) lists the complaints of this disorder as follows: "Headache, anorexia, spasmodic cough, sneezing, hemoptysis, bronchitis, constriction of the chest, gastrointestinal disorders, conjunctivitis, smarting of the eyes, lacrimation, and anemia."

Henderson and Haggard (16) show the physiological response to various concentrations of sulphur dioxide (table 84).

Reference to table 67 of the engineering section, showing the sulphur dioxide concentrations by department of the smelters, reveals that the average sulphur dioxide concentration varies from 0.015 at the blast furnaces to 11.90 parts per million at the converters and cranes. The highest maximum concentrations were found at the reverberatory furnaces and waste heat boilers and at the converters and cranes. The roasters and 
TABLE 84-Physiological Response to Various Concentrations of Sulphur Dioxide (16).

\begin{tabular}{|c|c|}
\hline & $\begin{array}{l}\text { Parts of sulphur } \\
\text { dioxide per million } \\
\text { parts of air }\end{array}$ \\
\hline Least detectable odor ${ }^{1} 2 \ldots \ldots$ & 3 to 5 \\
\hline Least amount causing immediate irritation to the eyes ${ }^{2} \ldots$ & 20 \\
\hline Least amount causing immediate irritation to the throat $2 .$. & 8 to 12 \\
\hline 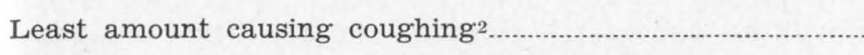 & 20 \\
\hline Maximum concentration allowable for prolonged exposure 2 & 10 \\
\hline $\begin{array}{l}\text { Maximum concentration allowable for short } \\
\text { exposure ( } 1 / 2 \text { to } 1 \text { hour })^{2} 3\end{array}$ & 50 to 100 \\
\hline Dangerous for even short exposure ${ }^{3}$. & 400 to 500 \\
\hline
\end{tabular}

1 U. S. Department of Interior, Bureau of Mines, Bulletin 98, 1915.

2 Fieldner, A., and S. Katz, Eng. and Mining Jour. 107: 693, 1919.

3 Lehmann, Arch. f. Hyg., 18, 180.

sinterers were found to produce maximum concentrations of 14.99 and 11.25 parts per million, respectively. It is seen by reference to table 84 that these concentrations will cause irritation to the throat. That exposures of this degree do occur frequently is shown by the fact that inflammation of the upper respiratory tract occurred in 52.7 percent of the smelter workers as compared to 9.5 percent in the coal mine workers, and 13.3 percent in the metal mine workers. This upper respiratory tract inflammation in the smelter worker was also observed to be greater in degree than that among the coal and metal mine workers.

Other symptoms listed by McNally were noted in the smelter workers examined during this study. Gastrointestinal disorders, exclusive of appendicitis requiring surgical intervention, were complained of by 30.0 percent of the workers; inflammation of the eyes or mild conjunctivitis was observed in 22.8 percent; and headache and frequent cough each were reported by about 7.0 percent of the smelter workers examined. Other toxic substances such as lead and arsenic are also capable of producing some of the above-named symptoms, but sulphur dioxide can probably be considered a factor of importance. The frequent occurrence of inflammation of the upper respiratory tract clearly indicates the need for further control of the sulphur dioxide hazard.

\section{Other Occupational Hazards in the Smelter Industry in Utah}

\section{Arsenic}

Arsenic poisoning in industry is caused by contact with or inhalation of the compounds of arsenic. The principal compounds with which the industrial worker is concerned are the oxides of arsenic, arsenical insecticides, and arsine (arseniuretted hydrogen).

The oxides and salts of arsenic act as local irritants or escharotics on the surfaces of skin or mucous membrane with which they come in contact. 
The results of irritation by these compounds are therefore an irritant dermatitis or eczematous condition sometimes with ulceration, which appears in the folds of the skin, edema of the eyelids and conjunctivitis, coryza, laryngitis, and pharyngitis. Pigmentation in the form of a brown discoloration usually confined to the eyelids, temples, neck, nipples, and folds of the axillae, is reported to be common (18). Other symptoms de occur, but usually only in the more severe cases which were not encountered in this study. Legge (19) reports that among the 135 cases of industrial arsenical poisoning occurring in England during the years 1900-31, "peripheral neuritis was present in only six, with tremor or cramps in 13 , epileptiform seizures in three, and gastric symptoms in 38 . The remainder were practically all rashes.

Only one man examined presented a mild dermatitis, questionably due to arsenic. Inspection of the records reveals no case of dermatitis in any smelter worker which can be traced directly to arsenic as the causative factor. That it does and can occur, however, is revealed by the past histories of a number of workers and the literature on the well-known dermatologic manifestations which appear in persons susceptible or abnormally sensitive to arsenical compounds.

Probably the most characteristic lesion produced in the upper air passages by arsenic salts in the form of dust is perforation of the nasal septum. The perforation never involves the anterior and lower margins of the cartilage, nor the bones to which it is attached, so that no deformity is present. Perforation may be complete in one month from the beginning of employment and may vary in size from $1 / 8$ to one inch in diameter. After the perforation is complete no further inconvenience is noted and many of the workers are unaware of the existence of the condition. The causes of perforation of the septum, according to Davis (20) are (1) syphilitic, (2) traumatic, (3) exposure to potassium and sodium bichromate, and (4) exposure to salts and oxides of arsenic.

The probable course of events is outlined by Dunlap (21): “ . . arsenic dust is breathed into the nose and, coming in contact with moisture, forms arsenous acid, which causes necrosis of the septal mucosa at Kiesselbach's area. The traumatism of the air currents alone often keeps this portion of the septal mucosa irritated, especially if there is a deflection or ridge of any sort. . . The inhalation of arsenous oxide and hydration to arsenous acid on this area of least resistance of the septal mucosa causes a tissue necrosis and defense reaction of hyperemia. Obstruction follows. This leads to vigorous blowing of the nose, all of which factors form the basis of the original abrasion."

The above causes, plus the presence of other irritating gases and fumes in the smelters and perhaps digital irritation, are probably responsible for the condition as met with in this study.

No other sign or symptom was noted in the examination of the smelter workers which could be attributed to the action of arsenic. The lack of signs or symptoms usually noted among workers exposed to arsenic, especially the dermatologic manifestations mentioned by Legge and others as being most prevalent, was partly due to the fact that the arsenic recovery plant was not in full operation during this investigation and had not been for some time previously. Another factor in this connection was the careful use of personal protective devices furnished by the companies 
to employees engaged as flue cleaners and baghousemen. (For a description of these precautionary measures see Report on the Engineering Study of Smelters in Utah; also table 63 showing the amount of arsenic to which various workers were exposed). It is also suggested that workers in occupations with high arsenic exposure might be less susceptible to intoxication or irritation by this substance, and that they might also have acquired a tolerance to arsenic. The gastrointestinal symptoms and complaints noted among the smelter workers, as well as the few neurologic signs and symptoms elicited, could very well be attributed to lead. The excessive amount of conjunctivitis and inflammation of the nose and throat was in all probability due to the presence of an irritating gas such as sulphur dioxide. Futhermore the conjunctivitis and inflammation of the upper respiratory tract were observed in smelter workers with little or no arsenic exposure. It is, of course, possible that arsenic contributed to these clinical manifestations, but they are most likely due to lead and sulphur dioxide.

A total of 81 smelter workers with perforation of the nasal septum was found during the course of this study ${ }^{1}$. It is of interest to note that no cases of perforation of the septum were found among the coal mine workers. One case was observed among the metal mine workers, but he also gave a history of a nasal operation. Syphilis was found to be present in three men with nasal perforations, and three others gave a history of extensive nasal operations. Exposure to arsenic could be traced in only one of the three workers with syphilis. These six, however, will be excluded from the following discussion.

All the remaining 75 men with perforated nasal septa had had ex. posures to arsenic for more than one year, although according to Legge (19) and others (21) (22), perforation can occur within one month from the beginning of exposure. Perforation of septum was observed in one worker, 24 years of age, who had been employed in the smelting industry for three years as an extra man. During the past year he was employed three times, for one month each time, as an arsenic furnaceman. He had no symptoms or complaints and was in good physical condition except for being slightly underweight. Spectrographic urinalysis revealed excretion of little more than normal amounts of lead and copper, but no arsenic. The last period of such employment was one month prior to the examination made during this study.

Workers presenting perforated nasal septa were engaged in the following occupations at some time during their employment experience in smelters: roasters, arsenic plant operators, maintenance men, general laborers, flue dust cleaners, baghousemen, pug mill operators, and Cottrell knockers. Each of these occupations offered the opportunity for a definite arsenic exposure. The majority of those employed on the roasters were operating the D. \& L. type machine; the others were engaged in the operation of wedge furnaces. The maintenance men include carpenters, electricians, pipefitters, welders, machinists, and others whose occupations require their presence in all parts of the plant. ${ }^{2}$

The nasal perforations observed in this study and presumably due to arsenic were distinctive and easily recognizable, differing considerably from the syphilitic or injured septum in shape, size, and appearance of

1 In addition there were nine persons with perforation of the nasal septum among the 120 workers excluded because of mixed dust exposure.

2 Almost all of these 75 cases with septal perforation worked in the lead smelter. 
border. The borders were usually smooth, with no ragged edges or protu. berances. They appeared dry and covered with a grayish or slate-colored membrane or thin crust, which seemed to be firmly attached. The border and adjacent tissue did not appear to be acutely inflamed or congested. The shape was usually round or oval and varied in size from about $1 \mathrm{~mm}$ to $2.5 \mathrm{~cm}$ or more. One perforation was observed to extend to the edges of the perpendicular plate of the ethmoid and vomer bones. A margin of septal cartilage of about $5 \mathrm{~mm}$, however, remained anteriorly and infer. iorly. There was no deformity and no inconvenience to the worker.

Symptoms of arsine poisoning usually appear a few hours after inhalation and may include a feeling of weakness followed by vertigo and faintness; headache followed by nausea and vomiting with epigastric pain; and jaundice and cyanosis might also appear. The specific action of arsine is due to its affinity for the hemoglobin of the red corpuscles. The arsenic compound is gradually oxidized, at which time hemolysis occurs, resulting in the disintegration of the red blood cells and a consequent severe anemia.

Although no workers were found at the time of this study to be suffering from the effects of inhalation of arsine or arseniuretted hydrogen, the occurrence of this potential hazard should at least be mentioned. The essential factor for the production of arsine is the presence of nascent hydrogen in solutions containing arsenic. The generation of this gas is possible in at least two locations in the smelter: (1) the assay laboratory, and (2) in the preparation of flue dust for the production of cadmium. Very small amounts of arsine will prove to be dangerous if exposure lasts over certain limits as table 85 shows.

\section{TABLE 85-Physiological Response to Various Concentrations of Arsine. ${ }^{1}$}

\begin{tabular}{l|r}
\hline & $\begin{array}{c}\text { Parts of arsine per } \\
\text { million of air }\end{array}$ \\
\hline Slight symptoms after several hours of exposure $2 \ldots \ldots \ldots \ldots$ & 30 \\
Dangerous for exposure of one hour ${ }^{3} \ldots \ldots \ldots \ldots$ & 50 \\
Fatal to man in exposure of 30 minutes $^{4}$ & 250 \\
\hline
\end{tabular}

1 Y. Henderson and H. Haggard. Noxious Gases. Chemical Catalog Company, Inc., New York, 1927 , p. 187.

2 Dubitsky. Quoted from Koelsch. I. Zentralbl. f. Gewerbehyg., VIII : 121.1920.

3 Kohn Abrest, E. Annales des Falsifications, VIII : 215, 1915.

4 U. S. Department of Interior, Bureau of Mines, Technical Paper 248, 1921, p. 67.

\section{Other Metals To Which the Smelter Worker Is Exposed}

The report of the engineering study (page 232) records various concentrations of a number of metals and gases not previously mentioned in the medical section to which the smelter worker is exposed. Most of these are intermittent exposures of short duration and frequently of low concentration. The metals included are antimony, cadmium, copper, zinc, selenium, silver, gold, mercury, bismuth, and manganese. The gases for which tests were made are carbon monoxide, hydrogen cyanide, and hydrogen sulphide. No clinical manifestations of intoxication were noted in any of the smelter workers examined which could be positively attributed to these 
substances. The absence of toxic symptoms in the presence of high atmospheric concentrations of some of the above substances indicate that, in some cases, effective protection was being received from personal respiratory protective devices. Copper in particular was present in substantial concentration in certain smelting operations. However, no definite evidence of copper poisoning was observed.

\section{Miscellaneous Physical Findings Among Smelter Workers}

\section{Cardiovascular Disease}

Cardiovascular disease appears to be no more frequent and no more serious among the smelter workers than among other industrial workers. Heart disease was found to be no more prevalent in those affected with silicosis as compared with those nonaffected. This is in agreement with other studies of dusty trades (1) (3) (4).

Heart disease as found in the smelter worker has been classified under broad etiological headings in accordance with a schedule prepared by the Heart Committee of the New York Tuberculosis and Health Association (23), which was sponsored by the American Heart Association and modified recently by Hedley (24).

Table 86 shows the distribution of heart disease in the smelter worker according to this classification. More smelter workers were affected by diseases of the arteriosclerotic-hypertensive group than were pottery workers, but the figures obtained for the smelter workers falling under this classification compare favorably with the coal and metal mine workers of Utah, and with results obtained in other studies (1). Arteriosclerotichypertensive heart disease increases in prevalence with advancing age and particularly in workers of 45 years and over.

Although a number of reports, including that of Viko (25), indicate that rheumatic heart disease has a high incidence in the Rocky Mountain region, such high incidence was absent in the smelter workers, only nine such cases being found.

Functional heart disorders appear to occur with much greater frequency in the smelter worker than in the pottery worker. This is due to the fact that in the smelter study cases of simple tachycardia and premature systole were included under this classification. These merely represent clinical observations recorded at the time of examination and are not to be considered as serious. Functional heart murmurs are also included under this classification, but these, too, are not of serious import from a cardiac standpoint, since no organic disease is demonstrable. They might, however, be an indication of some other disorder, which can usually be readily corrected.

Two cases of definite toxic heart disease were observed in the 1,391 smelter workers examined. One case was the result of a diphtheric infection some years before in a man of 35 years; the other was a mild case of thyrotoxic heart disease in a worker 56 years of age. The hearts of both of these men were fully compensated and the men appeared to suffer no inconvenience in the discharge of their duties.

The low incidence of syphilitic heart disease was in agreement with the paucity of other syphilitic manifestations. No case in this series was found in which a definite diagnosis of aortic aneurysm could be made. 
TABLE 86-Incidence of Heart Disease Among Smelter Workers, Classified According to Age, and Compared with Pottery Workers

\begin{tabular}{|c|c|c|c|c|c|c|c|c|c|c|c|}
\hline \multirow[b]{3}{*}{ Age } & \multicolumn{7}{|c|}{ Smelter industry } & \multicolumn{4}{|c|}{ Pottery manufacture } \\
\hline & \multirow[b]{2}{*}{$\begin{array}{l}\text { Number } \\
\text { in age } \\
\text { group }\end{array}$} & \multicolumn{3}{|c|}{ Number with heart disease 1} & \multicolumn{3}{|c|}{ Percent with heart disease } & \multirow[b]{2}{*}{$\begin{array}{l}\text { Number } \\
\text { in age } \\
\text { group }\end{array}$} & \multicolumn{3}{|c|}{ Percent with heart disease 2} \\
\hline & & $\begin{array}{l}\text { Arterio- } \\
\text { sclerotic } \\
\text { Hyper- } \\
\text { tensive }\end{array}$ & Rheumatic & Functional & $\begin{array}{l}\text { Arterio- } \\
\text { sclerotic } \\
\text { Hyper- } \\
\text { tensive }\end{array}$ & Rheumatic & Functional & & $\begin{array}{c}\text { Arterio- } \\
\text { sclerotic } \\
\text { Hyper- } \\
\text { tensive }\end{array}$ & Rheumatic & Functional \\
\hline All ages .................... & 1,391 & 120 & 9 & 86 & 8.6 & 0.6 & 6.2 & 1,627 & 4.5 & 1.0 & 0.1 \\
\hline $15-24$ & 130 & 4 & 0 & 5 & 3.1 & $\cdots$. & 3.8 & 350 & $\ldots \ldots$. & 1.1 & 0.3 \\
\hline 25-34 ....................... & 458 & 8 & 5 & 22 & 1.7 & 1.1 & 4.8 & 549 & 0.9 & 0.7 & ....... \\
\hline 35-44 & 387 & 17 & 1 & 30 & 4.4 & 0.3 & 7.8 & 370 & 2.2 & 1.1 & ....... \\
\hline 45-54 ….................... & 279 & 40 & 2 & 18 & 14.3 & 0.7 & 6.5 & 221 & 11.3 & 1.8 & …... \\
\hline 55 and over............ & 137 & 51 & 1 & 11 & 37.2 & 0.7 & 8.0 & 137 & 25.5 & $\ldots \ldots$. & ....... \\
\hline
\end{tabular}

1 Three cases of syphilis of heart or aorta and two of toxic heart disease were also found among smelter workers.

2 Three cases of syphilis of heart or arota and one of toxic heart disease were also found among pottery workers. 


\section{Cardiovascular Signs}

Arteriosclerosis - This was one of the criteria considered in establishing a diagnosis of arteriosclerotic-hypertensive heart disease. It becomes more prevalent with advancing age, as table 87 shows. A record of arteriosclerosis was made when thickening, beading, or tortuosity of the radial, brachial, or temporal arteries was found on palpation. It is interesting to note that the incidence of arteriosclerosis in the smelter workers is about the same as that found among Utah coal mine workers, the percentages being 12.9 and 10.3 , respectively. Many authorities hold that exposure to metallic fumes or dusts, especially lead, is liable to induce arteriosclerosis, but this contention is not supported by the observations made in the examination of Utah smelter workers.

\section{TABLE 87-Number and Percent of Smelter Workers Who Were Found to Have Arteriosclerosis, by Age.}

\begin{tabular}{|c|c|c|c|}
\hline \multirow{2}{*}{ Age } & \multirow{2}{*}{$\begin{array}{l}\text { Number in } \\
\text { age group }\end{array}$} & \multicolumn{2}{|c|}{ With arteriosclerosis } \\
\hline & & Percent & Number \\
\hline All ages ....................... & 1,391 & 12.9 & 180 \\
\hline 15-24 & 130 & 2.3 & 3 \\
\hline $25-34$ & 458 & 1.3 & 6 \\
\hline (1) & 387 & 5.7 & 22 \\
\hline 45-54 & 279 & 25.8 & 72 \\
\hline 55 and over & 137 & 56.2 & 77 \\
\hline
\end{tabular}

Blood Pressure-The systolic blood pressures of the smelter workers in Utah appear to be lower than those of other industrial workers who have been studied by the Public Health Service (2). In general, however, the diastolic pressures are the same or slightly higher than those of other industrial workers. This indicates a reduced pulse pressure in the Utah smelter workers which cannot be accounted for by the information at hand. A similar finding is observed in the coal and metal mine workers. It is suggested that this difference might be due to the higher altitudes in which the Utah workers live.

\section{TABLE 88-Average Systolic and Diastolic Blood Pressures of Smelter Workers, by Age, and Compared with 10,000 Male Industrial Workers.}

\begin{tabular}{|c|c|c|c|c|c|c|c|}
\hline \multirow{2}{*}{\multicolumn{2}{|c|}{ Age }} & \multicolumn{3}{|c|}{ Smelter workers } & \multicolumn{3}{|c|}{10,000 male industrial workers } \\
\hline & & $\begin{array}{l}\text { Average } \\
\text { systolic } \\
\text { blood } \\
\text { pressure }\end{array}$ & $\begin{array}{l}\text { Average } \\
\text { diastolic } \\
\text { blood } \\
\text { pressure }\end{array}$ & $\begin{array}{l}\text { Number } \\
\text { of persons } \\
\text { studied }\end{array}$ & $\begin{array}{l}\text { Average } \\
\text { systolic } \\
\text { blood } \\
\text { pressure }\end{array}$ & $\begin{array}{l}\text { Average } \\
\text { diastolic } \\
\text { blood } \\
\text { pressure }\end{array}$ & $\begin{array}{l}\text { Number } \\
\text { of persons } \\
\text { studied }\end{array}$ \\
\hline Under & $25 \ldots \ldots$ & 120 & 74 & 130 & 123 & 72 & 1,264 \\
\hline $25-29$ & & 122 & 77 & 230 & 126 & 75 & 1,122 \\
\hline $30-34$ & & 122 & 77 & 226 & 127 & 77 & 1,055 \\
\hline $35-39$ & ………… & 123 & 78 & 200 & 128 & 79 & 1,026 \\
\hline $40-44$ & 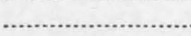 & 126 & 80 & 186 & 130 & 80 & 782 \\
\hline 45-49 & 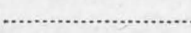 & 128 & 82 & 143 & 135 & 81 & 613 \\
\hline $50-54$ & & 132 & 82 & 134 & 139 & 82 & 365 \\
\hline $55-59$ & 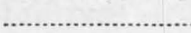 & 144 & 87 & 69 & 143 & 83 & 240 \\
\hline $60-64$ & …… & 145 & 86 & 44 & 149 & 86 & 122 \\
\hline 65 and & over & 141 & 84 & 23 & 156 & 84 & 78 \\
\hline
\end{tabular}


Hypertension--The percentage of workers with high blood pressure appears to be lower among the employees of the smelter industry examined in this study than it is in other industries in which the Public Health Service has previously made field studies $(1,2)$. If a pressure of $150 \mathrm{~mm}$ mercury is regarded as the upper limit of the range of systolic blood pressures in normal adults, it is possible to compare these employees with other industrial workers.

TABLE 89-Number of Workers with Systolic Blood Pressure Values in Excess of $150 \mathrm{~mm}$ Mercury, Classifed by Age.

\begin{tabular}{|c|c|c|c|c|c|}
\hline & \multicolumn{5}{|c|}{ Ages in years } \\
\hline & $20-29$ & $30-39$ & $40-49$ & $50-59$ & $60-69$ \\
\hline $\begin{array}{l}\text { 1,374 smelter workers } \\
\text { Number in each age group..... } \\
\text { Number with hypertension } 1 . . . . \\
\text { Percent with hypertension ..... }\end{array}$ & $\begin{array}{c}355 \\
6 \\
1.7\end{array}$ & $\begin{array}{r}426 \\
7 \\
1.6\end{array}$ & $\begin{array}{c}329 \\
22 \\
6.7\end{array}$ & $\begin{array}{c}203 \\
47 \\
23.2\end{array}$ & $\begin{array}{l}61 \\
20 \\
32.8\end{array}$ \\
\hline $\begin{array}{l}\text { 1,432 male pottery workers } 2 \\
\text { Number in each age group..... } \\
\text { Number with hypertension } 1 . . . . \\
\text { Percent with hypertension }\end{array}$ & $\begin{array}{c}569 \\
18 \\
3.2\end{array}$ & $\begin{array}{r}447 \\
26 \\
5.8\end{array}$ & $\begin{array}{l}256 \\
35 \\
13.7\end{array}$ & $\begin{array}{c}160 \\
34 \\
21.2\end{array}$ & $\begin{array}{l}51 \\
22 \\
43.1\end{array}$ \\
\hline $\begin{array}{l}9,540 \text { male industrial workers } \\
\text { Number in each age group.... } \\
\text { Number with hypertension } 1 . . . . \\
\text { Percent with hypertension } . . . .\end{array}$ & $\begin{array}{r}3,248 \\
136 \\
4.2\end{array}$ & $\begin{array}{r}3,293 \\
240 \\
7.3\end{array}$ & $\begin{array}{c}1,947 \\
320 \\
16.4\end{array}$ & $\begin{array}{l}818 \\
233 \\
28.5\end{array}$ & $\begin{array}{c}234 \\
112 \\
47.9\end{array}$ \\
\hline
\end{tabular}

1 Hypertension as here used refers only to a systolic blood pressure in excess of 150 mm mercury. 2 Data from Public Health Bulletin 244, table 22.

3 Data from Public Health Bulletin 162.

The percentage values for persons with systolic pressures of $150 \mathrm{~mm}$ of mercury or more, employed in the Utah smelter industry, increase rapidly with advancing age. All of these values, however, are considerably lower than those obtained for 1,432 male pottery workers and for 9,540 male industrial workers, but are about the same as in the coal mine and metal mine workers.

\section{Syphilis}

Of the smelter workers examined during this study, 1,468 blood samples were subjected to the Kahn serological test. Twenty-six of the latter number were recorded as a 3 - or 4-plus positive reaction. This incidence of 1.8 percent of positive serological evidence of syphilis in the smelter worker is about the same as that found in the coal workers and about twice the incidence found in the metal mine workers of Utah (see table 8 in Appendix V). In a survey (26) carried out by the Utah State Board of Health through the cooperation of the physicians of the State, it was estimated that at the time of the survey there were about 10,000 cases of syphilis in an estimated population of 521,000 . The incidence of syphilis in the smelter worker, therefore, is almost identical with that found in the general population of Utah.

Three additional blood samples were recorded as a 2-plus Kahn re- 
action. In the absence of further study and with no other recorded syphilitic stigmata, these cases can be considered neither affected nor nonaffected by syphilis.

Only one of the 29 smelter workers with positive serology gave a history of chancre; two were found to have absent patellar reflexes; one worker presented an inequality of the pupils; and three were found to have perforation of the nasal septum. One of the latter group had a definite exposure to arsenic fumes, while the other two of this group failed to give an occupational history of arsenic exposure.

\section{Summary and Recommendations}

A summation of the medical findings on smelter workers and recommendations for the protection and preservation of their health are included in the general summary and recommendations at the beginning of this report.

\section{References}

1. Flinn, R. H., W. C. Dreessen, T. I. Edwards, E. C. Riley, J. J. Bloomfield, R. R. Sayers, J. F. Cadden, and S. C. Rothmann: Silicosis and lead poisoning among pottery workers. Public Health Bull. 244. Washington, Gov. Print. Off. 1939.

2. Britten, R. H., and L. R. Thompson: A health study of 10,000 male industrial workers. Public Health Bull. 162. Washington, Gov. Print. Off. 1926.

3. Dreessen, W. C., J. M. DallaValle, T. I. Edwards, R. R. Sayers, H. F. Easom, and M. F. Trice: Pneumoconiosis among mica and pegmatite workers. Public Health Bull. 250. Washington, Gov. Print. Off. 1940.

4. Dressen, W. C., J. M. DallaValle, T. I. Edwards, J. W. Miller, R. R. Sayers, H. F. Easom, and M. F. Trice: A study of asbestosis in the asbestos textile industry. Public Health Bull. 241. Washington, Gov. Print. Off. 1938.

5. Sayers, R. R., J. J. Bloomfield, J. M. DallaValle, R. R. Jones, W. C. Dreessen, D. K. Brundage, and R. H. Britten: Anthraco-silicosis among hard coal miners. Public Health Bull. 221. Washington, Gov. Print. Off. 1936.

6. Assoc. Life Insurance Medical Directors and Actuarial Society of America: Medico-actuarial mortality investigations. Vol. I. Introduction. Statistics of height and weight of insured persons. Compiled and published by the Assoc. Life Ins. Med. Dir. and the Actuarial Soc. of America, New York. 1912.

7. National Tuberculosis Association: Diagnostic standards-Tuberculosis of the lungs and related lymph nodes. Tentative edition, 1938.

8. McPhedran, F. M.: Tracheobronchial lymphadenitis and its associated lesions. Penn. Međ. J. 32: 228-233. 1929. Also in 21st Ann. Rpt. Henry Phipps Inst.

9. Fellows, H. H.: Serial chest roentgenograms of 3,179 of fice employees, 1926-1938. J. Ind. Hyg. Toxicol. 22: 157-168. 1940

10. National Tuberculosis Association: Framingham community health and tuberculosis demonstration. Framingham Monograph No. 10, July, 1924. 
11. Syde.1stricker, Edgar, and R. H. Britten: The physical impairments of adult life. Amer. J. of Hyg. 11: 89 and 100. 1930.

12. Division of Labor Standards: Report on medical control, National Silicosis Conference. Bull 21, part 1. U. S. Department of Labor. Washington, Gov. Print. Off. 1938.

13. Gilch rist, H. L.: A comparative study of World War casualties from gas and other weapons. Page 44. Chemical Warfare School. Washington, Gov. Print. Off. 1931.

14. Teleky, L.: Protocol of the Session of the Grand Council of the Institute of Industrial Hygiene. Schriften des Institutes fur Gewerbehygiene, Frankfurt a. M., pages 24-45.

15. Orten, J. M.: The properties and significance of the reticulocyte. The Yale J. of Biol. and Med. 6: 519. 1934.

16. Henderson, Yandell, and H. W. Haggard: Noxious gases. New York, The Chemical Catalog Co., Inc. 1927.

17. McNally, W. D. :Toxicology. Chicago, Industrial Medicine. 1937. Page 439.

18. Lanza, A. J., and J. A. Goldberg: Industrial hygiene (by various authors). New York, Oxford University Press. 1939. Page 448.

19. Legge, Thomas: Industrial maladies. London, Oxford Unixersity Press. 1934. Page 82.

20. Davis, B. F., Two cases of perforation of the nasal septum due to inhalation of arsenic trioxide. J. Amer. Med Assoc. 68: 1620. 1917.

21. Dunlap, L. G.: Perforations of the nasal septum due to inhalation of arsenous oxide. J. Amer. Med. Assoc. 76: 568. 1921.

22. Hope, E. W., W. Hanna, and C. O. Stallybrass: Industrial hygiene and medicine. London, Balliere, Tindall and Cox. 1923.

23. Bainton, J. H., A. C. DeGraff, R: L. Levy, and H. E. B. Pardee: Criteria for the classification and diagnosis of heart disease. New York Tuberculosis and Health Association, Inc. Heart Committee. 3d ed. 1932. Approved by the American Heart Association.

24. Hedley, O. F.: Studies of heart disease mortality. An analysis of the accuracy of deaths recorded as being due to heart disease in Washington, D. C., during 1932, with a discussion of the defects of the present method of tabulating deaths and suggestions for a new system based upon etiological factors. Public Health Bull. 231. Washington, Gov. Print. Off. 1936.

25. Viko, L .E.: Heart disease in the Rocky, Mountain region. Amer. Heart J. 6: 264-273. 1930-31.

26. Utah State Board of Health: Biennial Report, July 1, 1936-June 30, 1938. 
APPENDIXES 


\section{APPENDIX I}

\section{RESULTS OF DENTAL EXAMINATIONS OF UTAH WORKERS}

It has been for some time the desire of the Division of Industrial $\mathrm{Hy}$ giene, United States Public Health Service, to include a detailed examination of oral conditions of patients examined during surveys conducted by the Division. A limited dental study of potters was reported in 1939 (1). With the cooperation of the Utah State Board of Health it was possible to include one dentist who made all the examinations on this study.

The dental examinations were made either before or upon completion of the physical examinations; and consumed approximately ten minutes each. A total of 2,365 dental record forms, representing 83 percent of the workers examined in the medical survey, was completed.

\section{TABLE 1-Number Examined in Each Age Classified by Industry.}

\begin{tabular}{|c|c|c|c|}
\hline Age group & Metal mines & Coal mines & Smelters \\
\hline Totals & 690 & 459 & 1,216 \\
\hline 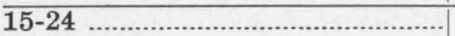 & 83 & 70 & 113 \\
\hline 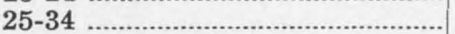 & 308 & 155 & 395 \\
\hline 35-44 & 162 & 131 & 347 \\
\hline $45-54$ & 90 & 82 & 256 \\
\hline 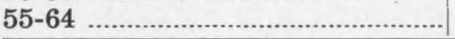 & 47 & 21 & 105 \\
\hline Average age ................................ & 36.0 & 36.5 & 39.0 \\
\hline
\end{tabular}

The purpose of this study was two-fold. First, it was desired to determine the dental status of representative groups of non-ferrous metal miners, coal miners, and smelter workers; second, to determine any possible relationship between that status and the industry in which these groups were employed. Accordingly, reference will be made to dental caries, edentulous workers, gingival conditions, and any special conditions resulting from exposure to certain heavy metals.

The data obtained from the individual worker were recorded on a chart stamped with the same number as was on his medical and laboratory forms. The dental record form, as shown in figure 1, is a slightly modified version of a chart suggested by Klein and Palmer (2).

Each worker was examined in good light with a mouth mirror and a well sharpened explorer. If necessary, any calculus or debris was cleaned away from the teeth so that an accurate check of gingival conditions could be made.

\section{Dental Caries}

It was decided to use 28 teeth for the study of dental caries. In doing this all third molars have been disregarded. The reason for this is easily seen when one considers how many third molars are congenitally absent, impacted, or fail to erupt. Unless a radiodontic examination is made it is frequently impossible to discern the status of these teeth. Since our information on third molars was uncertain it was decided for the sake of accuracy to omit them.

In determining the amount of dental caries in these industrial groups it seemed desirable to express the number of decayed, missing, and filled teeth in terms of teeth per 100 men examined. To compute this average the total number of decayed, missing, and filled teeth is divided by the 
U. S. PUBLIC HEALTH SERVICE-UTAH STUDY

Dental Record

No.

Date

Oral Cavity

: Normal.

Diseased

Gingivitis

: Mild

Severe

Pyorrhea

: Degree:

..I

III.

III.

IV.

Saliva

: Normal.

Viscid

Ropy

Odorous

Evidence of

Metallic Poisoning

Lead

Other

Occlusion

: Type:

I.............II

III

IV.

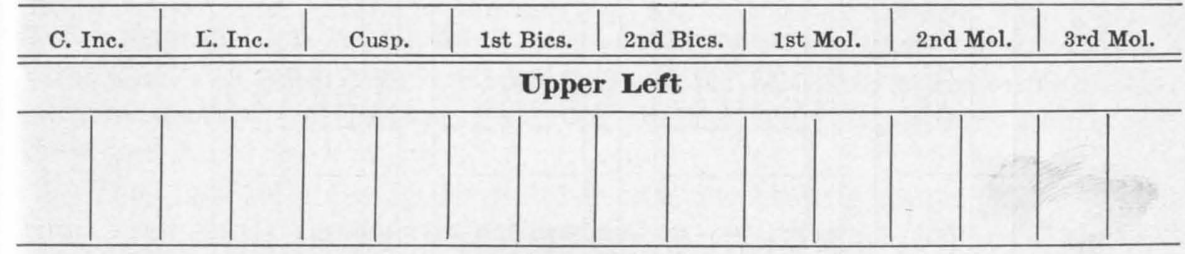

Upper Right

\begin{tabular}{l|l|l|l|l|l|l|l|l|l|l|}
\hline $\mid$ & & & & & & & & & & \\
\hline
\end{tabular}

Lower Left

\begin{tabular}{l|l|l|l|l|l|l|l|l|}
\hline $\mid$ &
\end{tabular}

Lower Right

\begin{tabular}{l|l|l|l|l|l|l|l|l|}
\hline $\mid$ & & &
\end{tabular}

FIGURE 1-Record form used in the dental survey. Each tooth or tooth position is represented by two boxes. In the left box is placed a symbol to show condition of the tooth; and in the right box a symbol to show the position of any caries, fillings, or other findings yielded by the tooth. For further details see publication mentioned in reference (2)

number of men examined, and that figure is multiplied by 100 . At this point it is well to say that no tooth is counted more than once. Accordingly, if the tooth contained both a filling and a carious lesion, it was counted as a filled tooth and not as carious. All teeth in which extraction was indicated were counted as missing teeth (3).

With respect to the data obtained on missing teeth, it is necessary to point out that the examination form made no differentiation between teeth extracted because of caries, and those extracted for other reasons, such as extensive pyorrhea. Thus, the rates shown are probably an overstatement of the caries attack rate in these groups. However, this limi- 
TABLE 2-Summary of Dental Caries.

\begin{tabular}{|c|c|c|c|c|c|c|c|c|c|}
\hline \multirow[b]{2}{*}{ Age } & \multirow{2}{*}{$\begin{array}{l}\text { Number of } \\
\text { workers } \\
\text { examined } 1\end{array}$} & \multicolumn{4}{|c|}{ Number of teeth } & \multicolumn{4}{|c|}{ Number per 100 men } \\
\hline & & $\begin{array}{l}\text { Total } \\
\text { D.M.F. } \\
\frac{2}{2}\end{array}$ & $\begin{array}{c}\text { Untreated } \\
\text { dental caries } \\
\text { D }\end{array}$ & $\begin{array}{c}\text { Missing } \\
\text { teeth } \\
\text { M } 3\end{array}$ & $\begin{array}{l}\text { Filled } \\
\text { teeth } \\
\text { F }\end{array}$ & $\begin{array}{c}\text { Total } \\
\text { D.M.F. } \\
2\end{array}$ & $\begin{array}{c}\text { Untreated } \\
\text { dental caries } \\
\text { D }\end{array}$ & $\begin{array}{c}\text { Missing } \\
\text { teeth } \\
\text { M }\end{array}$ & $\begin{array}{l}\text { Filled } \\
\text { teeth } \\
\text { F }\end{array}$ \\
\hline \multicolumn{10}{|c|}{ Metal Mines } \\
\hline Totals................................. & 593 & 7,528 & 1,878 & 3,078 & 2,572 & 1,269 & 316 & 519 & 434 \\
\hline 15-24 & 83 & 889 & 301 & 235 & 353 & 1,071 & 363 & 283 & 425 \\
\hline $25-34 \ldots .$. & 296 & 3,631 & 1,011 & 1,293 & 1,327 & 1,226 & 341 & 437 & 448 \\
\hline 35-44 & 135 & 1,720 & 372 & 777 & 571 & 1,274 & 276 & 575 & 423 \\
\hline $45-54$ & 59 & 965 & 154 & 550 & 261 & 1,635 & 261 & 932 & 442 \\
\hline $55-64$ & 20 & 323 & 40 & 223 & 60 & 1,615 & 200 & 1,115 & 300 \\
\hline \multicolumn{10}{|c|}{ Coal Mines } \\
\hline Totals.................................. & 382 & 4,478 & 1,326 & 2,097 & 1,056 & 1,172 & 347 & 549 & 276 \\
\hline 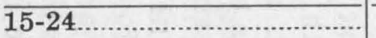 & 70 & 684 & 272 & 208 & 204 & 977 & 388 & 297 & 291 \\
\hline $25-34$ & 152 & 1,666 & 555 & 688 & 423 & 1,096 & 365 & 453 & 278 \\
\hline 35-44 & 112 & 1,489 & 351 & 770 & 368 & 1,329 & 313 & 687 & 329 \\
\hline 45-54 & 40 & 553 & 131 & 372 & 50 & 1,382 & 327 & 930 & 125 \\
\hline $55-64 \ldots \ldots \ldots \ldots \ldots \ldots \ldots$ & 8 & 87 & 17 & 59 & 11 & 1,087 & 212 & 137 & 138 \\
\hline \multicolumn{10}{|c|}{ Smelters } \\
\hline Totals.................................. & 1,024 & 13,373 & 2,901 & 5,561 & 4,911 & 1,306 & 283 & 544 & 479 \\
\hline 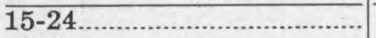 & 113 & 1,300 & 468 & 318 & 514 & 1,150 & 414 & 281 & 455 \\
\hline $25-34$ & 378 & 4,785 & 1,264 & 1,485 & 2,036 & 1,266 & 334 & 393 & 539 \\
\hline 35-44 & 298 & 4,081 & 737 & 1,887 & 1,457 & 1,369 & 247 & 633 & 489 \\
\hline $45-54$ & 179 & 2,451 & 352 & 1,392 & 707 & 1,369 & 196 & 778 & 395 \\
\hline $55-64 \ldots \ldots \ldots \ldots \ldots \ldots \ldots \ldots \ldots \ldots \ldots \ldots \ldots \ldots$ & 56 & 756 & 80 & 479 & 197 & 1,350 & 143 & 855 & 352 \\
\hline
\end{tabular}

1 Does not include edentulous patients. See table 3 .

3 Includes missing teeth and teeth indicated for extraction (3). 
tation should not affect comparisons within and between the groups of workers.

The populations represented in the following tables do not include any of the edentulous workers. Since it was not possible to determine the amount of dental caries that this group had before being reduced to the edentulous condition, none was included in the caries study.

Table 2 shows the total decayed, missing, and filled teeth as experienced by each age group in the three industries. The left side of the table gives the actual number of teeth found affected and the right side gives the number of teeth per 100 men.

An analysis of these data discloses very little difference among the industrial groups in total decayed, missing, and filled teeth. The coal miners have the lowest rate; 1,172 per 100 as compared with 1,269 for the metal miner, and 1,306 for the smelter workers. For specific age groups, it is observed that metal mine and smelter workers have slightly higher rates than coal mine workers among younger persons, while among older persons metal mine workers, but not smelter workers, have higher rates than coal mine workers.

The data on missing tooth rates are interesting, since the eventual end of all dental disease is reached when the tooth is lost. There is a definite increase in the number of missing teeth for each age group. It would seem from these data that a man 55 to 64 years of age who still had some teeth could be expected on the average to have nine teeth missing. It is also clear that with increased age the filled rate and untreated dental caries rates decrease because every tooth lost means one less which can become carious or filled.

\section{TABLE 3-Edentulous Workers Classified by Industry and Age.}

\begin{tabular}{|c|c|c|c|c|c|c|c|}
\hline \multirow{2}{*}{\multicolumn{2}{|c|}{ Age group }} & \multicolumn{3}{|c|}{ Number of edentulous workers } & \multicolumn{3}{|c|}{ Percent of edentulous workers 1} \\
\hline & & $\begin{array}{l}\text { Metal } \\
\text { mines }\end{array}$ & $\begin{array}{c}\text { Coal } \\
\text { mines }\end{array}$ & Smelters & $\begin{array}{l}\text { Metal } \\
\text { mines }\end{array}$ & $\begin{array}{c}\text { Coal } \\
\text { mines }\end{array}$ & Smelters \\
\hline & otals & 97 & 77 & 192 & 14.0 & 16.7 & 15.7 \\
\hline $15-24$ & ........... & 0 & 0 & 0 & 0 & 0 & 0 \\
\hline $25-34$ & -1-1-1-1-1-1-1-1-1 & 12 & 3 & 17 & 5.7 & 1.9 & 4.3 \\
\hline $35-44$ & 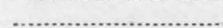 & 27 & 19 & 49 & 16.6 & 8.3 & 14.1 \\
\hline $45-54$ & (.).-. & 31 & 42 & 77 & 34.4 & 51.2 & 30.0 \\
\hline $55-64$ & ….................. & 27 & 13 & 49 & 57.4 & 61.9 & 46.6 \\
\hline
\end{tabular}

1 The populations upon which these percentages are based are shown in table 1 .

\section{Edentulous Workers}

Of the 2,365 persons examined, there were 366 , or 15.4 percent, who had had all teeth in both jaws extracted. Table 3 shows the number of employees by industrial groups who were found to be edentulous. The left side is the actual number for each age group, and right side gives the percentages affected.

An examination of table 3 shows that there is little difference between the total percentages of edentulous workers yielded by each industrial group. These percentages are 14.0 percent for the metal mine workers, 16.7 percent for the coal mine workers, and 15.7 percent for the smelter workers. However, in the age group 25-34 and 35-44 years, there is a smaller percent of edentulous persons among coal mine workers than among metal mine workers or smelter workers. In the relatively small 
population groups, $45-54$ and $55-64$ years, the position is reversed and coal mine workers show a larger percent edentulous than the other two indus. trial groups.

It is interesting to note how rapidly the number of edentulous men increases after the age of 35 . Thus, there are 3.0 percent edentulous under 35 years in the three idustris combined, while in the age group from 55-64, the number has increased to 51.0 percent.

It was found that 93 percent of the edentulous workers were wearing artificial dentures. It is not known how this compares with the general group of edentulous patients throughout the country.

\section{Gingivitis}

As the name implies, gingivitis is any local or general inflammation of the gingival tissue. Proper hygienic methods in the cleansing of the mouth would very likely clear up most of the gingivitis that was seen among these workers.

Gingivitis was diagnosed as either mild or severe, according to the following definition:

Mild-Refers to a general gingivitis characterized by a mild degree of swelling, redness, and soreness, but no pus. It does not refer to any local gingivitis.

Severe-Refers to a general gingivitis which is characterized by a more severe swelling, redness, soreness, and the presence of pus.

\section{TABLE 4-Number and Percent of Workers with Gingivitis.}

\begin{tabular}{|c|c|c|c|c|c|c|c|}
\hline \multirow{3}{*}{ Industry } & \multirow{3}{*}{$\begin{array}{c}\text { Number } \\
\text { of } \\
\text { workers } \\
\text { examined }\end{array}$} & \multicolumn{3}{|c|}{ Percent affected } & \multicolumn{3}{|c|}{ Number affected } \\
\hline & & \multicolumn{3}{|c|}{ Degree of gingivitis } & \multicolumn{3}{|c|}{ Degree of gingivitis } \\
\hline & & Mild & Severe & $\begin{array}{c}\text { Mild and } \\
\text { severe }\end{array}$ & Mild & Severe & $\begin{array}{c}\text { Mild and } \\
\text { severe }\end{array}$ \\
\hline \multicolumn{8}{|c|}{ 15-34 Years } \\
\hline Metal mines........ & 379 & 44.6 & 9.5 & 54.1 & 169 & 36 & 205 \\
\hline Coal mines & 222 & 37.4 & 5.4 & 42.8 & 83 & 12 & 95 \\
\hline 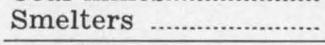 & 491 & 42.6 & 11.0 & 53.6 & 209 & 54 & 263 \\
\hline \multicolumn{8}{|c|}{ 35-64 Years } \\
\hline Metal mines.................. & 214 & 43.5 & 34.1 & 77.6 & 93 & 73 & 166 \\
\hline 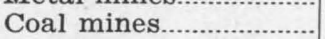 & 160 & 45.0 & 33.1 & 78.1 & 72 & 53 & 125 \\
\hline Smelters & 533 & 44.8 & 31.3 & 76.1 & 239 & 167 & 406 \\
\hline \multicolumn{8}{|c|}{ All Ages } \\
\hline Metal mines..................... & 593 & 44.2 & 18.4 & 62.6 & $26 \overline{2}$ & 109 & 371 \\
\hline Coal mines & 382 & 40.6 & 17.0 & 57.6 & 155 & 65 & 220 \\
\hline Smelters ........ & 1,024 & 43.7 & 21.6 & 65.3 & 448 & 221 & 669 \\
\hline
\end{tabular}

Table 4 shows the percentage of workers in each industrial group who are affected by gingivitis.

The data in table 4 show that age is a factor in gingivitis. The older group from 35-64 years shows a definite increase in the severe type of gingivitis, but no significant increase in mild gingivitis. This is very likely due to the fact that peridontal diseases become more prevalent as age increases.

Among persons 15-34 years of age, coal mine workers showed a smaller percent affected with gingivitis, particularly in the more severe form, than did metal mine workers or smelter workers. In the older age group, 
there was no appreciable difference in the percent of persons affected with either mild or severe gingivitis.

\section{Periodontoclasia (Pyorrhea Alveolaris)}

Periodontoclasia or pyorrhea is characterized by the breaking down and destruction of the alveolar tissue. It is a chronic infection, and pockets are formed between the gum tissue and the tooth root.

In the dental record form, pyorrhea was classified into four classes according to the severity of the disease. The criteria employed for dividing the affected workers into these classes are:

Class 1-Pockets up to $3 \mathrm{~mm}$ deep around less than half of the full complement of teeth.

Class II-Pockets up to $3 \mathrm{~mm}$ deep around more than half of the teeth.

Class III-Pockets more than $3 \mathrm{~mm}$ deep around less than half of the teeth.

Class IV-Pockets more than $3 \mathrm{~mm}$ deep around more than half of the teeth. This also includes all cases in which the remaining teeth are hopelessly pyorrhetic.

For purposes of comparison, it was decided to group those workers with pyorrhea into two broad age groups, under 35 years and 35 years and over. Table 5 gives the percent of employees who have various degrees of pyorrhea. There are no edentulous workers counted in this table, and the percentages are calculated from the populations used for the caries section.

\section{TABLE 5-Number and Percent of Workers Who Were Found to Have Pyorrhea.}

\begin{tabular}{|c|c|c|c|c|c|c|c|c|c|c|c|}
\hline \multirow{3}{*}{ Industry } & \multirow{3}{*}{$\begin{array}{c}\text { Number } \\
\text { of } \\
\text { workers } \\
\text { examined }\end{array}$} & \multicolumn{5}{|c|}{ Percent affected } & \multicolumn{5}{|c|}{ Number affected } \\
\hline & & \multicolumn{5}{|c|}{ Class of pyorrhea } & \multicolumn{5}{|c|}{ Class of pyorrhea } \\
\hline & & I & II & III & IV & $\begin{array}{c}\text { All } \\
\text { classes }\end{array}$ & I & II & III & IV & $\begin{array}{c}\text { All } \\
\text { classes }\end{array}$ \\
\hline \multicolumn{12}{|c|}{ 15-34 Years } \\
\hline Metal mines & 379 & 14.5 & 12.1 & 4.0 & 2.6 & 33.2 & 55 & 46 & 15 & 10 & 126 \\
\hline Coal mines.. & 222 & 16.2 & 7.7 & 4.5 & 0.9 & 29.3 & 36 & 17 & 10 & 2 & 65 \\
\hline Smelters .... & 491 & 26.5 & 7.7 & 4.7 & 0.8 & 39.7 & 130 & 38 & 23 & 4 & 195 \\
\hline \multicolumn{12}{|c|}{ 35-64 Years } \\
\hline Metal mines & 214 & 17.8 & 14.0 & 11.7 & 19.6 & 63.1 & 38 & 30 & 25 & 42 & 135 \\
\hline Coal mines.. & 160 & 16.2 & 13.1 & 19.4 & 20.0 & 68.7 & 26 & 21 & 31 & 32 & 110 \\
\hline Smelters .... & 533 & 26.1 & 13.1 & 16.5 & 10.9 & 66.6 & 139 & 70 & 88 & 58 & 355 \\
\hline \multicolumn{12}{|c|}{ All Ages } \\
\hline Metal mines & 593 & 15.7 & 12.8 & 6.7 & 8.8 & 44.0 & 93 & 76 & 40 & 52 & 261 \\
\hline Coal mines.. & 382 & 16.3 & 9.9 & 10.7 & 8.9 & 45.8 & 62 & 38 & 41 & 34 & 175 \\
\hline Smelters .... & 1,024 & 26.3 & 10.5 & 10.8 & 6.1 & 53.7 & 269 & 108 & 111 & 62 & 550 \\
\hline
\end{tabular}

In the age group 15-34 years it will be noted that the percent affected with class II and class IV pyorrhea, pockets around more than half the teeth, is higher for metal mine workers than for the other two industrial groups Smelter workers have a large percent of class I pyorrhea. When the total for all degrees of pyorrhea is considered, the percent affected for smelter workers is 39.7 percent, metal mine workers 33.2 percent, and coal mine workers 29.3 percent. The group 35-64 years of age does not 
show any consistent difference in the incidence of pyorrhea according to industry.

It would appear that there might be some factor common to the environment of metal mine and smelter workers not present in the environment of coal mines which migh influence the generally higher rate of dental caries, and the larger percent of edentulous persons, persons with gingivitis and pyorrhea. In both metal mines and smelters many of the workers are exposed to appreciable concentrations of lead. According to Aub, Fairhall, Minot and Reznikoff (5), lead workers commonly have bad teeth. The possibility that lead, even in comparatively small concentrations, may exert an unfavorable influence on the health of the gums, is substantiated by the observation that among persons 15-34 years of age working in the smelter which processed lead ores, there were 50.4 percent showing pyorrhea, while in the copper smelter there were 35.8 percent so affected.

\section{Exposure to Lead}

The lead line, or Burtonian line, is a fine line of granules of pigment deposited immediately below the gingival crest. Aub states that it is due to a deposit of lead sulphite about the blood vessels in the tips of the interdental papillae. Thus, we may expect to see more of it in patients who have periodontoclasia. In this study it was found that 80 percent of workers showing a lead line had pyorrhea. It is possible that in healthy mouths the lead line is not noticeable, although the worker may have toxic lead absorption. Aub also states that the lead line is practically pathognomonic of lead absorption, but not of poisoning.

The lead line is blue-black in color, and upon examination with a hand lens it can be seen as several rows of small dots. With good light the same pigmentation may be seen under the free gum margin next to the tooth. Frequently it is necessary to clean away any debris or pus before a definite diagnosis can be made.

In this study of lead miners and lead smelter workers, it was found that in workers employed in mines or smelters where they handled largely the high grade ores, such as lead carbonates, lead lines were occasionally found. At one metal mine a positive lead line was diagnosed in 40 out of 270 men. In the lead smelter there were 19 of 346 workers in which a lead line could be seen. The medical findings presented elsewhere will show how many of these men with lead lines actually had abnormal lead absorption.

\section{Summary}

1. Dental examinations were made of 690 non-ferrous metal miners, 459 coal miners, and 1,216 smelter workers.

2. These workers had caries rates (DMF) of 1,269 per 100 men for metal miners, 1,172 for coal miners, and 1,306 for smelter workers. It was found that both metal mine and smelter workers had slightly higher caries rates than coal mine workers among younger persons, while among older persons metal mine workers had higher caries rates than either smelter or coal mine workers.

3. The percentage of workers who had had all teeth in both jaws extracted, among persons under 45 years of age, was greater among metal mine and smelter workers than among coal mine workers, but among per- 
sons 45 years of age and over, coal mine workers had a more unfavorable experience than the other two industrial groups.

4. Gingivitis, either mild or severe, was found among 54.1 percent of the metal mine workers, 53.6 percent of the smelter workers, and 42.8 percent of the coal mine workers, 15-34 years of age. The percent affected for the corresponding industrial groups among persons 35 years of age and over was $77.6,76.1$ and 78.1 percent.

5. Periodontoclasia or pyorrhea was found in 39.7 percent of the smelter workers, 33.2 percent of the metal mine workers, and 29.3 percent of the coal mine workers under 35 years of age. When the more extensive pyorrhetic involvement is considered, metal mine workers show the largest percent affected. In the older age group, there was little difference by industry in the total percent affected with pyorrhea.

6. Lead lines were found in 40 workers at one metal mine and 19 workers at the lead smelter. In both of these, the lead exposure is chiefly from high grade lead ores.

7. It is possible that the unfavorable findings among the younger group of metal mine and smelter workers with respect to dental caries, edentulous condition, gingivitis and pyorrhea, may be related to the fact that many workers in these industries are exposed to appreciable concentrations of lead. It was shown that the incidence of pyorrhea was greater in the lead smelter than in the copper smelter. Disease conditions of the teeth and gums began to assume importance at an earlier age in metal mine and smelter workers than in coal mine workers, but after middle age was attained the difference between the industrial group was not so marked.

\section{References}

1. Flinn, R. H., W. C. Dreessen, T. I. Edwards, E. C. Riley, J. J. Bloomfield, R. R. Sayers, J. F. Cadden, and S. C. Rothmann: Silicosis and lead poisoning among pottery workers. Public Health Bull. 244. Washington, Gov. Print. Off. 1939.

2. Klein, Henry, and C. E. Palmer: A procedure for recording and processing of dental examination findings. J. Dental Research 19: 243. 1940.

3. Knutson, J. C., and Henry Klein: Studies on dental caries, Public Health Reports 53: 1021-1032. 1938.

4. Aub, J. C.: Lead poisoning. (In Textbook of Medicine, by Russell Cecil, 4th edition.) Philadelphia, W. B. Saunders and Co. 1937.

5. Aub, J. C., L. T. Fairhall, A. S. Minot, and P. Reznikoff: Lead Poisoning. Medical Monographs 7: 1663. Baltimore, The Williams and Wilkins Co. 1926. 


\section{APPENDIX II}

\section{THE PHYSIOLGOICAL RESPONSE OF PERITONEAL TISSUE TO} CERTAIN UTAH COAL AND METAL MINE AND SMELTER DUSTS

Samples of some of the dusts collected in the coal and metal mines and smelters of Utah were examined by the intraperitoneal injection method of Miller and Sayers (1) to determine their pneumoconiosis-producing potentialities. None of the dusts in this series have been examined in this manner previously and all were typical of frequently encountered industrial dusts inasmuch as they are mixtures rather than pure mineralogical entities.

Three well defined types of response are produced in the peritoneum by different dusts. Certain dusts are completely absorbed causing no visible damage. None of the dusts producing this type of reaction are known to cause pneumoconiosis. Another group of dusts produces a proliferative reaction, i. e., stimulates the production of fibrous tissue. Free silica in all of its forms causes this type of response. Dusts of this group are known to cause a nodular pulmonary fibrosis. In a third group the dust remains inert in the peritoneal tissue. A number of dusts of this group are known to produce pulmonary fibrosis of the diffuse interstitial type.

In interpreting the results of this biological method of dust testing it should be understood that the term "inert" is used to describe the observable response of peritoneal tissue and should not be interpreted to mean "inactive" or "innocuous." Such dusts as show a tendency to remain in the tissues should be considered potentially harmful, though not as dangerous as those causing a proliferative response. Silica (which produces a proliferative reaction) when mixed with an inert dust produces nodules of modified appearance with distinguishable features of both types of reactions. Correlation of the peritoneal reaction in guinea pigs and the pathological picture of certain of the pneumoconioses such as silicosis, asbestosis, and, with a mixed dust, anthraco-silicosis, have been described (2).

\section{Bituminous Coal Mine Dusts}

Rock Dust.-Sample of ground powdered rock dust used on walls to prevent coal dust explosions. Petrographic examination showed about 6 percent quartz. Chemical analysis showed 17.8 percent total silica. A well defined inert reaction was produced.

Coal Dust.-Sample taken from coal vein containing seams of slate graphic examination showed no quartz. Analysis showed 1.6 percent total silica. A well defined inert reaction was produced.

Coal Dust.-Sample taken from drilling coal at face near the top of a high coal vein. A definite inert reaction was produced.

Coal Dust.-Sample taken from coal vein containing seams of slate through the coal. An inert reaction showing a tendency toward slow proliferation was produced.

Rock Dust.-A ground sample of slate taken from the roof of a low coal vein. Petrographic examination showed about 50 percent quartz. Chemical analysis showed 79.1 percent total silica. A combined proliferative and inert reaction was produced, the former predominant. 


\section{Metal Mine Dusts}

Mine Dusts.-Sample taken from exhaust fan from lower part of mine (1400-foot level). Consisted mostly of sulfide ores. Petrographic examination showed about 35 percent quartz. This produced a combined proliferative and inert reaction.

Mine Dust.-Sample taken from outlet side of 700 -foot exhaust from upper part of mine. Consisted mostly of carbonate ores, lead and silver. Petrographic examination showed about 8 percent quartz. A distinct inert reaction was produced.

\section{Smelter Dusts}

Rafter Dust.-Sample taken ten feet from floor of iron foundry. Petrographic examination showed about 5 percent quartz. Chemical analysis showed 20.9 percent total silica. An inert reaction was produced.

Copper Ore Dust.-A sample of copper sulfide ore dust after concentration by floatation. Petrographic examination showed about 15 percent quartz. Chemical analysis showed 17.8 percent total silica. An inert reaction was produced.

Lead Ore Dust.-Rafter sample taken outside the sample mill above the bins as the ore cars are dumped. An inert combined with a slow proliferative reaction was produced.

Copper Ore Dust.-Rafter sample taken in sample mill where ore is ground and sampled. A combined inert and proliferative reaction was produced.

Inasmuch as all of the dusts tested by this method produced inert or proliferative reactions they should be considered harmful when inhaled.

\section{References}

1. Miller, J. W., and R. R. Sayers: The physiological response of peritoneal tissue to certain industrial and pure mineral dusts. Public Health Reports. 51: 1677-1688. 1936. Reprint No. 1787.

2. Sayers, R. R., J. J. Bloomfield, J. M. DallaValle, R. R. Jones, W. C. Dreessen, D. K. Brundage, and R. H. Britten: Anthraco-silicosis among hard coal miners. Public Health Bulletin No. 221. 114 pp. 1936. 


\section{APPENDIX III}

\section{SPECTROCHEMICAL ANALYSIS AS APPLIED TO SAMPLES FROM THE UTAH STUDY}

\section{Plan}

All samples of urine collected in the study were subjected to a qualitative spectrochemical analysis to determine which of 16 different elements might occur in them in unusual amounts. Quantitative analyses were made on samples for lead content, wherever indicated by the qualitative analysis and certain medical findings.

\section{Procedure}

After a review of the literature and some exploratory work in the laboratory, it was decided that two spectra of each sample would be adequate for the qualitative analyses. The two spectra were photographed on the same plate with the Littrow spectograph set for a different wave-length region for each spectrum. The wave-length range covered by the two spectra was from $2400 \mathrm{~A}$ to $3500 \mathrm{~A}$, a range which includes sensitive lines for all the elements under consideration. Different excitation conditions were used for the two spectra, which gave a better range of sensitivity.

Graphites were cut into 1-inch lengths and drilled to a depth of $5 / 8$ inch with a $1 / 8$ inch drill. They were then burned as anodes of the electric arc with a current of $22 \mathrm{amps}$, for 40 minutes. This procedure volatilized impurities and surface contamination and made the graphite porous.

Each graphite was then loaded with $0.2 \mathrm{cc}$ of urine (4 graphites for each urine, making two pairs of electrodes). The loading of each graphite with $0.2 \mathrm{cc}$ of urine was done to use more samples for the analysis, a technique developed for the hatting industry (1). This use of as much sample as possible was necessitated by the high threshold of some of the elements.

After loading, graphites were dried in the oven for 40 minutes at $100^{\circ} \mathrm{C}$. They were then used as electrodes of the electric arc $(25$ minutes at 22 amps.) and the spectra excited were photographed

One spectrum of each sample was photographed in the range 2400$3200 \mathrm{~A}$, with a $2 \mathrm{~mm}$ arc gap. This gave optimum conditions for mercury and as nearly as could be determined for arsenic. The other spectrum of each sample was photographed in the region 2500-3500 A with a $3 \mathrm{~mm}$ arc gap. A 30-micron slit width was used.

Plates (Eastman No. 33) were given full development (7 minutes) with Eastman D-61-a.

The spectra were examined with a low power binocular microscope. Presence or absence of characteristic lines of desired elements was determined in this way.

\section{Thresholds}

The samples were analyzed for silica, iron, mercury, phosphorus, calcium, sodium, lead, manganese, cadmium, arsenic, antimony, tin, silver, gold, copper, and bismuth. It was found that silica, iron, magnesium, phosphorous, copper, sodium, manganese, and lead occur in all samples. Attention was turned mainly to examination of samples for arsenic, cadmium, antimony, gold, silver, lead, and mercury. Since none of these except lead usually occurs in urine, it was thought 
desirable to determine the threshold or lowest limit at which each would be detected by the procedure used. Thresholds as determined are as follows:

Arsenic-not less than $0.1 \mathrm{mg}$ per 1 (100 gamma)

Cadmium-somewhat less than $0.1 \mathrm{mg}$ per 1

Antimony-very much less than $0.1 \mathrm{mg}$ per 1

Gold-considerably less than $0.1 \mathrm{mg}$ per 1

Lead-less than $0.01 \mathrm{mg}$ per 1

Mercury-around $0.05 \mathrm{mg}$ per 1

Silver-much less than $0.1 \mathrm{mg}$ per 1

Thresholds for tin and bismuth were not determined because of their secondary importance.

The threshold value of arsenic was very troublesome and must be considered as quite uncertain. This is due to the fact that, quite apart from the fact that arsenic is an insensitive and unstable element spectrographically, the most usable line was obscured by a diffraction pattern so that identification had to be attempted by means of lines of secondary sensitivity, and, using standard solutions, at times $0.1 \mathrm{mg}$ per liter of arsenic could be detected; at other times the threshold was much higher.

Lead Analyses-An attempt was made to estimate visually the lead content of the various samples, using the tabulations low (F), average $(\mathrm{T})$, and high $(\mathrm{H})$. This is a rather rough procedure unless spectra of standards of known concentrations are photographed on the same plate. Because of the emphasis placed on the grouping (F, T, and $\mathrm{H}$ ), a number of urine samples were analyzed quantitatively for lead by the spectrographic method to determine the range included in each group. It was found that the group marked $\mathrm{T}$ contained samples containing lead in amounts ranging from less than $0.01 \mathrm{mg}$ per liter to $0.15 \mathrm{mg}$ per liter, with the great majority of them having a content of less than $0.05 \mathrm{mg}$ per liter. Samples marked $F$ overlap this range but have low lead content. Samples marked $\mathrm{H}$ also overlap this range on the higher side. None of the samples of the $\mathrm{H}$ group that was analyzed quantitatively contained lead in amounts greater than $0.2 \mathrm{mg}$ per liter. The quantitative results indicate a grouping as follows:

$\mathrm{F}=0.01 \mathrm{mg}$ per liter or less

$\mathrm{T}=0.01-0.15 \mathrm{mg}$ per liter with the great majority less than $0.05 \mathrm{mg}$ per liter

$\mathrm{H}=0.10 \mathrm{mg}$ per liter or over

Quantitative determinations were made on the lead content of urine specimens of 15 coal miners, 80 smelter workers, and 36 metal miners by the technic of Armstrong and Brackett (2).

\section{References}

1. Neal, P. A., R. H. Flinn, T. I. Edwards, W. H. Reinhart, J. W. Hough, J. M. DallaValle, F. H. Goldman, D. W. Armstrong, A. S. Gray, A. L. Coleman, and B. F. Postman: Mercurialism and its control in the felt-hat industry. Public Health Bulletin No. 263. Government Printing Office, Washington. 1940.

2. Armstrong, D. W., and F. S. Brackett: Spectroscopic analysis of biological fluids for heavy metals. J. Ind. Hygiene \& Toxicol., Vol. 21. Nov. 1939. 


\section{APPENDIX IV}

\section{METHOD OF CACULATING WEIGHTED AVERAGE DUST EXPOSURES}

\section{(From Public Health Bulletin No. 221)}

Experience has taught us that the various operations comprising the processes of most dusty occupations are usually associated with dissimilar dust exposures. For this reason it is essential to estimate the amount of time spent in each activity in any one occupation and to determine the dust exposure for each activity in that occupation. Table 1 shows the results of such a differential dust study in the case of a Leyner driller.

\section{TABLE 1-Summary of Dust Exposure of Leyner Drillers in a Granite Quarry.}

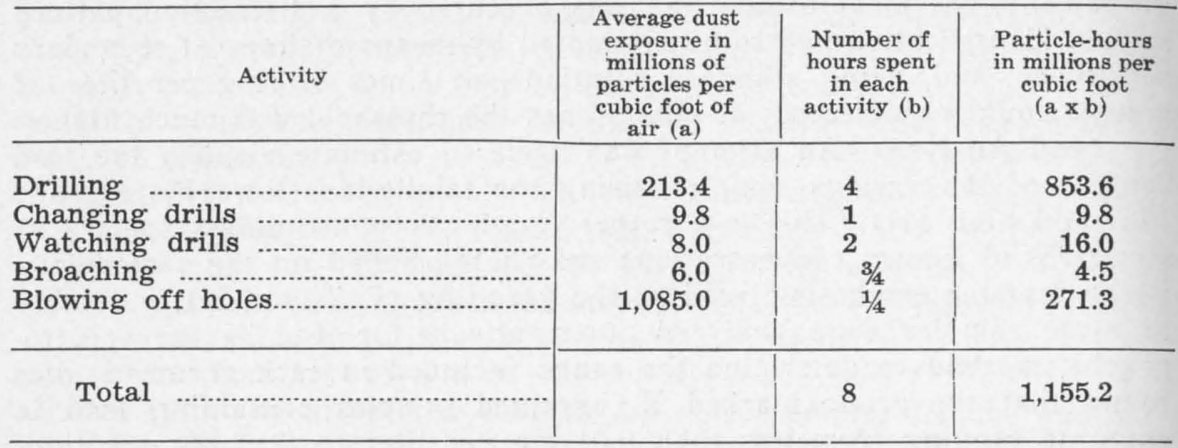

1,155.2 particle-hours in millions per cubic foot 8 hours

It will be seen from table 1 that a Leyner driller has five different dust exposures. A differential analysis, such as the one presented in table 1, yields several valuable findings. First, it enables one to obtain a true average dust exposure for workers engaged in the occupation of Leyner drilling. (In this case the weighted average is 144.4 as contrasted with 213.4 million particles per cubic foot found during drilling operations only.) Second, it enables one to determine which activity, or activities, contribute the most to the dust hazard. In this instance it is quite evident that the practice of blowing off holes by means of inserting a compressed air line into each hole is attended with an exceedingly great amount of dust; and though it is an activity lasting but 15 minutes of the 8-hour working day, it is one which is responsible for 23 percent of the total dust exposure. It is evident that 23 percent of the Leyner driller's dust exposure may be at once eliminated by the prohibition of this practice. And lastly, such an analysis indicates the necessity for devoting all one's efforts to the removal of dust during the drilling process, since this activity accounts for 74 percent of the total dust exposure, although a Leyner driller spends but one-half of the working day at his drill.

So far we have dealt with an industry in which the workers, as a rule, do not change their occupation. Often one encounters workers who have had several occupations, either in the same industry or in several differ- 
ent kinds of establishments. If the worker has been employed in various occupations in the industry under investigation, it is a simple matter to determine his total dust exposure during his entire trade life in that industry. This is important from the viewpoint of correlating a worker's dust exposure and his clinical condition. A typical example of such a case will suffice to clarify this point.

\section{TABLE 2-Total Occupational Dust Exposure of an Anthracite Coal Worker.}

\begin{tabular}{lc|c|c|c}
\hline & Occupation & $\begin{array}{c}\text { Number of } \\
\text { year in each } \\
\text { occupation }\end{array}$ & $\begin{array}{c}\text { Dust concen- } \\
\text { tration in } \\
\text { millions of } \\
\text { particles per } \\
\text { cubic foot }\end{array}$ & $\begin{array}{c}\text { Millions of } \\
\text { particle-years } \\
\text { per cubic foot }\end{array}$ \\
\hline Slate picker & 2 & 380 & 760 \\
Patcher & 2 & 71 & 142 \\
Mule driver & 3 & 71 & 213 \\
Miner's laborer & 3 & 480 & 1,440 \\
Miner & 15 & 480 & 7,200 \\
Section foreman & 5 & 7 & 35 \\
\hline
\end{tabular}

$\frac{9,790 \text { millions of particle-years per cubic foot }}{30 \text { years }}=326$ millions of particles per cubic foot.

In the above table the worker's occupations are arranged in the order of employment, the last one being his present occupation. It is obvious that had one considered this last occupation only the dust exposure for this individual would not have yielded a true state of affairs, nor would it have been possible to correlate this dust exposure with the man's clinical picture. In the above technic correct weight is given to the number of years spent in each occupation and the dust exposure associated with each occupation. Only by such an analysis is it possible to arrive at a fair estimate of a worker's dust exposure and his proper designation. That one is justified in resorting to such an analysis is evidenced by the fact that results obtained with this technic yield excellent correlations with the clinico-roentgenological studies conducted on anthracite coal miners. 


\section{APPENDIX V}

SUMMARY TABLES SHOWING THE INCIDENCE OF CERTAIN MEDICAL FINDINGS AMONG WORKERS IN THE COAL MINES, METAL MINES, AND SMELTERS IN UTAH.

TABLE 1-Average Age and Average Length of Employment for Workers in Coal Mines, Metal Mines, and Smelters with Employment in Utah Only, and in Utah and Outside.

\begin{tabular}{|c|c|c|c|}
\hline & Total & Utah only & $\begin{array}{l}\text { Utah and } \\
\text { outside }\end{array}$ \\
\hline Coal mines: & \multirow{3}{*}{$\begin{array}{l}507 \\
36.5\end{array}$} & \multirow{3}{*}{$\begin{array}{l}442 \\
35.2\end{array}$} & \multirow{3}{*}{$\begin{array}{l}65 \\
44.7\end{array}$} \\
\hline $\begin{array}{l}\text { Number of workers } \\
\text { Average age }\end{array}$ & & & \\
\hline Average number of years & & & \\
\hline $\begin{array}{l}\text { employed in coal mines.. } \\
\text { Metal mines: }\end{array}$ & 14.1 & 12.5 & 25.0 \\
\hline 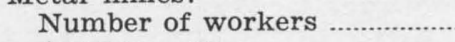 & \multirow{2}{*}{$\begin{array}{c}727 \\
36.0\end{array}$} & \multirow{2}{*}{$\begin{array}{l}686 \\
35.5\end{array}$} & \multirow{2}{*}{$\begin{array}{l}41 \\
44.2\end{array}$} \\
\hline Average age & & & \\
\hline $\begin{array}{l}\text { Average number of years } \\
\text { employed in metal mines. }\end{array}$ & \multirow[t]{2}{*}{11.1} & \multirow[t]{2}{*}{10.5} & \multirow{2}{*}{21.6} \\
\hline Smelters: & & & \\
\hline Number of workers & \multirow{2}{*}{$\begin{array}{r}1,391 \\
39.1\end{array}$} & \multirow{2}{*}{$\begin{array}{r}1,371 \\
38.9\end{array}$} & \multirow{2}{*}{$\begin{array}{l}20 \\
49.8\end{array}$} \\
\hline $\begin{array}{l}\text { Average age } \\
\text { Average number of years }\end{array}$ & & & \\
\hline employed in smelters....... & 12.8 & 12.6 & 25.5 \\
\hline
\end{tabular}

TABLE 2-Average Weight Deviation Percentages for Workers in the Three Study Groups, Classified by Diagnosis of Silicosis.

\begin{tabular}{|c|c|c|c|c|}
\hline \multirow[b]{2}{*}{ Study group } & \multirow{2}{*}{$\begin{array}{c}\text { All } \\
\text { workers }\end{array}$} & \multicolumn{3}{|c|}{ Diagnosis of silicosis } \\
\hline & & $\begin{array}{c}\text { 1st and } \\
\text { 2nd stage }\end{array}$ & $\begin{array}{c}\text { Border- } \\
\text { line }\end{array}$ & $\begin{array}{l}\text { Non- } \\
\text { affected }\end{array}$ \\
\hline Coal mines: & \multirow{3}{*}{504} & \multirow{3}{*}{13} & \multirow{3}{*}{25} & \multirow{3}{*}{463} \\
\hline 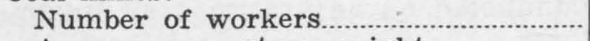 & & & & \\
\hline Average percentage weight & & & & \\
\hline Standard deviation & -12.7 & $\begin{array}{l}-6.2 \\
13.2\end{array}$ & $\begin{array}{r}-1.6 \\
10.2\end{array}$ & $\begin{array}{r}-1.3 \\
12.8\end{array}$ \\
\hline Metal mines: & \multirow[b]{2}{*}{727} & & & \\
\hline 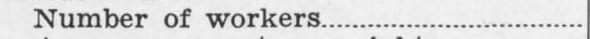 & & 66 & 42 & 619 \\
\hline $\begin{array}{l}\text { Average percentage weight } \\
\text { deviation } 1\end{array}$ & \multirow{2}{*}{.+ .4} & \multirow{2}{*}{$\begin{array}{r}-2.7 \\
12.4\end{array}$} & \multirow{2}{*}{$\begin{array}{r}+1.9 \\
9.8\end{array}$} & \multirow{2}{*}{+.6} \\
\hline Standard deviation & & & & \\
\hline Smelters: & \multirow{3}{*}{1,388} & \multirow[b]{2}{*}{37} & \multirow[b]{2}{*}{65} & \multirow{3}{*}{1,286} \\
\hline Number of workers...................... & & & & \\
\hline Average percentage weight & & -51 & +41 & \\
\hline 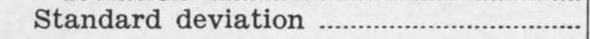 & 12.9 & 14.2 & 15.5 & 12.7 \\
\hline
\end{tabular}

1 Averages represent the percentage the workers fell below or above the average for life insurance applicants of comparable age and height. 
TABLE 3-Number of Workers in Utah Coal Mines, Metal Mines and Smelters, Classified by Age, and by Degree of Pulmonary Fibrosis as Shown by Known X-ray Findings.

\begin{tabular}{|c|c|c|c|c|c|c|}
\hline Age & $\begin{array}{c}\text { Total } \\
\text { number of } \\
\text { workers }\end{array}$ & $\underset{1}{\text { Linear }}$ & $\begin{array}{l}\text { Linear } \\
2\end{array}$ & $\begin{array}{l}\text { Ground } \\
\text { glass }\end{array}$ & Nodular & $\begin{array}{l}\text { Conglomer- } \\
\text { ate }\end{array}$ \\
\hline \multicolumn{7}{|l|}{ Coal mines: } \\
\hline Total. & 489 & 307 & 138 & 41 & 3 & $\mathbf{0}$ \\
\hline $15-24 \ldots \ldots \ldots \ldots$ & 77 & 69 & 8 & 0 & 0 & 0 \\
\hline $25-34 \ldots \ldots$ & 163 & 123 & 37 & 3 & 0 & 0 \\
\hline $35-44 \ldots \ldots$ & 137 & 66 & 55 & 16 & 0 & 0 \\
\hline 45-54 & 85 & 40 & 27 & 17 & 1 & 0 \\
\hline 55 and over... & 27 & 9 & 11 & 5 & 2 & 0 \\
\hline \multicolumn{7}{|l|}{ Metal mines: } \\
\hline Total & 719 & 456 & 161 & 64 & 23 & 15 \\
\hline 15-24 & 82 & 72 & 10 & 0 & 0 & 0 \\
\hline $25-34 \ldots \ldots$ & 319 & 245 & 62 & 9 & 3 & 0 \\
\hline 35-44 & 171 & 91 & 43 & 27 & 5 & 5 \\
\hline $45-54 \ldots \ldots \ldots-\ldots$ & 102 & 31 & 34 & 23 & 7 & 7 \\
\hline 55 and over... & 45 & 17 & 12 & 5 & 8 & 3 \\
\hline \multicolumn{7}{|c|}{ Smelters: } \\
\hline Total...... & $\mathbf{1 , 3 8 4}$ & 935 & 360 & 75 & 10 & 4 \\
\hline $15-24$ & 130 & 100 & 30 & 0 & 0 & 0 \\
\hline $25-34 \ldots \ldots \ldots \ldots$ & 456 & 336 & 115 & 5 & 0 & 0 \\
\hline 35-44 & 384 & 262 & 94 & 24 & 2 & 2 \\
\hline 45-54 & 278 & 164 & 76 & 33 & 3 & 2 \\
\hline 55 and over.... & 136 & 73 & 45 & 13 & 5 & 0 \\
\hline
\end{tabular}

TABLE 4-A Comparison of Average Systolic and Diastolic Blood Pressures of Workers Examined During Various Field Studies, by Age. ${ }^{1}$

\begin{tabular}{|c|c|c|c|c|c|c|c|c|c|}
\hline \multirow[b]{2}{*}{ Study group } & \multicolumn{9}{|c|}{ Age } \\
\hline & $\begin{array}{l}\text { Under } \\
25\end{array}$ & 25-29 & $30-34$ & 35-39 & $40-44$ & $45-49$ & $50-54$ & $55-59$ & 60-64 \\
\hline & \multicolumn{9}{|c|}{ Average systolic blood pressure } \\
\hline Utah coal mines.. & 122 & 124 & 124 & 122 & 126 & 123 & 133 & 138 & 133 \\
\hline Utah metal mines. & 124 & 123 & 122 & 122 & 127 & 127 & 132 & 138 & 137 \\
\hline Utah smelters .......... & 120 & 122 & 122 & 123 & 126 & 128 & 132 & 144 & 145 \\
\hline Pottery manufacture & 124 & 126 & 125 & 130 & 127 & 135 & 135 & 135 & 145 \\
\hline Truck drivers ..... & 126 & 129 & 129 & 127 & 128 & $135^{2}$ & (1... & ....... & \\
\hline \multicolumn{10}{|l|}{10,000 industrial } \\
\hline workers …......... & 123 & 126 & 127 & 128 & 130 & 135 & 139 & 143 & 149 \\
\hline \multicolumn{10}{|c|}{ Average diastolic blood pressure } \\
\hline Utah coal mines...... & 78 & 79 & 81 & 80 & 84 & 81 & 84 & 89 & 91 \\
\hline Utah metal mines.. & 78 & 78 & 77 & 78 & 84 & 83 & 85 & 91 & 84 \\
\hline Utah smelters ............... & 74 & 77 & 77 & 78 & 80 & 82 & 82 & 87 & 86 \\
\hline Pottery manufacture & 75 & 77 & 78 & 81 & 81 & 84 & 83 & 83 & 85 \\
\hline Truck drivers ............... & 80 & 82 & 84 & 82 & 83 & $88^{2}$ & & & .... \\
\hline 10,000 industrial & & & & & & & & & \\
\hline workers ............ & 72 & 75 & 77 & 79 & 80 & 81 & 82 & 83 & 86 \\
\hline \multicolumn{10}{|c|}{ Number of persons tested } \\
\hline Utah coal mines. & 79 & 91 & 79 & 84 & 57 & 49 & 38 & 18 & 7 \\
\hline Utah metal mine & 82 & 167 & 151 & 98 & 74 & 61 & 43 & 27 & 17 \\
\hline Utah smelters . & 130 & 230 & 226 & 200 & 186 & 143 & 134 & 69 & 44 \\
\hline Pottery manufacture & 345 & 288 & 241 & 206 & 144 & 112 & 94 & 66 & 40 \\
\hline Truck drivers ................ & 131 & 268 & 215 & 141 & 79 & 411 & ….... & ....... & \\
\hline 10,000 industrial & & & & & & & & & \\
\hline workers & 1,264 & 1,122 & 1,055 & 1,026 & 782 & 613 & 365 & 240 & 122 \\
\hline
\end{tabular}

1 Averages for persons over 65 years are not shown in this table.

2 Includes 11 men over 50 with average blood pressure of 142 systolic and 88 diastolic. 
TABLE 5-Number and Percent of Workers Examined During Various Field Studies with Arterial Hypertension, by Age. ${ }^{1}$

\begin{tabular}{|c|c|c|c|c|c|}
\hline \multirow{2}{*}{ Study group } & \multicolumn{5}{|c|}{ Age } \\
\hline & $20-29$ & $30-39$ & $40-49$ & $50-59$ & $60-69$ \\
\hline 507 Utah Coal Mine Workers: & & & & & \\
\hline Number in age group..................... & 163 & 163 & 106 & 56 & 9 \\
\hline Number with hypertension .... & 3 & 5 & 1 & 12. & 2 \\
\hline Percent with hypertension...... & 1.8 & 3.1 & 0.9 & 21.4 & 22.2 \\
\hline 727 Utah Metal Mine Workers: & & & & & \\
\hline Number in age group................. & 246 & 249 & 135 & 70 & 18 \\
\hline Number with hypertension .... & 8 & 4 & 0 & 12 & 6 \\
\hline Percent with hypertension...... & 3.3 & 1.6 & 6.7 & 17.1 & 33.3 \\
\hline 1,391 Utah Smelter Workers: & & & & & \\
\hline Number in age group................... & 355 & $426^{\circ}$ & 329 & 203 & 61 \\
\hline Number with hypertension .... & 6 & 7 & 22 & 47 & 20 \\
\hline Percent with hypertension...... & 1.7 & 1.6 & 6.7 & 23.2 & 32.8 \\
\hline 1,432 Male Pottery Workers: & & & & & \\
\hline Number in age group & 569 & 447 & 256 & 160 & 51 \\
\hline Number with hypertension .... & 18 & 26 & 35 & 34 & 22 \\
\hline Percent with hypertension....... & 3.2 & 5.8 & 13.7 & 21.2 & 43.1 \\
\hline 9,540 Male Industrial Workers: & & & & & \\
\hline Number in age group & 3,248 & 3,293 & 1,947 & 818 & 234 \\
\hline Number with hypertension .... & 136 & 240 & 320 & 233 & 112 \\
\hline Percent with hypertension....... & 4.2 & 7.3 & 16.4 & 28.5 & 47.9 \\
\hline
\end{tabular}

1 Hypertension as here used refers only to a systolic blood pressure in excess of $150 \mathrm{~mm} \mathrm{Hg}$.

TABLE 6-Incidence of Arteriosclerosis Among Workers in Utah Coal Mines, Metal Mines, and Smelters, by Age.

\begin{tabular}{|c|c|c|c|c|c|c|c|c|c|}
\hline \multirow{3}{*}{ Age } & \multicolumn{3}{|c|}{ Coal mines } & \multicolumn{3}{|c|}{ Metal mines } & \multicolumn{3}{|c|}{ Smelters } \\
\hline & \multirow{2}{*}{\begin{tabular}{|c|} 
Number \\
in age \\
group
\end{tabular}} & \multicolumn{2}{|c|}{\begin{tabular}{|c|} 
With \\
arteriosclerosis
\end{tabular}} & \multirow{2}{*}{$\begin{array}{c}\text { Number } \\
\text { in age } \\
\text { group }\end{array}$} & \multicolumn{2}{|c|}{$\begin{array}{c}\text { With } \\
\text { arteriosclerosis }\end{array}$} & \multirow{2}{*}{$\begin{array}{l}\text { Number } \\
\text { in age } \\
\text { group }\end{array}$} & \multicolumn{2}{|c|}{$\begin{array}{c}\text { With } \\
\text { arteriosclerosis }\end{array}$} \\
\hline & & Percent & No. & & Percent & No. & & Percent & No. \\
\hline All ages... & 507 & 10.3 & 52 & 727 & 9.8 & 71 & 1,391 & 12.9 & 180 \\
\hline $15-24$ & 79 & 2.5 & 2 & 83 & .... & 0 & 130 & 2.3 & 3 \\
\hline $25-34 \ldots$ & 170 & 2.4 & 4 & 323 & 3.4 & 11 & 458 & 1.3 & 6 \\
\hline $35-44 \ldots$. & 142 & 5.6 & 8 & 172 & 6.4 & 11 & 387 & 5.7 & 22 \\
\hline $45-54 \ldots$ & 88 & 25.0 & 22 & 104 & 24.0 & 25 & 279 & 25.8 & 72 \\
\hline 55 and over. & 28 & 57.1 & 16 & 45 & 53.3 & 24 & 137 & 56.2 & 77 \\
\hline
\end{tabular}


TABLE 7-A Comparison of the Incidence of Arteriosclerotic Hypertensive and Rheumatic Heart Diseases Among Workers Examined During Various Field Studies, by Age.

\begin{tabular}{|c|c|c|c|c|c|c|}
\hline \multirow[b]{2}{*}{ Study group } & \multicolumn{6}{|c|}{ Age } \\
\hline & Total & $15-24$ & $25-34$ & $35-44$ & $45-54$ & $\begin{array}{c}55 \text { and } \\
\text { over }\end{array}$ \\
\hline Utah Coal Mines 1 & & & & & & \\
\hline $\begin{array}{l}\text { Number in age group................ } \\
\text { Percent with heart disease: }\end{array}$ & 507 & 79 & 170 & 142 & 88 & 28 \\
\hline Arteriosclerotic hypertensive & 5.7 & 1.3 & 2.9 & 2.1 & 11.4 & 35.7 \\
\hline Rheumatic & 2.8 & 2.5 & 0.6 & 4.2 & 4.5 & 3.6 \\
\hline Utah Metal Mines 1 & & & & & & \\
\hline Number in age group.............. & 727 & 83 & 323 & 172 & 104 & 45 \\
\hline Percent with heart disease: & & & & & & \\
\hline Arteriosclerotic hypertensive & 6.7 & 4.8 & 1.2 & 7.6 & 13.5 & 31.1 \\
\hline Rheumatic & 2.3 & 2.4 & 1.9 & 2.3 & 3.8 & 2.2 \\
\hline Utah Smelters 1 & & & & & & \\
\hline Number in age group................. & 1391 & 130 & 548 & 387 & 279 & 137 \\
\hline Percent with heart disease: & & & & & & \\
\hline Arteriosclerotic hypertensive & 8.6 & 3.1 & 1.7 & 4.4 & 14.3 & 37.2 \\
\hline Rheumatic & 0.6 & & 1.1 & 0.3 & 0.7 & 0.7 \\
\hline Pottery Manufacture 2 & & & & & & \\
\hline Number in age group............ & 1627 & 350 & 549 & 370 & 221 & 137 \\
\hline $\begin{array}{l}\text { Percent with heart disease: } \\
\text { Arteriosclerotic hypertensive }\end{array}$ & & & & & & \\
\hline $\begin{array}{l}\text { Arteriosclerotic hypertensive } \\
\text { Rheumatic }\end{array}$ & 4.5 & & 0.9 & 2.2 & 11.3 & 25.5 \\
\hline $\begin{array}{c}\text { Rheumatic } \\
\text { Storage Battery }\end{array}$ & 1.0 & 1.1 & 0.7 & 1.1 & 1.8 & .... \\
\hline Number in age group........... & 757 & 74 & 246 & 217 & 157 & 63 \\
\hline Percent with heart disease: & & & & & & \\
\hline Arteriosclerotic hypertensive & 12.3 & .... & 1.6 & 7.4 & 29.9 & 41.3 \\
\hline $\begin{array}{c}\text { Rheumatic } \\
\text { Truck Drivers }{ }^{4}\end{array}$ & 1.2 & & 2.0 & 1.4 & 0.6 & .... \\
\hline Number in age group............... & 886 & 135 & 485 & 224 & 38 & 4 \\
\hline Percent with heart disease: & & & & & & \\
\hline Arteriosclerotic hypertensive & 6.1 & 5.2 & 4.7 & 7.1 & 18.4 & 25.0 \\
\hline Rheumatic & 1.7 & .... & 1.9 & 2.6 & & \\
\hline
\end{tabular}

1 Data for Utah studies are based on tables appearing elsewhere in this bulletin.

2 Public Health Bulletin No. 244.

3 Bulletin in press.

4 Totals were obtained from punch eards of truck drivers for the age groups shown here.

TABLE 8-Number and Percent of Postive Kahn Reactions Among Workers in the Three Study Groups on Whom Blood Tests Were Made.

\begin{tabular}{|c|c|c|c|c|c|}
\hline \multirow[b]{2}{*}{ Study group } & \multirow{2}{*}{$\begin{array}{c}\text { Number of } \\
\text { tests } 1\end{array}$} & \multicolumn{2}{|c|}{$1,2,3$, or $4+\mathrm{Kahn}$} & \multicolumn{2}{|c|}{3 and $4+$ Kahn } \\
\hline & & $\begin{array}{c}\text { Percent of } \\
\text { workers }\end{array}$ & $\begin{array}{c}\text { Number of } \\
\text { workers }\end{array}$ & $\begin{array}{c}\text { Percent of } \\
\text { workers }\end{array}$ & $\begin{array}{c}\text { Number of } \\
\text { workers }\end{array}$ \\
\hline Total... & 2,704 & 1.7 & 47 & 1.6 & 42 \\
\hline Coal mines.... & 552 & 2.2 & 12 & 1.8 & 10 \\
\hline Metal mines....... & 784 & .8 & 6 & .8 & 6 \\
\hline Smelters............... & 1,468 & 2.0 & 29 & 1.8 & 26 \\
\hline
\end{tabular}

1 Includes tests for workers in the mixed dust group. 
(SEAL)

Office of

Industrial Hygiene

and Sanitation

\section{TREASURY DEPARTMENT}

\author{
PUBLIC HEALTH SERVICE
}

WASHINGTON, D. C.

Mr. O. F. McShane, Commissioner,

The Industrial Commission of Utah,

State Capitol,

Salt Lake City, Utah.

Dear Mr. McShane:

With further reference to your correspondence with the Division of Labor Standards, the Bureau of Mines, and the Public Health Service, as well as our recent conversations on the subject of a possible survey of health hazards in Utah, I am inclosing a memorandum which may serve as an agreement for the guidance of all the organizations which are to take part in the cooperative survey. As I have outlined to you during our recent conversations, it will not be possible to start these surveys in the immediate future, due to earlier commitments. However, you may be assured that we shall endeavor to do all we can to expedite the work as much as possible.

In order that you and others in Utah may obtain more detailed information concerning the projected surveys, I shall be pleased to have someone from this Office come to your State in the near future in order to discuss the various phases of the problem with you and to effect arrangements for the conduct of these studies. It is my understanding that the Division of Labor Standards is also agreeable to sending a representative at the same time in order to take part in the proposed arrangements and to cooperate with the Public Health Service and any other Federal or State agencies who may be interested in the conduct of the proposed studies.

I shall be very pleased to receive your reaction to the plan outlined herein and trust that we may be of some assistance to you in connection with your industrial health problems.

Sincerely yours,

(Signed) R. R. Sayers

R. R. Sayers,

Medical Officer in Charge. 


\section{MEMORANDUM TO FORM THE BASIS OF A COOPERA. TIVE PROGRAM FOR THE CONDUCT OF A SURVEY OF INDUSTRIAL HEALTH HAZARDS IN THE STATE OF UTAH}

\section{Purpose:}

In order to enact legislation of a character that will compensate the worker for loss of time and injury to health resulting from exposure to industrial health hazards, it is essential that a survey be made of the industries in Utah which will have for its purpose the evaluation of the various factors bearing on this problem. Of equal importance is the fact that such basic data will be useful in the support and application of a program designed to control industrial health hazards in the State.

Plan:

In order to determine the exact nature of the industrial health problem in Utah, it is essential to carry out two types of surveys. The first should be preliminary in nature and designed to reveal the number of persons employed in the various occupations in an establishment, the nature of each particular occupation, the raw materials or by-products which are associated with each occupation, and certain information on welfare facilities afforded the workers in the industrial environment. This type of survey may well be considered as a general inventory of working conditions and should reveal the potential health hazards existing in this State. Once this preliminary survey has been completed, it will then be possible to determine which particular industrial health hazards are in need of further study. This second survey will be more specific in nature and will include such items as detailed engineering studies of the working environment in an attempt to determine the relationship between the environment and the health of workers, complete medical examinations of workers, analyses of any occupational morbidity and mortality data which may be available, and a study of any other factors which may throw light on the industrial health problem. In connection with both surveys, it may not be advisable to include all the industrial establishments in the State of Utah, but to select representative samples. This procedure has been found workable and one giving the information desired.

For the achievement of this program, full cooperation is indicated on the part of employers, employees, State and Federal agencies contributing personnel and guidance for this work.

\section{Agreement:}

In order to carry out the above plan successfully, the responsibilities of all the cooperating agencies must be fully understood and representatives selected by them should agree to the following procedure:

A. Preliminary Plant Survey.

1. The United States Public Health Service will undertake the responsibility of organizing and guiding this survey to its completion, including an analysis of the data obtained and the preparation of a report covering the results of the study.

2. The Division of Labor Standards of the U. S. Department of Labor and the U. S. Bureau of Mines will cooperate with the Public Health Service in this study and agree to furnish certain personnel needed in the conduct of this survey. 
3. The Industrial Commission of Utah agrees to cooperate to the extent of furnishing whatever personnel it may have available to aid in the conduct of this survey.

4. The representatives of the various employers in the State agree to render full cooperation to the various State and Federal agencies participating in the survey and give permission to enter the various establishments to the authorized representatives of the agencies conducting the preliminary survey. The employers also agree to furnish whatever information is needed to complete the first part of the plant studies.

B. Detailed Surveys.

1. The responsibility for the conduct of the detailed studies will also be undertaken by the United States Public Health Service with the cooperation of the Division of Labor Standards and the United States Bureau of Mines. The data obtained from these detailed studies will be analyzed and prepared in the form of a report by the Public Health Service with the assistance and cooperation of the other Federal agencies.

2. The employers agree to give permission to enter their plants for the purpose of studying the working environment, to allow the workers to be examined by the Federal field forces, and to cooperate in any other manner needed for the successful completion of this undertaking.

3. The employees agree to cooperate in accordance with the requiremtns of the field forces of the Federal agencies engaged in making the survey and especially to present temselves willingly for the medical examination necessary for the conduct of the second survey outlined in this plan.

4. It is further agreed that the results of both surveys will be analyzed and prepared in such a manner that when the data are made public, they will not divulge the results on any one particular plant or individual. In other words, the information will be disseminated in the form of a research investigation of potential and actual health hazards by industry groups.

Feb. 24th, 1937

We the undersigned hereby agree to cooperate with the United States Department of Public Health on the basis of the above memorandum.

RRS:JJB:vjk

Utah Chapter, American Mining Congress

by (s) A. G. Mackenzie, Secretary

Utah Coal Operators Association

by (s) B. P. Manley, Secretary

Utah Manufacturers Association

by (s) S. J. Stephenson, Secretary

Salt Lake City Chamber of Commerce

by (s) Gus P. Backman, Secretary

Utah State Federation of Labor

by (s) Paul M. Peterson. 






\section{Date Due}

\begin{tabular}{|c|c|c|c|}
\hline Nov 7 & 952 & & \\
\hline $18398=$ & ges: & AHO $\theta$ & 6.2003 \\
\hline AUd.T. & $74+4 L$ & & \\
\hline QDO $\pi$ & 874 & & \\
\hline Jul a & I'91 & & \\
\hline 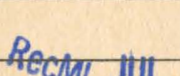 & & & \\
\hline & $20 \cdot 90$ & & \\
\hline NOY 27 & $9 ?$ & & \\
\hline Hov 2 , & ${ }^{\prime} 2 \quad M I$ & & \\
\hline $0 \times 2$ & 1994 & & \\
\hline & गU & 08200 & \\
\hline+24 & 1994 & & \\
\hline Noy 0 & 1994 & & \\
\hline BLL & पा 06 'g9 & & \\
\hline SFP 0 & 1999 & & \\
\hline (5) & & & \\
\hline
\end{tabular}




\section{|||||||||||||||||||||||||||| \\ 3. 1111.4004219426}

331.822

U58w U.S. National Institute of Health. Div. of Industrial Hygiene.

The working environment and the health of workers.

248980

DATE

ISSUED TO

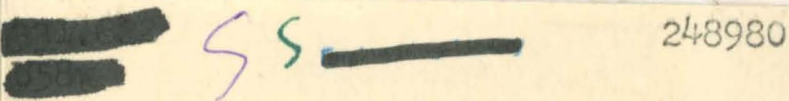


